Tesis

Doctorado en Historia

Facultad de Humanidades y Ciencias de la Educación

Universidad Nacional de La Plata

\title{
Imaginarios sociales de los trabajadores ferroviarios de Junín (1948-1973)
}

Doctoranda: Ana Leticia Sagastume

Director: Prof. Dr. Guillermo Quinteros

Agosto de 2021 


\section{Agradecimientos}

A Guillermo Quinteros, por guiarme en el recorrido nuevo que significó el Doctorado en Historia, exigiendo hasta el límite, aunque sin dejar de alentar, lo que hizo posible la conclusión de esta tesis. Gracias a su acompañamiento, trabajo y compromiso, puedo afirmar que ya no soy la misma. Gracias también por inspirar con el ejemplo, como docente, como investigador y como persona.

A los profesores del Doctorado de Historia, por su compromiso docente y por haber compartido lecturas y contenidos fascinantes.

A mi querida UNLP, por brindar un plantel docente de excelencia a través del Instituto de Posgrado de la Facultad de Humanidad y Ciencias de la Educación.

A la UNNOBA y a su Instituto de Posgrado, por brindarnos la oportunidad de cursar una carrera, muy cerca de casa, con un excelentísimo nivel docente.

A Gustavo, por impulsarme a trascender los límites, por su confianza y por su contención afectiva. Y, sobre todo, por resignar tiempos compartidos para que yo pueda concluir esta meta.

A Martín, por motivarme cada día en la búsqueda de respuestas.

A "mis" ferroviarios, por confiar y compartir generosamente sus vivencias. Especialmente, a Juan Dall'Occhio y a Ítalo Marone por estar siempre dispuestos, a lo largo de todos estos años, a responder a cada inquietud.

A Juan Carlos Cena, por allanar inmediatamente mis dudas ante cada pregunta, por su afecto y respeto, y por su confianza en la producción de este tipo de conocimientos.

A Alfonsina Iacullo (Archivo Histórico), por su cooperación en la búsqueda de documentos y su generosidad, siempre acompañados por una calidez y amabilidad inalterables.

Al Archivo Histórico de Junín y al Archivo Universitario de la UNNOBA Roberto Dimarco, por brindarme la posibilidad de acceder a fuentes documentales valiosas.

A Pablo Petraglia, por haber facilitado el acceso a documentos del Archivo Universitario.

A Guillermo Banzato, por sus comentarios enriquecedores.

A José Calcagni, por sus lúcidos aportes a partir de la lectura de algunas partes de esta tesis.

A la familia Ferrari, por compartir documentos relacionados con el ferrocarril que atesoraba Héctor Ferrari.

A Aroldo Taberna, por compartir materiales bibliográficos y documentos valiosos. 


\section{Índice}

$\begin{array}{ll}\text { Introducción } & 5\end{array}$

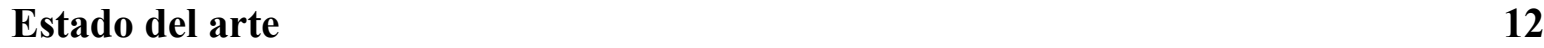

Marco teórico-metodológico $\quad 38$

$\begin{array}{ll}\text { Fuentes } & 53\end{array}$

Capítulo 1. La vida en el ferrocarril

El ingreso al ferrocarril como hito $\quad \mathbf{6 0}$

El progreso en la carrera ferroviaria $\quad \mathbf{6 6}$

Los distintos espacios de formación de los ferroviarios $\quad \mathbf{8 3}$

Los beneficios materiales y simbólicos de los trabajadores del riel $\quad \mathbf{1 0 2}$

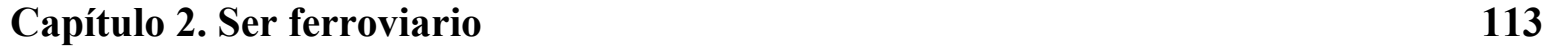

$\begin{array}{ll}\text { La identidad ferroviaria } & 114\end{array}$

$\begin{array}{ll}\text { La calidad como sello de identidad } & \mathbf{1 2 3}\end{array}$

Las relaciones humanas en el interior del ferrocarril $\quad \mathbf{1 3 4}$

La proyección de los ferroviarios en el desarrollo cultural de Junín $\quad \mathbf{1 6 1}$ 
La nacionalización: acontecimientos históricos y representaciones locales

La "escuela inglesa": representaciones sobre la eficiencia y calidad británicas

El trato entre jefes y subordinados: tradiciones y transformaciones

Conocimiento versus política: dos valores en disputa

Representaciones marginales

Capítulo 4. Crisis nacional, iniciativas locales

La crisis del ferrocarril en la década de 1960: recuerdos y representaciones locales

La "gran huelga" en Junín: una fractura en la "familia ferroviaria"

De plan en plan: proyectos para mejorar el servicio y disminuir el déficit

PERT, un método para incrementar la eficiencia

El control de la calidad aplicado a las tareas de reparación 


\section{Introducción}

Esta tesis aborda el estudio de los imaginarios sociales que se constituyeron en torno a la actividad ferroviaria en la ciudad de Junín, provincia de Buenos Aires, desde el enfoque de la historia oral. Se lo hace a partir de los testimonios sobre las experiencias y las representaciones de los trabajadores ferroviarios de la ciudad, que ingresaron a la empresa durante las décadas de 1940 y 1950.

Puede afirmarse que en Junín existió un complejo ferroviario de envergadura, a partir de las casi treinta hectáreas que ocupaban los Talleres ferroviarios en el centro geográfico de la ciudad, al cual se le sumaban otros edificios frente al predio, correspondientes a oficinas pertenecientes al Departamento de Mecánica. ${ }^{1}$ Los historiadores locales coinciden en señalar el vínculo entre el crecimiento demográfico, urbano y comercial de la ciudad de Junín con la instalación de los Talleres Ferroviarios en 1886. Así, Roberto Dimarco considera que la llegada de la primera locomotora en 1884 fue "el factor más importante del progreso de nuestro pueblo", así como del "aumento demográfico explosivo" que, según el autor, tiene lugar a partir de 1890 (Dimarco, 1993: 117). En la misma línea, Ana Laura Pompei plantea que "un factor fundamental de progreso que le permitió al antiguo Fuerte Federación realizar el despegue y marcar la diferencia con respecto a los demás poblados de la zona fue la llegada del ferrocarril”, la cual estuvo acompañada por "la instalación de talleres ferroviarios en 1886" (Pompei, 2011). ${ }^{2}$ En tanto, Melina Yuln asegura que la “...llegada del ferrocarril a Junín, en la década de 1880, resultó determinante para su crecimiento y desarrollo, y para su posicionamiento en la región del noroeste de la provincia de Buenos Aires” (Yuln, 2017: 101). Más cauto, José María Banfi señala que los talleres fueron durante los primeros años del siglo XX “el principal demandador de trabajo de la ciudad" y "un enorme polo de atracción alrededor del cual estaban vinculados porcentajes muy significativos de la población juninense" (Banfi, 2017: 10). ${ }^{3}$ Paralelamente, estas afirmaciones se condicen con las de numerosas fuentes orales en la ciudad, que destacan el rol prominente que el complejo ferroviario, integrado por los Talleres y las oficinas del Departamento de Mecánica, habría tenido en el desarrollo de la localidad en la primera mitad del siglo $X X$.

\footnotetext{
${ }^{1}$ De acuerdo a un folleto elaborado por el Departamento de Mecánica, el predio de los Talleres Junín estaba compuesto por 28,9 hectáreas, con una superficie cubierta de $66.836 \mathrm{~m}^{2}$ y $20.970 \mathrm{~m}^{2}$ de superficie de trabajo a cielo abierto (Departamento de Mecánica, Línea General San Martín (s.f.). Ferrocarriles Argentinos. Talleres Junin).

${ }^{2}$ Agradezco a Ana Laura Pompei por haberme facilitado el documento.

${ }^{3}$ Agradezco a José María Banfi por haberme facilitado el documento.
} 
Además del rol destacado en el crecimiento y desarrollo de la ciudad, algunas fuentes (como se verá) también resaltan la importancia que tuvieron los talleres ferroviarios de Junín en el contexto del país. El historiador local más conocido de la ciudad asegura que Junín fue "el centro ferroviario de mayor trascendencia en el orden nacional" (Dimarco, 1984: 7), mientras que un folleto elaborado por trabajadores de la empresa estima que los Talleres Junín constituían "el más importante centro reparador de material ferroviario del país". ${ }^{4}$ En tanto, los datos que emergen a partir del estudio que dio lugar al Plan de Mediano Plazo de 1969 parecen confirmar lo sugerido por los testigos: al comparar la envergadura de todos los talleres ferroviarios del país, los de Junín aparecen solo superados por los de Tafí Viejo, en relación a la cantidad de personal y superficie ocupada. ${ }^{5}$

De esta manera, las representaciones formuladas a partir de la experiencia de los mismos actores y las interpretaciones que algunos estudiosos han hecho sobre el tema, tanto en relación con la influencia de los Talleres en el desarrollo de la ciudad como con la trascendencia del complejo ferroviario en el concierto nacional, justifican poner el foco en las construcciones simbólicas que tuvieron lugar a partir de los hechos vinculados a la existencia del centro ferroviario local y que continuaron teniendo influencia en el período de estudio. Desde una metodología propia de la historia oral, esta tesis está centrada en recuperar los sentidos asociados a la historia del ferrocarril en Junín, así como las experiencias ferroviarias durante el período 1948-1973.

El inicio de la etapa estudiada se fundamenta en que las fuentes orales a las que se tuvo acceso al momento de iniciar la investigación ingresaron en las décadas de 1940 y 1950. En estos actores existe un consenso al considerar a la nacionalización que tuvo lugar en 1948 como un acontecimiento altamente significativo para la historia del ferrocarril y para su propia historia de vida en la empresa. Esto también se apoya en fuentes bibliográficas como la de J.E. Waddell (2016), quien señala que la nacionalización fue un acontecimiento fundamental para el devenir posterior del medio de transporte, ya que el Estado se convirtió en el único empresario de toda la red, ocupando tres funciones en simultáneo: la gestión, el control y la regulación (López et al., 2016: 156, 157). A su vez, el ferroviario e historiador aficionado J. C.

\footnotetext{
${ }^{4}$ Departamento de Mecánica, Línea General San Martín (s.f.). Ferrocarriles Argentinos. Talleres Junín.

${ }^{5}$ Pompei asegura que "los talleres ferroviarios de Junín con $289.000 \mathrm{~m}^{2}$ de superficie total continuaban siendo, al finalizar la década de 1960, los más extensos de todos los talleres ferroviarios de la Argentina (...). A su vez, con 2.545 empleados al 31 de mayo de 1969, eran los que mayor dotación de personal poseían, después de los talleres ferroviarios de Tafí Viejo en Tucumán" (Pompei, 2017: 46-47). En rigor, si se tiene en cuenta la superficie total, variable que Pompei toma en cuenta para la afirmación, los Talleres Junín se encuentran en segundo lugar, siendo superados por los Talleres de La Plata, que tenían $345.999 \mathrm{~m}^{2}$. Si, en cambio, se tiene en cuenta la superficie cubierta, los más grandes eran los de Tafí Viejo, con 89.648 y Junín se encontraba, nuevamente, en segundo lugar, con $68.375 \mathrm{~m}^{2}$.
} 
Cena destaca la transformación que significó la nacionalización en las relaciones laborales y en el nuevo sentido de pertenencia que tuvieron en adelante los ferroviarios hacia la empresa. Además, valora el acontecimiento en tanto hecho político, ya que considera al medio de transporte como un servicio público y una herramienta para la integración nacional (Cena, 2008: 132). En rigor, la nacionalización era un objetivo planteado por algunos sectores de la sociedad durante la década del cuarenta. Uno de los intelectuales que durante esos años más contribuyó a postular la solución de la nacionalización para resolver el problema de la soberanía nacional fue R. Scalabrini Ortiz quien la interpretaba como "el primer paso ineludible de la liberación económica” del país (Scalabrini Ortiz, 1946: 22).

En tanto, el final del período de estudio en 1973 se justifica en que durante este año culminó una etapa en el ferrocarril, caracterizada por las políticas ferroviarias que tuvieron impulso durante los gobiernos de facto de la Revolución Argentina, con amplia repercusión a escala local, iniciándose una etapa nueva con políticas diferentes en materia ferroviaria a partir del gobierno constitucional de Héctor Cámpora. De acuerdo a Waddell, la nueva gestión que en 1973 llegó al ferrocarril revirtió gran parte de las medidas adoptadas por el gobierno anterior dirigidas a modernizar la gestión de la empresa (Plan de Mediano Plazo de 1969). Como consecuencia de ello, se cerró el financiamiento del Banco Mundial para ese fin, abandonando los objetivos planteados previamente en relación a la incorporación de material rodante y a la renovación de la infraestructura necesaria para mejorar el servicio (López et al., 2016: 187). Incluso, según el autor, a partir de los gobiernos peronistas de 1973 muchas de las prácticas improductivas que se habían comenzado a desterrar con el Plan de Mediano Plazo se restablecieron. Como consecuencia de ello, algunos proyectos locales iniciados durante la gestión de Juan Carlos De Marchi, quien fue presidente de Ferrocarriles Argentinos hasta marzo de 1971, dejaron de ejecutarse o se siguieron ejecutando, pero sin el apoyo de la Gerencia y la Presidencia de la empresa.

Por otra parte, el asesinato del sindicalista ferroviario de Junín, José Luis Piva, perpetrado por otros gremialistas de la lista azul en marzo de 1972, también parece indicar que estaba iniciándose una nueva etapa signada por la violencia política en Argentina en los más diversos ámbitos, como los gremios, y por la mayor presencia de los sindicatos en la escena pública. En ese sentido, Waddell denuncia que, a partir de la tercera presidencia de Perón, en 1973, los gremios ferroviarios tuvieron una "participación inusitada en la gestión de la empresa y esta entró en una etapa de total politización y de luchas facciosas internas" (2016: 187). Para sostener su argumento, el autor ejemplifica que el control de pasajes estuvo, en adelante, a cargo de la Juventud Peronista. A su vez, señala que las distintas corrientes internas del 
peronismo pujaron por tomar el control de la empresa. Un acontecimiento que torna evidente esta afirmación es la asunción de un líder de La Fraternidad (Cesáreo Melgarejo) como presidente de Ferrocarriles Argentinos. De esta manera, durante los gobiernos constitucionales posteriores a la Revolución Argentina se evidencia un cambio en las políticas ferroviarias y una complejidad que amerita un estudio más profundo de ese período. Como se verá, los testimonios recogidos contribuyen a reafirmar este recorte.

A partir del relevamiento de nuevas fuentes históricas, las orales, esta tesis se abocó al estudio de los imaginarios sociales de los ferroviarios durante este período, recuperando el esquema colectivo de interpretación de sus experiencias individuales, su sistema de valores y creencias, la forma en que construyeron una representación de sí y de su finalidad en la sociedad, así como la manera en que esto permitió moldear conductas, encauzar energías y conducir a acciones comunes (Baczko, 1991: 3).

Basados en testimonios orales, este trabajo los incorpora conformando una narrativa cultural, ya que se considera que los recuerdos nunca están aislados, sino que los actores se encuentran inmersos en un orden colectivo que los contiene (Barela, 2009: 16). A su vez, se recurrió a otros tipos de fuentes para complementar las orales, tal como las bibliográficas y las documentales, y poder así establecer los vínculos entre aquellas historias individuales y los procesos y relaciones sociales (Martínez Omaña, 1999: 1).

En el capítulo 1 de esta tesis, se recuperan las historias personales de trabajadores de Junín que pertenecieron a diferentes áreas del ferrocarril y ocuparon puestos jerárquicos diversos. En ese sentido, se indaga en cuáles eran los modos de ingreso, las maneras de progresar en el escalafón, los espacios de formación que posibilitaron el ascenso a puestos de mayor responsabilidad, así como en los sentidos asociados, según ellos, a la actividad ferroviaria en la ciudad.

En el capítulo 2, se indaga en cómo fue posible la construcción de una identidad ferroviaria común a partir de trabajadores que realizaban tareas tan diversas, así como en los sentidos particulares a partir de los cuales se consolidaron las representaciones asociadas al centro reparador local. También se estudian los vínculos de afecto forjados en el interior del colectivo que dieron vigor a la representación simbólica de "familia ferroviaria", así como los sentidos asociados al rol que el ferrocarril habría tenido en el desarrollo económico, social y cultural de la ciudad de Junín.

Los capítulos que siguen se refieren, específicamente, a los acontecimientos históricos de los cuales los actores entrevistados, que ingresaron en la empresa en las décadas de 1940 y 1950, fueron tanto testigos como protagonistas. En el capítulo 3, se analizan las 
transformaciones en los sentidos y en las prácticas ferroviarias que tuvieron lugar a partir de la nacionalización de la empresa en 1948. De esta manera, se contraponen esas nuevas experiencias y representaciones con las tradiciones previas, cuando el ferrocarril era de capitales británicos, considerando continuidades y rupturas que acontecieron durante el período desde la óptica de los actores.

En tanto, en el capítulo 4, se analizan distintas dimensiones de la crisis ferroviaria que atravesó la empresa en la década de 1960, tales como la disminución de personal, la formulación de planes para disminuir el déficit y la pérdida de la eficiencia del servicio ferroviario. A partir de ello, se examina la influencia que estos factores tuvieron en las representaciones sobre el trabajador del riel y sobre la comunidad ferroviaria. Por otra parte, también se recuperan algunas iniciativas locales que, sobre el final de la década, intentaron plasmar un proyecto superador de las experiencias anteriores que incrementara la eficiencia de la empresa y mejorara el servicio a la sociedad, a partir del conocimiento de ferroviarios de la ciudad. Estas iniciativas perdieron impulso frente a las nuevas políticas ferroviarias implementadas a partir del gobierno constitucional de Héctor Cámpora, en 1973.

En definitiva, esta tesis resulta un aporte a la historiografía ferroviaria desde la perspectiva de los imaginarios sociales, a partir del estudio de un período de veinticinco años signado por algunos acontecimientos fundamentales, tales como la nacionalización de la empresa en 1948 y la crisis ferroviaria que se evidenció en la década de 1960, los cuales suscitaron profundas transformaciones en la interpretación de las experiencias y en los valores del colectivo. Al mismo tiempo, es de importancia destacar la elaboración y puesta en práctica de algunos proyectos e iniciativas implementados a escala local, porque intentaron brindar una respuesta superadora a la crisis ferroviaria del país, a pesar de que no perduraron en el tiempo.

El objetivo general de esta tesis es:

Comprender los imaginarios sociales de los trabajadores del ferrocarril en Junín, desde la nacionalización de la empresa en 1948 hasta 1973.

\section{Los objetivos específicos son:}

1. Indagar en los sentidos asociados a la actividad ferroviaria, a partir de las historias personales de los trabajadores dentro de la empresa.

2. Estudiar los modos en que se construyó una identidad ferroviaria local, así como las características de los vínculos forjados en el interior de la "familia ferroviaria".

3. Analizar la influencia de la nacionalización de 1948 en las prácticas y en los nuevos 
sentidos asociados a la actividad ferroviaria, así como las tradiciones previas que, desde la óptica de los actores, se habrían mantenido.

4. Analizar la influencia que la crisis ferroviaria de inicios de la década de 1960 tuvo en las representaciones sobre el trabajador del riel y de la familia ferroviaria, recuperando iniciativas locales de finales de la década que plantearon una propuesta superadora.

\section{Hipótesis}

La bibliografía sugiere que los ferroviarios hasta —al menos — 1943 conformaban una suerte de "élite" de la clase obrera, por las buenas condiciones laborales y los beneficios de los que gozaban estos trabajadores. El interrogante que surge en torno a esta cuestión es cómo se autopercibían los trabajadores ferroviarios de Junín posteriormente a la nacionalización de 1948 y en qué medida la actividad ferroviaria que desarrollaban en la empresa se vinculada con su propia existencia, conformando, de esta manera, una continuidad entre vida laboral y personal. También interesa indagar cómo se vio afectado ese imaginario de su labor en la sociedad, a partir de la crisis que tiene lugar en la década del sesenta. Se considera, en esa línea, que el trabajo ferroviario continuó siendo, luego de la nacionalización, una actividad prestigiada socialmente, lo cual puede haber estado asociado con las condiciones laborales o con la formación demandada para el ingreso y promoción, y que, a partir de 1960, pudieron haberse visto afectadas las representaciones en torno a su labor, como consecuencia de la crisis que tuvo lugar durante esta década.

En segundo lugar, distintas investigaciones señalan que los trabajadores ferroviarios conformaban una comunidad con fuertes lazos de identificación entre sus miembros, construida a partir de determinadas normas y representaciones que guiaban su accionar, y que establecía, al mismo tiempo, un imaginario determinado de lo que era "ser ferroviario". Este imaginario del "auténtico" ferroviario y de la "familia ferroviaria" parece haberse construido, tanto a partir de políticas empresarias previas a la nacionalización, como desde el accionar colectivo de los trabajadores plasmado en, por ejemplo, algunas luchas conjuntas. En ese sentido, interesa comprender cómo se construyó localmente la identidad ferroviaria en Junín, a partir de qué elementos y acontecimientos. ¿Es posible que la identidad ferroviaria a escala local se haya construido a partir de un imaginario que asociaba a los trabajadores con la calidad y que se enorgullecía por la calidad de los trabajos realizados por este centro de reparación? En este sentido, también interesa indagar en la vigencia del imaginario de "familia ferroviaria" durante el período estudiado, así como en las experiencias y representaciones que lo habrían sustentado. 
En tercer lugar, con la nacionalización de 1948 se inauguró un nuevo ciclo en la historia ferroviaria, ya que fue la primera vez que el Estado nacional pasó a ser empresario de la totalidad de la red, y a tener responsabilidades tanto en el diseño de las políticas ferroviarias, como en la ejecución y el control de las mismas. Se estima que este hecho involucró profundas transformaciones en las prácticas laborales de los ferroviarios de Junín, así como en los sentidos asociados a la actividad ferroviaria. Simultáneamente, se considera que existieron prácticas y valores transmitidos por la gestión británica que continuaron más allá de la nacionalización y, en todo caso, que esto podría haber dado lugar a una disputa en el plano cultural dentro del colectivo ferroviario. En torno a esto la pregunta que se plantea es: ¿cómo se resolvió esta disputa y en qué medida influyó en la construcción imaginaria de los ferroviarios?

Por último, la bibliografía histórica coincide en que durante la década del sesenta la empresa ferroviaria se encontraba en crisis, por una disminución paulatina en el mercado de transporte, el desgaste y la falta de modernización de infraestructura y material rodante, y una relación negativa ingresos-egresos creciente. Como consecuencia de ello, los distintos gobiernos del período pusieron en marcha diferentes planes que tenían por objetivos, básicamente, disminuir el déficit y mejorar el servicio. Frente a esa situación los Talleres de Junín ¿pudieron ser un lugar de resistencia a la decadencia? Se considera que las respuestas de los trabajadores ferroviarios a las crisis pueden haber surgido a partir de aquella identidad imaginada asociada a la "excelencia" de la mano de obra. 


\section{Estado del arte}

Al estudiar la historiografía argentina sobre el ferrocarril puede advertirse que los primeros trabajos sobre el tema intentaron analizar durante períodos largos, desde los orígenes del medio de transporte en 1857, el rol que tuvo el capital extranjero en el crecimiento de la red ferroviaria, así como el modo en que esto impactó en el desarrollo del país. Este es el caso de la obra emblemática y pionera sobre el tema de Raúl Scalabrini Ortiz (1940) Historia de los Ferrocarriles Argentinos en la que el autor detalla la génesis y desarrollo de cada uno de los ramales en Argentina, desde sus inicios en el siglo XIX hasta antes de la nacionalización. Para Scalabrini Ortiz, existe una paradoja ligada a la historia misma del medio de transporte en la Argentina: a la vez que resultó un modo de integrar el país, también fue una manera de someter y dominar. Es decir, mientras el ferrocarril permitió conectar regiones distantes y estimular el desarrollo en esas zonas, también tendió a favorecer el tipo de intercambio comercial que le interesaba a Gran Bretaña, principal inversor, y a latifundistas nacionales: la exportación de materias primas e importación de productos manufacturados, frenando, mediante ciertos instrumentos (como las tarifas de transporte), cualquier intento de desarrollo industrial nacional. En este trabajo el autor denuncia lo que considera una disputa entre dos modelos económicos en el país: el agroexportador, aliado a Gran Bretaña, que, según él, favorecía la existencia de una red ferroviaria dominada por esa nación y frenaba otras formas de desarrollo posibles; el nacional que, en caso de haber triunfado, podría haber propiciado un desarrollo más armónico entre regiones, así como un Estado independiente y soberano. Además, el autor observa que, si bien las primeras iniciativas ferroviarias fueron llevadas adelante por capitales nacionales, paulatinamente, los diferentes gobiernos, interesados en instaurar un modelo agroexportador para Argentina, promovieron por medios legales, facilidades y ventajas de distinto tipo la adquisición de los ferrocarriles por capitales extranjeros, principalmente de Gran Bretaña.

Siguiendo esa línea que plantea una postura crítica sobre el impacto de las inversiones británicas en Argentina, la obra de Ricardo Ortiz (El ferrocarril en la economía argentina, 1946) analiza, desde una dimensión económica, la influencia monopólica de los ferrocarriles de capital privado en la economía argentina.

Posteriormente la bibliografía ferroviaria se ha visto renovada con aportes significativos como el de Eduardo Zalduendo (1975), quien, desde una perspectiva de historia económica comparada, demuestra el rol que tuvo Gran Bretaña en la expansión ferroviaria mundial. Dicha expansión británica, de acuerdo al autor, estuvo orientada a estimular la propia 
industria a la vez que pretendió ejercer un control del comercio a nivel mundial. En Libras y rieles el autor analiza el papel que cumplieron los contratistas y sus asociados, quienes se beneficiaron particularmente en la etapa de construcción de los ferrocarriles, en detrimento de los pequeños inversores. ${ }^{6}$

Dentro del grupo de trabajos que analizan la evolución de la política ferroviaria en Argentina durante períodos largos, se encuentra la obra más reciente de Mario Justo López, Jorge Eduardo Waddell y Juan Pablo Martínez (2016), Historia del Ferrocarril en Argentina, la cual ha significado una contribución importante puesto que permite contextualizar cada uno de los recuerdos de los testigos a partir de los diferentes acontecimientos relevantes de cada momento histórico. Los autores emplearon el concepto de "políticas públicas" como criterio para seleccionar hechos y formular relaciones durante el período estudiado. En esa línea estudian la labor emprendida desde el Estado para elaborar una política pública como acción de gobierno durante 160 años. El libro se divide en seis períodos, cuyo recorte se realiza cada treinta años. En cada uno de los períodos se describe la evolución de cada política específica, en algunos momentos más favorables a la inversión de capitales privados y en otros a la inversión pública del servicio, así como los resultados obtenidos.

López plantea que el primer período (1857-1886) estuvo caracterizado por el pragmatismo, recurriéndose tanto a capitales públicos como privados, bajo la meta de desarrollar la red al máximo, y conviviendo, al mismo tiempo, con políticas públicas provinciales que propiciaron un desarrollo desordenado y caótico. Según el autor, durante el segundo período (1887-1916) se habría adoptado la explotación a través de la forma de empresa privada. En la tercera etapa (1917-1946) el Estado habría reforzado su rol de contralor frente a la actividad privada, al mismo tiempo que habría retomado sus iniciativas como empresario. El acontecimiento distintivo de la cuarta etapa (1947-1976) es la nacionalización ${ }^{7}$ que, para Waddell, fue un hecho inevitable, como resultado de la crisis de las empresas de capitales británico (a diferencia de lo que plantea Scalabrini Ortiz, para quien resultaba un hecho necesario para que el Estado emprenda una política soberana). Además, caracteriza esta etapa la ausencia de políticas firmes y definidas en torno al problema ferroviario. El quinto período (1977-2006), analizado por Martínez, se distingue por una serie de políticas discontinuas que,

\footnotetext{
${ }^{6}$ En esta etapa también surgieron contribuciones significativas como la de Lewis, 1983. De este período es el trabajo de Wright, 1980, quien se centra en el surgimiento del nacionalismo económico, generado a partir de la inversión extranjera en infraestructura.

${ }^{7}$ Puede profundizar en las condiciones en que tuvo lugar la nacionalización de ferrocarriles en López, 2008; López, 2016; Horowicz, 2005 (113-127). También Salerno ha realizado una contribución significativa al reflexionar acerca de la disolución de la Administración General de Ferrocarriles del Estado y el modo en que se organizaron los ferrocarriles a partir de 1948: Salerno, 2020.
} 
en su conjunto, habrían contribuido a disminuir la importancia del ferrocarril en el país. Para el sexto (2007-2016), en tanto, Waddell exhibe las consecuencias de las modificaciones de las políticas de concesiones y las reformas, que califican de infructuosas, para salir de la situación de crisis.

Otro aporte historiográfico valioso es Estudios sobre la historia de los ferrocarriles argentinos (1857-1947), [Schvarzer, Regalsky, Gómez (comp.), 2007] el cual ha contribuido en la comprensión de etapas previas a las abordadas en esta tesis que, no obstante, tuvieron influencia posterior. Esta obra es el resultado de artículos de diferentes investigadores analizan el mismo período de Scalabrini Ortiz, desde la fundación del primer ferrocarril hasta el momento previo a la nacionalización de las empresas británicas en 1947. El primer trabajo recrea las discusiones en torno al posible reparto de la tierra a lo largo de las vías para expandir la agricultura (Gómez y Schvarzer, 2007: 11-48); ${ }^{8}$ el segundo escrito (Barry, 2007: 49-90) analiza el caso de la venta del Ferrocarril del Oeste, de capital estatal, y permite exponer las discusiones entre dos corrientes: una tendiente a favorecer el capital privado y la otra a favor de la intervención estatal; ${ }^{9}$ el tercero y cuarto artículo abordan la denominada "Ley Mitre", tan debatida durante la nacionalización posterior, la cual fue, según los autores, un instrumento que permitió ordenar las inversiones privadas y que benefició a este tipo de capital (López, 2007: 91-122; Regalsky, 2007: 123-154); ${ }^{10}$ el quinto recupera las iniciativas estatales durante los gobiernos radicales (Salerno y Regalsky, 2007: 153-188); ${ }^{11}$ el sexto muestra las diferentes iniciativas inglesas por enfrentar su propia crisis, como consecuencia de las guerras y de la Gran Depresión de 1930, y mejorar los servicios a los usuarios con mínima inversión de capital, ante la inminente pérdida del monopolio del transporte por el avance de la industria automotriz (Waddell, 2007: 189-222). El último artículo, analiza el rol que tuvieron los comerciantes y terratenientes locales asociados con los sectores británicos para realizar una de las mayores inversiones del siglo XIX, así como la posterior concentración y las crisis de estas empresas (Lewis, 2007: 223-270).

Existe otro trabajo de referencia, El ferrocidio (2008), realizado por un exferroviario e historiador aficionado del ferrocarril, que ha sido empleado en esta tesis para contrastar el análisis histórico realizado por López et. al. (2016) y los recuerdos de los actores. En el inicio,

\footnotetext{
${ }^{8}$ Los autores han profundizado esas temáticas en trabajos tales como Schvarzer y Gómez, 2006; Schvarzer y Gómez, 2003; Schvarzer y Gómez, 2001.

${ }^{9}$ Sobre este tema puede profundizarse en Regalsky, 2007, Regalsky, 2008. Para ampliar sobre la cuestión ver también Gómez, 2009.

${ }^{10}$ Sobre los mecanismos de control de capital sobre las empresas ferroviarias a partir de la ley Mitre, ver también estudio de caso del Ferrocarril Sud de Waddell, 2013.

${ }^{11}$ Ver también Regalsky y Salerno, 2008.
} 
Juan Carlos Cena sintetiza someramente el origen de cada uno de los ramales para relatar en detalle el contexto de la nacionalización que tuvo lugar en 1948, sus logros y transformaciones. Luego continúa refiriendo lo que ocurre después de la caída de Perón en 1955, y durante los sucesivos gobiernos militares y democráticos que fomentaron — según sus investigaciones y su experiencia concreta - la debacle del medio de transporte. Congruentemente con otras memorias sobre el período, el autor identifica al gobierno de Arturo Frondizi (1958-1962) como el iniciador de una ofensiva directa contra el ferrocarril y contra los ferroviarios, en consonancia con una política que favorecía la industria automotriz. A partir de entonces recorre la historia del ferrocarril en todos los gobiernos que se suceden a Frondizi para concentrarse en el proceso privatizador del presidente Carlos Menem en los noventa, que dio lugar a la concesión de ramales, así como a la reducción abrupta y disminución de la calidad de los servicios. Aludiendo al subtítulo del libro "la telaraña de las privatizaciones", el autor muestra cómo los integrantes de un gobierno que califica de corrupto promovieron la concesión de los diferentes ramales en condiciones muy desventajosas para el Estado nacional y la sociedad civil. Bajo el argumento de una mejora en el servicio y la modernización de la red, esta política, según el autor, se llevó adelante y se continuó en los gobiernos sucesivos que también analiza: Eduardo Duhalde (2002) y Nestor Kirchner (2003-2007). Podríamos considerar que Cena (2008) intenta continuar la obra de Scalabrini Ortiz, que culmina en 1947, ya que, desde una retórica similar al autor, combina la exposición de datos cuantitativos que permiten sostener los argumentos, con los planteos expresados de manera apasionada y visceral. Lo hace a partir de ideas o preconceptos previos sobre el rol que debería tener el ferrocarril en el país, así como de los culpables de que esto no haya ocurrido de esta manera.

Existen otro grupo de trabajos que analizan durante períodos más acotados el rol del Estado en las políticas públicas en materia ferroviarias. Tal es el caso de Silvana Palermo (2001) que estudia la expansión que tuvieron los Ferrocarriles del Estado bajo los gobiernos radicales, concebidos por estos como un instrumento para el desarrollo regional y la integración de las provincias del norte con el centro y este del país. La autora plantea que, con su obra de gobierno, el radicalismo construyó líneas nuevas y amplió los servicios, pero también cuestionó la legitimidad de la fórmula liberal que asociaba progreso a orden. El gobierno radical, en cambio, proponía una fórmula nueva, que asociaba progreso con democracia, invirtiendo la lógica liberal al sostener que solo un gobierno legítimo podía modernizar las instituciones del Estado de modo tal de asegurar el progreso para todos. En ese sentido cuestionaba al "régimen" por no haber expandido la red ferroviaria en la dirección adecuada, ni haber logrado introducir las técnicas más modernas para mejorar el servicio ferroviario. Así, según la autora, la expansión 
de los Ferrocarriles del Estado ofreció al radicalismo no solo la oportunidad para asociar progreso con democracia, sino también nacionalismo con modernidad. De esta manera, los Ferrocarriles del Estado resultan, de acuerdo a Palermo, un excelente caso de estudio para explorar cómo imaginó el radicalismo el desarrollo económico y la modernidad de la Argentina. ${ }^{12}$

Dentro de este grupo de trabajos que analizan las políticas públicas emprendidas por el Estado en períodos puntuales, algunos tienen en cuenta como dimensión para su análisis el rol de los profesionales en el desarrollo del medio de transporte, así como la creación de una burocracia técnica. En otro trabajo posterior, Palermo (2006b) estudia cómo los ingenieros diplomados lograron, entre 1870 y 1910, una inserción exitosa en el ámbito estatal y fueron capaces de transformar a los Ferrocarriles del Estado en una empresa moderna. La autora explora la relación entre la formación del aparato estatal y el desarrollo de la ingeniería como campo profesional, así como los factores que contribuyeron a que los ingenieros se consolidaran como autoridad dentro de las empresas ferroviarias pertenecientes al Estado. En ese sentido, Palermo afirma que mientras el gobierno se fortaleció gracias a la labor de especialistas, estos alcanzaron un espacio donde desarrollar sus tareas profesionales, consolidando el prestigio de la disciplina e incursionando en la política. Dentro de la empresa, los ingenieros tuvieron la oportunidad de demostrar la utilidad de sus saberes, a partir de nociones vinculadas a la eficiencia. Esto condujo a que reclamaran el derecho de dirigir la administración y obtener el poder necesario para convertir a los Ferrocarriles del Estado en una empresa moderna, capaz de competir con las privadas.

Otro de los trabajos en esa línea es el de Elena Salerno (2015) quien analiza la formación de una tecnocracia especializada en los ferrocarriles, la cual habría estado en sintonía con la consolidación del Estado Nacional. La autora sostiene que con el ferrocarril en Argentina, los ingenieros se convirtieron en una burocracia técnica encargada del estudio, la construcción y el funcionamiento operativo. Aunque los primeros ingenieros que tuvo el ferrocarril se contrataron en el exterior, algunos años después comenzaron a ser formados en las universidades del país. Apenas graduados, ocuparon puestos en los diferentes organismos y ferrocarriles estatales. Así, la autora identifica dos tipos de carreras: por un lado, las de quienes se desempeñaron en funciones técnicas a lo largo de la red y por el otro, las de aquellos que

\footnotetext{
${ }^{12}$ Para complementar este tema puede leerse a López (2013), quien se refiere a la política ferroviaria del gobierno radical de Yrigoyen respecto de las empresas extranjeras. Sobre el tema, véase también: Goodwin, 1974; Palermo, 2006a; Palermo, 2012.
} 
ocuparon cargos de gestión. ${ }^{13}$

En otro trabajo Palermo (2007) estudia el rol que tuvieron distintos actores y agencias estatales en la construcción de los Ferrocarriles del Estado, desde 1862 a 1916, analizando, al mismo tiempo, los conflictos que se suscitaron entre ellos. En efecto, Palermo reconoce que tanto los legisladores como los profesionales del Ministerio de Obras Públicas contribuyeron al proyecto y construcción de una red ferroviaria estatal de envergadura. Sin embargo, la concentración de poder en manos del Poder Ejecutivo conllevó un proceso de centralización administrativa (representada por el Ministerio de Obras Públicas) que fortaleció el poder de los profesionales en detrimento de la autoridad legislativa. En su trabajo, se describen tensiones entre los expertos ministeriales y el Parlamento. Los primeros, intentaron subordinar las iniciativas parlamentarias a los nuevos criterios de eficiencia y rentabilidad que empleaban para el programa de construcción de las líneas estatales. A estos conflictos, se sumó otro: el Ministerio comenzó a planificar el diseño de la red estatal a partir del objetivo de integrar a los territorios nacionales, concibiendo a la de "obra pública" de una manera diferente al Parlamento que había operado hasta 1890. La urgencia estatal se trasladó, entonces, a aquellas regiones más alejadas de la sede del gobierno nacional, las regiones de frontera, generando un conflicto con las provincias. De esta manera, de acuerdo a la autora, los Ferrocarriles del Estado, nacidos como expresión del pacto entre el gobierno nacional y las provincias, en su segunda etapa de expansión (tras la crisis de 1890) se convirtieron en uno de los escenarios donde se desplegaron los enfrentamientos entre ambos, que vendrían a minar la unidad del partido de gobierno.

Existen otro grupo de investigaciones que abordan la problemática ferroviaria desde la perspectiva de la historia de las empresas. Tal es el caso de Laura Badaloni (2013), quien estudió las medidas tomadas por el Ferrocarril Central Argentino (FCCA) durante las primeras décadas del siglo XX para estructurar las labores ferroviarias de acuerdo a los principios tayloristas de administración científica del trabajo. Lo valioso del abordaje que realiza la autora es que emplea y relaciona fuentes diversas: de los representantes de la compañía (documentos elaborados por los ingenieros), por un lado; y de los trabajadores (publicaciones obreras), por el otro.

Badaloni plantea que los ingenieros que representaban la dirección de la compañía fueron, a la vez que difusores de las novedades de la organización científica del trabajo, ejecutores de los talleres que tenían a su cargo. De esta manera, implementaron la separación

\footnotetext{
${ }^{13}$ Para profundizar sobre este tema ver: Salerno, E. 2002; Salerno, 2006.
} 
entre las tareas de concepción y ejecución, el empleo de incentivos a la producción y un mayor control en los tiempos del obrero. Las fuentes obreras de aquel momento, por su parte, denunciaban los daños que la implementación de este paradigma estaba ocasionando en la salud de los trabajadores, al mismo tiempo que reclamaban el derecho de realizar las tareas a ritmos que consideraban "más humanos". En consecuencia, llevaron adelante actos de resistencia hacia la autoridad (pérdidas de tiempo y absentismos programados), los cuales pretendieron desafiar el monopolio del control del tiempo por parte de la dirección. En un periódico comunista se impugnaba también la voracidad de los propios compañeros que adherían mediante su accionar a esta organización científica del trabajo, a los que tildaban de egoístas y poco solidarios. En efecto, los reclamos obreros, si bien estaban centrados en la compañía, también iban dirigidos a los obreros, apelando a una ética proletaria. Esto permite interpretar, más allá de la resistencia obrera, que la empresa había logrado cierto consenso entre los trabajadores.

Dentro de lo que podría considerarse historiografía empresarial, Badaloni (2007) estudia también las estrategias desplegadas por el FCCA para controlar y coordinar la tarea de miles de empleados y garantizar el transporte de pasajeros y mercancías de manera eficaz. En ese sentido considera que la compañía combinó estrategias represivas con prácticas paternalistas, las cuales apuntaban a generar consenso entre los empleados e identificación hacia la empresa. Entre las prácticas represivas, Badaloni describe distintos instrumentos para disciplinar a los trabajadores, como los reglamentos internos y las órdenes de servicios, los cuales instruían respecto de lo laboral, pero también brindaban pautas en relación al aseo, la conducta y la lealtad a la empresa. Siguiendo a la autora, se intentaba crear la idea de que existía un poder omnipresente que observaba, escuchaba y controlaba, y que estaba constantemente preocupado por la eficacia de los empleados y su comportamiento. Paralelamente, se apuntaba a quebrar la solidaridad entre trabajadores, estimulando la delación para lograr ascensos. Por otro lado, entre las prácticas paternalistas Badaloni menciona: torneos de fútbol internos, competencias con premios monetarios, concursos literarios, premios anuales a las estaciones más limpias, creación de una escuela para niños del personal y de la Sociedad de Socorros Mutuos, el tren obrero, la construcción de viviendas. Las prácticas paternalistas y las acciones represivas constituyeron, según la autora, un dispositivo único cuyo propósito era el disciplinamiento de la mano de obra. Para Badaloni, si bien la política empresaria tuvo cierto grado de éxito en el intento de lograr identificación y consenso, falló al momento de impedir el conflicto social. Como prueba de ello, la autora presenta las huelgas que la empresa debió enfrentar en Rosario, especialmente la de 1917, la cual tuvo características de violencia 
inusuales.

En un trabajo posterior, Badaloni (2011) profundiza en la línea mencionada dando cuenta de las diferentes iniciativas empresariales del FCCA a principios del siglo XX, destinadas a quebrar las solidaridades horizontales entre los trabajadores e impedir la organización autónoma de los sindicatos, intentando suplantar a estos por vínculos de deferencia vertical. De esta manera, la "familia ferroviaria" se conformaba en base a "lealtades de hierro", logradas tanto a partir de estrategias de control y castigo, como de acciones paternalistas implementadas por la empresa, cuya meta era el involucramiento de los trabajadores con los intereses de la compañía. Una de estas acciones empresariales fundamentales, destinadas a fortalecer los lazos de identificación con la empresa, era la de brindar condiciones de trabajo atractivas, que incluían la estabilidad del personal y la posibilidad de lograr ascensos en la carrera. Para lograr esta identificación, la empresa también se valió de distintas acciones que intentaron avanzar sobre el tiempo libre de los trabajadores, proponiendo alternativas de esparcimiento (torneos internos, revista que mostraba la vida interna de la empresa). Si bien esta estrategia paternalista no habría sido del todo exitosa a la hora de impedir protestas por parte de los maquinistas, personal de Talleres y Tráfico, sí habría impactado de manera eficaz en los empleados de oficinas. Badaloni sugiere, finalmente, que algunas de las políticas de bienestar y ocupación del tiempo libre de la compañía pudieron ser apropiadas posteriormente por los trabajadores y llevadas adelante a través de sus sindicatos, en las décadas siguientes previas al peronismo. Además, sostiene que la idea de "familia ferroviaria", que continúa luego de la nacionalización del ferrocarril, podría rastrearse en los primeros años XX y pronunciada en inglés: the Railway Family. ${ }^{14}$

Este último trabajo de Badaloni resulta una contribución enriquecedora para la tesis, ya que sugiere que la génesis de la representación simbólica de "familia ferroviaria", tan presente entre los trabajadores del riel de las décadas posteriores a 1950, podría hallarse en las políticas empresarias británicas. De esta manera, el éxito de aquellas políticas habría sido tal que, una vez que la empresa británica dejó de existir, continuó vigente como representación, de la misma manera que algunas de las acciones empresariales que la fomentaron (condiciones laborales, alternativas de esparcimiento, etc.).

En esa línea, el trabajo de Joël Horowitz (1985) sugiere que los trabajadores del riel constituyeron, entre 1920 y 1943, lo que denomina una "comunidad ocupacional", es decir, una sociedad en la que sus integrantes estaban influidos de manera tal por el trabajo que la vida

\footnotetext{
${ }^{14}$ Otro trabajo sobre los sentidos asociados a la representación de “familia ferroviaria” de Junín: Sagastume, 2017.
} 
entera de cada uno estaba impregnada por los intereses, relaciones y valores del ámbito laboral. El sentido de pertenencia que los ferroviarios desarrollaron fue posible, según el autor, gracias a las diferentes formas organizativas que fueron asumiendo los trabajadores a través del sindicato de la Unión Ferroviaria, así como mediante la creación de sus propias cooperativas y mutuales. ${ }^{15}$ Este trabajo aborda un período posterior al de Badaloni (2011) y puede considerarse dentro del grupo de investigaciones sobre el ferrocarril que conforman la historia del movimiento obrero. Con todo, ambos trabajos, el de Badaloni y el de Horowitz, intentan comprender un fenómeno similar que parece haber tenido continuidad en momentos históricos diferentes: ya sea desde la representación de "familia ferroviaria" acuñada por la empresa británica o por los mismos trabajadores, o desde el concepto teórico de "comunidad ocupacional", estos intentan explicar los fuertes lazos de identidad del colectivo ferroviario. Precisamente, esta tesis también pretende realizar un aporte a la problemática de la identidad ferroviaria a partir de la segunda mitad del siglo XX.

En este trabajo, Horowitz sostiene que la Unión Ferroviaria, tras su fundación en 1922, se convirtió muy rápidamente en una de las organizaciones más importantes del movimiento obrero argentino e indaga en los motivos por los cuales tuvo tal grado de éxito como sindicato, habiendo podido concretar importantes convenios laborales e impidiendo despidos de trabajadores en contextos económicos del país poco favorables. Horowitz considera que, si bien esto estaba relacionado con el rol estratégico que tenía el ferrocarril para la nación, sus logros debían comprenderse, principalmente, por esa "comunidad ocupacional" que los ferroviarios constituían. En otras palabras, la identificación que los ferroviarios tenían por su actividad, sus compañeros y su sindicato les permitió convertirse en un gremio fuerte. Algunos de los logros obtenidos por el gremio durante el período fueron: sistema de promociones en base a la antigüedad, vacaciones, licencias por enfermedad, caja de jubilaciones, préstamos para el "hogar ferroviario", convenios para frenar los despidos, entre otros. Pero, además, los trabajadores del riel crearon otras entidades, a instancias del gremio, que fortalecieron el sentido de "comunidad ocupacional" a la vez que mejoraron su calidad de vida: la comunidad de guardas, comedores, cooperativas de consumo, asociaciones de ayuda mutua, bibliotecas, clubes. De esta manera, los ferroviarios pudieron transformarse, según el autor, en una suerte de élite dentro del movimiento obrero, con altos sueldos y buenas prestaciones sociales para

\footnotetext{
${ }^{15}$ Sobre las prácticas mutualistas de trabajadores ferroviarios y el contexto de surgimiento, puede ampliarse con el trabajo de D’Uva, 2019.
} 
sus trabajadores. ${ }^{16}$

En un trabajo posterior, Horowitz (2002) estudia los motivos por los cuales se desarrollaron intereses recíprocos entre los gremios ferroviarios y los gobiernos radicales de las primeras décadas del siglo XX. En efecto, mientras los gobernantes consideraban ventajoso acercarse a los potenciales votantes de la clase obrera y asegurar el orden social disminuyendo las huelgas, los trabajadores encontraron beneficioso contar con el gobierno como mediador frente a las compañías ferroviarias extranjeras.

Según el autor, distintos motivos favorecieron que los gremios tuvieran tal fortaleza frente a los gobiernos: el enorme poder desestabilizador que, potencialmente, los ferroviarios tenían, ya que eran capaces de paralizar al país; la capacidad de modelar al movimiento obrero general por estar dispersos en distintos puntos de la Argentina y moverse por toda la red; la comunidad ocupacional que constituían, con fuertes lazos de identidad y solidaridad. El gobierno, por su parte, contemplaba las ventajas de negociar con un gremio centralizado, luego de las olas de huelgas desatadas entre 1917 y 1920, generadas por las bases y que no respetaron las directrices de los líderes. En esa línea, La Fraternidad, que nucleaba al personal de conducción de locomotoras, constituía un modelo a tener en cuenta, por el control que ejercía sobre sus sindicados y por acudir a huelgas solo eventualmente. Por ello Horowitz considera que Yrigoyen estimuló en 1920 la creación de la Cofraternidad. Luego de la creación de la Unión Ferroviaria en 1922, que se convertiría en el gremio ferroviario más poderoso, los gobiernos aspiraron a mantener el orden social a cambio de concesiones, así como a hacerse populares entre los trabajadores. Sin embargo, según el autor, el éxito fue relativo: tanto La Fraternidad como la Unión Ferroviaria intentaron evitar el compromiso político directo con las administraciones.

Dentro de la historia del movimiento obrero, hay un grupo de investigaciones que abordan la temática a partir de algunos conflictos puntuales entre los trabajadores y las compañías ferroviarias (antes de 1948) o el Estado (luego de 1948). Ya se han mencionado algunos trabajos de Badaloni $(2007,2011)$ en los que la autora plantea las políticas empresarias que buscaron generar consenso e identificación hacia la compañía entre los trabajadores, pero que tuvieron pocos resultados en Rosario para eludir los conflictos de la huelga de $1917 .{ }^{17}$ También Palermo (2008) estudia la que considera la primera "gran huelga" ferroviaria. Su

\footnotetext{
${ }^{16}$ D’Uva (2020) matiza esta perspectiva que considera a los trabajadores ferroviarios como una élite de la clase obrera, cuando estudia las condiciones laborales de quienes trabajaban en cuadrillas en Vía y Obras.

${ }^{17}$ Existe otro conflicto ferroviario previo, en 1912, protagonizado por los maquinistas, que fue estudiado por Suriano (1991) y permite contextualizar las condiciones previas a la "gran huelga" de 1917. En este trabajo se analiza la actitud que tomaron distintos funcionarios del gobierno de Sáenz Peña frente a la conflictividad obrera.
} 
abordaje es, según plantea, "global" abocándose al estudio de la influencia de los discursos nacionalistas e internacionalistas en el lenguaje político de los trabajadores durante el primer gobierno democrático del país, de Hipólito Yrigoyen. En ese sentido, se plantea cómo la contienda mundial moldeó estos discursos.

Palermo postula que, antes de la Primera Guerra Mundial, las compañías de capitales británicos y franceses intentaron invisibilizar las divisiones de clase y los conflictos obreros fomentando una idea de "familia ferroviaria" cosmopolita, en la que convivían en armonía obreros de múltiples nacionalidades y diversas jerarquías ocupacionales. Para estimular este ideal llevaron adelante prácticas paternalistas que incluyeron distintas actividades recreativas para el conjunto de la "familia ferroviaria", así como programas de salud y vivienda con los cuales intentaban generar consenso en los trabajadores. Por su parte, los militantes obreros criticaban esta política empresaria que según ellos, intentaba eludir los conflictos y, en su lugar, incitaban a que los trabajadores tomaran conciencia y adhirieran a una solidaridad de clase.

La autora pone de manifiesto que, con la contienda mundial, algunas empresas persiguieron a trabajadores pertenecientes a las naciones enemigas (alemanes, austríacos), mientras presionaron a trabajadores connacionales para cumplir con sus obligaciones militares. Esto les dio la oportunidad a los militantes sindicales de denunciar los abusos de distinto tipo de las compañías extranjeras. La expectativa que tenían, según la autora, era que el gobierno elegido democráticamente, quien se había declarado neutral en la guerra, garantizara a los trabajadores derechos iguales para todos los habitantes de la nación argentina. Sin embargo, la represión estatal hacia los obreros en la huelga de 1917, que dejó un saldo importante de heridos y muertos, echó por tierra estas esperanzas hacia el gobierno democrático. Los funerales públicos realizados por los obreros, con amplia concurrencia de la comunidad ferroviaria, fueron, para Palermo, una manera en la que los trabajadores reforzaron la solidaridad de clase, poniendo en evidencia el fracaso del gobierno nacional para garantizar los derechos de los trabajadores, así como la falacia de la idea de "familia ferroviaria" multinacional y armónica proyectada por las compañías. ${ }^{18}$

Otro de los conflictos que ha suscitado la atención de los investigadores del ferrocarril y que es parte de algunas memorias ferroviarias son las huelgas de noviembre y diciembre de 1950, y enero de 1951. Estos conflictos tuvieron la particularidad de llevarse adelante por parte de organizaciones surgidas ad hoc, ya que la cúpula de la Unión Ferroviaria, por estar alineada

\footnotetext{
${ }^{18}$ Puede profundizarse en el tema en un trabajo de Badaloni (2016) en el que la autora analiza las políticas empresariales del Ferrocarril Central Argentino y las respuestas de los trabajadores en el contexto de la Primera Guerra Mundial.
} 
con el gobierno peronista, no apoyó estas huelgas.

Gustavo Nicolás Contreras (2009) analiza las fases de estas huelgas que comenzaron en noviembre de 1950 y culminaron en enero de 1951. En principio, contextualiza que estas fueron realizadas en escenario totalmente diferente a las anteriores: no solo le reclamaban al mismo gobierno que había nacionalizado los ferrocarriles, sino también al que había incorporado a los gremios en el directorio de la empresa. El conflicto se inició porque, en un contexto signado por la crisis económica, la dirección de Ferrocarriles intentó implementar políticas de productividad mediante la racionalización de la explotación de la fuerza de trabajo. Según el autor, la orientación productivista renegaba con muchas de las conquistas logradas por los trabajadores. Probablemente, como consecuencia de ello, se crearon las Comisiones de Enlace en las que los trabajadores comenzaron a discutir los problemas que los aquejaban. Uno de los puntos de desacuerdo con la gerencia fue la escala de sueldos propuesta para los sectores menos calificados que, según estos, era insuficiente teniendo en cuenta la inflación. Esta acción autónoma de los trabajadores suscitó un conflicto de jurisdicción con la Unión Ferroviaria. De hecho, ya desde la primera huelga, en noviembre de 1950, los trabajadores, además de apuntar a mejoras salariales. reclamaban la renuncia de la Comisión Directiva del gremio. En tanto, la Unión Ferroviaria, en la misma línea de la CGT, intentó restarle legitimidad a la huelga, acusando a los resistentes de opositores del gobierno.

En su trabajo, Contreras describe los conflictos que tuvieron lugar entre la cúpula del gremio y el gobierno nacional, por un lado, y los trabajadores nucleados en las Comisiones de Enlace, por el otro. También da cuenta de los conflictos en el interior del gobierno por el tratamiento del conflicto, particularmente entre el Ministerio de Transporte y el Ministerio de Trabajo que se disputaban su intervención en la resolución, llegando el primero a actuar en favor de las Comisiones de Enlace y siendo descalificada esta acción por el propio Perón. Además, el autor describe las profundas diferencias en el interior del sindicato, a partir de la creación de una Comisión Consultiva de Emergencia que exigió y logró la renuncia de la Comisión Directiva del gremio, hecho que tuvo como consecuencia la intervención del sindicato por parte de la CGT.

Luego de esta intervención, los trabajadores, además de reclamar por incrementos salariales, demandaban que se reabran las seccionales y se permita la celebración de asambleas, en vista a las elecciones fijadas para febrero. En todo momento, al mismo tiempo que cuestionaron a las cúpulas gremiales intentaron demostrar su apoyo a Perón, esperando que el presidente resolviera a su favor el conflicto. Sin embargo, luego de declarada la última huelga, el 23 de enero, Perón actuó en el sentido inverso: informó que los trabajadores que no se 
presentaran serían exonerados y entregados a la Justicia Federal, promulgó para el día siguiente la movilización del personal ferroviario y el procesamiento de acuerdo al Código de Justicia Militar, y negó cualquier legitimidad a las Comisiones de Emergencia. Como resultado de ello, el 26 de enero se levantó la huelga y los trenes volvieron a funcionar con normalidad. Contreras observa que el modo en que se resolvió este conflicto marcó un proceso de verticalización y centralización de los gremios, bajo el mando de Perón, concentrando el poder en las cúpulas sindicales y restándole libertad a las iniciativas de las bases.

Hugo Mengascini (2009) también estudia las huelgas de 1950-1951 en Tandil, así como la huelga de agosto de 1951 por parte de trabajadores de La Fraternidad. A partir de fuentes orales de ferroviarios de Tandil y diarios locales, el autor expone las profundas divisiones que generó el conflicto a escala local entre trabajadores que adhirieron y no adhirieron a tales huelgas. En el caso de los conflictos de los trabajadores de la Unión Ferroviaria, el autor demuestra que, a pesar de las directivas de la cúpula gremial, la presión de la CGT y la represión policial, los huelguistas se manifestaron para reclamar por mejoras salariales, demostrando un alto grado de solidaridad en la lucha por la libertad de presos y la reincorporación de los cesanteados. Esto provocó fragmentaciones entre los trabajadores: mientras los huelguistas fueron acusados por la CGT y la cúpula gremial de comunistas, socialistas y radicales que actuaban en contra del gobierno peronista, los resistentes acusaban a estos otros de ir en contra de los intereses de los trabajadores.

En este trabajo Mengascini también estudia la intervención, meses después, de La Fraternidad, lo cual dio lugar al desplazamiento de los líderes opositores más combativos, con el propósito de establecer un sólido control sobre los afiliados a partir de su reemplazo por líderes peronistas. De acuerdo al autor, esto provocó un descenso de la participación de los afiliados en la vida de los sindicatos y la división entre trabajadores fraternales que, durante un largo período y a partir de esa huelga, tuvieron dos Sociedades de Casas de Alojamiento y Comunas separadas. En ambas huelgas, Mengascini muestra las consecuencias que estos conflictos tuvieron en las divisiones dentro de los gremios, originadas por la introducción de orientaciones político-partidarias que los sindicatos, previo al gobierno peronista, habían intentado eludir.

También Badaloni (2013) recupera los recuerdos de trabajadores de Rosario y Pérez en torno a las huelgas de 1950 y 1951, así como la Marcha de la Paz en 1950 en contra del envío de tropas a Corea. En estos casos, según la autora, los trabajadores debieron enfrentar a la dirección sindical peronista, así como a los referentes políticos locales y nacionales. El gobierno respondió con dureza, tanto la huelga como la marcha pacifista, mediante represión y 
despidos, ya que, según interpreta Badaloni, la acción autónoma de los trabajadores no podía ser tolerada. Para la autora, el peronismo se apoyaba en la movilización de los sectores obreros y populares, aunque controlada, vigilada y restringida.

Desde una metodología propia de la Historia Oral y a partir de una perspectiva teórica que tiene en cuenta el plano de la memoria, Badaloni recupera fuentes documentales y las triangula con los recuerdos de los informantes, notando que no coinciden en su totalidad. Si bien los trabajadores comunistas u opositores destacaron en sus relatos la persecución, la cárcel, la tortura, muchos de los obreros peronistas recordaron su lealtad sin fisuras a Perón, olvidando las huelgas de 1950-1951 o confundiéndola con otra huelga importante, ocurrida diez años después: la huelga de 1961 realizada al gobierno de Arturo Frondizi. Aunque algunos de estos últimos recordaban la "Marcha por la Paz", no fueron capaces de evocar los numerosos ferroviarios que fueron despedidos como consecuencia de contradecir las directivas del gremio y del gobierno. De esta forma, la autora interpreta que, dado que el peronismo significó para la mayoría de los ferroviarios entrevistados un reconocimiento de sus derechos a nivel económico y simbólico, los acontecimientos del pasado fueron manipulados para que no dejasen evidencias de la acción antiobrera del gobierno peronista.

Este último trabajo resulta una contribución significativa para esta tesis, ya que Badaloni demuestra que los recuerdos de los actores sobre los hechos vividos están ligados a los sentidos que los testigos les otorgaron a los acontecimientos dentro del propio relato de vida, evocado desde el presente. Precisamente, desde la Historia Oral esta tesis se concentra en los significados que los actores les atribuyen a los acontecimientos vividos, así como en los hechos que los testigos seleccionaron como importantes o significativos dentro del propio relato de vida, contrastando esos recuerdos con otras fuentes bibliográficas y documentales.

Otra de las huelgas que ha dado lugar a diferentes trabajos de investigación fue la huelga de 1961, realizada en todo el país durante más de cuarenta días, con la consigna de defender la fuente de trabajo y al ferrocarril como medio de transporte, en el contexto de la reestructuración empresaria que pretendía realizar el gobierno de Frondizi. Para Luisina Agostini (2014), la huelga de 1961 fue clave en la historia del movimiento obrero ferroviario nacional, ya que mostró a una clase obrera fuerte en pos de defender a los ferrocarriles. A partir del análisis del discurso gremial de La Fraternidad, la autora señala que este acto de resistencia se fundamentó a partir de tres aspectos: la defensa de la idoneidad del oficio, la reivindicación de un pasado común y la lealtad gremial.

Muchas de las publicaciones analizan esta huelga desde la Historia Local. Tal es el caso de otro trabajo de Agostini (2017), quien estudia lo acontecido en la comunidad ferroviaria 
de "Laguna Paiva", denominada también por las memorias de trabajadores del riel como "Paiva, la heroica" a partir de los hechos ocurridos durante esta huelga en particular. En base al análisis de fuentes orales, Agostini sostiene que el taller ferroviario en Laguna Paiva permitió construir un colectivo social, a partir de sujetos que se identificaron con su fuente de trabajo y sus tradiciones, como parte de un sistema de saberes del mundo ferroviario.

Agostini (2009) también estudia las acciones disruptivas que acontecieron en Paiva durante la huelga del 61, cuando un grupo de mujeres, secundadas por los trabajadores ferroviarios varones, acarrearon durmientes para detener el tren y obstruir las vías, dirigiendo pedradas al conductor y al vehículo que osaba transitar durante la huelga. Este hecho dio lugar a la reacción de la policía, ocasionando un enfrentamiento entre los pobladores y las fuerzas de seguridad. Según la autora, la acción disruptiva en Laguna Paiva tuvo un alto impacto simbólico en la localidad, a partir de pobladores indignados que pretendieron actuar en defensa de la fuente de trabajo y en contra de las políticas frondizistas. A su vez, tuvo también un impacto a escala nacional porque, según Agostini, se demostró que las acciones colectivas desarrolladas localmente permitían sostener el desafío de los gremios en su conjunto. ${ }^{19}$

Otro trabajo que aborda las experiencias de la comunidad de Laguna Paiva en torno al ferrocarril es el de Florencia Schkolnik (2010). La autora plantea que la localidad tuvo al ferrocarril como principal empresa generadora de mano de obra y, en 1961, fue transformada en símbolo de la resistencia ferroviaria en todo el país. A partir de entrevistas realizadas a diferentes miembros de la sociedad paivense, Schkolink sostiene que el tejido social de la ciudad se habría construido en base al trabajo ferroviario como formador de identidad y que la huelga de 1961 abonó en la constitución de una identidad ligada a la lucha. Cuando el taller se cierra en la década del noventa, la ocupación, como formadora de identidad, se desvaneció, desapareciendo, según Schkolnik, ese "lazo invisible" que ataba a cada habitante de Paiva.

En otro trabajo, Agostini y Carolina Brandolini (2016) también exploran en las memorias de ferroviarios de Paiva sobre el cierre de los talleres y revelaron que ese pasado heroico sobre la huelga del 61 estaba presente en los entrevistados al momento de contrastar, precisamente, la pasividad o apatía de la población en los noventa con las acciones disruptivas desarrolladas por buena parte de los paivenses y de los integrantes de las familias ferroviarias en los sesenta. Esta comparación entre ambos escenarios por parte de los ferroviarios se fundamentaba en la interpretación de la existencia de un mismo proceso histórico que, según

\footnotetext{
${ }^{19}$ Otros autores abordan el conflicto ferroviario de 1961: Schneider, 2005; Scodeller, 2007.Un análisis sobre la crisis ferroviaria durante el gobierno de Frondizi puede encontrarse en Ortega, 2013.
} 
ellos, se inició en la década de 1960 apuntando a la privatización de los ferrocarriles y que se cristalizó en la década de 1990 con la concreción de aquel objetivo.

También Susana Costamagna (2010) recupera memorias sobre el ferrocarril de una localidad puntual. En este caso, Cruz del Eje, ciudad que, según plantea, tuvo a principios del siglo XX a la actividad ferroviaria como su principal motor de desarrollo. La autora se refiere a algunos sentidos asociados al ferrocarril por parte de los actores, entre ellos, la posibilidad de trabajar, estudiar y progresar en la estructura de la empresa. Precisamente, uno de los acontecimientos más importantes sobre los cuales los actores recuerdan haber transitado a lo largo de su experiencia de vida en el ferrocarril fue la huelga del 61, en la que evocan haber luchado a partir del objetivo altruista de defender al ferrocarril como medio de transporte al servicio de la sociedad. Otro de los acontecimientos que los actores coinciden en recordar, en este caso, de forma traumática, es el cierre de los talleres en 1978, durante la dictadura militar. ${ }^{20}$ Se trata de una evocación dolorosa para los cruzdelejeños, ya que refieren a lo que fue conocido como el "desguace" del ferrocarril, que incluyó el desmantelamiento de las instalaciones, la venta de tirantes, puertas y ventanas, la comercialización de maquinaria en uso a precio de chatarra, la quema de los registros y expedientes del taller. De esta manera, según los testigos, desaparecía una historia de casi un siglo en la ciudad, de la que ellos y generaciones anteriores habían sido parte. Pero esta situación de por sí dolorosa es acompañada por la impotencia de protestar y resistir, en el marco de la dictadura de Jorge Videla, en contraste con el accionar de los trabajadores durante la otra huelga transformada en símbolo, la del 61.

Ana Miravalles (2009), por su parte, recupera memorias de trabajadores de Bahía Blanca e Ingeniero White en las que los testigos vinculan algunos hechos ocurridos en 1958 durante el gobierno frondizista, con la denominada por ellos mismos como "huelga grande" de 1961. ${ }^{21}$ En su trabajo, la autora destaca un acontecimiento singular que ocurrió en esas localidades del Partido de Bahía Blanca, en diciembre de 1958, en las que miles de trabajadores marcharon hacia el Regimiento de Infantería, en reclamo de la movilización militar al ferrocarril decretada por el gobierno desarrollista. Como consecuencia de ello, fueron apresados y trasladados para alojarse en la cárcel de Villa Floresta y en la Base Naval de Puerto Belgrano. En sus relatos, los ferroviarios evocan los métodos empleados por los militares para convencerlos de retornar a sus tareas normales y aceptar el control militar, entre los que se incluyeron amenazas de fusilamiento y de abandono en altamar, falta de provisión de alimentos

\footnotetext{
${ }^{20}$ Otro trabajo recupera las memorias del cierre de Tafí Viejo: Sosa, 2014.

${ }^{21}$ Existe otro trabajo que analiza la movilización del personal ferroviario en Junín durante el mismo período: Marengo, 2021.
} 
y agua. La autora observa que, aunque la huelga de 1961 ocurrió dos años después, los trabajadores confundieron los recuerdos de esta, con las experiencias de 1958 en que se habían manifestado en contra de la movilización militar. ${ }^{22}$

Los trabajos mencionados antes sobre la huelga del 61 y los conflictos ferroviarios durante el gobierno de Frondizi (Agostini, 2017; Agostini y Brandolini, 2016; Schkolnik, 2010; Costamagna, 2010, Miravalles, 2009) tienen la similitud de plantear la temática desde la historia local, a partir del empleo de fuentes orales. ${ }^{23}$ En línea con este grupo de artículos, esta tesis intenta realizar una contribución en el conocimiento de la experiencia histórica de las comunidades locales, en este caso, de Junín. Si bien el período abordado en esta investigación no se ciñe a la década del sesenta, sino que abarca un lapso más amplio, los hallazgos de estos trabajos sirven a los efectos de comparar y contrastar las experiencias de esas comunidades con las de Junín.

Existen otras perspectivas en los estudios del ferrocarril que toman como dimensión central para el análisis al género. A los fines de esta tesis, estas investigaciones abonan en la comprensión respecto de las representaciones sobre los roles que debían cumplir esas mujeres y varones que integraban la "familia ferroviaria". De esta manera permiten observar continuidades en dichas representaciones (como la del varón proveedor), los conflictos que suscitaron algunos cambios históricos (por ejemplo, la mayor participación de las mujeres en el ámbito laboral en la década del sesenta), y la adaptación de roles y representaciones en coyunturas específicas (la participación de mujeres de la familia ferroviaria en la escena pública).

Algunos de estos trabajos que tienen en cuenta la dimensión de género indagan, por ejemplo, el rol de las mujeres en huelgas o conflictos gremiales puntuales. Tal es el caso de Palermo (2009b), quien estudia la huelga de $1917 .{ }^{24} \mathrm{La}$ autora advierte que aunque la participación de mujeres durante el conflicto fue muy activa, lo cual queda demostrado por los registros de la prensa obrera de la época, el tema no tuvo un lugar destacado en las memorias gremiales, ni tampoco fue desarrollado por estudios académicos posteriores.

Palermo postula que las mujeres tuvieron un lugar central en la organización de la huelga y se lanzaron a la política en las calles, intensificando su presencia en el espacio público.

\footnotetext{
${ }^{22}$ Ver también otro trabajo de la autora vinculado a la memoria histórica de los talleres de Bahía Blanca e Ingeniero White: Miravalles, 2011.

${ }^{23}$ Otros aportes desde la historia oral vinculados a las experiencias sobre la nacionalización en Junín: Sagastume, 2016b. Desde la historia oral y la memoria, la nacionalización y las políticas de bienestar del peronismo en Jujuy han sido abordadas en Castillo, 2012.

${ }^{24}$ Otro trabajo de la autora sobre el tema: Palermo, 2005.
} 
Organizaron y fueron oradoras en actos públicos, realizaron a acciones de propaganda que apuntaban a persuadir a otras mujeres y sus familias, intimidaron a las familias y trabajadores que no estaban a favor de la huelga, realizaron manifestaciones para impedir la salida de trenes, ocuparon estaciones, entre otras acciones colectivas. Fue, precisamente, gracias al activismo femenino, complementado con la militancia sindical masculina, que, según Palermo, los ferroviarios suscitaron la atención de las autoridades y de la sociedad.

Para Palermo, además, la huelga de 1917 fue un momento clave en la construcción del ideal ferroviario como hombre capaz de proveer seguridad económica a su familia, en base a la valoración de una masculinidad que debía ser responsable. ${ }^{25}$ En sus reclamos, los trabajadores plantearon la aspiración de lograr su respetabilidad en el mundo público y su autoridad en el mundo doméstico. Este afianzamiento de los derechos del varón trabajador como jefe de familia dependió, en parte, de la acción colectiva femenina y de la movilización de la familia en su conjunto. De esta manera, la defensa del hogar ferroviario les dio la oportunidad a estas mujeres de abandonar el espacio doméstico y participar en el espacio público haciendo política.

Solange Godoy (2020) estudia, también, desde una perspectiva de género, un conflicto que, en este caso, enfrentó a ferroviarios del Ferrocarril Mitre con las autoridades, por la incorporación de trabajadoras mujeres entre 1962-1964, poniendo de relieve tanto las continuidades de la representación de "familia ferroviaria" como los cambios que estaban operando en la sociedad. El enfrentamiento surgió porque los ferroviarios de la línea Mitre, agrupados en la Unión Ferroviaria, resistieron a la incorporación de camareras por considerar que estas mujeres que venían "de afuera” desvirtuaban el sistema interno de movilidad laboral, el cual contemplaba el ingreso en la carrera desde la escala más baja y promociones por antigüedad o concursos. Para la empresa, en cambio, contratar mujeres para el servicio de camareras representaba una mejora en cuanto a la atención al público y favorecía un cambio de imagen en la sociedad, mostrándose hacia el público como una compañía renovada y moderna.

Aunque el derecho de las mujeres a trabajar era reconocido por estos ferroviarios, según las fuentes consultadas por Godoy, existía consenso en que el varón era el representante "genuino" de la familia ferroviaria. En rigor, el conflicto estuvo dado por el modo de ingreso de estas mujeres, ya que, de acuerdo a las tradiciones previas, los ferroviarios debían ingresar como peones y realizar trabajos que demandaran fuerza física en sus inicios, lo cual era

\footnotetext{
${ }^{25}$ Desde una perspectiva de género, en otro trabajo la autora (Palermo, 2016) aborda específicamente el derecho a mantener el hogar manifestado por los trabajadores en la huelga de 1917. También D'Uva (2019) aborda la cuestión durante el período entre las huelgas de 1912 y 1917.
} 
incompatible con las concepciones de la época sobre la labor femenina. El trabajo de Godoy pone de relieve, entonces, el modo en que las representaciones sobre el trabajo ferroviario vinculadas al género se ponen en tensión con el intento de modernización del gobierno frondizista.

Desde una perspectiva que toma, nuevamente, como dimensión central al género, Godoy (2019) estudia la incorporación de mujeres en el ferrocarril en un período posterior, entre 1969 y 1973. La etapa abordada por la autora y que se corresponde con proyectos de modernización de la empresa durante una parte de la gestión de Juan Carlos De Marchi en Ferrocarriles Argentinos, reviste especial interés para esta tesis, habiendo sido poco estudiada por el resto de las investigaciones sobre el ferrocarril.

En su artículo, Godoy sostiene que el personal femenino que se incorporó durante esta etapa, principalmente para los puestos de azafatas y cómputos, era considerado por la empresa como un factor modernizante. En ese sentido es que la empresa bregó por asociarlas a la nueva imagen de Ferrocarriles Argentinos, en contraposición a la obsolescencia, vetustez y desorganización previas. La autora también muestra cómo esta incorporación de mujeres estuvo asociada a determinadas características, actitudes y representaciones sobre la femineidad, tales como la modestia, la belleza y la amabilidad, y sobre la labor femenina, ligada a la atención a niños y damas. De esta manera, Godoy demuestra que las consignas modernizantes de igualdad de la época, que mostraban a estas trabajadoras como expertas y profesionales en cada una de sus áreas, se entrecruzaron con los estereotipos tradicionales de mujeres bonitas, elegantes y al servicio de los varones.

Existe otro trabajo de Palermo (2015) que incorpora la dimensión de género para estudiar la sociabilidad de los trabajadores ferroviarios sindicalizados en la Argentina en las primeras décadas del siglo XX. Para estudiar la sociabilidad, la autora se centra en los espacios de encuentro que lo hacían posible. Principalmente, la sede gremial, a la cual concurrían varones de distintas edades, nacionalidades y oficios que experimentaban, no obstante, algo común: el trabajo en empresas consideradas, en aquel momento, de vanguardia, símbolos de civilidad y modernidad. Estos espacios se constituyeron en lugares de encuentro en los que los trabajadores podían conocer a otros dirigentes y militantes de otros lugares, instruirse, consolidar amistades y constituir su identidad gremial.

Palermo también estudia las celebraciones ferroviarias como instancias de socialidad, tales como el aniversario del gremio, las despedidas, las conmemoraciones de huelgas, entre otras. Algunas de ellas convocaban la participación de las familias, con sus mujeres y niños, reforzando los vínculos de camaradería entre los miembros. En ellas, las prerrogativas 
vinculadas a los géneros tendían a replicarse. Otras eran fiestas de varones, también denominadas "fiestas de compañerismo", en las que los ferroviarios demostraban su afecto surgido en la cotidianidad laboral. ${ }^{26}$ Para la autora, en todas estas experiencias, constitutivas del mundo del trabajo, las jerarquías del mundo laboral y las tensiones propias de las diferencias por edades, orígenes nacionales o ideológicas no desaparecían. Más bien, en la distensión de un festejo, pero también en la biblioteca o en las clases nocturnas, esas diferencias, sin diluirse, podían ponerse entre paréntesis, a partir de la existencia de una afinidad por compartir la experiencia de explotación, la conciencia de vivenciar diariamente la importancia de los vínculos solidarios. Según Palermo, mediante el conjunto de prácticas de sociabilidad los trabajadores construyeron una identidad gremial basada en la idea de la unión de hombres de oficio, de obreros conscientes y de varones dignos capaces de cumplir con el mandato de su género: ser buenos padres de familia, hombres proveedores y referentes confiables en sus comunidades.

En línea con este último trabajo de Palermo, esta tesis también recurre a estudiar las prácticas de sociabilidad de los trabajadores de Junín en la búsqueda de comprender cómo se construyó la identidad ferroviaria. En efecto, este trabajo permite la indagación en las prácticas que tuvieron continuidad en el tiempo, así como en aquellas que no parecen haber tenido relevancia en el período posterior al que investiga la autora.

Otro grupo de investigaciones sobre el ferrocarril estudia los saberes producidos por los trabajadores ferroviarios, ya sea en el ámbito laboral mismo o en escuelas creadas para tal fin. Este grupo de trabajos revisten especial interés para esta tesis, ya que uno de los puntos explorados por esta investigación está vinculado a los espacios en que los trabajadores ferroviarios se formaban como tales, así como en los motivos por los cuales estas experiencias les permitieron construir un relato de vida en común que abonó en su construcción identitaria. En particular, se destaca el trabajo de Luz Ayuso et al. (2010) que estudia las diferentes experiencias pedagógicas en el ferrocarril. Se trata de un abordaje realizado desde las ciencias de la educación, a diferencia de esta tesis que emplea fuentes orales e intenta reconstruir los sentidos asociados a la formación desde una perspectiva histórica, prestando especial atención a las transformaciones que habrían tenido lugar durante el período estudiado.

Los autores del trabajo mencionado postulan que los gremios propiciaron la articulación entre la educación y el trabajo, a través de escuelas seccionales y cursos de

\footnotetext{
${ }^{26}$ En otro trabajo, la autora se concentra en las celebraciones ferroviarias que conmemoraban la "gran" huelga de 1917: Palermo, 2009a.
} 
capacitación que ofrecían no solo formación profesional, sino también política-gremial. ${ }^{27} \mathrm{~A}$ esto se le sumó la oferta de formación técnica profesional que dependía del Estado y preparaba para el ingreso al trabajo (Escuelas Técnicas Industriales, Escuelas Técnicas de Artes y Oficios, Escuelas Fábrica). Los autores remarcan, no obstante, que uno de los lugares centrales en la transmisión de saberes era el espacio cotidiano de trabajo, en el que se generaba un vínculo pedagógico entre los más experimentados y los novatos.

También plantean que la existencia de una carrera educativa se encontraba ligada a la carrera laboral, contemplando perspectivas de ascenso en el escalafón. A su vez, esa carrera laboral organizaba un relato de vida continuo en el que el trabajo y la educación constituían el elemento articulador del proyecto de la propia existencia. En esa línea, se define al "Sistema de Saberes del Trabajo Ferroviario" como el conjunto articulado de conocimientos técnicos y no técnicos, experiencias, hábitos y costumbres legadas, tradiciones, rutinas, representaciones sobre el trabajo ferroviario, mitos y leyendas que, como entramado de saberes, constituyeron parte del "patrimonio colectivo" de todos los ferroviarios. Debido a que ese conjunto de "saberes socialmente productivos" articulaban el saber técnico con el relato de vida, no resultó posible, según los autores, llevar a cabo en el taller ferroviario la aplicación del modelo taylorista, que reducía al obrero a una tarea dentro de un proceso mayor, el cual no podía abarcar ni comprender en su totalidad. Esto se explicaría porque la identidad laboral, asociada a los saberes del trabajo ferroviario, producía una conciencia común basada en la posesión colectiva de un conjunto de saberes articulados de forma tal que la totalidad del proceso era indiferenciable del producto. Sumado a esto, los poderosos gremios asumieron, según los autores, una actitud corporativa que resistió cualquier tipo de transformación que intentó imponerse desde el exterior. Según Ayuso, el ferrocarril demostró durante toda su historia que otra organización y concepción del trabajo era posible: el sistema laboral ferroviario apuntaba a producir "socialidad". Por eso, no era posible separar el trabajo de la acción política ni intelectual. De este modo, los distintos ámbitos (familiar, laboral, sindical y educativo) se fusionaron en la construcción histórica de la identidad ferroviaria.

En esta línea que indaga en la producción de saberes producidos por los ferroviarios, Badaloni (2010) estudia las estrategias de calificación profesional de un grupo particular: los maquinistas y fogoneros en La Fraternidad, a principios del siglo XX en Rosario. ${ }^{28}$ La autora señala que los episodios de resistencia activa en los que participaron estos trabajadores se

\footnotetext{
${ }^{27}$ Sobre este tema también puede leerse un trabajo basado en testimonios orales sobre las experiencias de trabajadores que asistieron a la Escuela Técnica de Tafí Viejo: Sosa, 2017.

${ }^{28}$ Ver también trabajo de Barrancos (1989) sobre los maquinistas ferroviarios.
} 
combinaron con un creciente interés por el estudio y funcionamiento de las locomotoras, lo cual les permitió controlar los ascensos dentro del escalafón. En efecto, los trabajadores lograron crear la Escuela Técnica de Rosario en 1913 y, de esta manera, resistir los intentos de control por parte de la empresa en relación a la conservación, circulación y distribución de las destrezas propias de la profesión. En momentos de confrontación con la empresa, esto operó a favor de los trabajadores, ya que se trataba de una mano de obra altamente calificada y difícil de ser reemplazada por los que no pertenecían al sindicato.

Como Badaloni, Ayuso (2016) también abordó las estrategias de formación profesional de La Fraternidad, centrando su objeto de estudio en la articulación entre educación y trabajo que permitió que el gremio configure un modelo pedagógico propio. ${ }^{29}$ En una exhaustiva investigación, estudió lo que denomina "Red de Escuelas Técnicas de Autogestión Obrera" de todo el país, entre 1887 y 1927, período que se inicia con la fundación de las primeras escuelas y culmina con la consolidación de dicha red, cuando ya se había logrado que existieran mecanismos de ingreso y promoción en la carrera regulados por la corporación y que participaran representantes de La Fraternidad en las mesas de exámenes para la acreditación y certificación de idoneidad.

Ayuso sostiene que los foguistas y maquinistas se apropiaron de algunos elementos para la regulación de su saber, a la vez que sustentaron y consolidaron su poder, mediante la creación de escuelas en las seccionales de distribución federal y la producción de manuales y elementos propios para la enseñanza. De acuerdo a su investigación, La Fraternidad creó un subsistema de educación y trabajo en el ámbito ferroviario de alcance nacional, al margen de las iniciativas que ofrecía el Estado. En ese sentido, la autora enfatiza la importancia de poner de relieve otras formas educativas que se organizaron para alfabetizar y transmitir saberes, por fuera del Estado nacional, y que fueron ignoradas por la historiografía educativa.

Siguiendo a Ayuso, la tendencia al monopolio en la regulación de los mecanismos de producción, transmisión, certificación de los saberes del trabajo de los foguistas y maquinistas favoreció, al mismo tiempo, su empoderamiento político-gremial. Según la autora, esa acumulación de poder sustentado en el saber fue una construcción corporativa que se cerró sobre sí misma y se reprodujo "endogámicamente" a través de la regulación de los distintos mecanismos: el control de ingreso y expulsión de socios; la alfabetización y transmisión de saberes técnicos, políticos, gremiales y socioculturales; la participación en los mecanismos de

\footnotetext{
${ }^{29}$ Un trabajo previo de la autora sobre el tema: Ayuso, 2009. También puede ampliarse en Ayuso, 2019.
} 
discusión, toma de decisión y gobierno del gremio.

En definitiva, estas prácticas de un gremio cerrado sobre sí condujeron a que La Fraternidad sostuviera una solidaridad gremial "exclusiva" para el conjunto de los trabajadores de las locomotoras y "excluyente" para el resto de los trabajadores de otros oficios dentro de la industria ferroviaria, lo cual se tradujo en la consolidación de una identidad gremial alrededor del "ser fraterno", diferenciada del resto. Esa construcción identitaria y empoderamiento gremial, insiste Ayuso, estuvieron basadas en la apropiación progresiva que los fraternales hicieron de los mecanismos de regulación de los saberes del oficio.

Como parte del grupo de trabajo que han orientado el plan de investigación y la posterior interpretación de las fuentes, se encuentran algunas elaboraciones que no constituyen formalmente producciones de ciencias sociales, pero que sin embargo sirven para comprender los imaginarios ferroviarios a partir de las memorias mismas de los actores. En el libro Crónicas de terraplén (Cena, 2002), su autor brinda algunas pautas para entender la identidad que denomina "ferruca". Para el exferroviario, existen algunos "lazos invisibles" que aglutinan al colectivo desde la infancia, constituidos por lo que simboliza como "hilos de solidaridad". Además de este valor, aparecen otros asociados con la identidad de trabajadores del riel: coherencia, honestidad, compañerismo, lealtad. En contraposición a ello, se encontraban los “carneros", "buchones" y "alcahuetes" que, aun trabajando en el ferrocarril, transgredían el compromiso de lealtad y compañerismo que Cena señala como indisociable al "ser ferroviario" (Cena, 2002: 36).

De acuerdo a lo que sugiere el autor en El guardapalabras: memorias de un ferroviario (Cena, 1998), ser y convertirse en un genuino ferroviario conllevaba un aprendizaje informal logrado en la interacción con otros ferroviarios, en especial los mayores, muchas veces llamados por los novatos "maestros", no solo por el saber que habían demostrado en el oficio, sino también por otros aspectos más generales de la persona (Cena, 1998: 75).

Siguiendo a Cena en esta obra, el ferrocarril se extendía más allá del espacio laboral, influyendo en el resto de las esferas vitales de la persona. Tal es así que las amistades barriales eran reemplazadas por las surgidas en el medio laboral. De esa manera, con los compañeros no solamente se compartían los momentos de trabajo sino también los de ocio: cenas, bailes, encuentros, celebraciones. Por ello, el ferrocarril constituía el núcleo de la propia existencia y acompañaba a los trabajadores en cada una de las etapas vividas, desde la temprana juventud o adolescencia, hasta la vejez. Como consecuencia, los acontecimientos acaecidos en la década del noventa le significaron a Cena, como a otros ferroviarios, un profundo dolor porque antes de ello, absolutamente "todo" en su existencia personal estaba vinculado al ferrocarril (Cena, 
2002: 24). En ese sentido, en una de sus crónicas se relata la experiencia de un ferroviario que, luego de aquellos acontecimientos de los noventa permanece inmutable, mirando la pared, como síntoma de su depresión (Cena, 2002: 63).

En El guardapalabras... (1998), Cena también selecciona acontecimientos de la historia ferroviaria, relatando su experiencia personal, ya sea como hijo de ferroviario o como trabajador, o bien evocando la memoria de otros. Por ejemplo, la celebración por la nacionalización, la persecución a los peronistas a partir de 1955, la movilización militar durante el gobierno de Frondizi, la huelga de 1961. Sobre esta última, recupera toda una serie de memorias de lo que aconteció en distintos puntos del país donde la resistencia en contra de las medidas del gobierno resultó vigorosa, las cuales sirven para construir una narración épica de la que parecen emerger héroes y traidores. Esta narración particular, no solamente permite abonar en la construcción identitaria de lo que "debe ser" un genuino ferroviario (un luchador), sino que contribuye a conformar las memorias del colectivo sobre lo que sucedió en ese período.

Finalmente, existen un grupo de trabajos que investigan, desde distintas perspectivas, determinados aspectos del ferrocarril en Junín. Pablo Petraglia (2012) recrea la historia del Chalet de Mr York, ${ }^{30}$ edificio de estilo "pintoresquista inglés" que tradicionalmente funcionó como vivienda familiar del jefe ingeniero mecánico de la línea Buenos Aires al Pacífico. El autor recupera las biografías de cada uno de sus ocupantes, desde la década de 1910 hasta 1994, haciendo hincapié en la contribución que los primeros directivos hicieron al crecimiento de la empresa ferrocarrilera en la ciudad. Además, Petraglia realiza una reseña del surgimiento de las diferentes instituciones sociales y deportivas de Junín, así como el aporte que hiciera la comunidad británica para su fortalecimiento, en especial, esos primeros jefes ingenieros. Por otra parte, también da cuenta de la participación que tuvieron obreros ferroviarios en el Club Atlético Buenos Aires al Pacífico (BAP), enumerando sus logros deportivos.

Desde una perspectiva enfocada en el patrimonio histórico, Melina Yuln, Silvina Carrizo y Federico Monticelli (2017) estudian lo que denominan el "archipiélago ferroviario", conformado por una multiplicidad de construcciones vinculadas a la empresa que se ubican en distintos puntos de la ciudad. Los autores destacan el valor patrimonial de estas construcciones, no solo desde el punto de vista arquitectónico, sino también por la significación simbólica y cultural del ferrocarril en la ciudad. Esta afirmación se sustenta, según Yuln, en el rol que tuvo

\footnotetext{
${ }^{30}$ El edificio fue restaurado por la UNNOBA. El edificio cambió la denominación por "Edificio Reforma Universitaria", actual sede del Rectorado.
} 
el ferrocarril en el crecimiento y desarrollo de Junín que le permitieron erigirse como una ciudad importante del noroeste bonaerense, así como en la influencia que tuvo el medio de transporte en la identidad de la ciudad y de sus habitantes. El trabajo se basa en el relevamiento de planos técnicos que permitieron clarificar el estado de los edificios ferroviarios en Junín entre 1884 y 1950, correspondientes con la etapa británica. A su vez, se contrastaron situaciones edilicias pasadas y actuales del ferrocarril en Junín.

José María Banfi (2017), por su parte, describe el impacto que tuvo en Junín la llegada del ferrocarril, el cual, según el autor, incide positivamente en la expansión de otros servicios urbanos que van configurando paulatinamente la trama socioeconómica de la ciudad, consolidándose un perfil productivo basado en el sector terciario. A partir de la llegada del ferrocarril, la instalación, ampliación e inserción de los Talleres, además de conformarse una burocracia, se expanden diferentes servicios en la ciudad. Entre ellos, estudia los casos del Hospital Interzonal General de Agudos y del Departamento Judicial Junín.

En tanto, Ana Laura Pompei (2011) realiza un estudio histórico de los Talleres Ferroviarios de Junín, para concentrarse en el surgimiento de la Cooperativa de Trabajo de Junín. La autora plantea que, en sus inicios, los talleres creados por la compañía británica en 1886 se convirtieron en el principal motor de crecimiento socioeconómico de la ciudad y la principal fuente generadora de empleo hasta 1930. De hecho, el centro reparador que se había iniciado con 9 operarios, en 1926 ya contaba con 3.473 trabajadores. Entre 1930 y 1958, según la autora, el centro local tuvo una segunda etapa de esplendor por la envergadura que llegaron a tener los Talleres y la importancia que tenía el Departamento Mecánica en la ciudad Junín, del cual dependían no solo los talleres locales, sino también el resto de los de la línea San Martín. Aunque Talleres Junín nunca llegaría a superar la cifra de 1926 en relación al total de empleados, la cantidad de trabajadores siguió siendo fundamental para movilizar la economía de la ciudad. ${ }^{31}$ Adicionalmente, en el marco del proceso de sustitución de importaciones, Pompei señala que los talleres de Junín pasaron a convertirse de ser un centro exclusivamente dedicado a la reparación, a un centro de fabricación a través de técnicas poco ortodoxas, aunque eficaces. En línea con otras bibliografías ferroviarias, para la autora, a partir de 1958 y hasta 1989, tiene lugar un proceso de decadencia del ferrocarril en todo el país, del cual los Talleres se ven influenciados. Si bien es posible coincidir con Pompei en relación a la crisis que se inicia en la década del sesenta y se extiende durante todo el período para culminar en el proceso de

\footnotetext{
${ }^{31}$ Los registros señalan que los Talleres contaban en 1948 con 2.307 empleados, incrementándose paulatinamente hasta alcanzar en 1958 los 3.236 trabajadores (Pompei, 2011: 38).
} 
privatización de la década del noventa, esta tesis apunta a rescatar algunas experiencias de enorme significación local que tuvieron lugar entre 1969 y 1971 y que no han sido estudiadas debidamente por las investigaciones que abordan el tema. Se considera que, específicamente, durante la gestión de Juan Carlos De Marchi se ponen en marcha algunas iniciativas que tienen por meta paliar la crisis, brindando algunos elementos simbólicos fundamentales que abonan en la construcción de la identidad ferroviaria juninense.

Por último, en una investigación previa (Sagastume, 2016a) realicé un trabajo de recuperación de las memorias históricas de los trabajadores de Junín que habían ingresado en la empresa entre 1940 y 1950 y se habían retirado en la década de 1990. Las entrevistas realizadas para el mencionado trabajo se han integrado, aunque se les ha dado otro tratamiento. $^{32}$

\footnotetext{
${ }^{32}$ Existe otra publicación local que reproduce íntegramente trece entrevistas realizadas a ferroviarios de Junín como un modo de relatar la historia del ferrocarril en la ciudad "en primera persona", según plantean las autoras (Tarullo y Iacullo, 2013).
} 


\title{
Marco teórico-metodológico
}

Uno de los conceptos centrales en esta tesis es el de imaginario social. Nos basamos, principalmente, en los aportes de Bronislaw Baczko (1991) quien postula que las sociedades crean sus propias representaciones globales, las cuales no constituyen simples reflejos de la realidad social que existe por fuera de ellas. Estas representaciones globales son, en rigor, inventadas y elaboradas con materiales tomados del caudal simbólico disponible, teniendo un impacto en las mentalidades y comportamientos colectivos y ejerciendo, por tanto, funciones específicas en la vida social (1991: 8).

Los imaginarios sociales son definidos por el autor como las "referencias específicas dentro del vasto sistema simbólico que produce toda colectividad" (Baczko, 1991: 28). Para Baczko no se tratan de "adornos" de las relaciones económicas y políticas, antes concebidas como las únicas "reales", sino que tienen un rol preponderante en la sociedad (1991: 14).

\begin{abstract}
A través de estos imaginarios sociales, una colectividad designa su identidad elaborando una representación de sí misma; marca la distribución de papeles y las posiciones sociales; expresa e impone ciertas creencias comunes, fijando especialmente modelos formadores como el del "jefe", el del "buen súbdito", el del "valiente guerrero", el del "ciudadano", el del "militante", etcétera. Así, es producida una representación totalizante de la sociedad como un orden, según el cual cada uno tiene su lugar, su identidad y su razón de ser (Baczko,
\end{abstract} 1991: 28).

De esta manera, los imaginarios sociales se constituyen en una de las fuerzas reguladoras de la vida colectiva, que definen no solamente la pertenencia de los individuos a una misma sociedad, sino también sus divisiones internas, con sus instituciones. Al mismo tiempo, el autor señala que al momento de asignar una identidad colectiva también se están planteando los límites de esta. En otras palabras, las relaciones con los otros, lo cual incide en la construcción de representaciones acerca de quiénes son los "amigos" y "enemigos", "rivales" y “aliados" (Baczko, 1991: 28).

Por otra parte, los imaginarios sociales plantean una forma de conservar y modelar los recuerdos del pasado, así como de proyectar hacia el futuro los temores y las esperanzas. En efecto, según Baczko, la imaginación social es un campo de investigación histórica que recorre dos polos que se alimentan mutuamente: por un lado, las utopías, por el otro lado, las memorias colectivas. Precisamente, una de las funciones de los imaginarios sociales consiste en la 
organización y el dominio del tiempo colectivo sobre el plano simbólico (1991: 9). En definitiva,

El dispositivo imaginario asegura a un grupo social un esquema colectivo de interpretación de las experiencias individuales, tan complejas como variadas, la codificación de las expectativas y esperanzas, así como la fusión, en el crisol de una memoria colectiva, de los recuerdos y de las representaciones del pasado cercano o lejano (Baczko, 1991: 30).

En relación a la memoria, Baczko aclara que los acontecimientos del pasado importan menos que las representaciones imaginarias a las que dan origen y encuadran. De esta forma, intervienen en la producción de visiones del futuro, en especial, la proyección de obsesiones y fantasmas, esperanzas y sueños colectivos.

Además, el dispositivo imaginario no implica solamente un esquema común de interpretación de las experiencias individuales, sino que también provoca la adhesión a un sistema de valores e interviene en el proceso de interiorización por parte de los individuos. Por tal motivo, los imaginarios sociales son capaces de cautivar energías, moldear conductas y conducir a los individuos a acciones comunes (Baczko, 1991: 30).

De esta manera, según Baczko, si se pretende tener un papel privilegiado en la emisión de los discursos que conducen a los imaginarios sociales para ejercer una dominación simbólica sobre las mentalidades, resulta crucial controlar los circuitos de difusión y los medios en tanto instrumentos de persuasión, presión e inculcación de valores y creencias (1991: 31).

Otro de los postulados centrales del autor se refiere al vínculo entre imaginario y simbolismo: "Los imaginarios sociales se apoyan en el simbolismo". En ese sentido, Bazcko explica que los símbolos, a la vez que son capaces de instituir distinciones, introducen valores y moldean las conductas individuales y colectivas, en el marco de una constelación simbólica (1991: 29).

Los símbolos más estables, anclados en profundas necesidades, terminan por volverse una razón de existencia de accionar para los individuos y los grupos sociales, otras tantas condiciones simbólicas del cambio y de la inercia históricos. Los sistemas simbólicos sobre los cuales se apoya y a través de los que trabaja la imaginación social se construyen sobre las experiencias de los agentes sociales, pero también sobre sus deseos, aspiraciones e intereses. (Baczko, 1991: 29-30) 
En efecto, gracias a su tejido simbólico y a su compleja estructura, el imaginario social interviene en diversos niveles de la vida colectiva. Se desenvuelve, según el autor, a través de series de oposición (por ejemplo: correcto-incorrecto; valioso-no valioso, prohibido-permitido; verdadero-falso, etc.) que estructuran los aspectos afectivos de la vida colectiva, por medio de una red se significaciones. De esta manera, forman parte de complejos sistemas, entre los que se encuentran los mitos, las utopías, las ideologías (Baczko, 1991: 30).

Cornelius Castoriadis (1983) analiza en profundidad los vínculos entre los imaginarios sociales y el plano simbólico. El autor sostiene que el simbolismo — en tanto la capacidad de representar, a través de un significante, algo que no es-, nunca es "totalmente adecuado" ni tampoco neutro, porque toma sus signos de "de lo que ya se encuentra ahí". "Todo simbolismo se edifica sobre las ruinas de los edificios simbólicos precedentes y utiliza sus materiales" (1983: 208-209). Sin embargo, esto no implica una perspectiva determinista: “...el simbolismo a la vez que determina unos aspectos de la vida y de la sociedad (...) está lleno de intersticios y grados de libertad" (1983: 217).

En ese sentido, Castoriadis aclara que, si bien el discurso está "preso del simbolismo", no le está "fatalmente sometido" porque, precisamente, “...aquello a lo que el discurso apunta es a algo distinto del simbolismo: es un sentido que puede ser percibido, pensado, imaginado" (1983: 242). De esta manera, el autor afirma que el simbolismo remite a algo que está más allá de la combinación de signos (el sentido), lo cual permite producir nuevos sistemas de significados y significantes.

En efecto, el simbolismo involucra en sí un aspecto imaginario, en tanto la capacidad de representar algo que no está ahí (lo que el autor llama imaginario efectivo). Pero el imaginario de una sociedad o de una época (como imaginario último) sería el estructurante originario, el significante central, "fuente de lo que se da como sentido indiscutible e indiscutido". Así, según Castoriadis, el rol del imaginario resulta central para la organización de la vida de la sociedad, porque es lo que permite que el mundo sea captado de una manera práctica, afectiva y mental (1983: 252).

Para el autor, las significaciones sociales imaginarias definen, entonces, la identidad de determinada sociedad, las relaciones con el mundo y con los objetos que contiene, sus necesidades y deseos. En otras palabras, responden a las preguntas de quiénes somos, hacia dónde vamos, qué necesitamos, cuáles son nuestros sueños, interrogantes que, según el autor, no están planteados previamente. Más bien: "La sociedad se constituye haciendo emerger de su vida, en su actividad, una respuesta de hecho a estas preguntas (...) Es en el hacer de cada colectividad donde aparece como sentido encarnado la respuesta" (Castoriadis, 1983: 255). 
Como insiste el autor, quien intenta explicar el proceso de cambio histórico, las significaciones imaginarias, si bien determinan la vida social, no someten con "sus creaciones de una vez y para siempre" a los seres humanos. En efecto, "cuando el interior de la sociedad se hace exterior", mediante el distanciamiento y la crítica de lo instituido encarnados en los actos mismos, tiene lugar una grieta que puede dar lugar a la emergencia de algo nuevo. En rigor, lo que denomina "creación de la historia" involucra una invención humana que resulta viable en determinadas circunstancias, pero que, a la vez, desde el mismo momento en que existe, modifica a sus creadores sustantivamente.

Ligado al concepto de imaginario, se encuentra el de representación social. En este caso nos basamos en el trabajo de Denise Jodelet (1989) quien observa que, para el historiador, la representación resulta un elemento necesario de la cadena conceptual que permite pensar las relaciones entre lo material y lo mental en la evolución de las sociedades (Jodelet, 1989: 9). Se trata, entonces, de un saber práctico que les sirve a los individuos para actuar en el mundo, lo que implica que tiene un rol crucial en la vida social.

La autora define a la representación, entonces, como una forma de conocimiento que ha sido elaborado socialmente con un objetivo práctico, concurriendo a la construcción de una realidad común a un conjunto social. Sería, en otras palabras, un saber del sentido común que regula la relación de los individuos con el mundo, orientando y organizando las conductas y comunicaciones sociales.

Por su parte, Jean-Claude Abric (1994) define a las representaciones sociales como construcciones sociocognitivas que integran lo racional y lo irracional, tolerando e integrando contradicciones aparentes y dando lugar, muchas veces, a razonamientos ilógicos o incoherentes. Para el autor,

...la identificación de la visión del mundo que los individuos o grupos llevan en sí y utilizan para actuar o tomar posición es reconocida como indispensable para entender la dinámica de las interacciones sociales y aclarar los determinantes de las prácticas sociales (Abric, 1994: 14).

Abric sostiene que las representaciones sociales desempeñan un papel fundamental en las prácticas y en la dinámica de las relaciones sociales, respondiendo a distintas funciones. En principio, permiten a los actores sociales entender y explicar la realidad. En segundo término, contribuyen en la elaboración de una identidad social y personal compatible con los sistemas de normas y valores. En tercer término, orientan comportamientos y prácticas, ya que definen 
previamente la finalidad de una situación y producen un sistema de anticipaciones y expectativas (1994: 16-17). En ese sentido, la representación resulta prescriptiva de esos comportamientos o prácticas: "Define lo lícito, tolerable o inaceptable en un contexto social dado" (1994: 17). Posteriormente, las representaciones sociales intervienen luego de la acción, permitiendo a los actores explicar y justificar las conductas ante los demás. Como observa el autor, "la representación es determinada por la práctica de las relaciones", reforzando la posición social del grupo involucrado.

De esta manera, Abric señala que la representación es un elemento esencial para comprender los comportamientos y prácticas sociales, a partir de un doble sistema de determinación:

Por sus funciones en la elaboración de un sentido común, de construcción de la identidad social, por las expectativas y las anticipaciones que genera, está en el origen de las prácticas sociales. Por sus funciones justificadoras, adaptadoras y de diferenciación social, depende de las circunstancias exteriores y de las prácticas mismas. Es modelada o inducida por las prácticas (Abric, 1994: 18).

Otro de los conceptos empleados en esta tesis es el de identidad de Stuart Hall (2003). El autor la concibe como un proceso nunca terminado y en permanente construcción, apoyado en la contingencia y sujeto a la historización. Desde esta perspectiva, la identidad, una vez consolidada, no cancelaría la diferencia: "La fusión total que sugiere es, en realidad, una fantasía de incorporación” (2003:14). De esta manera, la identidad sería un proceso de articulación que Hall simboliza en la imagen de una "sutura", lo que sugiere una unión que no es homogénea ni definitiva, en las que claramente se puede advertir la huella de esa diferencia. Precisamente, para este autor, las identidades nunca se unifican, sino que se construyen a través de discursos, prácticas y posiciones diferentes, a menudo cruzadas y antagónicas.

Siguiendo esa línea, Hall cuestiona algunas perspectivas que plantean que el pasado común sea determinante en la construcción de la identidad. Más bien son los proyectos o visiones de futuro los que dan lugar a tal construcción identitaria:

En realidad las identidades tienen que ver con las cuestiones referidas al uso de los recurso de la historia, la lengua y la cultura en el proceso del devenir y no del ser; no de ‘quiénes somos' o ‘de dónde venimos' sino en qué podríamos convertirnos, cómo nos 
han representado y cómo atañe al modo en que podríamos representarnos (Hall, 2003:

$18)$.

Hall también sostiene que, para que el proceso de identificación se consolide, es preciso que tenga lugar la marcación y ratificación de límites simbólicos y la producción de efectos de frontera. Es decir, que exista un "afuera constitutivo", un "otro" a partir del cual sea posible definir lo que no se es. En efecto, las identidades siempre funcionan como un encuentro en que algo queda afuera y excluido de ella: "La unidad, la homogeneidad interna que el término identidad trata como fundacional, no es una forma natural sino construida de cierre, y toda identidad nombra como su otro necesario, aunque silenciado y tácito, aquello que le "falta"' (2003:19). Así, este proceso de cierre no daría lugar a una identidad fija y estable, sino que las identidades serían constantemente desestabilizadas por aquello que, precisamente, dejaron afuera.

El autor también postula que las identidades se constituyen en el campo imaginario, dentro de la representación y se relacionan con la invención de la tradición. Así y todo, Hall subraya que "la naturaleza necesariamente ficcional de este proceso no socava en modo alguno su efectividad discursiva, material o política" (2003: 18).

Otro de los aportes teóricos que empleamos para esta tesis es el de Raymond Williams en Marxismo y literatura (2000). Lo que interesa del autor es la descripción que realiza del proceso cultural como algo dinámico y en constante movimiento. Así, Williams plantea que dentro de dicho proceso cultural, la hegemonía ${ }^{33}$ es esencialmente dominante. Sin embargo, nunca lo es de modo total, sino que "debe ser continuamente renovada, recreada, defendida y modificada". Precisamente, por ser resistida y desafiada por presiones que no le son propias, es limitada y alterada por estas: "Las numerosas formas de oposición y lucha son importantes no solo en sí mismas, sino como rasgos indicativos de lo que en la práctica ha tenido que actuar el proceso hegemónico con la finalidad de ejercer su control” (2000: 135).

De esta manera, según el autor, el proceso hegemónico debe estar abierto y receptivo hacia las alternativas y la oposición que amenazan su dominación. Tal como sostiene: "La

\footnotetext{
${ }^{33}$ Sobre la hegemonía, Williams (2000) la define como "todo un cuerpo de prácticas y expectativas en relación con la totalidad de la vida" o como "un vívido sistema de significados y valores que en la medida en que son experimentados como prácticas parecen confirmarse recíprocamente". Luego, profundiza: “...es un sentido de la realidad para la mayoría de las gentes de la sociedad, un sentido de lo absoluto debido a la realidad experimentada más allá de la cual la movilización de la mayoría de los miembros de la sociedad —en la mayor parte de las áreas de sus vidas - se torna sumamente difícil. Es decir, en el sentido más firme es una 'cultura', pero una cultura que debe ser considerada asimismo como la vívida dominación y subordinación de clases particulares" (Williams 2000: 131-132). En lo que sigue, Williams se ocupa de analizar de qué manera la hegemonía logra imponerse como dominante en una cultura determinada, en sus relaciones con los aspectos residuales y emergentes.
} 
realidad del proceso cultural debe incluir siempre los esfuerzos y contribuciones de los que de un modo u otro se hallan fuera o al margen" (Williams, 2000: 135). Por lo tanto, al analizar lo dominante en un proceso cultural es necesario entenderlo como algo activo y formativo que, al mismo tiempo, se transforma.

En efecto, lo dominante en el proceso cultural se adapta, incorpora, neutraliza y limita las formas alternativas, pero también existen contribuciones que pueden constituirse en rupturas significativas, manifestándose como "independientes y originales". (Williams 2000: 136).

Aunque sea preciso tener en cuenta los aspectos dominantes de todo proceso cultural, Williams propone incorporar los conceptos de "residual" y "emergente", los cuales interesan particularmente para analizar algunos fenómenos que aparecen relatados por los actores en la presente tesis. Para el autor estos aspectos son significativos por sí mismos pero, al mismo tiempo, en sus relaciones con "lo dominante".

En el primer caso, lo residual se vincula con aquellos elementos formados en el pasado que todavía se hallan en actividad en el actual proceso cultural. Según Williams, se refiere a experiencias, significados y valores que no pueden ser expresados o verificados en términos de la cultura dominante pero que, no obstante, son vividos y practicados sobre la base del remanente de alguna formación o institución social y cultural anterior. En consecuencia, lo residual puede implicar un sentido alternativo o de oposición respecto de la cultura dominante, lo cual no debería confundirse con la manifestación activa de lo residual incorporada a la cultura dominante. De modo que lo fundamental sería reconocer el tipo de relación que establece lo residual respecto de la cultura dominante efectiva: en ciertos aspectos es incorporada a esta, otorgándosele un sentido en sus términos; mientras que en otros ella no puede permitir una práctica y experiencia residual, sin asumir ciertos riesgos.

En relación a lo emergente,

A diferencia de lo residual, que se relaciona con formaciones e instituciones del pasado, lo emergente se vincula con los nuevos significados, valores y prácticas culturales. No obstante, el tipo de relación que establece con lo dominante es similar: puede tener un sentido de oposición o alternativo, o bien puede constituirse en una nueva fase de la cultura efectiva (Williams 2000: 131-132). 
De esta manera, tanto lo emergente como lo residual se constituyen en prácticas que dificultan la continuidad de lo dominante. En suma, el autor formula la necesidad de pensar lo dominante, siempre en sus relaciones con lo residual y lo emergente:

Lo que realmente debe decirse, como modo de definir los elementos importantes, o lo residual y lo emergente, y como un modo de comprender el carácter de lo dominante, es que ningún modo de producción y por lo tanto ningún orden social dominante y por lo tanto ninguna cultura dominante verdaderamente incluye o agota toda la práctica humana, toda la energía humana y toda la intención humana (Williams 2000: 147).

Se considera que los aportes teóricos de Williams resultan de suma utilidad para analizar las consecuencias que tuvieron algunas transformaciones históricas que los actores experimentaron, las cuales, a la vez que conllevaron la emergencia de nuevas prácticas y valores, implicaron la convivencia con sentidos y tradiciones anteriores.

Para recuperar toda la trama simbólica de un grupo social del pasado, se ha optado por utilizar la metodología de la historia oral. Daniel James (2004) valora este modo de abordaje al conocimiento histórico porque puede "proporcionar acceso a informaciones empíricas básicas imposibles de obtener en otras fuentes más tradicionales", dándonos "acceso a un universo social y cultural que está mucho más allá del reino de las estadísticas oficiales" (2004: 125126). Sin embargo, el autor aclara que la importancia de la historia oral no radica en la posibilidad de acceder a hechos ignorados previamente que permitirían, de esta forma, expandir nuestro caudal de hechos históricos sobre el pasado reciente, sino que su valor reside en la posibilidad de adentrarnos, a través de las narraciones personales, en los relatos de vida en tanto "constructos culturales". En efecto, para James, los relatos de vida recurren a un discurso público estructurado por convenciones de distinto tipo (por ejemplo, de clase y de género), valiéndose, al mismo tiempo, de una amplia gama de roles, autorepresentaciones y narraciones posibles (James, 2004: 128).

Liliana Barela (2009), por su parte, puntualiza que la historia oral se lleva adelante con grupos de individuos que comparten diversas singularidades, como etnias, ocupaciones, pero cuyas vidas no se encuentran plasmadas en las fuentes escritas:

Los informantes, testigos presenciales que cuentan el relato de sus vidas, lo hacen en su doble calidad de individuos singulares y de sujetos colectivos. Cada uno de ellos es único, 
pero en el camino de construcción de su subjetividad han sufrido la influencia familiar, barrial, social, socioeconómica, cultural del medio en que han vivido o viven (Barela, 2009: 13).

Para Barela, como sujetos singulares encarnan de manera única e irrepetible los valores, modas, costumbres, normas, mitos del orden familiar, grupal, social que los incluye. Además, lo hacen dentro de un contexto social que no es estático, sino que está continuamente afectado por las tensiones de sus miembros.

En efecto, los principios, intereses y objetivos de acción constituyen elementos unificadores de las individualidades, que actúan como una estructura que las encadena, aunque sin fusionarlas. Según Barela, esta "doble condición del discurso" es lo que permite "hacer historia" a partir del relato individual (Barela, 2009: 14).

Siguiendo a la autora, en historia oral la meta es revelar el contexto cultural en que se transmite la información y así transformar una historia individual en una narrativa cultural, entendiendo de una manera más plena lo que sucedió en el pasado. La autora destaca que "uno nunca recuerda solo", ya que siempre se está inmerso en un orden colectivo que lo contiene.

El recuerdo colectivo presupone y se expresa solo a partir del recuerdo individual. Sin la presencia de ambos resulta impensable la formación de la conciencia y, por lo tanto, de la memoria colectiva histórica (Barela, 2009: 16).

En esa línea, la autora retoma el desarrollo de Maurice Halbwachs, sobre el concepto de "marcos sociales de la memoria": 34

Estos marcos o cuadros sociales, tales como la familia, la religión, la clase social son los portadores de la representación general de la sociedad, de sus necesidades y valores, incluyen una visión del mundo y al ser de naturaleza histórica, cambian. Por eso, la memoria es una reconstrucción desde el presente más que un recuerdo, es una interacción entre pasado y presente, y está cultural y colectivamente enmarcada porque es producida por sujetos activos que comparten una cultura. Lo que no encuentra sentido en ese cuadro, se olvida (Barela, 2009: 16).

\footnotetext{
${ }^{34}$ Halbwachs (2004) señala la necesidad de la repetición y de un entorno favorable para la memorización: los llamados marcos sociales o marcos colectivos de la memoria por los cuales los individuos "completan" sus recuerdos ayudándose con la memoria de los demás.
} 
Para Patricia Pensado Legliese (2015) la historia oral aporta herramientas para aprehender la subjetividad de una época, a partir de la singularidad del testimonio del sujeto:

La historia oral, como reflexión en torno al transcurrir de la existencia humana desde el presente, percibe la complejidad de la experiencia particular del individuo frente a su acontecer histórico (Pensado Legliese, 2015: 51).

Desde esta perspectiva, la historia oral como campo específico de abordaje, debe entenderse en el marco de la emergencia de la historia social. En efecto, a partir de los relatos de vida es posible analizar las convergencias culturales y políticas en las que el sujeto se constituye como un ser social que participa activamente en su comunidad, generando relaciones identitarias o actuando en la configuración de las relaciones privadas que dotan de sentido su “ser y estar" en el mundo (Pensado Legliese, 2015: 51).

Ronald Fraser (1993), por su parte, se ocupa de aclarar que la historia oral no constituye una especialidad dentro de la disciplina histórica (como sería la historia económica), sino que es una técnica que intenta "generar nuevos saberes gracias a la creación de nuevas fuentes históricas" (1993: 80). Para el autor, esta creación de fuentes orales es una acción que el testigo e historiador realizan en conjunto, ya que el segundo construye una narración a partir de los recuerdos del primero.

En el campo de las investigaciones que emplean la técnica de la "historia oral", Fraser identifica dos corrientes: la hermenéutica y la etnosociológica. En la primera, no interesan tanto la exactitud de los relatos de vida porque, precisamente, importa detectar la desviación de los hechos recordados. De esta manera, se da lugar a que la imaginación, el simbolismo y el deseo emerjan en el testigo. En esta línea se encuentran los desarrollos de Alejandro Portelli quien considera que la tarea del historiador oral es descubrir los sentidos que subyacen en la manipulación que los grupos hacen en los recuerdos:

...si las fuentes orales utilizadas en esta investigación no son siempre fiables para una rigurosa reconstrucción de los hechos, este dato nos servirá no para descartarlas sin para ayudarnos a ir más allá de la materialidad visible del acontecimiento atravesando los hechos para descubrir su significado (Portelli, 1989: 6).

En la segunda corriente que menciona Fraser dentro del campo de la historia oral, se intenta, en cambio, encontrar "líneas fuerza" en los diferentes relatos hasta hallar "puntos de 
saturación" (reiteraciones) que permiten identificar fenómenos que, entonces, no surgirían de la imaginación de los testigos. Posteriormente, esa saturación alcanzada se intenta destruir con otros relatos, lo cual contribuye a afinar o reconstruir el modelo. Aun cuando se trata de corrientes diferenciadas, Fraser observa que ambos utilizan aportaciones del campo opuesto: ni los hermenéuticos ignoran totalmente los datos; ni los etnosociologistas las formas de narración (1993: 84). En ese sentido el autor valora la emergencia del campo de la historia oral porque cuestiona la historia telelógica y el intento de explicar la realidad socio-histórica exclusivamente como resultado de estructuras objetivas puras (Fraser, 1993: 91).

$\mathrm{Si}$, en todo caso, importa detectar la desviación de los acontecimientos recordados respecto de los hechos vividos para así entender el sentido que las evocaciones cobran en el presente, será necesario, entonces, complementar los testimonios orales con otras fuentes, como las bibliográficas, documentales, estadísticas.

El uso complementario de fuentes de información posibilita también establecer los vínculos entre las historias individuales y los procesos y relaciones sociales que se desarrollan en un contexto más amplio (Martínez Omaña, 1999: 1).

Aunque James (2004) acuerda en la importancia de someter a prueba y verificar la exactitud fáctica de los materiales históricos encontrados en las entrevistas orales, también previene sobre la posible tendencia de que el interés del historiador se centre en los hechos, antes que en los informantes y sus relatos. Inclusive, en los momentos de interacción con los informantes, esto podría dar lugar a una intervención agresiva que ponga en peligro la relación con el testigo y destruya su narrativa (2004: 138-139). En su lugar, James propone poner el foco en discernir qué guiones culturales y dispositivos narrativos emplean los individuos al momento de interpretar su experiencia (2004: 140). Así, alienta a descubrir el "patrón clave de la estructura narrativa", la cual, contiene juicios de valor adoptados por el narrador para dar sentido a su vida y, al mismo tiempo, refleja la relación del informante con los modelos sociales dominantes. Esos patrones, según James, se encarnan en diversos modelos y dispositivos narrativos posibles, y proceden, en general, de formas y géneros literarios encontrados en las distintas expresiones de la cultura y literatura populares (James, 2004: 164).

Los relatos por parte del informante pueden incluir distintos tipos narrativos: una memoria episódica, asociada a lo cotidiano; una memoria preformada, centrada en estereotipos que revelan visiones del mundo; momentos hímnicos, “de profunda rememoración vinculados a la experiencia de vida" (James, 2004: 155). En efecto, la tarea del historiador oral es recuperar 
la memoria, contemplando que él mismo contribuye a moldearla y, en ocasiones, a desorganizarla (James, 2004: 156).

Inspirado en Walter Benjamin, ${ }^{35}$ James sostiene que la historia oral "comparte ese impulso de redención", de "dar voz a los que no tienen voz, a quienes no participan en el relato dominante de la historia" (James, 2004: 141). Paul Thompson (2004) coincide en este planteo al afirmar:

...la historia oral tiene el singular poder de permitirnos acceder también a las experiencias de aquellas personas cuyas vidas están al margen del poder y cuyas voces permanecen ocultas porque sus vivencias improbablemente sean documentadas en los registros (Thompson, 2004: 22).

De esta manera, la labor de esta apunta a la recuperación de la memoria de individuos, grupos o comunidades que, muchas veces, perdieron las "coordenadas espaciales", las cuales son esenciales en el proceso de rememoración. Como plantea el autor, cuando el espacio material y social se ha perdido, también se pierde la posibilidad de recuperar las identidades y experiencias (James, 2004: 151).

...la crisis de la memoria contemporánea en las comunidades de clase obrera es justamente la crisis de estos espacios sociales que han sido víctimas del poder destructivo de la desindustrialización, la dislocación social y la mera irrelevancia (James, 2004: 158).

En ese sentido, el fundamento ético planteado por el autor reside en la convicción de que esas vidas re-membradas — dice James citando a Barbara Myerhoff - constituyen documentos morales y su función es salvífica, implicando la afirmación tácita de que "todo esto no ha sido para nada" (James, 2004: 157-158). Esta tesis comparte tal fundamento y convicción.

En relación a la técnica empleada para la creación de fuentes orales, el trabajo se basa en los aportes teóricos hechos desde la antropología por parte de Rosana Guber (1991). Para la autora, la entrevista se constituye en "una de las técnicas más apropiadas para acceder al universo de significaciones de los actores" (Guber, 1991: 205).

\footnotetext{
${ }^{35}$ Ver Benjamin tesis 2, 2001: "El pasado lleva consigo un índice temporal mediante el cual queda remitido a la redención. Existe una cita secreta entre las generaciones que fueron y la nuestra. Y como a cada generación que vivió antes que nosotros, nos ha sido dada una flaca fuerza mesiánica sobre la que el pasado exige derechos".
} 
Guber define la entrevista como una relación social a través de la cual se obtienen no solo enunciados y verbalizaciones, sino también información procedente de la observación, como el contexto del entrevistado, sus características físicas y su conducta. En su modalidad no directiva, que es la que se emplea en esta tesis, la entrevista surge como una herramienta que busca conocer con mayor profundidad sobre uno o diversos tópicos. En principio, Guber advierte que la respuesta que brinda el testigo ante la pregunta del entrevistador no implica de por sí el acceso al conocimiento sobre determinado fenómeno, ya que eso estaría suponiendo que el universo de significaciones entre investigador e informante son idénticos. Más bien, al plantear las preguntas, quien investiga establece el marco interpretativo de las respuestas. En efecto, teniendo en cuenta que los universos de significaciones entre entrevistados y la investigadora son distintos, ha sido preciso reflexionar acerca del marco interpretativo del que se parte para ir accediendo, a medida que se avanza en el trabajo de campo, en el universo de significaciones de los actores.

Guber aclara que reconocer el universo de significados desde el que parte el investigador, no implica que este deba mantenerse en él. Por el contrario, el proceso del trabajo de campo transforma al propio investigador porque le permite ingresar paulatinamente en un sistema de sentidos diferentes: "Esa es la diferencia entre una investigación que busca descubrir y otra que pretende ratificar" (Guber, 1991: 211).

Para evitar extrapolar temáticas y marcos interpretativos, Guber sugiere que se asuma un control y reflexividad constantes a lo largo del trabajo de campo, así como en la instancia de análisis. Resulta fundamental que quien investiga se ubique, entonces, en una posición de desconocimiento y duda acerca de sus propias certezas, las cuales constituyen el fundamento de sus formas de actuar y concebir el mundo. Esto no implica negar la presencia del propio investigador en el campo sino, precisamente, reconocerla y asumir una reflexividad que debe estar presente a lo largo de todo el proceso.

Para reconocer su propio marco interpretativo, el investigador, en un principio, debería identificar las respuestas que subyacen a sus propios interrogantes, así como descubrir a qué preguntas responde implícitamente el informante. El desafío es incorporar temáticas del universo del informante que no hayan sido previstas por el investigador. Es decir, introducir paulatinamente categorías de los propios actores entrevistados. En otras palabras: introducirse en un universo cultural diferente. De esta manera, el acceso a ese mundo social, además de considerar el proceso de conocimiento del investigador, se vale de recursos técnicos que contemplan tanto la reflexividad del investigador como la de los informantes. Para eso, Guber identifica tres procedimientos. En primer lugar, la asociación libre, que implica asumir que el 
cuestionario y los tópicos constituyen "nexos provisorios" o "guías", que pueden sufrir transformaciones a lo largo del trabajo de campo (Guber 1991: 214). Este procedimiento sugiere que durante la interacción se deje que el propio informante introduzca prioridades en la conversación. En última instancia, el descubrimiento de nuevos interrogantes sería una muestra más de la capacidad de relativizar el universo propio. El segundo procedimiento se refiere a la atención flotante, es decir, "un modo de escuchar que consiste en no privilegiar de antemano ningún punto del discurso" (Guber 1991: 215). De esta forma, se introducen nuevas temáticas, a partir de la lógica de los entrevistados.

El investigador aprende a acompañar al informante por los caminos de su lógica, lo cual requiere gran cautela y advertir, sobre todo, las intrusiones incontroladas. Esto implica además confiar en que los rumbos elegidos por el baqueano llevarán al investigador a buen destino, aunque poco de lo que vea y suponga quede por el momento demasiado claro. Esos trozos de información, verbalizaciones y prácticas —es decir, las piedras, lianas, árboles y orillas que van atravesando a medida que se internan por la selvapueden parecer absurdas e inconducentes, pero son el camino que se propone recorrer. Sin perder sentido crítico y capacidad de asombro, se trata de confiar que se llegará a alguna parte (Guber, 1991.: 215).

Esa confianza a la que alude Guber se traduce, finalmente, en una categorización diferida (el tercer procedimiento) que implica interpretar los dichos del entrevistado en una instancia posterior, a los efectos de evitar las interferencias de los propios marcos interpretativos del investigador en el proceso de conocimiento y aprendizaje del universo del informante. Mediante este procedimiento, se relativizan conceptos y categorías propias (Guber 1991: 216), con el fin de penetrar y reconstruir la propia lógica del actor. Por consiguiente, el procedimiento de la categorización diferida implica el registro de información que el investigador no es capaz de comprender en ese momento, pero que podrá interpretar con posterioridad. En ese sentido, se considera que las herramientas cognitivas del investigador son provisorias, con lo cual es fundamental el registro de puntos de vista y supuestos, que adquirirán sentido en la medida en que avance el trabajo de campo.

Guber también brinda algunas recomendaciones para que la formulación de las preguntas en situación de entrevista contribuya a reconstruir el universo significativo del informante, recuperando su propia lógica. En primer término, evitar interpretar las digresiones del entrevistado como pérdidas de tiempo. "En vez de un desvío, se puede estar asistiendo a la 
expresión del mismo problema que le interesa indagar, pero en otros términos, los del actor" (Guber 1991: 222). En segundo lugar, se recomienda introducir la menor cantidad de interrupciones posibles, favoreciendo la libre asociación del testigo en su discurso. En ese sentido, el mismo silencio podría dar lugar, en ocasiones, a que el entrevistado se explaye en temas de su interés. Aun cuando las interrupciones, en momentos, pueden ser necesarias, la autora sostiene que estas deben ser controladas y suscitar la reflexión por parte del investigador, en cuanto a sus finalidades y posibles derivaciones.

La autora considera que durante la primera etapa del trabajo de campo el investigador debe armar un marco de términos significativos, así como aprender a distinguir lo relevante de lo secundario; lo que procede del informante de lo que, en cambio, proviene de sus propias inferencias y preconceptos. En una segunda etapa, resulta apropiado seguir manteniendo una actitud abierta hacia el entrevistado, aunque profundizando en determinada dirección. En efecto, a partir de la sistematización del material obtenido, se establecen los alcances de las categorías significativas identificadas en la primera etapa, dando lugar a nuevas formas de entrevista que pretenden indagar en determinados aspectos específicos (Guber, 1991: 232-233).

Otro punto que se tuvo en cuenta entre los aportes de Guber refiere al espacio físico en que debe llevarse a cabo la interacción. Para la autora, la entrevista no directiva debería plantear una relocalización del ámbito del investigador al del informante, ya que, según sugiere, a partir de situaciones cotidianas y reales es más fácil acceder al sentido de las prácticas y de las verbalizaciones.

Con todo, Guber alerta sobre la posible "ilusión de transparencia" en la que puede incurrir el investigador al momento de suponer, erróneamente, que las respuestas de los informantes derivan en la elaboración del investigador en términos teóricos. En otras palabras, "la verdad" del entrevistado no se constituye en la "verdad científica": "El mundo interpretado por los sujetos no es, entonces, la elaboración teórica que deberá realizar el investigador" (Guber, 1991: 247). 


\section{Fuentes}

Esta tesis está basada, principalmente, en fuentes orales, conformadas a partir de 30 entrevistas, de las cuales 28 estuvieron dirigidas a ferroviarios varones de distintas áreas que ingresaron en la empresa en Junín durante las décadas de 1940 y 1950. Esas 28 entrevistas a ferroviarios involucraron, en rigor, a 22 trabajadores del riel, teniendo en cuenta que, en casos puntuales y por el valor del testimonio, se consideró oportuno realizar un encuentro posterior para profundizar en algún aspecto. Las 2 entrevistas restantes se realizaron a personas que no pertenecieron a la empresa, pero que fueron testigos privilegiados en la ciudad de los fenómenos estudiados. ${ }^{36}$ Permitieron, en términos de R. Fraser (1993), afinar el modelo explicativo construido a partir del conjunto de relatos.

El año promedio en que ingresaron los 22 trabajadores entrevistados es 1950 mientras que el valor de la mediana para el año es 1952. Esto fundamenta el valor de sus testimonios para abordar el período estudiado (1948-1973), si se tiene en cuenta, al mismo tiempo, que la fecha de retiro de los entrevistados es posterior, en la totalidad de los casos, a 1973.

Salvo tres testigos que fueron separados o se jubilaron durante el autodenominado "Proceso de Reorganización Nacional", ${ }^{37}$ el resto superó los treinta años de servicio en la empresa, llegando, en algunos casos, a superar los cuarenta. Asimismo, se destaca que todos ellos tuvieron como principal o única fuente de trabajo a la empresa ferroviaria. En este sentido, también puede afirmarse que todos los testigos entrevistados estuvieron ligados al ferrocarril durante un período importante de su existencia.

Los ferroviarios entrevistados pertenecieron a distintas dependencias dentro del ferrocarril: Talleres, Departamento de Mecánica, Tráfico y Vía y Obras. Así y todo, se manifiesta como predominante la cantidad de trabajadores entrevistados que pertenecieron a Talleres, lo cual se justifica porque la gran mayoría de los ferroviarios en Junín trabajaron en esta dependencia. Las áreas de incumbencia de los testigos también son diversas: Tornería, Electricidad, Seguridad en el Trabajo, Conducción, Ornamental, Administración, Soldadura,

\footnotetext{
${ }^{36}$ Los dos testigos no ferroviarios fueron: Oscar Pellizi, periodista, hijo de ferroviario y persona ligada a la cultura de Junín por su pertenencia a la Biblioteca Florentino Ameghino y a la Asociación Cultural Dante Balestro. Brindó un testimonio sobre el vínculo entre el ferrocarril y el desarrollo cultura de la ciudad. Por su parte, Mateo Perkusic, empresario, compartió un espacio de formación con otros ferroviarios (Ciclo Técnico Nocturno de la Escuela Fábrica Yapeyú), aunque decidió montar su propia empresa en lugar de ingresar al ferrocarril.

${ }^{37}$ Es el caso de Carlos Violante, quien se jubiló anticipadamente en 1978 por problemas cardíacos y el de Bozzini e Ismael Tornello, quienes fueron separados de sus tareas durante el Proceso de Reorganización Nacional por su participación política en la Unión Ferroviaria. Cabe destacar, no obstante, que incluso esos tres actores fueron testigos del período estudiado.
} 
Ajustaje, Chapas, Calderería, Carpintería, Control de Calidad, Planificación, Métodos de trabajo, entre otras; lo que permite fundamentar el valor del conjunto de los testimonios. Debe aclararse, no obstante, que la movilidad laboral caracterizó a los trabajadores ferroviarios del período, lo cual implica que la gran mayoría perteneció a diversas secciones a lo largo de su carrera.

De la totalidad de los 22 entrevistados, 21 ingresaron en el escalafón laboral más bajo, esto es, como peones (sin formación previa) o aprendices (con formación técnica previa). La excepción está dada por el único profesional ingeniero del grupo, quien entró a la empresa en un escalafón superior, como primer ayudante del jefe de Laboratorio.

Es importante subrayar que la totalidad de los entrevistados ferroviarios lograron ascensos en su carrera y 11 de ellos llegaron a ser personal de dirección (50\% del total de los entrevistados), pasando a pertenecer a partir de ese momento a la Asociación de Personal de Dirección de Ferrocarriles Argentinos (APDFA).

A continuación, se detalla la lista de los ferroviarios que se emplean como fuentes de esta tesis, de acuerdo al orden de realización de la entrevista:

Cuadro $\mathrm{N}^{\circ}$ 1: Fuentes orales por orden de realización

\begin{tabular}{|l|l|l|l|l|l|l|l|}
\hline$N^{\text {o38 }}$ & Fecha & Nombre y apellido & Ingreso & Dependencia & $\begin{array}{l}\text { Área de } \\
\text { incumbencia }\end{array}$ & $\begin{array}{l}\text { Cargos/tareas que } \\
\text { menciona }{ }^{39}\end{array}$ & $\begin{array}{l}\text { Pertenen } \\
\text { cia } \\
\text { APDFA }\end{array}$ \\
\hline 19 & $29 / 04 / 11$ & Omar Calderoni & 1945 & Talleres & $\begin{array}{l}\text { Soldadura } \\
\text { Mantenimiento }\end{array}$ & $\begin{array}{l}\text { Aprendiz } \\
\text { Dibujante } \\
\text { Jefe de Ayudantes } \\
\text { Jefe de Mantenimiento }\end{array}$ & SÍ \\
\hline 27 & $05 / 07 / 11$ & Bruno Danielle & 1957 & $\begin{array}{l}\text { Dto. Mecánica } \\
\text { Vía y Obras }\end{array}$ & Vía y Obras & $\begin{array}{l}\text { Peón } \\
\text { Dactilógrafo } \\
\text { Proyectista } \\
\text { Ayudante } \\
\text { Ayudante de Distrito }\end{array}$ & SÍ \\
\hline
\end{tabular}

\footnotetext{
${ }^{38}$ La numeración de las entrevistas se realizó según el orden de aparición de los extractos de testimonios en la tesis.

${ }^{39}$ Los cargos que mencionan los testigos no constituyeron respuestas a preguntas puntuales de la entrevistadora, ya que se intentó reconstruir los relatos de vida en los términos propuestos por los mismos actores. Así y todo, la mayoría de ellos mencionan los cargos que tuvieron en la empresa y los ascensos que fueron logrando, por considerarlos hitos importantes en sus vidas. La excepción está dada por dos entrevistados (Abel Pinto e Ismael Tornello) que no mencionan los cargos y sus ascensos, en base a relatos que parecen responder una lógica diferente, más bien está caracterizada por comprender su propia historia en la empresa a partir de su participación política en el gremio Unión Ferroviaria. También es el caso de Omar Decarre, cuyo relato de vida gira en torno a su carrera artística como cantante de orquesta, por fuera de su puesto en el ferrocarril.
} 


\begin{tabular}{|c|c|c|c|c|c|c|c|}
\hline 16 & $06 / 05 / 11$ & Roberto Di Marco & 1951 & $\begin{array}{l}\text { Talleres } \\
\text { Dto. Mecánica }\end{array}$ & Administrativo & $\begin{array}{l}\text { Aprendiz } \\
\text { Capataz } \\
\text { Secretario }\end{array}$ & NO \\
\hline 26 & $\begin{array}{l}11 / 05 / 11 \\
23 / 10 / 17\end{array}$ & Juan Dall'Occhio & 1956 & Talleres & $\begin{array}{l}\text { Máquinas- } \\
\text { herramientas } \\
\text { Sistema de } \\
\text { Reparación por } \\
\text { camino crítico }\end{array}$ & $\begin{array}{l}\text { Aprendiz } \\
\text { Dibujante } \\
\text { Jefe de Talleres }\end{array}$ & SÍ \\
\hline 24 & $\begin{array}{l}31 / 05 / 11 \\
31 / 08 / 17\end{array}$ & Eridé Rinaldi & 1949 & Talleres & $\begin{array}{l}\text { Ornamental } \\
\text { Reparaciones } \\
\text { Control de } \\
\text { Calidad }\end{array}$ & $\begin{array}{l}\text { Aprendiz } \\
\text { Proyectista } \\
\text { Jefe de Reparaciones } \\
\text { Jefe de Talleres Junín }\end{array}$ & SÍ \\
\hline $\begin{array}{l}14 \\
29 \\
22\end{array}$ & $\begin{array}{l}16 / 06 / 11 \\
14 / 05 / 16 \\
03 / 08 / 18\end{array}$ & Ítalo Marone & 1950 & $\begin{array}{l}\text { Talleres } \\
\text { Dto. Mecánica }\end{array}$ & $\begin{array}{l}\text { Control de } \\
\text { calidad }\end{array}$ & $\begin{array}{l}\text { Desde el escalafón más } \\
\text { bajo (aprendiz) hasta el } \\
\text { cargo más alto en la } \\
\text { línea San Martín que } \\
\text { tuvo asiento en Junín: } \\
\text { jefe del Departamento } \\
\text { de Mecánica }\end{array}$ & SÍ \\
\hline 2 & $10 / 07 / 11$ & Aymar Crocco & 1947 & Talleres & $\begin{array}{l}\text { Tornería } \\
\text { Método } \\
\text { Planificación }\end{array}$ & $\begin{array}{l}\text { Aprendiz } \\
\text { Superespecialista } \\
\text { Jefe de Método } \\
\text { Jefe de Planificación y } \\
\text { Control }\end{array}$ & SÍ \\
\hline 8 & $27 / 07 / 11$ & Carlos Violante & 1952 & Talleres & Electricidad & $\begin{array}{l}\text { Aprendiz } \\
\text { Capataz }\end{array}$ & NO \\
\hline 4 & $28 / 09 / 11$ & Héctor Ferrari & 1945 & Talleres & $\begin{array}{l}\text { Seguridad en } \\
\text { el trabajo }\end{array}$ & $\begin{array}{l}\text { Aprendiz } \\
\text { Dibujante } \\
\text { Maestro } \\
\text { Jefe de Aprendices } \\
\text { Jefe de cursos de } \\
\text { capacitación } \\
\text { Jefe de Seguridad en el } \\
\text { Trabajo }\end{array}$ & SÍ \\
\hline 12 & $14 / 10 / 11$ & $\begin{array}{l}\text { La Fraternidad } \\
\text { (grupal) }\end{array}$ & Vs. & $\begin{array}{l}\text { Tráfico/ } \\
\text { Transporte }\end{array}$ & Conducción & $\begin{array}{l}\text { Aspirantes } \\
\text { Foguistas } \\
\text { Maquinistas }\end{array}$ & NO \\
\hline $\begin{array}{l}5 \\
18\end{array}$ & $\begin{array}{l}17 / 11 / 11 \\
03 / 11 / 17\end{array}$ & Miguel Mantino & 1951 & Talleres & Calderería & $\begin{array}{l}\text { Aprendiz } \\
\text { Cabeza de cuadrilla }\end{array}$ & NO \\
\hline 13 & $03 / 12 / 11$ & Dante Cruz & 1952 & $\begin{array}{l}\text { Tráfico/ } \\
\text { Transporte }\end{array}$ & Conducción & $\begin{array}{l}\text { Aspirante } \\
\text { Foguista } \\
\text { Maquinista }\end{array}$ & NO \\
\hline 6 & $23 / 12 / 11$ & Ismael Tornello & 1954 & Talleres & Chapas & No informa & NO \\
\hline 17 & $03 / 02 / 12$ & Oscar Bozzini & 1947 & Vía y Obras & Vía y Obras & $\begin{array}{l}\text { Peón } \\
\text { Artesano }\end{array}$ & NO \\
\hline
\end{tabular}




\begin{tabular}{|c|c|c|c|c|c|c|c|}
\hline & & & & & & $\begin{array}{l}\text { Encargado de } \\
\text { Reparaciones }\end{array}$ & \\
\hline 20 & $15 / 02 / 12$ & Valentín Martínez & 1947 & Talleres & Carpintería & $\begin{array}{l}\text { Oficial } \\
\text { Capataz }\end{array}$ & $\mathrm{NO}$ \\
\hline 1 & $27 / 02 / 12$ & José Poch & 1942 & Dto. Mecánica & $\begin{array}{l}\text { Administrativo } \\
\text { (Sueldos) }\end{array}$ & $\begin{array}{l}\text { Mensajero } \\
\text { Auxiliar } \\
\text { Secretario }\end{array}$ & NO \\
\hline 9 & $15 / 03 / 12$ & Abel Pinto & 1957 & Talleres & $\begin{array}{l}\text { Bastidores } \\
\text { Chapas } \\
\text { Calderería }\end{array}$ & No menciona & NO \\
\hline $\begin{array}{l}21 \\
30\end{array}$ & $\begin{array}{l}08 / 07 / 17 \\
09 / 09 / 17\end{array}$ & José Calcagni & 1953 & Dto. Mecánica & $\begin{array}{l}\text { Control de } \\
\text { Calidad }\end{array}$ & $\begin{array}{l}\text { Primer ayudante de } \\
\text { Laboratorio } \\
\text { Jefe de Laboratorio } \\
\text { Jefe de Control de } \\
\text { Calidad } \\
\text { Segundo jefe de Dto. } \\
\text { Mecánica }\end{array}$ & SÍ \\
\hline 10 & $12 / 07 / 17$ & Aroldo Taberna & 1953 & Talleres & $\begin{array}{l}\text { Coches y } \\
\text { motores } \\
\text { Planificación y } \\
\text { Control }\end{array}$ & $\begin{array}{l}\text { Aprendiz } \\
\text { Dibujante } \\
\text { Proyectista de obra } \\
\text { Proyectista principal } \\
\text { Jefe de sección }\end{array}$ & SÍ \\
\hline 23 & $25 / 10 / 17$ & Omar Decarre & 1953 & Talleres & $\begin{array}{l}\text { Ajustaje } \\
\text { Herramental } \\
\text { Fabricaciones }\end{array}$ & No refiere & SÍ \\
\hline 7 & $17 / 04 / 18$ & Abilio Murgia & 1954 & Talleres & $\begin{array}{l}\text { Método } \\
\text { Estudio del a } \\
\text { Reparación }\end{array}$ & $\begin{array}{l}\text { Aprendiz } \\
\text { Dibujante } \\
\text { Proyectista principal } \\
\text { Jefe de Métodos y } \\
\text { tiempo } \\
\text { Jefe de Estudios de } \\
\text { Reparación }\end{array}$ & SÍ \\
\hline 11 & $02 / 12 / 18$ & $\begin{array}{l}\text { Roberto } \\
\text { De Giulio }\end{array}$ & 1952 & Talleres & Tornería & $\begin{array}{l}\text { Aprendiz } \\
\text { Oficial } \\
\text { Superespecialista }\end{array}$ & $\mathrm{NO}$ \\
\hline
\end{tabular}

Fuente: elaboración propia

En el siguiente cuadro figuran los entrevistados que no pertenecieron al ferrocarril

\section{Cuadro $\mathrm{N}^{\circ}$ 2: Entrevistas a personas no pertenecientes al ferrocarril}

\begin{tabular}{|l|l|l|l|}
\hline $\mathrm{N}^{\mathrm{o}}$ & Nombre & Fecha & Vínculo con el ferrocarril \\
\hline 28 & Héctor Pellizi & $11 / 05 / 16$ & $\begin{array}{l}\text { Hijo de ferroviario. } \\
\text { Periodista. Ha escrito algunos artículos sobre el ferrocarril en Junín. } \\
\text { Integrante de la Biblioteca Florentino Ameghino, fundada por ferroviarios. } \\
\text { Fundador e integrante de la Asociación Civil "Dante Balestro", cuyo nombre } \\
\text { remite a un reconocido ferroviario fraternal de la ciudad. }\end{array}$ \\
\hline
\end{tabular}




\begin{tabular}{|l|l|l|l|}
\hline 25 & Mateo Perkusic & $06 / 07 / 17$ & $\begin{array}{l}\text { Recibió una formación técnica en la Escuela Fábrica "Yapeyú, junto a otros } \\
\text { ferroviarios que terminaron siendo personal de dirección (entre ellos E. Rinaldi, } \\
\text { I. Marone) } \\
\text { En su juventud, convivió en la pensión donde vivía con otros trabajadores del } \\
\text { riel. } \\
\text { Como empresario, empleó a trabajadores ferroviarios con conocimientos } \\
\text { técnicos. }\end{array}$ \\
\hline
\end{tabular}

Fuente: elaboración propia

Las entrevistas fueron realizadas, principalmente, en dos períodos: 2011-2012 y 2017 2018. En el primero, si bien se trabajó a partir de una guía de preguntas, se mantuvo una actitud abierta en la búsqueda de ir accediendo al universo de significados de los actores, es decir, sus propias categorías. Una vez que fue posible reconstruir una narración colectiva a partir de los múltiples relatos, se pasó a la segunda etapa en la cual se abordaron temáticas muy puntuales sobre las cuales se deseaba profundizar para la presente tesis. Específicamente, los modos y espacios de formación, reflexiones acerca de la experiencia inglesa y las transformaciones que implicó la nacionalización, los recuerdos de lo que aconteció en la huelga de 1961 en Junín y las iniciativas locales de finales de la década del sesenta e inicios del setenta para mejorar la eficiencia del ferrocarril. Cabe aclarar que, previo a ello, en 2016, fueron realizadas 2 entrevistas que tuvieron un carácter exploratorio y estuvieron dirigidas a la toma de decisiones para abordar la nueva etapa de investigación. Debido al valor de estos dos testimonios que permitió comprender con mayor profundidad la influencia del ferrocarril en el desarrollo social y cultural de la ciudad, estas dos entrevistas fueron tenidas en cuenta para la presente tesis.

El espacio físico para la realización de las entrevistas a los ferroviarios fue, en la mayoría de los casos, la vivienda de los testigos, la cual se consideró un lugar óptimo ya que, en la intimidad del hogar y bajo el amparo del ambiente cotidiano, resultaba más factible que afloren los recuerdos de los informantes. La excepción estuvo dada por las entrevistas a quien había sido secretario General de la Unión Ferroviaria (Miguel Mantino, 5 y 18) y la entrevista grupal a los jubilados de La Fraternidad (12), ambas realizadas en las sedes de los sindicatos, a partir de propuestas de los testigos involucrados. En el caso de La Fraternidad, debido a que este era un espacio de sociabilidad al que los agremiados jubilados aún concurrían de forma habitual, se evaluó que era adecuado no solo cambiar el lugar de la entrevista, sino también la modalidad de realización (grupal) para propiciar que, en la misma interacción, surgieran más fácilmente las evocaciones. En todos los casos, siempre se mantuvo una actitud abierta para pautar el encuentro, dejando que fuera el testigo quien definiera tanto el lugar, como el horario y el día de realización de la entrevista. 
Los encuentros fueron grabados a través de un dispositivo de audio. Tuvieron una duración estimada entre una hora y media, y dos horas y media. En todos los casos se les dio libertad a los testigos para interrumpir el encuentro si así lo deseaban, aunque en la gran mayoría de los casos fue la entrevistadora quien concluyó la interacción dando lugar, en ese momento, a que el entrevistado agregue o añada la información que considerara importante para concluir su relato. En los días posteriores a la grabación, se procedió a la transcripción de la totalidad de la entrevista, aún de los silencios y de las partes del discurso que, en aquel momento, se consideraron desvíos de los ejes de la entrevista. En efecto, elaboraciones analíticas ulteriores permitieron, en muchos casos, comprender los significados de los relatos que, en un principio, no cobraban sentido en el conjunto de la narración.

Luego de contar con esas fuentes orales transcritas en documentos escritos se establecieron los núcleos problemáticos que surgieron a partir del conjunto de las narraciones de los testigos. En lecturas posteriores de cada una de las entrevistas, se copiaron extractos de cada una de las entrevistas que correspondían a cada uno de los ejes o núcleos problemáticos. Este material fue el insumo central para el análisis posterior de las fuentes.

Si bien las fuentes orales constituyen la parte central de la presente tesis, estas fueron complementadas por otro tipo de fuentes que permitieron ampliar, corroborar o complejizar la información recordada e interpretada por los testigos. Entre estas fuentes se incluyen: notas de los diarios locales La Verdad, Democracia y Mundo Nuevo, archivos de la empresa del Archivo Histórico Municipal de Junín y del Archivo Universitario de la UNNOBA “Roberto Dimarco". A ello se le suma la bibliografía histórica que permitió contextualizar los acontecimientos y representaciones que emergieron en los relatos. 


\section{Capítulo 1}

\section{La vida en el ferrocarril}




\section{El ingreso al ferrocarril como hito}

"A mí me duele, porque lo he sentido tanto al ferrocarril, lo he defendido tanto... era todo lo que tenía, era mi vida", decía José Poch al evocar su historia de vida en el ferrocarril y el fin de lo que este actor consideraba el proyecto de la empresa estatal de ferrocarriles en Argentina. ${ }^{40}$ Este testimonio, que se reitera de manera similar en otros protagonistas, permite ilustrar la profunda ligazón que los trabajadores percibían entre la empresa y su propia trayectoria vital. Esto se evidencia también en el recuerdo, común entre los ferroviarios, sobre la fecha exacta en que ingresaron, como los casos de Aymar Crocco y Eridé Rinaldi, respectivamente, quienes rememoraban: "Yo entré el 13 de enero de 1947", 41 "El 14 de enero del 49 entré al ferrocarril". ${ }^{42}$

Podría decirse que el ingreso en la empresa constituía un hito, el inicio de una nueva etapa para estos trabajadores del riel que ingresaron en la empresa en las décadas del cuarenta y cincuenta del siglo XX y fueron testigos y protagonistas del devenir de la empresa nacionalizada por el presidente Juan Domingo Perón. Ese inicio era fundante en la historia de estos varones porque les permitía proyectar o imaginar toda una vida ligada al medio de transporte, tal como expresa Rinaldi:

\footnotetext{
"Antes, usted entraba a un trabajo y se jubilaba en ese trabajo. El empleado bancario se jubilaba como bancario, el maestro, el militar... Y el ferroviario, se jubilaba como ferroviario. No es como hoy que hay mucha gente que piensa entrar a un trabajo, estar cinco o seis años y después... independizarse, o cambiar, o buscar otra cosa... En ese tiempo, entrar a ser ferroviario era el deseo de mucha gente, especialmente, de aquellos que no tenían recursos para seguir una carrera." 43
}

El ingreso en la empresa era considerado una de las máximas aspiraciones a las que un joven de escasos recursos podía pretender en Junín, ya que constituía el punto de partida para poder cumplir con todas una serie de expectativas que los ferroviarios tenían en aquel momento, según aflora en sus relatos: contar con un sueldo suficiente, que les permitiera vivir sin privaciones, $\mathrm{y}$, fundamentalmente, seguro, que estuviera disponible más allá de las contingencias individuales por las que el trabajador tuviera que atravesar. Luego, poder formar una familia,

\footnotetext{
${ }^{40}$ Entrevista $\mathrm{N}^{\mathrm{o}} 1$ a José Poch, 27/02/2012 (en adelante E.N ${ }^{\mathrm{o}} 1$ ).

${ }^{41}$ Entrevista $\mathrm{N}^{\circ} 2$ a Aymar Crocco, 10/07/2011 (en adelante $\mathrm{EN}^{\circ} 2$ ).

${ }^{42}$ Entrevista N³ a Eridé Rinaldi, 31/05/2011 (en adelante EN³).

${ }^{43} \mathrm{EN}^{\circ} 3$.
} 
construir el hogar familiar y brindarles una vida digna a los descendientes. Además, ascender en la escala laboral de la empresa y, por tanto, incrementar la retribución, ascendiendo también en la escala social. Finalmente, retirarse de la empresa y "acogerse a los beneficios de la jubilación". ${ }^{44}$ Los testimonios que asocian el ingreso con un inicio venturoso se reiteran una y otra vez: "Entrar al taller era ganar la lotería", afirmaba Héctor Ferrari; 45 "En aquel tiempo el que entraba al ferrocarril se salvaba”, decía Miguel Mantino; 46 "¡Quién no quería entrar al ferrocarril? El que era ferroviario estaba ahí arriba", aseguraba Ismael Tornello. ${ }^{47}$

Una de las maneras en que el ingreso era posible era a través de la formación que otorgaba la Escuela de Artes y Oficios de Junín, creada en 1923, que en 1940 se transforma en Escuela Técnica de Oficios "Antonio Bermejo"48. En primer lugar, existía un acuerdo entre la institución educativa y la empresa por el cual los diez mejores promedios podían ingresar directamente al ferrocarril, "premiando" así el desempeño académico con el otorgamiento de una vacante en una fuente laboral considerada deseable. Esta tradición, que databa de la época en que el ferrocarril era de capitales ingleses, se mantuvo luego de la nacionalización de 1948.

Rinaldi, un ferroviario que entró como aprendiz y llegó a ser jefe de Talleres Junín, recuerda que los ingleses solían realizar una celebración en diciembre a la que invitaban a los diez mejores promedios de la Escuela. En enero, si esos estudiantes habían aceptado el ofrecimiento, podían ingresar a la empresa. Este ferroviario, con orgullo, recuerda que en el año de su ingreso (1949) los diez mejores promedios entraron a la sección Ornamental, "la más distinguida del personal obrero": "Era la sección más distinguida porque se fabricaban herramientas para el taller de Junín, Alianza, de Mendoza y para toda la línea". ${ }^{49}$ Aymar Crocco, por su parte, recuerda que su abuelo había hablado con el segundo jefe de Talleres, $\mathrm{Mr}$ O'Connor, quien le había manifestado, previo a su ingreso, que tenían la intención de que los alumnos que ingresaran por promedio, se siguieran capacitando para constituir, en un futuro, el personal de dirección de la empresa. En base a estas expectativas de progreso es que él, en

\footnotetext{
${ }^{44}$ Esta frase se emplea frecuentemente en la sección "Jubilaciones" de la revista Boletín Informativo BAP de la década del cuarenta, para informar respecto de ferroviarios que dejaban de prestar servicio por haber cumplido la cantidad de años estipulados en la empresa. De esta manera, puede afirmarse que la jubilación era una de las expectativas con las que el ferroviario ingresaba. Jubilaciones (marzo, 1947), BAP, Boletín Informativo, p. 33.

${ }^{45}$ Entrevista N ${ }^{\circ}$ a Héctor Ferrari, 28/09/2011 (en adelante EN 4 ).

${ }^{46}$ Entrevista No5 a Miguel Mantino, 17/11/2011 (en adelante EN ${ }^{\circ} 5$ ).

${ }^{47}$ Entrevista $\mathrm{N}^{\mathrm{o}} 6$ a Ismael Tornello, 23/12/2011 (en adelante $\mathrm{EN}^{\circ} 6$ ).

${ }^{48}$ Por Ley de 1923 se crea la Escuela de Artes y Oficios. El 27 de mayo de 1924 se realiza la primera apertura a la inscripción de alumnos. Las clases se inician el 15 de julio de ese año, con 74 alumnos. El cambio de nombre tuvo lugar en 1940 (por decreto 61940): pasó a llamarse Escuela Técnica de Oficios Antonio Bermejo. Agradezco a Aroldo Taberna por brindarme el documento: Escuela de Artes y Oficios de Junín, sus bodas de oro (1974), Historia de Junín, p. 3.

${ }^{49} \mathrm{EN}^{\circ} 3$.
} 
particular, decidió aceptar el ofrecimiento de la empresa. Aunque no puede constatarse la existencia de esa conversación, sí puede verificarse que los más altos puestos del ferrocarril, décadas más tarde, serían ocupados por antiguos estudiantes de la Escuela Técnica "Antonio Bermejo", quienes, en la mayoría de los casos, habían logrado nuevos créditos educativos. ${ }^{50}$

Otra forma en que los egresados de la Escuela Industrial (o de Artes y Oficio) podían ingresar era a través de una evaluación, pocos meses después del ofrecimiento que la empresa le habían hecho a los mejores promedios. Rinaldi recuerda: "A los tres o cuatro meses seguía entrando gente en el ferrocarril, por medio de un examen. Porque solían recurrían en ese entonces a la escuela para sacar muchachos". ${ }^{51}$ De esta manera, la formación técnica previa aparece en los relatos como un factor determinante en el ingreso en la empresa. Mientras que los "mejores promedios" habían probado, mediante su desempeño académico, su capacidad, estos nuevos aspirantes recibidos de la Escuela debían demostrarla mediante una evaluación. Tal fue el caso de Abilio Murgia, quien recuerda que, en 1954, cuando él terminó el ciclo básico de la Escuela Industrial "todo el grupo de egresados fue a buscar de ingresar en el ferrocarril": "En ese momento el crecimiento vegetativo del ferrocarril estaba muy bien con los egresados de la escuela industrial". 52

Los aspirantes también podían ingresar al ferrocarril —ya iniciada la década del cincuenta- a partir de la formación técnica en las Escuelas-fábrica, creadas durante el peronismo. ${ }^{53}$ Ese fue el caso de Carlos Violante quien ingresó en la sección Electricidad, en la cual también se retiró: “Empecé en el año 52, cuando salí de la Escuela-fábrica Yapeyú. Salías de ahí con una base, con una preparación, con oficio. Por ejemplo, fresadores, torneros, ajustadores, herrero, carpintero. Y después se podía entrar al ferrocarril que en aquel tiempo era una suerte". ${ }^{54}$ También fue la oportunidad en que Abel Pinto pudo ingresar: "Empecé en 1957, a raíz de haber ido a estudiar a la Escuela Fábrica que el gobierno peronista instaló en un montón de lugares. Allí se enseñaban distintos oficios: torneros, ajustadores, hojalateros, carpinteros. En general cuando los muchachos se recibían, entraban a trabajar a empresas

\footnotetext{
${ }^{50}$ Hasta 1949 el máximo diploma que la Escuela Antonio Bermejo otorgaba era el de "experto calificado". Luego de ese año, los estudiantes de dicha escuela tuvieron la posibilidad de acceder al título terciario de "técnico". Muchos de los estudiantes que se habían recibido como expertos calificados buscarían, años después, obtener un diploma como técnicos, para estar en condiciones similares a los egresados de la Escuela Técnica. Esta preocupación habría originado la creación del ciclo técnico nocturno en la Escuela Yapeyú. Este tema se profundiza más adelante.

${ }^{51} \mathrm{EN}^{\circ} 3$.

${ }^{52}$ Entrevista No7 a Abilio Murgia, 17/04/2018 (en adelante ENo7).

${ }^{53}$ En el período 1947-1951 se crearon 78 escuelas fábrica. De esta manera, el peronismo profundizó una política vinculada a la educación de adultos para el trabajo que se había iniciado en 1943 (Arguto, 2013: 6).

${ }^{54}$ Entrevista $N^{\circ} 8$ a Carlos Violante, 27/07/2011 (en adelante EN ${ }^{\circ} 8$ ).
} 
estatales como Ferrocarriles, YPF, Obras Sanitarias". 55

Sin embargo, si bien la formación previa era un factor importante a la hora de ingresar a esa fuente de trabajo considerada privilegiada, no era el único. Existía una tradición, que databa de la época de los ingleses y que continuó cuando el ferrocarril se estatizó, en la que se privilegiaba el ingreso de hijos de ferroviarios (o familiares con distintos grados de cercanía parental). Ese fue el caso de José Poch, quien ingresó en 1942, luego de que su padre solicitara su ingreso a un jefe inglés. "Los ingleses querían que los hijos de ferroviarios entraran al ferrocarril”, aseguraba Poch. ${ }^{56}$ Así y todo, la filiación era un factor importante pero no suficiente: Poch se había formado en la Escuela de Artes y Oficio y tuvo que rendir un examen y tener una revisación médica con resultados positivos, previo a su ingreso en la empresa.

Rinaldi, quien no tuvo familiares ferroviarios e ingresó por méritos académicos propios al haber estado dentro de los "mejores promedios", justifica esa modalidad inglesa que tomaba en cuenta otros valores, distintos a los meramente técnicos, para la selección del personal:

\begin{abstract}
"Los ingleses eran muy vivos. Cuando un operario pedía que su hijo entrara al taller, entraba siempre el que había tenido muy buen desempeño. O sea que ese era el mejor antecedente. No le iban a pedir ni a hacer análisis psicológico, ni nada de eso. Si (el padre) no había tenido medidas disciplinarias, si no había sido faltador, si no había sido enfermo consuetudinario... Porque, ¿sabe quién iba a cuidar que el hijo cumpla? El padre, no el jefe, no el supervisor. El padre iba a cuidar que ese hijo... porque había otro criterio también en ese tiempo. En cumplir. Sabía que ese hijo le iba a cumplir al pie de la letra con la disciplina, la obediencia." 57
\end{abstract}

El testimonio anterior permite reconocer que la empresa británica intentaba asegurarse de que el nuevo operario hubiera desarrollado ciertas conductas sociales, además de la formación técnica. En particular, el cumplimiento y la obediencia hacia los jefes, en el contexto de una sociedad en la que el padre parecía ejercer su autoridad en el núcleo familiar. ${ }^{58}$ Héctor Ferrari, quien ingresó en 1945, también recuerda que la empresa británica tenía en cuenta otros factores que tenían que ver con las actitudes esperables de los jóvenes ingresantes: "Los

\footnotetext{
${ }^{55}$ Entrevista N ${ }^{\circ} 9$ a Abel Pinto, 15/11/2012 (en adelante EN ${ }^{\circ}$ ).

${ }^{56} \mathrm{EN}^{\mathrm{o}} 1$.

${ }^{57} \mathrm{EN}^{\mathrm{o}} 3$.

${ }^{58}$ Esa obediencia y lealtad hacia los padres se seguiría reproduciendo en la empresa. No es casual que los ferroviarios refieran a la empresa como "la otra familia", la "familia ferroviaria", tema sobre el cual se ahondará en el segundo capítulo.
} 
ingleses siempre hacían entrar a los alumnos de la Escuela Industrial, a los mejores alumnos y no solo eso: estudiaban tu comportamiento en la calle. Antes de ingresar al ferrocarril tenías que rendir un examen. Pero averiguaban primero la seriedad que vos tenías". 59

Si bien la expectativa de conducta era un factor que incidía en la elección, la formación y la capacidad técnica que los aspirantes podían demostrar (al momento del examen) parecía ser el aspecto fundamental a tener en cuenta para el ingreso durante la gestión británica. Luego de la nacionalización de 1948, la formación siguió siendo un factor crucial. Sin embargo, existían otros "créditos" no técnicos que habilitaban la incorporación a la empresa. Aroldo Taberna, quien ingresó en 1953, lo expone con claridad, sugiriendo la importancia que luego de la nacionalización comenzó a cobrar la pertenencia al partido peronista y los vínculos personales con este tipo de actores: "Algunos entraban por el colegio industrial y otros entraban por razones políticas". ${ }^{60}$ Uno de los entrevistados, reconoce abiertamente lo que otros, por pudor, quizás no mencionan: "Yo entré acomodado, por alguien que era medio capo. Porque era peronista y andaba en la grande. Por él entré". ${ }^{61}$

Más allá de la ruptura que para los ferroviarios juninenses significó la nacionalización en relación a los valores tenidos en cuenta para ingresar y progresar, podríamos, no obstante, trazar una continuidad entre las prácticas de la empresa privada y la estatal: ambas contemplaban aspectos no técnicos del trabajador para su incorporación en la empresa. ${ }^{62}$ Mientras la empresa británica tenía en cuenta la capacidad del trabajador de obedecer a las órdenes de un jefe y ser disciplinado en su modo de trabajo, la empresa estatal iba a tener en cuenta, en algunos casos, la capacidad del ferroviario de ser leal a un partido, al gremio y a una persona particular que había favorecido su ingreso. Podríamos decir que las nuevas prácticas arraigan en un contexto propicio para ello.

Hasta aquí nos hemos referido al modo de ingreso de los ferroviarios de Talleres Junín, llamados también "talleristas", y a los que ingresaron en las oficinas del Departamento Mecánica de la línea San Martín (durante la gestión británica, Buenos Aires al Pacífico, en adelante, BAP) que tenía su sede en Junín e injerencia en otros talleres como Alianza y Mendoza, además de los depósitos de locomotora y de coches de vagones ${ }^{63}$.Los conductores

\footnotetext{
${ }^{59} \mathrm{EN}^{\mathrm{o}} 4$.

${ }^{60}$ Entrevista $\mathrm{N}^{\mathrm{o}} 10$ a Aroldo Taberna, 12/07/2017 (en adelante $\mathrm{EN}^{\mathrm{o}} 10$ ).

${ }^{61}$ Para preservar el vínculo del testigo con su comunidad, se omite la identidad del testigo, en este caso particular.

${ }^{62}$ Sobre la nacionalización se profundizará en el tercer capítulo.

${ }^{63}$ De acuerdo a Marone: "Si bien el taller era el que agrupaba la mayor cantidad de gente, para la empresa la dependencia más importante era la Jefatura del Departamento de Mecánica con asiento en Junín. De Mecánica no solo dependían los Talleres Junín, sino Mendoza (locomotoras diésel) y Alianza (de vagones), luego Avanzada y Palmira que eran de vagones, Retiro, Villa Mercedes y Mendoza que eran depósitos de locomotoras".
} 
de locomotora, agrupados en el gremio La Fraternidad, en cambio, constituían un colectivo más reducido que intentaba distanciarse de los "talleristas", incluso, en la forma en que se reconocían a sí mismos: eran "fraternales”, antes que ferroviarios, identificándose así con toda una comunidad nacional de conductores, foguistas y aspirantes diseminados a lo largo y a lo ancho de todo el país. ${ }^{64} \mathrm{Su}$ modo de ingreso, controlado por el gremio, y las expectativas que tenían en ese momento, mostraban algunas similitudes y divergencias respecto del resto de ferroviarios.

En primer lugar, a diferencia de los ferroviarios de Talleres, los estudios técnicos previos no facilitaban el ingreso (como sí contribuían a ello en el caso los "talleristas"), ya que la formación de conductores era posterior a la incorporación del aspirante y era controlada (como el ingreso) por las Escuelas Técnicas que el mismo gremio La Fraternidad administraba. ${ }^{65}$ Uno de los fraternales entrevistados, relata: "Mi padre, que era ferroviario, me anota para ingresar al ferrocarril, a la Fraternidad. Yo no sabía nada. Porque en esa época los que tenían más o menos estudio, veían cuál era el oficio para el cargo. Y los que no teníamos estudio... podíamos entrar a La Fraternidad". ${ }^{6}$

De forma similar a los ferroviarios de Talleres, los fraternales también tenían, al momento de ingresar, expectativas de progreso social dentro de la empresa, aspirando a convertirse en conductores, el puesto más alto dentro del colectivo. De acuerdo a lo que ellos mismos manifestaban, quienes estaban a cargo de la conducción percibían un sueldo análogo al de un jefe del más alto rango de Talleres, habiendo pasado solamente por tres agrupamientos: aspirante, foguista, maquinista ${ }^{67}$ Es decir, el progreso parecía ser más fácil, aunque el tiempo en cada agrupamiento podía ser más extenso. A la vez, al igual que los talleristas, proyectaban una vida entera realizando la misma tarea dentro de la misma comunidad laboral. Sin embargo, a diferencia del resto de los ferroviarios, las motivaciones del ingreso y las afirmaciones que más tarde harían para reforzar su identidad fraternal estaban vinculadas al ejercicio de una profesión sin jefes a los que obedecer y sin una rutina fija que cumplir. En la conducción, “el

\footnotetext{
${ }^{64}$ Sobre este tema Ayuso concluye: "La Fraternidad sostuvo una solidaridad gremial exclusiva para el conjunto de trabajadores de las locomotoras y excluyente para el resto de trabajadores de otros oficios dentro de la industria ferroviaria. Esta característica de los maquinistas y foguistas en el conjunto de ferroviarios se tradujo en una diferenciación respecto a los saberes y las prácticas de estos trabajadores cuyo efecto fue la construcción de una identidad gremial alrededor del ser fraterno (...) el elemento más importante para la construcción del poder gremial fue basar su poder corporativo en la apropiación del dispositivo de regulación del oficio" (Ayuso, 2017: 254-255). ${ }^{65}$ Sobre el rol de las Escuelas Técnicas en el control de saberes para el trabajo, ver también Badaloni, 2011 y Ayuso, 2017.

${ }^{66}$ Entrevista N ${ }^{\mathrm{o}} 12$ a jubilados de La Fraternidad, 14/10/2011 (en adelante EN ${ }^{\circ} 12$ ).

67 “...el gremio de los maquinistas se conformó como un grupo diferenciado y distinguido respecto del resto de los trabajadores ferroviarios" (Ayuso, 2017: 254).
} 
único jefe era el reloj", decía el instructor de máquinas Dante Cruz, ${ }^{68}$ y el espacio laboral, era un paisaje abierto y cambiante, el de la ventana de la locomotora. Uno de los fraternales recordaba así el momento previo a ingresar a La Fraternidad, cuando trabajaba en un comercio: "Tengo cinco hermanos y los cinco son maquinistas. Y yo veía cómo vivían ellos y decía, qué voy a estar en la tienda, todo el día encerrado". En tanto, un colega recuerda: "Un amigo me dijo que me iba a pasar una solicitud. 'No, no', le dije. Mi viejo, que era ferroviario, entraba a las cuatro de la mañana y se iba a la 1 de la tarde. Entonces, me hizo entender: 'Esto no es para venir todos los días a la misma hora. Esto es para la conducción, para conducir locomotoras"'. ${ }^{69}$

Podemos caracterizar, entonces, el ingreso en La Fraternidad a partir de dos valores centrales que los diferenciaban de los trabajadores que entraban a Talleres o al Departamento de Mecánica: independencia y estatus. Sobre el primer aspecto, uno de los fraternales ilustra: “En el taller estás rodeado de capataces, jefes. En cambio, nosotros nos subimos a la máquina y somos completamente independientes. Cumpliendo el horario mandamos nosotros." Sobre el segundo de los aspectos, refiere otro fraternal: "Nosotros estamos dentro de los profesionales. Lo que hacemos nosotros no lo hace nadie."

\section{El progreso en la carrera ferroviaria}

El ingreso en el ferrocarril como fuente de trabajo codiciada constituía solo el primer peldaño de una carrera en la que el ascenso en el escalafón era una posibilidad cierta para cada ferroviario. Como sintetiza Abilio Murgia al referirse a su carrera: "Siempre tuve la sensación de que iba para arriba". ${ }^{70}$

Potencialmente, estos trabajadores que habían ingresado en la escala más baja, como aprendices o peones, tenían la posibilidad de llegar al estamento más alto dentro del ferrocarril en Junín. Tal fue el caso de Marone: "Ingresé siendo aprendiz, que es el cargo más bajo, y me retiré como jefe del Departamento de Mecánica. Es decir, que hice la carrera en Junín, desde el puesto más bajo hasta el puesto más alto". ${ }^{71}$ Ismael Tornello, quien hizo una carrera relativamente corta en la sección Chapas, coincide en esta posibilidad potencial que tenían todos los operarios de ascender hasta la escala más alta de la empresa: "Yo ingresé como

\footnotetext{
${ }^{68}$ Entrevista N ${ }^{\circ} 13$ a Dante Cruz, 3/12/2011 (en adelante EN ${ }^{\circ} 13$ ).

${ }^{69} \mathrm{EN}^{\mathrm{o}} 12$.

${ }^{70} \mathrm{EN}^{\mathrm{o}} 7$.

${ }^{71}$ Entrevista $\mathrm{N}^{\mathrm{o}} 14$ a Ítalo Marone, 16 de junio de 2011, en adelante $\mathrm{EN}^{\mathrm{o}} 14$.
} 
aprendiz, y había distintas escalas. Podías llegar hasta jefe de Talleres. Siempre y cuando reunieras las cualidades". Bruno Danielle, de Vía y Obras, confirma esta posibilidad de progreso ilimitado: "Había posibilidad de ascender, hubo incluso quien llegó a la gerencia", 72

Este ascenso paulatino implicaba, en lo inmediato, una mejora en el ingreso, tal como lo recuerda en detalle Rinaldi, quien comenzó su carrera en 1949:

\begin{abstract}
"Había una Escuela de Aprendices dentro de talleres, eso permitía que instruido ahí, en seis meses, dabas examen y te aumentaban de categoría. Yo a los cinco meses, en mayo, cumplí los dieciocho años y me elevaron. Ya, de ochenta centavos que cobraba al principio, me fui a 1,5 la hora. Me adelantaron cuatro años. A los dos meses, en octubre más o menos, me pasaron de quinto año y me dieron el promedio. Es decir, sería el 100 por 100 del sueldo. O sea, yo ganaba 1,50, pasé a ganar casi 3 pesos la hora. En el mes eran 600 pesos. En noviembre me pasaron a oficial, también por el informe que daba el capataz, el supervisor de la sección. Y ya después en febrero, ahí sí tuve suerte, todas las secciones ornamentales, por sus características de trabajo, pasaron a ser especialistas. Y de ahí, de 1,93 que tenía la hora, pasé a 2,90. Más el promedio, que era un 100 por 100."73
\end{abstract}

La primera etapa en la carrera de los talleristas, de acuerdo al exjefe de Talleres Eridé Rinaldi, implicaba el ascenso a través de distintas instancias que el operario debía atravesar, casi ineludiblemente. Luego de ingresar como aprendiz o peón (de acuerdo a si el operario tenía, o no, formación técnica previa), el ferroviario podía ascender a medio oficial u oficial (según el área), luego especialista, superespecialista y más tarde encargado (a cargo de un grupo de personas de una sección). Los últimos estamentos del trabajo del taller eran capataz (a cargo de 2 más encargados, de dos o más secciones) y capataz general (a cargo de dos o más capataces). El caso de Marone puede servir para ilustrar cómo era el ascenso en la empresa, ya que fue el obrero ferroviario entrevistado que llegó al más alto puesto del ferrocarril en Junín. Este ferroviario confirma su paso en cada una de estas instancias, habiendo comenzado dentro del taller como aprendiz, pasando luego a oficial, más tarde a especialista y luego a súper especialista. En general, cada uno de estos pasos eran "escalones" que el operario atravesaba, con pocos o ningún salto abrupto de categoría. Esto implicaba que quienes llegaban a los puestos directivos tenían un conocimiento práctico de, al menos, un oficio, y un saber general sobre el funcionamiento del taller y de la empresa en Junín. Juan Dall'Occhio, quien también

\footnotetext{
${ }^{72} \mathrm{EN}^{\mathrm{o}} 6$.

${ }^{73} \mathrm{EN}^{\mathrm{o}} 3$.
} 
fue jefe de Talleres Junín, asegura: "Todos nosotros empezamos con ropa azul, todos. Que entraran como técnicos directamente, no conozco casos... Todos empezamos con el oficio, de alguna manera" ${ }^{74}$

Posteriormente a su experiencia en el taller, Marone pasó a la oficina técnica, lo que implicó una evolución significativa, no tanto desde el punto de vista material, sino desde el punto de vista simbólico. El salario, en sus inicios, no era sustantivamente mayor, aunque las expectativas sí lo eran. Esto es confirmado por otros testigos que, además, destacan la mayor comodidad y los menores riesgos a los que estaban sometidos. Roberto Dimarco, por ejemplo, quien luego de ascender a capataz de Tornería inició su carrera administrativa sin nuevos ascensos, se intenta diferenciar del personal de talleres por el tipo de trabajo que él realizaba: "Yo no puedo decir muchas cosas, primero porque yo no trabajaba en una máquina, sino que trabajaba en una oficina. Trabajar en una máquina es prácticamente estar al aire libre." ${ }^{75}$ Héctor Ferrari, quien culminó su carrera como jefe de Seguridad e Higiene en el Trabajo, destaca también este momento en su carrera ferroviaria, cuando le proponen trabajar en una oficina: "Yo no quería trabajar en la parte del taller. Era un trabajo, sí, pero bastante peligroso. Trabajar en la oficina... eso era lo que me interesaba. Un día me llamó el jefe de Talleres y me dijo si tenía interés en pasar a aprendiz técnico. Y le digo: ‘ ¡sí!'. 'Pero usted sabe...', me dice, ‘...que le tengo que rebajar el sueldo"”. Ferrari no lo dudó: aunque el ofrecimiento no implicaba un incremento en el salario, significaba una mejora en las condiciones laborales (al ser menos riesgoso), así como nuevas posibilidades de progreso. La apuesta de Ferrari — según su relatofue acertada: "En pocos meses estaba ganando lo mismo que ganaba en el taller. Pasé a los 900 pesos, 1000, 1200, 2000. Me fui para arriba enseguida". ${ }^{76}$

Otros testigos caracterizan el trabajo inicial en su carrera como exigido desde un punto de vista físico. Omar Bozzini, rememora sus inicios en Vía y Obras: "El trabajo primero era pala y pico en la vía. Se reparaba, se cambiaban rieles, se colocaban durmientes de quebracho que pesaban como 80 kilos. Era un trabajo pesado". ${ }^{77}$ Miguel Mantino también: "Yo estuve haciendo los guinches afuera, con una cuadrilla, a la intemperie. En el invierno te morías de frío, en el verano de calor, el hierro, era fuego. Fue bravo, pero se ganaba bien". ${ }^{78}$ De esta manera, aunque en momentos idealizan y se vanaglorian de estas "proezas" realizadas en la

\footnotetext{
${ }^{74}$ Dall'Occhio se refiere a la "ropa azul" que era el atuendo que utilizaban los talleristas, por el cual se distinguían de los trabajadores de oficina y del personal de dirección, quienes vestían de traje y corbata. Entrevista $\mathrm{n}^{\circ} 15$ a Juan Dall'Occhio, el 11/05/2011, en adelante $\mathrm{EN}^{\circ} 15$.

${ }^{75}$ Entrevista $\mathrm{N}^{\circ} 16$ a Roberto Dimarco, 06/05/2011, en adelante $\mathrm{EN}^{\circ} 16$.

${ }^{76} \mathrm{EN}^{\circ} 4$.

${ }^{77}$ Entrevista $\mathrm{N}^{\circ} 17$ a Oscar Bozzini, 03/02/2012, en adelante $\mathrm{EN}^{\circ} 17$.

${ }^{78}$ Entrevista $\mathrm{N}^{\circ} 18$ a Miguel Mantino, 03/11/2017, en adelante $\mathrm{EN}^{\circ} 18$.
} 
juventud en las que el cuerpo se ponía en riesgo, este tipo de trabajos, en general, se consideraban de menos valor frente a otro tipo de labores relacionadas con la planificación y la dirección. Juan Dall'Occhio da cuenta de algunas exigencias de los directivos que, a su vez, suponían otras ventajas frente los operarios rasos: "Los que trabajábamos en oficina teníamos horario de 35 horas contra 48 que tenían los otros. Ya cuando uno llegaba a ser proyectista de obra ya cobraba como un capataz de instrucción... Sí, el personal de dirección cobraba el doble, el triple o el cuádruple que el resto. Y las responsabilidades eran mayores. No trabajaban tanto con los brazos, trabajaban más con la cabeza."79

Siguiendo con el recorrido de Marone, en la oficina comenzó como dibujante, pasando a ser proyectista de obra y finalmente proyectista principal, el cual era el último estamento del personal obrero. Es preciso remarcar, no obstante, que la oficina a la que ingresó Marone no era "cualquier oficina", de las que había en Junín. Era la que muchos ferroviarios refieren y recuerdan como "la oficina técnica", que nucleaba a los "aprendices técnicos". ${ }^{80}$ Ferrari, quien ingresó en 1945 y también estuvo allí, rememora su paso por la oficina técnica como un período formativo en su carrera: "Me mandaron a cada sección del taller: fui a soldadura, carpintería, ajustaje. Estuve por todos lados y me tomaban pruebas, exámenes. Ellos preparaban de ese modo, buscaban que conocieras todas las secciones primero. Recién después ibas de jefe". ${ }^{81}$ Omar Calderoni, por su parte, aclara que ese recorrido por las secciones no involucraba el aprendizaje del oficio de cada área particular, sino la dinámica de cada sección: "El aprendizaje técnico era un mes en cada sección. No para, digamos, hacer un trabajo. Sino que estabas con un oficial y el oficial te enseñaba a vos todo el movimiento de la sección". ${ }^{82}$ Aroldo Taberna caracteriza a los aprendices técnicos como "muchachos que eran candidatos a ocupar cargos jerárquicos". "Eso fue lo que pasó. Allí estuvo Marone, por ejemplo", fundamenta. ${ }^{83}$

Tiempo después de llegar a proyectista principal, Marone se convirtió en jefe de oficina. El ferroviario subraya esta instancia como un nuevo hito en su carrera. "Ese es el primer peldaño del personal de dirección. Cuando yo ocupo esa vacante de jefe de oficina, dejo de pertenecer a la Unión Ferroviaria. Antes, siendo proyectista principal tenía que estar afiliado a la Unión Ferroviaria". ${ }^{84}$ Su carrera continúa luego como jefe de Sección, jefe de División para

\footnotetext{
${ }^{79} \mathrm{EN}^{\mathrm{o}} 15$.

${ }^{80}$ Debe diferenciarse a los aprendices de los aprendices técnicos. Los primeros eran operarios, con formación técnica previa, que recién iniciaban su carrera ferroviaria. Los segundos eran jóvenes que ya habían atravesado la experiencia práctica en el taller y apuntaban, en un futuro, a convertirse en directivos de la empresa.

${ }^{81} \mathrm{Al}$ haber ingresado previo a la nacionalización, cuando Ferrari dice "ellos" se está refiriendo a los jefes ingleses.

${ }^{82}$ Entrevista No 19 a Omar Calderoni, 29/04/2011, en adelante ENº19.

${ }^{83} \mathrm{EN}^{\mathrm{o}} 10$.

${ }^{84} \mathrm{EN}^{\mathrm{o}} 14$.
} 
finalmente convertirse en jefe de Departamento.

Los testimonios coinciden en caracterizar la carrera ferroviaria como un recorrido que involucraba el paso por tres estamentos. El primero, la labor en el taller, un trabajo exigido a nivel físico, que implicaba el conocimiento y aprendizaje de un oficio, el uso de indumentaria específica según el área (con los elementos de protección exigidos), siendo subordinado a uno o varios superiores. El segundo, el trabajo en la oficina o en el sector administrativo, lo que denotaba simbólicamente mayor prestigio frente a los talleristas, por ser un trabajo menos riesgoso, menos exigido a nivel físico, realizado en un contexto de mayor comodidad. Este agrupamiento, si bien se podía llegar a identificar con el personal de dirección por los lugares de trabajo, la indumentaria empleada y las posibilidades de progreso, seguía estando subordinado a uno o varios jefes. El tercero, el trabajo dentro del personal de dirección, quienes estaban a cargo de la planificación y organización de las tareas dentro del Taller y del Departamento de Mecánica, con grupos numerosos a cargo y responsabilidades en áreas específicas. Este último grupo se distinguía simbólicamente por la indumentaria empleada (traje y corbata), por los espacios en que llevaban adelante sus tareas específicas (oficinas, con personas a cargo), la libertad para movilizarse a lo largo de las casi treinta hectáreas que ocupaba el taller y el tiempo libre propio condicionado por las contingencias que pudieran surgir.

Aunque las posibilidades de progreso existían — de manera similar - para todos los operarios que ingresaban, de acuerdo a lo que los mismos testigos afirman, resulta lógico que no todos llegaran a la "cúspide", ya que la estructura misma de la empresa (piramidal) lo impedía. Como De Giulio que dice haber sido "tornero, siempre tornero", llegando a la categoría de superespecialista. ${ }^{85} \mathrm{O}$ como el caso de Oscar Bozzini, de Vía y Obras, que se queja porque "los pintores no tenían especialistas" y, a consecuencia de ello, no pudo "llegar más". ${ }^{86}$ También es el caso de Roberto Dimarco, quien dice no haber querido ascender para dedicar mayor tiempo a su "verdadera vocación", la historia: "Me quedé en seis horas. Seis es mejor que ocho". ${ }^{87}$ En todos estos casos, aparece la necesidad del testigo de explicar qué factores le impidieron ascender más: si fue una elección, limitación propia o un impedimento externo. Esto permite demostrar que existía un imaginario compartido que otorgaba mayor prestigio a ciertos

\footnotetext{
${ }^{85}$ Entrevista $\mathrm{N}^{\mathrm{o}} 11$ a Roberto De Giulio, 2/12/2018 (en adelante EN ${ }^{\mathrm{o}} 11$ ).

${ }^{86} \mathrm{EN}^{\mathrm{o}} 17$.

${ }^{87}$ Roberto Dimarco fue un historiador aficionado de la ciudad, que dirigió la revista "Historia de Junín" y escribió algunas publicaciones sobre historia de la ciudad como Manual de Historia de Junín. Cuando dice "me quedé en seis horas" está comparando la labor del sector administrativo con la de los operarios de talleres, que trabajan ocho horas. $\mathrm{EN}^{\circ} 16$.
} 
roles dentro de la empresa, encauzando las energías individuales de los ferroviarios hacia el objetivo de ascender en el escalafón. ${ }^{88}$

Ahora bien, ¿qué factores, según los testigos, posibilitaban un progreso en la carrera? ¿Y cuáles otros lo impedían? El conocimiento del ferroviario en un área específica emerge como uno de los principales factores que determinaban su ascenso en el escalafón. En el inicio de la carrera, el aprendiz, que se formaba en la Escuela de Aprendices del ferrocarril, estaba sometido a evaluaciones periódicas que, junto con el informe del supervisor, permitían su ascenso a oficial y luego a especialista. En tanto, era común que, para ascender a un puesto dentro de los estamentos medios y altos de la empresa, se publicaran vacantes que ponían en igualdad de condiciones a todos los interesados en presentarse. ${ }^{89}$ "Uno intenta hacer méritos para ir progresando, lo cual lo logra a través de una competencia sana porque se da a través de vacantes que se producen. Se rendían exámenes para poder promocionarse”, comenta Marone y Rinaldi asegura: "Había un reconocimiento hacia los que habían estudiado y se dedicaban al trabajo". 90

Si bien el mérito logrado a través del estudio y capacitación era el principal factor, no era el único. La antigüedad era otro aspecto que favorecía el ascenso, sobre todo en los estamentos más bajos de la empresa, la cual podía suponer una destreza mayor en el oficio particular. ${ }^{91}$ Este fue el caso de Dimarco, antes de pasar al sector administrativo: "Yo empecé como tornero. Y después, tenía años, entonces me correspondió a mí ser capataz. Y antes de pasar a la oficina, fui capataz general"92. También el de Carlos Violante:

\begin{abstract}
“Éramos compañeros primero, después uno quedaba de encargado, otro de capataz, por antigüedad, un poco de capacidad también, se combinaban las condiciones. Yo fui aprendiz de gente que era mayor que yo. Y después... a lo mejor se fue uno de esos mayores y fui quedando yo entre los más viejos, y fueron viniendo aprendices, chicos jóvenes"; 93
\end{abstract}

\footnotetext{
88 “... los imaginarios sociales provocan la adhesión de los individuos a un sistema de valores, interviniendo en su interiorización, moldeando conductas, cautivando energías y conduciendo a acciones comunes" (Baczko, 1991: $3)$.

${ }^{89}$ El artículo 51 del Escalafón Único del Personal establecía la obligatoriedad de publicar vacantes dentro de los treinta días de producidas. Esta política que ponía a disposición de todos los ferroviarios información relevante para su progreso permitía igualar las posibilidades de ascenso, en función de los méritos alcanzados. A su vez, el artículo 63 definía que los exámenes podrán exigirse en caso de ocupar un puesto diferente a la tarea y/o de una categoría superior. Escalafón Único del Personal de empleados y obreros del ferrocarril (1964), p. 31. Agradezco al Archivo Histórico de Junín por este documento.

${ }^{90} \mathrm{EN}^{\mathrm{o}} 14$ y EN 3 , respectivamente.

${ }^{91}$ El factor antigüedad, entonces, podía implicar también una valoración al saber específico del operario, a partir de la suposición de que una mayor práctica en el oficio, contribuía a una mayor destreza.

${ }^{92} \mathrm{EN}^{\mathrm{o}} 16$.

${ }^{93} \mathrm{EN}^{\circ} 8$.
} 
Y el de Valentín Martínez:

"Yo me quedé en Carpintería porque conocía de punta a punta el taller, qué había, qué no había.

Y terminé de capataz. Estaba el capataz general, que era Orlando Torres, y después venía yo."94

Para Rinaldi se combinaban dos factores en los ascensos dentro del estamento más bajo: antigüedad y capacidad. ${ }^{95}$

"Para encargado prevalecía mucho la antigüedad. El más antiguo de los oficiales pasaba a ser encargado. Si había dos encargados, el mayor pasaba a ser capataz y así. Pero después vino que había que rendir examen, ya no solamente era por los años. Los años le asignaban un porcentaje, pero fundamentalmente tenía que dar un examen. Cuando eran dos, tres o cuatro, el que salía bien en el examen pasaba a ser supervisor. Gremialmente, se defendía más la antigüedad. Pero el hecho de ser antiguo no quiere decir que sea mejor." $" 96$

Por otra parte, algunos ferroviarios que llegaron a puestos altos del ferrocarril también dan cuenta de la oportunidad que brindaban nuevas estructuras en la organización y actitudes personales vinculadas a un mayor grado de audacia, frente a actitudes menos propensas al cambio. "Cuando se organizaban dependencias nuevas, era cuando uno también tenía la posibilidad de progresar. Como había que cubrir toda una estructura departamental con jefe de división, jefe de sección, jefe de oficina, se abría una nueva posibilidad de progresar a través de esos movimientos", relata Marone. ${ }^{97}$ Juan Dall'Occhio, como Marone, expresa su orgullo por haber sido "uno de los jefes más jóvenes que tuvo el taller". Además de su formación técnica específica, el ferroviario explica este logro por actitudes personales propias vinculadas a la intrepidez y a la inquietud en el campo del conocimiento técnico: "Para progresar en la empresa, me ayudó un poco la suerte y un poco porque estaba preparado, porque siempre me interesó y fui estudiando. Fui ascendiendo a puestos que por ahí otros no se animaban porque

\footnotetext{
${ }^{94}$ Entrevista No20 a Valentín Martínez, 15/02/2012, en adelante ENº20.

${ }^{95}$ El Escalafón establecía las condiciones que debía reunir el ferroviario que se promocionara para un puesto mayor dentro del personal obrero. En cada caso, se definía que se daría preferencia al que "reuniendo la competencia necesaria resulte el de mayor antigüedad". Es decir, ambos factores eran tenidos en cuenta: saber y experiencia Escalafón Único del Personal de empleados y obreros del ferrocarril (1964), p. 42.

${ }^{96} \mathrm{EN}^{\mathrm{o}} 3$.

${ }^{97} \mathrm{EN}^{\mathrm{o}} 14$.
} 
se sentían inseguros." 98 Estas oportunidades implicaron que, por ejemplo, Marone tuviera que cambiar su espacio físico y de tareas específicas varias veces dentro de la carrera:

“Del taller pasé al Departamento Mecánica, donde me convertí en jefe de sección. Cuando se produce la creación del Departamento de Control de Calidad, pasé allí y llegué a ser jefe de división. Después, volví a Mecánica, pero con la misma categoría". ${ }^{99}$

En cambio, debido a cualidades expertas y a actitudes menos arrojadas, otros ferroviarios se vieron impedidos de seguir ascendiendo, encontrando un estancamiento en ese progreso dentro del estamento correspondiente al personal de dirección. Tal es el caso de Héctor Ferrari:

"Yo me quedé ahí (jefe de Seguridad e Higiene en el Trabajo), no sé por qué. En cierta forma no tuve la suerte que tuvieron otros, que pudieron ir a Buenos Aires. Como saben que vos te desenvolvés bien en determinada tarea, te embroman. Pueden pensar, si saco a este en tal tarea, a quién pongo." 100

\section{Y el de Abilio Murgia:}

"Anduve mucho tiempo en eso, en el método, movimiento de materiales, estudio de los tiempos, esa fue mi función. Y el tiempo fue pasando, y yo quedaba en la oficina sin la posibilidad de ser el jefe principal porque había que salir de la oficina. Y yo fui un poco conservador en ese sentido. Lo que hacía, me gustaba y yo me sentía capacitado, sentía que era lo que sabía, donde podía aportar cosas, sin agrandarme. Si tengo que tener un ascenso, lo tengo que tener en esto, pensaba, que es mi vida. Pero resulta que, de acuerdo al escalafón, había gente que ganaba una categoría más en Programación, en Materiales, en Producción y todo eso no tenía nada que ver con la Oficina Técnica. Y yo no podía ascender. Llegaron a venir compañeros que habían ingresado en la oficina cuando yo ya era proyectista, y ellos recién llegaban, de la misma edad, y vinieron a ser jefes. Teníamos una gran relación. Conmigo como que... nunca hubo ningún problema. Yo tampoco me mostré disconforme. Cada uno guardaba su posición. Los ayudé, colaboré, les aleccioné para que vinieran, alguno me decía 'me da no sé qué ser jefe tuyo'. No, ningún problema. Y después de muchos años me tocó a mí, en los últimos años del ferrocarril, ser jefe de la

\footnotetext{
${ }^{98} \mathrm{EN}^{\mathrm{o}} 15$.

${ }^{99} \mathrm{EN}^{\circ} 14$.

${ }^{100} \mathrm{EN}^{\circ} 4$.
} 
división Estudio de la Reparación. O sea, tuve mi momento, fui jefe de oficina, lástima que estaba en los últimos años."101

Puede caracterizarse a la antigüedad y a la capacidad, entonces, como dos aspectos que incidían en el progreso del ferroviario, susceptibles de ser medidos objetivamente, ya sea a través de exámenes o del legajo laboral. El tercer aspecto analizado antes tenía que ver con coyunturas específicas y decisiones personales a partir de la interpretación que cada trabajador hizo del contexto. El cuarto aspecto, que en lo sucesivo será analizado y que influía, según los testigos, en el progreso de los trabajadores, estaba relacionado con el entramado de relaciones personales. En primer término, Dall'Occhio y Ferrari evocan de manera muy similar el progreso inicial en sus respectivas carreras y el "pase a oficina", relacionado con un superior que detectó cualidades específicas en ellos. "Siendo mecánico, alguien debe haber visto algo en mí, porque yo tenía facilidad para el dibujo. Entonces pasé a una oficina técnica y seguí la carrera como técnico", dice Dall'Occhio. ${ }^{102}$ Abilio Murgia, por su lado, recuerda:

\begin{abstract}
"En muy corto tiempo de haber ingresado, un supervisor creyó ver condiciones en mí y lo apalabra al jefe de producción, no sé qué le habrá dicho. El tema viene, me parece, porque se cortaba mucho la electricidad a cierto horario de la mañana. Entonces estábamos tranquilos, y yo sacaba de mi bolsillo papelitos, porque estaba terminando un curso de pericia en inglés, quería dar los exámenes. Entonces este señor le habla al jefe de producción y me pasan a la oficina""103 (el subryado es mío).
\end{abstract}

De esta manera, el reconocimiento subjetivo de un superior hacia la capacidad y potencialidades que podía tener un subordinado era otro de los factores que, en el tramo inicial, podían influenciar en el progreso.

Rinaldi confirma que esta tradición, en la que los jefes reconocían intuitivamente las capacidades de los operarios (y no a través de datos objetivos, demostrables) tenía sus orígenes en la época en que el ferrocarril pertenecía a capitales británicos: "Los ingleses elegían a dedo y no se equivocaban. Pero eran patrones, era distinto. Cuando la cosa pasa a ser del Estado, usted no puede elegir con el dedo. Hay un escalafón de por medio, hay leyes. ${ }^{104}$

Sin embargo, también en el orden de las relaciones personales, luego de la

\footnotetext{
${ }^{101} \mathrm{EN}^{\mathrm{0}} 7$.

$102 \mathrm{EN}^{\circ} 15$.

${ }^{103}$ EN4. Nótese la similitud en la manera en que expresan el "padrinazgo" inicial que les permitió ascender. Esto permite inferir que el reconocimiento de talentos o capacidades específicas era una práctica común en la empresa. ${ }^{104} \mathrm{EN}^{\mathrm{o}} 3$.
} 
nacionalización habrían empezado a ser cruciales para el progreso en la empresa las vinculaciones con actores pertenecientes a partidos políticos, especialmente dentro del peronismo. Marone opina e ilustra:

\begin{abstract}
"Había una potencialidad joven importantísima, producto de todos esos años de convenios que se habían hecho con la Escuela (Antonio Bermejo). O sea, había un grupo importante de gente con preparación, con estudio. Pero detrás de eso se colaban unos cuantos que no tenían nada que ver con la escuela, ¿eh? Eran los que pintaban, los que empapelaban, los que iban al comité."105
\end{abstract}

Omar Calderoni, por su parte, también rememora, indignado, el escollo que tuvo que sortear en el inicio de su carrera:

\begin{abstract}
"Cuando me tenían que dar el título ${ }^{106}$ ya los ingleses no estaban más, estaban los peronistas. Y habían puesto de jefe de talleres a un tipo Yorio, ${ }^{107}$ que no sabía ni hablar ni escribir. Lo primero que me dijo es 'Calderoni, si querés que te dé el título de técnico me vas a tener que traer la afiliación'. Entonces yo como no era peronista y mi padre todo el mundo lo conocía que no era peronista, pero que tenía muy amigos peronistas, de otra época, entonces me consiguió la afiliación y yo seguí haciendo la carrera, te das cuenta." 108
\end{abstract}

De Giulio, quien reconoce haber ingresado por sus vínculos peronistas, denuncia que él se vio impedido de ascender por un viraje posterior en la política nacional: "Si hubieran estado los otros (peronistas), sí. Pero como ya cambió la política, yo me quedé.” Si bien la antigüedad era una variable que se tenía en cuenta para el ascenso dentro de los estamentos inferiores, de acuerdo a su experiencia, estos datos podían ser manipulados:

\footnotetext{
"Iba por edad, o sea, el más viejo ascendía. Pero alguno más acomodado a veces pasaba, como me pasó a mí. Yo entré en el 52 y había otro ferroviario compañero, que había entrado en el 57. Él era radical. Sin embargo, cuando lo ascendieron figuraba él con más antigüedad que yo... todo se cocina." 109
}

\footnotetext{
${ }^{105} \mathrm{EN}^{\mathrm{o}} 14$.

${ }^{106}$ Se refiere al título de técnico ferroviario en la Escuela de Aprendices que funcionaba dentro del ferrocarril.

${ }^{107}$ Nicolás Yorio fue jefe de Talleres entre 1951 y 1952 (Tarullo, 2013: 137).

${ }^{108} \mathrm{EN}^{\circ} 19$.

${ }^{109} \mathrm{EN}^{\mathrm{o}} 11$.
} 
En contraposición a los tres testimonios anteriores, Tornello se hace eco de estos discursos que, evidentemente, circularon dentro del colectivo ferroviario y los cuestiona, intentando rescatar los valores de los recursos humanos locales de la empresa ferroviaria:

\begin{abstract}
“Te aseguro que (el ascenso) no era por cuestiones políticas. Si vos no tenías capacidad para ese puesto, no llegabas. Venías de Buenos Aires a veces a tomarte exámenes. Lo que pasa que se distorsionó todo diciendo que era todo por acomodo, por peronismo, por radical y no era así. Si vos no tenías capacidad no ibas a ocupar un puesto que no te correspondía." $" 110$
\end{abstract}

Las carreras de Marone, Rinaldi, Dall'Occhio (y lo que ellos mismos relatan de sus recorridos), entre otras, parecen darle la razón a Tornello. ${ }^{111} \mathrm{Sin}$ embargo, es factible que la pertenencia a determinado agrupamiento político haya sido un factor que también pudo haber influido, entre otros, en el ascenso.

Con todo, puede sintetizarse que la empresa ferroviaria implementó mecanismos objetivos para evaluar los conocimientos técnicos de los ferroviarios (a través de exámenes o de los títulos alcanzados dentro de la educación formal) y para determinar su nivel de experiencia en determinada área y oficio (por medio de la antigüedad), con la finalidad de que el ascenso del ferroviario estuviera fundado en méritos. Sin embargo, existieron otras circunstancias de la esfera subjetiva que influenciaron en ese progreso: la intuición de un superior hacia las potencialidades de un joven operario (una tradición que tenía orígenes en el ferrocarril de capitales británicos) y, sobre todo, luego de la nacionalización, la pertenencia a determinada agrupación política o el vínculo personal hacia un actor político. Mientras la primera de las prácticas "subjetivas" no era censurada por los actores entrevistados (en otros términos, se la consideró apropiada y no contradictoria respecto del sistema de valores), la segunda sí fue cuestionada por buena parte de los ferroviarios (por ser incompatible en relación a dicho sistema o imaginario que diferenciaba lo "justo" de lo "injusto", lo "correcto" de lo "incorrecto"). ${ }^{112}$

El progreso del ingeniero José Calcagni dentro de la empresa se explica de una manera

\footnotetext{
${ }^{110} \mathrm{EN}^{\mathrm{o}} 6$. El testimonio de Tornello sobre este tema tiene valor porque, sin tener ascensos significativos, perteneció, dentro de la Unión Ferroviaria, a un sector que confrontó abiertamente con la hegemonía peronista: la lista rosa, de ideología de izquierda, la cual competía con la azul y la verde. Es decir, su defensa al sistema de selección del personal jerárquico no se explica porque su pertenencia a la Unión Ferroviaria.

${ }^{111}$ Estos tres ferroviarios ocuparon puestos jerárquicos dentro de la empresa. El primero llegó a ser jefe del Departamento de Mecánica, los dos segundos fueron jefes de Talleres.

${ }^{112} \mathrm{El}$ imaginario social estructura toda una red de significaciones que se articulan entre sí (series de oposición) y permiten legitimar/invalidar; justificar/acusar; incluir/excluir (Baczko, 1991: 30).
} 
diferente al del resto de los ferroviarios, ya que se inició en 1953 como ingeniero profesional en la División Química que dependía del Departamento de Mecánica. Bajo las órdenes del ingeniero Federico Lexner, este sector se ocupaba de controlar los materiales del taller, así como el agua. Cuando Lexner se jubiló, en 1961, Calcagni se hizo cargo de la división como jefe de ese laboratorio. Años después, en 1965, el gerente de la línea San Martín, en una reunión, se refirió a la posibilidad de ascenderlo a segundo jefe del Departamento de Mecánica de la línea San Martín, bajo las órdenes del ingeniero Sebastián Emilio Roqués, primer jefe en Junín. ${ }^{113}$ “Cómo se ve — recuerda Calcagni que le preguntó el gerente— en ese puesto?”. ${ }^{114}$ A la salida de dicha reunión, Calcagni se encontró con Roqués, quien le confirmó que él mismo le había hecho la propuesta al gerente. Así recuerda Calcagni este encuentro informal, la propuesta de Roqués y el temor a tomar a su cargo dicha responsabilidad:

“Le dije a Roqués que no conocía el taller, las líneas. 'Mirá, me dice, yo necesito a alguien que me cubra la espalda'... porque tenía unos pesos pesados... estos tipos estaban con un serrucho en la mano para cortarle la..., entonces me dice: 'Necesito alguien que me cubra la espalda, tiene que ser ingeniero, si no es ingeniero no corre...', venía la voz de Buenos Aires. Pero estaba Manso, Cristóbal en Mendoza. 'Manso es un muerto de frío, a Cristóbal no le tengo confianza', me dice. 'Vos andás bien en la parte técnica, en el laboratorio, en las licitaciones, no tenés problema con la división eléctrica, técnica, entonces esa parte la manejás vos', porque tuteaba... 'Yo manejo — me diceel movimiento tracción, material remolcado, en un año vos estás en conocimiento de todo'. Me lo pedía de tal manera que... Yo tenía miedo porque era una responsabilidad muy grande, pensaba que se me podía escapar algo, pero finalmente le dije que sí." ${ }^{115}$

Sin embargo, este ascenso no pudo concretarse en ese momento: "Vino la intervención al departamento y al taller, lo sacaron a Roqués, y todo eso quedó en nada". Unos meses después, Calcagni recuerda otra conversación informal:

“Allá por marzo del 66, Roqués ya no estaba, pero había conseguido traer un ingeniero
en Mendoza, que era ingeniero en combustibles, no químico, el ingeniero Lascano.
Entonces, viene Lascano todo apurado un día y me dice ‘¿Sabe que lo propusieron
como segundo jefe de departamento?'. 'No - le dije- eso fue hace un tiempo, pero

\footnotetext{
${ }^{113}$ Roqués fue jefe del Departamento de Mecánica entre 1960 y 1966 (Tarullo, R., 2013: 136).

${ }^{114}$ Entrevista No21 a José Calcagni, 08/07/17, en adelante, EN²1.

${ }^{115} \mathrm{EN}^{\circ} 21$.
} 
quedó en la nada'. 'No — me dice — ¡ahora, ahora!'. Me fui a la jefatura y pedí hablar con el ingeniero (Alberto) Young y le dije de lo que me había enterado. ${ }^{116}$ Ay, ¡cómo se enojó...! Él creía que era una cosa secreta... o se hacía. Y bueno, terminó reconociendo: 'Sí, es cierto, yo lo propuse'. 'Mire — le digo — no es la primera vez que me lo proponen. Le tengo que hacer la misma advertencia, no conozco el departamento, no conozco fuera de Junín, no conozco el manejo de todas estas cosas'. Entonces me dio una explicación bastante coherente. Era el tiempo en que esta gente se quería llevar la jefatura de departamento a Buenos Aires: 'Mire, yo me voy a llevar la jefatura del departamento a Buenos Aires. Acá en Junín queda el grueso del departamento, pero la jefatura se va allá'. Aparentemente era una solución para Junín, porque alguien que era de Junín quedaba a cargo de lo de Junín. Si él (Young) estaba en otro lado no importaba mucho. Bueno, la cuestión que le dije que sí. Y ahí fui jefe de departamento segundo por dos años, del 66 al 67.”117

Estas anécdotas recordadas por Calcagni permiten reconocer que para ascender a la más alta jerarquía de la empresa (en particular, de la línea San Martín), el saber específico acreditado, en el caso del ingeniero, por una institución universitaria- y las experiencias de gestión previas podían considerarse valores necesarios, aunque insuficientes. Lo que, en cambio, tenía una incidencia significativa era la red de relaciones interpersonales que el actor había capitalizado previamente y que permitían prever su lealtad hacia una persona particular o hacia determinadas políticas de la empresa. En otras palabras, en esos estamentos superiores, la esfera subjetiva (representada, en el caso de Calcagni, por la confianza que le tenía Roqués personalmente o la inferencia que de él hacía Young sobre su accionar futuro) pareció tener gran influencia en el ascenso, si se tiene en cuenta la ausencia de concursos o normativas específicas que pudieran justificar la selección en base a datos objetivos.

No debe llamar la atención el modo en que este tipo de decisiones o propuestas eran informadas o dadas a conocer a los involucrados. En contraposición a la publicación de vacantes de carácter obligatorio que existía para los estamentos menores, en los estamentos más altos de la empresa el modo de comunicación de las propuestas de ascensos parecía ser a través de conversaciones casuales, reuniones bilaterales y hasta rumores. Esto resulta congruente con el modo en que esas decisiones eran tomadas, en base a las consideraciones de unos pocos actores que concentraban el poder en determinado momento y en ausencia de normas públicas que pudieran fundamentarlas.

\footnotetext{
${ }^{116}$ Alberto Faustino Young fue jefe del Departamento de Mecánica entre 1966 y 1970 (Tarullo, R., 2013: 136).

${ }^{117} \mathrm{EN}^{\circ} 21$.
} 
También puede señalarse que, como este tipo de decisiones dependían de políticas externas a la empresa y no en acuerdos colectivos plasmados en determinados documentos, los cambios de responsables en este tipo de espacios eran comunes y, por tanto, la permanencia en este tipo de puestos de alta jerarquía era baja, a diferencia de lo que sucedía en los estamentos inferiores y medios de la empresa.

Un año después, Calcagni tuvo una nueva oportunidad de ascenso que surgió a partir de una propuesta realizada por él mismo a la empresa Ferrocarriles Argentinos. En esta iniciativa confluyeron su experiencia anterior (a cargo del laboratorio y como segundo jefe de Mecánica), por un lado, y su saber específico (su formación como ingeniero y posteriores capacitaciones en control de calidad).

“En la Gerencia (de la línea San Martín) me pidieron una exposición sobre control de calidad. Yo les dije que creía que se podía hacer pero no solo con los materiales, sino ocuparnos del control de las tareas de reparación. Y eso le gustó, yo creo que ya tenía la idea el gerente, el gerente se llamaba (Federico) Sidders, teniente coronel Sidders. Yo le presenté todo un panorama de cómo se podía hacer. De algún modo sabía que estaba interesado en eso, entonces preparé una exposición sobre esa base. Estuve dos o tres horas, porque él tenía conocimiento de control de calidad, entonces le propuse la formación de un organismo dentro de la empresa, encargada del control no solo del material, sino de las tareas, por ejemplo, de Vía y obras. Tal es así que más tarde él hizo una exposición delante nuestro, ante el presidente (Juan Carlos) De Marchi. ${ }^{118}$ Y cuando terminó De Marchi dijo: 'Ese organismo tiene que ser de la máxima categoría'... le dijo De Marchi a Sidders, al gerente del San Martín. 'Sí, hemos pensado que va a ser departamento', dijo Sidders. Y bueno, así fue."119

Esta nueva oportunidad de ascenso para Calcagni, que lo elevó a jefe del Departamento de Control de Calidad, fue posible en base a un conocimiento acumulado (por experiencia y formación) que le permitió gestar una nueva idea para resolver problemas concretos, apuntando a mejorar el servicio de los talleres ferroviarios de reparación. La posibilidad de concreción de esta nueva idea y, consecuentemente, su ascenso, se explican solo en parte por la capacidad creativa del profesional. También influyó significativamente la red de relaciones

\footnotetext{
118 Juan Carlos De Marchi fue presidente de Ferrocarriles Argentinos entre 1967 y 1971. La gestión del general De Marchi (4 de febrero de 2012). Recuperado de http://todotransporteferroviario.blogspot.com/2012/02/lagestion-del-general-de-marchi.html

Murió el general Juan Carlos De Marchi (25 de octubre de 2004). Recuperado de http://bassoenlared.com.ar/noticias/1276-MURIO-EL-GENERAL-JUAN-CARLOS-DE-M.htm

${ }^{119} \mathrm{EN}^{\circ} 21$.
} 
interpersonales que le permitieron comunicar su propuesta a actores que concentraban poder en la empresa (Sidders y De Marchi), así como un contexto político particular que propició que el proyecto sea acogido positivamente.

Puede describirse a la carrera de Calcagni por tres ascensos, luego de su ingreso como profesional ingeniero: el primero, por antigüedad, luego de que se retirara Lexner como jefe de División Química; el segundo, por la propuesta de otros actores de mayor jerarquía que lo elevaron a segundo jefe del Departamento de Mecánica; el tercero, por la creación de un área nueva propuesta por él mismo a la más alta jerarquía de la empresa, lo que le permitió convertirse en jefe del Departamento de Control de Calidad. Como se ha insistido en el análisis, para estos dos últimos ascensos de nivel superior, los vínculos interpersonales de este profesional fueron cruciales, por la confianza que en su persona depositaron Roqués, Young, Sidders y De Marchi, más allá de su probada capacidad profesional.

Por último, corresponde analizar los modos de ascender en la empresa del colectivo de los conductores, nucleados en el gremio La Fraternidad. Puede caracterizarse a la estructura de este agrupamiento como más simple, compuesta tan solo por tres estamentos (aspirante, foguista y maquinista) frente a las cuarenta categorías determinadas por el Escalafón Único del Personal Ferroviario. Sin embargo, el tiempo en cada estamento podía resultar más largo y, por consiguiente, el ascenso del trabajador más lento, en función de las demandas de conductores de la empresa:

"Entrabas de aspirante y a los seis meses te tomaban un examen para quedar efectivo. Después hacías el trabajo hasta llegar como foguista, ese es el segundo paso. El tercer paso era ir a rendir los exámenes. O sea que eran tres categorías, nada más: aspirante, foguista y maquinista. Nada que ver con talleres. Ellos se mueven por un sistema de vacantes. Ellos entran de peón y después si querés progresar tenés que estudiar para llegar a jefe de una estación o auxiliar. Es distinto a lo nuestro, nosotros teníamos tres pasos. Y aguantar... Nosotros estuvimos catorce años limpiando fierros. Ya los fierros nos veían y decían: 'Otra vez ustedes' Ya nos conocían (risas)". ${ }^{120}$

Esta dificultad para ascender que tuvieron algunos aspirantes a foguistas puede explicarse también por un contexto particular que, en la década de 1960, disminuyó la demanda

${ }^{120} \mathrm{EN}^{\circ} 12$. 
de personal por el paulatino reemplazo de la locomotora a vapor por la diesel eléctrica, tal como sostiene uno de los testigos:

"Todo eso ocurre porque se termina el período de la máquina que era a vapor y se pasó a la máquina que trabajaba con petróleo. Entonces disminuyeron la cantidad de personas para trabajar. En una locomotora que trabajaba a leña iban tres hombres. Al cambiar el servicio, cuando apareció el petróleo, ya se perdió un hombre. Entonces ahí empezó el receso, ya era más lerdo para salir a trabajar como foguista, que era a lo que nosotros aspirábamos de entrada." 121

Más allá de que en contextos históricos particulares el ascenso fuese más lento, todos los entrevistados llegaron a la máxima categoría dentro de La Fraternidad, es decir, se convirtieron en maquinistas. Dante Cruz relata la llegada a esta última categoría, casi de manera inevitable. "Llega un momento en que se pasa a maquinista", dice. ${ }^{122}$ Esto marca una diferencia respecto del resto de ferroviarios que trabajaban en Talleres o en el Departamento de Mecánica para quienes, aunque la posibilidad de ascender existía (potencialmente) hasta la más alta jerarquía, pero la misma estructura organizacional (piramidal) lo impedía. Mientras el resto de los ferroviarios se refiere a la existencia de jefes o subordinados al relatar sus historias de vida asociados a la empresa, los fraternales una y otra vez intentan exponer su igualdad, su fraternidad. "Era como si hubiéramos sido todos hermanos", cuenta uno de ellos. ${ }^{123}$ Lo mismo subraya Dante Cruz:

"En La Fraternidad no hay jefes, somos todos compañeros. Los directivos, los capos mayores, son compañeros nuestros. No nos tratamos como subordinados, nos tratamos como compañeros. Porque los mandamases de la dirección son puestos por nosotros."124

Una distinción simbólica dentro de ese colectivo de iguales podía ser la que expresa Cruz, cuando recuerda el momento en que sus compañeros lo designaron como instructor. "En ese tiempo en Junín había instructores de La Fraternidad que no tenían sueldo. Tuve el honor de que mis compañeros me eligieran para serlo". ${ }^{125}$ De esta manera, la distinción surgía por el reconocimiento del resto de fraternales sobre la autoridad que otorgaba el saber.

\footnotetext{
${ }^{121} \mathrm{EN}^{\circ} 12$.

$122 \mathrm{EN}^{\circ} 13$.

${ }^{123} \mathrm{EN}^{\circ} 12$.

${ }^{124} \mathrm{EN}^{\circ} 13$.

${ }^{125} \mathrm{EN}^{\mathrm{o}} 13$.
} 
Existía, no obstante, la posibilidad de lograr una categoría superior a la de maquinista, solo que por fuera del colectivo que los agrupaba. Cruz recuerda la posibilidad que tuvo de ascender a inspector y pertenecer así al personal de dirección:

\begin{abstract}
"Yo quise siempre estar siempre dentro de las filas de La Fraternidad. Un día vinieron a mi casa y me ofrecieron ser inspector. El que agarró, al poco tiempo, estuvo en Buenos Aires de inspector y apareció en Junín en auto. Mi señora me dijo: 'Ves'. Es la única vez que me echó en cara algo. Pero después vio que tenía razón yo, porque él nunca se pudo jubilar a los 55 años como me jubilé yo, porque era personal de dirección. Y los compañeros no lo miraban a él como a otros compañeros, como a mí, que se jubilaron bien, que eran fraternales, que fueron a las fiestas de fraternales. ${ }^{126}$ Muy diferente." ${ }^{127}$
\end{abstract}

De esta manera, la fuerte identidad hacia el colectivo y hacia el gremio La Fraternidad pudieron disminuir, en el caso de algunos fraternales como Cruz, la aspiración a ascender, a ir más allá de ese núcleo de pertenencia. Si se compara la experiencia de estos conductores de locomotora con la del resto de ferroviarios puede advertirse una diferencia sustantiva, ya que la identidad de estos últimos no ligaba la actividad ferroviaria específica con la pertenencia gremial. Mientras, por ejemplo, los ferroviarios de talleres construían su identidad ferroviaria a partir de la tarea específica que desarrollaban, la cual, a su vez, se vinculaba al quehacer ferroviario general (y con independencia de su posible identificación hacia el gremio), los maquinistas constituyeron su identidad asociando la tarea que desarrollaban (conducción de locomotoras) con la pertenencia al gremio. Sólo de esta manera puede comprenderse a Cruz cuando justifica por qué no quiso seguir ascendiendo: "Yo quise seguir perteneciendo a las filas de La Fraternidad". 128

\footnotetext{
${ }^{126}$ Una de las fiestas tradicionales se celebraba el 20 de junio, el día de fundación del gremio, en las sedes de La Fraternidad de todo el país. Cuenta uno de los fraternales en una entrevista: "Todo esto tiene olor a asado (sede de La Fraternidad). Nosotros festejamos el día del fraternal el 20 de junio. Entonces, se han dado casos en que yo ese día, había pagado mi tarjeta acá en Junín para ir a la reunión, pero me encontraba afuera, y esa fiesta se hacía en todas las seccionales. Y si yo me encontraba en una ciudad que no era mi sección, me llevaban a pasar las fiestas con ellos. O sea que había una camaradería..." ( $\left.\mathrm{EN}^{\circ} 12\right)$.

${ }^{127} \mathrm{EN}^{\circ} 13$.

${ }^{128} \mathrm{EN}^{\circ} 13$.
} 


\title{
Los distintos espacios de formación de los ferroviarios
}

Como se ha planteado en el apartado anterior, uno de los factores centrales que incidían en el progreso en el escalafón era la formación. A continuación se analizará el rol de los diferentes espacios instituidos en Junín para la educación de ferroviarios, que los trabajadores mencionaron como fundamentales en su formación: la Escuela Técnica Antonio Bermejo (luego llamada Escuela Industrial y antes denominada Escuela de Artes y Oficios), la Escuela de Aprendices que existía dentro del ferrocarril, la Escuela Nacional de Educación Técnica Nº3 "Yapeyú" (más específicamente el Ciclo Técnico Nocturno) y la Escuela Técnica de La Fraternidad.

La Escuela de Artes y Oficios (creada en 1923) formaba en diferentes saberes técnicos que habilitaban el ingreso en la empresa, desde antes de la nacionalización de 1948, cuando la empresa pertenecía a capitales británicos. Muchos ferroviarios mencionaron un convenio que existía entre la institución y el ferrocarril por el cual los mejores promedios podían ingresar directamente a la empresa, como un premio a su desempeño académico (Ver más arriba apartado “El ingreso...”). Quince años después de la inauguración de la Escuela, un documento del Departamento Mecánica de 1938 también refería a la selección de aprendices para el Taller en la Escuela de Artes y Oficio, en base a un examen de competencia, con el objetivo de “conseguir un mejor tipo de Aprendiz". "Este procedimiento dio el buen resultado que se esperaba por cuanto se ha conseguido formar un grupo de Aprendices dotados de cierta capacidad que los habilitaba más fácilmente para llegar a buenos operarios". ${ }^{129}$

De acuerdo a F. Arguto (2013), la inquietud por la propagación de saberes técnicos entre los trabajadores puede rastrearse desde comienzos del siglo XX, por parte de diversos sectores, como sindicatos, militares, religiosos:

\begin{abstract}
Mientras que para los sectores más conservadores era impulsado como un elemento de control social que permitiría el adoctrinamiento de los obreros y el mantenimiento del orden, por parte de los propios trabajadores y sectores "progresistas" era percibida la educación técnica con un potencial emancipador, que elevaría el nivel cultural de los obreros, enseñando al mismo tiempo un oficio que mejorase su calidad de vida. Asimismo, el aprendizaje de este tipo de saberes especializados era percibido como una solución para el problema de la eficiencia y la competitividad dentro de la industria nacional, permitiendo
\end{abstract}

\footnotetext{
${ }^{129}$ Ver más en: BAP (1938). Actividades, obligaciones, aspiraciones, p.13. Archivo Universitario de la UNNOBA Roberto Dimarco.
} 
sostener y profundizar el proceso de sustitución de importaciones vigente (Arguto, 2013, p.13).

En 1940 la Escuela de Artes y Oficios que existía en Junín cambió de nombre y pasó a llamarse Escuela Técnica de Oficios Antonio Bermejo, transformándose también sus planes de estudio de acuerdo a las reglamentaciones vigentes. Siguiendo a Arguto, una de las falencias de ambos tipos de estudio (de artes y oficios, y técnico de oficios) era que no habilitaban para el ingreso universitario. Fue, según el autor, a partir del golpe militar de 1943 que el Estado comenzó a desarrollar una nueva estrategia que apuntó a difundir masivamente la educación técnica concibiéndola dentro de un sistema más o menos integrado en el que era posible continuar la formación en niveles superiores. ${ }^{130}$

Probablemente como parte de este proceso que apuntó a superar las deficiencias a nivel nacional de esa educación fragmentada que databa de antes de la década del cuarenta, en 1948, la Escuela Técnica pasó a llamarse Escuela Industrial Antonio Bermejo, modificándose nuevamente sus planes de estudios. ${ }^{131}$

Sobre la enseñanza de la Escuela — tanto la de Artes y Oficios, Técnica e Industrial— los ferroviarios coinciden en recordar la calidad de la educación impartida, por el nivel de los docentes y la diversidad de los contenidos teóricos, técnicos y humanísticos brindados. Marone rememora:

\begin{abstract}
"Había gente muy capaz, tanto en la rama teórica como en la práctica. Nosotros teníamos fundición, herrería, carpintería, motores, tornería, fresaduría, ajustaje. Todos esos oficios paralelamente a la parte teórica: matemática, física, química, tecnología de los materiales, resistencia de los materiales, hasta religión... teníamos todo. Y la mayoría de los profesores eran técnicos egresados de la Otto Krause, ${ }^{132}$ con títulos de técnicos y hasta había ingenieros." 133
\end{abstract}

Algo similar recuerda Omar Decarre:

\footnotetext{
${ }^{130}$ Otros autores como Martínez S. coinciden en la transformación que tiene lugar a partir de 1943, cuando la educación para el trabajo era concebida como política de Estado, a diferencia del período previo en que este tipo de formación era impulsada por agrupamientos de la sociedad civil. Ver Hernández et al., 2017, 53-58.

${ }^{131}$ Historia y edificio. EESTN ${ }^{\circ} 1$ Antonio Bermejo Recuperado de https://www.eetljunin.com.ar/historia-yedificio/ : 31/07/2019.

132 “....en 1899 se funda la Escuela Industrial de la Nación 'Otto Krause' que alcanza un alto grado de importancia tanto por el nivel de los estudios que en ella se imparten cuanto por la disponibilidad de talleres, laboratorios y la existencia de un museo tecnológico; por ello, a comienzos del siglo XX es reconocida como uno de los seis mejores politécnicos del mundo" (Malatesta, 2008: 25).

${ }^{133}$ Entrevista $N^{\circ} 22$ a Ítalo Marone, 03/8/2018, en adelante EN 22.
} 
“Ajustaje, Carpintería y Tornería, Automotores, Tornería, Herrería y Fundición... todas las especialidades que tenía el ferrocarril te las enseñaban ahí, en el taller. En primer año había que recorrerse todas las secciones, un par de meses en cada una, y recién en segundo año se elegía la especialidad. En la parte teórica estaban todas las materias: había religión, geografía, historia, castellano, matemática, reforzada respecto de otras escuelas, porque en la escuela industrial se supone que la matemática es más primordial que un una comercial o nacional. Había que estudiar, ¿eh? Si querías eximirte tenías que estudiar." 134

Taberna también subraya "el orden y la disciplina que había en aquella época". "Te tenían así de cortito”, grafica. “¡Había un respeto...! Era impensado que se tratara a un profesor de la forma que se trata hoy en día...", continúa. ${ }^{135}$ De esta manera, como parte de los contenidos no curriculares, podemos inferir que también se enseñaba a los alumnos, indirectamente, a respetar la autoridad que representaba el docente, así como a obedecer sus indicaciones. Estos saberes incorporados en la conducta del aprendiz, le serían de suma utilidad una vez que haya ingresado al taller ferroviario: de él se esperaría respeto y obediencia hacia sus superiores. ${ }^{136}$

Este interés por disciplinar el comportamiento del joven estudiante puede rastrearse en la misma creación de la Escuela, cuando se solicita para el ingreso entre otras condiciones como la buena salud y la ausencia de defectos físicos, "la buena conducta con el informe de las autoridades de la localidad, o de personas respetables de la misma". ${ }^{137}$

Esta perspectiva que se tenía del rol que debía ocupar el joven estudiante y de la importancia de su formación y disciplinamiento, probablemente, se potenciaba por un edificio imponente en el que el estudiante se percibía empequeñecido. Recuerda Taberna con embeleso:

\footnotetext{
"Impresionaba el edificio... esas arcadas, esos corredores, los talleres. Siempre se mantuvo en buenas condiciones, no se acostumbraba a hacer inscripciones, los mismos profesores,
}

\footnotetext{
${ }^{134}$ Entrevista No23 a Omar Decarre, 25/10/2017, en adelante ENº23.

${ }^{135} \mathrm{EN}^{\circ} 10$.

${ }^{136}$ Sobre este tema puede leerse el trabajo de Sánchez Román (2008), quien sitúa algunos antecedentes en la formación impartida en las Escuelas de Artes y Oficio en la Liga Patriótica Argentina, quienes en la década del veinte fomentaron este tipo de espacios, apuntando según el autor, a "doblegar cualquier posible resistencia de los trabajadores" (2008: 273). En tanto, por parte de los sectores industriales, según el autor, se valoraba el aprendizaje industrial "no solo por su capacidad para mejorar la capacidad técnica de los trabajadores, sino también como un instrumento de control de los mismos" (Sánchez Román, 2008: 279). El peronismo no hizo más que continuar con esta tendencia en una educación que incluyera aspectos morales: "la enseñanza técnica no se entendía como algo específico, sino que debía contribuir a dotar al educando de valores, se debía instruir al ser humano y no solo al trabajador o al técnico" (Sánchez Román, 2008: 290).

${ }^{137}$ Escuela de Artes y Oficio de Junín (abril de 1974), Historia de Junín, p.3.
} 
el director, te inspiraban un respeto... Daba la impresión que fuera, no te digo una Universidad porque yo no la conozco, pero la educación era completamente distinta.”138

Algunos ferroviarios recuerdan también lo que implicó en el Taller ferroviario la incorporación de trabajadores con conocimientos teóricos y prácticos sobre los saberes del oficio, otorgados por esta institución educativa. Por un lado, significó un mejoramiento de la mano de obra del ferrocarril, pero, por otro lado, una transformación en las tradiciones anteriores por las cuales el oficial tenía la función de enseñar al novato el oficio. Rinaldi rememora: “Antes la dotación más grande del taller era de gente sin estudio que aprendía por práctica el oficio." 139 De esta manera, con la extensión de la educación institucionalizada, disminuyó la diferencia entre los trabajadores expertos en el oficio y los recién ingresados con formación previa, según lo que recuerda Marone:

\begin{abstract}
"Antes, entre los grupos extranjeros de inmigrantes podías encontrar especialistas en carpintería, soldadura, pintura. ${ }^{140}$ Entonces, eran ellos los que enseñaban a los que recién entraban. Con la Escuela Industrial, en cambio, los que estudiábamos teníamos una base al ingresar. Nosotros sabíamos lo que era una carpintería, una soldadura, una tornería, antes de ingresar a trabajar. Ahí la mano de obra en el ferrocarril más o menos se equilibró, no había tanta diferencia entre el gran especialista y el obrero. Entró gente con estudio y práctica de la Escuela Industrial, de la que el resto se fue nutriendo.”141
\end{abstract}

Esto habría implicado que las posibilidades de ascender en la escala laboral se igualaran entre los oficiales que aprendieron su oficio por práctica, y los aprendices recién ingresados, con formación teórica. Ese proceso, que habría ocurrido entre fin de 1940 e inicios de 1950, no estuvo exento de conflictos, tal como evoca Rinaldi:

"La gente sin estudios que llegaba a oficial era un poco contraria a tener el aprendiz, porque por ahí el aprendiz lo superaba. Cuando se producía algún adelanto de esa muchachada que quería subir, no les gustaba mucho a los oficiales". ${ }^{142}$

\footnotetext{
${ }^{138} \mathrm{EN}^{\mathrm{o}} 10$.

${ }^{139}$ Entrevista No24 a Eridé Rinaldi, 23/08/17, en adelante EN²4.

140 Sobre la extensión de la educación técnica, Sánchez Román señala: "Hasta la década de 1920, las necesidades de técnicos preparados en la industria argentina eran escasas y en muchas ocasiones se cubrían con expertos extranjeros. Sin embargo, a partir de esos años la necesidad de personal cualificado incrementó" (2008: 285).

${ }^{141} \mathrm{EN}^{\circ} 24$.

${ }^{142} \mathrm{EN}^{\mathrm{o}} 24$.
} 
De todas maneras, quien fuera jefe de Talleres Junín soslaya: "Tampoco era tanto problema. Como en todos lados ocurre, con el tiempo se supera". ${ }^{143}$ Sin embargo, puede imaginarse que la convivencia en la empresa de dos tipos de actores, con trayectorias y expectativas de ascenso diferentes, podría haber suscitado resquemores en ese momento.

\footnotetext{
"En la teoría teníamos preferencia nosotros, los que veníamos de la Escuela. En la práctica por ahí había alguno que tenía algún secreto que no le gustaba mostrar, en alguna fresadora, para hacer el trabajo más rápido o mejor. Siempre ocurre, más en un lugar así donde había muchos aprendices que al poco tiempo superaban a los oficiales sin Escuela." $" 144$
}

No obstante, tanto Marone como Rinaldi, que habían ingresado en la empresa con créditos educativos que los colocaban en una posición superior a quienes habían aprendido el oficio a través de la práctica, se iban a ver superados, al poco tiempo, por aprendices que ingresaban con títulos superiores a los de ellos. Marone recuerda, entre risas:

"Yo tengo un título muy especial de la Escuela (risas). Experto calificado mecánico (risas). Es un título que no dice nada. Ese es el título con que yo egresé de la Escuela Técnica, antes de ser Industrial. Entonces, cuando se convierte en Escuela Industrial, que primero se convirtió en Industrial ciclo medio y al muy poco tiempo empezó el ciclo superior, entonces ahí empezó a otorgar títulos de Técnico. Pero en vez de cuatro años eran seis y el programa cambiaba. Eso empezó cuando nosotros terminábamos del ciclo básico, entonces no salimos egresados de la Escuela Industrial, sino de la Escuela Técnica. Yo egresé en 1949. A partir de ahí los que ingresaban al colegio podían seguir hasta recibirse de técnicos, cosa que en mi caso no fue posible." 145

En consecuencia, algunos egresados de la Escuela Técnica se vieron en desventaja para poder ascender frente a los nuevos egresados de la Escuela Industrial, ya que sus títulos eran inferiores. "Yo estaba al frente de la oficina técnica y tenía muchachos trabajando, dibujando, que tenían más capacidad que yo, más instrucción”, cuenta Calderoni. ${ }^{146}$ Además, estos antiguos egresados estaban impedidos de complementar los estudios ya que el horario de la escuela coincidía con el laboral. Calcagni rememora:

\footnotetext{
${ }^{143} \mathrm{EN}^{\circ} 24$.

${ }^{144} \mathrm{EN}^{\circ} 24$

${ }^{145} \mathrm{EN}^{\mathrm{o}} 22$.

${ }^{146} \mathrm{EN}^{\mathrm{o}} 19$.
} 
"Había un grupo de muchachos que habían egresado hace algún tiempo, pero se sentían por debajo de otros que eran técnicos. En esa condición estaban Marone, Rueda, Rinaldi, Nicolai, muchachos que tenían conocimiento práctico muy importante, nadie era mejor que ellos en el taller, pero no tenían conocimiento teórico de las máquinas. Y se habían recibido, pero no eran técnicos. Y querían ser técnicos. Y ya eran técnicos los que venían de la Escuela Industrial. Pero ellos no podían asistir a la Bermejo porque eran cursos diurnos, y ellos trabajaban." ${ }^{147}$

En un principio, estos egresados intentaron, infructuosamente, que se creara un curso nocturno en la Escuela Industrial Antonio Bermejo para los antiguos egresados de la Escuela Técnica. Cuenta Marone:

"Nosotros pedíamos que el curso fuera nocturno, porque era la manera en que podíamos acceder al estudio, porque todos trabajábamos. Cuando se intentó por vía (Escuela) Bermejo no hubo forma, no se encontró la manera, no creo que haya sido por desinterés de la escuela, sino que al llegar a la autoridad superior probablemente no estaba en la mente de ellos generar un nuevo curso en Junín que permitiera a los exalumnos llegar a técnicos." $" 148$

La solución para estos ferroviarios inquietos tuvo lugar a través de la Escuela Fábrica Yapeyú, de reciente creación, la cual formaba en oficios. ${ }^{149}$ Rinaldi rememora:

\section{"Los mismos que egresamos de la Escuela Técnica hicieron fuerza ante la Comisión Nacional de Aprendizaje y Orientación Profesional. ${ }^{150}$ Un día vino acá el responsable a hacer una visita a la Escuela Fábrica, que estaba en la calle Rivadavia, no era la Escuela Industrial, sino que era otra escuela de un poco más bajo nivel. Él visitó la Escuela Fábrica y cuatro o cinco muchachos que éramos egresados le pedimos si podíamos seguir el ciclo técnico. O sea, en esa misma escuela que pertenecía a la Comisión de}

\footnotetext{
${ }^{147} \mathrm{EN}^{\mathrm{o}} 21$.

$148 \mathrm{EN}^{\mathrm{o}} 22$.

149 Existían en ese momento dos circuitos de formación técnica. Uno de ellos era la Dirección General de Educación Técnica, dependiente del Ministerio de Educación, el cual regentaba a todas las escuelas preexistentes, como las de Artes y Oficio, y las Técnicas. El otro, creado en 1944, correspondía a las instituciones dependientes de la Comisión Nacional de Aprendizaje y Orientación Profesional (CNOAP), dependiente, en aquel momento, de la que era la Secretaría de Trabajo y Previsión. Este otro circuito estaba encargado de organizar las EscuelasFábrica: "La CNAOP tuvo un papel muy importante, al poner el énfasis en la articulación de los estudios con el trabajo y en la formación de operarios medios con estudios terminales de corta duración (...) Desplegaba su quehacer en escuelas-fábrica donde los alumnos recibían todo lo necesario para el desarrollo de su formación en forma gratuita -uniformes, libros, instrumentales, herramientas y útiles-. Gozaban de una pequeña beca por mes y almorzaban dentro de la institución. Los estudiantes cursaban disciplinas básicas, tecnológicas y de cultura general, el énfasis estaba puesto en el 'saber hacer'.” (Martínez, 2013: 55).

${ }^{150}$ La CNAOP dependió hasta 1951 de la Secretaría de Trabajo y Previsión. En 1951 pasó a depender directamente del Ministerio de Educación (Malatesta, 2008: 17).
} 
Aprendizaje estaba el ciclo técnico, pero no acá en Junín, sino en Buenos Aires. ${ }^{151} \mathrm{Y}$ además había una universidad, aparte (la Universidad Obrera). Porque todas estas escuelas se hicieron con el criterio de que el obrero pueda seguir estudiando." 152

El recuerdo de Marone permite complementar el de Rinaldi:

“La Escuela Fábrica Yapeyú dependía del Consejo Nacional de Orientación Profesional que se creó en la época de Perón y les dio la posibilidad de estudiar a muchos chicos. Tenían menos requisitos y más libertades. Y entonces, aprovechando que acá se había creado la Escuela Yapeyú y que estaban dando clases muchachos que habían salido de la Bermejo, se empezó a ver la posibilidad de conectar a los interesados con alguna autoridad del Consejo. Y coincidió, en la época que se estaban haciendo esas gestiones, se había proyectado una visita del que era jefe. Entonces, qué mejor oportunidad de ver a este señor y plantearle nuestro interés, y en vez de crear el Ciclo Técnico en la Bermejo, crearlo en la Yapeyú. Ese grupo que se interesó en entrevistarlo estaba integrado por Rinaldi, Nicolai, Rueda, mi hermano mayor, entonces, cuando vino este hombre a Junín se entrevistaron, le contaron la inquietud que tenían, por qué querían completar esos estudios y formarse como técnicos. Había muchos jóvenes que lo hacían para tener acceso a la universidad, porque con el título que a mí me dio la Bermejo no podía seguir estudios superiores. Era para que muchos que no habían podido acceder a los estudios universitarios completaban ese curso nocturno y podían hacerlo. Cuando todo eso se le planteó a este hombre, tomó interés, lo habrá analizado con su grupo. Tuvimos la suerte que esta gente accedió y llegó el aviso de que lo iban a crear en el 53. Yo estuve en el Ciclo Técnico Nocturno del 54 al 57, soy de la primera camada."153

Probablemente para diferenciarse de los que egresaron de la Escuela Fábrica Yapeyú en el curso diurno y se formaban en un oficio, los ferroviarios que se recibieron de técnicos en esta institución no la nombran por su nombre (Yapeyú) sino que aluden a este momento formativo de sus vidas y a este espacio institucional como el "Ciclo Técnico Nocturno" (en adelante CTN). Taberna distingue:

“La Yapeyú se creó en el peronismo, vos sabés que hasta les daban los libros, le daban la ropa, tenían como una camisa de un color y un jardinero como de un color celeste,

\footnotetext{
${ }^{151}$ En rigor, las Escuelas Fábricas nucleadas bajo la CNAOP contemplaban la formación técnica y el título de técnico, la cual, sin embargo, no ofrecía la Yapeyú de Junín (Hernández et al., 2017: 55). Lo que estos ferroviarios lograron a partir de sus gestiones fue la inclusión de esta instancia superior que, incluso, habilitaba para el ingreso en la universidad.

${ }^{152} \mathrm{EN}^{\circ} 24$.

${ }^{153} \mathrm{EN}^{\circ} 22$.
} 
gris, y una camisa. Y tenían hasta un colectivo que los recogía. Tenían la ropa, los libros y los llevaban. Te estoy hablando del diurno, que era para los que habían terminado la primaria y seguían la secundaria ahí. En lugar del industrial, que ya era industrial, eso era Escuela fábrica. Ahí te preparaban más para un oficio. ${ }^{154}$ En cambio el nocturno era una cosa aparte."155

De acuerdo a Arguto (2013), durante el primer gobierno peronista se intensificó la estrategia que comenzó a delinearse en 1943 por la cual la educación técnica ocupaba un lugar destacado. ${ }^{156}$ Concretamente la primera Escuela Fábrica fue creada en el año 1946 y, hasta 1951, se habían creado 78 en todo el país, entre ellas la Yapeyú en Junín. En ese ámbito, entonces, pero con un nivel superior, tuvo lugar este CTN mediante el cual los nuevos graduados pretendieron colocarse en igualdad de condiciones para ascender en la escala laboral que los técnicos de la Escuela Industrial Antonio Bermejo. Si bien la mayoría de los alumnos del CTN fueron ferroviarios que, en general, llegaron a puestos altos en el ferrocarril, hubo algunas excepciones de estudiantes que lo hicieron por otras razones. Tal es el caso de Mateo y Rodolfo Perkusic, obreros de un taller metalúrgico y luego fundadores de la empresa Perkusic hnos., y de Abel Miguel, intendente de Junín que, según relatan otros compañeros, decidió estudiar allí para luego, finalizado el ciclo medio, poder acceder a la educación superior universitaria. $^{157}$

De aquel momento formativo los estudiantes destacan el sacrificio que les significó durante los cuatro años de formación. Mateo Perkusic rememora: "Entrábamos a las 7 de la noche y salíamos a las 10, entonces había que hacer un esfuerzo para cumplir con los horarios, no es fácil trabajar todo el día y luego estudiar, hay que tener ganas." ${ }^{158}$ Otros, con familia,

\footnotetext{
${ }^{154}$ Sobre la diferencia entre la formación entre Escuelas Técnicas y Escuelas Fábricas: “...ambos circuitos fueron, en tanto que organizaciones académicas, muy similares, lo cual se veía en la superposición de cursos y en la existencia de los mismos tipos de carrera en ambos circuitos, entre otros aspectos. En las escuelas técnicas había mayor énfasis en las materias de cultura general; y en las escuelas fábrica y de aprendizaje, mayor importancia de la práctica." (Hernández et al., 2017: 55-56). Sobre esto la autora sostiene que mientras la CNAOP fue, predominantemente, un sistema de formación de operarios, las escuelas industriales formaban preponderantemente técnicos. De esta manera, el planteo de Taberna está basado en esta diferenciación y basado en su experiencia con este tipo de espacios institucionales.

${ }^{155} \mathrm{EN}^{\mathrm{0}} 10$.

156 “....es posible aseverar que desde mediados de los años 40 la formación técnica es concebida como uno de los aspectos centrales de la planificación de la educación por parte del Estado y, en consecuencia, se diagrama y ejecuta, un subsistema particular que se aboca a cubrir esta área particular. De tal manera, se pone en marcha un conjunto de instituciones cuyo objeto esencial es brindar la preparación para el mundo del trabajo, especialmente el sector industrial" (Malatesta, 2008: 18).

157 Abel Miguel se graduó como ingeniero agrónomo. Fue intendente de Junín durante cuatro períodos consecutivos, entre 1983 y 2000. Abel Paulino Miguel (s.f). Recuperado de https://es.wikipedia.org/wiki/Abel_Paulino_Miguel: 8 de agosto de 2019.

${ }^{158}$ Entrevista $\mathrm{N}^{\circ} 25$ a Mateo Perkusic, 06/07/2017, en adelante $\mathrm{EN}^{\circ} 25$.
} 
como Calderoni también remarcan lo mismo: "Yo salía a las seis y pico del taller, y a las siete y pico estaba en la escuela. Y salía a las once. Así que fue un sacrificio de cuatro años, mi señora tenía a la hija mía chica." ${ }^{159}$ Por ese motivo, algunos no concluyeron el ciclo en ese momento, como Taberna: "Yo empecé... pero era muy pibe. Había que pasar por Sáenz Peña, ${ }^{160}$ se entraba a las 7 de la tarde y estaba así de chicos Sáenz Peña a esa hora... Aguanté seis meses y después me fui. Pasaron algunos años más y me empezó a picar, y ahí volví”. ${ }^{161}$ Otros, a pesar de la tentación, resistieron, como Perkusic: "Era el único soltero del curso, el resto eran casados y todos decían que en segundo año no iba a seguir. Y seguí". ${ }^{162}$ Por su parte, el ingeniero Calcagni, quien fuera docente del ciclo, valora: "Estos muchachos se levantaban a las 5 para ir al taller, trabajaban hasta las 5 de la tarde y a las 6 ingresaban en la escuela para salir a las 10 y media. Algunos de ellos estaban casados ya, tenían hijos, y bueno, con la familia muy poco." 163

El esfuerzo que emprendieron estos adultos jóvenes para estudiar estaba motivado, como ya se ha planteado, por la posibilidad de conseguir un título que los colocara en igualdad de condiciones frente a otros técnicos de la Escuela Industrial. Ligado a ello, esta formación les brindaba mayores conocimientos y herramientas para mejorar su desempeño en el ámbito laboral y realizar una carrera con más posibilidades de ascenso en el ferrocarril. Rinaldi afirma: “El CTN me sirvió para adquirir mucho más conocimiento y ser un apoyo dentro de la sección para los supervisores". ${ }^{164}$ Calcagni opina: "Estos muchachos después llegaron bastante alto en el ferrocarril." "65 Juan Dall'Occhio acuerda: "Los que nos recibimos en el CTN hemos tenido roles importantes en el ferrocarril o en la industria privada, como en el caso de Perkusic. Todos mis compañeros ocuparon puestos de dirección." 166 En el caso de Perkusic, los conocimientos le brindaron herramientas para crear la empresa:

"Uno realmente aprendió un montón de cosas que en el transcurso de los años las fue aplicando a la empresa. A Rodolfo y a mí nos sirvió para realizar cálculos matemáticos, para la construcción. Hoy nos da una gran satisfacción tener una empresa conocida en Junín. Sin lugar

\footnotetext{
${ }^{159} \mathrm{EN}^{\mathrm{o}} 19$.

${ }^{160}$ Roque Sáenz Peña es el nombre de la calle céntrica de Junín, donde se concentraban la mayoría de los comercios y lugares de esparcimiento.

${ }^{161} \mathrm{EN}^{\mathrm{o}} 10$.

$162 \mathrm{EN}^{\mathrm{o}} 25$.

${ }^{163} \mathrm{EN}^{\circ} 21$.

${ }^{164} \mathrm{EN}^{\mathrm{o}} 24$

$165 \mathrm{EN}^{\circ} 21$.

${ }^{166} \mathrm{EN}^{\mathrm{o}} 15$.
} 
a duda, es una de las pocas empresas importantes que hay en Junín. Y hay cosas que si no las hubiéramos aprendido en la escuela, no las podríamos haber hecho."167

Todos estos relatos tienen en común que en ellos aflora la valoración hacia el conocimiento que, en determinado momento, el estudiante no poseía y que, a través del esfuerzo, logró adquirir. En cierto sentido, esta búsqueda de aprender iba más allá de la acreditación que ofrecía la Escuela. Como describe Dall'Occhio: “Era la vocación, era la curiosidad por saber". ${ }^{168}$ Marone, con una anécdota, también da cuenta de esta motivación por contar con más conocimientos en una ciudad que no ofrecía como alternativa la educación universitaria: “Con (Rómulo) Cremanti a veces cumplíamos con el programa y después le decíamos 'Ingeniero, no podríamos hacer alguna clase particular, fuera de hora'. Y entonces le pedíamos que nos diera algo más de matemática, matemática superior con derivadas, por ejemplo." ${ }^{169}$ Murgia, también recuerda que este docente les brindaba algunos conocimientos que estaban fuera del programa: "En determinado momento, habiendo finalizado el ciclo técnico, Cremanti hizo un curso y vino acá y lo replicó. Fue como un agente multiplicador." 170

Este tipo de enseñanza en la que los contenidos brindados por el docente eran mayores a los explicitados por el programa fue posible, probablemente, por las características del alumnado, un grupo de jóvenes que ya trabajaban que, en su mayoría, tenían familia, y que tenían un interés genuino por aprender. Además, el espacio institucional recién creado y el grupo reducido de alumnos también podría haber propiciado que se gesten formas de relación con mayor grado de familiaridad y modos enseñanza más cercanos entre los docentes y los alumnos, si se la compara con la educación recordada por los actores de la Escuela Antonio Bermejo.

La siguiente anécdota recordada, entre risas, por Calcagni exhibe la existencia de un pacto implícito entre estudiantes y docentes por recorrer juntos un camino de enseñanzaaprendizaje, fundado a partir de vínculos más horizontales (o más adultos), si se los compara con los de la Escuela Industrial:

"El título que daba el CTN era de Técnico en Máquinas Herramientas. La última de las materias era, precisamente, Máquinas Herramientas. Y ocurrió algo. No había profesor

\footnotetext{
${ }^{167} \mathrm{EN}^{\mathrm{o}} 25$.

${ }^{168}$ Entrevista No26 a Juan Dall'Occhio, 23/10/2017, en adelante EN²6.

${ }^{169} \mathrm{EN}^{\circ} 22$.

${ }^{170} \mathrm{EN}^{0} 7$.
} 
para esa materia. Se dictaron todos los cursos, pero faltaba ese. Se esperaba que mandaran de algún lado, pero no había caso. En Buenos Aires, sí... pero ¿quién iba a venir a dar clases? Y pasó un mes. Y los muchachos: ¿y para cuándo? Apareció uno, que era ferroviario, estaba en Vía y Obras, ingeniero, se presentó al primer día de clases y los muchachos les tomaron examen a él (risas) Le empezaron a hacer preguntas, por qué esto, por qué lo otro, y la cuestión que el tipo se fue y no volvió más. Y pasó otro mes, entonces la cosa se estaba poniendo al rojo, decían: 'nosotros hemos hecho este sacrificio durante 3 años y ahora...' Y ahí vino la idea salvadora de Cremanti. Cremanti había sido profesor y era el vicedirector... entonces reunió a los muchachos y les dijo, 'ustedes no tienen profesor, yo algo sé de todo esto, teóricamente sobre las máquinas yo sé algo también. Ahora sobre el manejo de las máquinas ustedes son los que saben. Les propongo una cosa, yo les enseño lo que yo sé y ustedes me enseñan a mí lo que no sé. Lo que no sepamos ni ustedes ni yo lo estudiamos juntos...' La cuestión es que el curso terminó, los muchachos se recibieron y lo abrazaban a Cremanti... (risas)". ${ }^{171}$

De los docentes que fueron parte de su formación, algunos recuerdan con especial estima, precisamente, a Alfredo Cremanti. "Son esas personas que tienen carisma, que te llevan, que si no entendés te lo explican de otra manera para que lo entiendas, con mucha capacidad y rapidez”, evoca Marone. ${ }^{172}$ Perkusic recuerda que era muy exigente, que no hacía perder ni un minuto de la clase y "que era el más enérgico de todos" los profesores. ${ }^{173}$ Para Murgia fue el mejor de los docentes. ${ }^{174}$ En cambio, Taberna opina que el mejor fue Calcagni: “¡Me acuerdo llenar pizarrones con Calcagni! Era terrible. Para escucharlo tenías que tener todos los sentidos atentos, porque hablaba muy bajito. Le teníamos un poco de miedo (risas). A raíz de que uno estaba con todos los sentidos para escucharlo, aprendí matemática extraordinariamente". ${ }^{175}$ En tanto, Perkusic recuerda especialmente a Eridé Rinaldi: ${ }^{176}$ "Un tipo que nos explicaba y nos seguía insistiendo con que aprender el día de mañana nos servía para formarnos mejor y estar en otras condiciones para trabajar en el ferrocarril o por cuenta nuestra, como hicimos. Un tipo que se dedicaba a la escuela, que enseñaba bien y entendía al alumno". ${ }^{177}$

\footnotetext{
${ }^{171} \mathrm{EN}^{\mathrm{o}} 21$.

$172 \mathrm{EN}^{\mathrm{o}} 22$.

${ }^{173} \mathrm{EN}^{\mathrm{o}} 25$.

${ }^{174} \mathrm{EN}^{0} 7$.

${ }^{175} \mathrm{EN}^{\mathrm{o}} 10$.

${ }^{176}$ Luego de graduarse como técnico en el CTN de la Escuela Yapeyú, Rinaldi pasó a conformar el plantel docente.

$177 \mathrm{EN}^{\circ} 25$.
} 
Es importante advertir que, como ocurría en la Escuela Industrial, la formación en esta Escuela no se limitaba al aspecto técnico, sino que tenía un fin moralizador y disciplinador de los trabajadores, tal como sugiere el testimonio de Perkusic:

“En la Yapeyú nos enseñaban también que había que portarse bien, que había que trabajar bien, que había que hacer las cosas como dice el patrón. Porque hay muchos casos en que cuando uno es empleado no le hace caso al patrón. Pero en aquel momento era muy importante porque en el ferrocarril se tomaban muchos empleados que eran de la escuela-fábrica, pero tenían que tener una buena educación y una buena referencia, que realmente sea buena persona." 178

Los testimonios muestran que la experiencia formativa en el CTN fue satisfactoria para buena parte de los actores que la transitaron y puede haber favorecido una identificación hacia ese espacio institucional. Es probable que esa identificación se haya construido en contraposición a la Escuela Industrial si se tiene en cuenta que, como plantea Stuart Hall, el afuera es constitutivo en la construcción de identidad. En otras palabras, lo que no soy permite decir quién soy. Calcagni confirma:

\begin{abstract}
"Había cierta animosidad entre la Escuela Industrial y la Yapeyú, de algunos profesores. Una vez tuve una discusión con un profesor. La Escuela Industrial otorgaba el título de técnico mecánico y la industrial en técnico mecánico especialista en máquinasherramientas. No era de mecánica general sino de especialización, más restringido, pero de mayor profundidad. El título que recibían era diferente. Eran técnicos mecánicos especialistas en máquinas-herramientas. Era un curso que se daba solamente en la escuela Otto Krausse de Buenos Aires. ${ }^{179}$ Pero es una cuestión opinable y el profesor del Industrial siguió con su opinión y yo con la mía." 180
\end{abstract}

Rinaldi, graduado y docente, tanto de la Escuela Industrial como del CTN, también reconoce que existía una rivalidad entre ambos espacios de enseñanza: "El ciclo técnico que era nocturno rivalizaba un poco con el Industrial". ${ }^{181}$ Sin embargo, a diferencia de Calcagni, para Rinaldi “el ciclo de la Industrial era un poco más exigente, era mejor”. Luego, Rinaldi

\footnotetext{
${ }^{178} \mathrm{EN}^{\mathrm{o}} 25$.

${ }^{179}$ La Escuela Industrial Otto Krausse poseía un gran prestigio por el plantel de profesores, equipamiento y material didáctico. Un proyecto del ingeniero docente Pascual Pezzano, según la autora, constituyó el antecedente más importante de la creación de la Universidad Obrera (Malatesta, 2008: 26).

$180 \mathrm{EN}^{\circ} 21$.

$181 \mathrm{EN}^{\mathrm{o}} 24$.
} 
minimiza esta rivalidad: "Igual, no había problema. Marone y yo somos egresados del CTN y la jefatura de taller en aquel momento eran egresados de la Escuela Industrial”. Calcagni, por su parte, también evita profundizar sobre este aspecto en el segundo encuentro.

En concreto, el CTN fue una experiencia que se inició en 1954 y finalizó en 1968, cuando se fusionó con la Escuela Industrial. Esta incorporación incrementó significativamente el número de alumnos de la Escuela Industrial que en 1968 contaba con 238 y en 1969 pasó a tener 400 estudiantes. La matrícula seguiría creciendo en los años siguientes: 1970: 539 estudiantes; 1971: 619 estudiantes; 1972: 745 alumnos. ${ }^{182}$

Otro de los espacios institucionales dedicados a la enseñanza era la Escuela de Aprendices, la cual funcionaba dentro de la empresa desde antes de la nacionalización, cuando los ferrocarriles eran de capitales británicos. De esta manera, una vez que el operario había ingresado, tenía la posibilidad de iniciar o continuar su formación en la Escuela, lo que lo habilitaba para promocionarse y así mejorar su ingreso. Marone recuerda:

\begin{abstract}
"El ferrocarril tenía también un sistema de perfeccionamiento. Cuando ingresamos de aprendices teníamos que concurrir a una Escuela de Aprendices. Allí mejoraban los conocimientos o nivelaban a los aprendices de las distintas secciones. Preparaban a la gente joven que ingresaba, porque eran los que tenían el potencial necesario para transformarse en supervisores, encargados, capataces, jefes. Y bueno, a mí me tocó entrar en esa estructura en ese momento, con esa forma de promociones. Y ahí de aprendices pasábamos a oficiales, de oficiales a especialistas." ${ }^{183}$
\end{abstract}

\title{
Rinaldi complementa:
}

"El maestro de la Escuela daba un informe sobre el aprendiz, con la prueba escrita, cada cuatro meses. Por otra parte, estaba el informe del supervisor en el trabajo. Esos dos informes hacían que el operario pudiera pasar a medio oficial, oficial, especialista, según la sección que estuviera." 184

De acuerdo a Crocco, el plan de aprendizaje en la Escuela de Aprendices, era de tres años para los egresados de la Escuela de Artes y Oficio Antonio Bermejo, y de cinco para los que ingresaban sin formación. Según Rinaldi, los que venían de la Escuela Industrial estaban obligados a ir a la Escuela de Aprendices. "Teníamos que ir de prepo porque habíamos entrado

\footnotetext{
${ }^{182}$ Escuela de Artes y Oficio de Junín. Sus bodas de oro (abril de 1974). Historia de Junín.

$183 \mathrm{EN}^{\circ} 22$.

$184 \mathrm{EN}^{\circ} 24$.
} 
de aprendices", dice. ${ }^{185}$ Marone coincide: "Estaba más preparada para la gente que ingresaba al ferrocarril sin tener una preparación previa importante, pero bueno, nosotros egresados de escuelas técnicas teníamos que hacerla igual”. Así y todo, reconoce: “A mí me sirvió mucho, porque como yo venía de la escuela (técnica) seguí trabajando con el mismo criterio". ${ }^{186}$

Tanto Rinaldi como Marone se refieren a la Escuela de Aprendices como de menor exigencia, en comparación a sus otras experiencias formativas (la Escuela Bermejo y el CTN). Quien fuera jefe de Mecánica califica al nivel como "suficiente": "Se enseñaban muchas cosas de instrumentos, técnicos, propias del trabajo del ferrocarril, entonces estaba bien. No hacía falta que quien enseñaba fuera un ingeniero, en cambio en la Escuela Industrial cuanto más nivel tenía el profesor, mejor". ${ }^{187}$ Rinaldi adhiere: "Se enseñaba teoría, práctica no, porque la hacían en el lugar que trabajaban. Pero no era tan profundo". ${ }^{188}$

Uno de los docentes-encargados en la Escuela de Aprendices era Héctor Ferrari, quien evoca sus inicios en la Escuela:

"Yo siempre fui una persona tímida, y ahí me di cuenta al estar en frente a una clase de
treinta alumnos que me respetaban... en aquel momento se respetaba al maestro, muy
distinto a ahora, se respetaba una barbaridad... y me di cuenta que la forma práctica de
explicar un problema, cuando vos conocés bien el tema, las palabras te brotan solas." 189

Una anécdota de Ferrari permite, al mismo tiempo, ilustrar que la educación en la Escuela de Aprendices se trataba de una formación un tanto más flexible y con menor grado de exigencia, si se la compara con el resto de espacios de formación que se han analizado en el presente apartado:

"Yo era examinador en todas las materias. Y a mí me gustaba favorecer a la gente que conocía. Una vez había un soldador que tenía que rendir y sacarse setenta por ciento de promedio. Era el mejor soldador eléctrico que teníamos. Y había rendido la prueba y después tenía que rendir la parte teórica. 'Y no, yo no voy', decía. Prácticamente no sabía ni escribir. Yo le digo: 'No, vos presentate a la prueba, que de alguna forma vamos a arreglar'. Y le hice sacar cuarenta puntos. Las preguntas eran doce, la mayoría correspondientes a la especialidad, que era soldadura. 'Vos respondé lo que sabés'.

$185 \mathrm{EN}^{\mathrm{o}} 24$

$186 \mathrm{EN}^{\circ} 22$.

$187 \mathrm{EN}^{\circ} 22$

$188 \mathrm{EN}^{\mathrm{o}} 24$.

$189 \mathrm{EN}^{\circ} 4$. 
Después las otras preguntas eran de matemática, se podía arreglar. Basta que dé setenta.

Pero arreglábamos esos casos, por eso me tenían mucho aprecio la gente. En esos casos." 190

Esta contemplación y tolerancia hacia el operario que ilustra el recuerdo anterior puede explicarse, por un lado, porque al ferrocarril ingresaban en ese momento personas con diversas experiencias formativas previas (primaria, media y técnica completa o incompleta) a quienes había que nivelar en sus saberes para que mejoren la calidad de la labor en la sección: esa parecía ser la meta de la Escuela. Por otro lado, porque la aprobación de los exámenes implicaba mejoras directas en el ingreso. De esta manera, si el aprendiz los desaprobaba no percibiría ese aumento. Por eso, es posible que los vínculos y afinidades personales establecidos entre los maestros y los estudiantes hayan sido importantes a la hora de aprobar los exámenes y, por tanto, promocionarse en el ferrocarril en ese estadio inicial.

Debe señalarse, además, que la Escuela de Aprendices era concebida como un espacio complementario a la formación (práctica) que el ferroviario recibía en el trabajo, en el vínculo con el oficial que le enseñaba los secretos del oficio. ${ }^{191}$ Podemos hallar en esta modalidad las huellas de una forma de concebir el aprendizaje en oficios que databa desde antes de la nacionalización, cuando el ferrocarril pertenecía a capitales británicos.

\begin{abstract}
"Cuando entrabas te ponían con un oficial como aprendiz, que ya tenía conocimiento, que te transmitía lo que él sabía. O sea, que a los tres años el aprendiz ya sabía. Aparte que había una Escuela de Aprendices, te ponían a trabajar con un oficial. Y siempre hay alguien que tenía buen ojo para marcar a los buenos aprendices. Entonces a los mejores chicos los ponían con los mejores oficiales, y ahí salían los mejores operarios.” ${ }^{192}$
\end{abstract}

Esta tradición de enseñanza que, como se ha planteado, tenía raíces en la gestión inglesa, involucraba, además, la meta de la excelencia en el trabajo del taller, tal como sugiere Taberna a partir del testimonio anterior. La búsqueda de "los mejores aprendices" que llegarían a ser "los mejores operarios" se basaba en parámetros no objetivos, a partir de alguien que, con una visión certera, "marcaba", distinguía quienes tenían atributos de quienes no. Por tal motivo, cuando Ferrari, como encargado de la Escuela de Aprendices, dice abiertamente que le gustaba

\footnotetext{
$190 \mathrm{EN}^{\circ} 4$.

${ }^{191}$ De acuerdo a Ayuso, en el espacio cotidiano de trabajo "se impulsaron procesos de aprendizaje, de experiencia asistida entre trabajadores experimentados y novatos y de intervención creativa para la recreación y producción de saberes en las tareas y situaciones problemáticas que se presentaban" (2010: 63). La autora también menciona el Reglamento Interno Técnico Operativo (RITO), implementado en 1950 por el cual "todo empleado que tenga a otros a su cargo debe compenetrarse de la capacidad de sus subalternos, teniendo la obligación de enseñarle lo que no supieren e informar a la superioridad del progreso de los mismos.

$192 \mathrm{EN}^{\circ} 10$.
} 
"arreglar" ciertos casos y "favorecer" a aprendices que él conocía no estaba más que continuando con una tradición que lo antecedía, en la que un "ojo avizor" se atribuía la capacidad de juzgar las potencialidades del resto. Como se ha mostrado en otras instancias del trabajo, la existencia de dicha capacidad de algunos jefes (de reconocer las capacidades ajenas) siguió siendo considerada por el imaginario ferroviario como una práctica eficaz. Puede recordarse cuando Rinaldi decía: "Los ingleses elegían a dedo y no se equivocaban" (ver apartado "El progreso como...).

A esta altura, cabe preguntarse si la valoración hacia el estudio y el conocimiento que parece ser común en los relatos de ferroviarios se explica exclusivamente a partir de las posibilidades de progreso que se le abrían al trabajador dentro de la empresa. Para Rinaldi, esta sería la razón más importante: "Estudiábamos para tener más posibilidades dentro del ferrocarril. Con un estudio de técnico tenías un sobresueldo. Era un premio interesante, por eso muchos estudiaban, trabajando". ${ }^{193}$

No obstante, no solo se trataba de obtener acreditaciones por parte de instituciones reconocidas oficialmente. Marone, relata, entre risas, que antes de cursar en el CTN, se inscribió en un curso de ingeniería por correspondencia que le brindó algunos conocimientos que le permitieron contar con mayor seguridad para asumir nuevas responsabilidades: "Me había preocupado por mejorar mi capacidad técnica a través de un estudio, aunque sea por correspondencia. Si me daba un $10 \%$ de conocimiento de lo que me había dado el Industrial, en buena hora", expresa y luego añade: "Estas cosas me daban la posibilidad de tomar coraje... es decir, yo voy a aspirar a eso, porque considero que tengo la capacidad". ${ }^{194}$

Sin embargo, más allá de la consecuente mejora en la escala laboral, parece que el esfuerzo de estudiar apuntaba en el trabajador a un mejoramiento de las cualidades personales, a partir de la creencia de que la educación los convertía en mejores personas. Así lo expresa Murgia: "Yo me interesé siempre por ser cada vez mejor, por aprender cada vez más y ser cada vez más útil. Otra gente se interesaba además por otras cosas, como la política”, y luego añade, leyendo, una de las frases que ha escrito en un diario personal, en el que incluye fechas importantes de su vida y reflexiones de su experiencia: "Los desafíos (en alusión a los conocimientos que debió adquirir) fueron bendiciones que me hicieron crecer". ${ }^{195}$ En el mismo

\footnotetext{
${ }^{193} \mathrm{EN}^{\mathrm{o}} 24$.

$194 \mathrm{EN}^{\mathrm{o}} 22$.

195 EN'7.
} 
sentido, Perkusic vincula la búsqueda de aprender con otro valor, la honestidad: "Generalmente la persona que quiere aprender es honesta. Una persona que estudia quiere progresar". ${ }^{196}$

La siguiente anécdota con Dall'Occhio permite ilustrar que, en efecto, la búsqueda del conocimiento emprendida por estos actores podía trascender la utilidad o la conveniencia que este brindaba para el ascenso:

—JD: en uno de los años en que yo estudiaba en el Ciclo Técnico Nocturno, el ingeniero Cremanti hacía un curso en La Plata en el Instituto de Energía Atómica. El ingeniero salía del tren a las 4 de la mañana para hacer el curso y regresaba a las 10 y media de la noche. A las 10 nosotros salíamos para ir a nuestras casas pero nos quedábamos un grupito de ocho o nueve a esperarlo y que nos transmita lo que había aprendido... ¡Mirá el sacrificio que hacía Cremanti y también nosotros, lo que aguantábamos!

—ALS: ¿Y por qué lo hacían?

—JD: No sé. Era una vocación, era la curiosidad por saber." (el subrayado es mío) ${ }^{197}$

En suma, puede afirmarse que existía un imaginario compartido entre estos ferroviarios que consideraba a la educación como un valor que permitía no solo el ascenso social, sino un mejoramiento integral de la persona. ${ }^{198}$ Esa creencia brindó el terreno propicio para encauzar las energías individuales y someterse a la disciplina del estudio, dejando de lado otras actividades humanas posibles. ${ }^{199}$

Otro espacio institucional de formación entre ferroviarios lo constituía la Escuela Técnica de La Fraternidad, dependiente del sindicato de maquinistas, la que preparaba a aspirantes y foguistas para ser conductores de locomotora. ${ }^{200}$ "El foguista tenía colegios en La Fraternidad, acá en Junín, en Rufino, en Laboulaye, en todos los lugares donde había puntos de

\footnotetext{
$196 \mathrm{EN}^{\mathrm{o}} 25$.

$197 \mathrm{EN}^{\circ} 26$.

${ }^{198}$ De acuerdo a Baczko, los imaginarios sociales provocan la adhesión de los individuos a un sistema de valores, interviniendo en su interiorización, moldeando conductas, cautivando energías y conduciendo a acciones comunes (1991: 30).

${ }^{199}$ Es una mención recurrente la "tentación" que para los ferroviarios significaba el centro de la ciudad y la oferta de actividades vinculadas al ocio, en contraposición al esfuerzo que implicaba el estudio. Por ejemplo, cuando Juan Dall'Occhio comenta sobre su experiencia en el CTN: "En mi curso empezamos cuarenta y cinco y terminamos cinco, era difícil, estaban todos en el centro con las chicas y nosotros...". Taberna se refiere al CTN en el mismo sentido: "Había que pasar por Sáenz Peña, se entraba a las 7 de la tarde y estaba así de chicos Sáenz Peña a esa hora... Aguanté seis meses y después me fui”.

${ }^{200}$ Badaloni señala que la primera escuela técnica del país se fundó en 1908 en Las Flores (Badaloni, 2010: 115). De acuerdo a Ayuso en 1908 se funda también en Junín el Instituto Técnico de Maquinistas y Foguistas Jorge Stephenson (Ayuso, 2018: 378).
} 
relevo. Luego se rendía examen para ser, como fui yo, maquinista dependiente de la organización", cuenta uno de los fraternales. ${ }^{201}$

El lugar donde se preparaban los aspirantes a conductores era la sede del gremio, durante las tardes, luego de la jornada laboral:

"Este lugar (edificio del gremio La Fraternidad) era antes la sala de Reglamento. Acá se estudiaban todas las señales. Y la otra habitación que ahora ya no existe más, que ahora es una cocina, era Máquinas: menos la caldera y las ruedas, lo demás estaba todo ahí adentro, pieza por pieza. O sea que vos ibas aprendiendo por tocar la pieza. Entonces, esto era un colegio. Un instructor te daba el Reglamento y otro te daba lo que tenía que ver con Máquinas. Entonces, el que tenía ganas de progresar, se perdía el descanso acá adentro. Había que venir por cuenta de uno, acá no te pagaba el ferrocarril para estudiar." 202

Luego de la capacitación técnica que duraba tres años, brindada por instructores fraternales designados por el gremio La Fraternidad, los aspirantes rendían un examen que, aprobación mediante por parte de la empresa de ferrocarriles, los habilitaba como conductores de locomotora en todo el país. "A cada uno que pasaba cada examen le entregaban un certificado nacional que servía para todos los ferrocarriles. Era como tener un carnet de conductor para el auto, te das cuenta, solo que para los trenes", comenta uno de los fraternales. $^{203}$

Para Cruz, haber sido designado como instructor significó “un honor", ya que implicó un reconocimiento colectivo hacia su saber y capacidad. "Yo me preocupé por estudiar, me gustaba. Entonces al estar preocupado por el estudio, pasaron los años, hice el curso para ser instructor, estudié toda mi vida", comenta. ${ }^{204}$ En este sentido, puede advertirse una diferencia respecto de los espacios institucionales antes analizados: la Escuela Técnica de La Fraternidad no solamente controlaba los saberes del oficio, sino que también elegía dentro del mismo colectivo a los conductores que pudiera enseñar a los recién iniciados.

\footnotetext{
${ }^{201}$ Desde fines del siglo XIX, se comenzó a conformar un subsistema de educación y trabajo para la preparación de foguistas y maquinistas que se terminó de materializar en el siglo XX en una red de escuelas técnicas gremiales distribuidas a lo largo de la red ferroviaria argentina, organizadas, autogestionadas y financiadas por los trabajadores pertenecientes a La Fraternidad (Ayuso, 2017: 253). Gracias a esta red de escuelas, La Fraternidad fue capaz de controlar los saberes del oficio y ejercer poder sobre los ingresos y expulsiones. Ese monopolio del saber-hacer que concentraban les permitió, al mismo tiempo, contar con herramientas de gran eficacia en las disputas gremiales ante el gobierno y las empresas ferroviarias. El control que ejercieron los fraternales sobre los saberes del oficio y su empleo en las negociaciones laborales también fue desarrollado por Badaloni, 2010.

${ }^{202} \mathrm{EN}^{\circ} 12$.

${ }^{203} \mathrm{EN}^{\mathrm{o}} 12$.

${ }^{204} \mathrm{EN}^{\circ} 13$
} 
Además, la escuela técnica del sindicato produjo también sus propios materiales didácticos, tal como plantea Ayuso (2017), quien sostiene que la transmisión sistematizada y escrita de la experiencia acumulada por los maquinistas constituyó un elemento más de la identidad fraterna. De acuerdo a la autora, complementariamente al trabajo que realizaron en las escuelas seccionales, "los trabajadores asumieron la función docente a través de la producción de materiales para la difusión en distintos formatos" (Ayuso, 2017: 221). Los fraternales entrevistados recuerdan, en ese sentido, una producción local realizada por Dante Balestro.

—Fraternal A: Balestro era un maestro. Una eminencia, porque la máquina la conocía de $\mathrm{Pe}$ a Pa.

—Fraternal B: Dante Balestro hizo los manuales de las locomotoras diesel eléctricas. Las hizo él para todos los ferrocarriles, para todo el país. ¿Me entendés lo que te digo? El tipo investigó las máquinas... Porque las máquinas venían con todo en inglés, eran máquinas estadounidenses. Él tradujo todo y aparte investigó lo que es la locomotora cable por cable, la derivación. Investigó todas las fallas posibles que podía tener la locomotora y cómo tratar de evitarlas. Sobre eso hizo manuales y sobre estos manuales están todos los ferrocarriles trabajando.

-Fraternal A: Vos imaginate que venías andando con la locomotora y tenías una falla y el librito de Balestro estaba en la valija.

-Fraternal B: Vos te lo llevabas en la valija. Pelabas el librito ese y buscabas. Ahí encontrabas dónde estaba la falla.

-Fraternal C: Iba derecho a la falla.

-Fraternal A: Todo lo que decía un libro grandote, él lo simplificó en veinte páginas. ${ }^{205}$

Sin embargo, la tarea específica del maquinista no solamente se aprendía dentro de la Escuela, sino durante los viajes en locomotora y en las estadías en las casas fraternales, también llamadas "puntos de relevo", a través de la persona que ejercía autoridad sobre el foguista: el conductor a cargo.

“Antes estábamos cinco o seis años de foguista, y salíamos de viaje con distintos conductores. Con el concepto fraternal, los conductores se preocupaban de enseñarte, aparte de lo que hacía el instructor. Los conocimientos que se tienen sobre el vapor, el calor, son todos conocimientos físicos. Entonces, el foguista aparte de estudiar, hacía los

${ }^{205} \mathrm{EN}^{\circ} 12$. 
viajes y el conductor le enseñaba ciertas cosas. El foguista le preguntaba al maquinista. $L a$ forma de manejarse, de conducirse con los compañeros." ${ }^{206}$

El testimonio anterior señala que durante la misma práctica del trabajo se establecía un vínculo íntimo entre maquinista y foguista que favorecía la transmisión de saberes, no solos vinculados a la técnica misma de la conducción o la mecánica del vehículo, sino también sobre el imaginario fraternal que estaba conformado por comportamientos esperables, prioridades, prohibiciones, etc. En otras palabras, la educación del fraternal no se limitaba a la preparación técnica, sino que abarcaba otras dimensiones del trabajador, relacionadas con las conductas hacia sus pares y valores asociados a la identidad fraternal. ${ }^{207}$

\section{Los beneficios materiales y simbólicos de los trabajadores ferroviarios}

Miguel Mantino recuerda que los vecinos lo "paraban en la calle" para felicitarlo por haber ingresado. "Entrar era como una fiesta", asegura y añade: "El que entraba al ferrocarril en aquel tiempo se salvaba". ${ }^{208}$ El testimonio de Mantino, que había ingresado en 1951 como aprendiz de Calderería, es similar al de muchos otros ferroviarios que comparan el ingreso al ferrocarril, casi como una iniciación en la existencia, un salto cualitativo en su historia de vida. "Entrar al ferrocarril en aquel tiempo era una suerte", afirma Violante, que entró como aprendiz en Electricidad en 1952. ${ }^{209}$ “¿Quién no quería entrar al ferrocarril? El que era ferroviario estaba ahí arriba", dice Tornello, operario de Chapas desde 1954. Ferrari, quien ingresó en 1945 como aprendiz ajustador, compara la posibilidad de ingresar con un acontecimiento inusual como el de "ganar la lotería": "Era muy difícil entrar. El trabajo más importante que había en Junín era ese". 210

\footnotetext{
${ }^{206} \mathrm{EN}^{\circ} 12$.

${ }^{207}$ Sobre este tema Ayuso considera que los ferroviarios en general (no solo a los fraternales), conformaron un sistema de saberes del trabajo, que contemplaba conocimientos "técnicos y no técnicos, experiencias, hábitos y costumbres legados, mitos y leyendas que como entramado de saberes constituyeron parte del patrimonio colectivo" (Ayuso, 2010: 65). También Badaloni plantea que el universo de intereses de los maquinistas de inicios del siglo XX era vasto y trascendía lo meramente técnico, al analizar los libros de la Escuela Técnica de Rosario (Badaloni, 2010: 120). Ayuso, en su obra posterior dedicada a la red de escuelas técnicas de La Fraternidad también postula que el gremio se ocupó de establecer proyectos de formación "más allá de los saberes del oficio, alcanzando también la formación político gremial" (Ayuso, 2017: 144).

${ }^{208} \mathrm{EN}^{\circ} 5$.

${ }^{209} \mathrm{EN}^{\circ} 8$.

${ }^{210}$ Según Horowitz, los trabajadores ferroviarios de todo el país se distinguieron del resto de los trabajadores por los logros obtenidos por sus gremios más importantes (la Unión Ferroviaria y La Fraternidad), en etapas previas al peronismo. Por eso, algunos autores los han calificado como una "élite" dentro de la clase obrera. (Horowitz, 1985: 421).
} 
Esta "suerte" o "fuente de salvación" que significaba el ingreso al ferrocarril entre las décadas del cuarenta y cincuenta se asociaba, en primer lugar, con el salario, considerado a partir de dos aspectos: lo que cuantitativamente representaba para el consumo y la capacidad de previsión del futuro. En otras palabras, era un "buen sueldo" que, además, era "seguro". Para fundamentar el "buen ingreso" ferroviario, los trabajadores utilizan como recurso la comparación frente a otras actividades. Como De Giulio: “`Sabés lo que era ser ferroviario? Vos te imaginás mi hermano trabajaba en una tienda y ganaba 100 pesos por mes y yo ganaba al entrar 550". ${ }^{211}$ Rinaldi recuerda, por su parte, que recién ingresado percibía un sueldo superior al de su padre, quien era encargado de una usina eléctrica en Arribeños: "Mi padre, en ese tiempo, trabajaba en la usina y ganaba 120 pesos. Yo entré ganando más". ${ }^{212}$ Ferrari también compara con otras profesiones jerarquizadas por el nivel de ingreso:

\begin{abstract}
"En una oportunidad yo le decía a alguien que yo estaba muy bien. Y él me dijo: 'vos decís que ganabas buen sueldo, pero ¿a qué le llamás buen sueldo'. Mirá, yo ganaba a la par de un oficial militar. Como un teniente coronel. Muy superior a un gerente de banco. Nadie ganaba tanto como los ferroviarios." 213
\end{abstract}

Tornello también adiciona otra cualidad al sueldo ferroviario: la seguridad. "Siempre tuve miedo a enfermarme, que me pase algo. Y el sueldito en el ferrocarril lo tenía seguro, con eso me conformaba", expresa. ${ }^{214}$ Violante aclara en la misma línea: "Tampoco vaya a creer que el ferroviario era potentado. Se cobraba un poco más y era un sueldo seguro.”215

Algunos ferroviarios vinculan la mejora en el salario con las políticas del primer gobierno peronista. ${ }^{216}$ Como Rinaldi que asegura: "Después del 46, en la época de Perón los sueldos mejoraron". 217 O Marone, que ingresó en 1950:

\footnotetext{
${ }^{211} \mathrm{EN}^{\mathrm{o}} 11$

$212 \mathrm{EN}^{\circ} 3$.

$213 \mathrm{EN}^{\mathrm{o}} 4$

${ }^{214} \mathrm{EN}^{\mathrm{o}} 6$.

$215 \mathrm{EN}^{\circ} 8$

${ }^{216}$ Fiorito caracteriza al período 1946-58 por una elevación de los salarios en Argentina. La participación salarial en el producto en 1954 llegaría a un máximo del 48\%, a partir de la fuerte expansión industrial. No obstante, a partir de 1950 el alza de salarios habría quedado "rezagado nominalmente frente a los precios cuando los límites a la importación comenzaron a erosionar la capacidad adquisitiva de los trabajadores". Desde 1955 a 1959 , la participación salarial en el producto caería más de 10 puntos. "Sin embargo la resistencia salarial anclada en una muy fuerte organización gremial, mantendrá hasta el final de este período los intentos de recuperación de la capacidad de consumo real obtenida previamente" (Fiorito, 2015: 45-60). En un análisis temporalmente más extenso, Ferreres observa que desde 1910 a 1970 se incrementó paulatinamente el salario real de los obreros industriales, alcanzando su pico en los primeros años del setenta e iniciando a partir de él un proceso de declive (Ferreres, 2005: 9).

${ }^{217} \mathrm{EN}^{\mathrm{o}} 3$.
} 
“...si hablo de la época en que yo me transformé en empleado ferroviario, diría que la mejor época fue la primera, luego de la nacionalización. Porque yo pienso que es justo reconocer que por el peso que tenía gremialmente el servicio ferroviario, a través de la gran cantidad de gente que lo integraba, tuvo buenos ingresos. No era malo el ingreso de los ferroviarios. ${ }^{218}$

Esos ingresos buenos y seguros le significaban al trabajador un atributo positivo al momento de intentar formar una pareja. Una y otra vez se repiten los recuerdos, con cierta añoranza por el tiempo pasado, de la época en que "las chicas buscaban un ferroviario, no un doctor”. 219 "Había un comentario en aquella época. La madre le decía a la hija: ‘¿Es ferroviario? Bueno, entonces, sí"”, cuenta Valentín Martínez, entre risas. ${ }^{220}$ Dall'Occhio lo confirma: "las mamás que tenían hijas casaderas veían con muy buenos ojos que sus hijas se casaran con un ferroviario porque tenían un sueldo asegurado". ${ }^{221}$ De Giulio dice algo similar: "Vos tenías un viejo que tenía una hija y la hija se ponía de novia con un ferroviario y el viejo decía ‘ ¡hacelo entrar, hacelo entrar!"”.222 Dante Cruz, en tanto, hace la misma referencia pero para los conductores de locomotora: "Las chicas se ponían de novias con los fraternales. Porque tenían un buen sueldo".223

Algunos, como la esposa de Carlos Violante, también dan cuenta de un momento de cambio en el que la profesión ferroviaria había perdido el prestigio que tenía: "Antes, ser novia de un ferroviario era como ser de un médico, cuando tenía yo 18 años. Pero cuando yo me casé, a los 26, ya estaban todos tecleando, empezaba toda la bancarrota".224

\footnotetext{
${ }^{218} \mathrm{EN}^{\mathrm{o}} 14$. En contradicción con esta percepción hallada en los testimonios de mejora del poder adquisitivo durante el peronismo, Newland realiza un análisis de la evolución del salario (1939-56), por rubro, y sugiere que hubo sectores "beneficiados" y sectores "perjudicados". En este último grupo, de acuerdo a los datos que expone, se encuentran los empleados estatales, como los docentes y los ferroviarios. El autor señala que luego de la caída del poder adquisitivo entre 1939 y 1942 (por el inicio de la guerra), hubo una recuperación para los asalariados que solo benefició a un grupo, mayormente los del sector industrial textil y metalúrgico que denomina "beneficiados". En cambio, los salarios reales de los sectores "perjudicados" nunca alcanzaron los niveles previos a la contienda mundial (en la relación salario nominal-inflación). Al final del documento, añade algo con lo que, probablemente, intenta fundamentar esta percepción extendida de mejora durante el peronismo: "También cabe mencionar que la estimación de los salarios reales en el período no incluye beneficios no directamente remunerativos que percibieron los trabajadores, como beneficios laborales (vacaciones pagas, horas trabajadas), o jurídicos y sindicales. Tampoco otros elementos que pueden haber sido beneficiosos para los empleados como la expansión del sistema sanitario o educativo" (Newland, 2017: 98).

${ }^{219} \mathrm{EN}^{\mathrm{o}} 19$.

${ }^{220} \mathrm{EN}^{\circ} 20$

${ }^{221} \mathrm{EN}^{\circ} 15$.

${ }^{222} \mathrm{EN}^{\mathrm{o}} 11$.

${ }^{223} \mathrm{EN}^{\mathrm{o}} 13$.

${ }^{224}$ EN $^{\circ} 8$. Trinidad Picardo y Carlos Violante se casaron en 1961 momento en el cual, según expresa, los ferroviarios estaban "en bancarrota". En cambio, cuando los ferroviarios, según la testigo, eran aún "potentados",
} 
En suma, es notable la vinculación que los actores establecen entre los buenos ingresos y la formación de pareja, entre el cúmulo de relaciones posibles que podrían fijarse. Esto permite determinar que esta explicación, mantenida a lo largo del tiempo y repetida en el interior del colectivo, resultó válida para transmitir la preeminencia que tenía el ferroviario frente a otras profesiones. Quizás su eficacia discursiva pueda deberse a la evocación visual que propicia en quien la escucha, la cual, a partir de ella puede imaginar un cuadro completo de una época pasada en la que el ferroviario tenía un lugar prominente (luego, perdido) y en el que se establecían roles determinados para las y los jóvenes (ellas, a la espera de un buen partido con quien iniciar una nueva vida a partir del matrimonio; ellos, debiendo probar su solvencia), así como para sus progenitores (que aprobaban o no al novio). ${ }^{225}$ Además, esta vinculación reiterada en los relatos entre los buenos ingresos y la formación de pareja permite inferir que la constitución del matrimonio era una de las expectativas sociales de los jóvenes ferroviarios de la época, siendo parte del imaginario social de la época. Como plantea Baczko, los imaginarios sociales operan vigorosamente en las visiones de futuro, en las esperanzas y en los sueños colectivos, así como en los fantasmas y obsesiones de una sociedad (1999: 30).

También es posible advertir que dentro del imaginario social de la época figuraba como expectativa central la construcción de la casa propia, que sería, en la mayoría de los casos, el espacio de residencia de los miembros de la familia (el hogar familiar). ${ }^{226}$ "Gracias a la empresa logré tener mi casa, logré formar una familia”, comenta Marone. ${ }^{27}$ Tornello, por su parte, acuerda: "Esta casita es humilde, pero es muy difícil que hoy un obrero tenga la posibilidad de tener una. Y sin embargo yo la pude hacer, con esfuerzo, con trabajo, pero pude". ${ }^{228}$ "La recompensa que tuve fue esta casa, que la compré con lo que La Fraternidad me dio”, comenta Cruz. En tanto, Rinaldi confirma:

"El sueño del ferroviario era el de tener su casa. Eso es una cosa que era común. Los ferroviarios acá, casi todos, jeran dueños de sus casas! Muchos también lo lograban porque

era el año 1953, cuando ella tenía 18 años.

${ }^{225}$ De acuerdo a Baczko, a través de los imaginarios sociales las colectividades humanas marcan la distribución de los papeles y las posiciones sociales, además de expresar e imponer ciertas creencias comunes. "Así es producida una representación totalizante de la sociedad como un orden, según el cual cada elemento tiene su lugar su identidad y su razón de ser" (Baczko, 1999: 28).

${ }^{226}$ Horowitz sostiene que en la década del cuarenta una de las diferencias de los ferroviarios del resto de los obreros argentinos era la caja de jubilaciones. "Solo unas pocas industrias, políticamente importantes, contaban con esas cajas en el país", dice el autor. Una de sus iniciativas fue la creación del Hogar Ferroviario, entidad que otorgaba préstamos para la construcción o adquisición de viviendas. "En diciembre de 1941, ya se habían otorgado 15.201 préstamos de esta índole (...) A pesar de sus limitaciones, este programa permitió contar con casa propia a muchos ferroviarios que sin esta ayuda no habrían podido tenerla" (Horowitz, 1985: 432).

${ }^{227} \mathrm{EN}^{\circ} 14$.

${ }^{228} \mathrm{EN}^{\circ} 6$. 
tenían la colaboración de compañeros, que eran pintores, que eran carpinteros, que eran albañiles, electricistas. Cosa que en otros gremios no. Mi padre nunca pudo tener su casa. Nunca tuvo un sueldo que le permitiera ahorrar y tenerla." ${ }^{229}$

De esta manera, los ferroviarios establecen un vínculo directo entre la pertenencia a la empresa y el logro de dos de sus sueños, la casa y el hogar familiar, lo que permite inferir que estas expectativas compartidas que, al mismo tiempo, estaban íntimamente entrelazadas, eran también parte del imaginario de la época.

Otro de los recursos que los ferroviarios emplean para fundamentar sus buenos ingresos ferroviarios atañe a la posibilidad de adquirir una cantidad determinada de trajes al año. De Giulio, tornero, comenta: "Me acuerdo que cada traje valía 60 y yo ganaba 500. Entonces me hice tres, uno de cada color. ¡Andá a hacerte tres trajes ahora!”. ${ }^{230}$ Martínez, carpintero, recuerda las posibilidades que le brindaban los ingresos ferroviarios en su juventud: "En ese tiempo tenía cuatro trajes en el año. Al baile entrabas con corbata y todo, y si no, no entrabas". ${ }^{231}$ Marone, por su parte, expresa: "Yo, si quería comprarme dos o tres trajes juntos me los compraba. Es decir, tenía un buen pasar...". ${ }^{232}$ Ferrari, en el mismo sentido, vincula la posibilidad de compra de este tipo de indumentaria con el "buen ingreso" ferroviario: Yo me acuerdo que todos los años me compraba traje, corbata, zapatos, todo completo. ¡Todo completo! Y eso era porque uno estaba bien económicamente". ${ }^{233}$

Puede señalarse que este tipo de vestimenta, confeccionada a medida por un sastre, se usaba en ocasiones sociales en las que se acostumbraba vestir de manera elegante. Se contraponía con la vestimenta laboral que los operarios empleaban en el taller cotidianamente, diferenciando, a su vez, un tiempo de ocio y un tiempo de trabajo. Quienes tenían ocasiones de vestir, en más oportunidades, de esta manera, debían contar con más variedad de trajes y gozaban, además, de más privilegios sociales, ya que podían disfrutar de una mayor cantidad de tiempo libre, antes que de trabajo. En otras palabras, la cantidad de tiempo de ocio de una persona era directamente proporcional a su estatus social. Por lo tanto, resulta natural que la cantidad de trajes que una persona poseía se presente, en el caso de los testigos, como un símbolo de distinción. A partir de este signo los trabajadores del riel, entonces, fundamentan su preeminencia frente al resto de empleados de otros rubros.

\footnotetext{
${ }^{229} \mathrm{EN}^{\circ} 3$.

${ }^{230} \mathrm{EN}^{\mathrm{o}} 11$.

${ }^{231} \mathrm{EN}^{\circ} 20$.

$232 \mathrm{EN}^{\circ} 14$

${ }^{233} \mathrm{EN}^{\circ} 4$.
} 
Muchas veces, esa elegancia en el vestir, no solamente involucraba el tiempo de ocio, sino también el de trabajo. Dimarco ilustra: "Ganábamos bien. El peón iba a trabajar al ferrocarril con zapatos de gamuza en la época de Perón” y uno de los fraternales coincide: "Los conductores andaban de traje vestidos. Un chiche". ${ }^{234}$ De esta forma, a través de estas evocaciones sobre aquel trabajador que lucía elegante, con ropa de calidad y onerosa, no solo en tiempo de ocio sino en el del trabajo, se intenta reforzar las representaciones de un trabajador ferroviario como un empleado privilegiado.

Otro de los ejemplos que brindan los ferroviarios para fundamentar los salarios "buenos y seguros" se vincula con la capacidad de actuar como garantes, por el solo hecho de trabajar en la empresa. De Giulio exclama: “¡Ser ferroviario era lo mejor que había! Salíamos de garantías en los bancos, en cualquier lado... Siendo ferroviario bastaba." ${ }^{235}$ Ferrari acuerda: "Cualquier ferroviario podía salir de garantía, porque trabajaba en el ferrocarril". ${ }^{236}$ La solvencia del ferroviario también era verificada, en la misma línea, por la capacidad de obtener créditos en los comercios. Violante comenta: "En la juventud, por ahí íbamos a un baile o comer afuera, y pagábamos a fin de mes". ${ }^{237}$ Ferrari también rememora con nostalgia: "Era una belleza, en el sentido de que la gente, como ganaba bien, consumía muchas cosas. Yo me acuerdo que los ferroviarios tenían preferencia. En cualquier negocio te daban crédito, enseguida". 238

Una de las memorias más extendidas en el colectivo ferroviario que intentan demostrar la capacidad de consumo de este tipo de trabajadores y la importante influencia que tenía la empresa en la economía de la ciudad es la que refiere a los legendarios "días 7" de cada mes. ${ }^{239}$ "Cuando cobraba el ferrocarril acá en Junín, los comercios hacían una fiesta", cuenta Calderoni. Rinaldi también relaciona la alegría en la ciudad con ese día particular: "El día 7 se cobraba, era el día de pago. Y casi todo el mundo andaba con libreta en esa época, del carnicero, del panadero, del almacén. Era, no digo de fiesta, pero era un día muy bien recibido por la comunidad". Poch también refiere al dinamismo y vitalidad que se percibía en ese día

\footnotetext{
${ }^{234} \mathrm{EN}^{\mathrm{o}} 16$ y EN $\mathrm{EN}^{\mathrm{o}} 12$, respectivamente.

${ }^{235} \mathrm{EN}^{\circ} 11$.

${ }^{236} \mathrm{EN}^{\circ} 4$.

${ }^{237} \mathrm{EN}^{\circ} 8$.

${ }^{238} \mathrm{EN}^{\circ} 4$.

239 Halbwachs introduce el concepto de "marcos sociales de la memoria", los cuales permiten orientar los recuerdos individuales. Este concepto permite entender por qué un colectivo humano recuerda ciertos acontecimientos (como, en este caso, los días 7, pero también la cantidad de trajes que podían comprarse) y no otros (Halbwachs 2004: 36).
} 
particular: "En Junín el día 7 cobrábamos todos. Había un movimiento acá... El comercio, ¡cómo vendía! La gente iba a pagar todos los meses, como se hacía antes, con la libreta". ${ }^{240}$

Dall'Occhio también recuerda a los míticos días 7 y el gasto que los ferroviarios destinaban a s comercios de la ciudad:

\begin{abstract}
"El día 7, que se cobraba, todo ese dinero que llegaba a Junín se gastaba en Junín. No había supermercados cuyo dinero fuera afuera de la ciudad, sino que todo el dinero quedaba en la ciudad de Junín. Y vos veías que el comercio se movía en los días subsiguientes. Después había como una meseta hasta el nuevo 7."241
\end{abstract}

La influencia que el ferrocarril tenía en la economía de la ciudad es fundamentada a partir de la cantidad de empleados que la empresa tenía y que le habían permitido constituirse en la fuente de trabajo más importante de Junín. ${ }^{242}$ Como plantea Violante:

\begin{abstract}
“Acá llegó a haber hasta cinco mil, o cuatro mil personas que siempre cobraban buenos sueldos. Todo se volcaba y la plata quedaba acá ¡Era mucha plata! Antes vendían todos, los bares abiertos, diez o quince comercios en una cuadra que trabajaban todos. Los sastres, también". ${ }^{243}$
\end{abstract}

Resulta recurrente, además, la relación establecida entre la capacidad de consumo y la felicidad de los trabajadores. ${ }^{244}$ Bozzini lo describe de una manera muy expresiva:

\footnotetext{
${ }^{240}$ En orden de aparición: $\mathrm{EN}^{\circ} 19, \mathrm{EN}^{\circ} 3, \mathrm{EN}^{\circ} 1$.

${ }^{241} \mathrm{EN}^{\circ} 15$.

${ }^{242}$ Pompei se refiere a esta creencia reiterada de los 5000 ferroviarios, cuando, en rigor, el número máximo de personal empleado en los talleres de Junín fue de 3473 agentes en 1926 y de 3236 en 1958. "Es posible leer en diferentes informes, y está fuertemente arraigada en el imaginario popular, la idea de que llegó a ocupar unas 5.000 personas en su época de mayor esplendor..." (Proyecto Ferro Urbanístico 1998: 19). Tal afirmación, si bien es errónea, surge de vincular equivocadamente dos datos ciertos. En la localidad de Junín llegó a haber alrededor de 5.000 empleados ferroviarios, pero no todos ellos trabajaban en los talleres". (Pompei, 2011: 38).

${ }^{243} \mathrm{EN}^{\circ} 8$.

${ }^{244}$ Cuestas y Vence Conti (2017) sostienen que una de las políticas económicas del peronismo fue la de aumentar el mercado interno a través del incremento del consumo. En un análisis de lo que sucedió en la empresa de ferrocarriles, los autores sostienen que entre 1943 y 1949 hubo un incremento más significativo de los salarios del personal no calificado, respecto del calificado. Esto habría implicado que dicho caudal de ingreso se vuelque, en mayor medida, al consumo, en contraposición con lo que habría sucedido con personal más calificado, con una mayor capacidad de ahorro. Hacia 1949 esta tendencia cambia, con el objeto de contener la inflación y estimular el ahorro: los incrementos salariales fueron menores, relativamente, en el personal no calificado respecto del calificado. Así, se incrementó la brecha por calificación. Entre 1949 y 1951 las medidas fueron restrictivas respecto de los posibles incrementos salariales. "Se habían acabado los 'años felices' o 'la fiesta peronista", planteó el autor. A partir de 1951 se observó un estancamiento de los salarios reales y el aumento de la brecha por calificación, debido a una caída en la inflación.
} 
"En el día de pago el centro de Junín estaba lleno. ¿Por qué estaba lleno? Porque había plata de muchos ferroviarios. Y el trabajador, ¿qué hace con la plata? La tiene que gastar. Y había alegría porque había trabajo. El que tiene trabajo y cobra su sueldo tiene alegría. El que no tiene trabajo, ¿qué alegría puede tener? Tiene tristeza. Eso también nos ha pasado a nosotros". ${ }^{245}$

Puede inferirse que esta asociación entre buenos sueldos ferroviarios, por un lado, y la alegría (en los trabajadores) o la fiesta (en la ciudad) habrían abonado para construir una representación sobre el empleo ferroviario como prestigiado en la ciudad. "En ese tiempo entrar al ferrocarril era un honor", asegura Bozzini, y Crocco adhiere: "Ser ferroviario era un empleo preponderante, bien remunerado, bien visto". ${ }^{246}$ Sólo en menor medida aparecen otras vinculaciones, como en caso de Crocco que relaciona, además, el prestigio de ser ferroviario con el interés de los integrantes del colectivo por el conocimiento o la participación en proyectos sociales: ${ }^{247}$

"Era una posibilidad alentadora y bien vista en Junín el ser ferroviario o trabajar en los talleres. Cuando entré había oficiales con los cuales trabajé como aprendiz de muy buen nivel cultural. Eran asiduos concurrentes a bibliotecas, clubes... Era un plantel de gente muy bien conceptuada. Al entrar y ponerme en trato con ellos, hizo que me llenara totalmente mi idea de seguir siendo ferroviario." 248

A esta altura es posible preguntarse si el prestigio de la profesión ferroviaria de la ciudad y la identificación de los trabajadores se explica, en mayor medida, por la capacidad de consumo que demostraban estos trabajadores, o bien, si existían otros factores, como los aludidos antes por Crocco sobre el cultivo de capacidades intelectuales, que incidían en aquel imaginario que asociaba a los ferroviarios con trabajadores distinguidos. Rinaldi, de manera tajante y risueña, vincula esta preeminencia del trabajador frente al resto, directamente, con su ingreso y su capacidad de consumo:

\footnotetext{
$245 \mathrm{EN}^{\circ} 17$.

${ }^{246} \mathrm{EN}^{\mathrm{o}} 17$ y $\mathrm{EN}^{\circ} 2$.

${ }^{247}$ De acuerdo a Horowitz los gremios ferroviarios habrían tenido un rol crucial en el fomento de la educación entre los trabajadores: "El mejoramiento de la capacidad intelectual y técnica de los trabajadores era una inquietud primordial de los dos sindicatos ferroviarios". Por ello apoyaron desde la década del veinte la creación de bibliotecas y escuelas en todo el país, no solo para mejorar el conocimiento técnico sino para incrementar sus conocimientos en general, desde una perspectiva ilustrada (Horowitz, 1985: 439).

${ }^{248} \mathrm{EN}^{\mathrm{o}} 2$.
} 
ALS: ¿En un momento ser ferroviario era un honor?

ER: Sí, bueno, honor, honor, no sé. Era interesante por lo que ganaban (risas). ${ }^{249}$

Otra de las ventajas del trabajador ferroviario frente al resto se relaciona con los descuentos en pasajes, además de una cantidad de traslados gratuitos al año. "Había cuatros pasajes gratis al año. Y después se pagaba un 25 por ciento del valor del boleto. ¡Pagaba la cuarta parte del precio!", cuenta Rinaldi. Estas facilidades se relacionaban, también, con nuevas prácticas que se extendían dentro del colectivo de trabajadores: la posibilidad de vacacionar, a bajo costo, en hoteles gremiales. ${ }^{250}$ "Cuando había un casamiento, se le podía conseguir a los casados pasajes gratis. Se le daban diez días también en Alta Gracia, sin pagar nada. También, cuando tenías diez años de socio te podías ir diez días a la colonia Alta Gracia, gratis, con el pasaje ida y vuelta. Podías elegir entre Mar del Plata o Alta Gracia”, añade Poch.

Contar con servicios de salud de calidad era otra de las ventajas que los trabajadores ferroviarios mencionan, en comparación con el resto de los trabajadores. ${ }^{251}$ De Giulio, en relación al Hospital Ferroviario de Junín “Eva Perón”, inaugurado en 1949, ${ }^{252}$ comenta: "No había nada así ni acá ni en la república. Las maquinarias que había... ¡Cómo te atendían! Era una barbaridad". Mantino agrega:

\begin{abstract}
“Ese hospital lo hizo hacer (Juan Domingo) Perón y Eva Perón para los ferroviarios. Y era un hospital-escuela, en el que hacían residencia los mejores médicos de Junín. Mis tres hijas nacieron ahí. Fue uno de los mejores hospitales que tuvo la provincia, era un lujo. Venía la gente y se quedaba asombrada. Por el hospital pasaron los mejores médicos de Junín". 253
\end{abstract}

Así como estos trabajadores, que ingresaron entre las décadas del cuarenta y cincuenta, pudieron dar un salto cualitativo en su calidad de vida en relación a sus padres, gracias al estudio

\footnotetext{
${ }^{249} \mathrm{EN}^{\mathrm{o}} 24$.

${ }^{250}$ En 1939 se compraron los terrenos para construir el primer hotel gremial en Sierras de Córdoba, el cual fue inaugurado en 1942 "dotado de todas las comodidades y de una pileta de natación” (Horowitz, 1985: 441).

${ }^{251}$ Los gremios ferroviarios lograron crear el primer Policlínico Ferroviario de la ciudad de Buenos Aires en 1940. Previo a ello se realizó una campaña en todo el país, a través de un folleto explicativo con 160 mil ejemplares de tirada en el que se promocionaba los beneficios de la adhesión y se solicitaba la aceptación del descuento de un peso del salario del ferroviario (Cena, 2009: 105). Horowitz subraya la acogida que tuvo entre los trabajadores del riel, teniendo en cuenta la distancia de muchos ferroviarios de Buenos Aires, lugar donde estaba el primer y principal hospital: en 1941 ya habían adherido 24.358 afiliados y en 1943 más de 50.000 (Horowitz, 1985: 435).

${ }^{252}$ La piedra fundamental del Hospital Ferroviario fue colocada en 1944, cuando Juan Domingo Perón era vicepresidente. Su inauguración tuvo lugar en 1949. Un edificio que en 64 años pasó de policlínico a sede universitaria (16 de abril de 2018). Junínhistoria. Recuperado de http://juninhistoria.blogspot.com/2018/04/un-edificio-que-en-64-anos-paso-de.html

${ }^{253} \mathrm{EN}^{\circ} 17$
} 
técnico y nuevas condiciones en la empresa que favorecieron su progreso, en el mismo sentido apuntaron a que su descendencia los superara. Por eso, muchos apostaron a que sus hijos, cuando fueran adultos, estudiaran una carrera universitaria en ciudades donde había instituciones de educación superior, como La Plata, San Luis o Buenos Aires. Los ingresos permitían realizar este esfuerzo, algo que sus padres no pudieron hacer con ellos, ya que debieron, en muchos casos, cursar los estudios técnicos mientras trabajaban. Uno de los fraternales comenta:

"Yo planifiqué toda mi vida, desde que ingresé hasta que me iba a jubilar. Y me salió tal cual. Me casé, tuve dos hijos, quise que estudiaran, ninguno de los dos quiso estudiar y bueno, así seguí hasta mi último día de trabajo hasta que me jubilé. Estaba todo planificado para que mis dos hijos varones, si querían estudiar, pudieran hacerlo". ${ }^{254}$

Marone, en el mismo sentido, señala:

"Gracias a la empresa logré tener mi casa, formar una familia. Logré hacer de mis hijos cinco profesionales universitarios. Es decir, yo me brindé a la empresa y la empresa me brindó muchas posibilidades, de armar mi vida, mi estructura familiar. La posibilidad de hacer estudiar a mis hijos la tuve a través de lo que el ferrocarril me brindó como ingreso". 255

Crocco, por su parte, también corrobora esta confianza en la educación como determinante para el progreso social:

"Me atrapó totalmente esa carrera, a la cual le agradezco que me dio posibilidad económicamente que pudiera hacer estudiar a mis dos hijos una carrera universitaria y tener un humilde hogar, como ves que tengo". 256

Puede advertirse, entonces, que, aproximadamente, veinte años después a que ellos ingresaran, cuando su descendencia estuvo en edad de estudiar (a fines de la década del sesenta e inicios del setenta), los trabajadores evaluaron posibilidades superadoras de progreso social para sus hijos, quienes pudieron llegar a ser, en muchos casos, profesionales que brindaban servicios (como médicos, abogados, psicólogos, contadores, arquitectos, por mencionar algunas de las actividades que ellos refieren), en lugar de empleados en la industria (como la

\footnotetext{
${ }^{254} \mathrm{EN}^{\circ} 12$.

${ }^{255} \mathrm{EN}^{\circ} 22$.

${ }^{256} \mathrm{EN}^{\circ} 2$.
} 
ferroviaria). En el mismo sentido, el ferrocarril ya había dejado de ser la fuente de trabajo más codiciada que había en la ciudad: difícilmente, quien ingresara al ferrocarril en 1970 iba a considerar que eso había sido "ganar la lotería”, como sí lo habían interpretado sus colegas más antiguos. 
Capítulo 2

Ser ferroviario 


\section{La identidad ferroviaria}

Los testimonios recuperados sobre la experiencia de los actores en relación al ferrocarril en Junín permiten afirmar que existió una profunda ligazón afectiva con la empresa, la cual probablemente, se reforzó con la pérdida ocurrida en los noventa, cuando muchos de estos trabajadores fueron expulsados a través de un plan de jubilaciones anticipadas. ${ }^{257}$ De esta manera, a ese sentimiento de amor se le añadió otro de nostalgia por aquel pasado que canceló abruptamente una continuidad de generaciones ferroviarias en la que padres, hijos, abuelos habían sido parte. ${ }^{258}$ El testimonio de Bozzini exhibe un sentimiento de amor, al mismo tiempo que de dolor, hacia lo que la empresa representaba para este trabajador:

"Al ferrocarril lo quise, lo quiero, y lo voy a seguir queriendo. Porque en aquel tiempo entrar al ferrocarril era un honor (...) Yo al ferrocarril lo sigo amando, pero es imposible volver. Desgraciadamente el ferrocarril se terminó como era en ese tiempo."259

Marone, quien, a diferencia de Bozzini, llegó a tener el puesto más alto del ferrocarril en Junín, lo expresa, no obstante, en términos muy similares a los del pintor de Vía y Obras, ligando — como aquel— el "amor eterno" hacia la empresa, con el dolor: "Al ferrocarril lo quise, lo quiero y lo seguiré queriendo. Y me da lástima lo que ocurrió, mucha pena...".260 Rinaldi, por su parte, asegura:

"Lo que teníamos en común los ferroviarios era el amor por el ferrocarril, el amor por la fuente de trabajo. Porque todo el mundo se queja del patrón o de la actividad que desarrolla. El ferroviario no se queja. Al contrario. La valora y lamenta mucho no haber podido hacer algo para que esta fuente siguiera, porque no dependía del ferroviario, ni de la jefatura..."261

257 Durante el primer gobierno de Carlos Menem (1989-1995) se llevó adelante un plan de jubilaciones anticipadas, retiros voluntarios y despidos que, de acuerdo a Cena, disminuyó dramáticamente el personal de la empresa Ferrocarriles Argentinos en todo el país: de 87.000 agentes en 1991 pasó a contar con 3.000 en 1993 (Cena, 2008: 157).

${ }^{258}$ Marone, con un padre y hermanos mayores ferroviarios, lo manifiesta de esta manera al finalizar el encuentro: "La decepción que uno sufre es porque, ¡caramba! Mi generación fue la que cerró los ferrocarriles. Yo llegué al puesto máximo y cuando llegué ¡el ferrocarril se cerró! No los cerré yo, los cerró la política, los intereses que trascienden lo que puede hacer uno, por más afecto que uno le tenga a la empresa. Así que yo como palabra final te podría decir eso, que soy un integrante de la generación que cerró a los ferrocarriles. La culpa la tengo yo" $\left(\mathrm{EN}^{\mathrm{o}} 14\right)$.

${ }^{259} \mathrm{EN}^{\circ} 17$.

${ }^{260} \mathrm{EN}^{\circ} 14$.

${ }^{261} \mathrm{EN}^{\circ} 3$. 
A diferencia de sus compañeros, el profundo dolor de Calderoni le impide expresar algún tipo de sentimiento hacia la empresa: "Yo no siento nada por el ferrocarril porque ya no existe. Hay una cooperativa que repara coches, pero no es lo mismo que lo que había". ${ }^{262}$ Esa supuesta ausencia de sentimiento parece revelar, en el caso de Calderoni, lo contrario a lo que enuncia: la pérdida del objeto de amor/identificación (los ferrocarriles) habría dejado un sentimiento "huérfano" que, en ese contexto, el actor decide extirpar.

En general, en los ferroviarios esta ligazón afectiva hacia lo que la empresa simbolizaba es explicada y fundamentada por la seguridad que significaba un puesto en el ferrocarril, así como la oportunidad de ascenso social, en contraposición a otras empresas en los que el futuro podía ser más incierto y el progreso más esquivo o dificultoso. Ferrari afirma: "Todos querían al ferrocarril, porque ese era el medio de vida". ${ }^{263}$ Marone se explaya y vincula a la empresa, no solo con la historia de vida (personal, familiar), sino también con las expectativas (cumplidas) de lograr una vida mejor:

\begin{abstract}
"Uno quiso a la empresa porque la veía, la tenía ahí en frente, sabía cómo se manejaba, cómo eran las estructuras, qué posibilidades tenían los ferroviarios de progresar. Entonces, la fue viendo como una fuente de trabajo importante. Y la pensó como una fuente de trabajo para toda la vida. Si vos tenés esas expectativas, lo primero que hacés es querer a la empresa. A través del tiempo, y a través de los distintos lugares por los que fue pasando, y a través del progreso que uno pudo ir teniendo dentro, la fue queriendo. Era parte de la vida de uno". 264
\end{abstract}

Crocco, por su parte, va más allá del amor y expresa ese sentimiento a partir de una entrega hacia la organización que le permitió crecer y desarrollarse, en congruencia con aquella búsqueda personal, manifestada en el capítulo anterior, de ser parte de un colectivo comprendido por personas de "buen nivel cultural":

“Tuve una total devoción y me sentí atraído por una empresa en la cual uno podía desarrollar todos tus conocimientos, capacidades, en lo que hace a sus estructuras, sistemas de trabajo. Podías desarrollar todas las técnicas más modernas que podías obtener de los distintos libros."

\footnotetext{
${ }^{262} \mathrm{EN}^{\circ} 19$. La Cooperativa de Trabajo de Talleres Junín (COOTTAJ) a la que alude Calderoni se fundó el 12 de agosto de 1993, de acuerdo al Acta Constitutiva en la que participaron 24 trabajadores de los talleres ferroviarios de Junín reunidos en Asamblea. El inicio formal de actividades económicas tuvo lugar el 3 de enero de 1994, luego del cierre formal de los talleres, ocurrido el 31 de diciembre de 1993. Pompei, 2011: 76.

${ }^{263} \mathrm{EN}^{\circ} 4$.

${ }^{264} \mathrm{EN}^{\circ} 14$.
} 
Rinaldi también expresa ese vínculo afectivo con la empresa, a partir de la posibilidad de aprender y desarrollar nuevas capacidades:

"El cariño por el ferrocarril lo logré a través de ver lo que se hacía, de cómo se trabajaba y en cierto modo un poco me gustaba el diseño o la programación de los ingleses de buena limpieza, ordenamiento, buena organización, buena administración. Y como yo seguí estudiando, eso me interesaba sobremanera." ${ }^{265}$

Puede afirmarse, además, que la identificación de los trabajadores en tanto ferroviarios se relacionaba con la tarea específica desarrollada, es decir, la experiencia concreta y cotidiana del trabajador con la empresa. Valentín Martínez, por ejemplo, dice: “para mí era una bendición trabajar en el ferrocarril porque era el oficio mío, carpintero". Tornello, además, contrapone los recuerdos de aquel pasado de esplendor con el dolor que representa el presente, lamentándose: "Yo empecé en Chapas. Ese trabajo lo hacíamos nosotros, producíamos todo lo que sea chapas, los asientos... todos lo hacíamos nosotros. Ahora las ventanas no cierran...".266

Bozzini, como el resto, se identifica con su rol en el ferrocarril y, en algún sentido, califica al "verdadero ferroviario" como aquel que había ingresado en su área, Vía y Obras, como si este Departamento pusiera a prueba al ferroviario y el afecto que decía sentir:

"Para querer al ferrocarril, yo pienso, había que ingresar al departamento de Vía y Obras.

Porque una cosa es estar bajo techo, o en una oficina, y otra cosa es estar al rayo del sol o con rigurosos fríos en invierno." 267

Inversamente al testimonio anterior, Dimarco se distingue de los ferroviarios que debían apelar a su capacidad y resistencia física para desarrollar sus tareas cotidianas (como Bozzini). "Yo no puedo decir muchas cosas, primero porque yo no trabajaba en una máquina, sino que trabajaba en una oficina. Trabajar en una máquina del taller, era prácticamente estar al aire libre", expresa, marcando de esta manera una diferencia entre el personal que trabajaba en la oficina, al resguardado de las inclemencias climáticas, y el resto. ${ }^{268}$

Puede advertirse, entonces, que la identificación hacia el ferrocarril es expresada por los trabajadores a partir de la tarea específica desarrollada, oponiéndola, en muchos casos, con

\footnotetext{
$265 \mathrm{EN}^{\mathrm{o}} 3$.

${ }^{266} \mathrm{EN}^{\circ} 20$ y ENº.

${ }^{267} \mathrm{EN}^{\mathrm{o}} 17$.

${ }^{268} \mathrm{EN}^{\mathrm{o}} 16$.
} 
otros roles en la empresa. Resulta oportuno preguntarse, entonces, por qué es posible referirse, además, a una identidad ferroviaria común, tal como los testimonios del inicio del apartado parecen sugerir cuando revelan, de manera similar, el amor o cariño hacia el mismo objeto: el ferrocarril. Stuart Hall sostiene, precisamente, en contraposición a la concepción estática y homogénea sobre la identidad, que es un proceso nunca terminado, que se construye a partir de discursos, prácticas y posiciones, a menudo cruzadas y antagónicas. Esta identidad, una vez consolidada, no cancela la diferencia: "La fusión total que sugiere es, en realidad, una fantasía de incorporación. La identificación es, entonces, un proceso de articulación, una sutura, una sobredeterminación y no una subsunción" (Hall, 2003: 15). De esta manera, puede considerarse que la identificación ferroviaria ha sido un proceso complejo, el cual se construyó y articuló a partir de roles diversos que, incluso, oponían sus tareas a los otros: quien trabajaba en la oficina respecto del que trabajaba en el taller, quien tenía roles directivos frente a los que trabajaban en oficios y tareas prácticas, quien trabajaba en un área frente a otras, quien era jefe frente a sus subalternos, quienes planificaban frente a quienes empleaban la fuerza para el desarrollo de sus tareas.

Hall también postula que el proceso de identificación precisa, constantemente, marcar y ratificar sus límites simbólicos, es decir, producir lo que denomina "efectos de frontera": "Necesita lo que queda afuera, su exterior constitutivo, para consolidar el proceso" (Hall, 2003: 16). Desde esta perspectiva, puede observarse que, en algunos momentos, el relato exhibe una identificación hacia la tarea tan profunda que parece hacer peligrar la identificación hacia el ferrocarril, ya que ese "afuera constitutivo" lo conforman otros ferroviarios. Un ejemplo extremo lo muestran los maquinistas de locomotoras, agrupados en el gremio La Fraternidad, cuando plantean: "Nosotros nos referimos a nosotros, los fraternales, no sabemos lo que pasaba en Talleres. Ellos con su manera de vivir y nosotros con la nuestra". En otros momentos, en cambio, el "afuera constitutivo" está comprendido por trabajadores de otras profesiones o actividades. Martínez, por ejemplo, recupera un recuerdo de unidad cuando se intenta defender de los discursos de otros: "Muchos decían que los ferroviarios eran vagos, pero era mentira. Porque llegaban veinticinco coches y había que arreglarlos." 269 Rinaldi también se refiere a aquellos "otros" (comerciantes, empleados pertenecientes a otros gremios), que calificaban a los ferroviarios de vagos:

"Era el comentario de gente que estaba afuera que, por envidia, hablaba mal del ferroviario. Y el ferroviario alimentó a muchas familias de comerciantes, por ejemplo,

${ }^{269} \mathrm{EN}^{\circ} 12$ y EN 20. 
durante muchos años, a través de sus ingresos y con el consumo. El ferroviario tenía pase anual para toda la familia y la orden de rebaja del $75 \%$ de descuento en pasajes. Bueno, en otros gremios esos beneficios no los tenían, y aparentemente, les ha dolido. Entonces, no eran de hablar favorablemente del ferroviario. Como esos beneficios no estaban... calculo que ese ha sido el motivo de no defender al ferrocarril ante el desmejoramiento de la actividad." 270

Los fraternales también remiten a este tipo de discursos que asociaban a los ferroviarios con el calificativo de "vagos". Aunque a lo largo de la entrevista ellos se refieren a sí mismos como fraternales, por primera vez se autoidentifican como ferroviarios para presentar su desacuerdo frente a estos discursos externos que aludían, también, a la tarea de la conducción: "La gente no entendía cuando decía que los ferroviarios eran vagos y no querían trabajar, que los habían dejado tirado en tal lugar. El personal cumplía sus horas de trabajo y si llegaba a trabajar de más, era castigado dentro de la sección”, a lo cual otro conductor de locomotora, en esa entrevista grupal, añade: "El castigo tenía un porqué. Si yo trabajaba una hora más o media hora más, le estaba privando a otro compañero de que trabaje". ${ }^{271}$

Puede observarse, entonces, que ese "afuera constitutivo" ha sido el encargado de producir, en cada instancia del discurso, la identidad, la cual quedaba condicionada por la referencia a esos otros. Al mismo tiempo, puede advertirse que la identificación de los actores funcionó de manera múltiple, estando constituida por varios sustratos identitarios, los cuales podían ser empleados por los trabajadores de acuerdo a las necesidades discursivas de cada momento. $^{272}$

Por otra parte, es posible hallar en los relatos toda una serie de evocaciones vinculadas al placer del trabajo cotidiano y a la satisfacción por el aprendizaje o los logros alcanzados en la tarea, que refuerzan la ligazón afectiva hacia lo que el ferrocarril representaba para estos trabajadores. Un ejemplo del primer tipo lo constituye el testimonio de Bruno Danielle, quien rememora sensaciones y experiencias de aquellos años juveniles en los que el trabajo sacrificado, contemplaba momentos reconfortantes con sus pares una vez que la tarea había sido cumplida:

${ }^{272}$ Sobre el tema de las identidades, Bazcko plantea que es a través de los imaginarios sociales que una colectividad designa su identidad, elaborando distintas representaciones de sí misma: "Designar su identidad colectiva es, por consiguiente, marcar su 'territorio' y las fronteras de este, definir sus relaciones con los 'otros', formar imágenes de amigos y enemigos, de rivales y aliados; del mismo modo, significa conservar y modelar los recuerdos pasados, así como proyectar hacia el futuro sus temores y esperanzas" (Baczko, 1991: 28).
} 
“Cuando empecé como changarín del Departamento en Chacabuco, asistíamos a la locomotora a vapor, le dábamos agua, arena, aceite y grasa, cuando pedían desde las estaciones. Era un lindo recuerdo, de dos de la tarde a las diez de la noche. Asistíamos a trenes importantes, como el Internacional y otros más de carga. En Junín, comencé como ayudante de Vía y Obras. Recorría la vía, acompañaba. Era la práctica, trato directo con la vía... Si habremos hecho viajes en autovía. Muchos viajes los hacíamos en la zorrita abierta, con sol o lluvia. Anotábamos las deficiencias en puentes y alcantarillas para corregirlas (...). Más adelante yo estaba a cargo de una cuadrilla. Había días que eran suaves, de recorrido. Y había otros que eran de trabajo arduo, porque había algún descarrilamiento, pero lo hacía uno con gusto, con ganas. El compartir, el mate cocido a la tarde con los peones, ir a comprar galletas, azúcar. A la tarde, era un ratito, cinco o diez minutos. A veces lo preparaba yo mismo. Otras veces era la carne, el asado. Y muchos traían la comida preparada de la casa. Era una hora para comer, y muchos comían en media hora y se acostaban un rato. Trabajábamos codo a codo, era duro, y no había problema". 273

En el caso de los conductores de locomotora, también vinculan la experiencia cotidiana de trabajo, con un sentimiento placentero de libertad. Uno de ellos comenta: "Si yo volviera a nacer y el ferrocarril estuviera como en aquella época, haría lo mismo. Era una vida muy independiente, nadie te mandaba". Otro fraternal asiente y añade:

"Está bien, son momentos difíciles porque uno se pierde el nacimiento de un hijo, se pierde una reunión familiar para fin de año, porque te toca estar afuera. Pero nos subimos a la máquina y somos libres: cumpliendo el horario, mandamos nosotros. No así en un taller que estás rodeado de capataces, jefes. Está bien, uno tiene que comer arriba de la máquina, por ejemplo. Medio vida de gitano, pero extraordinario."274

Por otra parte, es posible hallar testimonios que exhiben satisfacción por los logros alcanzados en el desempeño de la tarea. En algunos casos también parecen manifestar admiración por las maquinarias y tecnología del taller, así como orgullo por el carácter arrojado del ferroviario, que era capaz de poner en riesgo su cuerpo para llevar adelante su tarea. Ferrari rememora:

\footnotetext{
${ }^{273}$ Entrevista No27 a Bruno Danielle, Junín, 05/08/2011, en adelante EN²7.

${ }^{274} \mathrm{EN}^{\circ} 12$.
} 
“Sabés lo que era trabajar en una locomotora a vapor! Todos se asombraban cuando venían a hacer las visitas de la escuela, porque nosotros estábamos trabajando en la fosa. En 100 metros, 6 o 7 fosas, o más. Y nosotros estábamos ahí debajo de la locomotora a vapor. Había dos grúas puentes, de cincuenta toneladas cada una. O sea que levantaban la locomotora y la cambiaban de vía. Y vos estabas trabajando y era una cosa común que pasaran las locomotoras por arriba. Era una cosa impresionante."275

Danielle dice algo similar:

"Yo trabajé en el descarrilo, trabajando a la par de los peones para darle ánimo, meterme debajo de los vagones que la grúa levantaba para poder armar los rieles. Para incentivarlos... A veces no querían meterse porque decían: ‘¿Y si se corta el cable?’. Entonces yo decía, yo me voy a meter. Y cuando yo me animaba, se animaban otros."276

\section{Y Calderoni:}

"Yo estaba en todo. Me metía en las calderas. La caldera tiene la caja de fuego atrás, donde se hace el fuego, y la caja de humo adelante, con la locomotora. Tiene tubos que van de atrás adelante. Entonces yo me metía adentro de la caja de fuego cuando la reparaban, a soldar los tubos. Había que soldar los tubos en la placa para que después cuando hicieran fuego, el fuego calentara los tubos y evaporara el agua que estaba alrededor de los tubos y se producía vapor para que la máquina caminara. Entonces esa es una parte bastante embromada porque yo estaba soldando ahí y tenía que taparme los oídos. Tuve suerte porque después de eso pasé a la oficina. La parte administrativa.”277

Estos relatos permiten afirmar que en el imaginario existía una fuerte asociación entre una cualidad como el coraje, por la cual el trabajador debía arriesgar el cuerpo propio, y lo que el "buen ferroviario" debía ser. ${ }^{278}$ Así y todo, tal como manifesta Calderoni en el extracto anterior, la expectativa era que esa demostración de arrojo quedara limitada a un momento de la vida, la juventud y los inicios de la carrera, en función de que lo que se esperaba del "buen

\footnotetext{
${ }^{275} \mathrm{EN}^{\mathrm{o}} 4$.

${ }^{276} \mathrm{EN}^{\circ} 27$.

$277 \mathrm{EN}^{\circ} 19$.

278 Baczko se refiere a que los imaginarios sociales, precisamente, marca la distribución de los papeles y las posiciones sociales: “... expresa e impone ciertas creencias comunes, fijando especialmente modelos formadores como el del 'jefe', el del buen 'súbdito', el del 'valiente guerrero', el del 'ciudadano', el del 'militante', etcétera. Así es producida una representación totalizante de la sociedad como un 'orden', según el cual cada elemento tiene su lugar su identidad y su razón de ser" (Baczko, 1999: 28).
} 
ferroviario": que progrese en su carrera. Precisamente, uno de los signos del progreso era el abandono de tareas que empleaban como principal recurso al cuerpo.

Por otra parte, otros testigos también exhiben un sentimiento de orgullo por el cumplimento de su tarea y el desarrollo de habilidades concretas que no necesariamente implicaban riesgos para la vida o la salud, fortaleciendo de esta manera su identificación con el rol dentro del ferrocarril. Tal es el caso de Poch, empleado de la oficina contable: "Estábamos todo el año trabajando, porque teníamos que hacer la boleta de pago, como corresponde a cada uno. Es un trabajo que no se aprende así nomás. Yo me preocupé y fui aprendiendo.”279 $\mathrm{O}$ Violante que exhibe esa admiración por la técnica y la satisfacción por haber logrado aprendizajes a partir del intento de resolución de problemas concretos en el ferrocarril:

"Cuando fui a la sección de alumbrado de trenes teníamos unos dinamos del tiempo de los ingleses que ya no andaban más. Y las fuimos haciendo andar porque no había nuevos. Hasta que ya vinieron los coches holandeses, con otro tipo de generadores eléctricos, de mucha más calidad, más sencillos para el trabajo y de mayor productividad también. Los que usábamos nosotros eran bujes de bronce con un eje de una pulgada, el bronce se gastaba y el servicio no entraba en reparación, y se gastaban todas las bobinas, era un desperdicio. Después nos tuvimos que amoldar a lo otro. Vinieron los coches japoneses que era una tecnología más sofisticada todavía, con un sistema a veces muy complicado que acá había que modificar muchas cosas para que anduvieran." 280

El orgullo personal respecto del rol que cada uno de estos ferroviarios tuvieron en la empresa también resulta evidente cuando detallan minuciosamente las tareas llevadas adelante y los aprendizajes que les demandaron. Este es el caso de Crocco:

"Yo tuve que hacer un plan de mantenimiento preventivo para todas las máquinas de talleres. Para eso tuve que hacer un curso en Buenos Aires. El mantenimiento preventivo es no esperar que la máquina se rompa, sino que se hace antes de que la máquina se descompusiera. Pero tenía que hacerse de una forma que no fuera ni cara ni barata. Por qué te digo esto. Porque si lo hacías muy seguido era muy caro y si lo hacías muy largo por ahí la máquina se te rompía. Tenía que estar al límite para que saliera justo. Así se mantenía las máquinas siempre en funcionamiento."281

\footnotetext{
${ }^{279} \mathrm{EN}^{\mathrm{o}} 1$.

${ }^{280} \mathrm{EN}^{\circ} 8$.

${ }^{281} \mathrm{EN}^{\circ} 2$.
} 
Y de Calderoni que, además, enfatiza las múltiples responsabilidades que tenía en la empresa:

"Yo tenía gente las veinticuatro horas, tal es así que me llamaban por teléfono cuando había un problema o algo. Yo estaba a cargo de Mantenimiento mecánico. Hacía todas las reparaciones mecánicas de las máquinas, de todo Talleres. Tenía a cargo la planta de oxígeno. Teníamos una planta modernísima. Teníamos la central térmica, que eran las tres calderas que había en el ferrocarril para producir vapor, para la calefacción de la mayoría de las secciones que era todo por cañería y para las máquinas de la herrería que trabajaban a vapor. El plantel estopa: en ese tiempo los vagones tenían en el rodado cojinetes de bronce, digamos que arriba del cojinete había una abertura donde se colocaba la estopa impregnada de aceite que era lo que lubricaba la rueda, a medida que trabajaba el vagón. Tenía la central eléctrica que eran los motores que daban la corriente a todo el ferrocarril. Tenía la parte de automotores, todo el transporte de talleres. Todo lo reparábamos nosotros. Tenía a los bomberos a cargo. Así que eran un montón de cosas. A mí por ejemplo me llamaban a las dos de la mañana, a las tres de la mañana. Yo estuve metido en todos los agujeros de talleres, vos te imaginás, porque con todo eso que yo tenía a cargo estaba todo el día paseando de un lado para otro". ${ }^{282}$

En suma, en estos ferroviarios existió una identificación con el rol que cada uno ejercía en la empresa, percibiendo que su función era fundamental para el desarrollo del ferrocarril y, por consiguiente, para el servicio brindado a la sociedad. ${ }^{283}$ Debe aclararse, sin embargo, que la valoración e identificación hacia la actividad propia no implicaba minusvalorar el resto de las tareas: todas, en su conjunto, permitían actualizar cotidianamente la función que el medio de transporte tenía en la sociedad. En efecto, esa estimación de la propia actividad como crucial

\footnotetext{
$282 \mathrm{EN}^{\circ} 19$

283 Adicionalmente, es posible hallar, en menor medida, algunos testimonios que se identifican, no con la tarea específica en la empresa, sino con la representación de un sector de los trabajadores. Tal es el caso de Tornello (ENº): "Yo era secretario de la Comisión Ejecutiva. Y yo tenía mucha relación... tenía devoción por el obrero. Para explicarte en una frase lo que yo sentía: 'la clase obrera al poder'. Porque siempre tuve visualizado al obrero como fuente de desarrollo de todo tipo de cosas. Para mí el desarrollo de cualquier tipo de sociedad, es el obrero el que lo hace. Así me sentía útil, me sentía partícipe". Para este actor, ese "afuera constitutivo" que produce identidad está conformado por los que no son obreros, por ejemplo, empleados que tenían a su cargo la dirección de la empresa. En tanto, Pinto (EN $\left.{ }^{\circ} 9\right)$, perteneciente a la lista rosa de la Unión Ferroviaria (la misma del testigo anterior) parece sugerir que aquel "afuera constitutivo" que produce la identidad, lo constituyen otros ferroviarios pertenecientes a otras listas del gremio (la verde o la azul): "Dentro del ferrocarril, yo estaba en un grupo que era lo más radicalizado que había. Había soplones, siempre los hubo en los gremios. Vos sabés que los servicios (de inteligencia) trabajan de esa manera, están metidos en todos lados, hasta en los barrios. Pero a nosotros no nos interesaba, porque hacíamos las cosas abiertamente. Usábamos la palabra y repartíamos volantes, ese era nuestro método de pelea. Básicamente la pelea era el salario." De esta manera, el rol con el cual estos ferroviarios se identificaban estaba ligado a su actividad gremial en el marco de un imaginario "de lucha" por la defensa del trabajo y de la mejora del salario para las clases obreras.
} 
para el desenvolvimiento del ferrocarril involucraba, al mismo tiempo, el compromiso de desarrollar la tarea de la mejor manera posible, ya que ello determinaba la calidad del servicio final. Calderoni lo sintetiza de una manera muy elocuente: "La intención que los ferroviarios teníamos era cumplir con lo que debíamos y dejar lo mejor posible las cosas. Eso no es mucho, pero es mucho." 284

\section{La calidad como sello de identidad}

Puede afirmarse que existió un imaginario social que tendió a caracterizar a los trabajadores ferroviarios de Junín, especialmente los que cumplían tareas en los Talleres, como de alto nivel de calidad. De acuerdo a Baczko, a través de los imaginarios sociales "una colectividad designa su identidad elaborando una representación de sí misma; marca la distribución de los papeles y las posiciones sociales; expresa e impone ciertas creencias comunes" (1991: 28). En ese sentido, es posible hallar múltiples representaciones que refieren a la excelencia de los trabajadores en cada uno de los oficios, lo cual lleva a considerar que esa asociación entre calidad, por un lado, y ferroviarios, por el otro, formó parte de la identidad ferroviaria, de la manera en que se autorepresentaron frente a otros colectivos. Esto se expresa con claridad en el testimonio de Marone:

"Si vos buscabas en Junín el mejor carpintero, estaba en el taller. Si vos buscabas el mejor pintor, estaba en el ferrocarril. Si vos buscabas el mejor tornero, estaba en el ferrocarril. Buscabas el mejor fundidor, el mejor herrero... El taller se nutrió de la mejor gente en las distintas especialidades." 285

Ferrari describe algo similar:

"La gente que trabajaba acá en Junín era lo máximo, los venían a buscar de la industria privada, todos era una belleza, los fundidores, los modelistas, unos técnicos especiales, los mejores de la Escuela Industrial venían a trabajar al ferrocarril.”286

\footnotetext{
${ }^{284} \mathrm{EN}^{\circ} 19$.

${ }^{285} \mathrm{EN}^{\circ} 14$

${ }^{286} \mathrm{EN}^{\circ} 4$.
} 
Lo mismo Martínez, quien vincula la calidad de los Talleres con la experiencia concreta en su especialidad:

“¡La mano de obra que había! En la ciudad no había esa mano de obra. Estaban todos ahí adentro. Me acuerdo que en ese tiempo entraban carpinteros-carpinteros." ${ }^{287}$

En tanto, Murgia se refiere a los atributos de los trabajadores en términos muy similares a lo que lo había hecho Marone:

"Si vos buscabas al mejor carpintero, lo tenías ahí, el mejor ebanista, lo tenías ahí, el mejor soldador, lo tenías ahí, el mejor plomero y gasista, lo tenías ahí, el mejor conocedor de aire acondicionado, lo tenías ahí, el mejor fundidor, lo tenías ahí y así podría seguir, el mejor fresador, el mejor tornero...Teníamos dibujantes que más que dibujantes eran artistas.”288

Esta similitud entre ambos testimonios (Marone y Murgia) que emplean el mismo verbo (buscar), ligándolo al mismo objeto (el mejor carpintero/ebanista/pintor, etc.), permite inferir que la identidad ferroviaria asociada a la excelencia en los oficios fue una construcción colectiva que tuvo lugar a partir de la puesta en común y jerarquización de ciertos recuerdos. ${ }^{289}$ Algunos contraponen, con nostalgia, aquel pasado en el que los trabajadores gozaban de prestigio por su capacidad y los momentos posteriores a la concesión de Ferrocarriles Argentinos. Como Calderoni:

“Antes, había una mano de obra dentro del ferrocarril que no la había en toda la República Argentina. Lo que se hacía dentro del taller no lo hacía nadie. Una mano de obra especialísima. Y eso se perdió todo, todo. Ahora hay mano de obra, sí, que vos ves que un coche sale bien pintadito, todo. Pero antes se fabricaban engranajes, se fabricaban cosas que no se hacía en un ente privado ni por casualidad..."290

Lo mismo Crocco, quien lamenta, a la vez, la pérdida a nivel local de esa capacidad técnica, representada por los especialistas en oficios de los Talleres Junín:

\footnotetext{
${ }^{287} \mathrm{EN}^{\circ} 20$.

${ }^{288} \mathrm{EN}^{0} 7$.

${ }^{289}$ Halbwachs planteaba que la memoria siempre es social. Según el autor, a través de la reiteración de ciertos recuerdos en entornos favorables, los individuos completan sus recuerdos apoyándose en los de los demás. De esta manera, esos marcos sociales de memoria permitirían orientar los recuerdos individuales. Esto explicaría, en parte, por qué los testigos coinciden en destacar ciertas memorias de su experiencia: la reiteración en entornos sociales determinados habría propiciado esa selección de acontecimientos y sensaciones (Halbwachs, 1994: 23). ${ }^{290} \mathrm{EN}^{\circ} 19$
} 
"Había una mano de obra de la más alta capacidad tecnológica. Había torneros, fresadores, matriceros, fundidores, de excelente calidad. Toda esa mano de obra quedó a la deriva. Así, de esa forma abrupta que se cerraron... no permitió... Junín no tenía capacidad de absorción de esa mano de obra."291

En la misma línea lo percibe Tornello que intenta exponer los factores que incidieron en el cierre de los talleres, la concesión de los Ferrocarriles en la década de 1990 $\mathrm{y}$, en consecuencia, la pérdida de la mano de obra:

"Había técnicos, ingenieros, gente de muchísima capacidad para cualquier tarea. Y eso se terminó, con el desguace del Estado, con el agravante de la burocracia sindical y la campaña en contra, que llevó a decir que los ferroviarios eran vagos." 292

Algunos testigos vinculan esa calidad de mano de obra con el equipamiento y las maquinarias disponibles en los Talleres Junín. Como De Giulio: “Afuera no había mano de obra como la había adentro. Lo que no se podía hacer en el ferrocarril, que era todo, afuera no se podía hacer. Por las máquinas que había". ${ }^{293}$ O Taberna:

\footnotetext{
"La mano de obra era magnífica. A mí me parece que era algo medio especial. Un tornero del ferrocarril no era lo mismo que un tornero afuera. Estaba preparado para realizar cualquier trabajo. Soldadores como los había allí, ya no hay, porque es muy difícil soldar materiales que no son ferrosos, como el hierro y el acero. Soldar bronce, aluminio, no lo hace cualquiera. Hoy no hay nadie que haga esos trabajos. Ahí tenés el espacio, la maquinaria, de cualquier tipo, la preparación". ${ }^{294}$
}

El ingeniero Calcagni, sin embargo, no acuerda con este tipo de apreciaciones referidas a la maquinaria disponible:

"Me sorprende que algunos destaquen la capacidad y modernidad de la maquinaria que, en muchos casos era la que dejaron los ingleses y justificaba la opinión de las autoridades superiores de la empresa en el sentido de que se trataba de un taller obsoleto."295

\footnotetext{
${ }^{291} \mathrm{EN}^{\circ} 2$.

${ }^{292} \mathrm{EN}^{\circ} 6$.

${ }^{293} \mathrm{EN}^{\circ} 11$.

${ }^{294} \mathrm{EN}^{\circ} 7$.

$295 \mathrm{EN}^{\circ} 21$.
} 
La postura de Calcagni parece ser congruente con algunas experiencias recordadas por los actores, como la de Violante, quien comenta la falta de insumos para llevar adelante las tareas de reparación en el área Electricidad:

"Yo recorría el taller buscando repuestos para mi especialidad, la parte eléctrica. Y ya cuando no había más material, porque estaban los 'entongues' de Almacenes, se tenía que hacer cualquier cosa para reemplazarlos. Empezamos a 'emparchar'. A lo mejor, una bobina de la luz de una locomotora, la sacábamos para hacer una bobina de otro coche. Total, eso no se iba a usar más y aparte que había orden de poder usarlo. Y así tiramos unos cuantos años. Los coches salían y salían bien. Salían a $0 \mathrm{~km}$. Impecables. Muy, muy buenos." 296

De esta manera, la calidad de la mano de obra es fundamentada en el testimonio anterior, no por la disposición de elementos y maquinarias sino, por el contrario, por la ausencia de insumos necesarios, instancia de dificultad que los actores habrían logrado superar gracias a su inventiva y capacidad. Eso habría dado como resultado un trabajo de calidad, aspecto que es remarcado por Violante a partir de los calificativos "buenos" o "impecables" en relación a los coches reparados. En la misma línea, el capataz de Electricidad enuncia algunas otras dificultades vinculadas al idioma o a la necesaria adaptación de los vehículos de origen extranjero que los operarios a su cargo lograron dominar, intentando persuadir, una vez más, sobre la capacidad del personal ferroviario, vinculada a la voluntad y creatividad:

"Venían a veces los coches con circuitos, con cosas ilegibles, por ejemplo en japonés. Y, es complejo... Y acá los muchachos se las arreglaban, en una semana te descifraban todo. Desarmaban todo el circuito y lo marcaban a gusto de ellos. Y los coches salían, con aire acondicionado, con todo. También le hacían modificaciones a los coches para que puedan andar acá, en la zona. Porque San Luis, Córdoba son pajonales. Los equipos extranjeros eran muy sofisticados para viajar en una vía limpia, de bases de cemento, un chiche. Pero acá tenían que viajar prácticamente en el desierto. Y había problemas con los filtros, se quemaban los filtros que eran carísimos. Los motogeneradores, el aire acondicionado. Eran equipos muy caros. Por un convenio mandaban una cantidad limitada y no mandaban repuestos. Y todo lo solucionaban esos chicos y, ojo, que no cobraban más que el sueldo común, de todos los meses. Ahí no le pagaban premio por ninguna hazaña."297

${ }^{296} \mathrm{EN}^{\circ} 8$.

${ }^{297} \mathrm{EN}^{\circ} 8$. 
De acuerdo al testimonio anterior, entonces, la falta de insumos, materiales y una tecnología acorde a las necesidades, habría favorecido el desarrollo de habilidades por parte de los operarios, en contraposición a otros testigos que destacan la alta tecnología de los Talleres Junín. En lo que sí coinciden unos y otros es en la calidad de la mano de obra, cualidad que permite construir la identidad de los trabajadores del riel en Junín.

De acuerdo a M.J. López, al momento de la nacionalización el servicio ferroviario en Argentina funcionaba de manera eficiente. Sin embargo, el material rodante era antiguo, lo que demandaba un mayor nivel de mantenimiento para prestar los servicios en buenas condiciones (López et al., 2016: 155). Posteriormente a la nacionalización, el Estado empresario adquirió nuevos materiales rodantes e, incluso, impulsó proyectos de fabricación con diseño nacional. ${ }^{298}$ Mientras estos últimos no llegaron a prosperar, ya que lograron fabricar pocas unidades en la mayoría de los casos, la política de compra de materiales rodante fue anárquica, en términos del autor, por la variedad de modelos, fabricantes y tecnologías adquiridas, al menos, hasta fines de los años sesenta:

Esta variedad conspiró con la recomendable estandarización de las unidades rodantes ya entendida desde antes de la nacionalización. Las compras generalmente se hicieron de apuro, ante necesidades impostergables, atendiendo solo a razones financieras y crediticias, sin estudios técnicos sobre si dichas unidades eran idóneas para el uso (...) ...debemos decir que el país hizo un importante esfuerzo en materia de modernización del material rodante, pero sin duda ese esfuerzo podría haber sido más eficiente y mejor utilizado. Recién a fines de la década del sesenta se establecieron las normas técnicas a seguir en el futuro y cierta uniformidad en los vehículos a incorporar de allí en adelante (López et. al, 2016: 191).

Puede inferirse que esa política errática en cuanto a la adquisición de material rodante que describe López, podría haber tenido su correlato en la adquisición de repuestos. López menciona, en ese sentido, que con la nacionalización de los ferrocarriles creció la industria ferroviaria argentina, proveedora de insumos. ${ }^{299}$ "Esa industria solo fue posible gracias a que

\footnotetext{
${ }^{298}$ Para suplir la falta de vagones, se diseñó el "Nuevo Vagón Justicialista", que, de acuerdo a López, se llegó a construir solo uno. El proyecto de Fábrica Argentina de Locomotoras, a cargo del ingeniero Pedro Scaggio, "llegó a construir solo tres locomotoras y algunas carrocerías en tres años de vida", siendo abandonado a partir del golpe de Estado de 1955 (López, 2016: 164-165).

299 J.C. Cena se pregunta: “¿Dónde está esa industria, donde están esos industriales llenos de prepotencia para desarrollar sus emprendimientos y por tratar de imponer, a como dé lugar, lo producido? Industriales que apelaron a todo para proveer a Ferrocarriles Argentinos maniatado: este se transformó en un formidable mercado cautivo. Mercado que no supieron defender, sino que hasta último momento trataron de succionar la flaca teta de un ferrocarril en estado de obsolescencia..." (Cena, 2008: 234-235)
} 
la empresa ferroviaria estatal compraba cualquier cosa a cualquier precio con el argumento de generar mano de obra local" (López y col, 2016: 195). En un informe de la Capacidad Técnica de los Talleres Junín que establece como período 1955-1966, elaborado por la Jefatura del Taller, se concluye que las maquinarias disponibles en el Taller eran satisfactorias, aunque reconoce que el suministro de materiales "no tiene afluencia que permita una normal prosecución de las tareas y entre la enorme variedad de materiales de difícil obtención para el servicio existen algunos de primordial importancia”. Al mismo tiempo, se puntualiza que la “carencia de repuestos para las unidades recientemente incorporadas al servicio", obligó, en los casos en que esto fue factible, a la fabricación de piezas en taller, lo que, al mismo tiempo, implicó incrementar la permanencia de coches. ${ }^{300}$ Esto resulta coincidente con lo expuesto por Violante, quien alude a que la falta de provisión de materiales necesarios para efectuar las tareas de reparación, sumada a la existencia de vehículos en desuso o no del todo apropiados para las necesidades nacionales, habría favorecido el surgimiento de nuevas habilidades por parte de los operarios, abonando el imaginario vinculado a la calidad de la mano de obra en los Talleres Junín.

Hasta aquí se ha expuesto cómo la identidad ferroviaria en Junín estuvo asociada a un imaginario sobre la capacidad técnica y el alto nivel de los trabajadores ferroviarios. En el mismo sentido, es posible hallar numerosas afirmaciones que subrayan la diversidad de áreas involucradas en la tarea de reparación dentro del predio de Talleres que, con sus casi treinta hectáreas, llegó a ser el segundo con mayor superficie cubierta y mayor personal de todos los centros ferroviarios reparados que existían en Argentina. ${ }^{301}$ Una de las estrategias discursivas más comunes para intentar mostrar la importancia y la envergadura de los Talleres Junín, frente al resto, ha sido la de enumerar las diferentes secciones y mostrar los vínculos entre ellas, frente al objetivo central de poner en marcha al tren y brindar un servicio eficiente. Así lo describe Pinto, enfatizando la diversidad y la coordinación del complejo ferroviario:
“Todo estaba enlazado porque cada sección cumplía una función que servía al tren. Los de Vía y Obras reparan las vías. Estaban todas las secciones, se reparaban máquinas en Primera Junta. Los vagones de carga se reparaban por Jean Jaures y Dorrego, se reparaban al aire libre. Los coches se reparaban en los galpones, en Tapicería, Carpintería, Pinturería. Se les hacía todo a los coches, había reparación liviana, reparación mediana y

\footnotetext{
${ }^{300}$ Capacidad Técnica de los Talleres Junín (s.f.), Archivo Universitario Roberto Di Marco.

${ }^{301}$ En 1969, solo los talleres de Tafí Viejo superaban a los de Junín, con 89.648 metros cuadrados de superficie cubierta y 2.731 agentes. Para ese año, Junín contaba con una superficie notoriamente menor (68.374 metros cuadrados), aunque con una cantidad de operarios bastante similar: 2.545 agentes (Plan de Mediano Plazo, 1972).
} 
reparación general. En general se hacía el coche completo, se lo dejaba cero kilómetro. Se hacía un programa de reparación, que permitía reparar entre treinta y cuarenta coches mensuales. Se trabaja muchísimo. También había fundición de hierro, aluminio, gomas, bronce. Los burletes se hacían acá. Y después se hacían miles de zapatas para todos los ferrocarriles ipara todos los ferrocarriles! Después estaba la sección Tornería, Herrería en la que se reparaban los ganchos y paragolpes, Electricidad. El ferrocarril tenía todas las ramas de la industria en general. Después había gente administrativa, se trabajaba con todos. Por eso era como una especie de familia." ${ }^{302}$

Como en Pinto, en Rinaldi es posible hallar una notable admiración por la dimensión de los Talleres Junín, en cuanto a diversidad de secciones y la capacidad técnica de cada una de ellas:

“El taller tenía más o menos treinta hectáreas. Tenía talleres de Tornería, completísimo. Herrería, completo. Un galpón, el más grande de todos, con tres puentes grúas de treinta y cincuenta toneladas para las locomotoras vapor. Se desarmaba por completo la locomotora a vapor y se la volvía armar. Otro taller de caldera, con dos puentes grúa. Se sacaba la caldera de la locomotora a vapor y se reparaba completa. La Herrería hacía todos los trabajos de movimiento, las palancas, fabricación de clavo de vía y varios elementos para vía y obra. Lo que unía los rieles era una barra con tornillos. Bueno, acá se fabricaba todo eso. Después estaba la parte de Coches de madera. También, se desarmaba todo y se hacía todo de nuevo. Acá había un aserradero completo. De los troncos de madera, se cortaban listones, se ponía a secar al aire y con el tiempo se hacían los asientos, las ventanas, las tablas. Después eso fue reemplazado por los coches metálicos. Estaba la sección Chapas que hacía todos los trabajos metálicos, las ventanas, las puertas, los pisos. Era una reparación integral. Y aparte estaba la sección Bogie que es la parte de debajo de los coches y las locomotoras, donde van el bastidor, las ruedas, los cojinetes, todo eso. Era completo, había otra parte de Carpintería. Y estaba también el taller grande, en otro galpón, de Pinturería. Se hacía dos tipos de pinturería: de locomotora, y de coches y vagones. Había un patio de vagones con un puente grúa que corría a lo largo y acá se reparaban los vagones de leche y alguna vez por accidente de los petroleros. ¡En aquel tiempo se transportaba la leche en vagones! Hubo épocas en que no dábamos abasto para arreglar locomotoras para el transporte de petróleo. Y acá también se reparaban los vagones. El taller tenía también su propia usina, tenía también su planta de vapor, su planta de reparación total de batería, baterías alcalinas, baterías de 
ácido-plomo. Tenía su servicio de agua. Es decir, tenía una planta con varias bombas de agua para todo el taller y para la estación ferroviaria, donde tomaban agua las locomotoras. Después había una instalación de vapor para máquinas de percusión, ya sea para remachar o para romper pisos. Esas son alimentadas a aire comprimido o a vapor. En el taller había dos instalaciones de vapor, una para la Pinturería y otra para el resto de las secciones donde se trabajaba con el elemento vapor de presión. Para el de herrería, para el manejo de los martinetes, los balancines, se usaba el vapor. O sea que era completísimo, era una industria... eran varias industrias dentro de un taller. El trabajo de la madera, el trabajo de chapas, el trabajo de locomotoras, de coches, era reparación integral. Y después Fundición. Había fundición de hierro, fundición de bronce, fundición de aluminio. Los cilindros de locomotoras son elementos muy grandes. Bueno, acá se hacían los planos, porque estaba el taller de modelista con veinte personas que, cuando yo entré, eran casi todos italianos. Había una Carpintería dedicada a fabricar los modelos para producir piezas. Piezas que después son labradas y terminadas a máquina... Se me están escapando un montón de especialidades... Soldadura, había soldadura eléctrica y autógena, había un galpón con veinte máquinas de soldadura eléctrica y diez o quince de soldadura acetilénica, soplete. Y después había secciones con uno o dos soldadores de cada especialidad. Después, dentro del taller estaban las oficinas. Estaba la oficina técnica del taller donde se hacían todos los planos. Se recurría a hacer el plano, por lo general siempre en tela, y había un grupo de dibujantes, proyectistas de obra, proyectistas principales, con un jefe a cargo." 303

Ferrari, como los trabajadores anteriores, se muestra fascinado al recordar el funcionamiento coordinado y el servicio eficiente que Talleres Junín era capaz de llevar adelante:

"Había cuarenta y cinco secciones. Estaba la sección para el oxígeno, porque se fabricaba oxígeno ahí. Nosotros acá le hacíamos cambio a un lugar que tenía acetileno. Ellos nos daban acetileno y nosotros les dábamos oxígeno. Entonces con eso hacíamos trabajar a los soldadores. En la sección Tornería, había una cantidad de fresadoras, gente muy especializada en cada máquina. Y se compraba toda máquina extranjera. Estaba también la parte de Aire Acondicionado. Le ponían una nave a los coches y se le probaba el aire acondicionado. La Carpintería era una nave que tenía media sección cubierta con bancos Hacían ventana. Y después estaban las máquinas que aserraban. Y todo el aserrín que producía eso iba... ¿vos sabés que abajo, en el piso, estaba la rejilla y el aserrín iba al piso,

${ }^{303} \mathrm{EN}^{\circ} 3$. 
debajo de la rejilla? Y había una cinta transportadora que la sacaba y la llevaba a un vagón. ¡Tenían todo tan sistematizado! La sección Pinturería también, tenía todo tan ordenado... Porque ahí se reparaba la locomotora a vapor, después coches, y después vagones. Y los coches los llevaban también en una mesa transportadora a la parte de Pinturería, que está allá por Primera Junta. ¡Era una nave gigantesca de Pinturería! Ahí se pintaba a soplete, se pintaba con muchas cosas. Secciones había de todo lo que se te podía ocurrir. La sección de Herrería era algo... ¿sabés los martillos gigantescos que había para aplanar? Hacían todas las manivelas de la locomotora a vapor. Los talleres en Junín, eran importantísimos, no faltaba ninguna especialidad. Estaba tapicería que tenía, qué sé yo, como treinta máquinas industriales. Tenía que ver con esto de los asientos de los coches. Estaba la sección Herramental, era toda la parte de herramientas." 304

Rinaldi destaca, adicionalmente, la autonomía de los Talleres, la capacidad de autoabastecerse, frente a otros servicios de transporte que requerían intervenciones externas. En ese sentido es que se refiere a la integralidad del centro reparador:

"El ferrocarril tenía sus vías propias, sus pasos niveles con personal a cargo, las estaciones con personal ferroviario. La policía ferroviaria, que dependía del ferrocarril. Servicio de bomberos para instalaciones ferroviarias. El servicio de agua en las estaciones era del ferrocarril, no de Obras Sanitarias. La electricidad era la usina que tenía acá el ferrocarril. Era un servicio in-te-gral. En cambio, el transporte automotor depende de otros servicios. De la policía que es Federal, el mantenimiento de los caminos era de Vialidad. Todo lo que es accidentes depende del pueblo que esté más cerca: bomberos, ambulancias. El arreglo de caminos que es fundamental depende de otras fuentes. O sea, hay una diferencia notable. Era un servicio íntegramente. Cosa que el de caminos no es así." 305

A partir de los testimonios anteriores puede afirmarse que el imaginario vinculado a la capacidad técnica de los Talleres Junín propició una identificación de los ferroviarios hacia el centro reparador. Ese orgullo por pertenecer a un espacio de esa magnitud y calidad que, al mismo tiempo, era autónomo, puede hallarse en numerosos testimonios, como en Violante:

“El de Junín era un taller bien dotado, bien plantado. Acá se hacía todo, desde fundir una pieza hasta terminarla y colocarla en los motores, en los coches de pasajeros. Era algo así como un orgullo. No como un orgullo, sino que era un orgullo. Y lo sigue siendo."306

$304 \mathrm{EN}^{\circ} 4$.

$305 \mathrm{EN}^{\mathrm{0}} 3$.

$306 \mathrm{EN}^{\circ} 8$. 
Ferrari también se refiere a la cualidad de completud en relación a los Talleres Junín: "No faltaba nada, ahí estaba todo, todo." Lo mismo Murgia, quien fundamenta el prestigio de los Talleres Junín, a partir de los atributos, antes mencionados, de la autonomía y la integralidad: "Talleres que fabricaban un coche entero adquieren un mérito mayor que el que hacía solo reparación." ${ }^{307}$ De esta manera, el proceso de identificación de los ferroviarios juninenses hacia los Talleres Junín, se construyó a partir del "afuera” representado por otros centros reparadores, en especial los Talleres de Tafí Viejo: ${ }^{308}$

“Talleres Junín fue uno de los mejores por la amplitud y por la calidad de las reparaciones. Porque había uno en Tafí Viejo, Tucumán, que rivalizaba un poco con Junín. Estábamos como River y Boca. Porque acá Junín hizo un montón de cosas importantes, ya que otros talleres eran más chicos. La cantidad de personal también hace a la importancia.”309

La comparación con los talleres de Tafí Viejo también aparece en otros testimonios, como el de Ferrari: "Los talleres de Junín eran con los de Tafí Viejo los más importantes de la República Argentina”, y el de Rinaldi: $:^{310}$

“Del 65 al 75 nos dieron una gran responsabilidad, porque Junín pasó a ser el taller de los coches de las cuatro líneas de trocha ancha: Mitre, Sarmiento, Roca y San Martín. Vinieron los coches a tratarse acá, coches de pasajeros. Y todos los coches de aire acondicionado, ya sea metálico, y de primera y los pullman, que eran japoneses y holandeses. Este taller pasó a ser el más importante del país, porque Tafí Viejo, que había sido el más importante, había cerrado. ${ }^{311}$ El Roca se había venido a menos. Talleres Rosario que hacía los coches del Mitre, también. Sí, hubo diez o doce años que fue cuando el taller tuvo más importancia, no tanto por la cantidad de gente que tenía, porque podía tener 1000 personas, 1200; sino por la calidad de trabajo que tenía que hacer, en lo referido a los coches. Los coches de más importancia se hicieron en esa época. Se hizo un coche bar, un coche cine, casi íntegramente acá. Teníamos el apoyo de la gerencia de mecánica, de Buenos Aires, los militares también estaban por ese lado también. Y la preferencia de los Talleres Junín fue

\footnotetext{
$307 \mathrm{EN}^{\circ} 4$ y ENº

${ }^{308}$ De acuerdo a Miguel Ángel Herrera Tafí Viejo era considerado, durante la década del cincuenta, el taller ferroviario más grande de Latinoamérica (Rozitchner et al., 2010: 218).

$309 \mathrm{EN}^{0} 7$.

$310 \mathrm{EN}^{\circ} 4$ y $\mathrm{EN}^{\mathrm{o}} 3$.

${ }^{311}$ En rigor, Tafí Viejo cerró en 1980. Sin embargo, durante ese período que coincidió con la presidencia de Juan De Marchi al frente de Ferrocarriles Argentinos (1967-1972), durante el gobierno de Juan Carlos Onganía, numerosos testigos coinciden en afirmar la "preferencia" que tuvieron los talleres locales, frente al resto, tema que se desarrolla en el capítulo 4.
} 
por la calidad de la mano de obra que había en el trabajo de esa especialidad, en lo que hace a coches."

Crocco, por su parte, manifiesta una fuerte identificación hacia el centro reparador local, lo que, según plantea, habría permitido encauzar las energías conjuntas hacia el objetivo de lograr la preeminencia de Talleres Junín: “Queríamos que Talleres Junín fuera el estandarte, porque, entiendo, era el principal centro reparador de Ferrocarriles Argentinos". En tanto, Dall'Occhio también destaca la importancia de los Talleres Junín frente al resto: $:^{312}$

"Este taller fue declarado taller piloto de todos los coches de pasajeros. ${ }^{313}$ Porque estaba considerado como el mejor taller de todos los talleres que había en el país. El mejor organizado, el mejor capacitado, el mejor mantenido. Por ejemplo, en un momento dijeron, vamos a hacer un tren sanitario. Y se hicieron tres coches. Un tren dormitorio para los médicos y enfermeras, un coche que tenía salas de rayos $\mathrm{X}$ que hubo que revestirlo todo con plomo adentro, tenía el sillón de dentista y una camilla y un quirófano para hacer pequeñas operaciones simples. Tenía todo lo que la medicina le puede aportar a... Bueno, una parte se hizo acá y otra parte en Rosario. Se hicieron diez coches dormitorios antiguos, los remodelamos todo a nuevo y quedaron fantásticos. Todo trabajo en madera. Se hicieron dos coches-cine. A lo largo de la vida del ferrocarril siempre se hicieron muchas cosas acá, pero eso se hizo desde el año 68 más o menos al 72, 73. Se hicieron también unos vagones especiales para llevar automóviles arriba del tren. La gente iba a algún lado y llevaba su automóvil arriba del tren. Hicimos un coche-bar, con asientos en formas extrañas, vino una arquitecta, Brandolini era su apellido, que hizo un diseño maravilloso, salió en las revistas europeas. Estaba la carrocería: la cáscara del coche era holandesa y estaba hace años acá como coche de pasajeros. Sacaron todos los asientos y la arquitecta trajo una madera africana, se forró todo lustrado a muñeca e hicieron un tapizado con formas ojivales, formas de castañas de cajú. Era maravilloso, incluso pusieron unos cuadros de Quinquela Martín. Se llamó Coche Bar 209".

En suma, el conjunto de testimonios expuestos en el presente apartado permite sostener que el imaginario vinculado a la excelencia de los trabajadores y a la capacidad técnica de los Talleres locales alentó, durante todo el período estudiado, la construcción y consolidación de una fuerte identidad asociada al centro reparador local. En otras palabras, el

\footnotetext{
$312 \mathrm{EN}^{\circ} 2$ y EN ${ }^{\circ} 15$.

313 La declaración de los Talleres de Junín como piloto se informa en un diario local: "Cuando en la reestructuración de los talleres ferroviarios de Junín se dispuso que el de Junín quedara como piloto, no hay duda que en tal determinación, el presidente de la EFEA, general Juan C. De Marchi, fue un visionario". Reacondicionan en los talleres de Junín coches metálicos del FA Sarmiento (27 de agosto de 1968). La Verdad, p. 9.
} 
orgullo de ser ferroviario estaba fundado en la pertenencia a una empresa que contaba con recursos humanos altamente calificados y con capacidad de producir resultados de calidad, los cuales permitían brindar un servicio esencial para el desarrollo del país y el traslado de las personas.

\section{Las relaciones humanas en el interior del ferrocarril}

En los dos apartados anteriores se analizó la identidad ferroviaria asociada a la labor específica desarrollada por cada actor y al imaginario de excelencia de los trabajadores y del centro reparador local. También es posible hallar en los relatos una fuerte identificación hacia el colectivo humano simbolizado a partir de la representación de "familia ferroviaria".

Los trabajadores del riel se ocupan de resaltar en el relato la armonía que existía en aquellos vínculos, en algunos casos con cierta nostalgia por una sociedad que luego se transformaría. "La relación entre ferroviarios era hermosa. Buenísima. Era otra sociedad y otra forma de vivir", se lamenta Tornello. Marone, en tanto, relaciona esa armonía con la ausencia de conflicto en los vínculos: "La relación entre ferroviarios siempre fue buena. Yo nunca tuve un conflicto. Siempre estuve en lugares donde había armonía, respeto”.

La calidad de las relaciones entre ferroviarios es explicada, por un lado, por los modos de establecer los vínculos cotidianos de manera amable: como en el testimonio anterior que Marone refiere al respeto. Por el otro, por la cooperación entre áreas en virtud de la prosecución de un objetivo mayor. Así lo plantea Crocco:

\footnotetext{
"Nos unía el propósito de que todas las cosas anduvieran y por eso se mantenía una relación agradable. Si había un descarrilo, el de Vía y Obras venía con la zorra para ayudarme, yo iba con el guinche, se colaboraba para la más pronta atención para liberar las vías para el tráfico. Como si había que tomar examen, se pedía: 'Publicame esta vacante, la necesito urgente'. Había buenas relaciones, se hablaba por teléfono, había una relación fluida entre los distintos departamentos. A nivel de dirección hacíamos reuniones, teníamos controles de gestión a las que asistía el jefe de departamento, los respectivos jefes de división, con la jefatura de los distintos centros reparadores. Eso era en lo que hacía al desenvolvimiento del departamento. Todo se hacía dentro de la mayor armonía y era una modalidad de trabajo de una empresa." 314
}

$314 \mathrm{EN}^{\mathrm{o}} 2$. 
Tornello, en tanto, vincula a la representación de "familia ferroviaria" con la convergencia de "todos" los trabajadores en relación a la meta final de servir al "desarrollo del ferrocarril", lo cual coincide con los postulados de Hall cuando plantea que el proceso de identificación tiene más que ver con el "devenir" que con el "ser": 315

"Éramos una familia porque estábamos orgullosos de nuestro trabajo. Porque nosotros participábamos en el desarrollo del ferrocarril, en el transporte de gente, en el transporte de carga. Todos estábamos al servicio del desarrollo".316

El orgullo al que alude Tornello en el testimonio anterior también aparece en el siguiente testimonio de Crocco cuando se refiere a la capacidad técnica de los trabajadores y a la cooperación entre áreas:

"Las relaciones eran buenas. Había hasta cierto grado de poder decir: 'Tornería tiene la mejor mano de obra', o 'Fundición tiene los mejores fundidores'. Había voluntad de que los trabajos fueran bien ejecutados. No había desidia entre este y aquel. Te vuelvo a decir, yo veía una total armonía en las dependencias. No había rivalidad de decir a aquel no le compro, a aquel no le hago. Se cumplía bien. No existía una rivalidad, nunca lo vi. Cada cual cumplía su función como correspondía. La conformación de la estructura del trabajo no permitía que se dijera: 'No, yo esto no lo hago para joderlo a aquel'. O: 'Hago un mal plano para que le salga mal el trabajo'. No existía eso."317

Agulhon (1994) considera que para estudiar la sociabilidad obrera es necesario detenerse en el espacio físico, en el lugar donde estos vínculos son posibles de desarrollarse. ${ }^{318}$

\footnotetext{
315 "Aunque parecen invocar un origen en un pasado histórico con el cual continúan en correspondencia, en realidad las identidades tienen que ver con las cuestiones referidas al uso de los recursos de la historia, la lengua y la cultura en el proceso de devenir y no de ser; no «quiénes somos» o «de dónde venimos» sino en qué podríamos convertirnos, cómo nos han representado y cómo atañe ello al modo como podríamos representarnos" (Hall, 2003: 17-18).

${ }^{316} \mathrm{EN}^{\circ} 6$.

$317 \mathrm{EN}^{\circ} 2$.

318 "Existe una diferencia considerable entre la sociabilidad de las clases superiores y la de la clase obrera (o popular en general). No existe asociación, ya sea informal (simple reunión de parroquianos) o formal (con estatutos, reglas escritas), sin que exista un lugar de reunión estable. Este lugar es un bien material, un capital. Para el rico, la dificultad no resulta grande. La sociabilidad informal se lleva a cabo, precisamente en los salones, de las grandes viviendas aristocráticas o burguesas. La sociabilidad formal del círculo de hombres se lleva a cabo en un local alquilado o comprado por cooperación; son gastos, sin embargo, fáciles de sobrellevar. El obrero, en cambio, es muy pobre y vive en la estrechez. El estudio de la sociabilidad obrera exige que, antes, nos preguntemos dónde se ejercía" (Agulhon, 1994: 56-57). El subrayado es mío.
} 
En línea con ello, Rinaldi interpreta la "unión”, con las características propias de la tarea ferroviaria $\mathrm{y}$, fundamentalmente, con el espacio compartido, al comparar la experiencia de haber sido trabajador ferroviario, con la de haber sido docente, otro rol que también ejerció a lo largo de su vida laboral activa. Para Rinaldi, ambas cuestiones obligaban a los trabajadores a un trato constante y daban como resultado vínculos de cooperación, propiciando a la vez actividades de enseñanza y aprendizaje no formal:

\footnotetext{
"Hay más contacto entre los ferroviarios de las mismas escalas que dentro de la actividad docente. A lo mejor, en la mesa de trabajo de planificación nos reuníamos cuatro o cinco a discutir un problema. En la actividad docente, en cambio, usted está aislado, va a su clase y listo. Por eso en la actividad ferroviaria los grupos de trabajo están más unidos. En el cuarto de herramientas éramos ochenta. Ochenta personas, en el torno, en la agujereadora, en el depósito de material. Y está dentro de un pequeño taller que tiene veinte metros por treinta. $\mathrm{Y}$ está casi en contacto permanente con los demás, por afilar una mecha, por hacer un comentario, por necesitar una herramienta. Si está en una oficina técnica tiene que guardar relación con el proyectista de obra, el proyectista principal. La agrupación requiere de una amistad más sincera, de no ocultar nada, especialmente los conocimientos. Ni envidia porque el otro sepa más, al contrario, aprovecharlo para aprender más." 319
}

La representación de familia ferroviaria también aparece en los relatos vinculada al tiempo diario compartido por el trabajo que incluso era, según manifestaban los actores, mayor que el tiempo compartido con el núcleo familiar del hogar. Marone cuenta: "Yo te diría que se podría hablar de una familia ferroviaria con cierto grado de integración. Porque nos veíamos todos los días: estábamos mañana y tarde juntos, estábamos más en el taller que en la casa”. Tornello cuenta algo similar: ${ }^{320}$

“En mi sección llegó a haber cien personas que uno veía todos los días. Estábamos ocho horas, de las seis de la mañana hasta las dos de la tarde. Vos le contabas tus problemas, el otro te contaba los suyos. Hablábamos de fútbol, de mujeres, por supuesto, de bailes. Eso hace que sea una familia. ¿Vos qué hacés cuando te sentás en tu mesa? Empezás a hablar del novio, la política. Y eso mismo pasaba en el ferrocarril. Entonces, era una familia.”

$319 \mathrm{EN}^{\mathrm{o}} 3$.

$320 \mathrm{EN}^{\circ} 14$ y EN 6 . 
Rinaldi, por su parte, realiza un cálculo preciso del tiempo compartido, lo cual le permite fundamentar la cercanía y profundidad en los vínculos establecidos dentro de la comunidad ferroviaria, la cual, aclara, se componía casi exclusivamente de varones:

\footnotetext{
"Se estaba, aunque no lo quiera creer, casi más tiempo que con la familia. Porque usted con el tornero que estaba al lado, o con el dibujante, tenía que estar ocho horas. Y a veces que teníamos sobretiempo para hacer determinada tarea, teníamos que estar doce o catorce horas ahí. Usted está ocho horas en el trabajo, media hora para salir y volver, tenés nueve horas o diez fuera de su casa, duerme ocho horas y ¿qué le quedan? Seis horas. Seis horas para estar con la familia. O sea que uno estaba más con el compañero de trabajo que con la familia. De ahí que uno llegaba a tener mucha intimidad con ellos, siempre con varones, eso sí. Porque en el taller no había mujeres, después comenzó a haber algunas, pero en la oficina de afuera". ${ }^{321}$
}

La intensidad de los vínculos establecidos entre ferroviarios no solo es fundamentada por la cantidad de tiempo diario compartido, sino por abarcar la mayor parte de la existencia de los trabajadores, ya que los ferroviarios solían ingresar en la adolescencia o en la juventud, y tenían la expectativa de permanecer en la empresa hasta el retiro. De ello se deriva que el ferrocarril era percibido como parte de la propia vida. Tornello lo explica así:

"La relación era muy, muy buena. Era una cosa muy especial, porque si yo te digo que entré a los 14 años, fui adolescente, fui adulto, me casé, tuve hijos, viví todo ahí. Y los compañeros míos, lo mismo. Así que éramos una familia. Una familia ferroviaria." 322

Aunque en los recuerdos evocados prevalece la cualidad de la armonía para caracterizar a las relaciones, algunos testimonios también exponen la existencia de conflictos al interior del colectivo. El mismo Tornello que en el testimonio anterior se refirió a la existencia de una familia ferroviaria, deja entrever las profundas diferencias entre las distintas líneas políticas de trabajadores ferroviarios de la Unión Ferroviaria, así como un sentimiento de dolor por haber padecido la marginación por parte de algunos de sus compañeros, como consecuencia de su pertenencia a la línea rosa, de izquierda:

$321 \mathrm{EN}^{\mathrm{o}} 3$.

$322 \mathrm{EN}^{\circ} 6$. 
"Yo tenía respeto por los compañeros. No había ningún tipo de animosidad de parte mía por la forma de pensar de otro. Pero era muy difícil. No era muy sencillo para mí convivir con gente que tenía intereses personales. O gente que intentaba verte como un enemigo, cosa que no era cierto, si somos hermanos de clase." 323

Para Marone, el gremio como actor político fue el responsable de la desarmonía en esa familia ferroviaria: "Mi experiencia es que la relación entre ferroviarios siempre fue buena. Si dejó de ser buena en algún momento puntual, era por un problema ajeno al ferrocarril. Cuando se metía el gremio y la política, se pudría todo". ${ }^{324}$ Desde esta perspectiva, pareciera prevalecer una concepción inmaculada de "familia ferroviaria", la cual habría perdido su pureza original por el accionar de los representantes gremiales, considerados, desde la óptica de Marone, como ajenos a dicha entidad imaginaria.

El ingeniero Calcagni quien, a diferencia del resto de los entrevistados, relata que entró "pensando que no era ferroviario", pero que al final le "gustó" y se "sintió" como tal, intenta derribar la concepción de "familia ferroviaria", exponiendo la existencia de recelos entre los actores. Quizás su análisis y la distancia que establece con esta representación responde a su rol como profesional en la empresa, lo cual lo diferenciaba del resto de los trabajadores y, al mismo tiempo, no favorecía la identificación:

\footnotetext{
"Se generaliza indebidamente la hermandad entre los ferroviarios, que existía sin duda entre pequeños grupos. Lo de la familia ferroviaria era entonces una metáfora que se metió por la vía de los discursos. La ambición y la envidia siempre existieron. Tal vez me digan que ni las familias se libran de ellas. Bueno, entonces sí." ${ }^{325}$
}

Si bien Poch, administrativo de Mecánica e integrante de la comisión directiva de la Unión Ferroviaria, coincide con el resto de ferroviarios de caracterizar a las relaciones como "buenas", al igual que Calcagni menciona a la ambición como fuente de diferencias: "Siempre hubo gente ambiciosa que quería llegar sin tener el conocimiento y la capacidad. Entonces hacían cosas que terminaban perjudicando al ferrocarril". 326

Con todo, en la mayoría de los testimonios prevalece la idea de cooperación entre los trabajadores. En ese sentido, uno de los valores que aparecen íntimamente ligados a la

\footnotetext{
${ }^{323} \mathrm{EN}^{\circ} 6$.

${ }^{324} \mathrm{EN}^{\circ} 14$.

${ }^{325} \mathrm{EN}^{\circ} 21$.

${ }^{326} \mathrm{EN}^{\circ} 1$.
} 
representación de familia ferroviaria es el de la solidaridad, a partir de prácticas vinculadas a la ayuda entre trabajadores, ante una necesidad o situación problemática puntual que el ferroviario estuviera atravesando. Miguel Mantino, quien fuera secretario general de la Unión Ferroviaria (lista verde), asegura: "Siempre nos hemos ayudado entre los ferroviarios. Cuando le pasaba algo a algún compañero todos tratábamos de solucionar el problema"327. Abel Pinto, por su parte, recuerda la cooperación entre ferroviarios para concretar una expectativa muy común de la época que, como se ha planteado antes, era parte del imaginario social: la construcción del hogar familiar.

\footnotetext{
"La mayoría de mis compañeros ferroviarios se hacían la casa, en el tiempo. Compraban un lotecito, lo iban levantando de a poco, cuando llegaban al techo ahí reunían a todos. Íbamos todos a hacer la losa, y el tipo tenía su casa, ya podía vivir, aunque no tuviera piso. Cada tanto había una losa para hacer... Muchísimos se han hecho la casa así, de a poco, en ocho o diez años se hacían la casa." ${ }^{328}$
}

La historia personal de Tornello tiene un hito crucial en 1976, cuando fue dejado cesante por su participación política en la Unión Ferroviaria. Ese acontecimiento expresa doblemente el valor de la solidaridad asociado a la "familia ferroviaria": por un lado, porque su cesantía es consecuencia de su actitud de entrega hacia sus compañeros, por el otro, por el accionar colectivo que este evento suscita:

\footnotetext{
"Cuando estuve preso, mi señora percibía el sueldo ferroviario. Hacían una colecta por mí, también por otros compañeros en mi situación. A ella no le faltó nada. Por eso te digo que era una familia. Ese dinero que le daban a mi señora fue el reconocimiento a una persona que había peleado por ellos, con equivocaciones y todo. Los compañeros reconocieron mi conducta". ${ }^{329}$
}

En Junín, entonces, la representación de familia ferroviaria es explicada por los actores, por un lado, por el tiempo compartido cotidianamente y a lo largo de toda la vida en el trabajo, así como por prácticas asociadas a valores comunes: solidaridad, cooperación.

En un trabajo sobre los ferroviarios de Argentina entre 1920 y 1943 Horowitz (1985) se refiere a los ferroviarios como una "comunidad ocupacional", ya que estos trabajadores,

\footnotetext{
${ }^{327} \mathrm{EN}^{\mathrm{0}} 5$.

${ }^{328} \mathrm{EN}^{\circ} 9$.

${ }^{329} \mathrm{EN}^{\circ} 6$.
} 
además de haber podido superar las barreras erigidas por las grandes diferencias de escalas salariales, categorías de tareas y empleadores, solían pasar parte de la jornada no laboral en compañía de otros trabajadores ferroviarios. Cita a Graeme Salaman quien define una comunidad ocupacional como aquella que:

“...representa una relación particular entre el trabajo y el resto de la vida; en su forma extrema, este tipo de relación es probablemente cada vez más inusual en las sociedades modernas. Los integrantes de las comunidades ocupacionales están de tal modo influidos por su trabajo, que su vida entera fuera de este se halla impregnada de las relaciones, intereses y valores desarrollados en él... Construyen su vida sobre la base de su trabajo; sus compañeros de tarea son sus amigos cuando la tarea termina, y sus intereses y actividades en los momentos de ocio giran en torno del trabajo" (Horowitz, 1994: 422).

En concordancia con el planteo de Horowitz, el tiempo compartido de los trabajadores de Junín no se reducía al trabajo, sino que también se extendía a los momentos de ocio y se vinculaba lo lúdico y el disfrute a partir de dos eventos principales: los encuentros deportivos y gastronómicos.

Respecto de los encuentros gastronómicos, Miguel Mantino, por ejemplo, no duda en explicar la existencia de una familia ferroviaria por este tipo de celebraciones: "Se formaban peñas y se hacían fiestas periódicamente. Por eso era como una familia". Ferrari, lo mismo: "Había una familia ferroviaria. Tal es así que de vez en cuando había reuniones de ferroviarios de distintas secciones. Nosotros también teníamos muy buena relación, los del personal de dirección”. Por su parte, Pinto cuenta: “Todas las secciones tenían su peña, comían un asado. Alguno llevaba una guitarra y cantaban”. Dall'Occhio, en tanto, da cuenta de que estos espacios comunes de disfrute le habrían permitido eludir o resolver conflictos propios del tiempo y espacio laboral:

"Como jefe, tuve una característica de crear un grupo de trabajo ameno. Siempre tuve grupos de trabajo bastante numerosos. En una oficina técnica tenía doce hombres, después llegué a tener como treinta. ¿Qué hacíamos para integrar ese grupo? Una o dos veces por mes nos reuníamos para comer juntos con la familia. Pero ese día cocinábamos los hombres. Las mujeres no trabajaban. En ese sentido se empezó a formar como una familia. Esa modalidad existía en las secciones del taller. Había lo que se llamaba peñas. Ponían una pequeña cuota por mes y hacían un asado, se reunían todos juntos. Le ponían un nombre a esa peña, pero no participaba la familia. Y yo me interesé más por que participara 
la familia. Y eso facilitó mucho nuestro trabajo, Se creó una gran camaradería en ese sentido, lo cual no solamente me sirvió para trabajar con mi gente, sino para encarar los problemas más agudos. Era cuando teníamos que atender problemas con las representaciones gremiales. Las representaciones gremiales buscan, por supuesto, defender las posiciones de sus representados, pero también buscan defender posiciones políticas que los encumbre, que los haga poderosos, que los haga importantes. Entonces, muchas veces, los pedidos eran más políticos que lo que hacía falta para mejorar el desempeño del área. Esa gimnasia del trato ameno con la gente me permitió soslayar una serie de problemas." ${ }^{330}$

El ocio puede ser concebido como un "tiempo no directamente productivo que puede ser empleado para el desarrollo de las redes de relaciones sociales de los individuos e, indirectamente, como tiempo para el acceso y acumulación de prestigio, liderazgo y poder, constituyendo por ello una fuente de status sociopolítico" (Escalera, 2000: 4). En efecto, el testimonio anterior de Dall'Occhio sugiere que este tipo de encuentros, realizados por fuera del tiempo laboral, podrían haber contribuido para legitimar su rol al frente del grupo de trabajo, así como para afianzar los lazos entre los integrantes y así converger en intereses compartidos en el ámbito laboral.

Rinaldi, por su parte, expone las diferencias en las celebraciones entre el personal jerárquico y no jerárquico. Su testimonio también sugiere que el modo diferente en que el personal de dirección llevó adelante estos encuentros implicó una estrategia para acceder y acumular estatus dentro del grupo de pares del personal de dirección, a partir de la compañía femenina que caracterizó a este tipo de celebraciones:

\footnotetext{
"Dentro de cada sección había como comisiones y se pagaba una cuota mensual de tres, cuatro pesos. Y dos veces al año se hacían reuniones con la familia. Ya sea en la Laguna de Gómez, en el Parque (Borchex). Y nosotros, en el Club Inglés lo hacíamos con los supervisores. Íbamos a comer un asado, y a jugar al truco, distintas cosas. Había secciones en las que se reunían los varones nada más. Claro, cuando se es operario no es tanto la reunión con la mujer. Pero cuando ya pasa a ser supervisor o de dirección, ya se une más con la mujer en la compañía de esa reunión, con otras personas del mismo escalafón. Sí, sí, la unión era bastante íntima..."
}

\footnotetext{
$330 \mathrm{EN}^{\mathrm{o}} 15$.
}

$331 \mathrm{EN}^{\circ} 3$. 
El siguiente testimonio de Crocco también expone la existencia de diferencias por el escalafón para los momentos de diversión que, de manera excepcional, no habrían sido tenidas en cuenta para su caso particular:

"Yo tenía (a cargo) un capataz que se llamaba Coloma, que conocía todos los rincones del ferrocarril porque estaba a cargo de la parte eléctrica, todas las cuevas, todo, todo. Y era un tipo muy jodón. Y él organizaba peñas de los encargados de la parte mía y hacíamos peñas en el Club Junín, en el Club Newbery. Cada tanto, cada dos o tres meses. Pero nunca me dejaron de lado por ser yo quien estaba a cargo de ellos. Era parte de ellos." ${ }^{332}$

De esta manera, la representación de "familia ferroviaria" es asociada a la unión entre trabajadores en torno a un valor común: la expectativa de disfrute a partir de la comida y, adicionalmente, otro tipo de placeres (música, baile, juego). Sin embargo, ese imaginario de comunidad que representa la idea de familia ferroviaria, no puede eludir las diferencias entre secciones y escalafones. En efecto, los encuentros no eran masivos, ni siquiera entre todos los trabajadores de Junín, aunque la representación de familia ferroviaria aluda a toda la Argentina. De hecho, cada peña tenía un nombre distintivo. Al mismo tiempo, establecían diferencias según el escalafón, tal como los testimonios de Rinaldi y Crocco parecen sugerir.

A pesar de las diferencias antes expuestas, puede afirmarse, no obstante, que el establecimiento de esos espacios de disfrute por fuera del tiempo laboral era una práctica extendida, común, entre los trabajadores del riel que favoreció la vigencia de la representación de familia ferroviaria.

Un ritual gastronómico que también parece haber contribuido en la construcción de familia ferroviaria han sido las despedidas al personal que se retiraba, luego de que los involucrados hubieran cumplido los años de servicio. Martínez relata orgulloso: "Cuando yo me jubilé, nos jubilamos, casi toda la sección fue a la cena. Tengo un diploma con la firma de todos". ${ }^{333}$ Danielle, por su parte, contextualiza:

"Las relaciones eran buenas. Cuando alguien se jubilaba se reunían para hacer una despedida. A esa despedida concurrían todos, hasta la jefatura máxima del distrito, aunque el que se jubilara fuera un peón." 334

$32 \mathrm{EN}^{\circ} 2$.

333 EN 20.

${ }^{334} \mathrm{EN}^{\circ} 27$. 
Esa participación a la que alude Danielle de buena parte de la comunidad ferroviaria en la celebración por el retiro del ferroviario (cualquiera sea su escalafón) revela una concepción empresaria en la cual cada uno tenía un rol en esa gran "familia" y que entre las máximas jerarquías y las menores había algo "común" que los unía. Al mismo tiempo, estos eventos parecen actualizar el imaginario según el cual existía un orden que se reiteraba generación tras generación y permitía prever que, una vez que la persona ingresaba, su vida entera se ligaría al ferrocarril. Como decía el ferroviario J.C. Cena de manera elocuente:

"El ferrocarril me vigiló el crecimiento. Estaba sujeto a él. Crecí desde él, objeto en movimiento y todo lo que este arrastrara. Por eso el ferrocarril es como si fuera mi otra anatomía, mi otro cuerpo, mi extensión ilimitada, mi otro dolor. Es que desde el Taller parto, y en ese Taller me injertan el tallo enrielado" (Cena: 1998, 26).

Aunque existieran normas en el taller que prohibieran cocinar en el tiempo de trabajo y compartir el almuerzo o merienda entre trabajadores, existían instancias en las que deliberadamente se incorporaba la comida como un modo de distensión de la jornada laboral. Crocco cuenta que, en el caso del personal de dirección, esto sucedía los días sábados, lo cual parece indicar que era un día diferente que, aunque se trabajara, se hacía a otro ritmo y con ciertos permisos:

\footnotetext{
"Nosotros en la jefatura nos reuníamos todos los sábados a la hora de la merienda. Se compraba galleta, fiambres, mate cocido. Se llevaban los estados de reparación de los coches. Entonces se hacían reuniones donde cada uno que estaba a cargo de una parte tenía que dar cómo va la reparación de la cosa. Para que el asunto se pusiera al tanto de todos. Eso se hacía una vez por semana por lo menos." ${ }^{335}$
}

Danielle, que no trabajaba en el Taller, sino en Vía y Obras, y por tanto, sus tareas eran, en general, en distintos puntos del trayecto y en espacios abiertos, relata que era costumbre, luego de la jornada exigida que tenían los que pertenecían a esta dependencia, identificados como "catangos" por su menor rango, compartir la merienda o el almuerzo entre los trabajadores: 
"Recuerdo momentos agradables, como compartir, el mate cocido a la tarde con los peones, ir a comprar galletas, azúcar. A la tarde, era un ratito, cinco o diez minutos. A veces lo preparaba yo mismo. A veces era la carne, el asado, había un cocinero. Y muchos traían la comida preparada de la casa. Era una hora para comer, y muchos comían en media hora y se acostaban un rato." ${ }^{\prime 36}$

Lo que, de acuerdo al relato de Danielle, estaba permitido para Vía y Obras, en cambio, estaba prohibido para el personal de Talleres por las características específicas de las tareas desarrolladas. Cuenta Dall'Occhio: "En el Taller, no se permitían las comidas calientes, como por ejemplo hacer un asado. Porque estaba vinculado con el vino". Sin embargo, el testimonio revela que la comunidad ferroviaria intentaba eludir estas prohibiciones: "Si alguna vez se ha hecho asado, se ha hecho a escondidas. Más de una vez me tocó arriar con el asado y llevarlo al asilo de niñas, lo cual no debe haberme creado mucha simpatía, pero las reglas eran para ser aceptadas". ${ }^{337}$ Calderoni también recuerda una anécdota con picardía:

"Si encontrabas a un tipo que estaba haciendo mate cocido entonces lo suspendían. Pero ahí adentro se hacía de todo, se hacían asados, chorizos, disimulado, ¿me entendés? La jefatura iba, muchas veces, sentía el olor a asado pero no podía localizar de dónde era. En una estufa a leña hacían una entrada arriba que no se veía cuando vos abrías la estufa, vos veías solo el fuego. Eso estaba arriba, la estaban haciendo con el calor de la estufa. Te voy a hacer un cuento, cuando yo estaba en soldadura el oficial que yo tenía que se llamaba Zanona, era uno de los mejores soldadores, había formado un grupito de cuatro soldadores, éramos cuatro soldadores, tipo ingleses. Los sábados llevaba churrascos de lomito y tenía un calentador dentro del armario. A la hora de la merienda lo iba haciendo en los calentadores y el supervisor que teníamos nosotros era un ruso. El tipo sentía olor a asado. No sabía de dónde venía. Y se sentía el olor donde estaba trabajando Zanona. Y yo estaba trabajando con Zanona. Y el supervisor un día dice: ‘A ver los comensales’ ‘¿Qué dice?, ¿cómo los comensales?', pregunta Zanona. 'Sí, le contesta, porque a estos les ha dado por comer sal, no sé por qué'. Después fue él el encargado de la sección cuando el ruso se fue." 338

La anécdota anterior de Calderoni muestra que, si bien las prohibiciones existían, también era recurrente el acuerdo de la comunidad ferroviaria perteneciente a los escalafones

\footnotetext{
${ }^{336} \mathrm{EN}^{\circ} 27$.

${ }^{337} \mathrm{EN}^{\circ} 15$.

${ }^{338} \mathrm{EN}^{\circ} 19$.
} 
menores de transgredir esa norma. ${ }^{339}$ Resulta sugerente que, nuevamente, el día elegido para la transgresión fuese el sábado, de la misma manera que la jefatura había optado por ese día para darse el permiso de comer galleta, fiambre y mate cocido de forma conjunta. Por último, la manera jocosa en que, tanto Dall'Occhio como Calderoni, relatan la transgresión, revela que las comidas compartidas realizadas de manera esporádica o eventual eran faltas consideradas no tan graves y, por tanto, que no ameritaban sanciones excesivas, ya que, probablemente, los mismos que tenían la potestad de sancionar en un momento una desobediencia a la norma, habían participado en otro momento de su carrera de una falta similar.

Además de las peñas, celebraciones y comidas, otros encuentros de la comunidad ferroviaria realizados por fuera del tiempo laboral que propiciaron la construcción de la "familia ferroviaria" eran los deportivos, los cuales favorecían la interacciones entre personal perteneciente a distintos escalafones y secciones. Tornello así lo cuenta:

“Por ejemplo, yo tenía quince años, el de montaje también. Organizábamos un partido de fútbol, de básquet, de lo que hubiera, y era una relación fluida. Hacíamos campeonatos, el deporte en el ferrocarril estaba a la orden del día". 340

Pinto explica las "buenas relaciones" entre trabajadores, precisamente, como consecuencia del deporte:

"La relación entre ferroviarios en general era buena. Se hacían campeonatos de fútbol entre todas las secciones. Dos años seguidos, en Iriarte, organizaban campeonatos de fútbol nocturnos. Iba un equipo conformado por ferroviarios a jugar allá”. ${ }^{341}$

Como el de Pinto, el testimonio de Marone permite reflexionar acerca del vínculo establecido entre los actores, el cual se habría ampliado más allá de Junín:

\footnotetext{
${ }^{339}$ Hay otras anécdotas que dan cuenta del acuerdo de ferroviarios del mismo escalafón para eludir las normas que intentaban hacer respetar los directivos. Cuenta Dall'Occhio: "Había códigos para proteger. Por ejemplo, cuando yo ingresé sentí que gritaban 'agua, agua, agua'. Yo pensé: 'Debe haber algún incendio'. Y era porque el jefe máximo estaba recorriendo el taller, quería decir que el jefe andaba cerca" (EN $\left.{ }^{\circ} 15\right)$. De Giulio, en tanto: "Vos no ibas a vender... si vos veías que alguien estaba haciendo una changa, vos no le ibas a decir al encargado. Lo hacías vos, lo hacía aquel, todos. Yo tengo algunos trabajitos, una raviolera, para cortar los ravioles, se tornea todo esto, se agujerea, se hace la rosca, y en la fresa te hacen el corte, la ruedita la hago yo, después el ajustador te hace esto" $\left(\mathrm{EN}^{\circ} 11\right)$.

${ }^{340} \mathrm{EN}^{\circ} 6$.

${ }^{341} \mathrm{EN}^{\circ} 9$.
} 
"Había peñas, había grupos deportivos y competencias, no solamente en Junín. Sino que todos los de Junín, por ejemplo, competían con los de Rufino o con los de Santos Lugares. Y venían equipos de fútbol, equipo de básquet, equipo de tenis. Después era al revés, participábamos y jugábamos allá”. 342

Podría afirmarse, entonces, que una de las maneras centrales en que la representación de "familia ferroviaria" estaba vigente entre los actores, como algo que se extendía más allá de los confines del propio taller $\mathrm{u}$ oficina, era a través de los encuentros deportivos. Dall'Occhio comenta:

"Esos encuentros deportivos se transformaban en amistades. Amistades que incluso se transformaban en visitas de un lado al otro. Por ejemplo, 'Venite a Mendoza y vení a conocer nuestra ciudad, nuestra provincia'. Se intercambiaban visitas, sobre todo con el personal de dirección, pero de todas maneras había una unidad como quien pertenecía a un mismo interés, de desarrollo cultural y de amistad" (el subrayado es mío). ${ }^{343}$

Por otra parte, en relación a los modos de vinculación entre actores con jerarquías diferentes en el ámbito laboral, es decir, las relaciones asimétricas entre jefes y el personal a cargo, prevalecen los testimonios que ponen el acento en la armonía o ausencia de conflicto, y el respeto entre ambos tipos de trabajadores. Por un lado, se enfatiza el respeto hacia la jerarquía del personal de dirección. Dice Dall'Occhio: "Había un código de mucho respeto en el trato. Mucho respeto hacia los superiores ¡No conozco que haya habido peleas en medio de tanta gente!". En tanto, Marone comenta: “Siendo joven fui jefe de gente más grande. Uno podría pensar que gente más grande podía reaccionar mal si le observaba o controlaba algo o trataba de enseñar. Mi experiencia, en cambio, es que la relación siempre fue buena." $" 344$

Probablemente, uno de los motivos que pueden explicar el respeto hacia los superiores dentro de la comunidad ferroviaria es el acuerdo compartido respecto de las normas que permitían el ascenso y que, por tanto, habían favorecido roles diferentes en la empresa. ${ }^{345}$ Estas normas se pueden clasificar, a grandes rasgos, en dos tipos: capacidad técnica y antigüedad. Respecto de las primeras, Marone insiste:

\footnotetext{
${ }^{342} \mathrm{EN}^{\circ} 14$.

${ }^{343} \mathrm{EN}^{\mathrm{o}} 26$.

${ }^{344} \mathrm{EN}^{\mathrm{o}} 15$ y EN $\mathrm{EN}^{\mathrm{0}} 14$.

${ }^{345}$ Se puede ampliar sobre este tema en "El progreso en la carrera ferroviaria" (Capítulo 1).
} 
"Yo tuve la suerte o la desgracia, de ser jefe con 21 años de gente que tenía 40, 50 años. Pero siempre con un gran respeto mutuo, nunca tuve conflicto con nadie. Se aceptaba que así fuera la cosa, porque cada uno se daba cuenta que tenía que ser así. No era que por ser viejo tenía que ser jefe, y por ser joven tenía que ser el último orejón del tarro. No, si las condiciones técnicas se daban, gente joven podía ocupar puestos de jefatura. Y la gente grande, lo aceptaba, lo respetaba." ${ }^{346}$

Respecto de las segundas normas (antigüedad), De Giulio comenta: "La relación con los jefes era buena, porque fueron trabajadores como nosotros, Caruso, por ejemplo. Trifiletti fue jefe mío y trabajó conmigo, ascendió porque era más viejo.” Violante, en la misma línea, expresa: “Éramos compañeros primero, después uno quedaba de encargado, otro de capataz, por antigüedad, un poco de capacidad también, se combinaban las condiciones, viste. Y sí, amigos, todos." Es sugerente que, en algunos relatos, como en el de Violante, aparezca la alusión a una relación entre iguales (amistad) que debe transformarse en el ámbito laboral, a partir de la relación desigual estipulada por el escalafón. De acuerdo a la experiencia personal de Marone, esto no le implicó mayores dificultades:

\footnotetext{
"Yo también tenía a cargo a amigos, con los que jugábamos al fútbol juntos. Porque era una edad... 21 años, te imaginás. Pero yo puedo quedarme muy tranquilo en ese sentido de que nos manejábamos en una atmósfera de mucho respeto. Afuera, podíamos jugar a la pelota, ir al cine, a bailar. Pero adentro, había un escalafón y se respetaba. Yo siempre decía que antes de ser un buen jefe prefiero ser un buen amigo, pero que el amigo me responda como jefe. Yo a él lo respetaba como amigo, y comparto como amigo. Pero él sabía que era jefe, y me respetaba como tal, después podíamos jugar juntos, hacer cosas juntos." 347
}

En cambio, para Tornello, las relaciones cercanas establecidas en el inicio de la carrera, en cambio, podían, en momentos, hacer tambalear la autoridad de quien la debía ejercer en un momento determinado:

\footnotetext{
$346 \mathrm{EN}^{\mathrm{o}} 14$.

${ }^{347}$ La amistad es un fenómeno social: "el amigo es un ser situado temporal, espacial, política y socialmente", pudiendo ser definida desde "el género, el parentesco, el ciclo de vida, la estratificación social", anudando "motivaciones e ideologías, normas y transgresiones” (Fernández, 2012: 23, 25).
} 
"En el ferrocarril se dieron circunstancias muy especiales. La relación con el jefe de talleres, no es lo mismo que la que se diera si fuera una empresa privada. El jefe mío, por ejemplo, fue primero oficial mío. Él era oficial, yo aprendiz. Él fue aprendiendo y después él era jefe. Así que yo no me dirigía en forma muy lejana a esa persona, porque yo tenía una relación de años con él. Entonces se hacía muy difícil, a veces, mantener por parte de él la autoridad y defender por parte mía lo gremial." 348

En otras palabras, podría plantearse que la afinidad, el respeto y la amistad logradas entre los trabajadores, como resultado de un inicio en la carrera más o menos similar (como peones o aprendices), a la vez que propició vínculos cordiales y de afecto, podría haber dificultado, en momentos, el vínculo desigual esperado a partir del escalafón (a partir del cual unos tenían el rol de dirigir, mientras otros el de obedecer). Quizás por ello, muchos jefes insisten en haber evitado aplicar medidas disciplinarias, en la búsqueda de mantener buenas relaciones. Crocco se enorgullece de nunca haber tenido que recurrir a ellas: "Nunca en mis cuarenta y cinco años, habiendo ejercido jefatura por más de veinticinco, casi treinta años, nunca suspendí a nadie. Siempre los llamé a la reflexión”. En tanto, Calderoni, también se muestra satisfecho por haber tenido que recurrir a ellas solo una vez en la carrera:

\footnotetext{
"Nunca tuve la intención de embromar a alguna persona. Porque algunos, no te voy a dar nombres, la única finalidad que tenían era ir a Talleres y joder gente. Buscar si estaban haciendo alguna macana. Abrir armarios a ver si había algún mate cocido dentro. Joder gente. Algunos creían que para mantener la disciplina había que andar buscando quién estaba mal parado y joderlo. Y eso no es disciplina. Yo nunca jodí a nadie, en toda mi vida ferroviaria suspendí a uno solo. Y lo suspendí porque un día entró al plantel y estaba trabajando en la morsa. Y le digo: ‘¿Qué estás haciendo?’. Claro, el tipo no me había visto y me dijo: 'Estoy haciendo un asunto para el bote'. Y de bronce. Le digo: 'Josecito, te tengo que suspender. Porque vos sabés que estas cosas no se hacen'. Y lo suspendí un día, pero el tipo comprendió cómo era el asunto, siempre fue amigo mío". ${ }^{349}$
}

Como Calderoni, Rinaldi recuerda, con malestar, haberse visto obligado a aplicar una medida disciplinaria, por la gravedad que el hecho revestía y el conocimiento de otros trabajadores, lo cual, en caso de haberla ignorado, podría haber implicado consecuencias para 
él mismo. Así y todo, él valora que esto no dañó el vínculo humano con el trabajador sancionado:

“El compañerismo del ferroviario es notable, también. Eso lo puedo ver ahora, después de veintipico de años. ¡Gente a la que le he aplicado medidas disciplinarias! Me ve ahora, me saluda, por ahí le digo 'muchacho', era muchacho en aquel entonces... Porque se había escapado del taller y otro le marcaba la tarjeta. Y yo fui el que le tuve que aplicar la medida disciplinaria, seis días de suspensión... El hombre salía a las seis de la mañana de su casa y volvía a las dos de la tarde. Hay medidas que usted no puede eludir. Porque hay medidas que usted puede decir, 'bueno, está bien, pero lo próxima...' Pero ya cuando hay conocimiento de otros compañeros, hay que aplicarla. Me dice: 'usted sabe que usted tenía razón. En su momento no lo comprendí' (risas). Pasa eso." 350

Por último, De Giulio cuenta haber cometido una falta y, quizás, gracias a su sinceridad, no haber sido sancionado. La anécdota ilustra que, en momentos, algunos jefes evitaban aplicar medidas disciplinarias de faltas consideradas menores por ellos mismos, con el objetivo de evitar conflictos con el personal:

“Un día me agarró ‘el inglés’ y yo estaba haciendo mate cocido. Me agarró justo. Me hizo ir a la oficina. Subo y me dice: ¿qué estaba haciendo? No sé cómo me salió eso. Le dije: 'Me iba a hacer un poco de mate'. Era manco, le faltaba el brazo. 'Qué le duele me dice'. 'Nada. Iba a comer un mate cocido con galletita, nada más. Bueno, deme los días que me tenga que dar'. 'Vaya, hágase el mate cocido y siga trabajando'. Me dijo eso porque le dije la verdad, si le hubiera mentido, no. Nunca me suspendió." ${ }^{351}$

En suma, puede afirmarse que lograr vínculos amables en las relaciones asimétricas, era considerado un valor dentro del colectivo ferroviario. Para Violante esto tuvo lugar, en gran medida, a partir de la nacionalización:

“Tenían la condición buena de exigirle relaciones laborales, relaciones humanas. Y si el tipo no estaba bien formado en ese aspecto, probaban al siguiente. Eso fue cambiando mucho después de la nacionalización. Tuvimos tipos fenómenos. Pedro Mendiburu, 
Jackson 'el inglés', que era argentino, pero hijo de ingleses, y le decían 'el inglés'. Un hombre muy accesible." 352

Una palabra que se reitera una y otra vez en los ferroviarios para referirse a este tipo de vínculos es "respeto". Crocco, por ejemplo, cuenta que ese era el modo en que se relacionaba con el personal que tenía a cargo. Luego se emociona profundamente, hasta el llanto, al relatar que, como consecuencia de ese trato, sus subordinados lo estiman como amigo, más que como jefe:

"Siempre tuve hacia ellos mi respeto (el personal a cargo). Primero estaba la parte humana, ¿verdad? Y por eso tengo la satisfacción de decir que tengo amigos. Pese a que a veces el jefe es el más resistido dentro del grupo humano... hoy la mayor parte de los integrantes de la división Planificación y Control...(silencio)... hacen reuniones (se quiebra), a las cuales me invitan (la voz se le hace más aguda, llora, luego tiene lugar un largo silencio). Podrás darte cuenta hasta donde llegan mis sentimientos (lo dice con la voz quebrada, luego un largo silencio). Me consideran un amigo, no el jefe. Soy Aymar para ellos (se quiebra la voz nuevamente). Un compañero más, un amigo... (continúa hablando con la voz quebrada). A esta edad me llena de satisfacción, tengo 80 años. Te das cuenta... Me tocás sentimientos..."353

Para los jefes, entonces, haber logrado la estima de los trabajadores a su cargo se expresa como un logro y resultado de un accionar sostenido durante toda la carrera. Además de aparecer en el testimonio anterior de Crocco, y en el de Rinaldi cuando dice: “¡Gente a la que le he aplicado medidas disciplinarias! Me ve ahora, me saluda...", también se puede observar en Marone: "Yo te puedo decir que a los ferroviarios que conozco y me conocen no tengo enemigos. Esa fue una línea de conducta que uno tuvo. Me llevo bien con todos." Y en Calderoni: $:^{354}$

“Todo el personal era amigo mío. Tal es así que cuando yo me jubilé, todavía mi señora estaba viva y salíamos nosotros por ahí, siempre encontrábamos alguno y decían: 'Señora, cuidelo a este, que este es una joyita'. Porque yo nunca jodí a nadie.”

$52 \mathrm{EN}^{\circ} 8$.

$353 \mathrm{EN}^{\circ} 2$.

$354 \mathrm{EN}^{\circ} 14$ y ENº19. 
Amigos, amistad son palabras que aparecen de manera frecuente para definir el tipo de vínculos establecidos entre los trabajadores que pertenecían a la comunidad del riel, a la "familia ferroviaria". En ese sentido, la amistad puede entenderse como un fenómeno social, definida desde "el género, el parentesco, el ciclo de vida, la estratificación social” y anuda "motivaciones e ideologías, normas y transgresiones". "El amigo es un ser situado temporal, espacial, política y socialmente" (Fernández, 2012: 23-25).

Además de los valores humanos vinculados al buen trato y al respeto, Marone también valora la solidez en los conocimientos y la generosidad de compartirlos, tanto de los jefes ingleses como los argentinos:

"Yo reconozco a muchos jefes que han sido coherentes con su accionar, gente respetable, gente que tenía las puertas abiertas si vos querías aprender algo, sin egoísmo. Gente que te reconocía si hacías las cosas bien, que es importante tener el reconocimiento. Yo no te puedo dar un solo nombre y apellido, pero te puedo decir que conocí muchos jefes de los cuales yo aprendí. Porque yo también llegué a ser jefe y alguna experiencia debía tener para conducir algo. $\mathrm{Y}$ esa experiencia no la adquirí en el patio de mi casa, la adquirí en mi trabajo, a través de gente coherente en su accionar, respetuosa, ordenada, con capacidad para resolver problemas. No fue uno solo, sino que fueron muchos. No fue alguien en particular el que me marcó, pero yo tomé muchas cosas de gente que era capaz, que tenía condiciones de mando, que eran excelentes personas y seres humanos. Pero sí, hubo personas que fueron más señeras que otras. Especialmente, cuando yo te hablaba del orden inglés, algunos de mis primeros referentes fueron ingleses. Uno se daba cuenta que esos tipos sabían lo que hacían y dónde estaban parados. Era gente que no era egoísta en enseñarte cosas, si vos tenías interés en aprender. Eran abiertos. En la época de la nacionalización esa gente desapareció, porque se fueron jubilando, se fueron. En ese momento hubo un grupo de profesionales que se incorporó, porque el ferrocarril no tenía ingenieros, tenía técnicos. Esos profesionales de ingeniería, también fueron referentes para mí, porque tenían mucha capacidad. Tenían sus condiciones técnicas y capacidad intelectual, producto de su nivel de estudio, que lo supieron transmitir." 355

Otro valor que emerge en los relatos es la plasticidad del jefe de abandonar momentáneamente su rol para realizar las mismas tareas que sus subordinados, como un modo de igualarse con ellos y dar el ejemplo. Dice Danielle:

$355 \mathrm{EN}^{\mathrm{o}} 14$ 
"Yo trabajé en el descarrilo. Trabajaba a la par de los peones para darle ánimo, meterme debajo de los vagones que la grúa levantaba para poder armar los rieles. Para incentivarlos... A veces no querían meterse porque decían: ‘¿Y si se corta el cable...?'. Entonces yo decía: 'Yo me voy a meter'. Y cuando yo me animaba, se animaban otros." ${ }^{356}$

Algo similar recuerda Bozzini de un jefe que, más que un capataz, era para él un "señor capataz": "Sin decir una palabra, él nos guiaba. Muy suavemente. Prácticamente, trabajaba junto a nosotros". 357

Dall'Occhio, por su parte, destaca la honestidad, el carisma y la elocuencia por parte de algunos de sus pares jefes:

"Yo siempre admiré a Rinaldi, por su capacidad, por su hombría de bien, su honradez, comprometido, serio, prudente. Y también admiré mucho a Mendiburu. Cada tanto se hacían reuniones con el ferrocarril Mitre, Roca. Había gente de la gerencia, cada tres o cuatro meses, unas mesas enormes. Empezábamos a tratar temas y a los diez minutos Mendiburu copaba la reunión. Todo el mundo convergía en las opiniones de Mendiburu. Era un hombre realmente notable, incluso le ayudaba el tono de voz. Tenía una personalidad, una presencia de imponer su... Cuando él hablaba todo el mundo lo escuchaba." ${ }^{358}$

De esta manera aparecen algunas cualidades asociadas al "buen jefe" en el imaginario de esta comunidad ferroviaria: sabiduría, generosidad en la transmisión de saberes, humildad, honradez, capacidad de liderazgo.

Se ha planteado líneas antes que existían dos prácticas llevadas adelante fuera del tiempo laboral, asociadas a la diversión y al disfrute, que "alimentaban" la representación de familia ferroviaria: los encuentros gastronómicos (cenas, peñas) y deportivos (partidos informales, campeonatos). En los relatos aparece también otra práctica asociada a lo lúdico que, no obstante, se llevaba a cabo en el tiempo propio del trabajo. En principio, pareciera haber sido local, por involucrar a una persona particular de Junín, aunque es posible que se haya reproducido en otras comunidades ferroviarias numerosas. Cuenta De Giulio: "El viejo Célico te miraba, te dejaba un día, dos, tres, y te ponía el sobrenombre.” Dall'Occhio no recuerda el nombre de quien ejercía esta función en la comunidad ferroviaria, pero sí su "tarea”. "Había un 
tipo que era especialista en colocar sobrenombres. Entonces, cuando había gente nueva lo llevaban por las secciones, a escondidas para que le ponga sobrenombres a los nuevos", cuenta entre risas. De ahí que De Giulio fue bautizado como "el coreano", por ser menudo: "Todos conocen al coreano. Como De Giulio no me conocen. Por sobrenombre conozco a muchos y si me decís el nombre no lo sé." Martínez, en tanto, fue renombrado dentro de la comunidad como "Picasso": "Porque a mí siempre me gustó el juego, el póker. Y caía la policía y picaba".359 Dall'Occhio se explaya:

\begin{abstract}
"A Coloma le decían 'Pecos Bill'. Porque caminaba como si le molestara la pistola. Un personaje era... Arrastraba gente con su ímpetu... Este tipo, por su personalidad, era muy entusiasta. Toda la gente lo seguía, no empujaba a la gente, no precisaba mandar, ordenar. Él decía vamos y la gente lo seguía. Por eso Mendiburu lo puso a él al frente, dijo, con este tipo hago cualquier cosa. Había uno que le decían bombilla tapada (hace un gesto como si estuviera intentando tomar mate de una bombilla tapada). A Rinaldi le decían 'el Patón', porque caminaba con pasos muy largos. A mí me decían 'Chañar ladeado', una estación de ferrocarril, porque yo caminaba con un hombro más alto que el otro, porque tengo una hipertrofia. El que ponía sobrenombres, no me acuerdo el nombre, pero era de lo más ocurrente. Y el sobrenombre no te lo sacabas nunca más. Había uno que le decían budín inglés, porque tenía como unos granitos negros, unas verrugas." 360
\end{abstract}

Los apodos, entonces, destacaban alguna cualidad de la persona y, a menudo, la exaltaban al punto tal de mofarse. Por eso, en algunos casos, estas prácticas lúdicas no eran celebradas. Cuenta Pinto: "Era costumbre tener apodos. Primero eran apodos como Tito, al que le decían Albertito. Después eran apodos ofensivos, o de mirarle algún defecto al otro. A mí me decían 'El pollo"”. También parece ser el caso de Tornello que no recuerda su apodo, vinculado a su identificación política: "El loco o el Rojo, no sé". 361

Sin embargo, puede sostenerse que los apodos podrían haber jugado un papel en aglutinar a los distintos actores a partir de la representación de "familia ferroviaria", en la cual cada uno tenía un lugar y un rol. A la vez, alimentaban el imaginario que sugería que la ferroviaria era una "segunda familia", similar a la de origen. Por tal motivo, para ingresar y a modo de bautismo, cada uno recibía un nombre que lo habilitaba como nuevo miembro.

\footnotetext{
${ }^{359} \mathrm{EN}^{\mathrm{o}} 11, \mathrm{EN}^{\mathrm{o}} 15$ y EN 20.

${ }^{360} \mathrm{EN}^{\mathrm{o}} 15$.

$361 \mathrm{EN}^{\circ} 9$.
} 
Si bien los maquinistas respondían a la apelación de "ferroviarios", ya que quienes no pertenecían al colectivo los identificaban como tales sin distinguir su tarea específica vinculada a la conducción, ellos mismos se autoidentificaban como "fraternales" diferenciándose así del resto de los trabajadores del riel. ${ }^{362} \mathrm{Al}$ plantear los modos en que ellos se vinculaban, precisamente, intentan distinguirse de sus colegas de Talleres. "El nuestro era un trabajo más armónico... en comparación a los de Talleres", dice uno de ellos y su compañero confirma: "Más de amigos, entiende... Había compañerismo". ${ }^{363}$ Así y todo, más allá de las diferencias que fundamentaban la distinción, existían numerosas similitudes en relación a los valores compartidos y prácticas.

A partir de la perspectiva de Agulhon (1994) que otorga una consideración especial al "lugar" como fundamento de sociabilidad de los sectores populares, pueden distinguirse tres espacios físicos principales donde la relación entre fraternales se desarrollaba: la sede del gremio La Fraternidad, las locomotoras y los denominados "puntos de relevo".

En primer término, la sede de La Fraternidad era el lugar destinado a la enseñanza de la conducción de locomotoras, por parte de maquinistas reconocidos por su saber y designados como "instructores" por el mismo gremio. Además, era el espacio donde se reunían los recién ingresados y los que detentaban la máxima autoridad según el escalafón: los maquinistas. "Se hacían reuniones los días lunes para explicar los problemas y ahí nos conocíamos con los aspirantes", comenta un fraternal. Los conductores de locomotora aparecen, entonces, como los más respetados dentro del colectivo, a partir del conocimiento en la profesión. A diferencia de lo que sucedía en Talleres, coincidía, en general, con una mayor edad y, por tanto, experiencia: "Nos íbamos entendiendo desde el joven al mayor. Siempre se respetaba al que tenía más autoridad que era el maquinista, por lógica. Era un respeto... para que le voy a decir. ". 364 De esta manera, las relaciones asimétricas establecidas por el escalafón eran concordantes con la autoridad que representaba el saber (en coincidencia con Talleres) y la experiencia que otorgaban los años en la actividad.

La "familia fraternal", como la "ferroviaria", también contaba con celebraciones específicas para celebrar su “comunión”, por fuera del tiempo laboral. Específicamente, los 20 de junio en todo el país se hacían cenas (asados) para festejar el Día del Fraternal. Precisamente, el lugar elegido era la misma sede gremial. "Esas fotos son todas de asados",

\footnotetext{
362 "La unidad, la homogeneidad interna que el término identidad trata como fundacional, no es una forma natural sino construida de cierre, y toda identidad nombra como su otro necesario, aunque silenciado y tácito, aquello que le "falta"' (Hall, 2003: 19).

${ }^{363} \mathrm{EN}^{\circ} 12$.

${ }^{364} \mathrm{EN}^{\circ} 12$.
} 
dice uno de los conductores mostrando imágenes de celebraciones anteriores y añade: "Todo esto —en alusión a la sede gremial— tiene olor a asado".

\begin{abstract}
"Nosotros festejamos el Día del Fraternal el 20 de junio. Entonces, se ha dado casos en que yo ese día, había pagado mi tarjeta acá en Junín para ir a la reunión, pero me encontraba afuera, y esa fiesta se hacía en todas las seccionales. Hablemos de Retiro, Rawson, Junín, Laboulaye, en todas las secciones se hacían fiestas. Y si yo me encontraba en una ciudad que no era mi sección, me llevaban a pasar las fiestas con ellos. O sea que había una camaradería... Lo único es que siempre hubo una tirantez con la gente de la Unión Ferroviaria." ${ }^{365}$
\end{abstract}

Otro de los espacios fundamentales en los que la sociabilidad fraternal se desenvolvía y que, al mismo tiempo, favorecía la identificación con el colectivo, era la misma locomotora, entendida como un lugar de trabajo y de enseñanza informal. Este saber que el maquinista, más experimentado, transmitía al foguista que lo acompañaba, estaba vinculado con habilidades del oficio, a partir de problemáticas concretas que surgieran en el contexto de un viaje. Por el otro, con valores compartidos por el gremio. Como dice Dante Cruz, el conductor enseñaba ciertas cosas, como "la forma de manejarse, de conducirse con los compañeros".366 Puede caracterizarse el vínculo establecido en la locomotora como íntimo, ya que involucraba, en general, dos personas que compartían muchas horas juntas (maquinista y foguista). Una de ellas era la que contaba con el conocimiento, tanto técnico como social y, que, por ese motivo, tenía el rol de transmitirlo al novato. Por eso era una relación asimétrica de respeto, cualidad que aparece mencionada en estos testimonios, al igual que en los ferroviarios no fraternales. Sin embargo, también era una relación de iguales que considera a la asimetría solo como momentánea, ya que se preveía que el foguista se convierta en maquinista en un futuro. Esto se expresa, por ejemplo, en el siguiente testimonio de Cruz:

\footnotetext{
"Si vamos el conductor y el foguista y vamos con un tren para allá, nos ponemos a hablar, se cruza uno, hay que desviar el tren, y bajamos, el conductor le pregunta al foguista si sabe de reglamento, de máquina. Entonces hay convivencia de compañeros." ${ }^{367}$
}

\footnotetext{
${ }^{365} \mathrm{EN}^{\mathrm{o}} 12$.

${ }^{366}$ Este aspecto fue profundizado en "Los distintos espacios de formación de los ferroviarios", Capítulo 1.

${ }^{367} \mathrm{EN}^{\circ} 13$.
} 
La igualdad, entonces, era parte del imaginario fraternal, a partir del mismo nombre del gremio que alude a una relación fraterna, de pares. Esto influyó en los modos de relación, tal como resalta Cruz: "No existe alguien que mande, porque todos, todos son fraternales. El sueldo es igual para el más nuevo como el más viejo. No hay antigüedad".368

Otro espacio que propiciaba el vínculo entre fraternales eran los puntos de relevo, viviendas de La Fraternidad en las que estos trabajadores residían luego de una jornada de viaje, muchas veces, junto a otros maquinistas y foguistas procedentes de algún otro punto del país. Allí, comían, dormían y compartían hasta que les tocaba poner en marcha otra vez el tren para volver a Junín o trasladarse a otra estación.

\begin{abstract}
"Ha habido un compañerismo terrible acá. Porque nos conocíamos en la máquina y después nos conocíamos en las piezas. Ahí compartíamos todo. Y era una fiesta para nosotros, porque cuando llegábamos a Mercedes, a Laboulaye, éramos veinte, veinticinco para comer... Y el primero que llegaba cocinaba para los veinticinco. Era todo joda. Los carniceros con nosotros festejaban, porque calculá que éramos 20, 25. Kilos de asado.”369
\end{abstract}

Como en el caso del resto de ferroviarios, los encuentros gastronómicos propiciaban vínculos de sociabilidad que, al mismo tiempo, cooperaban para aglutinarlos como colectivo "fraternal", diferenciado del resto.

"Siempre estaba el compañero que le gustaba hacer comidas elaboradas, como un guiso. Después estaba el que hacía asado. Decíamos: 'ah, está aquel en la pieza, entonces vamos a comer asado hoy'. Ya íbamos pensando qué íbamos a comer por quién estaba en la pieza." 370

De esta manera, las comidas compartidas constituían un modo de establecer lazos y afianzar la identificación hacia La Fraternidad. La intimidad que primero se establecía en la locomotora entre dos fraternales de diferente posición, en las "piezas" o puntos de relevo se extendía a otros fraternales, con los que también se convivía y con quienes se dormía:

\footnotetext{
${ }^{368} \mathrm{EN}^{\mathrm{o}} 13$

${ }^{369} \mathrm{EN}^{\circ} 12$.

${ }^{370} \mathrm{EN}^{\mathrm{o}} 12$.
} 
"Cuando se organizaron los lugares de relevo, todos nos hicimos socios y ahí compartíamos. Nuestra vivienda, nuestra cocina, nuestra pieza. Hacíamos la comida. En fin, se armó como un grupo familiar". 371

Esa alusión a la familia se fundamentaba en que en esas residencias debían llevar adelantes tareas propias del hogar familiar, tal como queda expuesto en el siguiente diálogo:

—Fraternal A: Había que limpiar, barrer las piezas, lavar los pisos. No teníamos una chica que nos viniera a limpiar. Era una casa normal.

—Fraternal B: No estaba la mamá. Entonces, los que no hacíamos nada en la casa porque estaba la mamá lo tuvimos que aprender de ellos... ellos nos enseñaron a cuidar.

-Fraternal C: nosotros convivíamos, ahí nos conocíamos más. Había de todo, como en una familia. Los buenos, los trabajadores, los regulares, los vagos que eran los que no limpiaban y había que renegar... Igual que en una familia. ${ }^{372}$

Por su parte, Cruz también resalta la convivencia como fundamento del vínculo logrado, el cual, en general los fraternales definen en términos de "compañerismo", antes que de amistad: "En la idiosincrasia nuestra como fraternal, se busca la forma de convivir. Alguno es mejor que otro, otro es un tiro al aire, pero por lo general se convive fraternalmente". ${ }^{373}$ Nuevamente, tanto en la entrevista con Cruz como en la grupal, se expone la existencia de una relación de iguales que es simultánea a una relación asimétrica, por la que aquellos que tenían autoridad debían guiar a los recién llegados. En efecto, cuando uno de los fraternales en el diálogo expresa "ellos nos enseñaron a cuidar", el testigo está aludiendo a los mayores, los que contaban con más años dentro del gremio y, por tanto, conocían sus normas. De esta manera, a diferencia de los ferroviarios antes analizados, la edad, constituía un atributo de autoridad por la capacidad que otorgaba de transmitir saberes, habilidades y experiencias.

Precisamente, una de las normas transmitidas de fraternales mayores a novatos era dejar la vivienda en las mismas condiciones en que había sido recibida, lo que involucraba el orden, la limpieza y la adquisición de mercadería. Esta actitud puede ser interpretada como de respeto y cuidado hacia el resto de los compañeros. 
"Los puntos de relevo son casas como la tuya. Tienen cocina, baño, heladera, aire acondicionado, cocina, todas las comodidades de una casa. Es decir que vos llegás y lo único que tenés que llevar es tus sábanas y tenés tu cama de una plaza, con frazadas, acolchado, todo. Después en la heladera tenés vino, gaseosa, cerveza, agua, soda, y en algunos lugares había latas de atún, latas de sardina. O sea que vos llegabas a las tres de la mañana, con hambre, y agarrabas una lata de sardinas, o de atún, y con las galletitas comías. No te ibas a dormir con el estómago vacío. Está todo previsto. Después a la mañana siguiente, te levantabas e ibas al mercado de al lado y reponías lo que vos comías y lo que vos tomabas. Eso hacía que hubiera un stock en la heladera permanente. Entonces vos llegabas y no estabas desamparado. Todos tenían que ir, higienizar la casa, limpiar. Era una casa, normal, nada más que nos hacíamos cargo nosotros." 374

Tanto en el testimonio anterior como en otros aparece el cuidado entre los fraternos como valor. En otras palabras, la protección entre pares frente al desamparo que representa el traslado hacia un lugar no familiar, en el que no se encuentran sus allegados y familiares cercanos. También lo dice otro conductor: "Es como si hubiéramos sido todos hermanos. O sea que nos cuidábamos unos con otros, había que protegernos. O sea que nos encontrábamos en una vivienda...". 375

Ese espacio en el que el colectivo compartía una vivencia conjunta era tan preciado, que una de las maneras de sancionar al fraternal que transgredía una norma era a través de la quita de tal derecho gremial. Cuenta uno de los fraternales: "La forma de castigo por no cumplir era a través de la vivienda. Y si te castigaban con la vivienda era lo peor, porque tenías que pagarte un hotel y además no tenías la libertad que tenías en la vivienda tuya". Otro compañero se explaya, dando cuenta de las normas establecidas por el gremio que, al ser infringidas, devenían en la temida sanción:

"Un tren de carga tenía nueve horas de trabajo. Un tren de pasajeros era de ocho horas. Y te castigaban por trabajar más. Uno de los castigos que todos nosotros le escapábamos era la vivienda. Porque si a vos te castigaban acá en el gremio, te castigaban en la sociedad de viviendas. A partir de eso tenías que pagar un hotel, y no era lo mismo. Entonces, todas esas cosas, nos enseñaron los viejos. Acá hay un reglamento, hay una forma de trabajo. Y nos tuvimos que adaptar todos a ese sistema." 376

\footnotetext{
${ }^{374} \mathrm{EN}^{\circ} 12$.

${ }^{375} \mathrm{EN}^{\circ} 12$.

${ }^{376} \mathrm{EN}^{\circ} 12$.
} 
Otro de los fraternales fundamenta la sanción gremial: "El castigo no era un castigo caprichoso. El castigo tenía un porqué. Era porque si yo trabajaba una hora más o media hora más, le estaba privando a otro compañero de que trabaje". De la misma manera, también se castigaba a quienes se retiraban después de determinada edad. El mismo fraternal justifica: "Se castigaba a la gente que se quedaba después de los 55 años. Porque no dejaba el lugar para que entren pibes jóvenes". Luego de detallar toda la serie de sanciones, el conductor resalta: "En La Fraternidad es donde me formé éticamente". ${ }^{377}$ Esta síntesis que el maquinista realiza sobre la importancia que tuvo el gremio en su formación, implica una manera de accionar respecto a sus pares en relación al cuidado y a la solidaridad que, al mismo tiempo, podía involucrar modos de actuar en el resto de la sociedad.

Por último, dentro de la comunidad local aparecen dos actores que se erigen como ejemplos dentro del colectivo fraternal, por su aptitud simbólica de representar y fomentar valores compartidos: Dante Balestro y Antonio Lemaggio. El primero, por su conocimiento, el segundo por su elocuencia y su capacidad de oratoria; ambos valores compartidos por los ferroviarios de Talleres. Dice uno de los fraternales: "Balestro era un maestro. Una eminencia, porque la máquina la conocía de Pe a Pa. Era lo máximo”. Otro fraternal asiente y confirma: "Hizo los manuales de las locomotoras diésel eléctricas. Las hizo él para todos los ferrocarriles, para todo el país". En tanto Lemaggio es recordado por su capacidad político-gremial. Cuenta uno de los fraternales: "El tipo se movía como pez en el agua en el Congreso de la Nación, en la Casa de Gobierno. Se paraba en Roque Sáenz Peña ${ }^{378}$ y se ponía a hablar y te juro que se paraba toda la gente a escucharlo. Era un militante de raza". ${ }^{379}$ Dante Cruz coincide recordando una anécdota de quien fuera presidente de la Mesa Coordinadora de Jubilados y Pensionados:

\footnotetext{
"Me acuerdo que él tenía una labia... conocimiento no tanto. Entonces un día teníamos que ir a gerencia, por un tema de la ley, entonces lo solicitaron a él por dos artículos. Entonces él dijo, 'Sí, pero que venga conmigo el compañero Cruz’. ‘¿Para qué?’, le dije después. 'Porque yo no me acuerdo cuáles son los artículos', me dijo (risas). 'Vos me los nombrás y me lo dejás a mí'. Yo le decía los artículos, los incisos, lo que decían y después agarraba él la máquina (dice, mientras hace un gesto circular con el dedo, cercano a la boca, en alusión a la capacidad de oratoria). Buen compañero era... Una labia bárbara tenía. Pobre Antonio." 380
}

\footnotetext{
${ }^{377} \mathrm{EN}^{\circ} 12$.

${ }^{378}$ Calle principal del centro comercial de la ciudad de Junín.

${ }^{379} \mathrm{EN}^{\circ} 12$.

${ }^{380} \mathrm{EN}^{\mathrm{o}} 13$.
} 
Como síntesis del presente apartado, puede afirmarse que tanto los ferroviarios de Talleres, Vía y Obras y Mecánica como los de "La Fraternidad” establecieron vínculos de amistad, afecto y compañerismo, lo cual dio vigor a la representación simbólica de "familia ferroviaria" o "familia fraternal", en cuyo interior se establecieron relaciones tanto simétricas como asimétricas. En el caso de los primeros, la asimetría se explicaba por un escalafón que diferenciaba al personal a partir de sus saberes técnicos y su antigüedad en la empresa. En cambio, los fraternales fomentaban una relación de igualdad, de hermandad, en la que, no obstante, existían actores con mayor autoridad, los conductores y, dentro de ellos, los mayores, que tenían por función guiar al resto a partir de su mayor experiencia.

Por otra parte, los intensos vínculos forjados, tanto en la familia ferroviaria como la fraternal, se explican por la cantidad de tiempo compartido en espacio físicos puntuales (en el taller, la oficina, los puntos de relevo, la locomotora, etc.) y a lo largo de distintos momentos de la existencia del trabajador (desde la juventud, pasando por la adultez hasta el inicio de la vejez), desde que iniciaron la carrera laboral y hasta su retiro y, muchas veces, incluso después de él. Ese tiempo compartido no solamente abarcaba el tiempo laboral, sino también el de ocio, a través de cenas, peñas y encuentros deportivos (en el caso de la "familia ferroviaria"), y de comidas y convivencia en los puntos de relevo (en el caso de la "familia fraternal").

Ambas comunidades también fomentaron valores en sus integrantes, entre los cuales la solidaridad entre compañeros aparece como común a ambas. Sin embargo, la solidaridad entre fraternales estaba asociada a las normas establecidas por el gremio y consensuadas por sus integrantes para ser practicadas dentro del tiempo laboral, en contraposición a lo que sucedía con el resto de ferroviarios, para los que la solidaridad abarcaba también la vida personal del trabajador $^{381} \mathrm{e}$, incluso, podía contraponerse a las normas establecidas para los espacios laborales. ${ }^{382}$

Así y todo, ambos trabajadores del riel exponen la existencia de normas. En el caso de los trabajadores ferroviarios de Talleres, Mecánica y Vía y Obras, las normas enunciadas procedían de la empresa y los encargados de hacerlas cumplir e imponer sanciones respectivas

\footnotetext{
${ }^{381}$ Ejemplos de esto son la colaboración para construir una casa, la colecta para el compañero preso o la ayuda a un compañero en problemas.

${ }^{382}$ El testimonio de De Giulio es elocuente en ese sentido, ya que asocia el compañerismo con la complicidad entre trabajadores del mismo nivel jerárquico para transgredir normas de la empresa: "Éramos todos compañeros. Y era así, tenía que ser así. Porque vos no ibas a vender. Si vos veías que alguien estaba haciendo una changa, vos no le ibas a decir al encargado. Lo hacías vos, lo hacía aquel, todos. Yo tengo algunos trabajitos, una raviolera, para cortar los ravioles." Las "changas", así llamadas por los trabajadores del riel, eran objetos realizados con fines personales para su uso en el hogar, hechas con recursos materiales y humanos de la empresa.
} 
eran los jefes de los distintos estamentos, cuya autoridad había sido establecida a partir de los nombramientos en los diferentes cargos. Sin embargo, en la práctica algunos jefes preferían evitar las sanciones que eran consecuencia del no cumplimiento de las normas, con el objetivo de mantener buenas relaciones hacia el interior del grupo de trabajo y la estima personal hacia ellos mismos, a menos que la falta fuera de una flagrancia tal que hiciera peligrar su autoridad. En el caso de los fraternales, en cambio, la aplicación de las sanciones parecía proceder del gremio como entidad que representaba al conjunto y el acuerdo respecto de los apercibimientos parecían ser consensuados e incluso fomentados por la mayor parte de los integrantes del colectivo, en el marco de una relación percibida y representada como "de iguales".

\section{El ferrocarril y el desarrollo cultural de Junín}

Entre los trabajadores entrevistados son comunes las representaciones que vinculan la existencia del conglomerado ferroviario en Junín con el desarrollo cultural, social, artístico, técnico y deportivo en la ciudad. Unida esta representación a la de la excelencia o calidad de los trabajadores del riel (tema que fue desarrollado en el apartado "La calidad como sello de identidad") se refuerza el orgullo y la identificación hacia el centro ferroviario local. Tornello sintetiza esta idea con claridad: "Hasta los mejores jugadores de fútbol estaban ahí adentro. Vos dirás, ¿cómo puede ser que todo lo mejor estaba ahí? Pero sí, es la verdad”. ${ }^{383}$

Algunos explican la participación de ferroviarios en distintos proyectos con el tiempo libre con el que contaban, otros por la cantidad de trabajadores que albergaba la empresa en su interior. Por ejemplo, Héctor Pellizi, hijo de ferroviario e integrante de la Biblioteca Florentino Ameghino, comenta: "Los ferroviarios salían a las 2 de la tarde y tenían tiempo libre, entonces se dedicaban a clubes, bibliotecas". ${ }^{384}$ Marone, por su parte, afirma: "En el ferrocarril había una cantidad numerosa de gente, cada uno buscó lo suyo como actividad fuera del ferrocarril, el que le gustaba la música hizo eso, y el que le gustaba la parte social fundaba bibliotecas, instituciones deportivas, clubes". ${ }^{385}$ Ya sea por el tiempo libre o por la cantidad de empleados, en lo que parece existir coincidencias es en lo que este complejo ferroviario favoreció para distintos aspectos de la vida de la ciudad.

Marone vincula el desarrollo de numerosas instituciones, como clubes, y "el progreso de la ciudad" con la existencia del ferrocarril en Junín y de ferroviarios puntuales que, en sus

\footnotetext{
${ }^{383} \mathrm{EN}^{\mathrm{o}} 6$.

${ }^{384}$ Entrevista No 28 realizada a Héctor Pellizi, Junín, 11/05/2016, en adelante ENº 28.

${ }^{385}$ Entrevista No29 realizada a Ítalo Marone, Junín, 14/05/2016, en adelante EN 29.
} 
palabras, "fueron creativos e intentaron hacer progresar a las instituciones". En definitiva, las cualidades de estos actores fueron determinantes en el desarrollo de las organizaciones.

"En todos los clubes había gente ferroviaria. Difícilmente un club no estuviese formado con algún directivo ferroviario. No te digo el Club BAP, porque ahí eran todos ferroviarios. ${ }^{386}$ Pero en todos los demás clubes deportivos, sociales, en las sociedades de beneficencia, en todos esos lugares había gente ferroviaria. En aquel entonces, vos ibas a una comisión y había cuarenta integrantes, y a lo mejor quince eran ferroviarios. Es decir, cerca de la mitad eran ferroviarios. Porque el ferroviario participaba, porque el ferrocarril le daba margen después de cumplir su horario y buscaban desarrollar algunas otras actividades en el orden social. Y bueno, muchas de esas instituciones se sostenían a través del trabajo de ferroviarios que en sus horas libres buscaban inclinarse hacia otras inquietudes sociales, deportivas, comunitarias." 387

Taberna relata algo similar respecto del desarrollo de clubes:

"La mayoría de los clubes tenían ferroviarios. La gente de La Fraternidad estaba muy ligada al club Ambos Mundos. ¿Cómo los puedo calificar? Las ideas de ellos eran de izquierda y estuvieron muy perseguidos en la época de Perón. Era gente que participaba en política. Ahora: en todos los clubes, Belgrano, ${ }^{389}$ Rivadavia, ${ }^{390}$ en todos había ferroviarios,

${ }^{386}$ El Club Buenos Aires al Pacífico fue fundado en 1892 por Francis Colin York, años después de la instalación de los Talleres Junín en 1886. En sus inicios, sus integrantes debían pertenecer a la empresa ferroviaria. Club Atlético Buenos Aires al Pacífico. Recuperado de https://es.wikipedia.org/wiki/Club Atl\%C3\%A9tico Buenos Aires al Pac\%C3\%ADfico: 10/2/2020.

\section{$387 \mathrm{EN}^{\mathrm{o}} 14$.}

${ }^{388}$ Ambos Mundos se fundó en 1922. (Ambos Mundos cumple hoy 96 años (22 de mayo de 2018). La Verdad, recuperado en: https://laverdadonline.com/ambos-mundos-cumple-hoy-96-anos/: 10/2/2020).

${ }^{389}$ El Club Atlético Villa Belgrano se fundó en 1925, bajo el nombre de Football Club Defensa, en el barrio obrero “Tierra del Fuego". Su misión central era fomentar la práctica de fútbol (Club Atlético Villa Belgrano, sus bodas de oro (octubre de 1975). Historia de Junín, p. 1).

${ }^{390}$ El Club Atlético Rivadavia se fundó en 1915. Su primer nombre fue Club Atlético de Foot Ball. En 1923 logró ascender a primera división de fútbol, compitiendo con Ambos Mundos. Su ubicación fue el entonces barrio obrero de "Tierra del Fuego": "En 1915 un grupo de jóvenes que practicaba el fútbol en las calles polvorientas del entonces 'Tierra del Fuego', hoy Barrio Belgrano, decidió crear un club de barrio". (Rivadavia cumple hoy 104 años (15 de noviembre de 2019). La Verdad. Recuperado de https://averdadonline.com/rivadavia-cumple-hoy104-anos/: 11/02/2020). 
Los Indios, ${ }^{391}$ Ciclista, ${ }^{392}$ San Martín. ${ }^{393}$ En el San Martín había muchos árabes y también había muchos ferroviarios. En el Club Argentino, barrio Las Morochas, ${ }^{394}$ también había árabes y ferroviarios." 395

Pellizi recuerda que la construcción de la cancha de básquet y el salón del Club Rivadavia fue, en parte, gracias a una donación de cemento gestionada por ferroviarios que participaban de la institución, en oportunidad de la construcción del Hospital Ferroviario en 1949. Quince años después, cuando se comenzó a construir el gimnasio del mismo club, el presidente era un obrero ferroviario, Carlos Gamazo. 396 "Sucedió en muchos clubes, los ferroviarios tuvieron una impronta muy interesante". Así, recuerda a ferroviarios destacados en algún aspecto de su conocimiento específico que, al mismo tiempo, eran miembros activos de clubes puntuales:

\begin{abstract}
"Había una persona que me impactó: Carlos Maltilla, quien fue presidente del Club Rivadavia. Cuando vinieron las locomotoras diésel, él se especializó en los circuitos eléctricos, era un tipo muy estudioso. Un día estábamos en el club y veía que don Carlos explicaba y explicaba... Porque esas locomotoras eran húngaras y había un señor a quien don Carlos le explicaba y le explicaba. Era un ingeniero húngaro que le estaba pidiendo explicaciones... don Carlos ya se había jubilado. Resulta que tenían un problema y no sabían cómo solucionarlo ¡y el tipo que le consultaba era un ingeniero! Después había un
\end{abstract}

\footnotetext{
${ }^{391}$ El Club Los Indios fue fundado en 1929 en el Barrio "El Picaflor", por una disidencia de un grupo de socios del Club Ciclista. (Los indios de Junín: trabajo en equipo y crecimiento (4 de julio de 2017). Democracia. Recuperado de https://www.diariodemocracia.com/mas-deportivo/basquet/165162-indios-junin-trabajo-equipocrecimiento/: 10/2/20.

392 El Club Ciclista Juninense se fundó en 1923 en el Barrio "Pueblo Nuevo", por inmigrantes italianos y españoles, (de quienes recupera dos de los colores de sus respectivas banderas), con la idea original de fomentar el ciclismo. Poco tiempo después incorpora el baloncesto, deporte en el cual se consolida. Ciclista arriba hoy a sus 96 años de vida (6 de noviembre de 2019). La Verdad. Recuperado de https://laverdadonline.com/ciclista-arriba-hoy-a-sus96-anos-de-vida/: 10/2/2020

${ }^{393}$ El Club General José de San Martín se fundó en 1933 en el barrio Villa Belgrano (barrio que hasta 1925 se denominó "Tierra del Fuego"). Primero se llamó Club Albion House, en 1934 pasó a llamarse Sportman y desde el año 1946 Club General José de San Martín. (Silvana Schiavoni: "Es nuestro sueño llevar a San Martín a lo más alto" (7 de septiembre de 2019). La Verdad. Recuperado de https://laverdadonline.com/silvana-schiavoni-esnuestro-sueno-llevar-a-san-martin-a-lo-mas-alto/: 10/2/2020.

${ }^{394}$ El Club Atlético Argentino, también apodado "El Turco", nació en 1935 en el Barrio Las Morochas para diferenciarse del club fundado en 1933 "Imperio Británico", que defendía la práctica de fútbol. Su origen nace a partir de la intención de algunos socios de "Imperio británico" de incorporar al baloncesto como deporte. (Argentino de Junín cumple hoy 78 años de vida (1 de octubre de 2013). Pick and roll. Recuperado de http://pickandroll.com.ar/argentino/noticias/00025948/argentino-de-junin-cumple-hoy-78-anos-de-vida/: $10 / 2 / 2020)$.

$395 \mathrm{EN}^{\circ} 10$.

${ }^{396}$ Sobre la contribución de Carlos Gamazo al Club Rivadavia: Rivadavia cumple hoy 104 años (15 de noviembre de 2019). La Verdad. Recuperado de https://laverdadonline.com/rivadavia-cumple-hoy-104-anos/. Gamazo fue presidente del Club durante siete períodos: de 1965, 1966, y de 1971 a 1975. Ver: Los 60 años del Club Rivadavia (1975, octubre). Historia de Junín).
} 
fresador que se llamaba Omar Antonio Cuesta, el 'Cacho' Cuesta, en la época de Frondizi lo cesantearon. El fresador es el que hace los engranajes y para eso se necesita una tabla trigonométrica. Bueno, Cacho era muy famoso porque no necesitaba del librito, sacaba las cuentas en el aire. Cuando lo cesantearon lo vienen a buscar de una fábrica. Pero era famoso por eso, por esa capacidad." ${ }^{397}$

Además de clubes, los ferroviarios tuvieron una participación activa en otro tipo de instituciones. Según Marone, la contribución de ferroviarios en este tipo de organizaciones fue crucial para el desarrollo de la ciudad en el aspecto social y cultural:

\begin{abstract}
"Muchas bibliotecas se fundaron con ferroviarios. Y uno dice ¿por qué no eran los intelectuales de la época los que hacían eso? A lo mejor de diez bibliotecas una las fundaba un intelectual, pero el resto la fundaba gente que no tenía nada que ver con la intelectualidad. Eran inquietudes sociales manifestadas a través de los trabajadores. Y como el ferrocarril era el lugar que más trabajadores tenía, era lógico que en esas instituciones hubiese gente ferroviaria. Por eso te hablaba de la integración. Porque los ferroviarios estaban integrados no solamente dentro del ferrocarril, sino en la sociedad. En bibliotecas, asilos, en cualquier institución que hubiera en la ciudad, en todas las actividades sociales, deportivas, comunitarias, en esos lugares siempre había un ferroviario." ${ }^{398}$
\end{abstract}

De acuerdo a Rinaldi, los ferroviarios también contribuyeron en la formación de asociaciones de ayuda mutua, como los "banquitos" y mutuales:

"Había varias secciones que tenían lo que se llama el banquito. Mediante una cuota de uno o dos pesos por mes, se asociaban cincuenta compañeros y se daban créditos. Porque en ese tiempo supo haber gente que prestaba dinero, y que a usted le daban diez pesos y usted debía como quince. Entonces, para evitar eso, se formaron banquitos en que usted ponía dos o tres pesos, se juntaban cien pesos, y se le iba prestando a aquellos que tenían necesidad económica. Después lo tenía que devolver, ¿eh? Había varios banquitos ferroviarios, que originaron lo que fue después la Mutual Ferroviaria que englobaba, primero, a todos los ferroviarios socios. Pagando una cuota mensual tenían asistencia médica, servicio fúnebre. El club BAP, creado por los ingleses, después seguido por los ferroviarios. O sea, muchas instituciones nacieron por la gente ferroviaria." 399

\footnotetext{
${ }^{397} \mathrm{EN}^{\mathrm{o}} 28$.

${ }^{398} \mathrm{EN}^{\circ} 14$

${ }^{399} \mathrm{EN}^{\circ} 3$.
} 
Algunos testigos remarcan que muchos artesanos o especialistas en oficios que trabajaban en la empresa, llevaron adelante iniciativas privadas o brindaron sus servicios a otras empresas de la ciudad y, de esta manera, contribuyeron al desarrollo de la ciudad en el aspecto técnico. Los distintos testigos coinciden en subrayar la calidad de la mano de obra que el ferrocarril contenía en su interior y que se expandía al resto de emprendimientos juninenses (ver apartado "La calidad como sello de identidad"). Ferrari comenta: "Los artesanos del ferrocarril eran muy importantes, muy buscados por todo Junín. Si tenías que hacer un trabajo difícil, los llamaban a los del ferrocarril". Por su parte, Dall'Occhio relata en el mismo sentido: "Bajo el aspecto de la capacidad había muchos ferroviarios que eran tentados por la industria privada, eran buscados por la calidad de la mano de obra”. En la misma línea, Marone afirma de manera tajante que "la mejor mano de obra estaba en el ferrocarril". En consecuencia, según recuerda, "algunos artesanos que trabajaban en oficios de manera independiente se enojaban con los ferroviarios que hacían trabajo extra, porque consideraban que era una competencia desleal". Dentro de esa mano de obra que puede calificarse como de "excelencia", de acuerdo al imaginario de los testigos, el exjefe de Mecánica evoca, por ejemplo, la tarea de un barnizador puntual que pertenecía a la empresa: "Era magnífico. Tenía una casa que uno se quedaba mirando las puertas y las ventanas por cómo las había barnizado". ${ }^{400}$ En ese sentido, para Taberna, el cierre de talleres que ocurrió en la década del noventa trajo como consecuencia una disminución en la oferta de oficios de la ciudad:

\footnotetext{
"Había muchos que tenían inquietudes y aprovechaban lo que habían desarrollado adentro, afuera. Te doy un ejemplo. Soldadura. Vos si querés arreglar una pava de acero inoxidable no la encontrás. Son especialidades que se fueron perdiendo. El soldador sabía soldar cualquier tipo de material. Entonces, esos muchachos trabajaban afuera, en la casa, y hacían esos trabajos que ahora no se encuentran." ${ }^{401}$
}

Marone explica la ampliación de la oferta de oficios en la ciudad como una consecuencia directa de un cambio en el régimen horario producido durante el gobierno de Perón:

"Se empezó a trabajar de las 4 a las 12, o de las 6 a las 14. Mucha gente a la tarde buscaba en ese momento tener un ingreso extra, entonces el que era carpintero del ferrocarril por

\footnotetext{
${ }^{400} \mathrm{EN}^{\circ} 4, \mathrm{EN}^{\circ} 15$ y EN 29.

$401 \mathrm{EN}^{\mathrm{o}} 10$.
} 
ahí también era carpintero particular. Y los que querían dedicarse a clubes y bibliotecas lo hacían." ${ }^{402}$

El testimonio anterior de Marone sugiere, además, que el salario pudo haber dejado de ser, en muchos de los hogares ferroviarios, paulatinamente y a partir de 1950, el único y exclusivo ingreso familiar, lo cual podría haber sido consecuencia directa de una menor preeminencia del trabajador del riel o de nuevas necesidades y expectativas de consumo que podrían haber motivado la incorporación de nuevas actividades para incrementar el ingreso. En el mismo sentido, Rinaldi también se refiere a este cambio por el que muchos ferroviarios suman otros trabajos e insinúa que esto podría ser consecuencia de un deterioro del ingreso ferroviario:

\footnotetext{
"En la época de los ingleses se ganaba bien y la Unión Ferroviaria defendía el hecho de tener otra actividad fuera. Y la verdad es que se respetaba mucho. Después empezó a haber una política en que no se mejoró mucho los sueldos, entonces la gente empezó a trabajar un poquito afuera."
}

A diferencia de otros testigos que destacan la ampliación de la oferta de oficios de calidad en la ciudad como una contribución al desarrollo técnico, Dall'Occhio señala que esto habría traído una disminución del rendimiento y de la calidad de la mano de obra en la empresa. Paradójicamente estos dos aspectos eran, precisamente, cualidades con las que el colectivo ferroviario se enorgullecía e identificaba:

\footnotetext{
"En un momento, el gremio empezó a presionar para tener horario continuo. En vez de trabajar horario cortado, de mañana y tarde, empezábamos a trabajar más temprano y a las dos de la tarde los operarios sin almorzar se iban a su segundo trabajo, pasando a ser su mejor trabajo, mejor que el sueldo del ferrocarril, mejor pago que el ferrocarril. Entonces llegaban acá y vos por ahí te encontrabas a un operario que estaba dormido. Incluso, a veces, al frente de una máquina, arriesgando que un tipo se te duerma y ocurra un accidente. Me parece que ahí se empezó a descuidar la cosa porque ese obrero en vez de trabajar ocho horas trabajaba doce o quince." 403
}

En otro orden, en relación a la búsqueda de la excelencia en los oficios desarrollados por ferroviarios de manera externa, Taberna recuerda especialmente a un conductor de 
locomotoras que, en su tiempo libre, se dedicaba a decorar fachadas de casas y otros frentes, empleando piedras laja. Lo que la anécdota ilustra es el nivel de refinamiento de este fraternal, tanto en la tarea de artesanía emprendida, como en prácticas ordinarias de la vida cotidiana en las que intentaba regirse con el mismo nivel de perfección y exactitud:

"Dante Balestro fue un personaje maravilloso. Don Dante trabajaba la laja, él fue un conductor extraordinario, pero le gustaba hacer esos trabajos, lo llevaban a las estancias para hacer los frentes de las estufas y él hacía los trabajos con un águila, por ejemplo. Allá en la casa de mi mamá hizo un torreón, acá en el edificio este, toda la entrada que hay de laja, las columnas, están hechas por Dante Balestro, fijate que hay una casita, un pescado, pero el pescado tiene su trampita... era un hombre muy capaz. ${ }^{404}$ El pescado está, pero lo tenés que encontrar. ¡Todo en laja! Hay una placa del consorcio en la que le hicieron un agradecimiento por el trabajo. En vida. Nunca cobraba lo que tenía que cobrar. Bueno, yo tuve que esperar un año para que me hiciera el trabajo ese. Me dijo: 'yo se lo hago, pero voy a tardar'. No importa. Entonces él iba, ponía la laja así, la miraba, y yo le cebaba mate. ¿Por qué te cuento esto? Yo iba y le preguntaba, don Dante, ¿está bien de caliente? 'Faltarían dos grados más de temperatura', decía (risas). Entonces yo le daba un golpecito de calor con el calentadorcito y le decía, ¿y ahora? 'No, ahora está bien'. (risas) Era un espectáculo. Era un hombre... yo hubiera estado toda la vida al lado, por los conocimientos que tenía, él te contaba, te hablaba... era para escucharlo... Y no sabía adónde había estudiado. ${ }^{" 405}$

Balestro también es recordado por su participación, a lo largo de toda su vida, en la Biblioteca Popular Florentino Ameghino. ${ }^{406}$ Sin haber culminado sus estudios medios, el fraternal colaboraba con la enseñanza de niños en edad escolar de manera informal. Pellizi rememora:

\footnotetext{
${ }^{404}$ La construcción del edificio donde vivía Taberna al momento de la entrevista fue responsabilidad del gremio Unión Ferroviaria. Está ubicado en la avenida San Martín 375 de la ciudad de Junín.

${ }^{405} \mathrm{EN}^{\circ} 10$.

${ }^{406}$ En la ciudad de Junín existe una plaza denominada "Don Dante Balestro", además de la Casa Popular con el nombre de este ferroviario fraternal, destinada a actividades culturales. Ver: Inauguraron ayer el Parque Central del Ferrocarril y la "Plazoleta Dante Balestro (3 de octubre de 2018). La Verdad. Recuperado de https://averdadonline.com/inauguraron-ayer-el-parque-central-del-ferrocarril-y-la-plazoleta-dante-balestro/ :5/2/2020. Para ampliar información sobre este actor local ver también: Retes M. (6 de octubre de 2012). Dante Balestro, un ejemplo de persona, Democracia. Recuperado de: https://www.diariodemocracia.com/locales/junin/44370-dante-balestro-ejemplo-persona: $\quad$ /5/2/2020). La Biblioteca Florentino Ameghino se fundó en 1917 en el barrio "Tierra del Fuego", por obreros. Sobre la biblioteca ver también: La biblioteca "Florentino Ameghino en la memoria de Dante Balestro (28 de febrero de 2018). Junínhistoria. Recuperado de http://juninhistoria.blogspot.com/2018/02/la-biblioteca-florentino-ameghino-enla.html: 10/2/2020.
} 
"Dante Balestro fue un autodidacta. Venían los chicos acá y tenían un problema de trigonometría y él se lo explicaba. Venía otro y tenía un tema con geografía, entonces él iba, buscaba los libros y lo explicaba. Algo sobre matemática, también. Es decir, era una persona culturalmente riquísima y los temas específicos los sabía, a pesar de que no sé si llegó a terminar sexto grado." ${ }^{407}$

Taberna cuenta algo similar en relación a la vocación de Balestro por la enseñanza:

“Él le enseñaba a los chicos en la biblioteca. Les buscaba los libros y los preparaba para dar las materias. En el galpón de máquinas, les enseñaba a los que querían ir a aprender la conducción. Estaban los Fiat Materfer que eran coches motores. Él les enseñaba, el mantenimiento, el manejo... Iba gratis, igratis! Al que quería, él le enseñaba. Lo que estuvo maravilloso es que lo declararon ciudadano ilustre en vida ${ }^{408}$."409

Así como Balestro manifestaba una inclinación por la enseñanza, hubo algunos ferroviarios que trabajaron como docentes en distintas instituciones, especialmente la Escuela Fábrica Yapeyú y la Industrial “Antonio Bermejo”. Marone, por ejemplo, siendo uno de los primeros alumnos del Ciclo Técnico Nocturno de la Escuela Yapeyú, recibió una oferta de su director para dar clases en los años anteriores. Esto, según enfatiza, fue el resultado de las buenas calificaciones obtenidas:

"Nosotros hicimos el primer año del el Ciclo Técnico Nocturno, y cuando pasamos el segundo se creó el segundo, y cuando pasamos el tercero se creó el tercero, cuando pasamos al cuarto se creó el cuarto y ahí salimos. Cuando salimos el ciclo técnico ya venía con un primer año, segundo año, tercer año. Ocurría que estos cursos necesitaban profesores. Entonces Cremanti nos ofreció que nos quedáramos en la escuela como docentes a los cuatro mejores promedios: Rinaldi, Rueda, Nicolai y yo. Así que seguimos la carrera docente ni bien terminamos. Empecé en el 58 como docente y me jubilé en el 91. Yo me jubilé de las dos cosas juntas. Fui docente 34 años. Trabajé mañana, tarde y noche. El Ciclo Técnico siguió, pero dejó de pertenecer a la Yapeyú, porque la Yapeyú se cerró y pasó a la Bermejo." ${ }^{\prime 10}$

\footnotetext{
$407 \quad \mathrm{EN}^{\circ} 28$.

${ }^{408}$ Fue declarado "Ciudadano Ilustre" el 23 de diciembre de 1996. Boletín Municipalidad de Junín. Recuperado de http://ga.junin.gob.ar/?seccion=boletin\&sub=hcd\&id=3576\&sub_hcd=ords\#barraNav: 30/12/2019.

$409 \mathrm{EN}^{\circ} 10$.

$410 \mathrm{EN}^{\circ} 22$.
} 
De la misma manera, Rinaldi subraya que el ofrecimiento estuvo relacionado con sus buenas calificaciones, lo que refuerza el imaginario de excelencia de los ferroviarios de Junín: “A los cuatro más altos promedios del ciclo técnico nos hizo entrar Cremanti como maestros de la escuela. Después se pasó al Industrial y seguí dando clases ahí”. ${ }^{411}$

Otro de los ferroviarios que hizo una carrera paralela como docente fue Abilio Murgia, quien comenzó en el anexo William Morris de la Escuela Profesional Bernardino Rivadavia, como profesor de Dibujo Técnico. Como en el resto de los testigos, el inicio de esta actividad de enseñanza surgió por un ofrecimiento externo: “A los 21 me ofrecen ser docente. Era como que... en mi época se respetaba mucho al docente, se lo valoraba... el docente mandaba en el aula". ${ }^{412}$ Su testimonio exhibe que la actividad gozaba de prestigio social y que el ofrecimiento implicaba un modo de premiar el buen desempeño académico previo. Además, el ferroviario expresa que la carrera docente le significó en distintos momentos desafíos intelectuales que, según sus palabras, lo motivaron a "crecer", lo que, en línea con el resto de los actores, da cuenta de una búsqueda de excelencia, a nivel individual, así como de compromiso con su rol y con sus alumnos:

\begin{abstract}
"A medida que fueron creciendo los cursos me fueron dando Matemática, por ejemplo, y mirando el programa acepté. Entonces, seguí estudiando, también di Física. Tenía mis cosas raras. Un día le pedí a la directora permiso para que los días viernes nos quedáramos un poco más porque quería complementar el curso de dibujo con algunos conceptos técnicos de las piezas que dibujábamos para que tuvieran conocimiento de la composición del material, la dureza, la resistencia. También estuve enseñando en la Escuela Industrial. Yo estuve 30 años, me fui a principios de 2012, con 74 años, no daba lástima, me parece que ahora tampoco doy lástima. Yo di Termodinámica, Conocimiento de Materiales y Representación Gráfica, eso como treinta años, también di Resistencia de los Materiales, Mecánica Técnica. O sea recorrí un espectro, y siempre agarraba a las materias con ganas, porque como digo en un escrito: 'Estas son bendiciones que me ayudaron a crecer'. Porque pensaba, aventurero no, pero decía: ‘Sí, puedo"”. 413
\end{abstract}

Además del aporte que en materia técnica, docente y social los actores de la empresa ferroviaria habrían hecho a la ciudad, muchos testigos recuerdan que el ferrocarril también albergó artistas de calidad y personas dedicadas a la cultura local. Marone, por ejemplo, se

\footnotetext{
${ }^{411} \mathrm{EN}^{\circ} 24$.

${ }^{412} \mathrm{EN}^{\circ} 7$.

${ }^{413} \mathrm{EN}^{\circ} 7$.
} 
refiere tanto a los músicos inmigrantes que habían llegado antes de la nacionalización, como al desarrollo artístico que tuvo su auge en las décadas del cincuenta y sesenta:

\begin{abstract}
"Los dos historiadores de Junín que yo conozco fueron ferroviarios, (Roberto) Dimarco 414 y (Jorge) Howden. ${ }^{415}$ Hubo también músicos: los españoles e italianos ya venían con sus instrumentos, empezaron a intervenir en fiestas, se formaron orquestas. En la época mía también había varias orquestas de tango compuestas por ferroviarios. Directores de orquesta como Arturo Viora en el $50^{416}$, Enrique Fusé en el $45,{ }^{417}$ Osvaldo López habrá sido del 52, (Raúl) Bianco sería del 56. ${ }^{418}$ Había cantores como (Omar) Decarre, Gallardo. Otro López, Héctor López, fundó el teatro La Antorcha, hizo una movida por el lado teatral. ${ }^{419}$ Él se dedicó a la parte artística siempre y después se metió de lleno en el teatro." 420
\end{abstract}

Pellizi, en la misma línea que Marone, enumera:

"Eduardo Dimarco, padre del que conocemos, escribió un poema muy interesante que se llamó 'El pito del ferrocarril'. ${ }^{421}$ En el coro Vocal J había ferroviarios, fue un coro muy importante, que incluso llegó a viajar a México. ${ }^{422}$ Ellos pertenecían a la Coart, a la

\footnotetext{
${ }^{414}$ Roberto Dimarco fue un historiador local que dirigió la revista Historia de Junín y escribió el libro Manual de Historia de Junín. Ver: Murió Roberto Carlos Dimarco, entrañable historiador de acontecimientos juninenses (2015, 11 de octubre). Democracia, Recuperado de https://www.diariodemocracia.com/locales/junin/116655murio-roberto-carlos-dimarco-entranable-historiado/: 5/2/2020. También puede definirse como un coleccionista, ya que en su hogar se albergaban múltiples objetos y documentos de valor histórico. Según el diario Semanario, él mismo se definía como un "junta cosas". Ver también: Canaparo, I. (11 de octubre de 2019). A cuatro años de la muerte de Roberto Carlos Dimarco, un verdadero artesano de la historia. Semanario. Recuperado de http://semanariodejunin.com.ar/nota/9287/a cuatro anos de la muerte de roberto carlos dimarco un_verdad ero_artesano_de_la historia: 5/1/2020. La donación de documentos y objetos de distinto tipo que realizó su hija a la UNNOBA permitió crear el Archivo Universitario que lleva el nombre de este historiador.

${ }^{415}$ Jorge Howden escribió el libro Junín. Fundación y gobierno 1827-1852 (Buenos Aires, 1961).

${ }^{416}$ Sobre Arturo Viora y Osvaldo López, ver: Canaparo, I. (5 de junio de 2017). El bandoneón de Lalo es un toldo de estrellas. Semanario. Recuperado de

http://semanariodejunin.com.ar/nota/315/el bandoneon de lalo es un toldo de estrellas: 5/1/2020.

${ }^{417}$ Según el Semanario Junín, Hugo Enrique Fusé, director de la orquesta Bristol fue un protagonista de la bohemia y nocturnidad juninense. Falleció el 13 de noviembre de 2018. Ver: Canaparo, I. (29 de noviembre de 2018) Tristes y melancólicos recuerdos de noviembre... Semanario. Recuperado de http://semanariodejunin.com.ar/nota/5762/tristes_y melancolicos_recuerdos_de noviembre hellip: 5/1/2020.
}

${ }^{418}$ Bianco fue un músico, pianista, director de orquesta y arreglador que falleció el 25 de julio de 2013. Ganci, D. (30 de julio de 2013). Falleció el maestro Héctor Raúl Bianco. Democracia.Recuperado de https://www.diariodemocracia.com/vida/sociedad/62551-fallecio-maestro-hector-raul-bianco/: 5/2/2020.

${ }^{419}$ El Teatro Independiente La Antorcha perteneció a la Coart, creada a su vez en 1966. Zapata menciona que todos los integrantes de la Coart fueron secuestrados en 1977, salvo Héctor López. La autora sugiere que la excepción se debió a la edad avanzada de López, que en ese momento ya contaba con más de setenta años (Zapata, 2008: 10).

${ }^{420} \mathrm{EN}^{\circ} 29$.

421 "Toda la cronométrica de la ciudad está regida por la cronométrica estridencia del pito del taller General San Martín (...) Hasta que la fiesta del domingo o del feriado pone una mordaza de silencio al implacable alarido de vapor". El pito del taller (1952, 6 de noviembre). La Verdad.

${ }^{422}$ De acuerdo a Zapata, durante la década del sesenta en Junín hubo un acrecentamiento de la importancia de las instituciones culturales nacidas en la década anterior (como el "Teatro La Antorcha")y el surgimiento de nuevas 
Coordinadora de Arte, y después muchos fueron presos en la dictadura. ${ }^{423}$ Entre los que eran parte del coro estaba Abel Pinto, Roque Gómez, un ferroviario barítono. No solamente Beto Mesa, que, en realidad, era un artista que en su tiempo libre era ferroviario. Era titiritero, hacía obras de teatro, cantaba. ${ }^{424}$ Después tenías a Héctor López que creó el teatro La Antorcha. El furor fue en los años sesenta. Y la mayoría de los que actuaban en La Antorcha habían estado en el ferrocarril., ${ }^{, 425}$

Uno de los artistas ferroviarios fue Omar Decarre, quien llegó a cantar en tres de las cuatro orquestas de tango de la ciudad que, según él, eran las más importantes que había en Junín:

"En los cincuenta había cuatro orquestas de tango, con diez o doce músicos por orquesta. Yo empecé en Osvaldo López, luego pasé con Arturo Viora, ${ }^{426}$ también integré la de Héctor Bianco. La única que no integré era la 'Bristol' aunque tenía amistad porque el director (Enrique Fusé) trabajaba en la sección Herramientas". 427

Todas las orquestas mencionadas estaban integradas por varios ferroviarios. Dos de ellas, además, estaban dirigidas por trabajadores del riel. Su testimonio parece sugerir que los vínculos generados en el ámbito laboral podrían haber potenciado las vocaciones artísticas.

\footnotetext{
organizaciones y grupos artísticos locales coro el coro vocal polifónico "Vocal J". Estos agrupamientos buscaron, según la autora, "una mayor profesionalización de la actividad artística" y "lograron complejizar tanto cualitativa como cuantitativamente, el ámbito cultural local". "Dicha complejización se debió, sobre todo, al hecho de que muchos de los integrantes de estas agrupaciones desempeñaban, en forma paralela, otras actividades artísticas como pintura, escritura o canto (Zapata, 2008: 3).

${ }^{423}$ Zapata observa que aunque los ferroviarios en Junín eran un colectivo organizado y sindicalizado, no fueron el blanco elegido por los represores del Proceso de Reorganización Nacional: "Si bien Junín se destacaba por ser una ciudad eminentemente ferroviaria, y con un amplio poder de sindicalización en este sector, no fueron los trabajadores ferroviarios los más reprimidos, sino aquellas personas relacionadas con el ámbito cultural, lo cual le confiere a esta sociedad una cierta singularidad" (Zapata, 2008: 17).

${ }^{424}$ Gilberto Alberto Mesa fue un titiritero y ferroviario secuestrado en 1976 durante la última dictadura militar. Es el único ferroviario local desaparecido de la ciudad. En la actualidad el Polideportivo, ubicado en el predio de lo que fueron los Talleres ferroviarios, lleva su nombre. Creó personajes para niños como "Payasín" y dirigió programas radiales destinados a niños como "Los duendes de los chicos" o "La peña de Don Zoilo". Ver: Inauguran mural en homenaje a Beto Mesa (25 de marzo de 2019). La Verdad. Recuperado de https://laverdadonline.com/inauguran-mural-en-homenaje-a-beto-mesa/: 5/2/2020. Héctor Pellizi recupera en una anécdota en la que se exhibe que el ferrocarril, así como un espacio de sociabilidad que podría haber estimulado vocaciones artísticas, también pudo haber sido un escenario de conflictos: "El Beto hacía arte comprometido, entonces en los títeres siempre había un rey que explotaba... porque él a través de su arte avivaba giles, así se lo consideraba. Los incluía a los chicos a través de los títeres y les bajaba línea política. Él trabajaba en la oficina. Un día llega un camión de dinero para pagar los sueldos, con muchos custodios, entonces Beto comenta ja, si estuviera Fidel Castro no pasaba esto. Y lo escucha un tal Burdese, que era de los servicios de inteligencia y trabajaba en el ferrocarril, era un infiltrado, le decían 'Risita' a Burdese. Bueno, después de esa conversación sobre Fidel a los dos días lo agarran al Beto."

$425 \mathrm{EN}^{\circ} 28$.

${ }^{426}$ Aunque Arturo Viora no trabajaba en el ferrocarril, dos de sus hermanos eran trabajadores del riel. Agradezco a Marcela Viora, sobrina nieta del artista, por esta aclaración.

${ }^{427} \mathrm{EN}^{\circ} 23$.
} 
Aunque el cantor entrevistado no le otorga relevancia, es notable que su "descubrimiento" como artista haya sido también en el espacio mismo de trabajo, lo que parece mostrar que este pudo funcionar como un ámbito de sociabilidad que favoreció el desarrollo cultural en la ciudad:

"Entré de chico (al ferrocarril) y ya cuando me fui haciendo de confianza con los compañeros por ahí canturreaba mientras trabajaba. No faltó quien me escuchara. Un señor que cumplió hace poco 90 años me descubrió: Osvaldo Ferro. Un día me dice: 'Yo te estoy escuchando cantar. Y me gusta cómo cantás'. No me dijo 'Cantás bien'. Con nosotros trabajaba Osvaldo López, él era afilador de mechas para perforar hierro. Entonces Ferro le dijo a López. Con el tiempo empecé a charlar con López. Por ahí me salieron invitando a un ensayo de su orquesta, cosa que me resistí un poco. Uno siempre tiene una cierta timidez... Pero fui a uno de esos ensayos. Entoné me acuerdo dos temas. Pero no pasó nada. Ya la orquesta tenía dos vocalistas. Al tiempo, no me acuerdo cuánto, se quedaron sin cantor. Entonces no sé, parece que en aquella práctica algo quedó, porque me invitaron para integrar esa orquesta". ${ }^{428}$

La carrera artística de Decarre lo coloca como cantor en la orquesta que dirigía Osvaldo López, desde 1956 hasta 1964, y en la que dirigía Arturo Viora desde 1964 hasta 1974. Sobre esta última orquesta, Decarre observa que cuando lo requieren para integrarla "se decía que era la mejor orquesta de la ciudad". "Parece que fui mejorando", fundamenta. En esta segunda etapa Decarre comienza a estudiar canto con quien le habrían dicho que era "el mejor profesor de tango" de Buenos Aires. Esto, junto al reconocimiento personal de que él no es el mejor, sino que su canto es "mejorable", que se exhibe el siguiente testimonio, demuestra el intento de este ferroviario de apuntar a la excelencia, de manera similar a lo hallado en otros testigos ferroviarios:

"En la inauguración de la Casa de Junín en Buenos Aires me encontré con un juninense que hacía mucho que no veía y me abordó y me dijo: 'Me gusta cómo cantás'. Tampoco me dijo ‘cantás bien'. ‘No te gustaría estudiar canto?’, me preguntó. ‘Porque yo soy amigo del mejor profesor de tango que hay en Buenos Aires', por ahí lo decía porque era amigo de él. 'Y cómo se tendrá acceso a eso'. 'Y bueno, porque si yo te lo estoy nombrando es porque de eso me encargaría yo'. 'Y quién sabe, cuánto cobrará'. Viste, yo con el sueldo ferroviario si bien no cobraba mal, pero no podía tirar manteca al techo, tenía gastos para

${ }^{428} \mathrm{EN}^{\circ} 23$. 
viajar, aunque tenía la rebaja. Así que tuve acceso a ese profesor, Norberto Massa. Y bueno, empecé a estudiar." ${ }^{429}$

Más adelante, aflora en Decarre una vocación docente, tarea de la cual se termina desalentando porque sus alumnos no parecían tener el mismo nivel de compromiso que él había tenido cuando decidió formarse. En otras palabras, no halla en sus estudiantes esa búsqueda de excelencia presente en él y en otros ferroviarios de la época:

"A partir de que me puse a perfeccionarme en el canto, me nació la idea de poder enseñar. Sobre todo, cuando me pasaba que veía a alguien que cantaba bien, pero le veía defectos, defectos vocales o algo por el estilo. Y eso se lo dije a mi profesor. Y me dijo: 'Eso me interesa mucho, te voy a incentivar la enseñanza. Te voy a dar la parte teórica de lo que te estoy enseñando, cosa que no hago con nadie, pero yo a vos te lo voy a dar. Como a los dos años me dice, me interesaría que empieces a enseñar canto'. 'Uh, no, como hago. Vos vivís en Buenos Aires, pero yo vivo en Junín, es medio difícil decirle a alguien querés que te enseñe canto'. 'Bueno, supongamos que no pase eso, pero alguno va a pedir que le enseñes'. Y efectivamente pasó eso. Vino un muchacho y me dijo: ‘¿Vos no me enseñarías algo de lo que a vos te están enseñando?'. 'Mirá vos sabés que hace tiempo que me está diciendo que empiece a enseñar'. 'Uh, entonces empezás conmigo'. Y así empecé a enseñar. Intenté hacerlo durante un tiempo, pero me acobardé, me cansaron ciertos alumnos. Porque con esto pasa lo que pasa con la escuela común, están los que estudian un poquito, algo, bastante, o mucho. Yo hacía como hacían conmigo, le daba los ejercicios de respiración, de vocalización, de canto. Pero yo me daba cuenta que semanalmente no habían repasado nada. Entonces... empecé a pensar que estaba tratando de remarla contra la corriente. Hubo un tipo al que esperaba y me dejaba esperando. ¡Yo me iba a Buenos Aires y el tipo vivía a diez, cinco cuadras y no podía venir! Poco a poco me empecé a quedar sin alumnos. Yo le comentaba a mi profesor lo que me pasaba con los alumnos con cierto fastidio. Y él me decía: ‘¿Y, te pagan? Bue, que se arreglen’. 'No, Norberto, vos vivís en Buenos Aires, yo vivo en Junín, entonces, un tipo que yo le doy los ejercicios y no me los hace no aprende, seguramente que dice por ahí que estudia canto con Omar. Entonces, la gente que lo escucha si ve que era malo y sigue malo, se va a ir preguntando qué le enseñará en lugar de canto. Entonces esos tipos te hacen perder el poco prestigio que vos podés tener. En cambio, Buenos Aires es muy grande'. Yo aparte me parece que no tenía buen carácter y al tipo que no estudiaba no lo trataba muy bien, y hacía algo para que se vayan. Hasta que un día decidí no seguir.”430 
La última parte del testimonio parece mostrar la importancia que, a nivel local, adquiere el prestigio y el "buen nombre" en una ciudad de mediana envergadura como lo era Junín. Como en el resto de los ferroviarios entrevistados, su relato trasluce la seriedad puesta en la actividad desarrollada y la intención de perfeccionarse al máximo de sus posibilidades en el área elegida.

En otro orden, Marone recuerda que hubo trabajadores del riel que se destacaron en distintos deportes, reforzando de esta manera el imaginario asociado a la excelencia de la empresa:

\begin{abstract}
"En la parte deportiva el ferrocarril tuvo figuras descollantes: (Bernabé) Ferreyra fue un goleador ferroviario. ${ }^{431}$ Coco Pelli fue el goleador que más goles hizo en la historia de Sarmiento. ${ }^{432}$ Hubo un montón de figuras que triunfaron en el fútbol argentino. Hébert Pérez jugó en Huracán. ${ }^{433}$ En el Atletismo tuvimos campeones olímpicos: Juan Fusé era un ferroviario que en el atletismo participaba en el martillo, también estaban (Manuel) Etchepare, (Emilio) Machiodi. Casi todos fueron campeones argentinos. Tres de ellos llegaron a ser campeones sudamericanos. Fueron a las Olimpíadas de Londres: Fusé, Etchepare y Machiodi. ${ }^{434}$ iRepresentaron a Argentina y trabajaban en el ferrocarril! Había gente que se destacaba. En el tiro, (Walter) Bauzá fue a las Preolimpíadas de México y a Rusia. ${ }^{435}$ Eran ferroviarios. En los deportes había ferroviarios muy destacados." ${ }^{436}$
\end{abstract}

\footnotetext{
${ }^{431}$ Bernabé Ferreyra, más conocido como "El mortero de Rufino", fue pintor en los Talleres Ferroviarios. En 1927 ganó el torneo de la Liga Deportiva del Oeste desde BAP. Luego jugó en Tigre, Huracán y Vélez Sarsfield, para consagrarse en River Plate entre 1932 y 1939 (Petraglia, 2012: 46). Mientras era pintor en el taller de Junín, fue también jugador del Club Sarmiento. Ver más en: Bernabé Ferreyra. Wikipedia. Recuperado de https://es.wikipedia.org/wiki/Bernab\%C3\%A9 Ferreyra: 7/2/20.

${ }^{432}$ Ernesto "Coco" Pelli se inició en las divisiones inferiores de BAP. En 1950 pasó a Sarmiento (Petraglia, 2012: 46-47). Según Petraglia, fue el máximo goleador de Sarmiento, con 138 goles en 297 partidos. Su época más destacada fue entre 1952 y 1962. Ver más en: Canaparo, I. ( 2 de enero de 2017) Cuarenta años sin el "Coco" Pelli, lapidario goleador de Sarmiento. Democracia. Recuperado de https://www.diariodemocracia.com/masdeportivo/futbol/152254-cuarenta-anos-coco-pelli-lapidario-goleador-sarmie/: 7/2/20.

${ }^{433}$ Se inició en las inferiores de BAP y debutó en Sarmiento en 1953. En 1959 se trasladó a Huracán (Petraglia, 2012: 46), Ver más en: Canaparo, I. (7 de noviembre de 2017). Dos años sin Hebert Pérez. Semanario. Recuperado en http://semanariodejunin.com.ar/nota/2132/dos anos sin hebert perez: 7/2/20.

434 Juan Fusé fue campeón sudamericano de lanzamiento de martillo en 1939 y 1945, y campeón nacional en 1933 y 1937 y participó en los Juegos Olímpicos de Londres 1948. Emilio Malchiodi fue campeón sudamericano de lanzamiento de disco y de bala en 1944 y 1949, campeón argentino en 1947 y participó en los Juegos Olímpicos de Londres 1948. Manuel Etchepare fue campeón sudamericano de lanzamiento de martillo en 1943, campeón argentino en 1947 y 1951 y participó en los Juegos Olímpicos de Londres 1948. Ver más en: Junín. Wikipedia. Recuperado de https://es.wikipedia.org/wiki/Jun\%C3\%ADn_(Buenos_Aires): 7/2/20.

${ }^{435}$ Walter Bauzá ganó la medalla de oro en los Juegos Panamericanos de Puerto Rico 1979. Participó en los Juegos Olímpicos de Los Ángeles 1984.

${ }^{436} \mathrm{EN}^{\circ} 29$.
} 
Decarre, por su parte, también recuerda una anécdota de un reconocido goleador a nivel nacional e internacional, quien, antes de dedicarse al fútbol profesional fue empleado de Talleres Junín:

"El ferrocarril tuvo muchos deportistas importantes. Por ejemplo Luis Artime, un gran jugador de fútbol de River, Independiente, Nacional de Montevideo. ${ }^{437}$ En Brasil también jugó. Trabajaba en la sección Chapas. Hay una anécdota que siempre se comentó. Cuando Artime anunció que se iba a jugar al fútbol a Buenos Aires el jefe de la sección donde él trabajaba lo llamó y le dijo: 'Mirá, Artime, el paso que vos vas a dar es muy importante, no te olvides que tenés muchas ventajas acá, tenés cuatro pases gratis en el año para viajar, tenés orden de rebaja para viajar'. 'Y no, yo me voy igual'. Porque lo habían llamado del Club Atlanta de Buenos Aires. Entonces le dijo: 'Yo ya tengo pensado que me voy a hacer profesional del fútbol'. Y qué profesional, aparte era un señor, en disciplina, en todo. Vive, se casó con una chica de Junín y está en Buenos Aires. El hijo fue también profesional de fútbol, Luis Fabián Artime.”438

Como síntesis del presente apartado puede afirmarse que las representaciones que asocian la calidad de los ferroviarios en materia deportiva, técnica, docente y artística, así como su rol en el desarrollo de la ciudad en el aspecto social y cultural, propiciaron aglutinar al colectivo a partir de una identidad vinculada al prestigio y a la excelencia de estos trabajadores. Parafraseando a Tornello en el inicio: "Todo lo mejor estaba en el ferrocarril". ${ }^{439}$

\footnotetext{
${ }^{437}$ Luis Artime se inició en Independiente de Junín y en 1958 pasó a primera división con Atlanta. Jugó en River Plate, Independiente y en Palmeiras de Brasil. En Nacional de Uruguay, donde estuvo desde 1969 a 1973, es considerado uno de los máximos goleadores. Luis Artime. Wikipedia. Recuperado de https://es.wikipedia.org/wiki/Luis_Artime: 10/2/20.

${ }^{438} \mathrm{EN}^{\circ} 23$

${ }^{439} \mathrm{EN}^{\circ} 19$.
} 


\section{Capítulo 3}

La nacionalización y la vara inglesa 


\section{La nacionalización: acontecimientos históricos y representaciones locales}

Para los ferroviarios juninenses entrevistados, la nacionalización constituye un hito en la historia del ferrocarril y en la experiencia vivida en la empresa, aun cuando la mayoría de ellos ingresaron luego de que el conjunto de compañías extranjeras, principalmente de origen británico, fueran nucleadas en la empresa Ferrocarriles del Estado. A partir de este acontecimiento, emergieron nuevas prácticas asociadas al trabajo, simultáneamente a que siguieron vigentes prácticas previas, asociadas a la gestión inglesa. Esta yuxtaposición generó tensiones a lo largo de toda la historia del ferrocarril estatizado que impulsó a sus actores a construir sentidos que apuntaran a interpretar lo vivido.

Calderoni asegura sobre este suceso: “Ahí empezó toda la decadencia. Fue degradándose de a poco, de ahí en más". Ferrari habla en términos similares: "Cuando se nacionalizaron los ferrocarriles se fue degradando". En tanto, Dimarco califica: "La nacionalización fue la desgracia". ${ }^{440} \mathrm{El}$ ingeniero Calcagni, por su parte, coincide en interpretar este acontecimiento como una bisagra en la historia ferroviaria, que separa una etapa de otra:

“Decayó mucho. Yo creo que la época de esplendor del taller se terminó con la nacionalización. Fue un taller de primera mientras estuvieron los ingleses y en los primeros tiempos de la nacionalización". ${ }^{441}$

Resulta recurrente que para explicar esa desgracia, degradación o decadencia que tuvo lugar, se oponga, como estrategia discursiva, la incapacidad de los argentinos de gestionar la empresa frente a la capacidad de los ingleses. Como comenta Dante Cruz:

“...los ferrocarriles andaban, y andaban bien. Hasta que los compramos... A partir de ahí fue la decadencia... Lo que somos nosotros, los argentinos. Nosotros... aunque no todos, porque había gente que cuidaba y quería al ferrocarril". ${ }^{442}$

Ferrari manifiesta algo similar, caracterizando el "ser-argentino" por la falta de hábito hacia el trabajo:

\footnotetext{
${ }^{440} \mathrm{EN}^{\mathrm{o}} 19,4$ y 16.

${ }^{441} \mathrm{EN}^{\mathrm{o}} 21$.

${ }^{442} \mathrm{EN}^{\mathrm{o}} 13$.
} 
"(Luego de la nacionalización) anduvo bien un tiempo, pero después a lo último se fue dejando de hacer muchas cosas que hacían bien los ingleses y nosotros no estábamos acostumbrados a esa cosa, al trabajo." ${ }^{443}$

En la misma línea, el ingeniero Calcagni diferencia la exigencia de los ingleses hacia los operarios, frente a la laxitud de los argentinos en el cumplimiento de las tareas:

"Los ingleses manejaron el ferrocarril al corte inglés: orden, imposibilidad de réplica, las cosas se cumplían. En el tiempo argentino la cosa cambió, se democratizó, entonces ya se hacía o no se hacía, se hacía bien o se hacía mal, igual pasa..."444

Por otra parte, son muy comunes las representaciones que asocian la idoneidad en los puestos de jefatura durante la gestión inglesa, en contraposición a la importancia de los vínculos personales en espacios de decisión cruciales durante la gestión de los Ferrocarriles del Estado.

\begin{abstract}
"Después de la nacionalización se fue deteriorando, como todo lo que es argentino. En vez de buscar gente idónea en la materia, nombraban por el amiguismo, como ocurre en los gobiernos subsiguientes. A lo mejor nombran un gerente de ferrocarril porque es amigo. Y para administrar el ferrocarril sabe como yo. Tenés que nombrar a gente competente, gente idónea, fuera de la política. Antes, los jefes que ponían los ingleses, eran jefes. Lo que pasa, como decía recién, en la época en que fue argentino estaba el amiguismo. Y a lo mejor había un ingeniero determinado y lo mandaban a Europa a comprar vagones, para $\mathrm{X}$ ferrocarril. Compraba los vagones y a lo mejor había que reformar la plataforma de las estaciones porque eran más bajos". ${ }^{445}$
\end{abstract}

Aparece otra palabra con que se caracteriza y asocia a la gestión del ferrocarril nacionalizado: política. Dimarco asegura: “Con la nacionalización entró la política. Con los ingleses, no estaba. Todo fue cambiando. Los ferroviarios tenían que afiliarse....al partido gobernante." ${ }^{446}$ Marone que, en congruencia con los testigos anteriores, caracteriza a la gestión inglesa por su capacidad y a la gestión argentina, por lo contrario:

\footnotetext{
${ }^{443} \mathrm{EN}^{\circ} 4$.

${ }^{444} \mathrm{EN}^{\circ} 21$

${ }^{445} \mathrm{EN}^{\circ} 12$.

${ }^{446} \mathrm{EN}^{\circ} 16$.
} 
"Cuando se nacionalizaron los ferrocarriles.... se transformó en una cartera política y lo único que se desarrollaron fueron los gremios. Los planteles no tenían el mismo nivel de preparación y yo te diría que fue decayendo." ${ }^{447}$

Marone, en el extracto anterior, introduce un nuevo término que, en el imaginario de estos ferroviarios quedó asociado a la nacionalización en un sentido negativo, junto al término política: gremio. Lo mismo plantea Ferrari:

"Cuando se nacionalizaron los ferrocarriles, con Perón, entró el gremialismo y se vino todo abajo. Era bravo, los gremialistas eran de temer. Ellos hacían paro y cosas. Al principio, estuvo bastante tiempo manejado como nos habían enseñado los ingleses, pero ya con la intervención del gremio que empezaba a molestar. Ellos hacían paro, en el tiempo de Perón fue eso" (el subrayado es mio). ${ }^{448}$

Aun cuando Rinaldi se declara un "fanático de la nacionalización” porque, de acuerdo a sus convicciones "toda la energía eléctrica, los ferrocarriles, el gas, el petróleo, los minerales, todas las fuentes naturales, tienen que estar nacionalizadas", critica que luego de que esta tuvo lugar...

“...entró un poco la política, jubilaron a los ingleses que habían estado como jefes y ya cambió bastante. Se introdujo bastante la política en el ferrocarril, en los talleres me refiero. Fue increíble el aumento de personal por razones políticas más que nada. En todo... menos en los lugares donde había que trabajar (risas). Donde había que producir algo..."

La risa de Rinaldi en la última parte del relato exhibe, al mismo tiempo, su desaprobación y resignación a la experiencia que transitó y que, en momentos, puede haber puesto en cuestión sus convicciones. La misma contradicción parece manifestar De Giulio al aprobar la nacionalización y, al mismo tiempo, preferir el tiempo inglés:

"Perón hizo un bien al nacionalizar, pero para los gremios no. A veces me contradigo.

Pero lástima, hubieran seguido los ingleses. Tendríamos trenes."

\footnotetext{
${ }^{447} \mathrm{EN}^{\circ} 14$.

${ }^{448} \mathrm{EN}^{\circ} 4$

${ }^{449} \mathrm{EN}^{\mathrm{o}} 3$.

${ }^{450} \mathrm{EN}^{\circ} 11$.
} 
Todo este conjunto de testimonios parece sugerir que las prácticas políticas, antes externas al ferrocarril, comenzaron a influir en el interior de la empresa luego de la nacionalización, lo cual generó resistencias respecto de las prácticas laborales anteriores, propias de la gestión inglesa. Al mismo tiempo, también parecen mostrar que el gremio como actor habría tomado una relevancia mayor en su poder de decisión dentro de la empresa estatal, frente a otros actores, como la jefatura. Ambas cuestiones, desde la óptica de estos ferroviarios juninenses que ingresaron en las décadas del cuarenta y cincuenta, habrían tenido resultados negativos en relación a la productividad. De esta manera, política y gremio son términos que adquieren, en general, connotaciones negativas y, en el contexto del relato de los testigos permiten, incluso, explicar el fracaso de la empresa estatal de ferrocarriles. El lamento de De Giulio, así como muchas otras referencias de los testigos al tiempo presente, en el que no hay trenes, dan cuenta de que este mojón o hito en la historia vivida (la nacionalización) es empleado, no solamente para dar cuenta de un momento importante de la experiencia transitada, sino también para explicar el porqué del presente. El siguiente diálogo con Valentín Martínez también expresa la función que el suceso cobra en la historia de vida y en la historia experimentada por los actores:

—VM: La nacionalización significó lo que pasó en el ferrocarril

-ALS: ¿Y qué pasó?

—VM: Y... ¿no ves cómo quedó? Pero, los viejos no tuvieron nada que ver ahí, gente de respeto y de confianza. Después, cuando llegó el peronismo gritaban 'Viva Perón' y ya estaba todo arreglado. Antes no era así. La política no, no... ${ }^{451}$

En términos de Williams (2000) que entiende a la hegemonía como un "cuerpo de prácticas y expectativas en relación con la totalidad de la vida", "un vívido sistema de significados y valores que en la medida en que son experimentados como prácticas parecen confirmarse" o "un sentido de realidad para la mayoría de las gentes de la sociedad", puede interpretarse que las tradiciones laborales vinculadas a la gestión inglesa actuaron como prácticas residuales frente a las nuevas prácticas que intentaron instalarse como dominantes a partir de 1948. Para este autor, lo residual se vincula con aquellos elementos formados en el pasado que todavía se hallan en actividad en el actual proceso cultural, es decir, experiencias,

${ }^{451} \mathrm{EN}^{\circ} 20$. 
significados y valores vividos y practicados sobre la base del remanente de alguna formación o institución cultural anterior. En esa línea, puede sostenerse que las tradiciones inglesas residuales pudieron haber actuado en tanto prácticas de oposición respecto de la nueva cultura dominante que pretendía consolidarse a partir de la nacionalización (Williams 2000: 131-147).

Puede observarse, además, que las críticas a la nacionalización que los testigos asumen en el presente apartado no están vinculadas al acontecimiento en sí, sino a las prácticas laborales que tuvieron lugar a partir del suceso. En otras palabras, a la gestión posterior de la empresa. Marone recuerda sobre este evento, que existía, en aquel momento, "un sentido nacionalista muy grande":

“En líneas generales (la nacionalización) se vivió con mucha euforia porque había un sentido de rescatar para la nación todo lo que estaba en manos extranjeras. Perón fue un ídolo porque rescataba para el país un montón de empresas de capitales foráneos. Creo que en líneas generales casi todo el mundo estaba de acuerdo, sin profundizar si para el futuro era todo bueno o había cosas que no eran tan buenas". 452

Poch, quien había ingresado en 1942, recuerda que aquel suceso "fue una alegría para Argentina", aunque también se lamenta de que "no llevó el mismo ritmo de los ingleses". ${ }^{453}$ En el mismo sentido, uno de los fraternales plantea, por un lado, su adhesión ideológica a la nacionalización y, por el otro, su disconformidad respecto de la eficiencia posterior de la empresa:

"Yo como argentino lo acepto, contento de que fue nacionalizado, pero después vienen las consecuencias. Que no anduvieron las cosas como debieran haber andado. Ese es mi concepto. O sea, se siguió trabajando, pero se vino un poco abajo el ferrocarril". ${ }^{454}$

Rinaldi, aun teniendo la convicción de que los servicios públicos debían ser de propiedad del Estado, tal como expuso antes, denuncia la utilización posterior de la empresa para fines político-partidarios:

"Lamentablemente, acá todo lo que se nacionalizó sirvió para hacer una empresa en cada una de ellas tremendamente grande. Porque fue el negocio para tener votos en las

\footnotetext{
${ }^{452} \mathrm{EN}^{\circ} 14$.

${ }^{453} \mathrm{EN}^{\circ} 1$.

${ }^{454} \mathrm{EN}^{\circ} 12$.
} 
elecciones por parte de los partidos políticos. Como desgraciadamente hubo distintos cambios, porque hubo varias clases de partidos, se aprovechó esa situación para desprestigiar cada una de esas empresas." 455

Tornello, representante gremial, a pesar de considerar que "la nacionalización fue lo mejor que puede haber ocurrido, porque no se puede concebir un país sin ferrocarril" y de estar a favor de las transformaciones en las relaciones laborales que tuvieron lugar a partir de 1948, reconoce abusos por parte de los trabajadores:

"La relación entre obrero y patrón, porque los ingleses eran patrones, era muy distinta a la época peronista. La disciplina era otra, los medios de producción eran otros. Con la nacionalización cambió abruptamente. Y tenemos que decir que también hubo excesos por eso de parte de algunos obreros. Porque si no decimos toda la verdad, queda como que aquello era todo malo y esto era todo bueno". ${ }^{456}$

Como recuerda Marone acertadamente, la nacionalización de los ferrocarriles ocurre en un contexto social en el que existía un intenso consenso nacionalista en la opinión pública. De hecho, las primeras tratativas del gobierno de generar una empresa mixta de capitales británicos y argentinos (septiembre de 1946) fueron rechazadas por los sectores nacionalistas por considerar que Perón estaba "traicionando los compromisos asumidos" y que esta alternativa constituía una "entrega vergonzosa" a favor de los británicos (López et al., 2016: 143). Según López, la propuesta de adquisición completa sorprendió a los mismos ingleses que en febrero de 1947 arribaron a un acuerdo con el gobierno argentino para vender los activos ferroviarios y no ferroviarios por 150 millones de libras. Este convenio recibió apoyo de la prensa que celebraba que "se había roto la cadena con el imperialismo" y que, aun reconociendo que el precio era alto, porque era superior a lo que el gobierno argentino había anunciado que iba a pagar, se apoyaba la acción porque mediante ella "se compraba la liberación". El autor observa que solo un diario de la época advirtió que "existían serias dudas acerca de la capacidad de las nuevas autoridades para administrar lo adquirido", una observación contemporánea a la época estudiada que parece ir en línea con lo que los propios testigos experimentarían posteriormente e interpretarían mucho tiempo después (López et al., 2016: 144).

Luego de diversas negociaciones, finalmente, el 1 de marzo de 1948 el gobierno

$455 \mathrm{EN}^{\circ} 3$.

$456 \mathrm{EN}^{\mathrm{o}} 6$. 
argentino tomó posesión de las empresas británicas ferroviarias. López critica la "irresponsable actuación de la oposición y los formadores de opinión nacionalista" que llevaron a preferir la compra a la formación de una compañía mixta. En ese sentido, el autor observa la falta de preparación que tenía el Estado para gestionar la empresa y brindar el servicio que, hasta el momento, se había brindado, así como afrontar los problemas demorados por la falta de inversión en materia ferroviaria durante 15 años.

“Perón cumple, ya son argentinos!”. Dos fantasías nacionalistas repetidas hasta el cansancio por la propaganda oficial, se convertían en creencia generalizada (...) la compra de los ferrocarriles debió haber cerrado una etapa y ser el comienzo de una nueva. El futuro cobraba más importancia que el pasado y nadie pareció comprenderlo (López et al, 2016: 146).

Siguiendo a López, con la nacionalización se puso en marcha un plan para alejar de los cargos al personal superior, a través de un sistema de jubilaciones anticipadas al que adhirieron 400 funcionarios. Además, de acuerdo al autor, comenzaron en forma inmediata los "maltratos" y privación de cargos. Algunos ferroviarios juninenses recuerdan con dolor esta transformación en las modalidades en que las relaciones laborales habían tenido lugar hasta el momento, como Crocco:

“Cuando se nacionalizan los ferrocarriles el jefe del taller Junín era Mr Murphy. ${ }^{457}$ Era un señor de un porte elegante y grandote. Antes, cuando este señor salía a recorrer las secciones, se corría la bolilla por todas las secciones. “¡Che, salió Murphy, salió Murphy!". Todo el mundo corría, todo el mundo trabajaba, todo el mundo en orden. Era un respeto total. Luego de la nacionalización, con el correr del tiempo, y antes de que Mr Murphy renunciara ni se molestaban ni en mirarlo, ni en saludarlo. Ahí se fue perdiendo y deteriorando el respeto." 458

Para López, mediante las medidas que, luego de la nacionalización, apuntaron a alejar a los directivos británicos de sus puestos, se destruyeron uno de los activos más importantes que se habían adquirido: la organización empresarial (López et a., 2016: 147). Desde esta óptica, las autoridades argentinas, en lugar de recuperar el saber y la experiencia de los

\footnotetext{
${ }^{457}$ Patricio Murphy fue jefe de Talleres desde 1940 a 1950. Ver más en: Petraglia, P. (30 de agosto de 2014). El maestro Luis Felipe Noé y los Muphy de Junín. Democracia. Recuperado en https://www.diariodemocracia.com/locales/junin/88471-maestro-luis-felipe-murphy-junin/: 6/2/2020.

${ }^{458} \mathrm{EN}^{\circ} 2$.
} 
británicos en la gestión de la empresa, intentaron reemplazarlo por un nuevo modo de gestión sin haber contemplado una etapa de transición que resultara útil para el nuevo rol que el Estado asumía ahora, como empresario. Sin embargo, la experiencia de los británicos seguiría estando presente como práctica residual de los trabajadores en lo que muchos ferroviarios juninenses coincidieron en denominar "la escuela inglesa", la cual aludía, a una modalidad de trabajo que será descripta y comparada en los próximos apartados.

Desde un plano político económico, Horowicz (2011) también critica las consecuencias que tuvo para la Argentina la nacionalización de los ferrocarriles, ya que la estatización de los servicios públicos en su conjunto consumió el noventa por ciento de las reservas argentinas de ese momento. Según el autor, esto impidió la concreción del conjunto de acciones previstas por el Plan Quinquenal, el cual apuntaba a transformar la estructura económica del país a partir del fomento de la industria. Específicamente, el costo de las nacionalizaciones en los primeros dos años del gobierno de Perón fue de 983 millones de dólares, de los cuales 645 millones estuvieron destinados a los ferrocarriles (dos tercios del total). Las reservas de Argentina eran de 1.100 millones de dólares, lo cual significa que el noventa por ciento de ellas fueron empleadas para nacionalizar. Si se compara esta cifra con el costo estimativo del Plan Quinquenal, de 1.270 millones de dólares, se comprueba que el 80 por ciento de este plan se dispuso para nacionalizar. "Nunca más, en toda la historia económica argentina, gobierno alguno dispuso del equivalente a un año completo de exportaciones $(1.100$ millones de dólares) como masa de reserva financiera, sin la contrapartida de una voluminosa deuda externa" (Horowicz, 2011: 121).

En rigor, el cincuenta y cinco por ciento de las reservas de aquel momento estaban compuestas por libras bloqueadas en bancos británicos, como consecuencia de las deudas que Gran Bretaña había adquirido con la Argentina por el envío de alimentos durante la contienda bélica que fue la Segunda Guerra Mundial. Para Horowicz, en un contexto en que Estados Unidos se erigía como la primer potencia mundial mientras Gran Bretaña perdía su hegemonía, Argentina contaba con un "aliado implícito" que habría permitido el empleo de esas libras bloqueadas para la adquisición de equipos industriales, ya que toda libra de libre disponibilidad era susceptible de transformarse en dólares destinados al mercado norteamericano. Según el autor, el gobierno argentino estaba en condiciones de utilizar las libras bloqueadas "con el sencillo trámite de una negociación diplomática inflexible” (Horowicz, 2011: 121).

La ausencia de una política orientada en ese sentido — compra de equipos industrialesimpone una reflexión: destinar el noventa por ciento de las reservas a las 
nacionalizaciones equivale a reconocer que el programa de inversiones del Plan Quinquenal no era prioritario... (Horowicz, 2011: 122).

Para el gobierno argentino las nacionalizaciones aportaban soberanía, autodeterminación, en el marco de un análisis - hecho por nacionalistas como Raúl Scalabrini Ortiz, Ricardo Ortiz y otros - por el cual Gran Bretaña había impedido el desarrollo industrial de vastas regiones del país a partir del manejo de tarifas, resultando un aliado de los terratenientes argentinos que se servían del ferrocarril para transportar carnes y granos hacia el puerto de Buenos Aires, mientras que los ingleses distribuían sus manufacturas a lo largo y a lo ancho del país. ${ }^{459}$ El contexto mundial, sin embargo, se había transformado: "La nacionalización del ferrocarril anunciaba (...) el comienzo del fin del dominio británico, cuando el dominio británico estaba herido de muerte" (Horowicz, 2011:124). El nuevo escenario, entonces, estaba caracterizado por una Gran Bretaña debilitada, imposibilitada de abastecer al mercado mundial.

Para el autor, la nacionalización de los ferrocarriles continuó beneficiando al sector agropecuario del país a través de las tarifas subvencionadas que generaron un déficit ferroviario, ocasionado, principalmente, por el transporte de carga. De esta manera, se terminaba atendiendo los intereses de los terratenientes que no requerían divisas, y solo muy limitadamente los intereses industriales. En cambio, para que la nacionalización contemplara adecuadamente los intereses industriales, hubiera sido preciso que se efectivizara sin divisas; es decir, que se pagara con moneda nacional. De esta manera, se hubiera alcanzado un doble propósito: entregar el ferrocarril al Estado y conservar divisas para la importación de equipos básicos (Horowicz, 2011: 125).

Adicionalmente, siguiendo al autor, la adquisición de los ferrocarriles siguió preservando la relación con Gran Bretaña, quien estaba interesada en desprenderse de esos bienes desde antes de la década de 1930 y seguía siendo el principal comprador a crédito de productos nacionales. En síntesis, si bien la nacionalización intentó representarse desde un plano simbólico como una ruptura frente a quienes habían sido los aliados principales de Argentina, implicó una continuidad no solo porque evitó conflictos con esta nación, sino también porque no tendió a modificar la estructura productiva que el país había tenido hasta el

\footnotetext{
459 "El ferrocarril extranjero extendió el área comercialmente cultivable con cereales y el perímetro de las praderas aprovechables para la cría del ganado, pero impidió sistemáticamente el comercio interior y las industrializaciones locales. El ferrocarril fue el arma primordial de que se valieron los extranjeros para sofocar todo progreso que de alguna manera pudiera hacer vaciar su hegemonía. Fueron, los nuestros, ferrocarriles coloniales destinados a mantenernos en la rutina sin salida del primitivismo agropecuario. Tal es la triste consecuencia que se deduce de nuestra historia ferroviaria, y tal fue la misión para la cual fueron construidos" (Scalabrini Ortiz, 1975: 18)
} 
momento. Esto estaba motivado porque desde la perspectiva de Perón, el desarrollo industrial era dependiente del desarrollo agropecuario: "veía en su solvencia toda la posibilidad de crecimiento industrial. Su fórmula sería así: a mayores exportaciones agrarias, mayor actividad industrial" (Horowicz, 2011: 126).

\section{La "escuela inglesa": representaciones sobre la eficiencia y calidad británicas}

Los sentidos que la nacionalización tuvo para la historia del ferrocarril son explicados por los ferroviarios juninenses a partir de las representaciones asociadas a la etapa en que la empresa era de capitales británicos. En otras palabras, las interpretaciones que los testigos hacen respecto de la experiencia vivida en los ferrocarriles del Estado son realizadas a partir de lo que podría denominarse la "vara inglesa": lo que el actor experimentó en sus treinta o cuarenta años como trabajador, frente a lo que emanaba de aquel modelo británico; lo que sucedió, muchas veces, frente a lo que debió suceder, según los testigos. Como dice Dimarco que evita contar anécdotas asociadas a su historia personal pero que, en momentos, ilustra de una manera muy sintética el imaginario compartido respecto de lo que los testigos coinciden en denominar "los ingleses" (para referirse a las personas a cargo de la gestión de la empresa de capitales británicos): "Todo lo lógico lo tenían ellos". ${ }^{460}$ Conviene aclarar, en este punto, que solo un tercio de los entrevistados experimentó directamente el acontecimiento histórico de la nacionalización como trabajador dentro de la empresa. Así y todo, para el resto los sentidos asociados a la experiencia británica en el ferrocarril funcionan con un vigor tal, capaz de permitir interpretar y comprender la experiencia transitada por ellos mismos. Esto se explica porque, por un lado, los testigos ingresaron a una comunidad de ferroviarios que sí transitó la experiencia inglesa y construyó relatos que tuvieron una reproducción exitosa entre sus miembros, o bien porque sus padres y abuelos ferroviarios fueron portadores de esos relatos que transmitieron a sus hijos o nietos en el entorno familiar. Por el otro, porque en los primeros años de la nacionalización ocurrió una transición en la que algunas tradiciones se mantuvieron, mientras nuevas prácticas comenzaban a instalarse.

Uno de los sentidos asociados a lo que, en adelante, se denominará "etapa inglesa" o "época inglesa" es el de la eficiencia. En esa línea, puede afirmarse que una de las narraciones más exitosas para probar esa cualidad asociada a "lo inglés" refiere a la puntualidad de los

$460 \mathrm{EN}^{\mathrm{o}} 16$. 
trenes. ${ }^{461}$ De Giulio, que ingresó al ferrocarril en 1952, comenta: “A mí me hubiera gustado que sigan los ingleses porque los trenes eran un reloj. Seguían los trenes bien cuando yo entré, andaban bien al principio." ${ }^{462}$ En tanto, uno de los fraternales evoca con emoción: "Uy, en aquel momento, los vecinos ponían el reloj a horario cuando pasaba el Cuyano, porque no perdía un minuto". ${ }^{463}$ Dall'Occhio, hijo de un jefe de estación y trabajador ferroviario desde 1956, recuerda cómo el tránsito del tren influenciaba en la vida cotidiana y marcaba los ritmos de la ciudad:

\begin{abstract}
"En la época de los ingleses la gente controlaba la hora con la llegada del tren. O sea, la gente ajustaba los relojes con la llegada del tren. Porque un atraso de un tren significaba un problema muy serio. Había que informar y justificar muy bien por qué se atrasaba. Había que ser muy guapo para contestar por qué esto había ocurrido. Era una carrera de regularidad ser conductor de locomotora." ${ }^{464}$
\end{abstract}

De la misma manera que afirmó antes Dall'Occhio, uno de los fraternales coincide en la necesidad de fundamentar los atrasos, en casos de que estos tuvieran lugar, y explica esta exigencia a partir de las condiciones de trabajo que brindaba la empresa británica:

\begin{abstract}
"En la época de los ingleses, si vos perdías tiempo con un tren de pasajeros un minuto, tenías que informar bien las causas y que estuvieran justificadas, ¿eh? Por qué lo perdías. Pero te daban las herramientas para que puedas cumplir. A lo mejor vos tenías que hacer una semiparada en una estación. Y ahí ya te perdías un minuto. Entonces tenías que documentar el motivo."
\end{abstract}

El llamado “Cuyano”, tren que partía de Retiro, pasaba por Junín y llegaba a Mendoza, es asociado por muchos ferroviarios a la mencionada puntualidad inglesa, aun cuando el tren habría continuado funcionando de manera similar, algunos años después de la nacionalización. ${ }^{466}$ "Yo creo que el Cuyano fue así durante la máquina de vapor", dice uno de

\footnotetext{
${ }^{461}$ Un documento de 1938 que se encuentra disponible en el Archivo Universitario de la UNNOBA "Roberto Dimarco", escrito por la gestión británica y dirigido a los trabajadores de Buenos Aires al Pacífico, decía: "El servicio de trenes está sujeto a horarios rígidos, que la Empresa está obligada a cumplir ineludiblemente. Para asegurar la puntualidad necesaria en este sentido es indispensable que las locomotoras funcionen de manera perfecta”. Ver más en: BAP (1938). Actividades, obligaciones, aspiraciones, p 7.

${ }_{462} \mathrm{EN}^{\circ} 11$.

$463 \mathrm{EN}^{\mathrm{o}} 12$.

$464 \mathrm{EN}^{\mathrm{o}} 15$.

$465 \mathrm{EN}^{\mathrm{o}} 12$.

466 “...el Cuyano recorre más de 1000 kilómetros en 15 horas y 15 minutos”. Ver más en: BAP (1938). Actividades, obligaciones, aspiraciones, p.14.
} 
los fraternales, cambio que habría tenido lugar en la década del sesenta. Un cuento recuerda que en 1952 "el Cuyano" era "uno de los trenes más prestigiosos del parque ferroviario argentino, a solo cuatro años de su nacionalización. El personal que lo conducía trabajaba para cuidar esa reputación brindando confort, puntualidad y calidad de atención al pasajero". ${ }^{467}$ Otro cuento titulado "Ese día paró el Cuyano" asegura que este tren tenía fama bien ganada de “cumplir sus horarios en invierno y verano, todos los meses, durante años, y era así”, pero, sin embargo, bajo la excepción de la huelga de 1961, se detuvo por los reclamos de los trabajadores. ${ }^{468}$

Danielle que ha tenido por afición guardar revistas y diarios de la época inglesa del ferrocarril, algunos de los cuales donó al Archivo Histórico Municipal de Junín, recuerda que en 1928 una revista ferroviaria aseguraba que "el famoso Cuyano era el tren más rápido de Sudamérica" y ejemplifica mediante el recuerdo de otro material la importancia que los ingleses le otorgaban a la puntualidad de este tren:

"En una revista aparece el detalle del horario en que paró en cada estación, donde cargaba
agua según la pendiente del terreno, dónde llegaba adelantado, dónde atrasado. Y este
tren llegó tres minutos atrasado a Retiro. Increíble. ¿Por qué? Porque tuvo una demora
extra, demasiado equipaje para bajar en Palermo, que son $6 \mathrm{~km}$ a Retiro. ¡No es nada!”. ${ }^{469}$

Este ferroviario, aun habiendo ingresado en 1953, exhibe, una gran nostalgia por el tiempo inglés. Cuando se da cuenta que una y otra vez evoca a los británicos, se justifica: "No es que tenga a los ingleses a flor de boca, pero ellos...", luego de lo cual enuncia algunas características asociadas a la gestión inglesa que permitirían fundamentar estas reiteraciones. Danielle reproduce otra anécdota que permite consolidar la asociación entre ingleses y puntualidad; e ingleses y eficiencia:

"Hay una anécdota de un hombre que está en los 90 años, (Pedro) Bertinotti, y él se inició
como peón en el galpón de locomotoras. Me cuenta que una vez lo mandó a llamar un
inglés, un tipo joven. Y le llamó la atención que en la oficina no había ningún papel. Porque
no se manejaban con papeles, para eso tenía el servicio de ayudantes. Y dice que había un
papelito nada más, un telegrama. Él entró, lo saludó y no le contestó. Y entonces el inglés

467 Marchesi, G. (16 de septiembre de 2016). El cuyano. Cuatro Palabras. Recuperado de http://www.cuatropalabras.com/articulo/cultura/cuyano/20160916004839002354.html: 20/3/2019

${ }^{468}$ Cormick, E. (2006). Entre gringos y criollos. Junín: Tres lagunas. Archivo Histórico de Junín.

${ }^{469} \mathrm{EN}^{\circ} 27$. 
lee, sin saludarlo: 'Cuyano atrasó en Laoboulaye veinte minutos, por obstrucción de la cañería de petróleo. Que no se repita'. Nada más le dijo (risas). 'Buen día', le respondió y salió con la cola entre las patas (risas). Y dice que ya estaban en la calle y decía el capataz de turno, vos vas a hacer esto, vos lo otro, vos lo otro... (risas). Eran muy estrictos. Para ellos el horario era fundamental, estricto, estricto. Antes vos decías, son las nueve y cuarto, porque pasaba el tren." 470

En tanto, Marone, también es parte de estos relatos que contribuyen a fortalecer el imaginario de la eficiencia asociado a la experiencia inglesa:

\begin{abstract}
"Yo calculo que el mejor momento fue antes de que yo entrara, cuando era inglés, porque tenían los servicios más eficientes, más en horario. Los trayectos, a pesar de que se hacían con locomotora de vapor, se cubrían a una velocidad muy importante. Se me ocurre que la época más floreciente del ferrocarril fue la anterior a la nacionalización." ${ }^{471}$
\end{abstract}

La eficiencia inglesa también quedó asociada en el imaginario con la exigencia hacia los trabajadores y con el uso eficaz del tiempo, así como de los recursos humanos y materiales. ${ }^{472}$ José Poch, quien ingresó en 1942, comenta: "Los ingleses nos enseñaron a cumplir, a trabajar siete horas y no nos podíamos despegar del escritorio porque teníamos mucho trabajo". Ferrari contrapone lo que sucedió luego de la nacionalización con lo que sucedía en la etapa en que el ferrocarril era de capitales británicos:

"Ellos tenían los encargados en cada parte y te hacían trabajar hasta que tocaba el pito.

Entonces, te limpiabas y recién cuando tocaba el segundo pito te ibas. En cambio, después de los ingleses, se lavaban con kerosene antes de que sonara el primer pito. Dejaban de trabajar como una hora antes y nadie decía nada. ¡Los ingleses no! Utilizaban bien el tiempo, se aprovechaba bien. Te hacían trabajar y rendir, como debe ser. Vos tenés que ganar lo que rendís, sino la empresa se viene abajo." ${ }^{473}$

\footnotetext{
470 EN 27.

$471 \mathrm{EN}^{\mathrm{o}} 14$

472 En el documento aludido del Departamento Mecánica de BAP, se expresa la visión que la gestión inglesa tenía sobre la calidad, la cual siempre podía ser mejorable, lo que implicaba, entonces, exigencia continua hacia los trabajadores: "Por amplio que sea el éxito en la consecución de una obra no es propio abandonar el deseo de una renovada superación. Mejorar lo que ya es bueno equivale a buscar su máximo perfeccionamiento". De esta manera, se intentaba inculcar en los trabajadores una autoexigencia para mejorar la calidad de su tarea, entendiendo que el trabajo realizado siempre es perfectible. Ver más en: BAP (1938). Actividades, obligaciones, aspiraciones, p.12. Archivo Universitario de la UNNOBA Roberto Dimarco.

$473 \mathrm{EN}^{\circ} 4$.
} 
En relación a la exigencia hacia los trabajadores Dimarco considera que esa exigencia de los ingleses estaba acompañada por un sentido de justicia, en relación al salario, y de sensatez, en relación a las posibilidades del trabajador:

“Mi papá se jubiló a los 50 porque los ingleses pagaban bien, pero exigían bien. Los talleres, en aquel momento, eran un hervidero de gente, que lo controlaban con más disciplina. Exigían los ingleses. Pagaban bien y exigían bien, entonces sabían que más de los 50 años el hombre no podía trabajar. Entonces los jubilaban, porque no rinde.”474

Esta práctica de la gestión inglesa que apuntaba a lograr el rendimiento máximo del trabajador para incrementar la productividad de la empresa también pudo haber tendido a distanciarse de la justicia manifestada por Dimarco y por Ferrari en el anterior testimonio cuando decía: “Te hacían trabajar y rendir, como debe ser". En cambio, en otra parte del relato, Ferrari cuenta jocoso (lo cual muestra su aprobación hacia ese acto) cómo los ingleses empleaban ciertos artilugios para engañar al trabajador y así pagarle menos por su tarea:

\footnotetext{
“Tenían tan controlado todo el sistema, que no le hacía falta controlar ni la disciplina, nada. Porque ellos tenían por ejemplo tasadores de precio, que son gente experimentada en determinada especialidad que van a un lugar de trabajo y entonces le dan un planito de un trabajo a realizar. Entonces él te toma el tiempo. Tiene que hacer tantas piezas, en tanto tiempo, para ganar tanto. O sea que ellos te pagaban lo que vos trabajabas. El que más trabajaba más ganaba. O sea que vos presentabas esa ficha de contrato y eso se iba sumando para después conformar el sueldo de cada uno. En cada especialidad tenías que ser una persona que conozca muy bien, porque te podían 'meter la mula' como quien dice. El tipo que hacía las pruebas te quería embromar, era muy canchero, ponía la velocidad mínima para hacerlo más despacito cuando te tomaban la prueba, para que después cuando era realmente te podían sacar ventaja." ${ }^{475}$
}

Otro de los recuerdos que pueden vincularse con el atributo de la eficiencia inglesa, que implicaba el aprovechamiento del tiempo del trabajador en la empresa, se refiere a la imposibilidad de circulación y la obligación de mantenerse en el puesto de trabajo. Ferrari recuerda: 
"Yo trabajé un año al mismo tiempo que mi papá, porque mi papá se jubiló en el 46 en el ferrocarril y yo entré en el 45. Pero no lo pude ver, porque en la sección que trabajaba él no le permitían deambular a otra parte. Hasta eso, tenían todo controlado los ingleses." ${ }^{476}$

Martínez, quien ingresó en 1947, asegura que "cuando estaban los ingleses era más serio, era más recto" e intenta ilustrar dos momentos que, de acuerdo a su óptica, sintetizan toda la historia vivida por él en el ferrocarril, uno anterior a la nacionalización y otro posterior, y que también dan cuenta del control sobre los empleados: "No era que uno le marcaba la tarjeta al otro, últimamente no iban a trabajar y le marcaban la tarjeta" ${ }^{477}$ Es de notar que el adverbio de tiempo empleado, "últimamente", involucra más de cuarenta años de la historia del ferrocarril del Estado. No es la primera ni la única vez que los entrevistados van a realizar este tipo de salto temporal.

Taberna recuerda que habiendo ingresado luego de la nacionalización, en 1953, aún se mantenían algunas tradiciones británicas en las prácticas laborales. La evocación que realiza resulta una mezcla de ternura y nostalgia por ese joven inexperto y temeroso a quien observa a través del tiempo, él mismo:

“Cuando yo entré todavía estaba esa disciplina, esa rigidez. Tenía como jefe a don Pablo Gandini, que era jefe de división. Él fumaba con pipa. Al fondo había una oficina vidriada en la que trabajaba él, levantaba la vista y veía todo. Yo no me olvido más. Hacía poco que había entrado, tenía un problema y había un muchacho conocido y lo llamé, me explicó el problema y se quedó charlando en el tablero. En lugar de uno, éramos dos. Estaba en el fondo yo. Recién empezaba, era muy nuevito. Bueno, Gandini levantó la cabeza y siguió trabajando. Volvió a levantar la cabeza, se vino, parecía una locomotora con la pipa, pisaba fuerte para colmo... ¡Uy, no me olvidé más en mi vida! ¡Nos dio un repunte! ¡Ay! Después se volvió y me dijo: 'Es la segunda vez que levanto la vista y los veo conversando...' 'No, yo lo llamé a él porque quería...' ‘'A ver, ¿cuál es el problema que tiene?' Yo no sabía qué decirle. ${ }^{\$ 478}$

Ese control sobre los movimientos de los empleados es rememorado a través de algunas descripciones muy precisas que asocian a las tradiciones inglesas con el orden:

\footnotetext{
${ }^{476} \mathrm{EN}^{\mathrm{o}} 4$

477 EN ${ }^{\circ} 20$,

${ }^{478} \mathrm{EN}^{\mathrm{o}} 10$.
} 
"La división técnica parecía un santuario cuando yo entré, impresionaba. Eran todos tableros. Ocupaba como media cuadra, en calle Newbery hacia España, estaba en el piso alto. Era toda gente inclinada trabajando sobre los tableros que hacía dibujos y proyectos que se hacían después en los talleres. Era extraordinario. Yo entré a medidados del 53, porque primero entré al taller. Todavía quedaba algo... Hasta el té. No podías tomar mate. Venía el conserje a las 3 de la tarde, uniformado, con traje, con la bandeja y las tazas de té. Se trabajaba de 8 a 12. Y de 1 y media a 4 y media. Mirá el horario. Después se empezó a trabajar horario corrido, en verano de la 6 de la mañana hasta la 1 de la tarde, después se trabajó definitivamente de 7 a $14 .{ }^{\prime 479}$

El relato de Taberna se distingue por sus evocaciones visuales y las memorias de los espacios físicos de trabajo. Una de las contribuciones que realiza es el recuerdo sobre los baños construidos durante la gestión británica, diseñados de forma tal que los jefes pudieran controlar el tiempo que allí pasaban los empleados, evitando así las actividades ociosas que en un espacio privado pudieran realizar y asegurándose de la cantidad de tiempo que los empleados le dedicaban al trabajo fuera la máxima posible. A diferencia de otros recuerdos vinculados a las tradiciones inglesas previas que él parece celebrar, Taberna recuerda este acontecimiento con indignación y aprueba que, luego de que él ingresara, en 1953, el diseño de esos baños se hubiera modificado:

"Yo lo alcancé a ver... los baños. Fijate que hasta denigrante era. Había unos baños en el taller que eran dos hileras. En la oficina era otra cosa. El que iba al baño se le veía la parte de acá para arriba (el torso y rostro). Era denigrante. Vos pasabas y veías quien estaba en el baño. Era para controlar, que no perdieran tiempo... Eso fue terrible. Después rompieron todo e hicieron puertas y baños comunes, como tiene que ser un baño. Vos fijate qué desprecio por la dignidad humana. Eran así (los ingleses)." ${ }^{480}$

Así como la gestión británica apuntaba al aprovechamiento máximo del tiempo del trabajador en la empresa, también promovía un uso eficiente de los recursos materiales. Dall'Occhio opina que "la mejor época del ferrocarril tiene que haber sido anterior a la nacionalización" y luego añade, sugiriendo esa disposición británica hacia la eficiencia: "Porque prácticamente los ingleses plantaban los árboles para hacer los vehículos. Acá se hacía todo”. Más tarde, Dall'Occhio exhibe un material impreso y se explaya sobre este punto: 
"Este boletín es del año 1938. Acá dice cómo cuidar el consumo de combustible de la locomotora. La locomotora a vapor usaba carbón de piedra, pero tiene mucha importancia cómo vos distribuís el carbón para el aprovechamiento del fuego, para que sea eficaz. Acá te dice que, si se ahorrara medio kilogramo de carbón por kilómetro recorrido, la economía que esto representa asciende a 197 mil por año. ¿Qué ocurre? Si vos en tu cocina metés el mechero fuerte para calentar una simple pavita para tomar mate, el agua hierve a cien grados y hierve de la misma forma a plena potencia que a media potencia. Entonces, tenés que bajar el mechero para consumir menos gas. Lo que te dice esta nota es que la locomotora tiene instrumentos que te dicen la cantidad de vapor seco producido. Una vez alcanzado ese nivel, vos tenés que ponerle carbón de a poco, no excederte de carbón, de manera que el consumo de carbón alcance para ir manteniendo el nivel de vapor y no ir metiendo palada y palada." ${ }^{481}$

En la misma línea, Danielle afirma, con admiración, sobre los ingleses,

“...ellos explotaban todo, hasta los cañaverales que se ponían donde había terraplenes para reforzar. y que no se disgregara la piedra. Los cañaverales los vendían. Los hacían cortar, venía el interesado y vendían paquetes de caña a los quinteros. Y vendían el hinojo que crecía como yuyo a los costados de las vías. ¡Increíble! Eso desapareció, el hinojo desapareció prácticamente. Venía el inspector de vía, el interesado iba al lugar y cortaban la cantidad que quisieran. Me acuerdo que eso se vendía por metro cuadrado. Cortaban, lo dejaban secar y después lo golpeaban y juntaban. Yo tenía siete, ocho años. Yo acompañaba a mi padre, ya que cuando el inspector de vía no podía ir se lo daban a él el trabajo." $" 482$

De acuerdo a Poch, empleado administrativo de Contaduría que además fue integrante de la Unión Ferroviaria, el cuidado de los recursos materiales caracterizaba a los ingleses, lo cual se transformó cuando la empresa pasó a manos del Estado:

-JP: En la época inglesa había cuatro inspectores que se repartían la tarea de cada coche, lo recorrían. Ahora se roban todo, en aquella época nadie robaba nada. Porque ellos pasaban y veían. Se empezaron a robar las cosas porque eran de bronce...

—ALS: ¿Cuándo comenzó a pasar eso?

${ }^{481} \mathrm{EN}^{\circ} 15$.

${ }^{482} \mathrm{EN}^{\circ} 27$. 
—JP: Cuando pasaron a manos argentinas. Como las perchas eran de bronce, vení pa'ca. ${ }^{483}$

Nótese, nuevamente, el salto temporal que realiza Poch, de la misma manera que lo hace Martínez: “antes”, en la época en que el ferrocarril era de capitales británicos; "ahora", luego de que el ferrocarril fue de capitales argentinos. Esto demuestra el enorme significado que tiene la nacionalización para los testigos, la cual se constituye en un hito biográfico que, al mismo tiempo, les permite explicar la historia del ferrocarril desde la propia experiencia.

Podría decirse, entonces, que los actores coinciden en "detenerse" en este acontecimiento, así como en "acelerar" otros procesos históricos transitados. Precisamente, Candau observa que recordar el pasado no implica para el actor tener conciencia, simultáneamente de la dinámica del acontecimiento. Mientras, a veces "la memoria contrae el tiempo", otras "se esfuerza por lentificar o eternizar el pasado" (Candau, 2002: 30). Halbwachs, pionero de los estudios de la memoria, también decía:

Hay horas bajas y días vacíos, mientras que en otros momentos, cuando los acontecimientos se precipitan o nuestra reflexión se acelera, o nos encontramos en un estado de exaltación o agitación afectiva, tenemos la impresión de haber vivido años en tan solo una horas del día (Halbwachs, 2004:92).

Esto implica comprender que los acontecimientos compartidos por los actores respecto de sus experiencias vividas están íntimamente ligados a los sentidos que para ellos tuvieron estos hechos, los cuales habrían sido construidos y reconstruidos a lo largo de toda la historia de vida del testigo.

En suma, "los ingleses", modo con que se intenta caracterizar un modo de gestión que se origina antes de la nacionalización, quedó asociada en el imaginario a una serie de cualidades como rectitud, disciplina, seriedad, orden, eficiencia. Danielle, aun habiendo ingresado luego de la nacionalización, se considera "de la escuela inglesa” y sintetiza varias de estas cualidades en un solo enunciado: "Yo soy de la escuela inglesa. Seguimos con esa tradición, ese respeto, esa seriedad, después se fue perdiendo. Pero en los inicios era todo rectitud." En la misma línea, Murgia, que ingresó en 1954, refiere a la experiencia británica y la contrapone con lo que sucedió después: "Sé lo que contaba la gente vieja que había orden, autoridad, disciplina, que después en alguna medida se perdió un poco. Porque se empezaron a dar otras condiciones". Marone, que ingresó en 1951, también recupera la experiencia inglesa a partir de relatos de

${ }^{483} \mathrm{EN}^{\circ} 1$ 
terceros: "A mí me contaba la gente que había trabajado en la época de los ingleses que era jodido disciplinariamente, pero en el trabajo, te enseñaban a trabajar."484

Varios de los testigos hacen referencia a la existencia de una "escuela inglesa", como dice Danielle en el enunciado anterior. Marone también dice:

\begin{abstract}
"Nosotros tuvimos una escuela inglesa. Yo a los ingleses no los quiero, pero por otras razones. Pero me doy cuenta que ellos tenían una escuela, que respetaban, que les servía para ordenarse y manejarse. Porque si no se hubiesen ordenado administrativamente, les hubiera resultado muy difícil manejar la empresa. Tanta gente, tantos problemas, tantas líneas. Si vos no tenés un orden administrativo llega un momento que salís a buscar algo y no lo encontrás. Uy, dónde está el documento ese, dónde está el documento aquel, dónde están los antecedentes de tal... Los ingleses lo tenían todo ordenadito, bien ordenadito y guardado. Todos los expedientes con numeración, identificación. $" 485$
\end{abstract}

De esta manera, la "escuela inglesa" refiere a una modalidad de trabajo propia de los británicos, que fue aprendida por los trabajadores ferroviarios locales y que implicó orden, organización y control de los materiales y de los recursos humanos. ${ }^{486}$ Rinaldi, que, como se ha dicho antes, se declaró un "fanático de la nacionalización”, valora el legado británico en la empresa y manifiesta, aun habiendo ingresado en 1949:

\begin{abstract}
"El cariño por el ferrocarril lo logré a través de ver lo que se hacía, de cómo se trabajaba y en cierto modo un poco me gustaba el diseño o la programación de los ingleses de buena limpieza, ordenamiento, buena organización, buena administración. Y como yo seguí estudiando, eso me interesaba sobremanera.”487
\end{abstract}

Marone insiste en el orden administrativo de los británicos y se explaya:

"Había muchas normas de organización de la empresa que se mantenían con las enseñanzas y el orden que tenían los ingleses. Y en el área administrativa, los ingleses

\footnotetext{
${ }^{484} \mathrm{EN}^{\mathrm{o}} 27,7$ y 14 .

${ }^{485} \mathrm{EN}^{\mathrm{o}} 14$.

486 "El cuidado y el orden en el uso de los materiales y herramientas son factores importantísimos (...) teniendo debidamente ordenados los materiales y herramientas; sabiendo que cada uno de ellos se encuentra en el lugar respectivo se facilita la tarea" Ver más en: BAP (1938). Actividades, obligaciones, aspiraciones, p.6. Archivo Universitario de la UNNOBA Roberto Dimarco.

${ }^{487} \mathrm{EN}^{\mathrm{o}} 3$.
} 
eran muy ordenados. En ese punto nosotros aprendimos mucho. Porque cuando nosotros egresamos de la escuela teníamos mucho conocimiento técnico, pero conocimiento administrativo, no. Cómo se manejaban los expedientes, cómo se ordenaban, cómo se guardaban, cómo se expedían, cómo se buscaban. Cómo se guardaban las cosas importantes y cuáles se dejaban de lado porque no eran tan importantes. Saber seleccionar las cosas importantes para guardarlas. Porque a veces a vos te parece que esto no tiene importancia hoy y lo tirás. Y a los diez años decís por qué no habré guardado aquello que me hubiese servido. Toda esa enseñanza los ingleses la aplicaron con mucha capacidad y creo, me animo a decir, que los argentinos que trabajábamos en el ferrocarril las aprendimos." ${ }^{488}$

Murgia también expresa admiración por el modo de documentar el material por parte de los ingleses:

\begin{abstract}
"Cuando yo entré había algunas reminiscencias de los ingleses. Cuando me empecé a inmiscuir, tuve acceso y empecé a mironear... en el panel de herramientas y de los planos, tuve acceso, vi que había cartones, que era una forma de hacer método, de programación, era una forma de decirle al obrero cómo tenía que hacerlo. Entonces, estaba el plano y estaban las herramientas. Vos ibas al cuarto de herramientas y decías dame el equipo tal, te daban la mecha que necesitabas, así vos no tenías problemas al armar la pieza. Había algo, aunque se ve que ellos eran una organización un poquito cerrada. Otra cosa que me di cuenta es que había gente que leía, que estudiaba y que sabía, no era casualidad que las cosas andaban como andaban." ${ }^{489}$
\end{abstract}

Lo que el testimonio anterior parece sugerir es que el aprendizaje de los trabajadores locales respecto de las prácticas laborales propias de la gestión británica pudo haber tenido lugar a través del acceso a los documentos archivados y dejados en la empresa por parte de los jefes anteriores, una vez que estos se fueron de la empresa. Aunque Murgia caracteriza a los ingleses como "una organización un poco cerrada", existen otros testigos que dan cuenta de enseñanzas transmitidas por jefes que fueron parte de la gestión anterior. Por ejemplo, Poch, quien parece diferenciarse de un colectivo del ferrocarril que "no sabía trabajar" y se identifica, él mismo, como parte de otro agrupamiento que fue instruido por los ingleses: "Yo aprendí a trabajar con los ingleses. Yo aprendí lo que ellos me enseñaron,

${ }^{488} \mathrm{EN}^{\circ} 14$

${ }^{489} \mathrm{EN}^{\circ} 7$. 
mientras había gente que esperaba que le dijeran lo que tenía que hacer. Había gente que no sabía nada de nada." Marone, como Poch, también refiere a los saberes transmitidos por los británicos: "Uno se daba cuenta que esos tipos sabían lo que hacían y dónde estaban parados. Era gente que no era egoísta en enseñarte cosas, si vos tenías interés en aprender. Eran abiertos. ${ }^{490}$ En tanto, Ferrari, quien estuvo tres años trabajando con la gestión británica, expresa respecto de los conocimientos que estos jefes compartieron con los jóvenes ingresantes:

“Lo que más admiré es la enseñanza que dejaron esta gente, la forma de trabajar. Toda esa formación que nos dieron y lo que han trabajado los ingleses en Argentina es impagable. Ellos también fueron los que me enseñaron a trabajar. En ese tiempo, no había mucha papelería, ni nada. Era todo muy práctico. Ellos te dejaban también trabajar a uno. Y si fallabas te corregían. Por eso te tomaban exámenes."491

Como en el testimonio anterior, existen algunas referencias a la practicidad de los ingleses y a la limitación en el uso de papelería, observación que a la vez que valorar el ordenamiento del material documental por parte de la gestión británica también pareciera tener la intención de contraponerse con la gestión nacional posterior, probablemente más burocrática. Martínez, decía, en relación al tiempo inglés: “Quiero lo de antes, porque había más respeto, era más prolijo. No había esa clase de... acá va una nota, ahí no corría." Danielle, en un relato anterior, contaba que los escritorios de los jefes ingleses parecieran estar libres de papeles: "Ellos no se manejaban con papeles, para eso tenía el servicio de ayudantes." ${ }^{492}$ Ferrari ahonda sobre este aspecto:

\footnotetext{
"Nosotros aprendimos mucho de ellos. Cuando estaban los jefes ingleses, nos enseñaban a trabajar en una forma muy... no había ninguna burocracia, nada. El jefe le hacía una nota en papel a Inglaterra para pedir una pieza, manuscrita. Y después cuando empezaron con la fotocopia, hacían veinte mil copias, una burocracia bárbara que no iba para ningún lado."493
}

Otra cualidad que quedó asociada en el imaginario a "lo inglés" y que los testigos

\footnotetext{
${ }^{490} \mathrm{EN}^{\mathrm{0}} 7,1$ y 14.

${ }^{491} \mathrm{EN}^{\mathrm{0}} 4$.

$492 \mathrm{EN}^{\circ} 20$ y 27.

${ }^{493} \mathrm{EN}^{\circ} 4$,
} 
recuerdan con admiración y nostalgia es la que podría denominarse "impecabilidad" ${ }^{494}$ Como en el resto de los atributos que los entrevistados traen a cuento, este, también, tienen la función en el relato de contrastar con lo que sucedería luego de la nacionalización. Uno de los fraternales rememora con impotencia:

\begin{abstract}
"Si usted hubiese visto las máquinas, que nosotros llamábamos las verdes, salían de los talleres lustradas. ¡Lustradas! Era una maravilla. Después se fue deteriorando, no había mantenimiento, limpieza. Como todo... a lo nuestro no lo queremos." ${ }^{\text {"495 }}$
\end{abstract}

En la misma línea, plantea Valentín Martínez: “Las secciones eran un lujo. Los pisos eran un lustre. La madera brillaba. Hoy están un desastre." ${ }^{496}$ Y Dall'Occhio:

"Acá vivía y vive el hijo de un maquinista irlandés. En una locomotora a vapor nosotros lo conocíamos de lejos porque venía vestido de blanco. La locomotora venía impecable. Todo eso se fue perdiendo." ${ }^{\prime 497}$

Los trabajadores ferroviarios también hablan con admiración de la calidad de las construcciones inglesas. Como en el resto de los enunciados de los testigos, esta calidad asociada a "lo inglés", se contrasta con la ausencia (de calidad) por parte de "los argentinos". El fraternal Cruz dice: "Lo que dejaron los ingleses... todas las estaciones con construcciones de primera. Ahora, los argentinos hacemos reparaciones y porquerías, no es lo mismo". Bozzini, trabajador de Vía y Obras e integrante del gremio de la Unión Ferroviaria, coincide: "Si uno ve lo que habían hecho, los kilómetros y kilómetros de vía, las instalaciones del ferrocarril, el chalet de Mr York, las oficinas generales, no sé si lo hubiéramos hecho". ${ }^{498}$ En el mismo sentido, plantea Ferrari:

“Los ingleses construyeron edificios, vías... ¡Vos sabés las vías que había en el ferrocarril en toda la república! ¡Y para mantener esas vías! Vos sabés que después se fue bajando el

\footnotetext{
${ }^{494}$ Una perspectiva de lo que para la gestión británica significaba la limpieza y que intentaban transmitir a los trabajadores puede encontrarse en el documento referido: "La limpieza general de talleres es otra cuestión de suma importancia, que no debe contemplarse únicamente desde un punto de vista estético sino teniendo en cuenta el beneficio práctico que reporta (...) cuando se observa una buena y ordenada disposición de las cosas, cuando en el taller existe orden, arreglo y aseo, el trabajo es siempre más agradable”. Ver más en: BAP (1938). Actividades, obligaciones, aspiraciones, p.14. Archivo Universitario de la UNNOBA Roberto Dimarco.

${ }^{495} \mathrm{EN}^{\circ} 12$.

${ }^{496} \mathrm{EN}^{\circ} 20$.

${ }^{497} \mathrm{EN}^{\circ} 15$.

${ }^{498} \mathrm{EN}^{\circ} 13$ y 17.
} 
rendimiento porque no hubo mantenimiento. Porque antes los ingleses tenían bien manejada cada dependencia. Las vías las mantenía el distrito de Vía y Obras. Después estaba el departamento Almacenes, que proveía de materiales. Después estaba el departamento de Materiales Remolcados, otra cosa. Después estaban los conductores de locomotoras..."499

Es posible hallar también algunas anécdotas que los trabajadores ferroviarios recuerdan con curiosidad y humor, que dan cuenta de lo que podría denominarse rigurosidad inglesa. En el marco del conjunto de testimonios, estos relatos parecieran cumplir la función, además de amenizar el intercambio a través del aporte de datos curiosos, exhibir cualidades propias de los británicos que contrastaban con las de los argentinos. Calcagni cuenta:

"Yo a veces me ponía a revisar expedientes de la época de los ingleses, por supuesto que ellos escribían todo en inglés salvo cuando tenían que dirigirse a un criollo, pero si, no entre ellos... Encontré una carta del hotel en Yacanto ${ }^{500}$ dirigida al jefe del laboratorio, una carta en la que le pedía un análisis del agua que le preguntaba por la aptitud de esa agua para hacer el té (risas). Los dos eran ingleses. Luego se envían frascos para la toma de muestra. Supongo que el resultado se le han comunicado telefónicamente. Me parece que eso demuestra lo puntillosos que eran los ingleses, para cualquier cosa, incluso para una tontería como esa, que probablemente no era una tontería." 501

Calderoni, en el mismo tono, entre jocoso y nostálgico, rememora:

"Eran tipos muy rectos. Cuando fui a la oficina me pusieron con un inglés que se llamaba Anderson, que hacíamos todos los proyectos en los tableros de dibujo. Había que hacer una reforma, entonces nos mandaban de talleres a sacar medidas, después pasarlo al plano para que lo fabricaran en el taller. Este inglés era una cosa tan metódica, que tenía en el escritorio de él un tablero acá y dos allá. Entonces, nosotros abríamos un poquito la ventana para que entrara el aire, entonces él decía, 'no, porque el aire entra acá, pega allá y me pega a mí'. Un tipo que en la casa limpiaba los picaportes con un trapo. Una vez se enfermó y yo fui a verlo. Y fui a ver al inglés y resulta que el tipo tenía tanto miedo a los virus y a los cosos, que se tapaba así para hablarme (se ríe), no

\footnotetext{
${ }^{499} \mathrm{EN}^{\circ} 4$.

${ }^{500}$ El hotel al que se refiere el entrevistado está ubicado en Villa Yacanto, una localidad de la provincia de Córdoba. 
me dio la mano, nada, nada." 502

Otra cualidad que en el imaginario aparece asociado a "lo inglés" es la astucia o viveza. Eridé Rinaldi considera:

\begin{abstract}
"Los ingleses eran muy vivos. Cuando un operario le pedía que un hijo entre al taller, entraba siempre que él haya tenido muy buen desempeño. O sea que eso era el mejor antecedente. No le iban a pedir ni a hacer análisis psicológico, no, no. Si no tiene medidas disciplinarias, si no ha sido faltador, si no ha sido enfermo consuetudinario... Porque ¿sabe quién iba a cuidar al hijo? El padre, no el jefe, no el supervisor". ${ }^{503}$
\end{abstract}

Ferrari, por su parte, también, parece ir en la misma línea cuando afirma:

"Los ingleses eran tan vivos que cuando les hacían problemas en alguna sección que había un caudillito que quería mandar, entonces el inglés lo ponía a él de jefe, al tipo que no quería trabajar, al vago que quería mandar. Y él defendía a los ferrocarriles a muerte."504

Como síntesis del presente apartado puede afirmarse, entonces, que los ingleses quedaron asociados en el imaginario a la eficiencia, atributo logrado a partir prácticas laborales en las que la gestión británica hacía un control riguroso de materiales, así como de los tiempos y movimientos del trabajador, logrando un aprovechamiento máximo de ambos recursos. Los espacios de trabajo, construidos con máxima calidad y mantenidos con sumo orden y limpieza, también contribuyeron a consolidar ese tipo de representaciones. Finalmente, todo este conjunto de prácticas laborales habrían permitido brindar un servicio de calidad que involucraba previsibilidad en los horarios de salida y llegada de trenes, así como confort en las instalaciones destinadas a los usuarios de trenes. ${ }^{505}$ Este imaginario asociado a "lo inglés" y la "escuela inglesa" habría operado fuertemente, aún luego de la nacionalización, en las prácticas laborales de los trabajadores ferroviarios, como un modo de actuar en la empresa y, también,

\footnotetext{
${ }^{502} \mathrm{EN}^{\mathrm{o}} 19$.

${ }^{503} \mathrm{EN}^{\mathrm{o}} 3$

$504 \mathrm{EN}^{\circ} 4$.

${ }^{505}$ La gestión británica parecía atender, tanto que el servicio fuera cumplido a término como con comodidades para los pasajeros: "(los coches) fueron preparados en forma que pudieran utilizarse en viajes de alta velocidad, con las preocupaciones técnicas necesarias para rodearlos de las mayores seguridades. El interior de estos coches fue cuidadosamente modificado en todas sus partes a efectos de dotarlos de comodidades (...). Se han colocado butacas individuales tapizadas con portalibros y apoya pie cuadrado se buscaron tonos delicados y a la vez alegres complementandonos con una iluminación profusa de modo que el conjunto resultará como aburrido siempre grato a la vista del Viajero" Ver más en: BAP (1938). Actividades, obligaciones, aspiraciones, p.15. Archivo Universitario de la UNNOBA Roberto Dimarco.
} 
como una frustración en torno a lo que no era posible de ser llevado adelante como consecuencia de nuevas prácticas que también comenzaban a instalarse en los ferrocarriles del Estado.

\section{El trato entre jefes y subordinados: tradiciones y transformaciones}

Otra cualidad que los entrevistados parecen añorar del "tiempo inglés" refiere al trato entre jefes y operarios, el cual es calificado por los ferroviarios como "respetuoso". Calderoni cuenta:

"Yo entré con la jefatura inglesa. Los jefes eran todos ingleses. Estaba Murphy, jefe de talleres. O’Connor el segundo jefe. Clark. Era un respeto y una cosa que vos no te podés imaginar porque había una puertita que estaba al lado del galpón de soldaduras que venía de la estación. Entraban los ingleses por ahí y esa puertita después iba junto a la oficina. Nosotros teníamos el galpón de soldaduras frente a la oficina donde estaba la jefatura, ¿viste? Cuando sentíamos que venían los ingleses nos poníamos a trabajar (risas). Porque a veces venían de la jefatura y entraban a la sección e inspeccionaban todo lo que estaba haciendo." ${ }^{506}$

Crocco recuerda, como Calderoni, que la sola presencia de un jefe de la gestión británica de alto rango, como Mr Murphy (jefe de talleres entre 1940 y 1950), generaba la movilización de los empleados y el cumplimiento de las tareas:

"Era un señor de un porte elegante y grandote. Cuando este señor salía a recorrer las secciones, se corría la bolilla por todas las secciones. 'Che, salió Murphy, salió Murphy'. Todo el mundo corría, todo el mundo trabajaba, todo el mundo en orden. Era un respeto total. ${ } 507$

Martínez recuerda algo similar: "En ese tiempo estaba Murphy y después había un jefe general inglés en Primera Junta. Cuando salía a recorrer, avisaban y todos se movían." ${ }^{\circ 08}$ En la misma línea lo hace Danielle:

"El trato en el trabajo, eran ellos, para eso eran los jefes, me entiende. Había respeto. Pero

\footnotetext{
${ }^{506} \mathrm{EN}^{\mathrm{o}} 19$

${ }^{507} \mathrm{EN}^{\circ} 19$.

${ }^{508} \mathrm{EN}^{\mathrm{o}} 20$.
} 
después en la calle, jugaban al fútbol juntos, al hockey, al tenis. Había una división, que era para mí lo que debía ser." 509

Ese respeto al que los testigos refieren una y otra vez parece exponer un tipo de vínculo basado en el reconocimiento de la autoridad que detentaba el personal superior, así como el temor a ser sancionados por las faltas que los operarios pudieran cometer por el no cumplimiento de las tareas asignadas, las cuales, a su vez, no se podían cuestionar. De acuerdo a Marone, este tipo de trato, procedente de la etapa inglesa, se mantuvo algunos años después de la nacionalización. Puede considerarse, además, que la convicción que los actores tenían respecto de que este era el modo de vinculación apropiado en el contexto laboral permitió que, una vez que ellos mismos se convirtieron en jefes (como Marone, Dall'Occhio, Rinaldi, Calderoni, Crocco, entre otros), incorporarlo en sus propias prácticas en el nuevo contexto:

"Duró un tiempito la misma tradición que traían los ingleses en el manejo de la empresa. La tradición era que el que era jefe era jefe, y el que no era jefe no era jefe. Y el que no era jefe tenía que respetar al jefe. Y lo que decidía la jefatura era palabra santa. Y las decisiones del área técnica, administrativa, se respetaban... porque los demás éramos empleados." 510

El ingeniero José Calcagni también expone, como Marone, la imposibilidad de cuestionar las decisiones de la denominaba "superioridad" en la época inglesa y contrapone esta modalidad en los vínculos laborales con lo que sucedería luego de la nacionalización. Al mismo tiempo, ese rigor en la asignación de tareas que debía ser respetado permite explicar, a partir de su argumentación, la eficiencia inglesa aludida en el apartado anterior, así como la falta de eficiencia del ferrocarril estatal:

"Los ingleses manejaron el ferrocarril al corte inglés: orden, imposibilidad de réplica, las
cosas se cumplían. En el tiempo argentino la cosa cambió, se democratizó, entonces ya
se hacía o no se hacía, se hacía bien o se hacía mal, igual pasa... En el tiempo de los
ingleses, cuando estaba Kimberley, ${ }^{511}$ pasó que un jefe inglés del taller tenía el programa
del trabajo para todo el mes y tenía que entregar 31 coches reparados. Y resulta que no
pudo cumplir y le quedó un coche sin terminar Era más criollo que inglés. Black puso 31.

${ }^{509} \mathrm{EN}^{\circ} 27$.

${ }^{510} \mathrm{EN}^{\circ} 14$.

${ }^{511}$ Rupert Ernest Kimberley fue jefe del Departamento de Mecánica desde 1927 a 1945 (Tarullo et al. 2013: 136). Durante su gestión, promovió la construcción de vehículos accionados por motores Diesel, con capacidad para 60 pasajeros cada uno. 
Pero a Kimberly no se le escapó y lo echó. Después... eso se arreglaba, no pudiste, bueno..."512

En otras palabras, la rigurosidad del sistema inglés al que aluden los testimonios anteriores en el que las decisiones debían ser acatadas sin cuestionamientos ni contemplaciones resultan el fundamento, bajo este argumento, de la eficiencia inglesa. Es probable que ese sea el motivo por el cual los actores insisten en añorar esa modalidad en el trato.

Por otra parte, los testigos describen que en ese tipo de vínculo existían dos categorías de actores: los jefes gozaban de la facultad de dirigirse al personal subordinado y los empleados comunes que carecían de esta posibilidad. Violante recuerda esa modalidad que primaba en la época inglesa y el cambio al que él mismo asistió como testigo:

\begin{abstract}
"Antes estaba el rigor del sistema inglés que vos no le podía parar para hacerle una pregunta a un jefe. El sistema inglés, viste, no, no, tenías que esperar, ir bien presentado, si no tomaban medidas disciplinarias. Con la nacionalización esto ya empezó a cambiar. Esta gente empezó a hacerse más compañero del obrero, más accesible, ¿viste? Y si un empleado le preguntaba alguna cosa de un coche o algo así, se paraba, le hablaba, como si fuera en familia. Una cosa muy linda. Y ahí se vio un cambio muy bueno." ${ }^{513}$
\end{abstract}

En la misma línea va el relato de Bozzini:

“A un jefe inglés no te podías dirigir. Era alguien inalcanzable. Después cuando el ferrocarril pasó a manos del Estado uno podía hablar con un superior, te atendía. Con los jefes ingleses no podíamos hablar, en cambio con los jefes que eran argentinos sí." ${ }^{514}$

Las normas de la empresa en la época inglesa contemplaban la posibilidad de que el empleado se dirija solo a su jefe inmediato para cualquier consulta o inquietud. Un documento del Departamento Mecánica de BAP puntualiza que cuando un empleado u obrero quiera presentar "alguna idea, proyecto o iniciativa que a su juicio pueda significar una ventaja para el mejor funcionamiento de una máquina, la perfección de una herramienta, el mejoramiento de un sistema (...) y se sienta animado por el deseo de prestar su cooperación al ferrocarril (...) debe dar a conocer esas ideas a su jefe inmediato que las elevará a la superioridad". ${ }^{515}$ De esta manera, dirigirse a un superior no directo podía ser considerada una falta grave y mucho más

\footnotetext{
${ }^{512} \mathrm{EN}^{\mathrm{o}} 21$.

${ }^{513} \mathrm{EN}^{\circ} 8$.

${ }^{514} \mathrm{EN}^{\mathrm{o}} 17$.

${ }^{515}$ Ver más en: BAP (1938). Actividades, obligaciones, aspiraciones, p.26. Archivo Universitario de la UNNOBA Roberto Dimarco.
} 
todavía si se trataba del jefe máximo, aunque más no sea para establecer un saludo de cortesía, tal como ilustra una anécdota entre Dall'Occhio y Calcagni:

—JC: Me acordé de otra de Kimberly. Salió del taller y se cruzó con un operario, y el operario le dijo: 'Buen día señor Kimberly'.

-JD: ¡Ay!

—JC: Lo trasladó a Mendoza.

—JD: Sí, no se podía hablar.

—JC: Es como un acto de desprecio, algo así como "plebeyo, cómo osas dirigirme la palabra a mí..$^{516}$

Marone también se hace eco de esta modalidad en el trato que involucraba a quien fuera jefe máximo de Mecánica hasta 1945: "Los ingleses eran medio jodidos, no trataban con los empleados. Cuando Kimberley pasaba no volaba una mosca, no tenía trato con los empleados".517 Taberna, por su parte, añade la prohibición que tenían de cruzar la mirada con este jefe, lo cual permite afirmar que, aunque esto no fue experimentado directamente por estos ferroviarios, quedó plasmado en la memoria del colectivo a partir de los relatos de otros:

"Había un jefe de departamento que cuando pasaba por el taller no lo podían mirar. O sea que él pasaba recorriendo todo, y el que estaba trabajando agachaba la cabeza, no lo podían mirar. Creo que era Kimberly. Uno que usaba guantes. Yo no lo vi, te aclaro." ${ }^{518}$

Este mismo ferroviario también recuerda que esta modalidad en el trato también era acompañada por una disposición del espacio de trabajo:

\footnotetext{
"En la oficina vos entrabas por la puerta principal, había un pasillo largo, y al final del pasillo a la derecha estaban las oficinas del jefe de departamento, pero antes de esas oficinas había una reja. O sea que ahí no podías pasar. Yo pasé años trabajando en la división técnica y no hubiese llegado nunca al fondo, a ese lugar. Vos fijate que los ingleses tenían una disciplina estricta. Los ingleses, siempre ellos. Marcando diferencias entre el personal. O sea, acá estamos nosotros y allá ustedes." 519
}

Algunas de esas tradiciones en el trato personal entre jefes y empleados de menor rango se habrían mantenido luego de la nacionalización, con algunas variaciones. Taberna,

\footnotetext{
${ }^{516} \mathrm{EN}{ }^{\circ} 21$.

${ }^{517} \mathrm{EN}^{\mathrm{o}} 14$

${ }^{518} \mathrm{EN}^{\mathrm{o}} 10$.

${ }^{519} \mathrm{EN}^{\mathrm{o}} 10$.
} 
quien en los dos enunciados anteriores parece desaprobar esa modalidad inglesa que implicaba desprecio hacia el personal subordinado, sin embargo, en el siguiente testimonio parece acordar con la modalidad de trato distante y respetuoso entre personal jerárquico y subordinado que se mantuvo luego de la nacionalización:

"Yo era el más chico con 16 años, se hizo una peña que se llamaba 'Los de Riba' que todos los meses se pagaba una cuota y se hacían unas fiestas impresionantes en el Club Inglés, iba toda la oficina. Gandini era el jefe de la oficina, y Mitchell era jefe de presupuesto, o sea era el segundo jefe de la división técnica. Uno estaba en una punta y otro estaba en la otra punta. Vos sabés que yo iba a cobrarle, siempre estaba con la cabeza gacha. Yo iba y me paraba al lado, no le hablaba, con la lista y él seguía trabajando. Por ahí levantaba la vista y me veía. Y me preguntaba qué quería. Don señor Mitchell, vengo a cobrar la cuota... Y entonces sacaba y me pagaba. ¡Pero vos fijate el respeto que tenía! Si él no levantaba la cabeza y me preguntaba yo no lo interrumpía. Otro ejemplo, estaban los escritorios puestos y el baño atrás. Uno de los empleados tenía un librito de cowboys o esas pavadas en el cajón, y estaba leyendo, entusiasmado. Pasó Mitchell que iba al baño, siempre con el cigarro prendido. Pasó por al lado y no dijo nada. Este estaba tan entusiasmado que no se dio cuenta. Cuando salió del baño cerró el cajón. Y pasó Mitchell y sin pararse le dijo: 'La próxima vez que te agarre leyendo te mando dos días a tu casa'. Yo creo que ni el día de hoy leyó más. Otra. Arriba se hacían los dibujos y había una máquina que sacaba los planos, primero salía con el color característico, después había que secarlo, con una máquina que no sé qué se hizo, era para el museo, de la época de los ingleses, una máquina viejísima... bueno, eso estaba en la terraza, había una pequeña habitación donde funcionaba eso. Primero había una escalera de caracol para subir. Después hicieron una de cemento, más grande. Y esa escalera de cemento daba a la puerta de esa oficinita. Había un muchacho que había tomado la costumbre todas las mañanas de irse arriba a leer el diario La Verdad y allá se tomaba mate porque era un poquito más abierto... Y bueno, se engolosinó, iba todos los días. Yo no sé si a Mitchell le avisó alguno, y un día sube la escalera. Entonces, lo vieron y dijeron: 'Ahí viene el inglés', así le decían a Mitchell. Este salió como para la terraza, que estaba después de la máquina. Y había unas tomas de aire, que eran así como unas columnas, salió y se puso detrás de la columna, se escondió (risas). El inglés salió derecho y se fue detrás de la columna. Se tuvo que entregar. ¿Sabés lo único que le dijo? Por eso te digo el respeto que había de uno mismo a esa gente. Le dijo: 'Mirá, me parece que yo no soy tan jodido como para que vos me hagas estas cosas'. La cuestión es que no fue más a leer el diario, se anotó en el ciclo técnico, se recibió de técnico mecánico y después tuvo un puesto de dirección. No precisó más que eso. No le gritó, nada. Le dijo eso. ¡Mirá vos el respeto que le tenían! ¡Era un respeto extraordinario! Yo lo recuerdo 
como un gran jefe. Era recto, esa disciplina que tenían. Una barbaridad. Don Carlos Mitchell. ${ }^{, 520}$

También Dall'Occhio recuerda una falta cometida por él mismo, aproximadamente una década después de la nacionalización, que implicó dirigirse a superior no directo, como consecuencia de lo cual fue reprendido por su superior inmediato:

“A mí me pasó, yo estaba en el taller tomando unas medidas, y pasaba Caruso, ${ }^{521}$ era el jefe del taller y no me acuerdo qué consulta hice, yo era muy joven, tenía 19 años, no sabía que eso no se hacía, cuando vuelvo a la oficina me dicen que eso no se podía hacer, cuando usted necesita hablar con el señor Caruso usted me dice a mí y yo voy a hablar." 522

Este hecho da cuenta de que, aunque había tradiciones y normas que se mantenían luego de la nacionalización, otras se transformaron. Mientras aquel empleado, por un simple acto de cortesía a Mr Kimberley antes de 1945, fue castigado mediante el traslado, Dall'Occhio que, aproximadamente en 1957 estableció un tipo de comunicación más próxima haciéndole a Caruso un planteo laboral concreto, solo fue regañado verbalmente por su superior directo. Gracias a esta falta cometida, además, el joven tuvo la oportunidad de aprender normas de la empresa y de la comunidad ferroviaria, antes desconocidas por él mismo. En otras palabras, más de dos décadas después de que Kimberley dejara de ser el jefe máximo, la norma que impedía dirigirse a un superior no inmediato seguía vigente, aunque los castigos contemplados para este tipo de faltas no eran los mismos. El siguiente testimonio de Marone da cuenta de este cambio que implicó una transformación en el trato de los ingleses que aún permanecía luego de la nacionalización:

"Yo entré con 18 años y había gente de 50, que había vivido toda la época inglesa. Ellos nos contaban a nosotros de cuando estaban los ingleses. Ya los ingleses últimos que quedaban tenían otro trato porque ya no eran dueños del circo. Pero mientras eran dueños del circo: ¡disciplina, castigo para los que no hacían las cosas bien!" 523

En suma, estos actores, que fueron empleados del ferrocarril en Junín desde las décadas de 1940 y 1950, se apropiaron de algunos aspectos de las prácticas laborales inglesas, como el valor del respeto entre jefes y subordinados, mientras otros los desestimaron, como el

\footnotetext{
${ }^{520} \mathrm{EN}^{\circ} 10$.

${ }^{521}$ Carlos Rafael Caruso fue jefe de Talleres Junín desde 1954 hasta 1968 (Tarullo et al., 2013: 137).

${ }^{522} \mathrm{EN}^{\circ} 15$.

${ }^{523} \mathrm{EN}^{\circ} 14$.
} 
menosprecio que algunos jefes ingleses podían tener por los operarios locales. De esta manera, fueron construyendo un imaginario, en el sentido de una representación totalizante de la sociedad (como un orden), que tomó como "insumo" representaciones anteriores porque, tal como plantea Castoriadis: "Todo simbolismo se edifica sobre las ruinas de los edificios simbólicos precedentes" (1983, 208).

Puede interpretarse que el respeto que los empleados añoran y que es parte de aquella visión de cómo debían ser los vínculos, fue seleccionado como valor porque se consideraba que la diferenciación jerárquica estaba basada (y debía estarlo) en capacidades diferentes (por formación o talentos personales) y que la obediencia del personal subordinado hacia la jefatura contribuía a la eficiencia de la empresa. Sin embargo, las prácticas humillantes de la época inglesa fueron desechadas, a partir de la nueva convicción de que cada aprendiz que ingresaba tenía la potencialidad de convertirse en jefe, sin estar excluidos de antemano por una cuestión de nacionalidad. Ese respeto defendido como un valor, en el marco de un proceso social dinámico, iba a entrar en conflicto con otros valores que emergieron luego de la nacionalización y que serán analizados más adelante.

\section{Conocimiento versus política: dos valores en disputa}

Entre los ferroviarios entrevistados, la administración inglesa es asociada con la búsqueda de la excelencia, entre otras cuestiones, por la selección que hacían para el ingreso de los nuevos operarios, optando por los jóvenes que demostraran contar con mayores capacidades. Concretamente, los diez egresados que hubieran tenido los mejores promedios del año de la Escuela de Artes y Oficio Antonio Bermejo podían ingresar directamente al ferrocarril, como premio a su desempeño académico ${ }^{524}$. Si a lo largo del año existían nuevas vacantes, los interesados, que eran mucho ya que era una fuente laboral considerada "prometedora", ${ }^{525}$ podían tener la oportunidad de ingresar mediante un examen. Es decir, la capacidad y formación eran los principales valores tenidos en cuenta, a los que se sumaban la pertenencia a una familia ferroviaria, que parecía otorgarle a la empresa la certeza en la previsión de una conducta obediente y disciplinada por parte del nuevo trabajador.

Sobre el examen que la empresa realizaba a los aspirantes, en un documento del BAP se especificaba que era teórico-práctico y tenía como finalidad “conseguir un mejor tipo de

\footnotetext{
${ }^{524}$ Sobre este tema se puede profundizar en el apartado "El ingreso al ferrocarril como hito", capítulo 1.

525 Sobre este tema se puede profundizar en Los beneficios materiales y simbólicos de los trabajadores del riel, capítulo 1.
} 
aprendiz". El procedimiento de selección habría dado buen resultado ya que, según se plantea en el mismo documento, "se ha conseguido formar un grupo de aprendices dotados de cierta capacidad que los habilita para llegar más fácilmente a ser buenos operarios de oficio (...) y aún para poder desempeñarse en puestos más importantes".

Una vez que los jóvenes hubieran ingresado en la empresa, la formación continuaba en el espacio de trabajo. Por un lado, los aprendices trabajaban a la par de los oficiales, quienes les iban enseñando los saberes prácticos del oficio y, por el otro, asistían a la Escuela de Aprendices, una formación que duraba tres años. Sobre esta formación, el documento aludido plantea:

"La Superioridad se interesa de distintas maneras en favor de los aprendices. A tal efecto trata de estimular sus aptitudes de distintos modos con el fin de que se capaciten (...) por lo tanto cada uno de nuestros aprendices debe (...) poner toda su mayor preocupación e interés para que sus conocimientos aumenten progresivamente y se perfeccionen cada vez más. No solo dentro de la rama que corresponde a la especialidad de trabajo de cada uno de ellos sino también en toda materia que deje vislumbrar una posible ventaja para su porvenir." 526

De esta manera, a través de este documento la empresa expresaba el valor que le otorgaba a la formación de los empleados, ya que consideraba que cuanto más formados estén, mayores beneficios le podrían brindar al ferrocarril. Al mismo tiempo, apelaba a que ellos mismos se interesaran por su capacitación y perfeccionamiento, teniendo en cuenta las ventajas que esto significaría en su "su porvenir"; incluso se refiere a la posibilidad de desempeñarse en "puestos más importantes", estableciendo una suerte de promesa que, a mayor capacitación, mayores serían los beneficios económicos y simbólicos en BAP.

La formación en la Escuela de Aprendices les permitía a los operarios que, al rendir el examen anual, pudieran mejorar sus ingresos. Calderoni, que ingresó con la gestión inglesa, recuerda el estímulo de esta jefatura a la formación y especialización, así como la exigencia de desarrollar al máximo sus capacidades:

"En el primer examen que yo di (en la Escuela de Aprendices) me saqué setenta puntos. Entonces, me llamó el jefe inglés y me dice, 'Calderoni, anduvo bastante bastante flojo en el examen’. ¡Yo había sacado setenta puntos! 'Los cinco centavos se los voy a dar igual',

\footnotetext{
${ }^{526}$ Ver más en: BAP (1938). Actividades, obligaciones, aspiraciones, p.14. Archivo Universitario de la UNNOBA Roberto Dimarco.
} 
pero dice, 'especialícese, preocúpese', bue, qué sé yo (risas)." 527

Esta formación en la empresa que involucraba una instancia teórica (en la Escuela de Aprendices) y otra práctica (en el taller, junto a un oficial) se habría mantenido luego de la nacionalización, según Taberna, quien ingresó en 1953:

\footnotetext{
"Yo entré como aprendiz, esa modalidad venía de los ingleses, que consideraban que para ser un buen oficial se necesitaban tres años de aprendiz, entonces te ponían al lado de un oficial que te iban enseñando a trabajar. Y sabían, ¿eh? Ellos tenían un ojo clínico. Entonces, a los mejores chicos los ponían con los mejores oficiales, y ahí salían los mejores operarios". 528
}

De esta forma, la "escuela inglesa" apuntaba, a través de la formación en la empresa, a que cada operario perfeccionara al máximo sus capacidades técnicas, especialmente, los jóvenes que en el ingreso exhibían cualidades superiores al resto, como sugiere el testigo anterior y otros ferroviarios, como Rinaldi, quien plantea: "Los ingleses elegían a dedo y no se equivocaban". Con la nacionalización, paulatinamente, iban a cobrar importancia otros valores para el ingreso y progreso en la empresa. Poch, aunque fue integrante de la comisión ejecutiva de la Unión Ferroviaria, a la que muchos van a culpar por esta transformación, reconoce:

\footnotetext{
"Yo aprendí a trabajar con los ingleses. Yo aprendí lo que ellos me enseñaron, mientras había gente que esperaba que le dijeran lo que tenía que hacer. Había gente que no sabía nada de nada. Porque cuando se compraron los ferrocarriles, se empezaron a desvirtuar muchas cosas. A políticos que no sabían nada los acomodaban, los ponían de jefes, y no sabían nada de nada. Vinieron jefes que eran políticos. Entró la política y se fueron todos los jefes de antes." 529
}

Waddell (2016) sostiene que una de las medidas más criticables de los primeros años de la administración nacional de los ferrocarriles fue, precisamente, la expulsión de los empleados británicos, la cual no solamente involucró a los cuadros gerenciales, sino también a los cuadros medios y técnicos, y "contra todo aquel que tenía un origen británico: la política gubernamental fue limpiar las empresas del elemento imperialista". El autor considera que las consecuencias fueron "desastrosas" para la posterior gestión, ya que gran parte de los

\footnotetext{
${ }^{527} \mathrm{EN}^{\mathrm{o}} 19$.

${ }^{528} \mathrm{EN}^{\mathrm{o}} 10$.

${ }^{529} \mathrm{EN}^{\mathrm{o}} 1$.
} 
despedidos pertenecían a las oficinas técnicas, eran ingenieros y especialistas en transporte ferroviario. Siguiendo al autor, el gobierno argentino renunció a un saber adquirido durante más de ochenta años de experiencia en desarrollo ferroviario. Adicionalmente, sustituyó esos cuadros técnicos por "argentinos sin experiencia y que solo llegaban a posiciones importantes por su pertenencia al partido oficial o por amiguismo con el líder o sus colaboradores inmediatos" (López et al., 2016: 161-162).

En línea con este planteo, entre los ferroviarios entrevistados prevalece la representación que asocia la nacionalización con la importancia que cobró la pertenencia política para el ingreso y las promociones. Al mismo tiempo, el gremio de la Unión Ferroviaria habría tomado una capacidad de decisión dentro de la estructura de la empresa que no tenía con la administración anterior. A esta situación, los ferroviarios que se dicen llamar de la "vieja escuela" se opusieron, tensión que caracterizó toda la historia del ferrocarril estatal en Junín. Calderoni cuenta con una mezcla de humor e indignación:

\footnotetext{
"La política estuvo presente siempre, después de que se fueron los ingleses. Tal es así que los políticos pusieron a gente, gente en distintos lugares, gente que era inexperta. Yo era ayudante de un jefe, de un jefe que salió del peronismo. Y yo era ayudante de él, pero él no hacía nada y yo tampoco. Porque no tenía conocimiento. Entonces yo me la pasaba fenómeno. Y otro muchacho que estaba conmigo lo pasaron con un inglés que había quedado. Entonces él lo tenía cortito todo el día y yo me reía porque él estaba todo el día laburando y yo lo miraba (risas)." 530
}

Podríamos afirmar, a partir del testimonio anterior de Calderoni, que para acceder a algunos puestos de jefatura los valores políticos que detentaba una persona, determinada por su arco de relaciones con actores locales y nacionales, comenzaron a ser tanto o más importantes que los valores ligados a la preparación o conocimiento para el puesto. El testimonio de Rinaldi que, si bien exhibe que el conocimiento no había dejado de ser importante para el ascenso, expresa este cambio en el que otros atributos en el trabajador habían empezado a ser cruciales:

\footnotetext{
"Yo entré por la escuela, nada que ver con la política. Pero hubo una época, que si usted no estaba afiliado al partido peronista no tenía ascenso y no tenía ingreso. Muchos de mis compañeros que han tenido ascenso, lo lograron por antigüedad también, pero fundamentalmente tenía que estar registrado en algún comité."531
}

\footnotetext{
${ }^{530} \mathrm{EN}^{\circ} 19$.

${ }^{531} \mathrm{EN}^{\mathrm{o}} 3$.
} 
Marone también rememora una anécdota en la que se impide el ingreso de una persona con calificaciones excelentes de la Escuela Industrial por su posible pertenencia partidaria, lo que muestra la importancia que iba tomando el gremio como actor en el plano de las decisiones:

“...empezaron a promocionar a través de la política del gremio, y no a través de los méritos de mucha gente, que a lo mejor era mucho más merecedora de ser promovida y no lo fue por una cuestión política. Eso se vio muy clarito en la época peronista. Yo me acuerdo cuando nosotros entramos desde la Escuela Industrial, entraban los mejores promedios de cada año. Bueno, en el grupo mío, de los mejores promedios, había un muchacho que el papá trabajaba en el ferrocarril y era una persona muy identificada con el socialismo. Y cuando llegó el momento de que los egresados de la escuela ingresáramos al Taller, a ese muchacho, no se le permitió el ingreso. Ahora, ¿quién no le permitió el ingreso? Los gremialistas, que sabían, que este chico era hijo de este otro hombre que era socialista, y ellos querían que no ingresara gente que no fuera de la orientación política de ellos. O por lo menos querían que ingresara gente que no tuviera orientación política, como me pasaba a mí. Como de mí no conocían si tenía una orientación política... Porque a lo mejor podía pasar que aun conociendo que no era peronista, si no era activista, podía correr. Pero este muchacho tenía la particularidad de que el papá era activista. Dentro del gremio todo el mundo sabía que era socialista, como sabían quién era comunista y demás. El chico no participaba en política, pero el papá sí. Cuando estabas adentro pasaba lo mismo. Si se generaba una vacante importante, algún salto dentro de la estructura, primero tenías que tener la conformidad del gremio. Esa fue una política sucia que se aplicó desde el Estado". ${ }^{332}$

Calderoni, por su parte, cuenta su experiencia personal en la que se le exigió su afiliación para seguir ascendiendo en la empresa:

"Cuando me tenían que dar el título de Técnico Ferroviario (en la Escuela de Aprendices) ya los ingleses no estaban más, estaban los peronistas. Y habían puesto de jefe de talleres a un tipo que se llamaba Yorio, que no sabía ni hablar ni escribir. Lo primero que me dijo es 'Calderoni, si querés que te dé el título de técnico me vas a tener que traer la afiliación'. Entonces yo como no era peronista y mi padre todo el mundo lo conocía que no era peronista, pero que tenía muy amigos peronistas, de otra época, entonces me consiguió la afiliación y yo seguí haciendo la carrera, ¡te das cuenta?"533

\footnotetext{
$532 \mathrm{EN}^{\mathrm{o}} 14$.

${ }^{533}$ Nicolás Yorio fue jefe de Talleres entre 1951 y 1952. ENº19.
} 
Las anécdotas anteriores de Calderoni y Marone tienen la capacidad de ilustrar que aquella tradición por la cual la administración inglesa elegía a "los mejores" de la Escuela de Artes y Oficios (luego Industrial) no era lo único que se transformaba. Con este cambio también comenzaba a horadarse el prestigio ligado a la actividad ferroviaria. El mismo Marone, en una entrevista que tuvo lugar años después, lo plantea:

“...se le daba prioridad a quienes pegaban carteles en épocas de elecciones y no a los que a lo mejor tenían condiciones técnicas para poder progresar dentro de la empresa. Todas esas cosas fueron quitándole valor al ferroviario, porque ya empezaron las críticas, la desvalorización y así terminamos. Se fue desvalorizando el trabajo ferroviario. Cuando nosotros ingresábamos al ferrocarril generalmente éramos todos de escuela, al poco tiempo de la nacionalización, ingresábamos diez de la escuela y veinte del gremio o de la política, que eran las dos cosas que participaban con más fuerza en el manejo de la empresa. Pero ya no eran gente de escuela, gente de estudio." 534

Resulta muy significativa la comparación en la que Marone estima que, luego de la nacionalización, por cada diez que ingresaban por méritos académicos, ingresaban otros veinte por relaciones personales con actores políticos ligados a la empresa o gremiales. Esto lleva a interpretar que el valor simbólico que implicaba ingresar al ferrocarril a través de la Escuela estaba perdiendo su potencia como signo de orgullo personal y, con ello, también se dañaba el prestigio ferroviario que, aunque se intentó sostener por medio de las prácticas posteriores que intentaban poner en vigencia los valores heredados, habría quedado asociado en el imaginario a la administración británica. Por eso muchos se identifican con la "escuela inglesa", aun habiendo ingresado luego de 1948.

Algunos testigos, como Martínez, parecen verificar, por experiencia propia, la importancia que podían adquirir las relaciones personales:

“...en política nunca me quise meter. Y yo era muy amigo de Palma, que fue de la CGT. Cuántas veces él me preguntó, qué precisás, qué precisás. Y yo tenía dos hijos y una hija, le podría haber pedido trabajo, pero no lo hice." ${ }^{535}$

En tanto, De Giulio fue uno de los que reconoce haber ingresado por vínculos personales: "Yo entré porque conocía a un peronista ahí adentro, que era medio pariente lejano de mi mamá". Sin embargo, fue también su afinidad partidaria inicial la que más adelante le 
impidió seguir ascendiendo:

-ALS: ¿Cómo fue su carrera?

-RD: Tornero, siempre tornero.

—ALS: ¿A veces había algunos que ascendían?

—RD: Sí, sí, los más acomodados. Ya cuando yo... si hubiera estado los otros, sí. Pero como ya cambió la política, yo me quedé.

—ALS: ¿Por qué cambió la política?

— RD: Y, cambió... Te imaginás que entraban los radicales, los peronistas, todas esas cosas. ¡Quién no era peronista en el ferrocarril? Y después iba por edad, el más viejo ascendía. Alguno más acomodado pasaba, como me pasó a mí. Yo entré en el 52 y había otro ferroviario, que había entrado en el 57, sin embargo, cuando lo ascendieron figuraba él con más antigüedad que yo. Todo se cocina.

-ALS: ¿Y por qué lo ascendieron?

-RD: Porque era radical. ${ }^{536}$

Este diálogo permite mostrar que, si bien el peronismo intervino fuertemente en las decisiones durante la primera parte de la gestión de los Ferrocarriles del Estado Argentino, los gobiernos posteriores al derrocamiento de Perón también habrían incidido en los puestos de la empresa. En ese contexto, el gremio, que mantuvo un vínculo profundo con el peronismo durante toda la historia de los ferrocarriles del Estado, cobraba más o menos importancia de acuerdo al signo político del gobierno de turno y, sobre todo, en función de si el gobierno era o no constitucional. Rinaldi cuenta: "Cuando los gobiernos estaban a favor de ellos, podían influir para ingresar gente. En la época de los militares, la comisión de reclamo no existía." 537 En tanto, Marone:

"Mientras los movimientos militares estaban al mando del proceso, la influencia de los gremios era prácticamente nula, la política, menos. Entonces, durante esos tiempos no se manejaba tan arbitrariamente los ascensos y las promociones. Porque no había un gremialista o un político que saliera a decir: 'A este no lo promuevas porque no es de mi color político'. En los gobiernos militares, la política y los gremios estaban anulados. Esas situaciones no se daban. Pero, cuando entraban los gobiernos constitucionales, en el caso de Frondizi, Illia, el mismo Alfonsín, volvía la política y el gremio volvía a tener cierta 
manija. Se daba así." ${ }^{538}$

Crocco considera que no pudo ascender durante el peronismo por su falta de pertenencia al partido y también sugiere que en otros gobiernos constitucionales le fue negada esta posibilidad. Le cuesta plantear explícitamente que el reconocimiento a su preparación tuvo lugar durante el gobierno de Juan Carlos Onganía (1966-1970):

"La política pesaba mucho. A mí me pesó mucho. El no pertenecer a ningún gremio político, por varios años, me afectó. Los cargos se hacían a dedo, designándose un poquito a nivel extra..., como te puedo decir, extraorganizativo. La política siempre influyó. Yo, lamentablemente, debo decirlo, me duele decirlo, que tuve oportunidad de progresos, cuando los gobiernos no fueron democráticos. Me duele decirlo ¡Me duele decirlo!"539

La importancia que, a partir de la nacionalización, comenzó a adquirir el gremio de la Unión Ferroviaria como actor con poder de influencia en la empresa se evidencia en los mismos testimonios de los formaron parte de él. Por ejemplo, cuando Bozzini plantea que, a ellos, como representantes de los trabajadores, los jefes los tenían que tratar quisieran o no quisieran ("por fuerza") y cuando, incluso, se coloca en un lugar de preeminencia frente a los trabajadores comunes ("una cosa es estar al frente del gremio y otra es ser obrero"):

"Nosotros íbamos a talleres, a Tráfico, a las oficinas. Íbamos y conversábamos con los compañeros. Aunque no nos llamaran. Ahí nos enterábamos o visualizábamos cómo estaban. Por ahí nos atendía un jefe y por la manera de atendernos, nos dábamos cuenta cómo actuaba ante sus subordinados. Algunos eran intratables, otros no. A nosotros nos tenían que tratar por fuerza, porque éramos representantes de los compañeros. Porque una cosa es estar al frente del gremio y otra cosa es ser obrero... el obrero a veces solo no se puede defender". 540

Las relaciones de fuerza, en el nuevo contexto, se habían transformado. El gremio, entonces, contaba con un poder que antes no tenía, lo cual le planteaba conflictos a los integrantes de la jefatura que persistían en la intención de regirse a partir de los viejos esquemas en que, como decía Marone, "lo que decía la jefatura era palabra santa". ${ }^{541}$ Decarre cuenta cómo los jefes, luego de la nacionalización, se vieron impedidos de ejercer el poder de castigo que antes tenían hacia sus subordinados, lo que habría dificultado el cumplimiento de las tareas y,

\footnotetext{
${ }^{538} \mathrm{EN}^{\circ} 14$.

${ }^{539} \mathrm{EN}^{\circ} 2$.

${ }^{540} \mathrm{EN}^{\circ} 5$.

${ }^{541} \mathrm{EN}^{\circ} 14$.
} 
en definitiva, disminuido la eficiencia de la empresa:

“...cuando yo entré (1953) ya empezaba a tallar la política, empezó el gremialismo a meterse a incursionar dentro de la parte laboral. Empezaron los actos de indisciplina, ya los jefes empezaron a verse limitados en tomar una medida disciplinaria con alguien, porque venía un gremialista y al jefe lo dejaba pagando porque le levantaba una media disciplinaria que le había puesto un jefe por haber cometido un acto de indisciplina. No, no, venía un gremialista y decía: 'Esto, no, déjemelo a mí, porque voy a tomar medidas yo'. Entonces los jefes empezaron a verse limitados y a tener que, en una de esas, permitir cosas que antes no se permitían." ${ }^{542}$

Ese poder que, luego de la nacionalización, el gremio de la Unión Ferroviaria comenzó a tener por su identificación con el gobierno peronista, contrastaba con lo que sucedía previamente, en la administración británica. Además, según Calderoni, aquellos gremialistas de la vieja gestión gozaban de una autoridad frente a los trabajadores y a la jefatura que los nuevos sindicalistas, de la nueva etapa del ferrocarril nacionalizado, no tendrían:

“...la Comisión de Reclamo antes eran tres tipos y se le tenía tanto respeto a la comisión de Reclamo como si fueran jefes. Porque vos no le ibas a hacer un reclamo que los tipos sabían que era una pavada. Te retaban a vos. Ahora la comisión que se había formado le daba curso a todas las barbaridades que los tipos reclamaban. $\mathrm{Y}$ estaban todo el tiempo reclamando cosas". 543

En la misma línea parece ir el testimonio de Martínez: “Los viejos que habían sido de la Comisión de Reclamo hasta el tranvía se pagaban cuando iban a Buenos Aires. Últimamente cuando iban, iban al mejor hotel, al mejor todo." ${ }^{544}$ Nótese que tanto Martínez como Calderoni contrastan la etapa previa a la nacionalización con la posterior, a través del uso de adverbios de tiempo (antes, ahora, últimamente) a partir de los cuales, nuevamente, es posible afirmar, por un lado, el hito que representó la nacionalización, y por el otro, la continuidad que interpretan que existió en la historia del ferrocarril a partir de ese acontecimiento.

Murgia también diferencia a los gremialistas previos y posteriores a la nacionalización. Aunque reconoce los logros alcanzados en beneficio de los obreros ferroviarios gracias al poder que los nuevos sindicalistas habían cobrado en la empresa, también describe el abandono de

\footnotetext{
${ }^{542} \mathrm{EN}^{\mathrm{o}} 23$

${ }^{543} \mathrm{EN}^{\circ} 19$.

${ }^{544} \mathrm{EN}^{\mathrm{o}} 20$.
} 
prácticas que lo ligaban a la cotidianeidad del trabajador y, en consecuencia, la pérdida de sentido de su propio rol como representante del obrero.

\begin{abstract}
"Siempre en el ferrocarril existió el delegado, pero antes estaba al pie de su trabajo, según tengo entendido. Hacía un poco más de la obligación. Matizando con su trabajo, se ocupaba del reclamo del compañero. Después ya vino el delegado que tenía cierta comodidad. Había delegados que prácticamente no trabajaban. Andaban siempre en la gestión, que este problema, que este otro. Vino otra forma de hacer gremialismo. Obvio que ellos consiguieron muchas cosas para el personal. Yo me acuerdo en la época de los ingleses mi madre remendando el traje azul que usaban los ferroviarios, y que mi padre se lo tenía que comprar. Y el zapato de trabajo también se lo tenía que comprar. Ya cuando vino este cambio de que era argentino, la ropa te la empezaron a dar, también los zapatos. Y después la actualización de los sueldos con la inflación. Pero el gremialista empezó a ser otra cosa, empezó a ser una persona más cómoda". ${ }^{45}$
\end{abstract}

No obstante, es preciso aclarar que la importancia de los vínculos con actores políticos y gremiales para el ingreso y las promociones en Talleres Junín, en el Departamento de Mecánica y Vía y Obras, no habría sido tal para el colectivo de los conductores de locomotora (perteneciente a Tráfico), nucleados en el gremio La Fraternidad, al menos de acuerdo a sus protagonistas. "Política en el ferrocarril siempre hubo. Ahora en La Fraternidad, no había política", asegura Cruz. "En La Fraternidad no había política. De la puerta para afuera puede ser, pero para adentro ni se nombraba", dice otro colega en una entrevista grupal.

Little (1979) estudió la relación de los gremios con el gobierno peronista. Según el autor, durante la primera etapa (1946-1951) el peronismo intentó expandir y consolidar la idea de un sindicalismo dominado por el Estado. En ese sentido, intentó suprimir cualquier tipo de oposición, así como la diversificación sindical. En una segunda etapa (1951-1955), se impuso un control monolítico sobre los sindicatos obreros y una incorporación de ellos al movimiento peronista (Little, 1979: 364).

En el caso puntual de La Fraternidad, Little considera que cooperó con el peronismo hasta que esto le planteó un dilema de principios. Concretamente, señala dos conflictos que tuvo con este movimiento: el primero, en 1945, cuando se desafilió de la CGT por negarse a proclamar públicamente su apoyo a Perón, al considerar que esto violaba los principios estatutarios del sindicato. El segundo, en 1951 cuando el secretario General de la CGT les

\footnotetext{
${ }^{545} \mathrm{EN}^{\circ} 7$.
} 
exigió a los delegados fraternales la participación en actividades proselitistas de apoyo a la candidatura de Perón. Frente a esto, el gremio se negó a participar, bajo el argumento de que sus principios estatutarios eran incompatibles con la acción política. Esto le valió al gremio su intervención por parte de la CGT. En relación a la Unión Ferroviaria, el autor categoriza a este gremio como "peronista independiente", ya que aceptó las políticas del Estado implementadas, aunque se guardó el privilegio de una acción autónoma en determinados casos.

Siguiendo a Little, a partir de 1951, Perón les exigió a los gremios el apoyo a su candidatura y la lealtad al movimiento. De esta manera, los sindicatos nucleados en la CGT pasaron a ocupar una posición subordinada al Estado. Incluso La Fraternidad, uno de los gremios que originalmente mantuvo distancia con Perón, durante este período lo apoyó abiertamente y postuló a algunos de sus dirigentes como candidatos, lo cual parece constituir parte de los "olvidos" del colectivo fraternal cuando asegura que jamás participó en política. ${ }^{546}$

El trabajo de Little permite mostrar el vínculo que durante los primeros años del peronismo tuvieron los gremios ferroviarios con el gobierno y, como lo mismos testigos denuncian, "con la política", lo cual para algunos contradijo la función misma de los sindicatos que, desde esa óptica, debía ocuparse de la mejora de las condiciones de los sindicados sin injerencia en la política partidaria externa a la empresa. En el caso de La Fraternidad, el vínculo fue conflictivo en sus inicios y de apoyo recién en los últimos años. En el caso de la Unión Ferroviaria fue de apoyo abierto durante todo el período, salvo en ocasión de la huelga de 1951 en el que las bases sostuvieron una huelga en contra de Perón. Sin embargo, es de notar que mientras los fraternales aseguran que la política estuvo siempre "afuera" del gremio, probablemente porque no incidió en las prácticas laborales y las normas previas para el ingreso y las promociones, los trabajadores de Talleres y de Mecánica denuncian la injerencia que el gobierno le dio a la Unión Ferroviaria en estas dos cuestiones, lo cual habría transformado prácticas previas que estaban consensuadas por el colectivo.

Durante este período la Unión Ferroviaria se convirtió en un actor con poder de decisión, capaz de disputar y competir con otro actor que, durante la administración británica, había monopolizado las decisiones: la jefatura. En ese sentido, Rinaldi manifiesta: “A mí me cansó, me significó un tropiezo la parte gremial. Yo andaba muy bien con esa gente, pero... dificultaba mucho las tareas." Ferrari, por su parte, califica a los gremialistas como "bravos",

\footnotetext{
546 “...la memoria colectiva es más la suma de los olvidos que la suma de los recuerdos pues, ante todo y esencialmente, estos son el resultado de una elaboración individual, en tanto que aquellos tienen en común, precisamente, el haber sido olvidados. Por lo tanto, una sociedad se encuentra menos unida por sus recuerdos que por sus olvidos" (Candau, 2002: 64).
} 
“de temer", porque "ellos hacían paro y cosas". Danielle cuenta que "los gremios atosigaban". Marone plantea con claridad el conflicto entre los dos actores mencionados, el sindicato y el personal jerárquico:

“En el ferrocarril, la participación política y gremial pasó a ser más importante que el peso de la propia estructura directriz de la empresa. La estructura directriz de la empresa estaba armada con gente que había venido de la época de los ingleses con sus modos de promocionar y seguía... Cuando llegó la nacionalización, ya dejó de tener peso esa línea estructural y pasó a tener mucha más importancia las decisiones políticas y gremiales, que las decisiones de la propia gente que manejaba, que conducía la empresa."547

En rigor, el conflicto estaba dado por los valores tenidos en cuenta para ingresar y acceder a las promociones. Para unos, la identificación con el partido peronista, los vínculos personales con algunos de sus líderes y la militancia eran valores que permitían predecir un accionar futuro del trabajador, en favor de la transformación cultural que se estaba intentando gestar. Para otros, la preparación y el talento personal eran los valores que debían privilegiarse. Ambas corrientes lucharon por imponerse a lo largo de todo el proceso: la primera con un apoyo político inicial por parte del gobierno peronista; la segunda, tomando insumos de tradiciones anteriores correspondientes a la administración británica y transmitiendo dichos valores a partir de relatos de lo que habían sido o hecho "los ingleses".

Podría plantearse, en términos de R. Williams (2000), que estos dos "sentidos de realidad" convivieron a lo largo del período estudiado y se disputaron la hegemonía dentro de la organización. ${ }^{548}$ Por ejemplo, Rinaldi, cuenta que sus logros se vinculan con su preparación:

"Yo no tuve en ese sentido mala suerte, a mí me respetaron siempre. O sea, no pasó por encima mío alguien que fuera apañado políticamente. Pero sí que ha entrado mucha gente, acomodada, en esas condiciones. Sea más debajo de uno, pero en forma política." 549

Marone también se refirió, en distintos momentos de la narración, a que sus promociones se debieron a su formación y a que esta posibilidad la tuvo porque, aunque no apoyaba explícitamente al peronismo, tampoco lo enfrentaba. Es decir, no representaba un

\footnotetext{
${ }^{547} \mathrm{EN}^{\mathrm{o}} 4$.

${ }^{548}$ De acuerdo a Williams la hegemonía constituye todo un cuerpo de prácticas y expectativas en relación a la totalidad de la vida: nuestros sentidos y dosis de energía, las percepciones definidas que tenemos de nosotros mismos y de nuestro mundo. "Es un vívido sistema de significados y valores -fundamentales y constitutivos- que en la medida en que son experimentados como prácticas parecen confirmarse recíprocamente. Por lo tanto, es un sentido de realidad para la mayoría de las gentes de la sociedad" (Williams, 2000: 131).

${ }^{549} \mathrm{EN}^{\mathrm{o}} 3$.
} 
conflicto porque se mantenía pasivo en las diferentes coyunturas políticas. En el siguiente enunciado expresa la convivencia entre ambos valores para el ingreso y progreso:

"Había gente muy capaz, pero no era del signo político y por ahí se complicaba. De todas maneras, el que tenía inquietudes, lo hacía. Después, la fortuna, las circunstancias que se podían presentar les daban a algunos la posibilidad de mejorar y a otros de llevarse una amargura porque con todo lo que había hecho y estudiado, le negaban la posibilidad de un ascenso. Se mezcló la política, el gremio y se empezó a complicar bastante todo. Igualmente yo, particularmente, no me puedo quejar." 550

Danielle, por su parte, cuenta:

"Para esos tiempos ya había gente que influía en la ubicación de la gente. Muchos candidatos eran de los gremios y lógicamente tenían que tener conocimiento del ferrocarril. Pero, había otra gente que era tanto o más capaz de la que proponían ellos." 551

Rinaldi brinda pautas para analizar, por un lado, por qué el peronismo intentó privilegiar a personas leales al partido en los inicios:

“...después que se nacionalizó, había una corriente dentro del ferrocarril muy contraria al manejo político de la empresa: el socialismo y el comunismo. El peronismo recién surgía. Entonces había puestos que necesitaban tener gente que fueran más políticos que de conocimiento. Que supiera mandar y... favores. Entonces, hubo varios jefes, supervisores que fueron puestos por el partido, por el comité. Por ejemplo, el jefe de personal es el que permitía que hubiera ingresos de parte del partido peronista. Y después, en algunos cargos pusieron jefes afines al peronismo, cuando se producían vacantes, por los ingleses que se iban yendo. Bueno, hubo personas que no desentonaban mucho pero no les correspondía. Ahí el caso de capacidad y antigüedad no corrieron. Eso fue hasta el año 55, 56, más o menos." ${ }^{552}$

La postura de Waddell (2016) parece ir en línea con la experiencia vivida por estos ferroviarios y las interpretaciones por ellos realizada cuando asegura que en la nueva empresa recién creada, a los partidarios "se los premiaba y recibían ascensos" y a los contrarios se los "trasladaba a regiones inhóspitas". Incluso su denuncia es mucho más grave y directa que las de la mayoría de estos testigos cuando plantea que "(los ferrocarriles) se convirtieron en centro

\footnotetext{
${ }^{550} \mathrm{EN}^{\circ} 14$.

${ }^{551} \mathrm{EN}^{\circ} 27$.

${ }^{552} \mathrm{EN}^{\circ} 3$.
} 
de caza de brujas, de espionaje y de persecución para quienes no eran del partido gobernante" (López et al., 2016: 162). ${ }^{553}$

Para Rinaldi, luego de 1955 se continuó “buscando a gente por el conocimiento". Lo que interesa no es tanto la precisión temporal que establece para referirse al momento en que los valores vinculados al conocimiento habrían sido tenidos en cuenta nuevamente, sino la lúcida interpretación que el testigo hace respecto de lo que permitió que esto haya sido posible: el consenso de los pares.

“Sabe qué pasa? Una cosa que se ha mantenido bastante es que ha habido muy buenos supervisores, muy buenos empleados, que han gozado mucho del apoyo de sus compañeros para ir subiendo. Y que han hecho una buena escuela. O sea, que han trabajado para mantener su ubicación hacia arriba, hacia delante." ${ }^{554}$

La persistencia de viejos valores frente a los nuevos también se manifiesta en el testimonio de Marone:

“Había una potencialidad joven importantísima, producto de todos esos años de convenios que se habían hecho, por el cual todos los años ingresaba gente joven proveniente de la escuela. Detrás de eso se colaban unos cuantos que no tenían nada que ver con la escuela, ¿eh? Eran los que pintaban, los que empapelaban, los que iban al comité. Pero había un grupo importante de gente con preparación, con estudio." ${ }^{555}$

Calcagni resume las consecuencias que este proceso habría tenido. Por un lado, la pérdida de la eficiencia de la empresa estatal y, por el otro, la pérdida de prestigio de la profesión ferroviaria:

\begin{abstract}
"Más o menos en los cincuenta ser ferroviario dejó de ser un honor. Yo creo que pasó en otras empresas del Estado, en las que empezó a influir demasiado la política en el manejo de las empresas. Cuando más que la eficiencia empieza a ser importante el manejo político,
\end{abstract}

\footnotetext{
${ }^{553}$ Los recuerdos de Marone sobre las huelgas de 1951 parecen ir en línea con este planteo del autor cuando rememora que, luego de estas manifestaciones, el gobierno persiguió a los opositores a su partido: "Perón aprovechó ahí para meter en cana a un montón de opositores. Acá en Junín hizo una barrida linda. Y también había mucha delación, los que eran comunistas, los que eran radicales, si se habían manifestado en contra del gobierno en algún momento. Una lástima porque, a raíz de eso se generó mucha antipatía entre gente que se conocía de toda la vida" $\left(\mathrm{EN}^{\circ} 14\right)$.

${ }^{554} \mathrm{EN}^{\circ} 3$.

${ }^{555} \mathrm{EN}^{\circ} 14$.
} 
la cosa cambia." ${ }^{\prime 56}$

En definitiva, puede afirmarse que a partir de la nacionalización tuvo lugar una transformación en la cultura ferroviaria en la que nuevos valores y prácticas se instalaron en grupos determinados, mientras que otros valores y prácticas, que tomaban como referencias materiales simbólicos precedentes, persistían e intentan imponerse también. El resultado de ello desencadenó un proceso conflictivo. Precisamente, como plantea Baczko sobre el imaginario, este es "el lugar de los conflictos sociales y una de las cuestiones que están en juego en esos conflictos" (1999: 28).

\section{Representaciones marginales}

Podría resumirse hasta aquí que existieron dos representaciones predominantes en el colectivo de estos ferroviarios juninenses respecto de la historia vivida. Una que sostiene que en la etapa en que el ferrocarril era de capitales británicos se apuntaba a lograr la máxima eficiencia de la empresa y, por ello, se promovía que los empleados mejoran sus capacidades al máximo, a partir de la formación y dedicación. De esta manera, la posibilidad de brindar un servicio de excelencia (trenes confortables y a horario) a la sociedad, se vinculaba con la exigencia y el impulso que la empresa hacía para que los trabajadores ferroviarios mejoraran la calidad de su trabajo mediante el estudio y el aprendizaje en el ámbito laboral.

Por el otro lado, la segunda representación predominante en el colectivo estudiado, que resulta complementaria a la anterior, refiere a que la nacionalización fue el acontecimiento que transformó estos acuerdos. De esta manera, la formación y la capacidad dejaron de ser atributos que aseguraban el progreso en la empresa por parte de los empleados, porque, antes que esto sucediera, la eficiencia del servicio había dejado de ser un horizonte para los funcionarios de la empresa. En su lugar, se habría hecho un uso político de la empresa y se habrían privilegiado los valores políticos en los empleados, por sobre los valores vinculados a su formación, capacidad y talento.

No obstante, el vigor de las dos representaciones previas, de los mismos testigos se desprende una tercera representación, menos fuerte que las anteriores, que permiten matizar aquellos relatos. En contraposición a las dos representaciones predominantes, estos relatos

${ }^{556} \mathrm{EN}^{\circ} 21$. 
marginales permiten complejizar el análisis y suscitan nuevas preguntas.

La primera representación que, en pocas palabras, asocia a la gestión inglesa con el valor del conocimiento es matizada por la vivencia de Taberna, hijo y nieto de ferroviarios. Este trabajador que llegó a pertenecer al agrupamiento del personal de dirección, ocupando un cargo gremial en APDFA, asegura que no todos los ingleses lucían el atributo que, supuestamente, intentaban fomentar en los empleados: "Por el solo hecho de ser inglés ocupaban cargos... algunos eran buenos y otros eran ingleses." Dall'Occhio, por su parte, cuenta una anécdota que ha circulado en el colectivo ferroviario y que pareciera tener la función de contradecir, en tanto memoria, la asociación entre ingleses y eficiencia, ingleses y calidad, ingleses y excelencia. Es notable que este recuerdo, que involucra al principal jefe inglés que tuvo Junín desde 1927 hasta 1945, no haya surgido en el primer encuentro, sino recién en el tercero:

\footnotetext{
"A los ingleses les gustaba mucho (hace un gesto con el dedo índice hacia la boca, en la que se comprende la supuesta afición de los británicos por el consumo de bebidas alcohólicas). Bueno, (Rupert) Kimberly no venía bien esa mañana y se chocó una columna de hierro redonda, donde estaban los cables de alta tensión. Claro, hubo varios que se dieron cuenta que se había llevado por delante la columna, se golpeó la cara. Una semana después corrieron la columna porque estaba mal ubicada (risas). Esa no la vi yo, porque yo a Kimberly no lo conocí, pero era vox populi. Y no me extraña." ${ }^{557}$
}

Si se analiza, esta anécdota extiende la afición de este inglés particular a todos los ingleses (“a los ingleses les gustaba...") y, en ese sentido, lleva a poner en duda la ligazón entre los británicos y la eficiencia. Es de notar que si, como afirma Dall'Occhio, el relato era vox populi, ninguno de los entrevistados hizo referencia a él. Probablemente, porque ella tenía la potencialidad de horadar la sólida representación construida sobre los británicos, en el que estos estaban asociados con los atributos ya enunciados como los de la seriedad, el respeto, la justicia.

Una representación que también quedó asociada a la gestión británica es la que vincula la especialización en determinado saber con la posibilidad de lograr un ascenso en la escala laboral. Esto imprimía a las promociones que tenían durante la administración inglesa un sentido de "justicia” que, luego se perdería, en la gestión posterior en la que como decía Decarre "empezó a tallar más la política". ${ }^{558}$ Sin embargo, estas representaciones que presentan un estado de cosas también entran en contradicción con algunos relatos puntuales. Marone 
reconoce, recién luego de mi observación explicitada en el diálogo, que los jefes, antes de 1948, eran en su gran mayoría británicos:

“(durante la administración británica) los puestos altos eran para los ingleses. Pero de todas maneras se valoraba a la gente de abajo en las promociones más de trabajo. Podías ser un oficial, un especialista, un encargado, un capataz. En ese nivel en que nos manejábamos los criollos ahí sí se valoraban al que más valía. Pero podías llegar hasta la supervisión. Ahora, la dirección la agarraban ellos. El manejo era de ellos. Cuando se nacionalizaron los ferrocarriles, en cambio, se empezó a tener acceso a los cargos de dirección, pero ya empezó a hacerse política."

En ese sentido, Marone recuerda la existencia de un solo jefe argentino durante la gestión británica. La interpretación que hace él de esta excepción no hace más que alimentar, una vez más, la representación que liga la excelencia con los ingleses, ya que lo habría elegido porque "era bueno".

"Yo conocí un solo no inglés jefe (durante la administración británica). Víctor García, jefe de personal. Yo a veces lo veo con el hijo y le digo: 'Tu viejo debe haber sido muy bueno' (risas) porque fue el único gallego que llegó a ser personal de dirección cuando estaban los ingleses". 559

Es de notar que los relatos que horadan las que parecen sólidas representaciones proceden de los mismos actores que las construyeron, quienes cuentan que las posibilidades de progreso en sus carreras se debieron al esfuerzo que hicieron por capacitarse. Marone, Rinaldi, Dall'Occhio, Ferrari, Calderoni, por ejemplo, tuvieron la oportunidad de acceder a puestos de jefatura como consecuencia del retiro del personal superior de origen británico, proceso que tuvo lugar luego de la nacionalización. Ferrari rememora: "Antes, muchos de los jefes de departamento eran ingleses. Después empezó toda la camada de acá, que era gente muy capaz”. Marone, que en su testimonio insiste en denunciar reiteradamente la injerencia de la política en el ferrocarril, considera que para su caso particular, no tuvo influencia, es decir, su caso y el de un puñado constituirían una excepción: "Las posibilidades de ascenso se me fueron dando y nunca tuve un compromiso de acción política o gremial". ${ }^{560}$ Además, también refiere a las nuevas oportunidades que se les abrieron a los trabajadores locales que los impulsaron a

\footnotetext{
${ }^{559} \mathrm{EN}^{\mathrm{0}} 22$.

${ }^{560} \mathrm{EN}^{\circ} 4$.
} 
capacitarse para, precisamente, ocupar los cargos de dirección que iban a quedar vacantes:

"Todavía en los cincuenta había muchos jefes ingleses, pero ya desaparecían. Empezábamos a promocionarnos los criollos en los puestos de supervisión y dirección, cosa que antes no ocurría porque lo ocupaban los ingleses o los descendientes de ingleses. Entonces, notábamos que teníamos que tener en lo posible una preparación técnica un poco superior, para el momento en que los ingleses se fueran yendo." ${ }^{561}$

Tornello, un gremialista que, por su pertenencia a la lista rosa, puede considerarse marginal dentro de la Unión Ferroviaria y que podría, por ese motivo, criticar a otros integrantes del gremio que tuvieron un vínculo con el peronismo (de la lista azul o verde) cuestiona la representación que liga las promociones con vínculos políticos o gremiales. A su vez, su relato parece confirmar que esas representaciones, que muchos testigos reproducen, circulaban en el colectivo:

\footnotetext{
"No era por cuestiones políticas. Te aseguro que no. Si vos no tenías capacidad para ese puesto, no llegabas. Venían de Buenos Aires a veces a tomarte exámenes. Lo que pasa que se distorsionó todo diciendo que era todo por acomodo, por peronismo, por radical y no era así. Si vos no tenías capacidad no ibas a ocupar un puesto que no te correspondía." ${ }^{562}$
}

El intercambio con los testigos para esta investigación apuntó a que ellos dejen fluir libremente el relato de su vida en el ferrocarril, empleando como instrumento principal la entrevista en profundidad. El objetivo era comprender las interpretaciones y significados que les dieron a los acontecimientos vividos, rescatando así los sucesos del pasado procesados por la experiencia posterior y las expectativas e interpretaciones de la situación presente (Sautu, 2004: 45). De esta manera, mis intervenciones fueron mínimas y tuvieron el objetivo de encauzar nuevamente el relato hacia el objetivo de la investigación, o bien, estimular el recuerdo en algún aspecto puntual. Sin embargo, solo en el tema que se desarrolla en el presente apartado mi intervención fue algo más activa, con la finalidad de promover interpretaciones no explicitadas previamente por ellos y, también, de contribuir a una mejor comprensión del fenómeno estudiado. A continuación, se reproduce un diálogo

\footnotetext{
${ }^{561} \mathrm{EN}^{\mathrm{o}} 14$.

${ }^{562} \mathrm{EN}^{\mathrm{o}} 6$.
} 
con Poch que busca, justamente, ampliar la comprensión:

—JP: Cuando se compraron los ferrocarriles se empezaron a desvirtuar muchas cosas. A políticos que no sabían nada los acomodaban, los ponían de jefes, y no sabían nada de nada.

-ALS: Pero muchos ferroviarios me contaron que había concursos...

—JP: Sí, por capacidad. Y también había becas. Para ascender había que rendir examen.

-ALS: Entonces, ¿cómo dice que se metió la política?

_JP: Porque vinieron jefes que eran políticos. Cuando entró la política se fueron todos los jefes.

—ALS: Mendiburu, Marone ¿fueron políticos?

—JP: No, era gente muy capaz.

-ALS: Entonces, ¿algunos por política y otros no?

—JP: Claro, algunos sí, otros no. Pero la cosa es que despacito se fue metiendo la política. No sé podía meter de lleno porque, lógicamente, ahí nos conocíamos todos las capacidades que teníamos. ${ }^{563}$

Años después, realicé una entrevista que no respetó la modalidad habitual, ya que las anteriores, salvo la de los fraternales jubilados, fueron encuentros entre la entrevistadora y el testigo en la intimidad del hogar del ferroviario. En esta oportunidad, el encuentro era con una persona a quien antes no había contactado y que pertenecía al selecto grupo de profesionales que trabajó en Ferrocarriles Argentinos en Junín: el ingeniero José Calcagni, presentado por Juan Dall'Occhio, quien también participó en la entrevista. Dado que ya hacía un tiempo que venía trabajando sobre el tema, me permití realizarles preguntas más directas que pudieran poner en cuestión las representaciones imaginarias predominantes que los ferroviarios construían, las cuales ligan a la nacionalización con la política y al "tiempo inglés" con la valoración de las capacidades individuales. Lo que primero se observa es el desconcierto ante la pregunta, lo cual se expresa a través de un silencio reflexivo, seguido de algunos enunciados que parecerían confirmar mi inquietud inicial:

-ALS: Ustedes dicen que es con el peronismo que el ferrocarril decae. Pero si uno observa los nombres de quienes fueron jefes de Talleres y de Mecánica en Junín, y ocuparon los más altos cargos en la línea, antes de la nacionalización eran ingleses y, luego, muchos eran graduados de la Escuela Industrial. Entonces, pareciera que se abrieron oportunidades

${ }^{563} \mathrm{EN}^{\circ} 1$. 
de ascenso para los argentinos con la nacionalización. ¿Qué opinan?

(un breve silencio, luego se retoma la conversación)

—JC: Sí, hasta la nacionalización fueron todos ingleses. Acá en Junín, el primero fue Carrió, ${ }^{564}$ después Schwartz, ${ }^{565}$ después Roqués, ${ }^{566}$ todos argentinos.

—JD: Caruso $^{567}$ estuvo también pero muy poco tiempo. Estuvo Diego González. ${ }^{568}$

-JC: Muy buen jefe de departamento.

—JD: Después estuvo Nadín, ${ }^{569}$ después Marone. ${ }^{570}$

-JC: Estuvo Taylor ${ }^{571}$ también.

-ALS: La pregunta sería: ¿es posible que los argentinos hayan tenido mejores posibilidades de progreso luego de la nacionalización?

-JD: Sí, fue mayor cuando llegaban a niveles superiores. Indudablemente.

-JC: ¿Comparando? Claro, antes los que ascendían eran los ingleses.

—JD: Bajo esa mirada, sí. Pero estás hablando de 4 mil operarios de los cuales podían ascender 20 .

—JC: Ascendieron algunos argentinos casi al final del tiempo de los ingleses. Pero, en general, nunca pasaban de jefe de sección.

_JD: Pero ocurría una cosa. Mi padre fue jefe de estación del último ramal que se hizo en la línea San Martín, Laboulaye a Sampacho. El primer jefe de estación de Malena fue mi padre. En el medio de La Pampa, ni ranchos había. Perdí un hermano porque el parto se atendía como los animales. Mi padre hizo la forestación de la estación y todos los años recibía una nota del jefe del departamento de Tráfico felicitándolo hasta que llegó una de la Administración que vino con el escudo inglés, en un papel transparente. En una hay un mes de sueldo de premio, cuando mi papá en plena guerra juntaba huevos para mandarlos a Inglaterra para los heridos de guerra. Qué sé yo, tenían sus cosas los ingleses. ${ }^{572}$

El intercambio anterior posee diversos puntos para analizar. En primer lugar, ante el nuevo planteo interpretativo que les presento a los ferroviarios al inicio, la primera respuesta de los testigos es el silencio, el cual puede entenderse como un sentimiento de sorpresa y un momento que emplean para reflexionar acerca del argumento presentado. A continuación,

\footnotetext{
${ }^{564}$ Roberto Francisco Carrió fue jefe del Departamento de Mecánica en 1954 (Tarullo et al., 2013: 136).

${ }^{565}$ Bernardo Schwartz fue jefe del Departamento de Mecánica desde 1955 hasta 1960 (Tarullo et al., 2013: 136).

566 Sebastián Emilio Roqués fue jefe del Departamento de Mecánica desde 1960 hasta 1966 (Tarullo et al., 2013: 136).

${ }^{567}$ Carlos Rafael Caruso fue jefe de Talleres Junín desde 1954 hasta 1968 (Tarullo et al., 2013: 137).

568 Diego González fue jefe del Departamento de Mecánica desde 1978 hasta 1989 (Tarullo et al., 2013: 136).

${ }^{569}$ Roberto Nadín fue jefe del Departamento de Mecánica entre 1989 y 1990 (Tarullo et al., 2013: 136).

570 Ítalo Marone fue jefe del Departamento de Mecánica entre 1990 y 1991 (Tarullo et al. 2013: 136).

${ }^{571}$ Federico Dobson Taylor fue jefe del Departamento de Mecánica entre 1970 y 1977 (Tarullo et al., 2013: 136).

$572 \mathrm{EN}^{\mathrm{o}} 21$.
} 
puede observarse un reconocimiento implícito de la validez del argumento, con la afirmación de Calcagni que conviene en que "hasta la nacionalización (los jefes) fueron todos ingleses". Seguido de tal reconocimiento, la conversación se vuelve a desviar en la enumeración de todos los jefes del Departamento de Mecánica que hubo argentinos, luego de la nacionalización. Esto puede interpretarse como una nueva manera de eludir el argumento de la entrevistadora, a partir del intento de estos dos ferroviarios jubilados de hacer memoria y recordar nombres y cualidades de estos jefes ("Muy buen jefe", dice en un momento Calcagni). Ante este desvío de la conversación, les vuelvo a inquirir, directamente, si los argentinos, luego de la nacionalización, tuvieron mayores posibilidades de progreso. Los testigos, en este caso, no pueden evitar reconocer la validez de la argumentación, la cual se sostiene, ni más ni menos, por los acontecimientos que ellos mismos relataron: los de estos jefes de Mecánica que aparecen en este diálogo, sumados a los que refieren a su propia historia de vida en la que el esfuerzo y el estudio jugaron un rol clave en su progreso. Luego de este reconocimiento, Dall'Occhio intenta contraargumentar, con el planteo de que los puestos de dirección eran, en realidad, pocos, en relación a la totalidad de empleados que había en los ferrocarriles del Estado. Es decir, que los ingleses, si bien no permitían el acceso de los argentinos a los cargos de dirección, procedían con justicia para el personal perteneciente a los escalafones medios e inferiores. Con ello, el ferroviario intenta mitigar o restarle valor al planteo de que muchos argentinos progresaron en la empresa luego de la nacionalización en base a sus capacidades y formación, de una manera que hubiera sido impensada durante la administración británica. No conforme con ello, Dall'Occhio intenta volver a poner en valor a los ingleses evocando sus recuerdos como hijo de ferroviario, la sobriedad en que su familia vivía y el reconocimiento simbólico (carta de felicitación) y material (un mes de sueldo) que los directivos británicos hicieron por la dedicación y los servicios de su padre en beneficio de la empresa. A esta altura, su valoración a la gestión británica se tiñe de aspectos emotivos que no contribuyen a sostener contraargumentación ("Qué sé yo, tenían sus cosas los ingleses”). Este trabajador ferroviario no es el único que, perteneciendo a una familia ferroviaria y habiendo vivido de niño durante la gestión inglesa va a exhibir un sentimiento de admiración y aprecio por los británicos que no tiene correlato con los sucesos a partir de los cuales plantea su defensa a la gestión. Por ejemplo, Dimarco, hijo de otro ferroviario, expresa su admiración por los ingleses de una manera que, en apariencia, resulta contradictoria: "Mi experiencia me dice que los ingleses eran una porquería, pero eran buenos tipos". O Ferrari, que asegura que "los ingleses eran algo 
espectacular". ${ }^{573}$ Puede afirmarse que lo que es común en estas expresiones es la fascinación que ejerció el colectivo británico en muchos ferroviarios, que ha quedado en la memoria colectiva e influido en la experiencia posterior. ${ }^{574}$

En el presente apartado, entonces, se han presentado algunas experiencias y recuerdos por parte de los mismos actores que parecieran haber matizado toda una serie de representaciones arraigadas en el colectivo ferroviario en relación a los ingleses y al significado que tuvo la nacionalización. De esta manera, se ha logrado mostrar que aun cuando la administración británica quedó predominantemente asociada en el plano imaginario a la valoración de las capacidades individuales, fue, en rigor, luego de la nacionalización que los trabajadores locales tuvieron mayores oportunidades concretas de progresar en la empresa. También, aun cuando la gestión de los Ferrocarriles del Estado Argentino quedó mayormente asociada, desde el imaginario, al uso político de la empresa, beneficiando de esta manera a los que eran cercanos al partido y no a los más capaces, se ha demostrado que muchos de nuestros protagonistas ascendieron por sus propias aptitudes, las cuales habían logrado con estudio y esfuerzo. Por otro lado, si se observa la representación que vincula a la gestión británica con la excelencia, en este análisis se puso en evidencia que algunos actores centrales que formaban parte de esta administración no eran los más aptos y exhibían algunas cualidades reprochables, de acuerdo al sistema de valores imperante en el colectivo (por ejemplo, alcoholismo).

Es preciso aclarar, sin embargo, que lo que se intentó analizar y demostrar líneas antes no tuvo como meta denunciar la inexactitud de los recuerdos que los actores le dieron a la experiencia vivida, ya que se apuntaba a conocer las interpretaciones y los sentidos que les dieron a los acontecimientos históricos de los que fueron testigos. En esa línea, se considera que el relato de vida nunca puede ser una unidad coherente ni estar desprovisto de aspectos emocionales asociados a los recuerdos. Más bien, lo que se pretendió evidenciar es que los imaginarios sociales implican un esquema colectivo de interpretación de las

\footnotetext{
$573 \mathrm{EN}^{\mathrm{o}} 16$ y 4.

${ }^{574}$ Un trabajo de Badaloni (2006) puede contribuir a comprender la adhesión de los empleados a las prácticas y normas implementadas por la administración británica. La autora estudia el caso del Ferrocarril Central Argentino en Rosario, en las primeras décadas del siglo XX y sostiene que la empresa llevó adelante prácticas paternalistas que tuvieron un carácter disciplinador, buscando quebrar la la solidaridad entre empleados para reemplazarla por vínculos verticales y de identificación con la empresa (Badaloni, 2006: 509). En un trabajo posterior, la autora estudia la eficacia de la representación de la "familia ferroviaria", generada a partir de prácticas que tenían por objetivo el involucramiento de los trabajadores con los intereses de la compañía. Por ejemplo, la posibilidad de lograr ascensos y hacer carrera en la empresa, favorecía la generación de relaciones de lealtad con la empresa la que quebraban las solidaridades horizontales para sustituirlas por vínculos de deferencia vertical (Badaloni, 2011: 158).
} 
experiencias individuales $\mathrm{y}$, en esa construcción, pueden dejar afuera algunos acontecimientos capaces de hacer tambalear el edificio simbólico construido colectivamente. Porque, como señala Bazcko, los sistemas simbólicos sobre los cuales se apoya y trabaja la imaginación social, se construyen, a partir de las experiencias de los agentes sociales, pero también a partir de sus deseos, aspiraciones, intereses: "Todo campo de experiencias sociales está rodeado de un horizonte de expectativas y recuerdos, de temores y esperanzas" (Baczko, 1999: 30). En ese sentido, podría sostenerse que los imaginarios sociales poseen una potencia unificadora que permite conducir a los individuos a acciones comunes y, por tanto, precisan presentar una constelación de representaciones que involucran normas, valores, recuerdos y esperanzas apropiadas para moldear esas conductas y movilizar las energías de los actores.

Gracias, entonces, a que se han reiterado los encuentros con algunos de los protagonistas, a que se ha logrado una relación de confianza entre los testigos y la entrevistadora y, en consecuencia, a que se ha podido guiar la conversación de modo tal que se profundice en algunos aspectos puntuales, han podido emerger algunos recuerdos marginales que, a la vez que mostraron la naturaleza ficcional de los imaginarios sociales, permitieron complejizar nuestra mirada sobre ese pasado recordado. Esta naturaleza ficcional a la que se alude, no implica restarle valor al imaginario, ya que como plantea Castoriadis, este es central para la organización de la vida colectiva porque permite que "el mundo sea captado de una manera práctica afectiva y mental”. Por eso, según el autor, lo imaginario social puede ser más real que lo real (Castoriadis, 1983: 235, 252). 


\section{Capítulo 4}

\section{Crisis nacional, iniciativas locales}




\section{La crisis del ferrocarril en la década de 1960: recuerdos y representaciones locales}

Al momento de la nacionalización el sistema ferroviario funcionaba de manera eficiente, con trenes a horario y un servicio de calidad. Sin embargo, la nueva empresa estatizada presentaba varios problemas a resolver a futuro, entre ellos, la diversidad de trochas y la existencia de una red con líneas superpuestas entre sí e instalaciones duplicadas (galpones, depósitos), producto de la diversidad de empresas que existían antes de la nacionalización y de las políticas que los gobiernos previos promovieron en materia ferroviaria. Al mismo tiempo, la falta de inversión durante las últimas décadas de administración británica implicó que el material rodante adquirido fuera antiguo y demandara mayor mantenimiento, precisando, a su vez, contar con mayor personal para el desarrollo de estas tareas (López et al., 2016: 153-154).

A estos problemas preexistentes que demandaban una nueva organización e inversiones urgentes, se le sumaron otros generados por la gestión peronista y que, en lo concreto, condujeron a que la nueva empresa estatal fuera deficitaria: el no aumento de tarifas frente a la inflación, combinado con el incremento de salarios del personal. Además, las tarifas baratas también estimularon una mayor demanda del servicio de carga y de pasajeros, lo que tuvo como consecuencia directa la sobreexplotación del material rodante, incrementando, a su vez, el deterioro y los costos de mantenimiento en un círculo vicioso que, de acuerdo a Waddell, condujo a "un déficit de explotación que no se pudo revertir más y fue el gran problema del sistema ferroviario a lo largo de la segunda mitad del siglo XX” (López et al., 2016: 155).

En la misma medida que el personal fue en aumento luego de la nacionalización, el transporte de cargas disminuyó, producto de la competencia con el transporte automotor. De acuerdo a Waddell, de 158 mil trabajadores que había en 1947, al final del gobierno peronista, en 1955, se había alcanzado la cifra de 210 mil trabajadores. Con la "Revolución Libertadora" que derrocó a Perón la cifra siguió en ascenso: en 1957 llegó a haber 218 mil trabajadores. Esto implicó un aumento del 38\% del personal de los ferrocarriles del Estado en la década que fue de 1947 a 1957 (López et al., 2016: 160). En Junín, de 2.307 agentes que había en los Talleres al momento de la nacionalización, se pasó a un incremento de 3.236 en una década, lo que significó un 40\% de aumento de personal (Crocco, 2010). Mientras tanto, el transporte de cargas decrecía y el de pasajeros se incrementaba notablemente, entre otros factores, por la expansión del turismo social, el proceso de migración interna en el suburbano de Buenos Aires y la falta de inversión del gobierno en la construcción de caminos y conservación de rutas. 
En ese contexto, el gobierno peronista tuvo una política de mantener bajas las tarifas de pasajeros, lo que le provocó a los Ferrocarriles del Estado un desequilibrio creciente entre ingresos y egresos. Si bien realizó inversiones en material rodante, estas no fueron suficientes frente a las necesidades que planteaba el mayor tráfico de pasajeros y la falta de inversión que se arrastraba de las últimas décadas de gestión británica.

De esta etapa también data la adquisición de las primeras locomotoras diésel eléctricas, lo que implicaba un primer paso para la modernización del sistema. Sin embargo, en este punto la política peronista pareció errática porque, al mismo tiempo que adquiría locomotoras diésel eléctricas, se financiaba otro proyecto de locomotoras a vapor (López et al., 2016: 166).

Otro problema que presentaba el sistema ferroviario al momento de la nacionalización fue la existencia de una red desproporcionada, con algunas líneas redundantes y que carecían de conectividad, producto de políticas gubernamentales anteriores que habían estimulado la actividad privada sin planificación por parte del Estado. En ese sentido, el gobierno peronista no llevó adelante medidas para resolver los problemas previos. De acuerdo a Waddell, luego de la nacionalización no hubo una apropiada planificación ferroviaria:

Los ferrocarriles siguieron funcionando con la inercia que traían de antes de la nacionalización. No se encararon verdaderos estudios ni se articularon propuestas de solución para ellos y de mejoras contundentes del servicio (López et al., 2016: 168).

Luego del derrocamiento de Perón, la Revolución Libertadora llevó adelante algunos programas para encarar planes de modernización que permitieran paliar lo que se consideraban los problemas centrales del ferrocarril en aquel momento: la obsolescencia de vías y de material rodante, agravada por el aumento del tráfico de pasajeros, y, sobre todo, el déficit. Sobre este último Waddell señala que no solo era un problema que afectaba al sector, sino que lo trascendía, ya que condicionaba cualquier política económica nacional (López et al., 2016; 172). De ahí que este déficit se instale, poco a poco, en la opinión pública, como el gran problema ferroviario de las próximas décadas.

Entre las medidas que la Revolución Libertadora implementó pueden mencionarse la creación de la Empresa Ferrocarriles del Estado, que significó uniformar criterios de administración de toda la red, y separar la explotación de los ferrocarriles (a cargo de la empresa) de la autoridad de aplicación y fijación de políticas (a cargo del Ministerio de Transporte). También se redactó el RITO (Reglamento Interno Técnico Operativo) que 
reemplazó los viejos reglamentos de las empresas privadas. Sin embargo, no se pudo plantear una solución para el problema del déficit, que seguía en aumento por el incremento del transporte de pasajeros que implicaba mayores gastos (en personal y mantenimiento) que ingresos (por las tarifas bajas).

Cuando Arturo Frondizi asumió la presidencia en 1958, se planteaba como prioridad que el país saliera de la dependencia y desarrollara, poco a poco, sus industrias de base. Existían dos actividades consideradas estratégicas para lograr el desarrollo autónomo del país: la industria petrolera y la automotriz, lo que, en poco tiempo, condujo a la instalación de muchas empresas automotrices. Esto tuvo consecuencias negativas para la actividad ferroviaria que, paulatinamente, iba perdiendo la hegemonía como medio de transporte y que, con estas medidas, decrecía en importancia. Además, en ese contexto, el ferrocarril estaba asociado a una etapa que se quería dejar atrás, cuando la economía estaba regida por la actividad agroganadera (López et al., 2016: 174).

En el inicio del gobierno de Frondizi, bajo la gestión del secretario de Transportes Alberto López Abuin, se inició una etapa de modernización del material rodante, incorporando, por ejemplo, locomotoras diésel y tomando medidas para desarrollar la industria ferroviaria nacional, con la instalación de dos plantas industriales en Córdoba para la construcción de motores y la fabricación de coches de pasajeros y coches motores. Por esos años, en 1959, la CEPAL había elaborado un informe que planteaba que el estado de la red y del material rodante era antiguo e inconveniente para poder prestar un servicio correcto y aceptable. También se planteaba la decreciente participación del ferrocarril en el mercado de transporte, como consecuencia de la falta de modernización. Abiun se basaba en este diagnóstico (López et al., 2016: 175).

El exjefe de Mecánica de la línea San Martín, Marone, recuerda que hubo una etapa de expansión del ferrocarril, por la adquisición de coches de pasajeros en 1952, y de locomotoras, durante la primera etapa del gobierno de Frondizi. Asimismo, identifica a la gestión del gobierno desarrollista como el inicio de la declinación del ferrocarril:

"Fue una buena época cuando se hizo la primera compra de material ferroviario importante que hizo el Estado, después que se fueron los ingleses. Que fue cuando compraron las locomotoras diésel eléctricas, cuando compraron coches de pasajeros holandeses, japoneses. En ese momento se estaba brindando un servicio muy bueno. Eso fue hasta el 60."575

${ }^{575} \mathrm{EN}^{\circ} 14$. 
Muchos ferroviarios de Junín vivieron de una manera muy crítica el pasaje de la máquina de vapor a la diésel eléctrica que tuvo lugar en esta época. Sus representaciones respecto de esta etapa vinculan la declinación del ferrocarril en los sesenta, durante el gobierno de Frondizi, con esa transformación tecnológica. Ese es el caso Tornello:

"Para mí la mejor época del ferrocarril fue hasta el 61, que fue la decadencia con el gobierno de Frondizi. Con la famosa dieselización. Cortaban máquinas enteras con caldera, con sopletes, ¿por qué? Porque ya querían terminar con el ferrocarril." 576

Resulta significativo cómo el testigo anterior asocia la destrucción física de la máquina a vapor con el intento de destruir el ferrocarril como medio de transporte y, con ello, a la comunidad ferroviaria. Esto aparece en otros testimonios como el de Violante que, con nostalgia, recuerda ese tipo de tecnología perimida:

"Hubo momentos bravos, que desaparecieron las máquinas a vapor como por encanto. Máquinas que hubieran podido dar mucho más. Inclusive, hoy, en Inglaterra las tienen produciendo, como ferrocarriles históricos, y transportan pasajeros, como un museo ambulante. A vapor, que son las mismas que usábamos acá. Y cumplían una función como cualquier otra. El asunto es tener potencia para tirar una cantidad de rodados que llevan un peso y nada más." 577

En la misma línea va el testimonio de Mantino, exdelegado de la Unión Ferroviaria, quien recuerda el gobierno de Frondizi con esta destrucción: "Primeramente entraron a romper máquinas, sacaron las calderas a vapor y arrancamos con el petróleo que quería modificar todo. Y rompían las máquinas, todo como para chatarra.” El fraternal Dante Cruz también se lamenta:

"Con el gobierno de Frondizi, fue desapareciendo la locomotora a vapor. Las locomotoras las cortaban y las vendían como chatarra. Es una locura lo que se hizo ahí. Aparte de eso estaban las playas con locomotoras tiradas, oxidadas, rotas... Quién cobró eso, no sé. Somisa compraba, quién lo cobró no sé." ${ }^{\text {578 }}$

\footnotetext{
$576 \mathrm{EN}^{\mathrm{o}} 6$.

${ }^{577} \mathrm{EN}^{\circ} 8$

${ }^{578} \mathrm{EN}^{\mathrm{o}} 13$.
} 
Sorprendentemente, en algunos ferroviarios la locomotora a vapor quedó asociada a la época de esplendor del ferrocarril, cuando este era de capitales británicos o durante la primera etapa de la nacionalización. En cambio, la locomotora diésel eléctrica, que podría haber significado el inicio de la modernización para el ferrocarril fue, para algunos, el símbolo del inicio de la decadencia y la crisis ferroviaria, en su asociación con otras representaciones de la época sobre acontecimientos fundamentales (como la huelga del 61 y las medidas tomadas por el gobierno de Frondizi que tuvieron como consecuencia la merma de personal).

Sin embargo, también es oportuno señalar que quienes aspiraban a convertirse en conductores de locomotoras y habían ingresado en los sesenta, tenían algunos motivos concretos para asociar esta etapa con un momento crítico en sus carreras, ya que con el abandono de la locomotora a vapor se ponía fin a las expectativas de ascenso con que habían ingresado. Uno de ellos lo explica en detalle:

\footnotetext{
"Nosotros entramos con el pie izquierdo. Estuvimos catorce años en el depósito de locomotoras, en las tareas de reparación, limpieza. Un ingeniero se recibe a los siete, ocho años. Nosotros llevamos catorce años limpiando fierros, fijate si no nos fue mal de entrada. Pero todo eso ocurre porque se termina el periodo de la máquina que era a vapor, que trabajaba con leña, carbón, pasó a la máquina que trabajaba con petróleo. Entonces disminuyeron la cantidad de gente para trabajar. En una locomotora que trabajaba a leña iba el maquinista, el foguista y uno más, o sea que en cada servicio iban tres hombres. Al cambiar el servicio cuando apareció el petróleo, ya se perdió un hombre. Entonces ahí empezó el receso, ya era más lerdo para salir a trabajar como foguista, que era lo que nosotros aspirábamos de entrada. La locomotora diesel no precisaba una atención como la máquina a vapor. Era la niña bonita en esa época. Entonces por esa razón nosotros estuvimos catorce años siendo aspirantes."
}

Es preciso aclarar que la vinculación entre la crisis ferroviaria y la desaparición de la máquina a vapor no fue la única interpretación entre los ferroviarios de Junín. Amparándose en su saber técnico, José Calcagni se sorprende de la "posición nostálgica en defensa de la locomotora de vapor de algunos ferroviarios, que aprovechaba apenas poco más del $10 \%$ de la energía del combustible, en tanto la diesel eléctrica se aproximaba al 40\%." 580 En la misma línea que el ingeniero, Dall'Occhio brinda argumentos que fundamentan el reemplazo de la

\footnotetext{
${ }^{579} \mathrm{EN}^{\mathrm{o}} 12$.

${ }^{580}$ Entrevista No30 realizada a José Calcagni, 9 de septiembre de 2017, en adelante ENº30.
} 
vieja tecnología, basado en el uso de combustibles, la necesidad de mantenimiento y la demanda de personal:

“...en la época de Frondizi es cuando se dio la conversión, que ya venía generándose en todos los países europeos porque la tracción a vapor es antieconómica completamente. El rendimiento del combustible empleado para la tracción obtenida es muy baja. Es mucho combustible para poca tracción. Y la locomotora necesitaba mucho personal para atenderla en períodos mucho más cortos. Era sumamente costoso. Viene la locomotora diésel, vos apretás un botón y está en marcha, mientras que con la otra vos tenés que comenzar seis horas antes para que produjera vapor y se ponga en marcha. Aparte podía andar $300.000 \mathrm{~km}$ sin una reparación general, mientras que la otra a los $100.000 \mathrm{~km}$ la necesitaba. La conversión era como pasar de la chata al camión. O del avión a hélice a una turbina. Y bueno, había algunos que tenían que cambiar de oficio y se resistían. A nadie le gusta cambiar de oficio cuando estás habituado a hacer algo. Hubo mucha resistencia. Y había opiniones, qué sé yo. Pero en realidad no había nada que siguiera justificando que siguiéramos con la máquina a vapor." 581

Al final del enunciado, Dall'Occhio deja entrever la existencia de conflictos por este cambio tecnológico, un recuerdo que es compartido por Murgia, exjefe de Métodos y Tiempo y de Estudio de la Reparación, quien también añade que de esta época data también el reemplazo del coche de madera por el metálico.

"Lo que ocurre es que la actividad siempre es dinámica, aunque uno se haga una rutina. Por ejemplo, en los sesenta desapareció el coche de madera, la locomotora de vapor. Vino el coche metálico y la locomotora diesel eléctrica. ¿Te imaginás cuánto cambio sucedió en el ferrocarril? Cuando vos estudiás una organización industrial, hay un concepto que es la resistencia natural al cambio. Una persona que por muchos años hizo algo de determinada manera, si vos le querés hacer cambiar algo, aunque sea algo que lo beneficie, el tipo siempre se va a resistir. $\mathrm{Y}$ en aquel momento a lo mejor, los gobiernos, los teóricos dicen, tenemos que cambiar esto y lo otro y ahí viene un tire y afloje. Evidentemente hubo un cambio, si desapareció la locomotora a vapor, los repuestos no son los mismos que la diesel eléctrica. Otra tecnología, la gente se tuvo que capacitar. En la misma época, también se reemplaza el coche de madera. Y bueno, 
se cambia la forma de trabajo, todo eso produce reclamos, protestas. Pero bueno, yo, me mantuve al margen de esas cosas. Me quedé muy enfrascado en lo mío." 582

Si bien la incorporación paulatina de estas locomotoras significó una evolución innegable en materia ferroviaria, existían algunos problemas que impedían que el servicio del ferrocarril mejorase por la mera introducción de esta tecnología. Marone hace alusión a ellos:

“...cuando vino la locomotora diésel eléctrica, parecía que íbamos a mejorar sustancialmente todo. Sin embargo, los servicios en regularidad, en velocidades, no fue demasiado lo que se ganó. Porque había un problema fundamental que eran las vías. Las vías necesitaban mantenimiento continuo e importante, en cuanto al gasto, para poder facilitar que los trenes que circulaban sobre esas vías lo hicieran a velocidades importantes."

Siguiendo a Waddell, luego de la renuncia del secretario de Transporte López Abuin en 1959, que llevó adelante una gestión que apuntó a la modernización del ferrocarril, sobrevino una nueva etapa en la que el gobierno enfocó sus esfuerzos en paliar el déficit ferroviario. En ese momento, el ministro de Hacienda era Álvaro Alsogaray, quien presentó como principal desafío eliminar el déficit nacional. Para ello, eliminar el déficit ferroviario era fundamental, ya que era la principal causa de desequilibrio fiscal de la nación. Las políticas que intentó implementar, junto al ministro de Obras y Servicios Públicos, Alberto Constantini, implicaban el aumento de tarifas y la reducción de los gastos de explotación. Para esto último, se propuso la transferencia al sector privado de algunas áreas periféricas como restaurantes, imprentas, limpieza, servicios de carga y descarga. Esto incrementó las tensiones con los gremios ferroviarios y, finalmente, Alsogaray renunció (López et al., 2016: 176).

Luego de esta renuncia, se instaura una nueva etapa en materia de política ferroviaria, a inicios de 1961, en la que sus protagonistas fueron Roberto Alemann, ministro de Hacienda, y Arturo Acevedo, ministro de Obras y Servicios Públicos. En este corto pero crucial período de la historia ferroviaria, se proponen medidas drásticas para resolver el déficit ferroviario, entre ellas, el cierre de ramales que no cubrieran los costos de explotación y la cesantía de personal. Como consecuencia de la clausura de los primeros ramales, en junio de ese año, la transferencia al sector privado de algunos servicios y la incorporación de los primeros coches

\footnotetext{
${ }^{582} \mathrm{EN}^{\mathrm{o}} 7$.
}

${ }^{583} \mathrm{EN}^{\circ} 22$. 
motores para pasajeros, que permitían prescindir del foguista, los conflictos entre los trabajadores y el gobierno se intensificaron. Luego de una huelga de dos días que tuvo lugar el 27 de octubre, el gobierno tomó como represalia la clausura de varios ramales y talleres, lo que desató la gran huelga ferroviaria, conocida como "huelga del 61" (López et al., 2016: 177).

Meses antes de que ella se desatara, Frondizi había pronunciado un discurso conocido como "La Batalla de Transporte" en el que calificaba al sistema ferroviario como "pésimo" y explicitaba deficiencias serias en el servicio, a partir de la falta de higiene en los vagones e instalaciones sanitarias, el retraso en los horarios, tanto para pasajeros como para mercaderías, el hacinamiento de los pasajeros, entre otras cuestiones. En relación al déficit, el presidente aclaraba que este resultado, que implicaba que los gastos fueran superiores a los ingresos, no siempre era antieconómico. Sin embargo, en el caso de los ferrocarriles estatales, sí lo era: "En nuestro caso ocurre todo lo contrario: estamos obligando al contribuyente a pagar las pérdidas de un servicio pésimo, que lejos de beneficiarlo lo perjudica." ${ }^{, 544}$

Esta descripción que realizaba el presidente exhibe un servicio que, en la década del sesenta, tenía serias deficiencias, lo cual contrasta con los recuerdos y representaciones que caracterizan a la época inglesa en relación a la puntualidad e higiene de los trenes. Los testimonios de los ferroviarios de Junín también expresan que, en esta etapa, el prestigio de la actividad ferroviaria estaba en decadencia y que el ferrocarril estaba dejando de ser la fuente de trabajo codiciada que antes era en la ciudad. Rinaldi recuerda: "Hasta el año 60 siguió entrando personal, pero se debe haber cortado por esa época, en el gobierno de Frondizi”. Crocco complementa: "En ese momento se fue mucho personal porque se aplicó una ley de jubilación anticipada". ${ }^{585}$ En el mismo sentido, Calderoni rememora:

“...en la época de Frondizi se fue mucha gente, fue mermando. La gente como le daban plata, le daban una indemnización muy buena y creyó que iban a hacer negocios. Ponían algún negocito y, ¿qué pasó? Se fundieron. Antes de Frondizi yo creo que fue la mejor época. Porque después cuando estuvo Frondizi que hizo ese asunto de las indemnizaciones, ya el cupo del ferrocarril se vino abajo. Quedaron mil y pico operarios, se empezó a hacer que todo el personal que tenía, se vaya yendo, pero no incorporaban, ¿me entendés? Hubo un tiempo por ejemplo que la Escuela Técnica, todos los años los aprendices que se recibían y querían entrar al ferrocarril, tenían la posibilidad de rendir examen y entrar al ferrocarril. Pero después eso cerró, no entraron

\footnotetext{
${ }^{584}$ Frondizi, A. (9 de julio de 2017). Discursos: La batalla del transporte. 5 de junio de 1961. Recuperado de https://www.visiondesarrollista.org/discursos-la-batalla-del-transporte/: 8/5/2020.

${ }^{585} \mathrm{EN}^{\mathrm{o}} 3$ y 2.
} 
más. Entonces no hubo más aprendices en el ferrocarril. No se fue renovando. Estaba la gente que estaba y nada más." 586

Tanto en el testimonio anterior como en el de Crocco se señala que, por un lado, a partir del gobierno de Frondizi tuvo lugar un plan de jubilaciones anticipadas. En la empresa Ferrocarriles del Estado Argentino esto significó la merma de alrededor 40.000 trabajadores. ${ }^{587}$ En Junín hubo una baja de 629 agentes en los Talleres, lo que implicó una disminución del 20 por ciento de trabajadores. ${ }^{588}$ Por el otro lado, a partir del relato de los testigos, puede advertirse que la Escuela Industrial Antonio Bermejo (antes Escuela Técnica y de Artes y Oficios) iba dejando de ser paulatinamente, el espacio de formación al que los jóvenes acudían con la expectativa de ingresar al ferrocarril, el cual había sido la fuente de trabajo más codiciada de la ciudad.

El Plan de Jubilaciones Anticipadas y de Indemnizaciones implementado durante el gobierno de Frondizi significó, sin embargo, para unos pocos, la oportunidad de progreso. Este fue el caso de Dall'Occhio quien según plantea, tuvo mayores posibilidades de ascender por el retiro de ferroviarios valiosos que dejaban sus puestos. Para este trabajador que llegó a ser jefe de Talleres, si bien el ferrocarril "empezó a perder importancia" a partir del gobierno de Frondizi, "a muchos les fue mejor, sobre todo a los que estaban más capacitados".

\begin{abstract}
"Cuando fue la huelga del 61, varios amigos míos, técnicos, se retiraron del ferrocarril con una indemnización que le daban y algunos se fueron de profesores al Colegio Industrial. Aprovecharon el momento y me hicieron pasar a mí un momento un poco dramático porque me decían: 'Qué vas a seguir haciendo en el ferrocarril, si vos tenés condiciones, vamos al Colegio Industrial que tienen vacantes'. Yo estaba a punto de casarme y me parecía que dar un paso así era un poco arriesgado. Y me quedé. Pero tentaba la indemnización. Y ese fue uno de los motivos por los cuales yo pude ascender. Fue un golpe de suerte. Porque se fue gente de mucha valía dentro del ferrocarril." 589
\end{abstract}

Resulta significativo que la misma escuela que antes preparaba a técnicos para ingresar al ferrocarril, al inicio de la década de 1960 se valía del personal ferroviario para formar su

\footnotetext{
${ }^{586} \mathrm{EN}^{\mathrm{o}} 19$.

${ }^{587}$ Según los datos elaborados por López a partir de información oficial del Ministerio de Obras Públicas, en 1961 la red ferroviaria contaba con un total de 200.590 trabajadores. Al año siguiente pasó a contar con 152.153 (López et al., 2016: 317). En línea con lo que ocurrió en Junín, esto significó una disminución de alrededor del 20 por ciento de agentes.

${ }^{588}$ De 3058 trabajadores que había en Talleres Junín, se pasó a contar con 2429 agentes en 1962 (Crocco, 2010).

${ }^{589} \mathrm{EN}^{\circ} 15$.
} 
plantel docente. De acuerdo a lo que deja entrever Dall'Occhio, las representaciones que consideraban al ferrocarril como el mejor empleo de la ciudad, propias de las décadas del cuarenta y cincuenta, ya no seguían vigentes y, en su lugar, la docencia parecía ser una fuente de trabajo tan atractiva o incluso más que la ferroviaria.

Pocos años después del momento puntual al que Dall'Occhio hace referencia, Mateo Perkusic, con 15 años, ingresó a la Escuela Fábrica Yapeyú de Junín para cursar el Ciclo Técnico, luego de haber cursado el Ciclo Básico en la ciudad de Colón. Era el año 1963 y Mateo trabajaba junto a su hermano, en un taller metalúrgico. La idea de ingresar en el ciclo técnico apuntaba a mejorar sus condiciones de vida, a partir de las posibilidades que brindaba la formación. Sin embargo, a los Perkusic no les interesaba ingresar al ferrocarril. De hecho, terminó formando una empresa. En cambio, el resto de sus compañeros eran ferroviarios, en su gran mayoría mayores de treinta años y con familia, quienes apuntaban a contar con titulaciones que les permitieran promocionarse en el ferrocarril.

"En aquella época yo no quise entrar al ferrocarril porque ya no estaba funcionando como antes. El ferrocarril se venía, como quien dice, para abajo y cada vez había menos gente. Salían los que se iban y no los reemplazaban". ${ }^{590}$

Algunos ferroviarios interpretan también que la disminución del personal estuvo relacionada con la importancia que comenzó a cobrar el transporte automotor, a partir de las políticas implementadas durante el gobierno desarrollista. Pinto comenta: "El problema ferroviario empezó en la época de Frondizi, porque él trajo toda la industria automotriz. Paulatinamente fue bajando la cantidad de operarios". ${ }^{591}$ En el mismo sentido, Rinaldi recuerda:

\footnotetext{
"Hubo momentos que por retiros voluntarios se quería achicar. Por determinadas políticas que datan de mucho tiempo antes. Despacito, despacito querían hacer prevalecer el servicio de camiones, caminos. Yo diría que era norteamericano, con respecto al plan ferroviario que era de características inglesas. Porque acá a pesar de que se fabricaba mucho, venían muchas cosas de Inglaterra. En el año 60, creo, hubo un plan Larkin, ${ }^{592}$ él era un militar norteamericano. Imponía en forma lenta el deterioro
}

\footnotetext{
${ }^{590} \mathrm{EN}^{\mathrm{o}} 25$.

${ }^{591} \mathrm{EN}^{\circ} 9$.

592 El conocido comúnmente como "Plan Larkin" fue, en rigor, el Plan de Largo Alcance presentado por Frondizi en 1962, meses antes de su destitución. Fue elaborado por el ingeniero estadounidense Thomas B. Larkin. El acuerdo para iniciar el estudio se efectuó el 1 de octubre de 1960 (Schneider, 2006: 171).
} 
de los ferrocarriles y la eliminación. No hablaba de la eliminación, pero sí a su concentración mínima. Y, por otro lado, el auge de las carreteras." ${ }^{\circledR 93}$

En rigor, el plan desarrollista de Frondizi pretendía acompañar la racionalización del sistema ferroviario con una política de impulso al transporte automotor y de desarrollo de la red vial de caminos. Concretamente, en junio de 1961, el gobierno acordó un crédito con el Banco Mundial de 48,5 millones de dólares para la construcción y mantenimiento de carreteras (Schneider, 2006: 171-172).

De esta manera, la década del sesenta aparece en el imaginario ferroviario como el fin de una etapa de esplendor para el ferrocarril, el cual había sido la fuente de trabajo más codiciada de la ciudad, y su personal, los trabajadores más prestigiosos y envidiados por el resto de los asalariados. Al mismo tiempo, la pérdida de la hegemonía del ferrocarril como medio de transporte en el contexto nacional y la disminución en la calidad del servicio constituyen otros dos factores que contribuyeron a consolidar las representaciones vinculadas al deterioro del ferrocarril y a la crisis ferroviaria que se inicia en los sesenta y, que desde el imaginario, continúa en los siguientes treinta años, culminando con el cierre de los talleres del Estado y la concesión de ramales a entes privados en los noventa.

\section{La "gran huelga" en Junín: una fractura en la "familia ferroviaria"}

En el inicio de 1961 el vínculo entre el gobierno de Frondizi y los gremios ferroviarios ya era tenso, como consecuencia de la transferencia al sector privado de algunas actividades complementarias del servicio ferroviario. Con el anuncio del ministro Acevedo de clausura de ramales en junio de 1961 el conflicto se agravó aún más. A fin de octubre hubo un paro ferroviario de dos días y, como represalia, el gobierno decretó la clausura de ramales y talleres. Entre los talleres figuraban los de Cruz del Eje, Stroebel, Alianza, Liniers, Rosario, La Plata, San Antonio Oeste y Santa Fe (Lucita, 1999: 147). Esto suscitó una huelga que tuvo características particulares, por la gran adhesión en todo el país, la participación conjunta de los dos gremios ferroviarios más importantes que no solían actuar mancomunadamente y la extensión del conflicto más allá de cualquier previsión posible, a lo largo de 42 días. Tales

\footnotetext{
${ }^{593} \mathrm{EN}^{\circ} 3$.
} 
características hicieron que la huelga quedara como un hito en la historia ferroviaria argentina y un recuerdo ineludible en la memoria de los trabajadores. Además, las atrevidas y valientes acciones desplegadas fomentaron la construcción mitológica de héroes y heroínas.

Puede considerarse que existe una memoria ferroviaria que asocia la identidad del colectivo con el espíritu de lucha y solidaridad. Juan Carlos Cena, quien comenzó como ferroviario de los talleres Córdoba y tuvo una intensa vida sindical, fue quizás uno de los que contribuyó en abonar en esta construcción identitaria, a partir de una serie de libros dirigidos a un público amplio (Cena, 1998, 2002, 2008, 2009, 2012). En sus escritos, aparecen elementos que vinculan al "ser ferroviario" con el valor de la solidaridad entre los trabajadores, lo cual plantea a la reunión de pares en el marco de un sindicato como un hecho lógico y consustancial, y a las huelgas, como los acontecimientos "naturales" en que esta solidaridad quedaba plasmada.

\footnotetext{
"Ser ferruca es una identidad que lleva tiempo de construcción, que no admite ni vencidos, traidores ni quebrados y requiere en cambio de resistentes sacrificados. Estas particularidades están unidas por una fina malla tejida y entretejida en varios tiempos. Unos calmos, otros agitados y de persecución, otros más o menos. La malla se teje con hilos de solidaridad, del entramado solo se concibe teniendo un profundo sentido solidario y amor a la vida. A esto le llamamos espíritu ferroviario. Creo, creemos, que no hay espíritu ferroviario si no hay solidaridad. Al revisar la lucha de los ferroviarios, se puede apreciar que, en todos los tiempos, no hubieran podido existir sin ese entramado solidario, sin ese urdido que nos protegía (...). Nosotros los ferroviarios somos el ferrocarril... somos como somos, es decir, como fuimos; trabajadores trashumantes solidarios-constructores de nuestras propias organizaciones gremiales y sociales-protagonistas de epopéyicas luchas a través de 150 años" (el subrayado es mío; Cena, 2009: 34, 35).
}

Una de las memorias que, precisamente, le brindaron materiales simbólicos valiosos para construir una identidad ferroviaria asociada a la lucha es la huelga del 61. En este evento aparecen elementos ricos desde el punto de vista narrativo, capaces de facilitar su reproducción en el interior del colectivo: por ejemplo, el sacrificio de los trabajadores que estuvieron sin cobrar durante más de cuarenta días; la existencia de "héroes" (los ferroviarios que participaron en la huelga y algunos actores que cooperaron con ellos) y de "villanos" (los ferroviarios traidores, la policía, el gobierno); la solidaridad de trabajadores no ferroviarios que dieron legitimidad a la "causa" (comerciantes que les fiaron alimentos, la población que realizó 
donaciones, trabajadores pertenecientes a otros gremios que, obligados por las fuerzas de seguridad, se negaron a conducir los trenes en solidaridad con sus pares); la consigna de la defensa del ferrocarril planteada como "una causa de todos", a diferencia de otras huelgas realizadas por reclamos salariales.

Cena (2009) recupera relatos de lo que ocurrió durante esta huelga en los distintos centros ferroviarios del país. En Laguna Paiva, por ejemplo, destaca el rol de las mujeres, quienes antes "ignoraban su grandeza" y fueron protagonistas de "un episodio heroico y honroso". Basado en un boletín de La Fraternidad, cuenta que las mujeres "desgarraron sus ropas para empaparlas en kerosén y hacerlas antorchas", y así detener el tren que quebraba la huelga. De esta manera, estas mujeres "exhibieron el pecho descubierto a la balacera" y "con extraordinario valor hicieron retroceder a los esbirros cebados", venciendo su propio pudor para sumarse a la causa de sus maridos y así defender la fuente de trabajo de la familia ferroviaria:

\footnotetext{
"Más de treinta años pasaron, y cuando los veteranos protagonistas hablan de conceptos como virtudes morales, invocan a Homero en medio del incendio, narran el regreso de las mujeres, semidesnudas, en enaguas, en jirones, juntando los brazos en cruz para disimular su desnudez, cuentan cómo todos giraron las cabezas en sentido contrario para no mirar, se les nublan los ojos con una emoción que aún no se disipó, que sigue allí, casi intacta, en Laguna Paiva" (Cena, 1998: 160).
}

En otra de las memorias sobre esta huelga, Cena recuerda que en Rosario, en medio de una manifestación en la que los huelguistas eran perseguidos por la policía, se interpuso "una niñita de 14 años":

\footnotetext{
“Creyó que podía detener a los cosacos enardecidos. Al ver la escena, el compañero que llevaba la bandera volvió sobre sus pasos: los cosacos, sorprendidos, habían frenado los caballos. El ferroviario envolvió a la niña con su bandera, la cargó y siguió su carrera hacia un lugar seguro (...). Tiempo después, los ferroviarios quisieron homenajear la valentía de esta niña que llena de indignación había saltado a la calle para interponerse entre aquel compañero y los milicos. Le entregaron la bandera del sindicato; ella, desde ese día, fue su custodia y abanderada" (Cena, 1998: 160).
}

Cena relata otro episodio en Tafí Viejo. Los huelguistas, para evitar ser apresados por los militares, dormían en los nichos vacíos de los cementerios, en complicidad con el sepulturero. Este acontecimiento curioso permite abonar en la representación que describe a los 
ferroviarios como sacrificados, por abandonar las comodidades del hogar, y valientes, por vencer sus propios temores a la muerte y a los fantasmas del cementerio.

“...se metían ahí durante el día, respiraban por unas rendijas que les dejaban los compañeros sepultureros de ocasión. De noche, resucitaban por el hambre y el frío; como sombras entre las sombras, llegaban mujeres, hijos, amigos, a traerles comida, ropa y novedades (...) El sepulturero, aquí a contrapelo de su oficio, cuidaba vidas. Acostumbrado al silencio de las ánimas, calmaba el julepe de los visitantes que eran muy valientes, pero no tanto en cuestiones de aparecidos, resucitados, espectros y la cosa ésa de la luz mala" (Cena, 1998: 164).

Basados en estos relatos que se reprodujeron con éxito en parte del colectivo ferroviario, surgieron numerosos trabajos que analizan el impacto de la huelga del 61 en la construcción de la identidad ferroviaria. Muchos de ellos recuperan recuerdos de ferroviarios de localidades puntuales en las que el ferrocarril desempeñó un rol crucial en la vida económica, social, cultural de esa ciudad. ${ }^{594}$

Algunos ferroviarios de Junín recuerdan la huelga del 61 como parte fundamental de la historia ferroviaria, retomando una identidad asociada a la lucha y a la resistencia. Mantino, de identidad peronista, comienza el relato contraponiendo la experiencia de los ferroviarios en gobiernos populares y en gobiernos no populares. Desde su óptica, este último caso sería el del gobierno de Frondizi, el cual, aunque fue un gobierno constitucional, es recordado por movilizar o militarizar al personal ferroviario. En concreto, la movilización implicaba que el personal de la empresa adquiriera estado militar y quedara, en el caso de no obedecer determinada orden, bajo la jurisdicción castrense y sometido al Código de Justicia militar. Esto fue posible a partir de la implementación del Plan Conintes (Conmoción Interna del Estado) por el cual el gobierno pretendió desarticular protestas laborales haciendo uso de la represión estatal, otorgándole, a su vez, una amplia jurisdicción a las Fuerzas Armadas. 595

\footnotetext{
${ }^{594}$ Hay varios trabajos en Vias Argentinas (2010) que recuperan memorias sobre la huelga del 61 en Cruz del Eje (Costamagna, 2010: 201-204), Laguna Paiva (Schkolnik, 2010: 133-144; Raíces, 2010: 145-166), Tafí Viejo (Herrera, 2010: 215-238). Luisina Agostini ha publicado varios artículos sobre la experiencia de los ferroviarios de Laguna Paiva, considerando a la huelga del 61 como una acontecimiento inscrito en una historia de lucha previa que permitió forjar la identidad, no solo ferroviaria, sino de la comunidad paivense (Agostini, 2014: 109-119; Agostini, 2016: 91-119). También pueden encontrarse algunos trabajos sobre la huelga del 61 en Cena (2009) basados en las experiencias de Bahía Blanca e Ingeniero White (Miravalles, 2009: 223-240) y Laguna Paiva (Agostini, 2009: 283-298). Pueden mencionarse también otros trabajos basados en la experiencia de la huelga en distintos puntos del país: Mengascini, 2007; Castillo, 2012; Scodeller, 2007.

${ }^{595}$ El 27 de noviembre de 1958 se ordenó la movilización militar del personal ferroviario por decreto el 10.394. Los argumentos fueron que la actitud asumida por los trabajadores del riel representaba un perjuicio al orden público y que era necesario el funcionamiento normal de los servicios públicos para el bienestar de la Nación. El personal movilizado que no obedeciera a órdenes impartidas sería retirado inmediatamente de su lugar de trabajo
} 
"Fueron años duros también, cuando vinieron los golpes militares... Cuando sacaron a los gobiernos populares se nos complicó mucho. Estuvimos movilizados, tuvimos una huelga una vez de cuarenta y cinco días. ¿Por qué? Porque estaban entregando los ferrocarriles... Fue en el 61."596

Aunque Mantino recuerda la militarización del ferrocarril y la vincula directamente con la huelga del 61, es preciso aclarar que el Plan Conintes, técnicamente, no estaba en vigencia en ese momento ya que el decreto 9880/58 fue derogado el 1 de agosto de 1961. En su lugar estaba en vigencia la Ley 15.293 de Represión de las Actividades Terroristas (aprobada el 21 de julio de 1960), que consideraba a delitos comunes (antes dentro del Código Penal), tales como incendio, descarrilamiento, acopio de armas de fuego, entre otros, como "delitos terroristas" (Bisso y Carnagui, 2005). Así y todo, tales dispositivos legales implementados por el gobierno desarrollista impusieron un clima social conflictivo entre los trabajadores y las autoridades del gobierno que se pone de manifiesto en la persecución que recuerda Mantino de las fuerzas de seguridad hacia los huelguistas. Al mismo tiempo ello se condice con las memorias de la huelga de otros lugares del país, en las que se narra que los trabajadores debieron esconderse de las fuerzas de seguridad que pretendían obligarlos a trabajar:

\begin{abstract}
"Venían los cosacos, la policía y nos andaban buscando. Yo no dormía en mi casa, un día en lo de una abuela, otra en la de un amigo, otra en un campo, porque nos andaban buscando, pero principalmente a los que manejaban los trenes, ellos fueron los más perjudicados porque sí o sí los llevaban. Fueron 45 días. Algunos comercios de Junín juntaban la yerba, el azúcar para compañeros que estaban sin cobrar, a la Unión Ferroviaria. Juntaban, donaban los comerciantes porque querían que arregláramos. Fue duro." $" 597$
\end{abstract}

De esta manera, el discurso de Mantino se inscribe en otras memorias nacionales sobre la huelga que destacan la lucha conjunta de los trabajadores del riel en defensa de la fuente de trabajo y del medio de transporte, a partir de la convicción de que el gobierno frondizista era hostil hacia los ferroviarios y contrario al desarrollo del ferrocarril. Al igual que en testimonios recuperados en otros trabajos sobre la huelga, Mantino también subraya la solidaridad de los

\footnotetext{
y trasladado a institutos penales de las Fuerzas Armadas. En el juzgamiento previo intervenían un juez de instrucción militar o bien consejos de guerra especiales. (Fayó, 2007).

${ }^{596} \mathrm{EN}^{\circ} 5$.

${ }^{597} \mathrm{EN}^{\circ} 5$.
} 
comerciantes respecto de la causa de los trabajadores ferroviarios, lo que resulta una estrategia discursiva que permite otorgarle mayor legitimidad al reclamo.

Bozzini perteneció, como Mantino, a la lista verde de la Unión Ferroviaria. Su testimonio va en la misma línea al recordar al sindicalista José Piva a quien considera "un mártir":

"La huelga del 61 acá duró siete días más porque había uno compañeros cesantes y José Piva la estiró para que los reincorporaran. Se bancó los 47 días al frente de la seccional de Junín, era el presidente, luchó. Una barbaridad como amigo y como dirigente, se debía a los compañeros." 598

Algunos de los fraternales jubilados también recordaron esa huelga. "Teníamos que escondernos, porque nos querían hacer trabajar y teníamos que disparar. Estábamos en rebeldía", cuenta uno ellos, a lo cual un compañero comenta: "Mi papá me contaba que los milicos te iban a buscar a tu casa. Estaban de paro y el paro era un derecho."

Los diarios locales de la época muestran que la huelga ocupó un lugar central en la vida social de la ciudad. Diariamente, los periódicos narraron en sus páginas principales cómo se fueron desarrollando los acontecimientos, tanto nacionales como locales. Los actores que aparecen como voceros de la huelga son los dos gremios involucrados, la Unión Ferroviaria y la Fraternidad, quienes periódicamente realizaron comunicados que se publicaron en los diarios La Verdad y Democracia. En muchos de estos comunicados oficiales, los gremios rechazaron las posiciones de algunas entidades o funcionarios de la ciudad, en tanto, también valoraron el apoyo de otros actores, lo que describe un acontecimiento conflictivo, que llegó a dividir a las instituciones y población de la ciudad.

Por ejemplo, el 1 de noviembre, la Fraternidad rechazó la posición del intendente Osvaldo Pagella, quien había dicho que apoyaba la reestructuración ferroviaria y le preguntó públicamente: “¿dónde se le dará trabajo estable y dignamente remunerado a los 75.000 ferroviarios cesantes que tiene dispuesto el Poder Ejecutivo Nacional, si tenemos en cuenta que

\footnotetext{
598 Aunque no hay ninguna referencia en los diarios de la época al accionar de Piva en los últimos días de huelga, sí aparece este actor como orador y uno de los protagonistas en varios actos ferroviarios, acompañado por otros representantes de la Unión Ferroviaria y de La Fraternidad. Diez años después de la huelga, Piva iba a morir asesinado en la vía pública, en el marco de una disputa por las elecciones entre dos listas de la Unión Ferroviaria, la verde y la azul. De ahí a que Bozzini lo considere un mártir. Concretamente, el 18 de marzo de 1972 José Piva fue acribillado por representantes de la lista azul, mientras acompañaba a Lorenzo Pepe, de la lista verde. Ver: Piva, A. (18 de marzo de 2012). Hace cuarenta años asesinaron a mi viejo José Raúl Piva. Democracia. Recuperado de https://www.diariodemocracia.com/locales/junin/32803-hace-anos-asesinaron-viejo-jose-raulpiva/
} 
ya fueron cerrados 8 talleres con más de 12.000 cesantes?" ${ }^{959}$ En el mismo ejemplar del diario, la Unión Ferroviaria también cuestionó a la Sociedad de Comercio de Industria por no apoyar al gremio ferroviario: “¿Cree (...) que la desocupación de 75.000 trabajadores que crean en el país un tremendo problema de orden social les permitirá a ellos vivir con tranquilidad como componentes de la comunidad? ¿Cree (...) que está en condiciones de absorber la mano de obra? ¿Cree (...) que está exenta de responsabilidad ante el grave problema que le creará sus representados, comercios que dependen del trabajador ferroviario?". ${ }^{600}$

De esta manera, ambas organizaciones gremiales se erigieron como voceros del conflicto ante la opinión pública y presionaron públicamente a otros actores locales a apoyar la causa. Así, lograron el respaldo del bloque de concejales de la UCRI, el cual se trasladó a Capital Federal para entrevistarse con un diputado y entregar un documento al secretario técnico de la Presidencia, dirigido a Frondizi, en el cual se destacaba que Junín era "un centro ferroviario de vital importancia que adquirió relevancia demográfica y económica basado en el pivote principalísimo de los Talleres General San Martín”. Por tanto, de acuerdo al documento, cualquier medida que pueda "destruir las posibilidades de seguir manteniéndolo atentaría contra la marcha sin pausa en el camino del progreso". ${ }^{601}$ También tuvieron el apoyo de la CGT y, en un comunicado del 11 de noviembre, la Unión Ferroviaria le agradece por su participación en el paro de 72 horas, que tuvo lugar del 7 al 9 de noviembre, y señalan "la incomprensión" de los gremios que no se adhirieron. ${ }^{602}$

Por otra parte, en los diarios también pueden leerse avisos en los que la Administración de los Ferrocarriles invitaba a los ferroviarios "al egreso voluntario percibiendo, de inmediato, las indemnizaciones pautadas". ${ }^{603} \mathrm{Al}$ respecto, Mantino recuerda:

“...en el 61 ofrecían una indemnización y mucha gente se fue, porque empezaba a desaparecer parte del ferrocarril. Muchos compañeros nuestros creyeron que con esa plata se iban a salvar y al contrario. Al final la mayoría perdió, muy poco se salvaron con esa plata." ${ }^{604}$

Periódicamente, los diarios también informaban la cantidad de personas que solicitaban el retiro de la empresa, aclarando que quedaban exentos del beneficio de la

\footnotetext{
${ }^{599}$ Posición de La Fraternidad ante la carta del señor intendente. (1 de noviembre de 1961). La Verdad, p. 2.

${ }^{600}$ Comunicado de prensa de la Unión Ferroviaria. (1 de noviembre de 1961). La Verdad, p. 2.

${ }^{601}$ Gestiones sobre el problema ferroviario realizó una comisión de concejales de la UCRI. (1 de noviembre de 1961), La Verdad, p. 2.

${ }^{602}$ Comunicado de la Unión Ferroviaria. (11 de noviembre de 1961). La Verdad, p. 1.

${ }^{603}$ Ferrocarril General San Martín. (10 de noviembre de 1961). La Verdad, p. 2.

${ }^{604} \mathrm{EN}^{\circ} 5$.
} 
indemnización el personal que se hubiera plegado a la huelga. Esto permite imaginar un escenario local dividido entre dos posiciones: quienes apoyaban y sacrificaban su bienestar por la causa, y quienes rechazaban la huelga o aprovechan las oportunidades que el contexto les brindaba. A su vez, también permite reflexionar acerca de las medidas tomadas por el gobierno nacional para erosionar el acto de fuerza, las cuales, de acuerdo a los testigos, tuvieron cierto grado de eficacia.

A excepción de algunos testigos que tuvieron un rol activo en el gremio Unión Ferroviaria como los que fueron mencionados, en los ferroviarios de Junín no fue posible hallar la construcción conjunta de una memoria sobre la huelga que haya quedado ligada a una identidad ferroviaria heroica, luchadora, solidaria. Esto puede explicarse, solo en parte, porque en aquel momento algunos de los testigos pertenecían al gremio Asociación del Personal de Dirección, el cual no se plegó al reclamo. Sin embargo, tampoco esta memoria aparece en trabajadores del riel que no pertenecían en ese momento al personal jerárquico. Por ejemplo, un obrero común y afiliado de la Unión Ferroviaria, como De Giulio, lo único que recuerda de la huelga "es que estábamos todos parados". Violante, por su parte, parece quitarle legitimidad a los gremios cuando afirma que las huelgas, en general eran "más del tinte político que del tinte gremial". "Muchas eran por intereses", afirma. ${ }^{605}$

En relación a la huelga del 61, Violante recuerda que estuvieron 42 días parados, pero confunde los motivos que, de acuerdo a lo que plantearon los gremios, no eran los tradicionales, es decir, aumento de sueldo o mejora de las condiciones laborales. En este caso, las motivaciones que se señalaron eran más elevadas: la defensa del ferrocarril y de la fuente de trabajo. En cambio, Violante dice: "La huelga esa, como todas, han sido por mejoras salariales, condiciones, esto y lo otro, pero en el fondo eran cuestiones políticas". Este capataz de Electricidad equipara esta huelga con todas las demás y también confunde el año de la huelga:

-ALS: Usted me hablaba de una huelga de cuarenta días...

CV: Cuarenta y dos.

—ALS: ¿En qué época fue?

CV: Y, 68... más o menos. No te puedo decir.

—ALS: ¿Y por qué fue?

${ }^{605} \mathrm{EN}^{\mathrm{o}} 11$ y 8. 
- CV: Por problemas gremiales. Y ahí ya vinieron, por un lado el Ministerio de Transporte, por el otro lado las agrupaciones ferroviarias y no llegaron a un acuerdo. Los días se fueron pasando... Después, se arregló todo. ${ }^{606}$

El mismo sentimiento de apatía hacia los motivos del reclamo se observa en el diálogo con Valentín Martínez, carpintero del ferrocarril:

—ALS: ¿Recuerda huelgas en el ferrocarril?

—VM: Sí, una vez, no sé cuántos días estuvimos, más de cuarenta.

—ALS: ¿Usted participó en la huelga?

-VM: Sí, siempre que hicimos paro, paré.

-ALS: ¿Por qué era la huelga?

-VM: Y, paraban por cualquier cosa.

-ALS: Y aunque usted no estuviera de acuerdo, ¿adhería a la huelga?

—VM: Y, tenía que parar, porque era la mayoría no iba yo a... (el subrayado es mío).

Poch, administrativo de la sección Contable del Departamento Mecánica, recuerda con dolor la huelga del 61 y considera que "fue un error", poniéndose a distancia de otras memorias que, como se ha planteado, le otorgan a los huelguistas un valor heroico por el sacrificio que hicieron en pos de una causa noble, la defensa del ferrocarril. Esto resulta más llamativo si tenemos en cuenta que José fue delegado de la Unión Ferroviaria en buena parte de su carrera y, más tarde, siguió cumpliendo un rol en el sindicato como representante de los jubilados.

"Me acuerdo de la huelga del año 61. Estuvimos cesantes treinta días, porque nos adherimos a la huelga. Después nos dimos cuenta que cometimos un error, porque la parte administrativa no tendría que haber adherido. Si eso era del Taller. Nos arrastraron. Y, como nosotros paramos, no cobraba nadie en el ferrocarril. Nosotros le dijimos al gremio: 'Miren que si nosotros paramos, ustedes no van a cobrar por varios meses'. Tuvimos que aguantar dos meses sin cobrar. Nosotros no tendríamos que haber parado. El sueldo de la gente es sagrado, querida. Y después, tuvimos que trabajar a sobretiempo. Como estuvimos en huelga, después tuvimos que laburar más horas." ${ }^{607}$

${ }^{606} \mathrm{EN}^{\mathrm{0}} 8$.

${ }^{607} \mathrm{EN}^{\circ} 1$. 
Como Mantino, quien decía que en la huelga del 61 los más perjudicados fueron los conductores de locomotora, puede advertirse en el testimonio de Poch un intento de poner distancia de los huelguistas y sus motivos al afirmar que el reclamo "era del Taller" y que fue “arrastrado". Esto pareciera poner en cuestión, nuevamente, que el valor de la solidaridad haya funcionado como sentido aglutinante en esta huelga, de manera similar, en todos los centros ferroviarios del país. Más bien, si se tiene en cuenta que los imaginarios sociales plantean una representación totalizante de la sociedad, puede afirmarse que estos dispositivos simbólicos acerca la huelga podrían haber tenido la función de conducir a acciones comunes, a partir de las memorias de acciones ejemplares del ferroviario. Si bien esto puede haber sido eficaz en ciertos sectores, pareciera que no fue del todo exitoso en el colectivo ferroviario en su conjunto.

De la misma manera que Martínez y Violante, quienes no parecieran haber estado involucrados con los motivos enunciados sobre la huelga, otros actores que en ese momento pertenecían a la Unión Ferroviaria también parecen haber olvidado detalles fundamentales. Tal es el caso de Murgia:

—ALS: Ud. mencionó una huelga importante.

-AM: En la época de Frondizi. Creo que tenía que ver con algún cierre de ramales y alguna otra cosa. Honestamente no la recuerdo bien. Acá hicimos el paro, todo tranquilo. Lo único que recuerdo es que con un compañero nos solíamos encontrar en el Rex a la tarde a tomar un refrigerio.

-ALS: ¿Ud. pertenecía a la Unión Ferroviaria en ese momento?

-AM: Me parece que... Frondizi empezó en el 58.

-ALS: La huelga fue en el 61.

-AM: En el 61 a ver, yo no recuerdo bien pero me parece que siendo proyectista principal estábamos en la Unión Ferroviaria. Yo me acuerdo que hice la huelga con mis compañeros. No me acuerdo mucho más. No recuerdo los detalles que podrían afectar al taller, yo creo que era algún cierre de ramales y disminución de personal (el subrayado es mío). ${ }^{608}$

El siguiente diálogo con Decarre muestra que el recuerdo de la huelga no brota por sí solo, como sucede con otras evocaciones espontáneas de su historia de vida. Más bien, es preciso indagar y volver a preguntar para que el recuerdo aflore. Como Violante, muestra que confunde el año de la huelga con el gobierno de facto correspondiente a la denominada "Revolución Argentina":

${ }^{608} \mathrm{EN}^{\circ} 7$. 
-OD: en un momento la pasamos mal acá, en un momento había más militares dentro del taller que operarios, me parece que era la época de Onganía. En el año 61 hubo una huelga de cuarenta y pico de días, había militares adentro.

-ALS: ¿La recuerda?

-OD: Sí.

—ALS: Cuénteme sobre esa huelga.

-OD: Yo la padecí.

—ALS: ¿Por qué la padeció?

-OD: Porque estuve cuarenta y pico de días en mi casa.

-ALS: ¿Y por qué estuvo en su casa?

-OD: Por la huelga ferroviaria.

—ALS: ¿Y de qué era la huelga?

-OD: Los motivos en sí... no sé si me voy a acordar por qué era. No creo que sea por sueldo.

-ALS: ¿A usted lo obligaron a estar en su casa?

-OD: Sí, todo el taller estuvo de huelga. Y me parece que estaban los militares custodiando el taller.

-ALS: ¿Para qué custodiaban, para que no ingresen? ${ }^{609}$

-OD: Sería.

—ALS: ¿Por qué no iba a trabajar?

-OD: Porque estaba decretada la huelga.

—ALS: ¿La Unión Ferroviaria la había decretado?

-OD: Sí.

—ALS: ¿Y por qué los militares estaban adentro?

-OD: No sé.

-ALS: Bueno.

- OD: Pero te terminó, cuando nosotros volvimos a trabajar seguían los militares adentro.

Portaban sus fusiles, caminaban por las secciones y, cualquier acto de indisciplina te llevaban al cuartel y te pelaban. Muy típico de ellos.

-ALS: ¿Y los militares que hacían ahí?

-OD: No, no te sé decir (el subrayado es mío). ${ }^{610}$

\footnotetext{
${ }^{609}$ Esta pregunta pretendía suscitar algún tipo de reacción en el entrevistado sobre los recuerdos de aquel momento, sugiriendo que los militares estaban allí para asegurar el cumplimiento de la huelga cuando, en rigor, los militares pretendían asegurar el ingreso de los trabajadores que así lo quisieran al Taller (en contra de los huelguistas). Su respuesta desinteresada demuestra que el testigo pretende evitar referirse al recuerdo de ese momento. ${ }^{610} \mathrm{EN}^{\circ} 23$.
} 
En el diálogo con Decarre se evidencia que él, como otros actores que también adhirieron, no parece haber estado consustanciado con los motivos de la huelga y simplemente afirma haber participado por su pertenencia formal, en ese momento, a la Unión Ferroviaria. A su vez, el recuerdo de la huelga parece estar asociado a un sentimiento de dolor, por la experiencia de un período en que los militares tuvieron presencia efectiva en el ferrocarril.

Marone, quien, como personal jerárquico no adhirió a la huelga, también refiere a ese momento como doloroso para el colectivo ferroviario que, en rigor, se habría iniciado al inicio del gobierno de Frondizi, en 1958:

\begin{abstract}
"Era la época en la que estaban los militares en el ferrocarril. Porque Frondizi los hizo intervenir a los ferrocarriles. Entonces aplicó una política propia del cuartel. Les cortaban el pelo a los que llegaban tarde, cosas así. Hubo una huelga muy grande de cincuenta y pico días cuando estuvo Frondizi. En la época en que estaban los militares interviniendo, fueron a parar a la cárcel de Caseros un montón de ferroviarios. Los militares agarraban a los activistas. La mayoría de la Unión Ferroviaria, pero también había de La Fraternidad. El que hacía huelga, el que paraba, el que era activista, el que iba a arengar a los demás... mucho zurdo, aprovecharon a meter en cana a muchos zurdos. Y caían de otro lado también, radicales. Los gobiernos militares aplicaban disciplinas que estaban acostumbrados en el cuartel. Acá costaba aceptar esa forma en la empresa" (el subrayado es mío). ${ }^{611}$
\end{abstract}

Rinaldi también recuerda de una manera dolorosa la intromisión de los militares en los asuntos ferroviarios:

\footnotetext{
"A los que entraban tarde que entraban, los llevaban a los cuarteles y los pelaban. Sí, los pelaban. Le pasaban la máquina. Los llevaban en un camión a los cuarteles y allá le cortaban el pelo. Y después al mediodía ya lo largaban y al otro día seguían. Eso es una arbitrariedad, no se puede hacer. Que lo suspendiera, que tomara otra medida. Pero ¡cargarlo en un camión! ¡Y volverlo a traer! Después el antecedente que le quedaba en la foja de servicio... No lo considero correcto. Hay muchas formas de aplicar sanciones, pero no tan humillantes. No con una persona que trabaja y que accidentalmente se encontró que se durmió ese día. Cuando estaban ellos era bravo, era bravo. Después recorrían las secciones. Y si encontraban alguno sentado... aplicaban severas medidas.
}

${ }^{611} \mathrm{EN}^{\circ} 22$. 
Suspensión y eso. O dormitando, también. Y algunos los han echado también. Yo igual nunca tuve problemas con los militares Tampoco estaba cerca de ellos (risas)." ${ }^{612}$

La experiencia de los ferroviarios de Junín en relación a la etapa de la movilización parece haber sido similar a la de otros trabajadores del riel de otros puntos del país. Como la de Cena, en Talleres Córdoba quien relata, por un lado, lo vivió como observador y, por el otro, las consecuencias que personalmente experimentó por haber llegado tarde al Taller:

"Los milicos llegan y se instalan en depósitos, talleres, estaciones, en todas las oficinas de personal. Controlan la asistencia, el aliento y el olor a pata. Quieren controlar todo (...). Entre los milicos, el reglamento y los alcahuetes, actualizan las listas, controlan las llegadas tarde, las ausencias sin aviso, las enfermedades. Todo se sanciona, se aplican arrestos en el propio taller. Hay cortes de pelo y algunos encanados (...) Un día, me quedé pegado a la sábana y llegué tarde (...) Un oficial controlaba a cada uno de los que llegaba tarde y disponía, por la cara, si ibas al vagón o no. Cuando me tocó el turno, encaré, subí, y en un escritorio vi al oficial que interrogaba. Preguntó el motivo de mi llegada tarde, dónde vivía, mi oficio y una serie de nimiedades (...) Yo escuchaba su exposición pedagógica, apoyado en una cadera, displicente y tranquilo. Hasta que dijo que ellos habían venido para enseñarnos a trabajar. Instantáneamente salí del letargo; me salió un ¡ah! que sonó como un eructo. Me reía como los ventrílocuos, con la panza. Al uniformado se le desencajó el rostro y gritó de corrido: Cinco días de arresto en el depósito, y lo pelan" (Cena, 1998: 119).

Todos estos recuerdos de los actores permiten interpretar que la presencia de los militares en los talleres ferroviarios a partir del gobierno de Frondizi generó rechazos en los trabajadores ferroviarios, cualquiera haya sido la pertenencia gremial. En el caso de los trabajadores de los escalafones más bajos, porque imponía sanciones no habituales y, como dice Rinaldi con precisión, muy humillantes. En el caso del personal de dirección porque, por un lado, cuestionaba un reglamento consensuado por el conjunto que establecía qué faltas debían castigarse y cuáles eran las sanciones estipuladas para cada una de ellas. Por el otro, porque a pesar de su rol de personal jerárquico, ellos habían iniciado sus carreras de la misma forma que sus pares, como trabajadores rasos, quienes ahora sufrían el castigo por parte de agentes extraños a la empresa. Por tanto, existía un sentimiento de identificación por una

${ }^{612} \mathrm{EN}^{\mathrm{0}} 3$ 
historia compartida y, en ese sentido, el daño que se le infringía a un trabajador del riel, cualquiera fuera posición en el organigrama, no les era ajeno.

Estas experiencias dolorosas relacionadas con la presencia de los militares en el ferrocarril pueden haber provocado que algunos actores - como Decarre o Murgia - eviten referirse al tema puntual de la huelga en el contexto de la entrevista. Incluso, podrían explicar la falta de precisión en relación a los acontecimientos del resto de los actores. Sin embargo, es posible que no sean la única causa del "olvido" o supresión del recuerdo de estos ferroviarios.

En sus escritos, Cena brinda algunas pautas que permiten interpretar que el acontecimiento de la huelga, a la vez que brindó experiencias que permitieron abonar en una identidad ferroviaria asociada a la lucha nacional, también suscitó conflictos en el interior del colectivo ferroviario que se mantendrían en los años subsiguientes. Por ejemplo, cuando rememora, con un lenguaje que evidencia su desaprobación hacia otros trabajadores del riel, que durante el gobierno frondizista se intentaba hacer correr trenes, "conducidos por krumiros reclutados entre la escoria y carneros del personal de dirección, o de otros sindicatos, que perjudicaban la huelga por vocación" (Cena, 1998: 159). O cuando especifica que un tren que pasaba por Mechita, "conducido por carneros y custodiado por cosacos", fue detenido por una marcha de mujeres (Cena, 1998: 161). O cuando ironiza que en Villa Luro, en el contexto de la huelga, se abrió una "escuela de krumiros" en la que se dictaba "cursos de krumería práctica" (Cena, 1998: 163). El relato de la huelga que Cena realiza establece una división tajante entre, por un lado, los fraternales y los sindicados en la Unión Ferroviaria que, según él, fueron los que llevaron adelante el sacrificio (los héroes) y, por el otro, los trabajadores señaleros y del Personal de Dirección (los traidores). Es posible que estos conflictos en el interior del colectivo y de la comunidad de Junín, sean claves para entender por qué los recuerdos de la huelga no se consolidaron localmente y se pretendieron suprimir.

Cena critica que la Asociación de Personal de Dirección, en 1957, se realizó en el contexto de la persecución a peronistas, luego del derrocamiento de Perón: "Mientras a unos los ilegalizaban y los corrían a palos, o los movilizaban, a otros se los premió con una partida de nacimiento". Posteriormente, durante el gobierno de Frondizi los integrantes de este agrupamiento no adhirieron a la huelga y hasta la habrían intentado boicotear de diversas maneras en retribución al pago de un retroactivo que el gobierno les abonó:

"En una solicitada, el carneraje insta a los compañeros a solidarizarse con las autoridades y recomienda a sus afiliados que se presenten a conducir los trenes de emergencia. Felizmente, la solicitud fracasó y ellos quedaron ante todos, ferroviarios 
y pueblo, como cómplices. Habían recibido, a cambio del gesto, un jugoso aumento salarial con retroactividad al año 60" (Cena, 1998: 167).

La falta de adhesión a la huelga de los señaleros fue, según Cena, más dolorosa para el conjunto ferroviario:

\begin{abstract}
"La actitud de engrosar las filas lanudas en forma orgánica, con ferroviarios, jodió, porque, aunque fueran de otros sindicatos, estos hombres eran parte de la familia. Los de Dirección, como los tíos lejanos, pero los señaleros no. Hasta ayer habían vivido en el mismo rancho, habían sido nuestros hermanos" (Cena, 1998: 167).
\end{abstract}

El relato de Cena pone en evidencia los conflictos preexistentes que la huelga profundizó y los nuevos que suscitó en el interior del colectivo ferroviario, estableciendo una separación, desde la óptica de quienes defendieron el acto de resistencia, entre los que adhirieron y los que no, entre ferroviarios auténticos y traidores (carneros, krumiros, lanudos). Sin embargo, es preciso advertir, como fue expuesto en algunos de los testimonios locales, que no todos los que adhirieron desde la Unión Ferroviaria lo hicieron por convicción, lo cual pone en entredicho la representación imaginaria que evoca la huelga como acto de resistencia monolítica de los trabajadores del riel en defensa de la fuente del trabajo y del medio de transporte.

Esa separación o distancia que ilustra Cena cuando nombra a los "tíos lejanos" dentro de la familia ferroviaria, en alusión a los del personal de dirección, también es autopercibida por quienes eran parte de este agrupamiento en la ciudad de Junín. Por ejemplo, cuando se le pregunta a Crocco por la huelga del 61, el ferroviario aclara con cierto orgullo: "Yo no participé de la huelga porque era personal de dirección". Marone, por su parte, proyecta su identidad como integrante del personal jerárquico a partir del modelo de estructura empresarial que regía en la etapa en que el ferrocarril era de capitales británicos: “Como éramos personal de dirección era como si fuéramos los patrones y los patrones tenían que estar presentes”. En la misma línea, Ferrari comenta:

\footnotetext{
"En el año 61, hubo una huelga general, como de tres meses. Que entraron los militares adentro, y a mí me iban a buscar a mi casa la policía para hacer guardia. Porque los puestos claves tenían que estar... yo era ahí personal de dirección" (el subrayado es mío). ${ }^{613}$
}

\footnotetext{
${ }^{613} \mathrm{EN}^{\circ} 4$
} 
Rinaldi también pone distancia del conflicto en función de su pertenencia a la Asociación del Personal de Dirección de Ferrocarriles Argentinos (APDFA):

\begin{abstract}
"La de Frondizi fue porque echó como a ochocientos ferroviarios, de cada línea. Acá de talleres eran como ochocientos y pico. En ese caso los sueldos estaban bien... Me parece que esta huelga fue porque la política de reducir personal obrero. Igual, no recuerdo mucho porque yo pertenecía al personal de dirección, ya. No participaba. El personal de dirección no participó de la huelga. El personal obrero, más que nada. Nosotros igual íbamos, no había nada que hacer. No me acuerdo mucho..." (el subrayado es mío). ${ }^{614}$
\end{abstract}

Aun siendo Marone y Rinaldi, en ese momento, de APDFA, parecen estar mejor informados de los motivos de la huelga que muchos de los representados de la Unión Ferroviaria, como Violante, Martínez o Decarre, que dicen no recordar los motivos de la huelga o los confunden. El exjefe de Mecánica, rememora:

\begin{abstract}
Las huelgas en general eran por mejoras salariales. Pero en la época de Frondizi el argumento no era tanto ese. La política ferroviaria que quería aplicar era resistida. Si no, en general, eran por cuestiones salariales y de alguna forma se arreglaban. Pero en lo que hace a la política empresarial, una de las huelgas más importantes que a mí me tocó vivir, fue en la época de Frondizi." ${ }^{615}$
\end{abstract}

A su vez, el siguiente diálogo con Marone tiene la virtud de explicitar con claridad la existencia conflictos en el interior del colectivo ferroviario y de la comunidad de Junín, a partir de la huelga del 61:

—ALS: ¿Cómo fue el acatamiento en Junín?

-IM: Fue importante. Acá el único gremio que no adhirió era el personal de dirección, te diría. Yo ya era, por eso me pararon en la esquina para no dejarme ir a trabajar. Había piquete de los huelguistas que no querían... éramos pocos los que íbamos a trabajar porque el personal de dirección no éramos muchos. El personal de dirección no adhirió, entonces había que ir a trabajar y soportar un poquito. Después los milicos pusieron muchos controles alrededor del ingreso, para que no se arrimaran los huelguistas a

${ }^{614} \mathrm{EN}^{\mathrm{o}} 3$.

${ }^{615} \mathrm{EN}^{\mathrm{o}} 14$. 
querer coartar los que iban a trabajar. Éramos los que estábamos en las jefaturas, tanto del taller como de la oficina. No sé qué otro dato querés.

—ALS: Ya está un poco cansado. ¿Quiere que cortemos?

-IM: No, no, para nada.

-ALS: ¿Cómo hicieron para suplantar a los conductores?

-IM: Ese fue uno de los problemas, como el personal de dirección no adhirió a la huelga, los militares te obligaban a correr los trenes. Te daban un curso rápido de manejo de las locomotoras, a mí no me tocó gracias a Dios, pero tuve compañeros que tuvieron que ir a manejar los trenes.

—ALS: ¿Y ocurrió algún accidente?

-IM: No, accidente no. Pero hubo mucho disgusto. Acá nos conocemos todos. Mirá aquel fue a manejar un tren, qué carnero que es. Esas cosas son inevitables. ${ }^{616}$

De esta manera, Marone evoca el clima de tensión que caracterizó a estas siete semanas $\mathrm{y}$, en un momento del diálogo, hasta parece ofuscarse por el intercambio que lo conduce al recuerdo de aquel evento, cuando dice con cierta brusquedad: "No sé qué más querés saber". Al mismo tiempo, el exjefe de Mecánica deja entrever que, durante este conflicto, el personal jerárquico debió soportar presiones de distintas direcciones que pretendían conducir su accionar: por un lado, de los militares que los obligaban a realizar cursos para reemplazar a los maquinistas, lo cual era una acción que pretendía socavar la huelga; del mismo gremio que los nucleaba desde hacía cuatro años y les indicaba que debían presentarse a sus puestos de trabajo; de los propios compañeros ferroviarios de Tráfico, Talleres y Mecánica, integrantes de la Unión Ferroviaria y La Fraternidad, que claramente censuraron su acción, algunos de los cuales los trataron abiertamente de "carneros".

Aunque muchos ferroviarios optan por no evocar o no recuerdan estos conflictos, siendo Marone el único que hace referencia a ellos, la reconstrucción que hacen los diarios locales parece indicar que la rivalidad entre los directivos, por un lado, y los integrantes de la Unión Ferroviaria y La Fraternidad, por el otro, alcanzó una magnitud importante en esos momentos. En los primeros días de diciembre y a más de treinta días del inicio del conflicto, se publicaron avisos con listas de trabajadores de los que se "prescinde de su servicio", arguyendo el motivo en la "reestructuración ferroviaria" que diseñó el gobierno. ${ }^{617}$ Entre ellos se encontraban militantes y delegados de ambos gremios, a los que se los invitaba a presentarse

\footnotetext{
${ }^{616} \mathrm{EN}^{\mathrm{o}} 22$.

${ }^{617}$ Ferrocarril General San Martín. Comando de Coordinación y Seguridad en el Transporte. (3 de diciembre de 1961). La Verdad, p.2.
} 
para que les sea abonada la indemnización. Las extensas listas publicadas fueron firmadas por el Comando de Coordinación y Seguridad de Transporte de la Empresa de Ferrocarriles del Estado “General San Martín”. Días después, La Fraternidad y la Unión Ferroviaria emitieron una solicitada conjunta en la que denunciaron a la jefatura de "cómplice" para la confección de las listas “con el representante de coordinación”. En una muy dura misiva los acusaron de "alcahuetes" y "serviles" por haber causado un "tremendo dolor" en los cesanteados y sus familias. A su vez, invitaron a la comunidad a que se sume a la repulsa: "Repudiamos y solicitamos al pueblo de Junín que así lo haga con estos energúmenos que hacen vista gorda y oídos sordos a los graves problemas que estos hechos provocan y olvidándose que ellos también pertenecen a la familia ferroviaria". A continuación, mencionaron nombres específicos de personas que, en ese momento, tenían cargos jerárquicos y habría actuado en la confección de listas, tales como como Sebastián Roqués, Luis Ceva, Nicolás Marotta, Ralph Jackson, Pedro Mendiburu, entre otros, considerando que actuaron con "insensibilidad" y prestando un servicio que estaba fuera de escalafón. ${ }^{618}$ Esta solicitada permite imaginar un clima de tensión que fue mucho más allá del recuerdo de Marone que, en la primera parte del diálogo, rememora que en esos días solo "hubo que soportar un poquito".

Es posible advertir entonces, el contraste entre las dimensiones que adquirió el conflicto entre los trabajadores, según los diarios locales, y lo poco que los testigos son capaces de evocar al ser entrevistados. Esto último puede explicarse porque luego de que el conflicto se resolvió con la reincorporación de los cesanteados, tanto unos como otros debieron seguir conviviendo en la empresa: los que habían soltado toda una serie de calificaciones ("energúmenos", "alcahuetes", "serviles") hacia sus superiores con aquellos que, supuestamente, habían colaborado en la confección de listas e intentado sabotear el acto de resistencia emprendido por los gremios ferroviarios más importantes. ${ }^{619}$

Según Portelli, la memoria es una constante búsqueda de sentido que entrega al olvido lo que no tiene significado en la actualidad, pero también lo que tiene "demasiado significado". De esta manera, existen memorias no olvidadas, sino suprimidas, que reaparecen "en formas perturbadoras" cuando se suelta el control: "La memoria es también — diría casi sobre todo, o en todo caso más útilmente- algo que sirve para molestarnos, para poner en duda las certidumbres que nos tranquilizan". Gracias, entonces, a que la memoria no puede controlarse del todo y que, en determinados momentos, aflora lo que perturba, es posible, según el autor,

\footnotetext{
618 Solicitada. Unión Ferroviaria y La Fraternidad. (9 de diciembre de 1961). La Verdad, p. 2.

${ }^{619}$ La solución del conflicto habría ocurrido el 15 de diciembre: Solución del diferendo ferroviario. Se dispuso la reincorporación ayer de todos los cesanteados (16 de diciembre de 1961). La Verdad, p. 1
} 
"comprender mejor quiénes somos y a través de qué procesos nos hemos vuelto los que somos" (Portelli, 2013: 3-10).

En ese sentido, puede considerarse que la huelga del 61 constituye una memoria perturbadora porque pone en evidencia una fractura de la comunidad ferroviaria de Junín y cuestiona el imaginario de "familia ferroviaria" unida y sin fisuras. Ese "disgusto" entre ferroviarios al que refiere Marone al final del diálogo, que muchos otros se ven imposibilitados de rememorar, o simplemente evitan, podría, siguiendo a Portelli, contribuir en la comprensión del proceso posterior que tiene lugar durante las tres décadas siguientes y que, finalmente, deviene en un acontecimiento insoslayable, el que, precisamente, causa más dolor entre los trabajadores del riel porque pone fin definitivo a la familia ferroviaria: el cierre de Talleres y la concesión de las líneas en la década del noventa.

\section{De plan en plan: proyectos para mejorar el servicio y disminuir el déficit ferroviario}

Waddell sugiere que ninguno de los actores puede considerarse un triunfador de "la gran huelga ferroviaria", ya que mientras Frondizi fue destituido de su cargo tres meses después, los gremios siguieron reclamando por el cierre de algunos ramales y la reducción paulatina de personal (López et al., 2016: 178). El análisis de Cena va en la misma línea ya que considera que "se ganó parcialmente": "60.000 ferroviarios se fueron a través del encanto de las indemnizaciones, fue el primer síntoma del debilitamiento de la robustez de la fortaleza de los trabajadores del riel" (Cena, 2008: 138). Al mismo tiempo, el surgimiento del transporte automotor como alternativa durante los 42 días de huelga, implicó la reducción drástica posterior del transporte ferroviario de cargas y de pasajeros (López et al., 2016: 178). En definitiva, el ferrocarril iba perdiendo su importancia como medio de transporte en el país.

Puede considerarse al Plan de Largo Alcance como un intento de brindar algún tipo de solución por parte del gobierno a lo que consideraba el "problema ferroviario". Presentado inmediatamente después de la finalización de la huelga, en febrero de 1962, el plan contemplaba el cierre de doce talleres ferroviarios, el despido de casi 60.000 empleados, la reducción de ramales improductivos y el reemplazo de materiales rodantes obsoletos y locomotoras a vapor por tecnología moderna. Waddell califica a este plan, de "ambicioso" porque planteaba un plan de acción a diez años y, al mismo tiempo, contenía un estudio integral del transporte en Argentina que incluía, además del ferrocarril, a los caminos y a la navegación. Para llevarlo adelante se preveía la financiación externa a través de un crédito al Banco Mundial, además de la reasignación de recursos a partir de la venta de chatarra de materiales 
obsoletos. Este plan, también denominado "Plan Larkin" en alusión al ingeniero norteamericano que llevó a cabo los estudios, obtuvo un rotundo rechazo por parte de los gremios ferroviarios y nunca se llevó adelante. De hecho, a poco más de un mes de su presentación, Frondizi fue derrocado por un golpe militar (López et al., 2016: 179-181). Así y todo, el Plan Larkin fue convertido por las memorias ferroviarias posteriores en un símbolo de la ofensiva del gobierno nacional hacia el ferrocarril durante la etapa de conflicto, cuando, en rigor, su presentación fue ulterior a la huelga ${ }^{620}$ Incluso, se asocia el cierre de ramales con la implementación de este plan, lo cual constituye un error histórico habitual. ${ }^{621}$

Durante el gobierno de Arturo Illia se llevaron a cabo algunas mejoras que tuvieron como meta modernizar el servicio, como la incorporación de material rodante y la finalización de los talleres Spurr, los primeros diseñados para la reparación y mantenimiento de locomotoras diésel eléctricas. Al mismo tiempo, la oferta de pasajeros aumentó considerablemente y se reabrieron solo algunos de los ramales clausurados por Frondizi, apuntando con ello a distender la relación con los gremios. También se establecieron algunos servicios de pasajeros rápidos y con mayor confort, como "El Aconcagua" o "El Aconquija". Además, se formuló un plan de acción para el ferrocarril desde el Consejo Nacional de Desarrollo (Conade), presentado oficialmente en 1965, que pretendía mejorar la eficiencia, mediante la incorporación de tecnología moderna y un régimen tarifario apropiado, previendo un aumento de la carga por un crecimiento de la economía. Estos planes quedaron en suspenso, como consecuencia del derrocamiento de Illia (López et. al, 2016: 182-183).

El nuevo presidente de facto Carlos Onganía puso al frente de Ferrocarriles Argentinos a Juan Carlos De Marchi, quien estuvo en la empresa entre 1967 y $1971 .^{622}$ Su gestión es recordada especialmente entre algunos ferroviarios de Junín que evocan visitas de este presidente al Taller y su apoyo a diversos proyectos locales. Algunos explican este vínculo humano y laboral amistoso por la familia de procedencia de De Marchi, que, según aseguran, era juninense. También consideran que su gestión fue muy buena para Junín y para el ferrocarril en general, como consecuencia de que este militar tenía familiares ferroviarios y, por tanto,

\footnotetext{
${ }^{620}$ Durante los días de huelga, los diarios consultados de la época no hacen alusión a la intención del gobierno de implementar el Plan de Largo Alcance o Plan Larkin, lo cual sugiere que la construcción que asocia este plan con el conflicto fue posterior.

${ }^{621}$ Este error se reprodujo en algunos libros que recuperan memorias ferroviarias de la huelga del 61 y también en El Ferrocidio de Cena (2008), quien comenta que "el 22 de marzo de 1961 fue presentado oficialmente al Ministro de Obras y Servicios Públicos, don José Mazar Barnet, los resultados de los estudios de un informe que llevaba el nombre de Transportes Argentinos, Plan de Largo Alcance". Si bien es cierto que el Plan fue presentado durante la gestión de Mazar Barnet, esta comenzó recién el 16 de enero de 1962.

622 Murió el general Juan Carlos De Marchi (25 de octubre de 2004). Recuperado de http://bassoenlared.com.ar/noticias/1276-MURIO-EL-GENERAL-JUAN-CARLOS-DE-M.htm: 30/6/2020.
} 
conocía al ferrocarril. Marone asegura: "Era hijo de un jefe del taller de Junín. Como el padre era ferroviario él tenía mucha vinculación con el ferrocarril." ${ }^{263}$ Dall'Occhio, en cambio, dice que su abuelo (y no su padre) era ferroviario juninense. Como Marone, él también recuerda especialmente su gestión por los proyectos que pudieron implementarse:

\begin{abstract}
"En esa época hicimos unas cuantas obras de mucho presupuesto. Eso se lo debemos a De Marchi, que era un militar ferroviario de Junín, digo ferroviario porque tenía alma de ferroviario, venía de un abuelo ferroviario y le dio mucho impulso. Se hicieron unas cuantas obras importantes que nos permitieron desarrollar trabajos, prolongamos, instalamos vías." 624
\end{abstract}

Al igual que sus compañeros, Crocco destaca la gestión de este militar por sobre el resto. Su testimonio sugiere la importancia que los vínculos personales habrían cobrado en esta etapa floreciente para el ferrocarril en Junín, algo que es sugerido por muchos testigos:
"Me quiero referir a una administración que para mí fue muy buena. La que tuvimos en el año 68 hasta el año 73, creo. La del general De Marchi, que era oriundo de Junín, con el que estuve después de haberse retirado por una cosa extraferroviaria. Porque él era presidente de la Asociación de Tiro Deportivo y mi hijo practicaba tiro, entonces me encontré con él". ${ }^{625}$

Aunque los tres actores antes mencionados sugieren que De Marchi había nacido en Junín, los datos hallados en otras fuentes informan que el militar lo había hecho en la ciudad de Buenos Aires. ${ }^{626}$ En rigor, el nombre completo del presidente de Ferrocarriles, el cual no usaba públicamente, era Juan Carlos De Marchi Sexton, ya que su madre era Adela Amanda Sexton, quien sí había nacido y vivido en la ciudad. ${ }^{627}$ Es decir, el vínculo con la ciudad era, en principio, a través de los familiares por vía materna. En relación al vínculo con el ferrocarril, al menos tres de sus tíos y hermanos de su madre, Alfredo, Alberto y Miguel Sexton habían sido ferroviarios de las dependencias locales de la línea San Martín. ${ }^{628}$ Por otra parte, por la vía

\footnotetext{
${ }^{623} \mathrm{EN}^{\circ} 22$

${ }^{624} \mathrm{EN}^{\circ} 26$.

${ }^{625} \mathrm{EN}^{\circ} 2$.

626 Falleció el general (R) De Marchi (29 de octubre de 2004). Recuperado de https://www.lanacion.com.ar/politica/fallecio-el-general-r-de-marchi-nid649224/

627 Álvarez Uriondo (s.f.) Juan Carlos De Marchi Sexton. Recuperado en https://gw.geneanet.org/gentuc?lang=es\&p=juan + carlos\&n=de + marchi + sexton

${ }^{628}$ De acuerdo a María Emilia Sexton, Alberto, su padre, llegó a ser jefe de sección en el Departamento Mecánica y Miguel, su tío, jefe de división. En tanto, un diario de la época informa que Alfredo Sexton fue colaborador
} 
paterna, el padre de Juan Carlos De Marchi, Eugenio De Marchi, habría sido jefe de estación en la provincia de Mendoza de la línea San Martín. ${ }^{629}$ Es decir, el vínculo de De Marchi con el ferrocarril era tanto por vía materna como paterna. María Emilia Sexton, prima del General, intenta ilustrar con una anécdota los profundos sentimientos que unían al militar con el ferrocarril y las convicciones que tenía acerca del rol que el medio de transporte debía ocupar en el desarrollo nacional:

"Él fue durante mucho tiempo secretario general de la Asociación Latinoamericana de Ferrocarriles. Cuando cumplió 80 años, en el año 1999, yo viajé a Buenos Aires para celebrarlo. Para que te des una idea de lo importante que era para él el ferrocarril, le habían hecho una torta con un ferrocarril a escala". ${ }^{630}$

Otra anécdota de Crocco parece revelar que el padre del general, Eugenio De Marchi, supo vincularse con los ferroviarios del Taller, requiriéndoles algunas de sus habilidades:

\begin{abstract}
"Me acuerdo que cuando De Marchi visitó los Talleres Junín fue al Cuarto de Herramientas y le preguntó jocosamente a Osvaldo Méndez: ‘¿Siempre hacen changas acá?', a lo que este le contestó: ‘Nosotros no hacemos changas’. De Marchi se río y le replicó: ‘¿No se acuerdan que le hicieron la mira ortóptica a mi papá para el fusil?"”. ${ }^{631}$
\end{abstract}

Este recuerdo de Crocco sugiere que el General tenía un conocimiento profundo de las prácticas ferroviarias, al remitirse a partir de códigos propios de la escala más baja del colectivo ferroviario. Las “changas" eran los trabajos que realizaban los ferroviarios, haciendo uso de las instalaciones y recursos del Taller, pero con fines personales. Eran prácticas prohibidas por las normativas oficiales, pero aceptadas como legítimas por parte del colectivo. De Giulio describe esta contradicción con claridad: "Las changas estaban permitidas. Pero no para vender, sino para vos, para la casa. Había que tratar de que no te vieran los jefes. Pero igual ellos sabían que vos lo hacías." 632 De esta manera, el militar, al referirse a estas acciones cotidianas de los

\footnotetext{
directo del jefe del departamento de Mecánica Federico Taylor. Ver: Asumió el nuevo jefe del Departamento de Mecánica del FCSM. (2 de octubre de 1969). La Verdad, p. 1.

${ }^{629}$ Agradezco los aportes de María Emilia Sexton, prima del General, en relación a los vínculos del militar con la ciudad y con el ferrocarril, a través de un contacto telefónico que tuvo lugar el 3 de agosto de 2020. También agradezco a Alfonsina Iacullo por haberme facilitado el contacto.

${ }^{630}$ Testimonio telefónico con María Emilia Sexton, 3/8/2020.

631 Testimonio telefónico con Aymar Crocco, 5/8/2020.

${ }^{632} \mathrm{EN}^{\circ} 11$.
} 
trabajadores que se realizaban de manera oculta parece, por un lado, favorecer un acercamiento entre él y los operarios comunes, matizando las diferencias jerárquicas. Al mismo tiempo, le está mostrando que su saber es vasto y minucioso, y no circunscrito a las políticas ferroviarias. Puede interpretarse casi como una advertencia dirigida al resto del personal: a pesar de su alto rango, ninguna acción de los ferroviarios escapa a su control y conocimiento.

En relación a la gestión del general De Marchi como presidente de Ferrocarriles Argentinos, Waddell la divide en dos etapas, cuyas políticas, según el autor, resultaron contradictorias entre sí. Durante los primeros dos años de administración se ampliaron los servicios de pasajeros de manera notable, a costa de una sobreutilización del material rodante. Esto tuvo como principal consecuencia que la mayoría de las locomotoras diésel para 1968 se encontraran fuera de servicio, lo que implicó el reacondicionamiento de viejas locomotoras a vapor. En la segunda etapa, en cambio, se eliminaron o disminuyeron las frecuencias de trenes de pasajeros con muchos ramales secundarios, así como se ampliaron los servicios en las líneas troncales, apareciendo algunos servicios de mayor velocidad y confort (López et al., 2016: 184). Un ejemplo de ello fue "El Libertador", que salía de Buenos Aires hacia Mendoza y San Juan y se promocionaba, en aquel momento como "un expreso decorado con el mejor gusto y disfrutando de la atención más eficiente", contando con "coches pullman totalmente alfombrados con sillones reclinables", "camarotes diseñados para transformarse en íntimo saloncitos", ofreciendo el servicio de Snack Bar, "comedor de primera categoría", sala de lectura y "atención a cargo de atentas ferromozas". 633 En definitiva, la nueva política de la administración de De Marchi apuntaba a desalentar el tráfico de los trenes de poca demanda y ampliar y mejorar la oferta de las líneas troncales.

A nivel organizacional, una importante transformación operó durante la gestión de este general y presidente de Ferrocarriles Argentinos mediante la creación de un organismo central superior que, de acuerdo a Waddell, implicó la competencia entre este y las gerencias de las seis líneas, creando, en términos del autor "una instancia burocrática más que conspiraba con la eficiencia del sistema” (López et al., 2016: 184). Rinaldi recuerda este cambio: "Cuando se hicieron cargo del ferrocarril los militares habían seis líneas ferroviarias, que empezaron a depender de un ente central en Buenos Aires, en Retiro." 634

A escala local, durante este período también tuvieron lugar transformaciones en la estructura empresarial. En concreto, en 1968 Talleres Junín fue dividido en tres, lo cual también

\footnotetext{
${ }^{633}$ Ferrocarriles Argentinos (s.f), El Libertador, folleto, (Archivo Universitario Roberto Di Marco).

${ }^{634} \mathrm{EN}^{\mathrm{o}} 3$.
} 
implicó una división espacial en el predio: Taller de Coches y Vagones, ${ }^{635}$ Taller de Coches Motores, Taller de Fabricaciones Varias. En general, estos cambios son interpretados favorablemente por los ferroviarios locales, quienes asocian el período con una etapa de modernización de la empresa y de crecimiento para el centro ferroviario de Junín. Ferrari recuerda: "Una vez vino un ingeniero de Buenos Aires que tenía nuevas ideas. Transformó el taller e hizo tres talleres. Había tres jefes de talleres." Murgia asocia este cambio en la estructura empresaria con la implementación de prácticas innovadoras en relación al trabajo:

"Vino una etapa en que se hizo una transformación grande en el ferrocarril. Se dividió el taller en tres. Uno de coches, otro de coches motores y otro de fabricaciones varias. Se llegó a hacer un alambrado perimetral para dividir los sectores. Eso habrá sido por el año 68. Y creo que aproximadamente eso habrá durado hasta el 72, los tres talleres con sus equipos directivos independientes. Bueno, cuando se hizo esa división, hubo mucho movimiento, porque también se intentó cambiar el sistema de reparación de los coches que era lo más fundamental del taller." ${ }^{636}$

Rinaldi, a diferencia de sus compañeros, cuestiona este cambio que habría tendido a complejizar la estructura burocrática de la empresa:

"En ese tiempo había un taller de casi tres mil personas, dos mil ochocientas y los militares dijeron: 'Es una barbaridad que haya un jefe de talleres y veinticuatro ayudantes de dirección para un taller tan grande' ${ }^{637}$ Entonces lo dividieron en cuatro talleres, con tres talleres principales. El de Coches motores, el de Coches y vagones, y el de Fabricaciones. O sea, cada cual agrupando sus especialidades de producción. Y otro aparte: Mantenimiento, de menor categoría que los otros tres talleres. O sea que había tres jefes de talleres y un jefe de mantenimiento, de menor categoría. Pero a eso le dio a cada uno, una oficina técnica, una oficina especial, todo. ¡De veinticinco, pasamos a ser ciento cuarenta jefes! Jefes me refiero, con categoría de oficina primera, segunda, sección primera, segunda, tercera, división tercera, segunda, primera y departamento, departamento segundo.”638

\footnotetext{
${ }^{635}$ En 1970 cesó la reparación de vagones y la totalidad de los recursos fue volcada a la reparación de coches de pasajeros de la línea San Martín y Sarmiento. Esta observación fue tomada de una monografía que perteneció a la empresa y que está disponible en el Archivo Histórico de Junín, a partir de una donación de Eridé Rinaldi. Agradezco a la directora del mencionado Archivo, Alfonsina Iacullo, por la referencia citada. [Rinaldi, E. (22 de abril de 1977). Talleres Junín. (monografía). Archivo Histórico de Junín].

${ }^{636} \mathrm{EN}^{\circ} 7$.

${ }^{637}$ En 1967, Talleres Junín contaba con 2583 agentes; 2600 en 1968; 2530 en 1969; y 2408 en 1970 (Crocco, 2010).

${ }^{638} \mathrm{EN}^{\mathrm{o}} 3$.
} 
De este período correspondiente a la gestión de De Marchi data también el Plan de Mediano Plazo, presentado en 1970 y formulado a partir de un estudio realizado por el Banco Mundial entre 1968 y 1969. El plan proponía en los siguientes cinco años la adquisición de más de 500 locomotoras diésel eléctricas para eliminar definitivamente a la tracción a vapor, la renovación del material rodante mediante la compra de coches eléctricos y remolcados, el mejoramiento de las vías para permitir el tránsito de trenes de mayor velocidad, así como el cierre de nueve mil kilómetros de las que fueran económicamente poco convenientes. La inversión prevista era de 840 millones de dólares, la cual debía ser financiada en parte por el Banco Mundial (López et al., 2016: 185).

Calcagni destaca las mejoras que este plan implicaba en el servicio:

“El plan que presentó De Marchi significaba la reconstrucción de importantes sectores de vías que permitirían circular trenes a $160 \mathrm{~km}$ por hora, la incorporación de locomotoras, la reparación de vías a Córdoba, a Mendoza, Mar del Plata, para que pudieran correr a esa velocidad. Estaba todo listo, las vías que corrían, las que desaparecían..."639

En el mismo sentido Dall'Occhio valora este plan y el rol que tuvieron los militares de este período:

"Los militares que estaban en esto, eran ingenieros. Ninguno de ellos tuvo nada que
ver con todo ese proceso doloroso que ocurrió después. Porque Fabricaciones Militares
tiene una parte de ingeniería. Y estos militares tenían un uniforme,
pero...prácticamente eran todos ferroviarios como nosotros."

Esta apreciación referida al valor que estos funcionarios castrenses le otorgaban al ferrocarril parece condecirse con la de otro ferroviario, Juan Carlos Cena, quien señala que para "estos militares", que lograron hacer vencer su postura frente a "los tecnócratas del Ministerio", el ferrocarril tenía un rol estratégico (Cena, 2008: 139). Dall'Occhio recuerda los objetivos de este plan:

"Nosotros teníamos 40 mil kilómetros de vía, es decir, una vuelta a la tierra. Con este plan se reducían a la mitad, más o menos. Porque no eran redituables. Quedaban

${ }^{639} \mathrm{EN}^{\mathrm{o}} 30$.

${ }^{640} \mathrm{EN}^{\mathrm{o}} 15$. 
redes troncales con algunos ramales importantes. El plan también contemplaba una modernización del tren rodante, eso estaba previsto hacerlo." ${ }^{\prime 41}$

Cena, exferroviario e historiador aficionado, y Waddell, académico especializado en historia política y económica, son dos autores que no suelen coincidir en sus interpretaciones acerca de los acontecimientos vinculados a la historia del ferrocarril en Argentina. Sin embargo, ambos valoran que este plan fue formulado "por la misma empresa ferroviaria" y sus actores (López et al., 2016: 185). Una de las consultoras que intervino para su formulación fue la francesa Sofrerail, la cual conformó una comisión que, de acuerdo a Cena, estuvo "integrada por especialistas ferroviarios conocedores del estado de situación de los ferrocarriles" (Cena, 2008: 303). Uno de estos especialistas locales que participó de este estudio fue Dall'Occhio, quien recuerda:

"Yo viajé en el año 69, 70 a Francia. En ese momento, a través del Banco Mundial de Desarrollo se había conseguido un crédito para desarrollar una modernización del ferrocarril. Por eso hicimos intercambio de técnicos. Incluía no solamente la parte comercial, sino también el mantenimiento de vías, suprimir vías que ya no se justificaban..." 642

Calcagni, por su parte, recuerda la participación del exjefe de Talleres Roberto Starface ${ }^{643}$ en el estudio realizado a través de Sofrerail:

"Sofrerail intervino activamente para introducir normas de servicio utilizadas en Francia. Estuvo representada por técnicos franceses que incorporaron a su equipo a varios ferroviarios argentinos. Entre ellos recuerdo al ingeniero Straface, hasta hacía poco antes jefe del taller de Junín. Había estado en Francia y conocía un poco de los ferrocarriles franceses, y una vez me dijo, muy divertido: 'Cuando estaba en el taller proponía cosas y nadie me llevaba el apunte; ahora las propongo desde Sofrerail y todos corren"." ${ }^{644}$

El Plan propuesto, presentado a partir del estudio realizado por Sofrerail, comenzó a aplicarse en 1970, a partir de un préstamo del Banco Internacional de Reconstrucción y Fomento (BIRF). Gracias a él se renovaron vías y material rodante, y se incorporó tecnología informática y de gestión. Una de las medidas llevadas adelante, como consecuencia de este plan, fue la reorganización de la empresa ferroviaria a partir de cuatro regiones que

\footnotetext{
${ }^{641} \mathrm{EN}^{\circ} 15$.

${ }^{642} \mathrm{EN}^{\circ} 15$.

${ }^{643}$ Roberto Starface fue jefe de Talleres desde 1966 a 1972 (Tarullo et al., 2013: 137).

${ }^{644} \mathrm{EN}^{\circ} 30$.
} 
reemplazaban a las seis gerencias anteriores. En el caso del Ferrocarril San Martín conformó, junto con el Ferrocarril General Mitre, la Región Central (López et al. 2016: 185). Para algunos ferroviarios de la ciudad, como Crocco. esto significó una oportunidad de progreso en su carrera personal, ya que su responsabilidad fue mayor:

"Cuando se centralizaron las líneas y se unificaron por ejemplo la línea San Martín y Mitre, fui designado por Ferrocarriles Argentinos, a cargo de Planificación y Control de las dos líneas. Entonces, tenía a cargo de la línea Mitre los desvíos a Rosario, Córdoba, Tucumán." ${ }^{\circ 45}$

Sin embargo, el Plan de Mediano Plazo solo llegó a concretarse a medias (López et al, 2016: 185-186). Dall'Occhio recuerda el fracaso de este proyecto con la visita de su protagonista central, en una narración que incorpora algunos elementos literarios propios de la tragedia:

"Un día de invierno, yo fui a la puerta norte y había una reunión de gente, y yo dije 'qué pasa acá'. Me encuentro a un grupo que estaba rodeando a un señor muy alto, canoso, que estaba hablando. Era De Marchi. Había una niebla que apenas nos veíamos. De Marchi estaba vestido de civil porque venía a despedirse de la gente, porque no había podido... todo el proyecto había sido descartado. Y el dinero que vino para el ferrocarril fue a parar para comprar armas para que después pasara lo que pasó en Malvinas". ${ }^{646}$

Así, el frío de invierno y la confusión de la niebla en el relato de Dall'Occhio contribuyen a describir un clima hostil que anuncia el fin de una etapa floreciente para el ferrocarril en Junín. La evocación de Dall'Occhio en la que este militar realiza una visita sin la indumentaria propia de su rol, también da cuenta de la existencia de un vínculo privilegiado entre el expresidente de Ferrocarriles Argentinos y los Talleres Junín que habría concluido con el fin de su gestión.

En rigor, De Marchi dejó de cumplir funciones en Ferrocarriles Argentinos en marzo de 1971 y la última visita oficial, registrada por los diarios, data de febrero de 1971, poco antes de que dejara la empresa. En la nota se señalaba que "en forma imprevista" había visitado los talleres locales el presidente de Ferrocarriles, quien "acababa de anunciar la puesta en marcha del denominado Plan de Mediano Plazo”. También se informaba que De Marchi había

${ }^{645} \mathrm{EN}^{\mathrm{0}} 2$.

${ }^{646} \mathrm{EN}^{\mathrm{o}} 15$. 
dialogado "sin protocolos con varios grupos de operarios" y se había entrevistado "con jefes locales". ${ }^{647}$ La fecha de la visita, en verano, y el motivo expuesto, la presentación del Plan, parecen indicar que existió una visita posterior en invierno, tal como recuerda Dall'Occhio. Esto reforzaría el planteo de la relación personal de respeto y aprecio mutuo que existió entre el general y las autoridades ferroviarias locales, ya que en ese momento De Marchi ya no tenía vínculo alguno con la empresa y su visita en Talleres, ningún fundamento. Sin embargo, también es posible que Dall'Occhio haya impreso a su recuerdo personal, triste, sobre el abandono del Plan, ciertos atributos propios al invierno y que, De Marchi, aun manifestando públicamente que su visita se debía a la puesta en marcha de ese plan, en la intimidad de los directivos ferroviarios haya confesado, en cambio, su fracaso. Ambas posibilidades abonan en la interpretación de la relación de afinidad que existió entre los actores involucrados.

Crocco también recuerda un diálogo personal con De Marchi, relacionado con el fracaso del Plan de Mediano Plazo: "Me dijo que, lamentablemente, no pudieron concretar lo que tuvieron previsto. Pero para mí la de De Marchi fue una de las mejores presidencias que tuvimos."

Muchos testigos destacan a este período, que coincide con la administración de De Marchi, como de auge para el ferrocarril en Junín. Calcagni señala: "En ese momento no notaba mucho interés por lo que se hacía en Junín. Era la época del general De Marchi, que estuvo hasta el 71, cuando se fue de embajador a Perú". Dall'Occhio, por su lado, también rememora particularmente esta etapa en que él asumió una responsabilidad mayor y Talleres Junín se habría erigido como modelo frente al resto de centros ferroviarios:

\footnotetext{
"Cuando se hizo un acuerdo con los franceses para la intervención de una nueva tecnología de trabajo a través de la consultora Sofrerail este taller fue declarado taller piloto de todos los talleres de Ferrocarriles Argentinos, por algo lo habrán designado así..." 648
}

Esta referencia de Dall'Occhio sobre la designación de los Talleres Junín como "piloto" aparece en un diario de la época fechado el 27 de agosto de 1968 en el cual se informaba que la denominación fue dispuesta por el mismo presidente de Ferrocarriles Argentinos, a partir de la reestructuración general que involucraba a todos los talleres ferroviarios del país. En la nota se aduce que esta designación fue producto de "la acumulación

\footnotetext{
${ }^{647}$ El General Juan C. De Marchi estuvo en Junín (25 de febrero de 1971) Mundo Nuevo, p. 5.

${ }^{648} \mathrm{EN}^{\circ} 26$.
} 
de antecedentes" de los talleres locales, los cuales nunca carecieron de "personal capacitado" y “posibilitaron esos planes que ahora están en plena ejecución”. Concretamente, la crónica daba cuenta del reacondicionamiento de coches metálicos de pasajeros del Ferrocarril Sarmiento: "Es dable apreciar el grado de terminación en el revestimiento interior como así mismo en pisos y tapizados, además de una excelente presentación exterior. (...) No hay duda ya que se va consolidando cada vez más la estabilidad esa fuente de trabajo (...) Con todo lo alcanzado y las perspectivas que se abren, el fantasma que tanta zozobra ocasionará cuando se lanzó a rodar la versión de un posible cierre, ha desaparecido". De esta manera, este artículo sugiere que había culminado una etapa adversa para los talleres locales y el ferrocarril en general y se iniciaba otra, más favorable y auspiciosa, “con planes de mayor producción” y "un panorama de mayores estímulos para todos". 649

Además del vínculo cercano que algunos actores locales entablaron con el entonces presidente de Ferrocarriles Argentinos, general De Marchi, expuesto líneas antes, algunos testigos también recuerdan la relación personal establecida con quien fuera administrador de las líneas San Martín y Mitre. Dall'Occhio rememora dos proyectos en los intervino el coronel Jorge Carlucci, la preparación del stand en la Exposición Rural de 1970 y la puesta en marcha del Coche Bar 209:

“Acá vino un coronel, un tal Carlucci, que tenía una fama de un tipo tremendo, alto,
enorme, con esa voz que tienen ellos, impostada. Y el tipo dice, tenemos que hacer
una exposición representando al ferrocarril. Así que vamos a llevar los coches a la
Rural, los vamos a poner allá, vamos a poner un ingeniero que diseñe un stand.
Vamos a llevar una locomotora. Habíamos traído unos carretones para llevar los
coches de aire acondicionado que pesan 50 mil kilos, con motor a vapor. Bueno,
entonces, estábamos colocando unas señales, estábamos, digo, yo no participaba. En
realidad, el que estaba a cargo de todo eso era un tal (Pedro) Coloma, que le decían
cowboy, el Pecos Bill, porque arrastraba gente con su ímpetu. Este tipo, por su
personalidad, era muy entusiasta. Toda la gente lo seguía, no empujaba a la gente, no
precisaba mandar, ordenar. Él decía: 'Vamos', y la gente lo seguía. La cuestión es
que ya habían puesto una señal, y estaban colocando otra. La señal es una columna
de hierro, pesadísima, con el brazo ese que sube y baja, que es la que da la entrada a
los trenes. Y llega el coronel Carlucci y empieza a mirar, dice: 'Esto está muy lerdo',
'Esto está mal'. Entonces dice Carlucci: 'Esta columna está torcida'. Y ya no aguantó

${ }^{649}$ Reacondicionan en los Talleres Junín coches metálicos del FC Sarmiento (27 de agosto de 1968). La Verdad, p. 1 . 
más Coloma y dice: 'Lo que pasa es que acá hay que hablar menos y hacer más fuerza’. ¡Ay! ¡Yo no sabía dónde meterme! Viste que ellos tienen las chaquetitas con los botones dorados. Carlucci hizo así, track, y se la abrió de una sola vez. Yo creí que lo mataba. No sé si no se le salieron los botones. Se arremangó, se puso al lado de Coloma y se puso a hacer fuerza. Sudaron como chivos y la enderezaron a la segunda que estaban levantando. Y una vez que la levantaron, sucios como chanchos por la tierra que volaba y se te pegaba en la transpiración, y Perico Coloma lo agarra a Carlucci del hombro y le dice: 'Decime dónde carajo la ves torcida'. ¡Así! Yo hice el servicio militar y te digo que no sé qué habría pasado si hubiera hecho eso. Me desorientó de tal manera. Dice: 'Yo la veo torcida'. Dice Coloma, ya tuteándolo: 'Te aseguro que no, traemos la plomada y vas a ver que no. Sabés lo que pasa, estamos arriba del médano. Fijate la horizontal con el camino, está inclinada la tierra, fijate el horizonte, fijate la ruta y plantale la columna arriba'. 'Aja, sí, es cierto, es una ilusión óptica', dice. Esa fue una de las anécdotas de cuando vino Carlucci acá. La otra fue que hicimos un Coche-Bar 209, con asientos en formas extrañas, vino un arquitecto que hizo un diseño maravilloso, salió en las revistas europeas. Hizo un viaje de prueba de acá a Buenos Aires e iba a hacer otro viaje de Buenos Aires a Junín. Junto con los que estaban como responsables de la remodelación del coche, estaba un amigo nuestro que se llamaba Antonio Sengia, todos les decíamos 'el loco' Sengia porque tenía esos arranques de loco. Sube al coche la señora del coronel. Ella había traído unos casettes, pone música. Y este Sengia dice: 'Coronel, le solicito permiso para sacar a bailar a su esposa'. ¡Ah! Nos queríamos morir. Fue y le dijo: 'Señora, me concede esta pieza'. 'Como no, caballero'. Y salieron a bailar. Y pasaron un viaje maravilloso. El tipo se olvidó del uniforme, estaba re-contento, chocho. Porque el coche, incluso salió en las revistas europeas..." $" 650$

Puede sostenerse, entonces, que entre el personal de dirección de los Talleres Junín y el coronel Carlucci se gestó un vínculo humano de estima y cortesía, que fue más allá de lo laboral. Esto se evidencia en los intercambios epistolares entre ambos actores, los cuales fueron posteriores al período en que el militar tuvo responsabilidades en la administración de las líneas:

"Carlucci en su carrera militar ligó un ascenso. Puso el coche-bar, el coche-cine, la exposición en Buenos Aires que fue muy importante, la exposición en Junín, y le sirvió para su carrera militar a tal punto que lo hicieron responsable de gobernador

${ }^{650} \mathrm{EN}^{\circ} 15$. 
de Catamarca. ${ }^{651}$ Cuando se hizo cargo de la gobernación, el personal de dirección de Junín le hizo una carta para que tuviera éxito en su gestión y nos contestó una carta hermosa, yo tengo una copia guardada, que había trabajado con un equipo que había hecho un gran esfuerzo, que a eso él lo había afirmado en su carrera militar. Es decir, el tipo más temido se transformó en una persona de lo más agradable." ${ }^{652}$

La afirmación de algunos actores respecto de la importancia que adquirieron los talleres locales durante la gestión de De Marchi y de Carlucci, gracias tanto a la convergencia de proyectos entre los talleres locales y la administración central, así como a la empatía entre los actores involucrados, también la sugieren algunas crónicas de la época. En noviembre de 1970 Mundo Nuevo informaba sobre la visita del coronel para conocer el avance del Coche Bar, "una moderna unidad" que se construía "a ritmo acelerado" en Talleres Junín para "acompañar a una vez concluido a los trenes de lujo del Ferrocarril San Martín". ${ }^{653}$ Algunos días después, el mismo medio informaba sobre el premio recibido por el administrador Carlucci, por parte de la Sociedad Rural, en virtud del stand de Ferrocarriles Argentinos en la Exposición Rural de Junín, organizada por el gobierno de la Provincia de Buenos Aires. El stand ocupaba cuatro hectáreas e intentaba "reflejar la capacidad y potencialidad de Ferrocarriles Argentinos". "Es el producto del trabajo, la cooperación y el entusiasmo puestos de manifiesto por todo el personal de nuestra línea”, decía la nota que cita al Boletín Semanal 1123 del Ferrocarril San Martín. La foto que acompañaba la crónica mostraba al general De Marchi visitando la exposición en agosto de 1970 y felicitando, según versa en el epígrafe, al personal ferroviario interviniente representado por el trabajador Pedro Coloma. ${ }^{654}$

En diciembre, finalmente se inauguró el tren de lujo El Libertador, lo cual dio lugar a una nueva visita del general De Marchi a la ciudad. La crónica describía las comodidades de este servicio y subrayaba que el coche-bar fue construido "íntegramente en Junín”. En esta nota se narraba que De Marchi "visiblemente emocionado" por los trabajos realizados en Talleres Junín a los que califica como "sencillamente maravillosos". "No existen palabras para definirlos", decía en una entrevista exclusiva. En su discurso público, el presidente reconoció "los problemas de la empresa" e instó a "estar fuertemente unidos y luchar como corresponde", aclarando que su visita a Junín estaba vinculada a felicitar a los trabajadores por el trabajo

\footnotetext{
${ }^{651}$ En rigor, Jorge Carlucci fue gobernador interventor de la provincia de Catamarca durante el Proceso de Reorganización Nacional, entre el 12 de mayo de 1976 y el 13 de diciembre de 1978. Ver: Gobernadores de Catamarca (s.f.). Recuperado de https://esacademic.com/dic.nsf/eswiki/1295696

${ }^{652} \mathrm{EN}^{\circ} 15$.

${ }^{653}$ El coronel Carlucci visitó la ciudad. (4 de noviembre de 1970). Mundo Nuevo, p. 1 y 16.

${ }^{654}$ Destacan stand ferroviario (11 de noviembre de 1970). Mundo Nuevo, p. 5.
} 
realizado y no a hablar sobre las dificultades. Prometía, para esto último, una nueva visita en un futuro. ${ }^{655}$ Estas notas demuestran el valor que esta administración le otorgaba a la labor realizada por ferroviarios locales, así como la importancia que le atribuían al rol del ferrocarril en el país, en contraste con otras administraciones previas que pusieron el acento en el déficit que la empresa significaba para la nación.

En definitiva, los distintos planes ferroviarios que en menos de diez años presentaron los gobiernos del período, ya sea constitucionales o de facto, como el Plan de Largo Alcance en 1962, el Plan Nacional de Desarrollo en 1965 y el Plan de Mediano Plazo en 1970, dan cuenta de una década de crisis para el ferrocarril, ya que todos estos proyectos inconclusos pusieron el acento en la necesidad de mejorar el servicio, modernizar las unidades, recuperar la demanda o disminuir el déficit. Aunque por este motivo puede afirmarse que el ferrocarril estaba atravesando una situación crítica, a fines de la década del sesenta e inicio del setenta es posible advertir, en particular durante la administración del presidente De Marchi, el apoyo a la gestión de los Talleres Junín. Esto habría dado lugar a la puesta en marcha de diferentes proyectos que permitieron consolidar algunas representaciones que asocian este período con una etapa de esplendor para el centro ferroviario local.

Es probable que este apoyo de la administración central de Ferrocarriles hacia los Talleres Junín haya estado motivada no solamente por el supuesto vínculo familiar que De Marchi tenía con la ciudad de Junín, o por la identificación entre las autoridades locales y nacionales, sino también por la necesidad del gobierno nacional de establecer alianzas con determinados sectores, en el contexto de un clima social conflictivo en algunos centros del país. Algunos meses antes de la presentación del Plan de Mediano Plazo y de las actividades que fueron relatadas, el gobierno nacional debió enfrentar dos estallidos sociales violentos: el “Cordobazo", en mayo de 1969, y el "Rosariazo", en septiembre del mismo año. Mientras la primera fue una revuelta popular protagonizada por obreros de distintos gremios y estudiantes, a la que luego se sumaron vecinos y militantes, desatada en contra del régimen por la falta de libertades democráticas y la brutalidad policial, la segunda tuvo como protagonistas a los trabajadores del riel (Gordillo, 2003: 352-355). El "Rosariazo" fue una rebelión masiva que estuvo originada en los reclamos de trabajadores ferroviarios de los talleres de Rosario, Pérez y Villa Diego y que devino, con el correr de los días, en acontecimientos de mayor tensión, culminando el 17 de septiembre con el incendio de autos y ómnibus por parte de los manifestantes, enfrentamientos con las fuerzas policiales, el incendio de la estación ferroviaria

655 “El Libertador”: una obra realizada en Junín para el país. (14 de diciembre de 1970). Mundo Nuevo, p. 14. 
Arroyito, el ataque a varias plantas industriales, garitas y sucursales bancarias. Finalmente, el "Rosariazo" terminó irradiando hacia otros centros ferroviarios del país, como los de Santa Fe, Córdoba, Bahía Blanca y Tucumán, quienes manifestaron su protesta de diversas formas: atentados al personal jerárquico que cumplía tareas, descarrilamiento de trenes, ataques a vagones, corte de energía de señales, obstáculos en vías, sabotajes en talleres, explosivos en vías y boleterías (Gordillo, 2003: 358-360). En Junín, la situación fue mucho más pacífica. Si bien la Unión Ferroviaria convocó a un paro en solidaridad de los trabajadores del FC Mitre y "en contra de las políticas de la Empresa de Ferrocarriles Argentinos, exigiendo la reincorporación de los cesanteados por causas gremiales y (...) el respeto al cumplimiento de las paritarias nacionales", ${ }^{656}$ no se registraron disturbios. De hecho, los jefes y supervisores concurrieron a trabajar, mientras la policía estuvo acuartelada como medida preventiva ${ }^{657}$ Los trenes, a su vez, corrieron con normalidad, habiéndose cancelado algunos servicios puntuales de carga de larga distancia. ${ }^{658}$

En este contexto, es posible presumir que las autoridades máximas de Ferrocarriles Argentinos hayan intentado construir una base de apoyo hacia su gestión a partir de Talleres afines y menos conflictivos. En ese sentido es que también podría explicarse el acercamiento que existió en el período entre las autoridades del centro ferroviario local, la gerencia de la línea San Martín y la Presidencia de Ferrocarriles Argentinos, y que habría dado lugar a la puesta en marcha de diferentes proyectos.

\section{PERT, un método para incrementar la eficiencia}

Una de las iniciativas implementadas en los Talleres Junín durante este período se denominó "Programación por Camino Crítico", también llamado por muchos ferroviarios "Sistema PERT" (Program Evaluation and Review Technique). El nuevo método de trabajo llegó al taller local de la mano del ingeniero Jaime Sraell ${ }^{659} \mathrm{y}$, entre los ferroviarios que fueron responsables de su ejecución, estuvo Juan Dall'Occhio. Básicamente, PERT consistía en reducir los tiempos de permanencia de los coches que llegaban para ser reparados a los Talleres Junín, estableciendo las cantidades máximas y mínimas de horas involucradas en cada instancia de

\footnotetext{
${ }^{656}$ Adhieren al paro en Junín. (17 de septiembre de 1969). La Verdad, p. 2.

${ }^{657}$ Prolongan el paro de los ferroviarios de Junín. (18 de septiembre de 1969). La Verdad, p. 2.

${ }^{658}$ El conflicto ferroviario en nuestra ciudad. (19 de septiembre de 1969). La Verdad, p. 2.

${ }^{659}$ El ingeniero Sraell, según datos aportados por Marone y Dall'Occhio, estuvo durante un corto período como colaborador de quien fuera jefe del Departamento de Mecánica, el ingeniero Alberto Young. Este ayudante directo de la máxima autoridad ferroviaria en Junín, no era de esta ciudad ni de la línea San Martín, sino que procedía del Ferrocarril Sarmiento.
} 
reparación, así como las prioridades para que el vagón fuera capaz de brindar un servicio en buenas condiciones, descartando así las reparaciones innecesarias. De esta forma, se pretendía incrementar y acelerar la cantidad de reparaciones, haciendo un uso eficiente de los recursos humanos y materiales. Para este procedimiento, establecer cuál era el "camino crítico", es decir, la serie de tareas que no admitían demoras, porque comprometían la permanencia del coche en el taller, resultaba crucial. "El Camino Crítico — explica Calcagni- es el de mayor duración, al que hay que destinar los recursos que se liberan en las tareas más cortas". ${ }^{60}$

Aunque este método volvió a poner en la escena central a la eficiencia que, en el imaginario ferroviario, estuvo asociado al legado inglés, pretendió ser superador de esa experiencia anterior. Dall'Occhio cuenta:

"Yo entré a trabajar al ferrocarril en el 56, y me fui interiorizando sobre cómo se hacían las reparaciones. La cuestión es que en ese momento la reparación quedaba condicionada a los supervisores. Tenían un sistema de trabajo a destajo, donde le daban vales. Después en contaduría formaba parte de un incentivo al sueldo. Una reparación general implicaba una cantidad de vales importantes, de manera que cada uno quería tener ese trabajo porque equivalía a lograr un incentivo. ¿Qué pasaba? Que los vehículos se los desarmaba íntegramente sin ninguna necesidad y no había un control de eso. En determinado momento vino acá un ingeniero Sraell que trajo este sistema nuevo, en un acuerdo con la dirección de la empresa. Eso sucedió en el año 68. Nos mostró la técnica de camino crítico. Por otro lado, cuando me toca viajar a Francia becado por el ferrocarril, vimos que al vehículo en la entrada del taller se le hacía una inspección y se determinaba en particular qué era lo que había que hacerle. No desarmar por desarmar, y volver a armar. Con eso se acortaban los tiempos de permanencia del vehículo en el taller y el gasto de mano de obra por unidad. En vez de reparar seis o siete coches por mes, vos podés reparar $20 \mathrm{y}$ tenerlos en condiciones. ${ }^{{ }^{661}}$

Previo a la puesta en marcha del nuevo método que pretendía, como sugiere Dall'Occhio, incrementar la cantidad de vehículos reparados en determinado lapso de tiempo, el área involucrada trabajó junto a operarios de diferentes secciones con el objetivo de analizar cada una de las tareas involucradas en la reparación. El testimonio de Murgia deja entrever que la puesta a punto del método en Junín implicó la participación de los ferroviarios de todas las secciones, lo que condujo a contar con un conocimiento cabal del trabajo de Talleres: 
"Primero hay que hacer una evaluación de todas las tareas y asignarles un tiempo. Se utilizaron a las personas más idóneas en cada tarea y ellas dijeron un tiempo probable, un tiempo pesimista y un tiempo optimista. Se hizo un tiempo aleatorio y con ese tiempo aleatorio se fue haciendo una programación de todas las tareas, con el conocimiento de toda la gente. Así estudiando aparece el camino crítico y los otros caminos que no lo son." ${ }^{962}$

Dall'Occhio también recuerda, como Murgia, que se trató de un trabajo participativo en el que se valoró el saber y las opiniones de los trabajadores de los talleres, lo que habría propiciado un mayor consenso del conjunto en la puesta en marcha del método.

\footnotetext{
“Traíamos gente muy especializada de taller, los traíamos tres meses a la oficina, los vestíamos con su corbata y su camisa, dejaban su ropa azul. Después no se querían ir más (risas). Pero bueno salían felices de lo que habían hecho, porque le contaban a su familia. Así que lo hacían con mucho entusiasmo." ${ }^{\circ 63}$
}

El testimonio anterior ilustra con claridad las diferencias jerárquicas que existían en Talleres establecidas a partir de la indumentaria: los que vestían ropa azul, los operarios; los que vestían traje y corbata, los jefes. De cualquier forma, esta modalidad implicó una valoración hacia el conocimiento específico de los operarios y una participación en la toma de decisiones que los involucraban. Como consecuencia probable, esa labor conjunta puede haber dado lugar a un mayor compromiso de los trabajadores con el método implementado.

Por otra parte, la puesta en marcha del método también trajo aparejado la introducción de nueva tecnología que mejorara la calidad del trabajo, al mismo tiempo que implicara un uso más eficiente de los recursos humanos:

"Teníamos un equipo integrado por los mejores especialistas que captaba el taller, los llevábamos a la oficina por un tiempo, y empezábamos a analizar: ‘¿Por qué este trabajo lo hacemos así?' 'Y... porque siempre lo hicimos así'. 'Sí, pero no veo que esa sea la mejor manera, ¿cómo podríamos ahorrar tiempo y que al operario le signifique menos esfuerzo?'. 'Y bueno, si tuviéramos tal herramienta...' Muchas veces, los buenos operarios sabían que existían esas herramientas o nosotros, ya con cierto grado de conocimiento técnico, sabíamos que existían y logramos que esos equipos se 
compraran. Por ejemplo, acá en el país no se conocía el remache pop, se usaba el tornillo. Y el tornillo chiquito donde hay chapas delgadas, para unir elementos, requiere tiempo, repasar la rosca, a veces se rompe, se tenía que usar mucho tiempo para la tarea. Mientras que colocar un remache pop era algo sencillo, fácil.”664

Los estudios previos a la ejecución del plan insumieron, de acuerdo a Dall'Occhio, un lapso de dos años, a partir del año 1968. Una vez culminada esta etapa se comenzó a implementar el sistema PERT, el cual implicaba el respeto de una serie de pasos establecidos. Luego de que el coche fuera sometido a una inspección, se determinaba si la reparación debía ser general o parcial. El ferroviario detalla:

\footnotetext{
"Se determinaba qué es lo que había que hacer y se emitían las órdenes de trabajo. Estas órdenes pasaban al taller. El vehículo, después, debía pasar por los distintos sectores: Tapizado, Pintura, Mantenimiento interior y así hasta la salida a Tráfico. Cada una de estas cosas tenía tiempos previstos." ${ }^{665}$
}

De acuerdo a este método, entonces, el respeto de los tiempos establecidos resultaba crucial. El testimonio de Dall'Occhio deja entrever que esta modalidad estandarizada de trabajo, por pautar una serie de pasos, era, no obstante, dinámica y estaba en constante evaluación en la búsqueda de la incorporación de nuevos instrumentos que permitieran acortar la estadía del vehículo en el taller:

\begin{abstract}
"El camino crítico se compone de las tareas que se suceden indefectiblemente, una detrás de la otra, para las que no hay tiempos de espera. O sea, hay un camino que determina la permanencia del vehículo. La reparación de la batería, no, la reparación del bogie, no, la reparación del ventilador, no, porque son pequeñas reparaciones. Pero lo que tiene que ver con la carrocería del vehículo, ahí es donde las intervenciones son muy duras, prolongadas, y van determinando el camino crítico. Ahí es donde yo tengo que poner a la gente de Método a trabajar para ver cómo puedo acortar eso, introduciendo tecnología y determinando si conviene reparar algo o conviene comprarlo nuevo." $"{ }^{666}$
\end{abstract}

En la misma línea Murgia, quien fuera jefe de Métodos y Tiempo, se explaya:

\footnotetext{
${ }^{664} \mathrm{EN}^{\mathrm{0}} 26$

${ }^{665} \mathrm{EN}^{\mathrm{o}} 26$.

${ }^{666} \mathrm{EN}^{\mathrm{o}} 26$.
} 
"Ese camino crítico te indica que vos no te podés demorar en los distintos pasos, porque si no se demora la permanencia del coche en sitio, en el taller. Si vos decís 30 días, que no pase de los 30 días. Porque después hay otras tareas que tienen mucho margen. Por ejemplo, entra un coche y de entrada le sacás la batería, y la batería ¿en cuánto se repara? En dos días, ponele. Entonces, lo que más hay que mirar es ese camino crítico.”667

Paralelamente, se llevaron adelante otras acciones que apuntaron a implementar una modalidad de trabajo superadora de las que se conocían hasta el momento. Concretamente, se comenzó a documentar datos técnicos que brindaban especificaciones sobre la reparación que debía realizarse. "Todo estaba descrito en una cartilla. Ese trabajo estaba a cargo de Avilio Murgia, que tenía un equipo de trabajo formidable”, comenta Dall'Occhio. Sobre este punto, Murgia explica:

"Empezamos a cambiar en muchos aspectos respecto de la actividad anterior que se hacía a partir del palabrerío del que supuestamente conocía. 'No, no, no', dijimos. Vamos a hacer el plano con todas las normas, con el tratamiento térmico, la terminación superficial, con el sistema de ajustes y tolerancia... con todo. Si había que hacer un cálculo de resistencia se hacía. Entonces la orden se cumplía con ese plano. Se hacía una ficha normalizada de actividades y se hacía todo como se tenía que hacer. El plano tenía un número y la orden tenía un número. Entonces, en la orden figuraba el número del plano, y en el plano el de la orden. Entonces cuando vos mirabas la orden, sabías a qué plano le correspondía, veías si se había hecho, se volvía a revisar, a corregir, tenías en cuenta si había habido alguna novedad en el proceso de fabricación...”668

Dall'Occhio considera que la implementación del sistema PERT constituyó un "éxito total", luego de que se vencieran las resistencias iniciales del personal en torno al cambio en la modalidad de trabajo que, en definitiva, implicaba disminuir la cantidad de horas de trabajo y, por consiguiente, de personal, destinadas a las tareas de reparación:

"Siempre el miedo a quedarse sin trabajo. ¿¿Qué vamos a hacer con las horas-hombre que nos sobran?', preguntaban. De a poco, cuando ellos se fueron dando cuenta de que no se iban a quedar sin trabajo y que, en cambio, estaban trabajando mucho mejor. Eso se logró en el 70, 71. Entonces, ¿qué ganamos? Que nos sobraba mano de obra a pesar de que teníamos la mitad de personal, porque habían decrecido las dotaciones. Sin

${ }^{667} \mathrm{EN}^{\circ} 7$.

${ }^{668} \mathrm{EN}^{\circ} 7$. 
embargo, conseguíamos mantener en régimen los vehículos en servicio, en buenas condiciones. 'Vamos a reparar vehículos de otras líneas', dijimos. Y empezamos a reparar vehículos al Mitre, al Sarmiento, al Roca. Con menos gente, nos sobró capacidad de trabajo. ¿Te das cuenta que fue explosivo? Fue tan explosivo que toda la gente estaba de acuerdo." $" 669$

Además de la ampliación del servicio de reparación a otras líneas, Dall'Occhio también menciona como logro que los coches comenzaron a circular "en servicio de kilometraje no vencido":

\footnotetext{
"Un coche tenía $130.000 \mathrm{~km}$ de servicio sin que entrara al taller, pero había coches que estaban recontra pasados, estaban circulando en malas condiciones. Así que con ese sistema conseguimos hacer reparaciones más cortas, más continuadas, con menos tiempo en el taller". ${ }^{670}$
}

Tanto Murgia como Dall'Occhio consideran que a partir de la implementación del Sistema PERT, los talleres ferroviarios de Junín se destacaron frente al resto de centros reparadores del país. "Fuimos muy eficaces y eso fue lo que determinó que el taller Junín fuera el taller piloto", asegura Dall'Occhio. En el mismo sentido, Murgia recuerda:

\footnotetext{
"Me parece que eligieron a la (línea) San Martín como piloto y a Talleres Junín, que fue uno de los más grandes y prestigiosos que tuvo Ferrocarriles Argentinos. Era como una prueba piloto y viendo el progreso de las distintas actividades, con los distintos tipos de coches, se fue haciendo. Él (Talleres Junín) era el guía de todo eso.”671
}

A pesar de que el entusiasmo de Dall'Occhio le impide expresar dificultades en la implementación del sistema PERT, los recuerdos de otros testigos inducen a considerar que el "éxito" que plantea del Camino Crítico duró menos de cinco años. Eso se debió a que en la empresa parecen haber convivido políticas contradictorias: unas que impulsaban este tipo de proyectos que apuntaban a incrementar la eficiencia de la empresa, otras que dificultaban su implementación. Murgia explica que la falta de insumos condicionó la ejecución del Sistema PERT:

\footnotetext{
${ }^{669} \mathrm{EN}^{\mathrm{o}} 26$

${ }^{670} \mathrm{EN}^{\mathrm{o}} 26$.

${ }^{671} \mathrm{EN}^{\mathrm{0}} 7$.
} 
“Acá, una de las desgracias que tenemos en el país, es que no terminamos de concretar nada. Por ejemplo, lo de PERT no es para que fracase. Se hizo un trabajo muy sesudo, se tomó gente del taller de las más capacitadas para hacer el trabajo de programación y se hizo un trabajo muy importante. Pero qué pasa, cuando se quiere empezar a trabajar tenés que tener todas las provisiones de materiales, como se dice, just on time, justo a tiempo. Si no tenés los materiales justo a tiempo, si no podés hacer ingresar los vehículos porque Material Remolcado los usa, porque tenía la necesidad imperiosa de formar trenes y le faltaban coches.... entonces, ese, que tenía que entrar porque ya estaba en tiempo, pero todavía estaba bastante bueno, y seguía trabajando, entonces todo se desmorona. Si se puede considerar un fracaso lo fue por eso. Porque no se cumplen las pautas. Fue del 68 al 72 que duró el PERT. Obviamente, el gobierno militar desapareció a esa altura. Se estuvo trabajando, se estuvo trabajando, pero en general no prosperó. Porque se fue a los manotazos de ahogado. O sea, toda la documentación que se preparó para hacer la programación se trató de usar, se trató de seguir como se pudo. Pero se fue desvirtuando." ${ }^{672}$

El ingeniero Calcagni coincide con Murgia en que el fracaso de PERT se debió a la falta de provisión de los materiales necesarios:

"No sé cuántos coches alcanzaron a salir con ese procedimiento, pero para que el sistema funcione los elementos tienen que estar ahí. El PERT falló en parte porque la tarea que tenía que cumplir Almacenes, Abastecimiento, no fue buena. El suministro no fue el necesario. Si no están los elementos, la tarea que tiene que durar tres días, a lo mejor dura quince. A veces porque no se licitaban a tiempo, porque no se compraban a tiempo. En parte falló por eso. Yo oí decir que falló. No, no falló, los que fallaron fueron ustedes. Es como decir que falla la máquina cuando se corta la luz. El PERT no falla, pero en la aplicación, si no está todo preparado y listo, no va a andar. Entre los comienzos del estudio y el término, puede haber durado dos o tres años y tal vez me excedo." $" 673$

Por último, Dall'Occhio atribuye el éxito del sistema PERT al apoyo con que contó Talleres Junín durante la presidencia de De Marchi. De su testimonio se desprende que posterior a esa gestión del militar, el centro reparador local dejó de contar con el aval suficiente para impulsar diferentes proyectos:

$672 \mathrm{EN}^{\mathrm{o}} 7$.

${ }^{673} \mathrm{EN}^{\mathrm{o}} 21$. 
"Al principio hicimos unas cuantas obras de mucho presupuesto. Eso se lo debemos a De Marchi, que nos dio mucho impulso. En esa época se hicieron unas cuantas obras importantes que nos permitieron desarrollar trabajos. Por ejemplo, cuando vinieron los coches metálicos de 35 metros de largo nosotros necesitábamos que cupieran veintidós, no once, y nos dieron presupuesto para ampliar. Conseguimos el lavadero de coches en la entrada, para que la gente tuviera un coche limpio. Después empezamos a tener problemas de presupuesto con otras intervenciones. En la época de Menem no teníamos presupuesto para compras prácticamente" (el subrayado es mío). ${ }^{674}$

En suma, la implementación del sistema PERT en los Talleres Junín, con la participación de técnicos y operarios locales, contribuyó a consolidar una identidad asociada a la excelencia de la mano de obra local y de eficiencia en cuanto a la capacidad de trabajo. Dado que el método no cumplió las expectativas de continuación y evolución, es posible afirmar que la memoria de muchos ferroviarios quedó anclada en esta y otras experiencias exitosas de lo que eran capaces de hacer los trabajadores en su conjunto, como una manera de reforzar una identidad vinculada al prestigio de los talleres locales y de sus ferroviarios. Paralelamente a ese sentimiento de orgullo por lo que sucedió, emergieron otros: de añoranza, por lo que fue y dejó de ser, y de dolor, por lo que podría haber sido si las condiciones en la empresa hubieran sido otras.

\section{El control de la calidad aplicado a las tareas de reparación}

Otra de las experiencias del período que, junto con la Programación por Camino Crítico, abonó en la construcción de una identidad asociada a la excelencia de los ferroviarios de Junín estuvo ligada a la creación del Departamento de Control de Calidad. Esta nueva área surgió a partir de una propuesta del ingeniero Calcagni, quien, aunque era de Junín y había iniciado su carrera en el Departamento de Mecánica local, en ese momento trabajaba en la gerencia de la línea San Martín ubicada en la ciudad de Buenos Aires.

Calcagni había iniciado su labor en el ferrocarril en el año 1953, como ayudante del jefe del Laboratorio Químico. En ese momento, esta área se ocupaba de controlar tanto el agua empleada en las locomotoras a vapor, como los materiales que llegaban al Taller y a la línea San Martín, mediante ensayos químicos, físicos y mecánicos. Calcagni reseña: “En tiempo de los ingleses el área se llamaba Laboratorio Químico. Cuando se nacionalizó se creó la División Química que, en un principio no tenía la categoría de las otras, pero con el tiempo fue

${ }^{674} \mathrm{EN}^{\circ} 26$. 
adquiriendo más importancia”. En 1961, Calcagni se hizo cargo de la jefatura de esta división y, en 1967, se trasladó a Buenos Aires para trabajar en la Gerencia de la línea San Martín. Durante ese período de ocho meses en el que estuvo residiendo en la capital argentina, le solicitaron una exposición sobre su especialidad. El ingeniero recuerda:

\begin{abstract}
"Cuando estuve en la gerencia me pidieron una exposición sobre control de calidad, y yo les dije lo que creía se podía hacer con material rodante también, no solo seguir con los materiales, sino ocuparnos del control de las tareas de reparación. Y eso le gustó al gerente, teniente coronel (Federico) Sidders. ${ }^{675}$ Me pidió una exposición sobre la posibilidad de aplicar el control de calidad también a la reparación. Yo le presenté todo un panorama de cómo se podía hacer. Estuve dos o tres horas. Entonces le propuse la formación de un organismo dentro de la empresa, encargada del control no solo del material, sino de las tareas, por ejemplo, de Vía y Obras. Tal es así que más tarde él hizo una exposición delante nuestro, ante el presidente De Marchi. Y cuando terminó De Marchi dijo: 'Ese organismo tiene que ser de la máxima categoría' y Sidders le contestó 'Sí, hemos pensado que va a ser departamento'. Y bueno, así fue. Entonces me dijo que fuera a Junín, y yo, que había estado afuera de Junín durante ocho meses, lo estaba esperando.”676
\end{abstract}

Una vez que Calcagni regresó a Junín, formó un equipo de trabajo con algunos técnicos ferroviarios de los Talleres o del Departamento de Mecánica de Junín, entre ellos los técnicos Eridé Rinaldi, Ítalo Marone y Reynaldo Angeluzzi, y el ingeniero Roberto Nadín. De esta manera, esta gesta tuvo características eminentemente locales, aunque el grupo también estuvo integrado por personal de los talleres de Alianza y Mendoza. "Prácticamente, (Sidders) me dio carta blanca para organizar el departamento. Primero, había que elegir a la gente y darle cursos de control de calidad, porque eran técnicos, pero en control de calidad no sabían tanto", cuenta Calcagni. Rinaldi recuerda: "Estaba Calcagni a la cabeza, también Marone, (Roberto) Nadín y yo. Hasta al jefe de talleres le di cursos y hasta a un jefe de Buenos Aires. Tuve que dar cursos de control de calidad a todos los inspectores de Mendoza”. Así durante el año 1968 trabajaron durante la puesta en marcha del proyecto, el cual comenzó a implementarse en enero de 1969.

Taberna evoca ese período de transformación, como fecundo para el ferrocarril en general y para el complejo ferroviario local:

\footnotetext{
${ }^{675}$ Sidders fue gerente de la línea San Martín hasta 1969, previo a Jorge Carlucci.

${ }^{676} \mathrm{EN}^{\circ} 21$.
} 
"Cuando se creó la división de Control de Calidad, en la época de los militares... porque con los militares evolucionó muchísimo el ferrocarril... vino un cambio. Toda esa estructura orgánica que venía de la época de los ingleses, la cambiaron. Ellos tomaron como hacen a los norteamericanos y empezaron a trabajar de otra forma. Crearon la División de Control de Calidad que no existía y pusieron la mejor gente. Calcagni, que tuvo que formar de cero la división. Hasta el personal administrativo era el mejor. Hubo un cambio profundo. Había un gerente de línea, el coronel Sidders, que aparte de ser militar era ingeniero militar y tenía mucho conocimiento. Fue la época de De Marchi como presidente de Ferrocarriles Argentinos, De Marchi era de raíces ferroviarias, entonces..." ${ }^{977}$

Marone, uno de los integrantes del equipo, caracteriza esta nueva impronta del ferrocarril con la introducción de saberes y prácticas castrenses:

“(Control de Calidad) fue un invento de los militares también. La característica que tuvo la intervención militar... no fue el hecho de que el gobierno era militar, sino que el jefe máximo militar, De Marchi, tenía mucha vinculación con el ferrocarril. Entonces en ese tiempo intentaron meter en la organización ferroviaria algunas ideas propias de los militares y un poco eso fue lo que llevó a crear un Departamento de Planificación y Control, porque a los militares la planificación y control les gusta mucho. Crearon una División de Formación, para mejorar en los estudios a muchos. Y también se creó el Departamento de Control de Calidad que no existía en el ferrocarril, pero que ellos los tenían en las distintas fábricas militares. Porque en ese momento la tarea de control de la calidad de los trabajos la hacían los propios departamentos, con sus propios inspectores y cuando compraban materiales los propios inspectores de mecánica los controlaban. Las reparaciones las controlaban los mismos capataces que había en las distintas secciones. Pero lo que se quiso hacer, porque los militares eran muy amigos de separar funciones, es no dejar que uno que fabricara y también controlara, entonces la fabricación la hacía uno, el control, otro." 678

En línea con lo que describe Marone, Dall'Occhio también recuerda que esta separación de funciones significó una transformación respecto de la modalidad de las prácticas ferroviarias anteriores en las que el control era ejercido por la misma área que desarrollaba las tareas de producción. De esta manera, fueron los militares de este período quienes habrían introducido esta metodología. Dall’Occhio recuerda entre risas: "El gerente (Federico Sidders) 
dijo, cuando se instauró el sistema en el taller, lo recuerdo como si fuera hoy: 'yo quiero que el jefe de control de calidad esté peleado con el jefe del taller', así lo dijo”. Calcagni no recuerda la anécdota, pero reconoce: "En cierto modo eso fue lo que pasó. No nos llegamos a pelear, pero las discusiones eran muy ásperas". Luego, el ingeniero aclara lo que esto implicó en las prácticas laborales: "Que estemos peleados significaba que el Control de Calidad se metía en todo lo que el Taller no quería que nos metieramos". ${ }^{679}$ Marone, por su parte, describe:

\footnotetext{
"En esa época empezó a pensarse en alguna forma de organizar el grupo de inspectores y de qué manera manejarse en el control de los trabajos, ajeno al establecimiento que hacía el trabajo. Control de calidad tenía sus inspectores. Entonces entraban en el Taller, llegaban adonde estaba trabajando Vía y Obras, lo que fuere, y controlaban lo que hacían Vía y Obras, pero no dependían de Vía y Obras, sino de Control de Calidad. Y Control de Calidad reportaba a la jefatura, si había muchos rechazos, si el porcentaje de trabajos era bueno..." 680
}

La tarea del Departamento fue abarcativa e involucró tanto el control de la calidad de los materiales e insumos empleados para el trabajo, como los servicios que brindaban terceros. "Hasta se analizaba el agua que se tomaba en las estaciones: todos los días llegaba el tren y había un inspector que estaba controlando el agua, químicamente”, ejemplifica Dall'Occhio. Marone añade: "Se inspeccionaban tanto los materiales que se compraban, como los trabajos que la industria privada hacía para el ferrocarril. Por ejemplo, si se hacía un contrato con Fiat, había que mandar los inspectores a Fiat". Pero lo que representó un cambio sustancial de la forma de trabajo anterior fue el control de la calidad aplicado a las tareas de reparación en el Taller o Vía y Obras. Marone problematiza: "En lo que es los materiales es una cosa, pero en los trabajos de reparación no es tan fácil. Cuando el trabajo está terminado es una cosa, en el proceso es otra". ${ }^{681}$ En ese sentido, fundamenta:

\footnotetext{
“A veces, si no controlás el proceso, la pieza terminada sale mal. Si vos vas a controlar un motor diésel, no podés controlar una vez que lo ponen en marcha. Tenés que controlar cómo lo repararon, el motor de tracción, el cigüeñal, cualquier otra parte que corresponda. Se necesita un control de proceso. Claro que es importante controlar la pieza terminada, si sirve o no sirve. Pero si controlás el proceso tenés posibilidad de que la pieza terminada llegue bien. Si no controlás el proceso, cuando llega la pieza
}

\footnotetext{
${ }^{679} \mathrm{EN}^{\mathrm{o}} 21$.

${ }^{680} \mathrm{EN}^{\mathrm{o}} 22$.

${ }^{681} \mathrm{EN}^{\mathrm{o}} 21$ y 22.
} 
terminada puede pasar un desastre. Hay cosas que se controlan durante el proceso para favorecer la unidad terminada, y hay otras que no son tan importantes y se espera la unidad terminada para controlar." ${ }^{682}$

Para ese control de las tareas, la otra iniciativa que se estaba poniendo en marcha, paralelamente, Programación por Camino Crítico (Sistema PERT), resultó un aporte valioso. Calcagni rememora:

"Cuando se decidió implementar el Control de Calidad a las tareas de reparación, ya teníamos medio trabajo ya realizado. Porque para implementarlo necesitábamos conocer cada una de las tareas. Y en el Taller se estaba estudiando la aplicación a reparaciones y mantenimiento del PERT. Entonces, nos sirvió ese desglose o individualización de tareas del PERT para el control que teníamos que hacer nosotros. Incluso para calificar un valor de demérito. Siempre trabajando con otros sectores del Taller o de Vía y Obras para determinar los valores". ${ }^{683}$

Esta identificación de cada una de las tareas implicó, a la vez, establecer normas que brindaran parámetros para evaluar la calidad de una actividad. De esta manera, esa explicitación normativa resultaba superadora de la tarea de inspección que se hacía previamente. Rinaldi detalla:

\footnotetext{
"Se establecían normas de calidad en todos los trabajos que se hacían, y eso tenía que ser respetado en toda la línea del ferrocarril. Por ejemplo, un rodado tenía que tener cierto diámetro y la tolerancia en milésimas... Esa es una norma de calidad que tiene que respetarse a lo largo de todo el control que se haga. Antes, había una inspección, pero sin mucho control. Una inspección un poco práctica, porque no había teoría. En cambio, se establecieron normas y leyes que debían reunirse en cada proceso de reparación. O sea, normas de trabajo y normas de calidad que es lo mismo." ${ }^{964}$
}

De acuerdo a Calcagni, en aquel momento existían diferentes metodologías para establecer la calidad de un producto. Una de ellas tenía lugar en la instancia final de la producción: "Lo que llevaba a separar lo bueno de lo malo, lo que servía de lo que no servía y que, muchas veces, implicaba pérdidas importantes". Otra era denominada "control de calidad estadístico", es decir, "el control de muestras periódicas, para determinar si existía una

\footnotetext{
${ }^{682} \mathrm{EN}^{\circ} 22$.

${ }^{683} \mathrm{EN}^{\mathrm{0}} 30$.

${ }^{684} \mathrm{EN}^{\circ} 24$.
} 
variabilidad normal o fuera de lo normal”. En este caso, la metodología implementada para el control de tareas se denominaba “control por demérito". Calcagni detalla en qué consistía:

"El control por demérito fue el que utilizamos nosotros, pero no para la producción, porque nosotros no producíamos nada. No se trataba de controlar piezas sino tareas, asignándoles valores según la importancia de las mismas. Las tareas en reparaciones y mantenimiento fueron identificadas y valoradas con deméritos de 5 a 100. Los valores altos debían ser indefectiblemente corregidos. Los menores podían ser tolerados, salvo que la suma del resto de tareas alcanzara cifras importantes. Porque hay que decir que no todas las fallas tienen la misma importancia. Puede haber fallas muy importantes que nos da la certeza de que puede haber un problema grave que ocasione un accidente o signifique un riesgo para la persona. En ese caso el demérito es determinar el valor, se le daba un valor numérico, pongámosle 100. La cuestión es que se le va dando diversos puntajes, 50, 60, y todavía otras menores que tienen que ver con el acabado, terminación, que no provocan problemas importantes, simplemente de aspecto, en ese caso pueden ser 20,10 puntos o menos. Esas gráficas de control, en este caso, suman la cantidad por el puntaje. Es decir, que el peso de cada una depende tanto de una cosa como de la otra. Aquella que puede producir riesgos muy importantes de por sí determina el rechazo, si no se presenta, entonces, la cantidad de las otras menores también podría provocar rechazo, pero siempre que el número sea importante." ${ }^{685}$

Marone también contrasta el modo de inspeccionar previo respecto de la puesta en marcha del método, con normas precisas. De acuerdo a su testimonio eso, al mismo tiempo, permitió conformar estadísticas para dar cuenta de la calidad de determinado establecimiento, según la cantidad de aceptaciones y de rechazos.

"Cada tarea tenía un código y es sobre ese código van a trabajar los inspectores. Cuando los inspectores inspeccionan no dicen 'yo investigue si el gancho estaba torcido', sino que ese gancho tiene un código. Resultado, rechazo-aceptación. Y de esa forma sacaban estadísticas. Para determinar si un establecimiento tiene calidad, a través de esos controles, de la estadística, vos después decís si tiene muchos rechazos o aceptaciones, los rechazos lo marcábamos con una raya negra, y las aceptaciones con una raya roja, entonces identificábamos a través de un gráfico si un establecimiento tenía más negros que rojos. Una forma de sacar estadísticamente el nivel de calidad del establecimiento.”686

${ }^{685} \mathrm{EN}^{\mathrm{0}} 30$.

${ }^{686} \mathrm{EN}^{\circ} 22$. 
El siguiente testimonio de Calcagni sugiere que la creación de este nuevo departamento en la estructura de la empresa se fundamentaba en la existencia de algunas representaciones sociales que consideraban que el servicio de trenes y el trabajo realizado por ferroviarios había disminuido en su calidad en las últimas dos décadas:

\footnotetext{
"Se sabía que las reparaciones, el mantenimiento, eran deficientes. Se veía por la cancelación de servicios, interrupción de servicios, retrasos, pero además estaba en la mente de todos que el trabajo no era bueno. Entonces esta gente (los militares) venían a corregir todos los males, y se interesaron por esto. Habían hecho estudios como el PERT, Control de Calidad, se habían preparado para manejar los ferrocarriles." ${ }^{687}$
}

Para Rinaldi, en cambio, esta iniciativa no surgió porque el ferrocarril estuviera en crisis, sino "por llegar a hacer algo superior a lo que se hacía". "No era suficiente con una inspección, había que establecer una norma más estricta, que iba a durar en el tiempo", sostiene.

De acuerdo a Dall'Occhio, el control de calidad aplicado a tareas resultó "una revolución en cuanto al mantenimiento de trenes, brindando mayor seguridad en el servicio". De esta forma, si los inspectores determinaban, a partir de una evaluación por deméritos, que el coche no estaba en condiciones para circular, el Departamento tenía la potestad de impedirlo, aunque esto estuviera en desacuerdo con el jefe de los Talleres. Así, la metodología dio lugar tanto a la aceptación por parte de algunos empleados, como a la resistencia de otros. "A muchos no les gustó porque era mucha más la exigencia", dice Rinaldi. Sin embargo, como el ferroviario plantea "llegó un momento en que debieron aceptarlo y se estableció en toda la línea, de Buenos Aires a Mendoza, San Juan”. En el mismo sentido, Calcagni reconoce que si bien "el personal, en general, colaboró, también hubo algún sentimiento en contra de lo nuevo del personal antiguo, capataces, incluso de algún jefe". ${ }^{688}$ Pero lo determinante en el devenir del método no era el consenso o la falta de este por parte de los empleados, sino el acompañamiento del Estado y sus agencias a través del resto de políticas ferroviarias. Al menos, durante la gestión del presidente De Marchi y del administrador Sidders, este apoyo parece haber existido, aunque algunos testimonios dejan traslucir que se fue debilitando luego de que ambos dejaran sus cargos. Calcagni relata:

"Al principio teníamos pleno apoyo, mientras estuvieron en el Departamento los que lo
iniciaron y en la Gerencia los que lo respaldaron. Después su influencia se mantuvo,

${ }^{687} \mathrm{EN}^{\circ} 30$.

${ }^{688} \mathrm{EN}^{\circ} 21$ y 24. 
pero sin la fuerza inicial. Hubo una serie de cambios rápidos: la gerencia del San Martín desapareció; se fundió con la del Mitre y apareció la Región Central. Su gerente, un militar, era exgerente del Mitre (Jorge Carlucci). Control de Calidad continuó trabajando de la misma manera, aunque ya sin un apoyo como el de Sidders". ${ }^{689}$

De esta manera, cuando se fusionaron las gerencias del San Martín y Mitre, se amplió el alcance de control de calidad a esas dos líneas. Por eso el ingeniero manifiesta haberse visto favorecido en su carrera, aunque "a los militares de aquellos días ya no les interesaba tanto el control de calidad":

"Crearon la Gerencia de Control de Calidad, pero de corte tradicional. Estuve en esta gerencia un tiempo y luego pasé a la Gerencia de Mecánica. En la práctica, era el 'ojo' de la Gerencia de Mecánica puesto en talleres y depósitos de locomotoras; en este caso para observar el cumplimiento de las recomendaciones de los laboratorios regionales" (el subrayado es mío). ${ }^{690}$

Así, el concepto de control de calidad se fue extendiendo a otras líneas, de acuerdo al testimonio anterior de Calcagni, aunque sin el mismo nivel de exigencia. Marone recuerda también la ampliación de ese saber a otras líneas:

"Hasta ese momento nadie hablaba de control de calidad, pero después los militares lo repartieron en todas las líneas. Hasta tuvo una gerencia de control de calidad en Ferrocarriles Argentinos. Se hizo grande. ${ }^{\circ 691}$

Tanto lo que señala Calcagni como Marone es que la aplicación del control de calidad dependió de cada establecimiento o línea. Calcagni comenta:

“Cuando Control de Calidad pasó a otras líneas, cada uno la encaró como quiso, no creo que haya funcionado muy bien. Por ejemplo, en Mitre empezaron a trabajar, pero tomaron un camino completamente distinto, porque no se ocupaban de la reparación de vagones, ni de coches... nosotros controlábamos Vía y Obras y mientras los de Vía reparaban, se controlaban el trabajo que hacían. Eso no lo hacían en otras líneas. Siguieron con el laboratorio, con el control de materiales, pero material rodante, nada." 692

\footnotetext{
${ }^{689}$ EN 30.

${ }^{690} \mathrm{EN}{ }^{\circ} 30$.

${ }^{691} \mathrm{EN}^{\circ} 22$.

${ }^{692} \mathrm{EN}^{\mathrm{o}} 30$.
} 
En tanto Marone relata:

"En algunos establecimientos (el control de la calidad) fue importante y en otros no pasó nada. Dependía de los jefes. Algunos, cuando veían que había muchos rechazos se preocupaban, el jefe reunía a los operarios y capataces y les decía: 'Miren, tenemos muchos rechazos, vamos a tratar de mejorar y controlar más de cerca'. Entonces se preocupaban, tenían amor propio y veían cómo mejorar su establecimiento. Y había otros que no daban bolilla, le daba lo mismo que tuvieran 10 ó 20 rechazos. Lo que nunca se aplicó fue una serie de premios y castigos, porque vos a través de eso podés mejorar también. El que tiene muchos rechazos debería tener un castigo, no sé de qué forma, una reprimenda. Eso no se alcanzó a hacer." ${ }^{693}$

Esa aplicación dispar, según el establecimiento, muestra que, en lugar de ser una exigencia para los vehículos reparados, el control de calidad para las tareas pasó a ser, en muchos casos, una información de valor aportada a los responsables de la reparación. En definitiva, tal como sucedió con el sistema PERT, el proyecto inicial se frustró porque no fue acompañado por el resto de políticas empresariales que debieran haber asegurado, por ejemplo, el suministro de materiales necesarios para realizar un trabajo óptimo. Algunas anécdotas, como la siguiente de Calcagni, ilustran el problema:

\footnotetext{
"Una vez nosotros hicimos el control de vía, dejamos una cantidad muy grande de observaciones, tal sector tiene que remover, bueno. Y el jefe de departamento de Vía y Obras se quejó al gerente, y le dijo: 'si a mí me dan los elementos que necesito yo le hago una vía nueva, pero con lo que tengo no puedo hacer más que eso, entonces, qué me viene con control de calidad'. Entonces, es un problema del ferrocarril, porque todo el ferrocarril estaba en esas condiciones, no solo la Vía". ${ }^{694}$
}

Con todo, la experiencia de creación del Departamento contribuyó construir entre los trabajadores ferroviarios una idea que asocia este período con proyectos de avanzada, de vanguardia, tal como lo sugiere Calcagni:

"En aquel momento, nadie hablaba de control de servicios, me refiero a la bibliografía de antes. Pero hoy se aplica a control de servicios, en un banco, los tiempos de atención de caja; en un supermercado, igual. Antes era producción, ahora es todo, producción y 
servicio. Y nosotros lo aplicamos al servicio hace cincuenta años. Cuando cualquiera veía que era posible aplicarlo, pero nadie lo hacía." ${ }^{695}$

Calcagni también observa que esta metodología, que se implementó adecuadamente en sus inicios y deficientemente en los años subsiguientes, de acuerdo a su perspectiva, hubiera tenido algunas otras dimensiones en que insertarse:

\begin{abstract}
"Una vez el teniente coronel Sidders me preguntó si no podíamos aplicarlo a Tráfico, y me parecía que era abarcar mucho, pero sí, era posible. Eso habría sido muy interesante, pero ya era demasiado, y aceptó el argumento y no se hizo. En Tráfico sería cómo es el viaje de un pasajero, si está bien atendido, los baños, si tiene todo a su disposición, cómo es el servicio de un restaurante, etcétera." ${ }^{696}$
\end{abstract}

De esta manera, la memoria queda teñida, como con la experiencia del PERT, de lo que podría haber sucedido en la empresa si se hubiera dado apoyo a este tipo de políticas. "(Control de Calidad) debió haber tenido un éxito extraordinario, pero hubo resistencias", se lamenta Calcagni. Taberna, en tanto, expresa con claridad esa nostalgia arraigada al recuerdo, también presente en otros ferroviarios, de lo que debería haber sido y no fue:

“Calcagni siempre tuvo un perfil bajísimo. Él, su manera de vida y nada más. Para mí es un ingeniero que estuvo desaprovechado, como tantos en este país. Desaprovechamos a gente con mucha capacidad. Acá, lamentablemente, cuando se podrían haber hecho las cosas bien, sacaron al coronel Sidders, pusieron a otro gerente... O sea, lo que pasa siempre en nuestro país, hay intereses, y había intereses en que el ferrocarril no evolucionara, al revés, hacer lo que consiguieron hacer, hacerlo bolsa. Lo único que tenían que esperar era la oportunidad, como esperaron, no te lo voy a nombrar porque trae mala suerte." ${ }^{697}$

En definitiva, la creación del Departamento de Control de Calidad fue una experiencia que contribuyó a reforzar un imaginario asociado a la excelencia técnica local, en relación a la capacidad que sus especialistas tenían para brindar respuestas apropiadas a los problemas que el ferrocarril presentaba en un momento de crisis. Esta iniciativa, implementada paralelamente a la de Programación por Camino Crítico, cooperó para que los ferroviarios de Junín consideren

\footnotetext{
${ }^{695} \mathrm{EN}^{\mathrm{o}} 30$.

${ }^{696} \mathrm{EN}^{\mathrm{o}} 30$.

${ }^{697}$ Como muchos ferroviarios al hablar de sus penurias, Taberna realiza un salto temporal de décadas y se refiere, sin nombrarlo, al presidente Carlos Saúl Menem que concesionó los ferrocarriles del Estado en la década del noventa y puso fin a una historia de generaciones ferroviarias. Es conocida la asociación de Menem con la "mala suerte" por ser "mufa". Por eso muchos ferroviarios evitan nombrarlo.
} 
que el período (de finales de los sesenta e inicio de los setenta) fue uno de los de mayor esplendor en la historia del complejo ferroviario local. Por otra parte, esas dos experiencias, que demostraron el empuje del ferrocarril en Junín y de alguna manera fueron frustradas por las políticas ferroviarias posteriores, propiciaron que entre los trabajadores locales emerja un sentimiento de nostalgia, asociado al período, por lo que efectivamente sucedió y pudieron demostrar en conjunto, y por lo que podría haber sido si se hubiera dado apoyo a ambos proyectos. 


\section{Conclusiones}

En las décadas de 1940 y 1950 ingresar como trabajador en la empresa ferroviaria de Junín constituía un hito en la historia de vida de los jóvenes varones de escasos y medianos recursos, porque les permitía iniciar una nueva etapa con menor incertidumbre en el porvenir, y en consecuencia, imaginar la concreción de los proyectos que formaban parte de las expectativas de la época. Entre ellos, se contaban la formación de una pareja y su formalización a través del matrimonio, la construcción de la vivienda y del hogar familiar, la generación de una descendencia que tuviera aseguradas las condiciones materiales y simbólicas necesarias para su existencia, y el consumo de bienes y servicios de distinto tipo por parte de las familias ferroviarias. Todo ese conjunto de expectativas era posible de ser materializadas porque el salario de los ferroviarios se encontraba por encima de la mayoría de los salarios de quienes trabajaban en otras ramas de la producción, además de contar con beneficios adicionales propios del ferrocarril.

En efecto, puede afirmarse que durante las décadas mencionadas el empleo ferroviario se representaba en el plano imaginario como uno de los más codiciados de Junín, situación que comenzaría a transformarse a partir de la década de 1960. A partir de ese momento, la labor ferroviaria perdería paulatinamente su preeminencia frente a otras ocupaciones de la ciudad.

Si bien muchas representaciones vinculan las mejoras materiales en los ingresos de los trabajadores ferroviarios con las políticas que tuvieron lugar durante el gobierno peronista, algunos autores — como hemos visto en el capítulo 1- cuestionan esta afirmación. Plantean que existió una pérdida del poder adquisitivo de los trabajadores ferroviarios a partir de la Segunda Guerra Mundial que no se recuperó. A pesar de que se reconoce que hubo incrementos monetarios en los sueldos a partir de 1943, los salarios reales no alcanzaron los niveles previos a la contienda bélica. Además, existe coincidencia en que a partir de 1949 las medidas del gobierno fueron restrictivas respecto de los posibles aumentos salariales. ${ }^{698}$ Esto se evidenció con la huelga de 1950-51 en la cual los trabajadores ferroviarios le reclamaron al gobierno aumentos urgentes. Cabe preguntarse, entonces, por qué entre los testigos prevalece esta asociación que vincula los años del peronismo con los buenos ingresos. En parte, se puede explicar por el conjunto de beneficios promovidos por el gobierno junto a los gremios ferroviarios, tales como vacaciones en hoteles gremiales, servicios de salud de calidad, pasajes gratuitos para las familias ferroviarias, planes de vivienda, los cuales permitieron cumplir las

${ }^{698}$ Ver Cuestas y Vence Conti, 2017; Newland, 207; Fiorito, 2015; Ferreres, 2005. 
expectativas que eran parte del imaginario de la época. Pero también por las distintas oportunidades de formación que implicaban promociones concretas en la carrera ferroviaria.

Desde luego, debe señalarse que la determinación de muchos trabajadores del riel de esforzarse en la adquisición de saberes técnicos y conseguir acreditaciones educativas que les permitieran lograr ascensos en sus carreras, fue acompañada por un contexto político y social que promovió la educación de adultos. En efecto, previo a la nacionalización existía en Junín la Escuela Técnica Antonio Bermejo y la Escuela de Aprendices dentro de la empresa, mientras que, luego de la nacionalización, se creó la Escuela Fábrica Yapeyú y un ciclo superior en la Escuela Industrial en la que se brindaba el título de "técnico". Motivados por estas oportunidades de promoción en la carrera que se les presentaban a los trabajadores ferroviarios, un grupo de empleados realizó gestiones con el gobierno nacional para crear un ciclo superior en la Escuela Fábrica Yapeyú, consiguiendo el objetivo. En este sentido, pueden observarse en los testigos consultados el predominio de representaciones que valoraron la educación y capacitación como un modo de lograr el codiciado ingreso en esta empresa, así como los ascensos dentro de ella.

De esta manera, la formación institucionalizada jugó un rol importante en los ingresos y promociones en la empresa, en un contexto histórico en el cual pareciera comenzar a perder vigor la tradición en que los saberes de oficio eran transmitidos de manera informal, en el mismo ámbito laboral, del oficial al aprendiz. Así y todo, pueden observarse otras dimensiones tenidas en cuenta para ingresar y lograr promociones que no estaban vinculadas a la formación: previo a la nacionalización, la consideración subjetiva de la jefatura inglesa respecto de las aptitudes del operario y, posterior a ella, la pertenencia a determinado partido político, en especial, el peronista. Además, luego de la nacionalización, la pertenencia a una familia ferroviaria continuó siendo importante para el ingreso en la empresa, así como la antigüedad para los ascensos, sobre todo en los estamentos inferiores.

De acuerdo a las representaciones de los testigos, todos los empleados del ferrocarril ingresaban en la escala laboral más baja, pero tenían — potencialmente - la posibilidad de llegar al puesto más alto del ferrocarril. En ese recorrido, el trabajador debía atravesar distintos estamentos, entre los cuales, "el pase a oficina" constituía para los "talleristas" un nuevo hito en la carrera, ya que significaba un ascenso simbólico que, en principio, no necesariamente contemplaba una mejora material en el ingreso. Sin embargo, implicaba una superación respecto del tipo de tareas previas, en este caso, menos arriesgadas y con menos exigencias físicas, llevadas adelante en un contexto de mayor comodidad (en una oficina, en lugar de en un taller o a cielo abierto) y con el uso de una indumentaria que se identificaba con la del 
personal de dirección. Luego de ello, el ferroviario tenía la posibilidad de seguir ascendiendo a puestos de dirección y, potencialmente, hasta los más altos que ofrecía Junín (jefe de Talleres o del Departamento de Mecánica). De acuerdo a lo que manifiestan muchos testigos, la preparación en temáticas específicas jugaba un rol importante, ya que les brindaba confianza a los actores que se postulaban, a la vez que generaba consenso en los subalternos respecto de la autoridad que representaba el nuevo jefe.

Por consiguiente, la adquisición de conocimientos se presentaba como una dimensión determinante en las promociones y controlable por los mismos empleados, en cuanto a que un ascenso dependía - sobre todo- del propio esfuerzo. A partir de ello, se observa una fascinación en algunos trabajadores ferroviarios por el saber mismo, el cual podía llegar a convertirse en una búsqueda personal intrínsecamente ligada a una finalidad de su propia existencia. En esos casos, los ascensos eran interpretados, simplemente, una consecuencia lógica de los aprendizajes adquiridos. En otros testimonios se advierte que ascender implicaba lograr una capacidad de consumo superior y, por ende, la capacitación se transformaba en un importante aliciente económico. Así, el sistema de promociones del ferrocarril y las oportunidades que este brindó, produjo tanto trabajadores motivados por el deseo de aprender y educarse, como de ferroviarios movilizados por la posibilidad de progresar social y materialmente.

En definitiva, puede afirmarse que la posibilidad que el ferrocarril brindaba de beneficiarse con promociones y de ascender socialmente, de contar con un sueldo seguro y suficiente, de desarrollar las capacidades personales, en otras palabras, de lograr una vida acorde con el imaginario de la época, dio lugar a un proceso de identificación de los trabajadores con la empresa. En primer lugar, esto es expresado por los testigos en términos afectivos (“cariño", "devoción”, "amor" hacia el ferrocarril), lo que demuestra la profunda ligazón del ferroviario con la empresa, aludiendo también en sus testimonios al dolor y nostalgia por la pérdida del objeto del amor, a partir de la desaparición de la empresa del Estado en la década de 1990.

En segundo lugar, la identificación de los trabajadores en tanto "ferroviarios" es expresada a partir de la tarea específica que cada uno desarrolló en la empresa. Específicamente, esa identificación con el rol o la función, se vincula en los testimonios con el placer cotidiano de llevar adelante la actividad, con la satisfacción por los logros alcanzados, así como con la posibilidad de desarrollar habilidades específicas y adquirir conocimientos. En otras palabras, los ferroviarios exhibían su orgullo por considerar que su propia tarea era fundamental, importante, para lograr un desenvolvimiento satisfactorio del ferrocarril en su conjunto. Se 
percibían a sí mismos como parte de una totalidad que se orientaba a la prosecución de un mismo objetivo: brindar un servicio ferroviario de calidad.

En tercer lugar, puede observarse en los testigos una identificación hacia el complejo ferroviario de Junín, manifestada a partir del orgullo por pertenecer a este. Dicha identificación hacia el centro ferroviario local es expresada a partir de dos atributos o características principales: por un lado, el alto nivel de calidad de los trabajadores de Junín, coincidiendo, en muchos de los testimonios, en que eran "los mejores" de la ciudad; $y$, por el otro, la capacidad técnica del complejo ferroviario local, subrayándose especialmente la magnitud y autonomía de los talleres de Junín en tanto complejo industrial. De allí que se construyó y consolidó una identidad asociada al centro ferroviario local, a partir de representaciones sobre la excelencia de los recursos humanos, altamente calificados, así como sobre la capacidad de producir resultados de calidad.

En cuarto lugar, existió una identificación a partir de la representación de "familia ferroviaria" que aludía a una manera de simbolizar al conjunto de los trabajadores de la empresa a lo largo y a lo ancho de todo el país, pero que en lo concreto se sustentaba a partir de las interacciones cotidianas de los ferroviarios en el ámbito laboral. En rigor, se puede afirmar que existieron comunidades de afecto que estaban condicionadas por los espacios comunes de trabajo y que se fundaban en el tiempo compartido entre trabajadores, no solo de manera diaria, sino a lo largo de toda la carrera y de la vida: desde el ingreso hasta el retiro, desde la adolescencia hasta la vejez. Ese tiempo no solo incluía la jornada laboral, sino que se extendía hacia los momentos de ocio, a partir de distintas actividades deportivas y celebraciones que también abonaron en la representación de "familia ferroviaria". Familia que involucraba tanto relaciones simétricas referidas en términos, de "amistad", "afecto" y "compañerismo", así como relaciones asimétricas entre jefes y subalternos en las que el modo de vinculación predominante y esperado estaba fundado en el "respeto" entre actores desiguales, involucrando en ambos casos valores, normas y sanciones. Esa desigualdad se fundaba en la autoridad que otorgaba tanto la estructura organizacional, a partir de los distintos escalafones, como en el mayor conocimiento que el personal jerárquico poseía. No obstante, es preciso aclarar que, en los momentos de ocio, en el marco del disfrute por el festejo o la competencia deportiva, las desigualdades existentes entre actores tendían a diluirse momentáneamente y se daba lugar a vínculos más horizontales.

Por último, la identidad ferroviaria local también se constituyó a partir de representaciones que plantearon que el desarrollo cultural, social, artístico, técnico y deportivo de Junín estuvo íntimamente ligado a la existencia del ferrocarril en la ciudad y a la 
participación de sus trabajadores. Así, los testigos señalan que los mejores artesanos o especialistas en oficios, como así también los mejores deportistas, docentes, músicos de la ciudad, habían sido ferroviarios. De ello se infiere que existía la idea muy arraigada de que la sociedad juninense mejoraba en su conjunto por la acción que desarrollaban los actores ferroviarios, al mismo tiempo que la empresa se beneficiaba de los miembros de esa misma sociedad.

Recapitulando, la identidad ferroviaria en el colectivo estudiado puede ser explicada a partir distintas dimensiones: por la pertenencia a la empresa que posibilitó cumplir con las expectativas individuales y que eran parte del imaginario de la época, por el rol que cada actor ejerció en algunas de las dependencias que había en Junín, por la percepción de integrar una comunidad diseminada en todo el país que poseía ciertas normas y valores a partir de la representación de "familia ferroviaria", o por ser parte de un complejo local cuyos actores apuntaban a la mejora continua y se caracterizaban por orientarse al logro de resultados de máxima calidad, tanto en sus intervenciones internas (dentro de la empresa) como externas (en la ciudad de Junín).

Del mismo modo, el "afuera constitutivo" que permitió construir la identidad ferroviaria en Junín, varía de acuerdo a las dimensiones que el testigo tome como referencia en cada instancia discursiva. Desde una perspectiva más general, el "ser ferroviario" se construyó dejando afuera a todos aquellos que no pertenecían a la empresa, por ejemplo, a trabajadores de otros rubros. Tampoco reviste demasiada dificultad comprender la construcción identitaria de los ferroviarios de Junín, en oposición a otros centros de envergadura, como los Talleres de Tafí Viejo.

Por el contrario, la problemática cobra mayor complejidad cuando la definición de ser ferroviario se estableció a partir de la actividad u oficio desarrollado, a la dependencia o a la función, porque, entonces, los límites simbólicos eran otros trabajadores del riel, lo cual hacía peligrar el proceso de identificación mismo. Esto, sin embargo, parece ser resuelto por los testigos cuando enuncian un objetivo mayor, un horizonte común compartido por el colectivo: brindar un servicio ferroviario de calidad a la sociedad. A la vez, también se advierte que el "proceso de cierre" se constituyó a partir de las alusiones negativas externas hacia los trabajadores del riel ("los ferroviarios son vagos") que suscitaron la reacción o defensa de los valores o atributos considerados propios del colectivo.

Parece de más difícil resolución aun cuando el "ser ferroviario" se caracterizó a partir de determinados valores y normas de acción, dejando afuera, en esta "producción de efectos de frontera" a otros ferroviarios que, por ejemplo, no eran solidarios, anteponían sus intereses 
personales (antes que los colectivos) o no respetaban las normas establecidas para las promociones, por poner de relieve solo algunos de los planteos expuestos por los testigos. Si bien, como plantea Hall, la identificación es proceso de articulación (y no una fusión) que contempla "discursos, prácticas y posiciones diferentes, a menudo cruzadas y antagónicas" (2003: 14), puede señalarse que fue en la dimensión de los valores y de las normas cuando mayormente parece haber peligrado dicha construcción.

Así y todo, puede considerarse que la identidad ferroviaria en Junín fue un proceso exitoso, ya que actores que ejercieron diversas actividades y con distinto grado de responsabilidad, en establecimientos o edificios distantes entre sí, se representaron a sí mismos como "ferroviarios", coincidiendo en la selección de ciertos recuerdos y representaciones sobre el pasado común. Esto, sin embargo, no implica negar la existencia de tensiones dentro del colectivo, a partir de valores en pugna, que pudieron desestabilizar el proceso de identificación. Futuros trabajos podrán determinar si estas tensiones que, en nuestro caso, se describen para el período 1948-1973, se habrían consolidado en las dos décadas posteriores y si podrán brindar algunas pautas que permitan comprender la disolución de la empresa del Estado en la década de 1990 y el fin de la historia colectiva de los ferroviarios.

Algunos de los sentidos que los ferroviarios tomaron como valores para construir su identidad estaban relacionados con la gestión británica en el ferrocarril, previa a la nacionalización de 1948, la cual sintetizan como "escuela inglesa". Esta fue una experiencia transitada por ellos mismos al inicio de la carrera, o narrada por sus compañeros y familiares, y recuperada, reconstruida y actualizada en las prácticas posteriores de estos trabajadores. Esta "escuela inglesa" aludía a un tipo de enseñanza transmitida por los jefes británicos y aprendida por los trabajadores locales que se orientaba a la eficiencia y a la calidad, tanto en el trabajo como en el servicio ferroviario; lo que implicaba un correcto aprovechamiento de los recursos materiales y humanos, un control riguroso de los tiempos, tanto de los trabajadores como de los servicios de trenes, y una exigencia estricta hacia el cumplimiento de las tareas. Subsidiarios a estos valores centrales, los trabajadores ponderaron positivamente otras asociaciones con "lo inglés", tales como el orden y la limpieza en las instalaciones, la disciplina en el trabajo, la rectitud y la practicidad (en contraposición a la administración burocrática posterior). Este imaginario fundado en las memorias vinculadas a la gestión británica jugó un papel muy importante en las prácticas laborales posteriores a la nacionalización y confrontó con las nuevas modalidades que emergieron, cuando, de acuerdo a las representaciones de los testigos, la eficiencia y la calidad dejaron de ser los valores orientadores del trabajo colectivo. 
Otro de los sentidos asociados a la gestión británica estaba vinculado con la valoración de la jefatura hacia los conocimientos de los ferroviarios, tanto para los ingresos a la empresa como para las promociones dentro de ella. Por consiguiente, durante la "época inglesa", de acuerdo a las representaciones de los testigos, solo los mejores operarios ingresaban al ferrocarril (a partir de las calificaciones obtenidas en la Escuela de Artes y Oficios o los exámenes que habilitaban para el ingreso) y los ascensos en la escala laboral estaban regidos por el mérito personal. Este criterio siguió siendo defendido por muchos de estos trabajadores, pero habría comenzado a convivir, luego de la estatización de la empresa, con otros valores tenidos en cuenta para ingresar y progresar, tales como la pertenencia al partido peronista o los vínculos personales con los representantes gremiales y políticos.

A partir de lo que manifiestan muchos de los entrevistados, el poder que comenzó a tener el gremio de la Unión Ferroviaria, identificado con el peronismo, en tanto actor dentro de la estructura de la empresa, implicó una crisis respecto de las normas previas que regían para la movilidad del personal. En ese sentido, se puede observar la existencia de una tensión entre las tradiciones previas, defendidas por muchos trabajadores, y los nuevos valores y prácticas emergentes, vinculadas con el nuevo rol del gremio y con la influencia de la política partidaria dentro de la empresa. Esta tensión no lograría resolverse en favor de los valores defendidos por los testigos, generando aflicción y frustración entre los trabajadores de la "vieja escuela"; pero tampoco en favor de los actores emergentes, ya que la resistencia hacia el proceso de cambio parece haber sido significativa. De cualquier forma, es posible advertir, como consecuencia de estas transformaciones, un deterioro en el prestigio de la profesión ferroviaria y en la calidad del servicio ferroviario que se hace evidente, fundamentalmente, a partir de la década de 1960.

Otra de las transformaciones que tuvieron lugar luego de la nacionalización involucra a las relaciones laborales, las cuales, de acuerdo a los ferroviarios que valoran la "escuela inglesa", eran "más respetuosas" durante la gestión británica, sobre todo desde el personal subalterno hacia el superior. De esta forma, los trabajadores del riel valoran un tipo de trato entre los "jefes ingleses" y los operarios argentinos, en el que los subalternos solo podían dirigirse al superior directo en ocasiones y con motivos fundamentados. En efecto, se establecía una distancia entre ambos actores, que no solamente comprendía a las interacciones cotidianas, sino que tenía un correlato, sobre todo en las oficinas, en la disposición de los espacios: mientras el superior podía visualizar fácilmente los movimientos de los empleados, estos últimos tenían dificultad de acceder al "territorio" exclusivo del jefe.

Por otra parte, de acuerdo a las representaciones de los testigos, durante la administración británica las decisiones tomadas por la "superioridad" debían ser acatadas sin 
cuestionamientos. En caso contrario, la jefatura contaba con la potestad de sancionar a los empleados, llegando incluso a la posibilidad de despedir a quien hubiera incurrido en una falta considerada grave. Todas estas características en la modalidad de vinculación entre jefes y subalternos fueron sintetizadas por la "rigurosidad" del sistema inglés, permitiendo explicar, bajo este razonamiento, la eficiencia de la empresa gestionada por los británicos.

Precisamente, uno de los valores que los trabajadores argentinos intentaron recuperar, a partir de las representaciones sobre los británicos antes planteadas, estaba relacionada con este tipo de trato respetuoso que se le debía tener al personal superior. Sin embargo, a diferencia de lo que sucedía durante la administración británica, ese respeto no solamente estaba fundado en lo establecido por el escalafón laboral, sino también en el conocimiento que en la materia específica detentaban los jefes, siendo el consenso importante en esa construcción de la autoridad.

En la misma medida en que los trabajadores locales tomaron como valor aquel respeto para sus propias prácticas laborales, también desecharon otras que consideraron humillantes por parte de los ingleses. Durante la gestión del ferrocarril estatal, además, introdujeron nuevas prácticas que apuntaban a generar un trato más “cercano" y "humano" entre jefes y subalternos, al entender que el respeto debía ser algo mutuo y no una obligación solo de los obreros. Esto estuvo influenciado, probablemente, con las nuevas representaciones sociales sobre el rol del trabajador en la sociedad, así como con el poder creciente del sindicato de la Unión Ferroviaria. Sin embargo, es posible advertir la añoranza por el respeto perdido hacia los jefes, lo cual estaba relacionado con una disminución de poder de este agrupamiento para tomar decisiones en relación al trabajo y al ingreso del personal, así como para implementar sanciones drásticas hacia los subalternos.

Se advierte, entonces, una tensión entre el sindicato y el personal de dirección durante el período estudiado, por lo que ambos actores parecen tener distinto grado de influencia y capacidad de incidir en cada contexto histórico particular. Concretamente, durante la mayoría de los gobiernos constitucionales este gremio habría ejercido sus prácticas con mayor libertad, mientras que durante los gobiernos dictatoriales se vio limitado. Probablemente, esto condujo a que algunos de los integrantes del personal de dirección plantearan que, durante los gobiernos ilegítimos, se actuó, sin embargo, con mayor justicia en relación a las promociones y que en este contexto ellos mismos pudieron "progresar", lo que deja entrever la existencia de un conflicto insoluble, capaz de poner "en jaque", en esas circunstancias, la representación de "familia ferroviaria". Esto, teniendo en cuenta, que, inversamente, algunos representantes gremiales manifiestan haber sido perseguidos durante los gobiernos de facto. 
Más allá de estas tensiones, puede sostenerse que en el plano simbólico la experiencia británica quedó asociada a la capacidad de administrar apropiadamente la empresa a partir de valores y prácticas mencionadas antes (tales como la búsqueda de la eficiencia y calidad en el trabajo y en los servicios ferroviarios, la valoración hacia los conocimientos y esfuerzo de los trabajadores para el ingreso y las promociones, el respeto hacia la jefatura, etc.). En contraposición a ello, la administración del Ferrocarril del Estado resultó, desde esta óptica, incapaz de gestionar adecuadamente a la empresa, a partir de los mismos criterios. Desde la perspectiva de los actores, entonces, la nacionalización del ferrocarril en 1948 se presenta como el hecho que da lugar al inicio de la "decadencia" y "desgracia" de esa empresa tan amada por estos trabajadores y constituye el acontecimiento que, incluso, permite explicar su fracaso, el cual se evidencia en la década de 1990.

A pesar de estas representaciones contrapuestas y complementarias referidas a las administraciones británica y nacional, existen algunos recuerdos expresados por los actores que permiten complejizar y matizar la experiencia relatada. En principio, la rectitud e idoneidad de los británicos queda puesta en cuestión a partir de algunos acontecimientos puntuales, como el alcoholismo de la autoridad máxima en Junín, que lo llevó a tomar medidas arbitrarias y no regidas por los principios con los que se asociaba a "lo inglés". A la vez, la dificultad de los argentinos de ascender a puestos de dirección durante la administración británica también pone en duda aquella representación que planteaba la valoración que los ingleses hacían de las capacidades individuales y del esfuerzo en el estudio por parte de los trabajadores del riel.

Por el contrario, los trabajadores locales tuvieron mayores posibilidades de promocionarse en altos puestos directivos durante la gestión estatal del ferrocarril, la cual implementó algunos mecanismos objetivos, que antes no existían, para ponderar las capacidades. Esto también pone en entredicho la asociación entre nacionalización y poca valoración de las capacidades individuales. En la misma línea, fue a partir de la década de 1950 que surgieron nuevos espacios de formación en Junín que habilitaron a estos trabajadores a capacitarse y obtener titulaciones que les permitieron ocupar puestos de dirección, oportunidades que anteriormente no tenían.

Aunque las representaciones que asocian la nacionalización con el inicio de la "desgracia" o "decadencia" puedan resultar desmedidas si se tiene en cuenta la importancia de un acontecimiento que prometía definir una política ferroviaria nacional acorde a las necesidades de la sociedad, en rigor, el modo en que la nueva empresa del Estado enfrentó los problemas que ya arrastraba la condujo a una situación crítica. A pesar de que la falta de inversión en material rodante y mantenimiento durante las últimas décadas de la administración 
británica se intentó paliar con algunas adquisiciones, estas fueron insuficientes frente a un incremento en la demanda del servicio de pasajeros. Esto condujo a una sobreexplotación del material rodante y a un mayor deterioro del mismo. Por otra parte, a la vez que se incrementó el transporte de pasajeros, decreció notablemente el de cargas, como consecuencia de la competencia del transporte automotor. Ante todo, mediante una política que sostuvo bajas las tarifas y aumentó los gastos de salario destinados al personal, se produjo un desequilibrio entre ingresos y egresos que continuó y se profundizó durante las décadas siguientes. De esta manera, el déficit ferroviario resultó el gran problema enunciado por los gobiernos que se sucedieron a Perón, junto con la necesidad de modernizar y mejorar la tecnología disponible.

A diez años de la nacionalización, el ferrocarril presentaba serias deficiencias en cuanto a la calidad de su servicio (demoras, falta de limpieza) al mismo tiempo que se instalaba como problema el déficit ferroviario. Según se proponía, el programa de gobierno de Frondizi apuntaba a lograr la autonomía y sacar de la dependencia al país, para lo cual era prioritario el desarrollo de las industrias de base y el logro del autoabastecimiento petrolero. Bajo este modelo, se dio lugar a la instalación de las empresas automotrices y se proyectó la construcción de carreteras, lo cual significó para el ferrocarril la pérdida definitiva de la hegemonía como medio de transporte en el país. En efecto, el desarrollo del ferrocarril estaba asociado con una etapa que se pretendía dejar atrás, cuando la economía nacional estaba regida por la actividad agroganadera. De esta manera, el gobierno desarrollista concebía al sistema ferroviario complementario de otros y, para funcionar adecuadamente, de acuerdo al modelo de país que se intentaba proyectar, era prioritario modernizar la tecnología disponible y el material rodante con el objetivo de lograr un servicio eficiente.

Una de las primeras medidas que tomó el nuevo gobierno fue la incorporación de locomotoras diésel para reemplazar a las locomotoras a vapor. Resulta significativo que muchos ferroviarios evoquen con dolor la destrucción de las máquinas a vapor que tuvo lugar durante esta etapa, y que liguen esa imagen de desguace con la supuesta destrucción que Frondizi intentó llevar adelante en la empresa ferroviaria. De esta forma, el recuerdo del desarmado de las máquinas a vapor para convertirlas en chatarra se transforma en una suerte de ícono de la política desarrollista que intentaba, desde esta perspectiva, desmantelar a la empresa. Así, las medidas del gobierno que introdujeron tecnología moderna a través de la incorporación de locomotoras diésel, en lugar de quedar asociadas a la búsqueda de un servicio más eficiente, quedaron ligadas a una etapa de desmoronamiento, desintegración y decadencia de la empresa ferroviaria. 
Es posible que la potencia de tal imagen (la destrucción física de las máquinas a vapor) que ha permanecido en la memoria del colectivo radique en su capacidad de sintetizar el definitivo abandono de una etapa valorada por los ferroviarios asociada a la administración británica, así como en la potencialidad para expresar los sentimientos que este acontecimiento suscitó: desamparo, desconcierto, angustia. Pero también es probable que su fortaleza radique en el recuerdo de algunos otros hechos asociados al gobierno frondizista, que causaron profundo dolor en la comunidad ferroviaria en su conjunto. En primer lugar, la movilización del personal ferroviario, que conllevó la presencia de los militares en todas las instalaciones del ferrocarril para controlar a los trabajadores y castigarlos a partir de normas castrenses, imponiendo prácticas humillantes y dejando en suspenso los reglamentos internos de la empresa. En segundo lugar, la huelga del 61 en la que se enfrentaron encarnizadamente el gobierno frondizista y los dos gremios ferroviarios más importantes durante más de cuarenta días, dejando secuelas agudas en la "familia ferroviaria", la cual pasó a ser más reducida (por los retiros voluntarios fomentados por la administración) a la vez que menos cohesionada (por las divisiones internas que puso en evidencia).

Resulta innegable que ya en este momento la actividad ferroviaria estaba dejando de ser aquella fuente laboral prometedora que los jóvenes de escasos recursos aspiraban a conseguir para tener asegurado su porvenir. Consecuentemente, las escuelas de formación técnica que existían en Junín iban dejando, paulatinamente, de ser los espacios a los que esos jóvenes acudían para capacitarse, con la esperanza de ingresar al ferrocarril. Al mismo tiempo, también la empresa como tal estaba perdiendo su prestigio por la disminución de la calidad de los servicios, lo cual implicó un deterioro en la reputación de la que gozaban los ferroviarios en la sociedad. Todo ello da cuenta de un proceso de degradación que, precisamente, ponía en cuestión el imaginario de calidad en el que los trabajadores de Junín se habían basado para construir su identidad.

En este marco, el Plan de Jubilaciones Anticipadas y de Indemnizaciones para el personal ferroviario, que tuvo lugar durante el gobierno de Frondizi, profundizó el proceso de degradación de la profesión ferroviaria, ya que implicó una disminución significativa del personal de más del 20\% para 1962. En efecto, el ferrocarril ya no constituía una fuente laboral tan atractiva como lo había sido en el pasado. Pero más significativo aún, pudo ser la huelga del 61 ya que el imaginario de la comunidad unida se vio seriamente amenazado por los conflictos al interior del colectivo.

Esta huelga nacional fue una respuesta de los trabajadores ferroviarios al plan de reducción de personal de la administración de Frondizi, así como al cierre de ramales y talleres. 
Si bien buena parte de las memorias de otros centros ferroviarios del país evocan este suceso como un hecho de unidad de los trabajadores en defensa de la fuente de trabajo y en contra de las políticas frondizistas, el análisis de lo acontecido en Junín demostró, por el contrario, que el conflicto generó divisiones entre quienes adhirieron a la huelga y quienes no. Es en este sentido que la huelga tuvo consecuencias en el proceso identitario. Concretamente, las diferencias entre el personal de dirección, por un lado, y los sindicatos de la Unión Ferroviaria y La Fraternidad, por el otro, llegaron a un punto culmine en los últimos días de la huelga, acusando los segundos a los primeros de colaborar con los funcionarios del gobierno en perjuicio de los trabajadores que resistían. Dado que los gremialistas asociaban la identidad ferroviaria con la solidaridad entre los trabajadores en determinados acontecimientos, como las huelgas, dejaron afuera de esas representaciones (o definiciones de lo que era ser un ferroviario) a quienes no los apoyaron: específicamente, al personal de dirección. No obstante, el análisis de los testimonios mostró que muchos de los trabajadores que sí adhirieron a la huelga, lo hicieron pasivamente, posiblemente para evitar conflictos con el gremio al que pertenecían, sin ser conscientes de la situación crítica que, de acuerdo a los sindicatos, ameritaba el acto de resistencia extraordinario.

Estos recuerdos locales permiten cuestionar memorias de otros centros ferroviarios del país que tomaron, entre otros materiales, a la huelga del 61 para construir la identidad ferroviaria, ya que, según plantean, habría permitido unir a la mayoría de los trabajadores a partir de determinados valores y proyecciones. Inversamente, los olvidos y confusiones hallados en los testigos de Junín, incluso los intentos de eludir la rememoración, ponen en evidencia que su evocación podría resultar un riesgo a la representación de "familia ferroviaria" que intentaron sostener a lo largo de su relato. Sin embargo, esa "memoria suprimida", como le llama Portelli, al aflorar, como efectivamente ocurrió en algunos testigos, podría contribuir en la comprensión del devenir posterior del medio de transporte. Futuras investigaciones podrán intentar determinar si el proceso de desmembramiento que se empieza a advertir en esta huelga, el cual se expresa a partir de representaciones diversas sobre la identidad ferroviaria, continúa en las décadas siguientes e incide en el desenlace que finalmente tiene la empresa estatal en la década de 1990; un final que es también el epílogo de la tragedia narrada por los ferroviarios para referirse a su propia historia de vida en la empresa.

De lo que parece no haber discusión entre los ferroviarios es en considerar a la década del sesenta como el final de una etapa de esplendor para el ferrocarril a partir de distintas dimensiones: la pérdida de la hegemonía del transporte ferroviario frente a la competencia del transporte automotor, la disminución en la calidad de los servicios y el desprestigio de la 
profesión ferroviaria. Consecuentemente, los distintos gobiernos de esa década proyectaron diferentes planes que apuntaron a enfrentar los problemas considerados más relevantes en aquel momento: disminuir el déficit, incrementar la demanda y mejorar el servicio a través de la modernización de maquinaria y material rodante. En particular, una de las iniciativas más valoradas localmente tuvo lugar durante la presidencia del general Juan Carlos De Marchi (1967-1971) en Ferrocarriles Argentinos, al final de aquella década. Los ferroviarios asocian esta etapa con un período mejoramiento del servicio ferroviario en general, así como de jerarquización de los talleres Junín en el país, a partir de políticas y prácticas que plantearon el resurgimiento de viejos valores orientados a la calidad y a la eficiencia, pero que, sin embargo, lo hacían a partir de proyectos que eran novedosos para la época. De esta manera, las experiencias de esta etapa brindaron materiales valiosos para recomponer la identificación ferroviaria que en Junín estaba asociada a la alta calidad de los recursos locales, así como de los resultados del trabajo.

Uno de los fundamentos que los testigos emplearon para explicar la importancia que durante este período tuvieron los Talleres Junín fue el vínculo afectivo que tenía el presidente de la empresa, general De Marchi, con la ciudad y con el ferrocarril, por tener familiares juninenses, algunos de los cuales pertenecían a la empresa. Pero, además, los testigos interpretan que la preeminencia de Junín estuvo relacionada con la capacidad técnica del centro ferroviario local y la alta calidad de sus trabajadores. Entre los acontecimientos que los actores destacan para demostrar la importancia que los talleres locales adquirieron fue su declaración como "piloto", en 1968, por parte de Ferrocarriles Argentinos. En definitiva, los testigos coinciden en que se trató de un corto período de florecimiento para el ferrocarril en Junín, luego de la ofensiva frondizista y de las tensiones entre valores que caracterizaron al peronismo y al período posperonista.

De acuerdo a los testigos, existen dos experiencias significativas a partir de las cuales el complejo ferroviario de Junín habría sido capaz de demostrar su capacidad técnica y así erigirse como uno de los más importantes del país. Una de ellas se denominó "Programación por Camino Crítico" (también llamada “Sistema PERT”), la cual se orientaba a incrementar la cantidad de coches reparados, disminuyendo, simultáneamente, la cantidad de horas destinadas a la reparación. En rigor, PERT era una técnica militar norteamericana que fue implementada en Junín por un ingeniero que estuvo en el Departamento de Mecánica durante un corto período y trabajó en la aplicación del método junto a técnicos ferroviarios locales. Mediante la aplicación de este método, según los ferroviarios que participaron, se logró incrementar la 
cantidad de vehículos mensuales reparados, aún con menos cantidad de personal; lo que permitió, a la vez, comenzar a reparar coches de otras líneas.

Otra de las iniciativas destacadas por los testigos del período fue la creación del Departamento de Control de Calidad para la línea San Martín, propuesta que fue realizada por un ingeniero de Junín a las máximas autoridades de los ferrocarriles. En rigor, este proyecto coincidía con la orientación que los ingenieros militares que estaban a cargo del ferrocarril pretendían darle a la empresa, al separar las tareas de control de las de planificación y ejecución. Esta iniciativa resultaba novedosa para la época porque ampliaba la medición de la calidad que, hasta el momento, estaba circunscripta a los materiales, a las tareas de reparación. De esta manera, desde un espacio que gozaba de autonomía respecto del Taller se determinaba la calidad de cada una de las tareas llevadas adelante en el centro reparador, a partir de parámetros objetivos que habían sido analizados y establecidos previamente. El Departamento, hipotéticamente, era capaz de limitar la salida de un tren, si encontraba que no estaban dadas las condiciones de seguridad aceptables, así como de evaluar la calidad de los establecimientos y de cada una de las tareas realizadas.

En conjunto, ambas iniciativas (PERT y Control de Calidad) se orientaron a dar respuesta a la demanda social de mejorar el servicio ferroviario, optimizando el uso de recursos humanos y materiales. En ese sentido, estas experiencias tomaron como insumo valores anteriores asociados a la administración británica que permanecieron en el colectivo ferroviario durante los veinte años posteriores a la nacionalización en relación a las definiciones de cómo debían ser los resultados del trabajo ferroviario y que, en particular, durante la gestión de De Marchi encontraron un contexto propicio para expresarse. Cabe aclarar que, si bien se advierte una continuidad en cuanto a los valores que orientaban la labor, los métodos empleados, en rigor, se correspondían con las técnicas más modernas de la época que apuntaban a establecer parámetros objetivos para definir los mencionados valores de calidad y de eficiencia, en contraposición a la inspección práctica que caracterizó a los ingleses.

En suma, tanto PERT como Control de Calidad permitieron consolidar en Junín una identidad asociada a la capacidad técnica y a la excelencia de la mano de obra local. Las dificultades que tuvieron ambas iniciativas de desarrollarse más allá de la gestión de De Marchi y obtener el apoyo político necesario para continuar, no impidieron que la memoria de estos ferroviarios quedara anclada en esas vivencias que parecían definir quiénes eran, de qué eran capaces y qué habrían podido hacer. Así, se trató de experiencias que, a la vez que produjeron sentidos para construir la identidad y el imaginario ferroviario, también dieron lugar a 
sentimientos de frustración, impotencia y nostalgia a partir de las conjeturas de lo que los ferroviarios habrían podido lograr si se les hubiera dado apoyo a estos proyectos. 


\section{Referencias bibliográficas}

Abric, J. C. (1994). Prácticas sociales y representaciones. México: Ediciones Coyoacán. Agostini, L. (2009). La huelga de los obreros ferroviarios de Laguna Paiva en 1961. Organización y formas de acción. En Ferroviarios. Sinfonía de acero y lucha (1. a ed.). La Nave de los Locos.

(2014). Oficio, memoria y lealtad. Elementos constitutivos de la identidad fraternal durante la huelga ferroviaria de 1961. Historia Regional, XXVII (32), 109-124.

(2017). Tras los pasos de "Paiva La heroica". La comunidad ferroviaria de Laguna Paiva movilizada en 1961. En Lugares de lo colectivo en la historia local (1. ${ }^{\text {a }}$ ed., pp. 101-121). María Muratore Ediciones.

Agostini, L., \& Brandolini, C. (2016). El ocaso de Laguna Paiva, "la ciudad del riel". Repercusiones y representaciones de los trabajadores ferroviarios sobre el cierre de los talleres. Páginas Revista Digital de la Escuela de Historia, 8(18), 97-119.

Agulhon, M. (1994). Historia vagabunda: etnología y política en la Francia contemporánea. Universidad Nacional Autónoma de México, Instituto de Investigaciones Dr. José María Luis Mora.

Arguto, F. (2013). La creación de la Universidad Obrera Nacional: técnica y progreso durante el peronismo. X Jornadas de Sociología. Facultad de Ciencias Sociales, Universidad de Buenos Aires.

Ayuso, M. L., \& Arata, N. (2009). De artesanos a trabajadores: dos estudios sobre la regulación de los saberes del trabajo. Educação Unisinos, 13(3), 211-219.

Ayuso, L., Jiménez, A., Sessano, P., \& Telias, A. (2010). Sistema de saberes del trabajo ferroviario: soporte de una construcción socialmente productiva. En Vías Argentinas (1. ${ }^{\text {a }}$ ed., pp. 59-82). Milena Caserola.

Ayuso, M. L. (2017). Red de Escuelas Técnicas de Autogestión Obrera. La Fraternidad, entre la política y la pedagogía (1887-1927) (1. ${ }^{\mathrm{a}}$ ed.). Prohistoria Ediciones. 
(2019). Aportes desde la pedagogía a los estudios del trabajo: las propuestas de formación de los trabajadores ferroviarios de "La Fraternidad" entre 1887 y 1927. Prohistoria. Historia, politicas de la historia, 9(25).

Baczko, B. (1991). Los imaginarios sociales. Memorias y esperanzas colectivas. Ediciones Nueva Visión.

Badaloni, L. (2007). Prácticas empresariales paternalistas: sus alcances y límites en el disciplinamiento y control de la mano de obra. El caso del Ferrocarril Central Argentino durante las primeras décadas del siglo XX en Rosario y alrededores. Anuario INHES, 22, 507-524.

(2010). Saberes Técnicos, libros y protestas. La Escuela de foguistas, maquinistas y personal de Locomotoras de la sección Rosario del Ferrocarril Central Argentino. Galileo Galilei, 1, 109-134.

(2011). La familia ferroviaria a principios del siglo XX. Bienestar y lealtades de hierro en el Ferrocarril Central Argentino. En Conflictividad y consentimiento en las relaciones laborales. Prácticas obreras y empresarias en la Argentina del siglo XX. Prohistoria Ediciones.

(2013). Control, memoria y olvido. «Marcha de la Paz» y huelga ferroviaria durante el primer gobierno peronista. Programa Interuniversitario de Historia Política del siglo $X X$. http://historiapolitica.com/datos/biblioteca/trabajadoresperonismo_badaloni.pdf (2016). Ingenieros británicos, ferroviarios comunistas y organización del trabajo en los talleres del Ferrocarril Central Argentino en las primeras décadas del siglo xx. Revista de Historia Industrial, XXV (63).

(2017). Listas negras y protesta obrera. El Ferrocarril Central Argentino y sus trabajadores durante la Primera Guerra Mundial. Historia Crítica, (66), 45-65.

Banfi, J. M. (2017, septiembre 5). Expansión ferroviaria, desarrollo urbano y expansión de los servicios en la construcción del territorio bonaerense: el caso de Junín (BA) 19201960. SIMPOSIO: Transportes e serviços nos mercados regionais e nacionais na América Latina (séculos XIX e XX), Valencia, España. 
Barela, L., Conde, L. G., \& Miguez, M. (2009). Algunos apuntes sobre historia oral. Inst. Histórico de la Ciudad de Buenos Aires.

Barrancos, D. (1989). Organización obrera y formación laboral a principios de siglo: Los maquinistas ferroviarios y los trabajadores gráficos. Buenos Aires: Universidad Tecnológica Nacional.

Benjamin, W. (2001). Tesis de filosofía de la historia. Barcelona, España: Etcétera.

Bertaux, D. (1989). Los relatos de vida en el análisis social. Historia y fuente oral, 8796.

Bisso, M., \& Carnagui, J. L. (2005). Legislación sobre el" terrorismo" y posición de los partidos políticos en la Argentina de los años 60. In IV Jornadas de Sociología de la UNLP (La Plata, 23 al 25 de noviembre de 2005).

Candau, J. (2006). Antropología de la memoria. Nueva visión.

Castillo, F. (2012). Memorias y peronismo: narrar las experiencias históricas de los ferroviarios, Jujuy, Argentina. Cuadernos de la Facultad de Humanidades y Ciencias Sociales-Universidad Nacional de Jujuy, (41), 73-87.

Castoriadis, C., \& Vicens, A. (1983). La institución imaginaria de la sociedad (Vol. 1). Barcelona: Tusquets.

Cena, J. C. (1998). El guardapalabras: memorias de un ferroviario. La Rosa Blindada. (2002). Crónicas de terraplén. La Rosa Blindada. (2008). El Ferrocidio (2. ${ }^{\text {a }}$ ed.). La Rosa Blindada. (2009). Ferroviarios, sinfonía de acero y lucha (1. ${ }^{\mathrm{a}}$ ed.). La Nave de los Locos. (2012). Ferrocarriles Argentinos. Destrucción/Recuperación (1. ${ }^{\mathrm{a}}$ ed.). La nave de los locos. 
Contreras, G. N. (2009). Ferroviarios. Un capítulo de sus luchas: las huelgas de fines de 1950 y principios de 1951. En Ferroviarios. Sinfonía de acero y lucha (1. ${ }^{\mathrm{a}}$ ed., pp. 170192). La Nave de los Locos.

(2011). Las huelgas ferroviarias durante el primer gobierno peronista, Argentina, 1950-1951. In Organizaciones obreras y represión en el ferrocarril: una perspectiva internacional (pp. 403-432). Fundación de los Ferrocarriles Españoles.

Cormick, ER (2006). Entre gringos y criollos. Buenos Aires: Tres Lagunas.

Costamagna, S. (2010). Resistencia y cierre de los talleres ferroviarios de la línea Belgrano en Cruz del Eje. En Vias Argentinas (1. ${ }^{a}$ ed., pp. 201-213). Milena Caserola.

Costilla, A. (2013). Conciencia de clase sobre rieles: iniciativa obrera en la lucha ferroviaria de 1950-1951. In XIV Jornadas Interescuelas/Departamentos de Historia. Departamento de Historia de la Facultad de Filosofía y Letras. Universidad Nacional de Cuyo.

Crocco, Aymar (2010). Talleres Junín. Reseña histórica y potencialidad alcanzado. HCD de la provincia de Buenos Aires, La Plata.

Cuesta, E. \& Vence Conti, A. (2017). Sesenta años de políticas económicas y su impacto en los salarios en Argentina, de Perón al siglo XXI (1943-2001). Diálogos Revista Electrónica de Historia, 18(1), 117-143.

D’Uva, F. (2019). Ayuda mutua, solidaridad gremial y género entre los trabajadores ferroviarios. Argentina, 1912-1917. Boletín del Instituto de Historia Argentina y Americana Dr. Emilio Ravignani, (51).

------------ (2020). Los trabajadores de Vía y Obras en los ferrocarriles de la Argentina a comienzos del siglo XX. Condiciones laborales, experiencias y vida cotidiana en el campamento. Mundos do Trabalho, 12, 1-24.

Dicósimo, D., \& Simonassi, S. (2011). Trabajadores y empresarios en la Argentina del siglo XX: indagaciones desde la historia social, Laura Badaloni, y Julia Soul Academia.edu. Prohistoria Ediciones. Recuperado de 

ARGENTINA_DEL_SIGLO XX

Dimarco, R. (1993). Manual de Historia de Junín. Junín: Ediciones Salido

Escalera, J. (2000). Sociabilidad y relaciones de poder. Kairos, 4(6).

Fayó, I. U. (2007). La institucionalización de la intervención de las Fuerzas Armadas argentinas en política interna. La ley 13234: inauguración de una nueva modalidad represiva, 1958-1961. En XI Jornadas Interescuelas/Departamentos de Historia. Departamento de Historia. Facultad de Filosofía y Letras. Universidad de Tucumán.

Fernández, S. (2012). Sociabilidad y amistad. Los desafíos de una relación interdisciplinaria. Revista Páginas, (4), 3-11.

Ferreres, O. J. (2005). Dos siglos de economía argentina, 1810-2004: historia argentina en cifras. Editorial El Ateneo.

Fiorito, A. (2015). Patrones de desarrollo y distribución del ingreso en la argentina. Documento de trabajo, 70.

Fraser, R. (1993). La historia oral como historia desde abajo. Ayer, (12), 79-92.

Godoy, S. (2019). ¿Mujeres para una empresa moderna?: Algunas reflexiones en torno al trabajo femenino ferroviario en Argentina (1969-1973). Workshop Los mundos del trabajo y los estudios sobre el ferrocarril en Argentina, ISHIR, Rosario.

(2020). El conflicto de las camareras en el Ferrocarril Mitre: tensiones en el mundo del trabajo en contextos de modernización y reestructuración (1962-1964). Revista Notas históricas y geográficas, 24, 168-202.

Gómez, T. (2009). Conflictos políticos y económicos en la privatización del FF. CC. del Oeste en 1889. INDUSTRIA, DESARROLLO, HISTORIA, 35.

Goodwin, P. (1974). Los ferrocarriles británicos y la UCR, 1916-1930. Ediciones La Bastilla.

Gordillo, M. (2003). Protesta, rebelión y movilización: de la resistencia a la lucha armada, 1955-1973. Nueva historia argentina, 9, 1955-1976. 
Guber, R. (2004). El salvaje metropolitano: reconstrucción del conocimiento social en el trabajo de campo. Buenos Aires: Paidós.

Halbwachs, M. (2004). La memoria colectiva (Vol. 6). Prensas de la Universidad de Zaragoza.

Hall, S. (2003). Introducción: ¿quién necesita identidad? Cuestiones de identidad cultural, 13-39.

Hayes, M., Hayes, I., Dominguez, M. A., Arosteguy, M. A., \& Diez Tetamanti, J. M. (2007). Estación Patricios, empalme de la resistencia.

Hernández, A., Martínez, S., Belladonna, S., Dussel, I., Fernández, N. N., Ferreira, M. V., ... \& Zaffaroni, A. (2017). Investigaciones en la escuela secundaria: política y trabajo.

Historia y presente de los Talleres de Tafí Viejo. (2010). En Vias Argentinas. Ensayos sobre el Ferrocarril (1. ${ }^{\mathrm{a}}$ ed., pp. 215-236). Milena Caserola.

Horowicz, A. (1991). Los cuatro peronismos. Buenos Aires: Planeta.

Horowitz, J. (1985). Los trabajadores ferroviarios en la Argentina (1920-1943). Desarrollo Económico, 25(99), 421-446.

(2002). Los radicales, Alvear y la búsqueda de apoyo entre los obreros ferroviarios. Cuadernos de Historia, 5, 85-108.

James, D. (2004). Doña María: historia de vida, memoria e identidad política. Ediciones Manantial.

Lewis, Colin. British Railways in Argentina, 1857-1914. A Case Study of Foreign Investment. Londres: University of London, Institute of Latin American Studies, 1983.

López, M. J. (2008). El problema ferroviario argentino y la nacionalización de las compañías de capital británico en 1948. Tst: Transportes, Servicios y telecomunicaciones, (15), 112-145.

(2013). La política ferroviaria del primer gobierno radical 1916-1922. Hindustri@: Revista de historia de la industria, los servicios y las empresas en América Latina, (7), 1-1. 
(2016). Ganancias y pérdidas de los inversores británicos en la venta de los ferrocarriles al Estado argentino en 1947-1948. América Latina en la historia económica, 23(2), 122-166.

López, M. J., \& Waddell, J. (2007). Nueva historia del ferrocarril en la Argentina. 150 años de política ferroviaria (1.a ed.). Lumiere.

López, M. J., Waddell, J., \& Martínez, J. P. (2016). Historia del Ferrocarril en Argentina (1. ${ }^{\mathrm{a}}$ ed.). Lenguaje Claro.

Lucita, E. (1999). La patria en el riel: un siglo de lucha de los trabajadores ferroviarios. Ediciones del pensamiento nacional.

Malatesta, A. (2008). La etapa fundacional de la Universidad Obrera Nacional. La conexión universitaria entre el aula y el trabajo. Buenos Aires: Editorial de la Universidad Tecnológica Nacional.

Marengo, M. E. (2021). ¿ De talleres a cuarteles? Control estatal, militarización y resistencia de los obreros en el nodo ferroviario de Junín, provincia de Buenos Aires (1958-1959). Aletheia, 11(22), e090-e090.

Mengascini, H. (2007). Conflictos y huelgas ferroviarias durante el período peronista. El caso de los trabajadores ferroviarios de Tandil (1946-1955). Terceras Jornadas sobre la política en Buenos Aires en el siglo siglo XX, Facultad de Humanidades y Ciencias de la Educación, UNLP.

(2009). Conflictos y huelgas ferroviarias durante la época peronista. En Ferroviarios. Sinfonía de acero y lucha (1. a ed., pp. 193-217). La Nave de los Locos.

Miravalles, A. (2009). Las primeras resistencias ferroviarias. En Ferroviarios. Sinfonía de acero y lucha (1. ${ }^{\mathrm{a}}$ ed., pp. 223-240). La Nave de los Locos.

(2011). Los talleres invisibles.

Monticelli, F., Yuln, M., \& Carrizo, S. (2017). Archipiélago ferroviario de Junín. Bitácora 27, 3, 101-110. 
Newland, C., \& Cuesta, E. M. (2017). Peronismo y salarios reales: otra mirada al período 1939-1956. Investigaciones y Ensayos, (64), 75-98.

Ortega, F. A. (2013). De la modernización a la racionalización. Políticas adoptadas por Frondizi ante la crisis ferroviaria (1958-1962). H-industri@: Revista de Historia de la Industria, los Servicios y las Empresas en América Latina, (7), 1-1.

Palermo, S. (2001, septiembre). Democracia, progreso y modernidad: el radicalismo y la expansión de los Ferrocarriles del Estado. Latin American Studies Association.

(2005). Peligrosas, libertarias o nobles ciudadanas: representaciones de la militancia femenina en la gran huelga ferroviaria de 1917. ponencia presentada en $X$ Jornadas Interescuelas/Departamentos de Historia, Rosario.

(2006a). Del Parlamento al Ministerio de Obras Públicas: la construcción de los Ferrocarriles del Estado en Argentina, 1862-1916. Desarrollo Económico, 215243.

(2006b). Elite Técnica y Estado Liberal: la Creación de una Administración Moderna en los Ferrocarriles del Estado (1870-1910). Estudios Sociales, 30(1), 9-42. https://doi.org/10.14409/es.v30i1.2569

(2007, marzo 29). Actores e instituciones en la construcción de los Ferrocarriles del Estado (1862-1916). $V^{\circ}$ Coloquio de Historia de Empresas. Investigaciones en curso en la historiografía argentina.

- (2009a). Fiestas y celebraciones públicas desde una perspectiva histórica: los festejos tras la gran huelga ferroviaria de 1917. Temas de Patrimonio Cultural 27.

(2009b, octubre 14). De las organizaciones sindicales a las familias trabajadoras: nuevas miradas sobre los protagonistas de la gran huelga ferroviaria de 1917 en Argentina. V Congreso de Historia Ferroviaria, Palma.

(2012). Los Ferrocarriles del Estado entre la política electoral y la modernidad administrativa: la revista "Riel y fomento" a comienzos de 1920. Estudios del ISHIR, 2(3), 59-83. 
(2015). Vida sindical y sociabilidades masculinas: los trabajadores ferroviarios en la Argentina de principios del siglo XX. Archivos, IV (7), 37-58.

(2016). El derecho a mantener el hogar: las demandas obreras en la gran huelga ferroviaria desde una perspectiva de género. Argentina, 1917.

Omaña, M. C. M. (1999). EL USO DIVERSO Y COMPLEMENTARIO DE LAS FUENTES DE INFORMACIÓN EN HISTORIA ORAL (1). Razón y palabra, (15), 7.

Pensado, P. (2015). El acontecer histórico en el relato de vida. En Clío Revista de pesquisa histórica, $\mathrm{N}^{\circ} 32,2$.

Petraglia, P. G. (2012). El chalet de Mr. York. UNNOBA.

Pompei, M. L. (2011). Historia de los Talleres Ferroviarios de Junín [Tesis de Licenciatura, inédita]. UNNOBA, Junín.

Portelli, A. (1989). Historia y memoria: la muerte de Luigi Trastulli. Historia y fuente oral, 5-32.

-(2013). Sobre los usos de la memoria: Memoria-monumento, memoria involuntaria, memoria perturbadora. Revista Sociohistórica Universidad Nacional de La Plata. Facultad de Humanidades y Ciencias de la Educación. Centro de Investigaciones Socio Históricas, 32. http://www.memoria.fahce.unlp.edu.ar/art_revistas/pr.6125/pr.6125.pdf

Regalsky, A. (1995). Las compañías francesas de ferrocarriles y su repercusión en el desarrollo regional de Santa Fe y Buenos Aires, 1880-1930. Las inversiones extranjeras en América Latina, 1930, 193-213.

(2007). Políticas públicas, capital extranjero y estructura de mercado: El desarrollo de los ferrocarriles en la Argentina antes de 1914. Revista de Instituciones, Ideas y Mercados, 46, 171-203.

(2008). Entre el Estado y el mercado. Competencia y regulación ferroviaria en la Argentina de comienzos del siglo XX. Revista de Historia Industrial. Economía y Empresa, 17(38), 51-78. 
Regalsky, A. M., \& Salerno, E. (2008). En los comienzos de la empresa pública argentina: la Administración de los Ferrocarriles del Estado y las Obras Sanitarias de la Nación antes de 1930. Investigaciones de Historia Económica, 4(11), 107-136.

Rozitchner, L., González, H., Sorín, J., Aramendy, C., Bril, N., Raíces, E., Rodeiro, M., López, M. P., Ferrer, C., Cinat, N., \& Schkolnik, F. (2010). Vias argentinas. Ensayos sobre el Ferrocarril (1. ${ }^{\mathrm{a}}$ ed.). Milena Caserola.

Sagastume, A. (2016a). El mundo ferroviario. Memorias de trabajadores de Ferrocarriles Argentinos (1948-1993) (1. ${ }^{\mathrm{a}}$ ed.). Maipue.

(2016b). Ferroviarios en la encrucijada de la nacionalización. Junín, Provincia de Buenos Aires 1948. Cuadernos de H ideas, 10(10), 1-19.

(2017). La familia ferroviaria de mediados del siglo XX. Junín, provincia de Buenos Aires. In XVI Jornadas Interescuelas/Departamentos de Historia. Departamento de Historia. Facultad Humanidades. Universidad Nacional de Mar del Plata.

Salerno, E. (2002). Los comienzos del Estado empresario: La Administración General de los Ferrocarriles del Estado (1910-1928). CEED.

(2006). La burocracia técnica de los ferrocarriles del Estado en Argentina, 1910-1948. In ponencia presentada en IV Congreso de Historia Ferroviaria, Málaga. (2015). Los ingenieros, la tecnocracia de los Ferrocarriles del Estado. $H$ -

Industri@, 9(16), 13-34. $\quad$ Recuperado de https://dialnet.unirioja.es/servlet/articulo? codigo $=5178294$

(2020). El final de la primera empresa estatal nacional: la Administración General de los Ferrocarriles del Estado (AGFE). Pasado Abierto, 6(12).

Sánchez Román, J. A. (2008). De las escuelas de artes y oficios a la Universidad obrera nacional: Estado, elites y educación técnica en Argentina, 1914-1955. CIAN-Revista de Historia de las Universidades, 10, 269-299.

Scaglione, M. (2015). Museo «Memorias Ferroviarias» [Tesis, Facultad de Ciencias Económicas]. http://hdl.handle.net/10915/47510 
Scalabrini Ortiz, R. (1946). Los ferrocarriles deben ser del pueblo argentino. Buenos Aires, Reconquista.

(1975). Historia de los Ferrocarriles Argentinos (7. a ed.). Editorial

Plus Ultra.

Schkolnik, F. (2010). Paiva, voces entre rieles. En Vias Argentinas. Ensayos sobre el Ferrocarril (1. a ed., pp. 133-144). Milena Caserola.

Schneider, A. (2005). Los compañeros: Trabajadores, izquierda y peronismo, 1955 1973.

Schvarzer, J., \& Gómez, T. (2001). El Ferrocarril del Oeste en la Argentina: entre las demandas de la ciudad y el campo (1854-1870). En II Congreso de Historia Ferroviaria: Aranjuez, 7 a 9 de febrero de 2002 (p. 9). Fundación de los Ferrocarriles Españoles.

(2003). El Ferrocarril del Oeste: la lógica de crecimiento de la primera empresa ferroviaria argentina a mediados del siglo XIX. Ciclos en la historia, la economía y la sociedad, 13(25), 41-64.

(2006). La primera gran empresa de los argentinos. El

Ferrocarril del Oeste. Buenos Aires: Fondo de Cultura Económica.

Schvarzer, J., Regalsky, A., \& Gómez, T. (2007). Estudios sobre la Historia de los Ferrocarriles Argentinos (1857-1940) (1. a ed.). Universidad de Buenos Aires.

Scodeller, G. (2007). La huelga ferroviaria de 1961 en la provincia de Mendoza. In $I$ Jornadas Nacionales de Historia Social 30, 31 de mayo y 1 de junio de 2007 La Falda, Córdoba. Centro de Estudios Históricos Carlos SA Segreti; Universidad Nacional de La Plata. Facultad de Humanidades y Ciencias de la Educación. Centro de Estudios de Historia Americana Colonial.

Simonassi, Silvia, B., Laura. (2013). Trabajadores, empresas y comunidades urbanas: reflexiones introductorias. Avances del Cesor, X(10), 101-111. http://www.academia.edu/22233631/Trabajadores_empresas_y_comunidades_urbanas_ reflexiones_introductorias 
Suriano, J. (1991). Estado y conflicto social: el caso de la huelga de maquinistas ferroviarios de 1912. Boletín del Instituto de Historia Argentina y Latinoamericana Dr. Ravignani, Tercera Serie, 4, 91-115.

Sosa Martos, A. O. (2014). Un largo camino a la privatización, memoria y resistencia en los trabajadores de los talleres de Tafí Viejo (Tucumán-Argentina).

(2017). Entre la escuela y el taller: Una relación perdurable en la memoria de los obreros ferroviarios taficeños

Tarullo, R. y Iacullo A. (Ed.). (2013). Ferroviarios: nuestra historia. Universidad Nacional del Noroeste de la Provincia de Buenos Aires, UNNOBA, Sede CABA.

Thompson, P. (2004). Historia oral y contemporaneidad.

Waddell, J. E. (2013). El mecanismo de control del capital de las empresas ferroviarias a partir de la Ley Mitre (disertación doctoral, Facultad de Ciencias Económicas. Universidad de Buenos Aires).

Williams, R. (1980). Teoría cultural. Marxismo y literatura, 91-164.

Wright, WR (1980). Los ferrocarriles ingleses en la Argentina: su influencia en el nacionalismo económico, 1854-1948. Emecé Editores.

Yuln, M., Carrizo, S., \& Monticelli, F. (2017). Archipiélago ferroviario en Junín. Bitácora 27, Universidad Nacional de Colombia, 3, 101-110.

Zalduendo, E. A. (1975). Libras y rieles: las inversiones británicas para el desarrollo de los ferrocarriles en Argentina, Brasil, Canadá e India durante el siglo XIX. Editorial E1 Coloquio.

Zapata, M. (2008). Represión cultural y dictadura. El caso de COART en Junín. In $V$ Jornadas de Sociología de la UNLP 10, 11 y 12 de diciembre de 2008 La Plata, Argentina. Universidad Nacional de La Plata. Facultad de Humanidades y Ciencias de la Educación. Departamento de Sociología. 


\section{Documentos de Archivos y fuentes online}

Club Atlético Villa Belgrano, sus bodas de oro (octubre de 1975). Historia de Junín.

Escuela de Artes y Oficios de Junín, sus bodas de oro (abril de 1974). Historia de Junín.

Los 60 años del Club Rivadavia (octubre de 1975). Historia de Junín.

Jubilaciones (marzo de 1947), BAP, Boletín Informativo, p. 33. Disponible en Archivo Histórico Municipal de Junín.

Escalafón Único del Personal de empleados y obreros del ferrocarril (1964). Disponible en Archivo Histórico Municipal de Junín.

Plan de Mediano Plazo, Ferrocarriles Argentinos. Disponible en Archivo Histórico Municipal de Junín.

Departamento de Mecánica, Línea General San Martín (s.f.). Ferrocarriles Argentinos. Talleres Junín [folleto]. Disponible en Archivo Histórico Municipal de Junín.

BAP (1938). Actividades, obligaciones, aspiraciones. Disponible en Archivo Universitario de la UNNOBA Roberto Dimarco.

Capacidad Técnica de los Talleres Junín (s.f.). Disponible en Archivo Universitario Roberto Di Marco.

Ferrocarriles Argentinos (s.f), El Libertador [folleto]. Disponible en Archivo Universitario Roberto Di Marco.

Rinaldi, E. (22 de abril de 1977). Talleres Junín [monografía]. Disponible en Archivo Histórico Municipal de Junín. 
Di Marco, R. (1984). El ferrocarril en Junín. Municipalidad de Junín. Disponible en Archivo Histórico Municipal de Junín.

Cormick, E. (2006). Entre gringos y criollos. Junín: Tres lagunas. Disponible en Archivo Histórico Municipal de Junín.

El pito del taller (6 de noviembre de 1952). La Verdad. Disponible en Archivo Universitario de la UNNOBA Roberto Dimarco.

Posición de La Fraternidad ante la carta del señor intendente. (1 de noviembre de 1961). La Verdad, p. 2.

Comunicado de prensa de la Unión Ferroviaria. (1 de noviembre de 1961). La Verdad, p. 2 .

Gestiones sobre el problema ferroviario realizó una comisión de concejales de la UCRI. (1 de noviembre de 1961), La Verdad, p. 2.

Comunicado de la Unión Ferroviaria. (11 de noviembre de 1961). La Verdad, p. 1.

Ferrocarril General San Martín. (10 de noviembre de 1961). La Verdad, p. 2.

Ferrocarril General San Martín. Comando de Coordinación y Seguridad en el Transporte. (3 de diciembre de 1961). La Verdad, p.2.

Solicitada. Unión Ferroviaria y La Fraternidad. (9 de diciembre de 1961). La Verdad, p. 2.

Se dispuso la reincorporación ayer de todos los cesanteados (16 de diciembre de 1961). La Verdad, p. 1.

Reacondicionan en los talleres de Junín coches metálicos del FA Sarmiento (27 de agosto de 1968). La Verdad, p. 9. 
El coronel Carlucci visitó la ciudad. (4 de noviembre de 1970). Mundo Nuevo, p. 1 y 16.

Destacan stand ferroviario (11 de noviembre de 1970). Mundo Nuevo, p. 5.

“El Libertador": una obra realizada en Junín para el país. (14 de diciembre de 1970). Mundo Nuevo, p. 14.

Adhieren al paro en Junín. (17 de septiembre de 1969). La Verdad, p. 2.

Prolongan el paro de los ferroviarios de Junín. (18 de septiembre de 1969). La Verdad, p. 2.

El conflicto ferroviario en nuestra ciudad. (19 de septiembre de 1969). La Verdad, p. 2.

Asumió el nuevo jefe del Departamento de Mecánica del FCSM. (2 de octubre de 1969). La Verdad, p. 1.

El General Juan C. De Marchi estuvo en Junín (25 de febrero de 1971) Mundo Nuevo, p. 5

Reacondicionan en los Talleres Junín coches metálicos del FC Sarmiento (27 de agosto de 1968). La Verdad, p. 1.

Marchesi, G. (16 de septiembre de 2016). El cuyano. Cuatro Palabras. Recuperado de http://www.cuatropalabras.com/articulo/cultura/cuyano/20160916004839002354.html

Frondizi, A. (9 de julio de 2017). Discursos: La batalla del transporte. 5 de junio de 1961. Recuperado de https://www.visiondesarrollista.org/discursos-la-batalla-deltransporte/

Retes M. (6 de octubre de 2012). Dante Balestro, un ejemplo de persona, Democracia. Recuperado de: https://www.diariodemocracia.com/locales/junin/44370-dante-balestroejemplo-persona 
Piva, A. (18 de marzo de 2012). Hace cuarenta años asesinaron a mi viejo José Raúl Piva. Democracia. Recuperado de

https://www.diariodemocracia.com/locales/junin/32803-hace-anos-asesinaron-viejojose-raul-piva/

Canaparo, I. (2 de enero de 2017) Cuarenta años sin el "Coco" Pelli, lapidario goleador de Sarmiento. Democracia. Recuperado de https://www.diariodemocracia.com/masdeportivo/futbol/152254-cuarenta-anos-coco-pelli-lapidario-goleador-sarmie/

Canaparo, I. (5 de junio de 2017). El bandoneón de Lalo es un toldo de estrellas.

Semanario. Recuperado de :

http://semanariodejunin.com.ar/nota/315/el_bandoneon_de lalo es un toldo de estrel $\underline{\text { las }}$

Canaparo, I. (7 de noviembre de 2017). Dos años sin Hebert Pérez. Semanario. Recuperado en http://semanariodejunin.com.ar/nota/2132/dos anos sin hebert perez

Canaparo, I. (29 de noviembre de 2018) Tristes y melancólicos recuerdos de noviembre... Semanario. Recuperado de http://semanariodejunin.com.ar/nota/5762/tristes_y melancolicos_recuerdos_de_novie $\underline{\text { mbre hellip }}$

Canaparo, I. (11 de octubre de 2019). A cuatro años de la muerte de Roberto Carlos Dimarco, un verdadero artesano de la historia. Semanario. Recuperado de http://semanariodejunin.com.ar/nota/9287/a_cuatro_anos_de_la_muerte_de_roberto_car $\underline{\text { los_dimarco un verdadero_artesano de la historia }}$

Ganci, D. (30 de julio de 2013). Falleció el maestro Héctor Raúl Bianco.

Democracia.Recuperado de https://www.diariodemocracia.com/vida/sociedad/62551fallecio-maestro-hector-raul-bianco/: 5/2/2020

Petraglia, P. (30 de agosto de 2014). El maestro Luis Felipe Noé y los Muphy de Junín. Democracia. Recuperado de https://www.diariodemocracia.com/locales/junin/88471maestro-luis-felipe-murphy-junin/ 
La gestión del general De Marchi (4 de febrero de 2012). Recuperado de http://todotransporteferroviario.blogspot.com/2012/02/la-gestion-del-general-demarchi.html

Murió el general Juan Carlos De Marchi (25 de octubre de 2004). Recuperado de http://bassoenlared.com.ar/noticias/1276-MURIO-EL-GENERAL-JUAN-CARLOSDE-M.htm

Historia y edificio. EESTNº1 Antonio Bermejo (s.f.). Recuperado de https://www.eetljunin.com.ar/historia-y-edificio/

Un edificio que en 64 años pasó de policlínico a sede universitaria (16 de abril de 2018). Junínhistoria. Recuperado de http://juninhistoria.blogspot.com/2018/04/un-edificio-que-en-64-anos-paso-de.html

Ambos Mundos cumple hoy 96 años (22 de mayo de 2018). La Verdad. Recuperado de https://laverdadonline.com/ambos-mundos-cumple-hoy-96-anos/

Rivadavia cumple hoy 104 años (15 de noviembre de 2019). La Verdad. Recuperado de https://laverdadonline.com/rivadavia-cumple-hoy-104-anos/

Ciclista arriba hoy a sus 6 años de vida (6 de noviembre de 2019). La Verdad. Recuperado de https://laverdadonline.com/ciclista-arriba-hoy-a-sus-96-anos-de-vida/

Los indios de Junín: trabajo en equipo y crecimiento (4 de julio de 2017). Democracia, Recuperado de https://www.diariodemocracia.com/mas-deportivo/basquet/165162indios-junin-trabajo-equipo-crecimiento/

Silvana Schiavoni: "Es nuestro sueño llevar a San Martín a lo más alto" (7 de septiembre de 2019). La Verdad. Recuperado de https://laverdadonline.com/silvanaschiavoni-es-nuestro-sueno-llevar-a-san-martin-a-lo-mas-alto/

Argentino de Junín cumple hoy 78 años de vida (1 de octubre de 2013). Pick and roll. 
Recuperado de http://pickandroll.com.ar/argentino/noticias/00025948/argentino-dejunin-cumple-hoy-78-anos-de-vida/:

Rivadavia cumple hoy 104 años (15 de noviembre de 2019). La Verdad. Recuperado de https://laverdadonline.com/rivadavia-cumple-hoy-104-anos/

Inauguraron ayer el Parque Central del Ferrocarril y la Plazoleta Dante Balestro (3 de octubre de 2018). La Verdad. Recuperado de https://laverdadonline.com/inauguraronayer-el-parque-central-del-ferrocarril-y-la-plazoleta-dante-balestro/

Falleció el general (R) De Marchi (29 de octubre de 2004). Recuperado de https://www.lanacion.com.ar/politica/fallecio-el-general-r-de-marchi-nid649224/

Álvarez Uriondo (s.f.) Juan Carlos De Marchi Sexton. Recuperado en https://gw.geneanet.org/gentuc?lang=es\&p=juan + carlos\&n=de+marchi + sexton

Gobernadores de Catamarca (s.f.). Recuperado de https://esacademic.com/dic.nsf/eswiki/1295696

La biblioteca "Florentino Ameghino" en la memoria de Dante Balestro (2018, 28 de febrero). Junínhistoria. Recuperado de http://juninhistoria.blogspot.com/2018/02/labiblioteca-florentino-ameghino-en-la.html.

Murió Roberto Carlos Dimarco, entrañable historiador de acontecimientos juninenses (11 de octubre de 2015). Democracia. Recuperado de https://www.diariodemocracia.com/locales/junin/116655-murio-roberto-carlos$\underline{\text { dimarco-entranable-historiado/ }}$

Inauguran mural en homenaje a Beto Mesa (25 de marzo de 2019). La Verdad. Recuperado de https://laverdadonline.com/inauguran-mural-en-homenaje-a-beto-mesa/ Junín. Wikipedia. Recuperado de https://es.wikipedia.org/wiki/Jun\%C3\%ADn_(Buenos_Aires) 
Luis Artime. Wikipedia. Recuperado de https://es.wikipedia.org/wiki/Luis_Artime

Abel Paulino Miguel (s.f). Recuperado de

https://es.wikipedia.org/wiki/Abel_Paulino_Miguel

Bernabé Ferreyra. Wikipedia. Recuperado de

https://es.wikipedia.org/wiki/Bernab\%C3\%A9_Ferreyra

\section{Fuentes orales}

Entrevista No 1 a José Poch, Junín, 27/02/2012.

Entrevista N² a Aymar Crocco, Junín, 10/07/2011.

Entrevista N³ a Eridé Rinaldi, Junín, 31/05/2011.

Entrevista N4 a Héctor Ferrari, Junín, 28/09/2011.

Entrevista No5 a Miguel Mantino, Junín, 17/11/2011.

Entrevista No6 a Ismael Tornello, Junín, 23/12/2011.

Entrevista $\mathrm{N}^{\circ} 7$ a Abilio Murgia, Junín, 17/04/2018.

Entrevista No 8 a Carlos Violante, Junín, 27/07/2011.

Entrevista Nº a Abel Pinto, Junín, 15/11/2012.

Entrevista ${ }^{\circ} 10$ a Aroldo Taberna, Junín, 12/07/2017.

Entrevista No11 a Roberto De Giulio, Junín, 2/12/2018.

Entrevista $\mathrm{N}^{\circ} 12$ a jubilados de La Fraternidad, Junín, 14/10/2011.

Entrevista No13 a Dante Cruz, Junín, 3/12/2011.

Entrevista $\mathrm{N}^{\circ} 14$ a Ítalo Marone, Junín, 16/06/2011

Entrevista Nº15 a Juan Dall'Occhio, Junín, 11/05/2011.

Entrevista No 16 a Roberto Dimarco, Junín, 6/05/2011.

Entrevista Nº17 a Oscar Bozzini, Junín, 03/02/2012.

Entrevista $\mathrm{N}^{\circ} 18$ a Miguel Mantino, Junín, 03/11/2017.

Entrevista Nº19 a Omar Calderoni, Junín, 29/04/2011.

Entrevista No20 a Valentín Martínez, Junín, 15/02/2012.

Entrevista N²1 a José Calcagni, Junín, 08/07/17.

Entrevista No 22 a Ítalo Marone, Junín, 03/8/2018.

Entrevista No23 a Omar Decarre, Junín, 25/10/2017.

Entrevista N²4 a Eridé Rinaldi, Junín, 23/08/17. 
Entrevista No25 a Mateo Perkusic, Junín, 06/07/2017.

Entrevista №26 a Juan Dall'Occhio, Junín, 23/10/2017.

Entrevista №27 a Bruno Danielle, Junín, 05/08/2011,

Entrevista No28 realizada a Héctor Pellizi, Junín, 11/05/2016.

Entrevista No29 realizada a Ítalo Marone, Junín, 14/05/2018.

Entrevista No30 a José Calcagni, Junín, 09/09/17. 